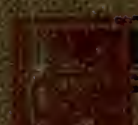

$\frac{85}{85}$ 
From the collection of the

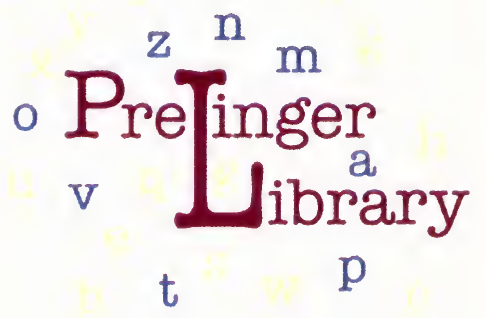

San Francisco, California 2006 

SCIENCE OF HOME AND COMMUNITY 


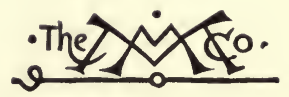

THE MACMILLAN COMPANY

NEW YORK - BOSTON - CHICAGO - DALLAS

ATLANTA - SAN FRANCISCO

MACMILLAN \& CO., Limited

LONDON - BOMBAY - CALCUTTA

MELBOURNE

THE MACMILLAN CO. OF CANADA, LTD. TORONTO 


\section{SCIENCE OF HOME AND COMMUNITY}

A TEXT-BOOK IN GENERAL SCIENCE

BY

GILBERT H. TRAFTON

INSTRUCTOR IN SCIENCE AT THE STATE

NORMAL SCHOOL, MANKATO, MINN.

New Tark

THE MACMILLAN COMPANY

1919

All rights reserved 


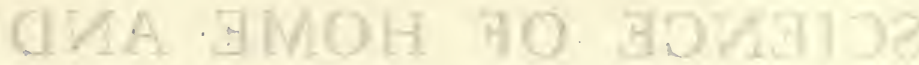 VTIИUMMOD}

2073022

COPYRIGHT, 1919,

By THE MACMILLAN COMPANY.

Set up and electrotyped. Published October, rgrg.

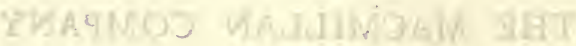

Norwood 吿ess

J. S. Cushing Co. - Berwick \& Smith Co.

Norwood, Mass., U.S.A. 


\section{PREFACE}

Education for the present life of the child should be the chief purpose of our schools. This book seeks to carry out this principle so far as science is concerned. We are living in the midst of a great scientific age. Applications of science more and more dominate our life, and they will continue to do so in ever-increasing degree. Any sane system of education must see to it that boys and girls living in the midst of these applications, which form such an important part of their everyday life, are educated in terms of this environment, in order that they may better appreciate it and adapt themselves to it. This book is an attempt to make clear to boys and girls answers to some of the questions naturally arising in their minds concerning the common applications of science.

The book is not written as an introduction to, or preparation for, any later science work. It is written to meet the present needs and interests of boys and girls just entering the adolescent period. We do not know the future of the child, but we do know his present. The satisfaction of these present needs is the best possible and the only sound foundation for any further work in science that he may do in later years.

If a course in General Science is to be worthy of an established place in the school curriculum, it must fulfill two requirements : first and foremost, it must appeal to the pupils; and second, it must be well organized around centers of children's interests. 
The author has tried to meet these two requirements by finding the basis for both the selection and the organization of material in the applications of science to the child's immediate life. It seems best to group these applications around two great centers, the home life and the community life. There are certain phases of science that are more conspicuous in the home circle, while there are other phases that are more prominent as one goes out into community life. These phases are closely interrelated, and in some cases no sharp line can be drawn between them; but the author believes that from the child's standpoint this division forms a natural basis for organizing the text.

The material has been organized from the human rather than from the scientific point of view. The child sees first the uses made of various things, then he is interested to understand something of the construction and mode of operation of the machines involved, and finally he wishes to know what their history has been. Consequently the great inventions have been treated from the four standpoints of their uses, their history, their construction, and their working.

This is not a textbook in General Science in the sense that it attempts to cover a little of all the sciences, just for the sake of covering them all. The extent to which any particular science is included depends on the part that the science plays in the immediate life of the child. Whether any particular science or any particular topic in a science should form a part of the course depends on the number and value of the elements that it possesses in common with the child's life. As a matter of fact, the two sciences that are especially conspicuous in the child's daily life, and hence dominate the text, are physics and hygiene.

The author acknowledges his indebtedness to the following firms for their courtesy in allowing illustrations from their publications to be used as copy for illustrations made for this book: American Book Co., The Century Co., Doubleday, 
Page and Co., E. P. Dutton and Co., Everybody's Magazine, Ford Motor Co., Ginn and Co., Harper and Brothers, The Norman W. Henley Publishing Co., George W. Jacobs and Co., J. B. Lippincott Co., A. C. McClurg and Co., Frederick A. Stokes Co., Whitcomb, and Banams. The illustration of the first telephone is taken, with Mr. Casson's permission, from his book, "History of the Telephone."

G. H. T.

Mankato, Minn. 


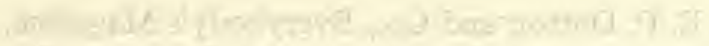

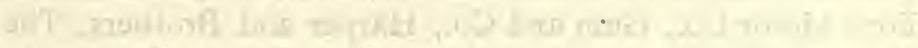

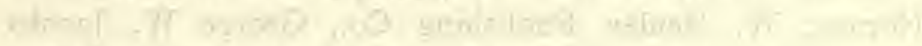

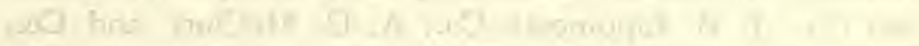

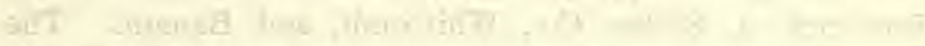

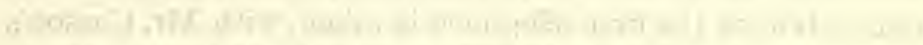

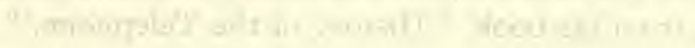
! 11 93 


\section{NOTE TO TEACHERS}

THE practical work outlined in this book has been divided into four kinds: laboratory exercises, demonstrations, field exercises, and projects. The demonstrations are to be done before the class either by the instructor or by some pupil. It is intended that the laboratory exercises shall be performed by each pupil. The extent to which each pupil can do the laboratory exercises will depend on the equipment and the facilities available for individual work. If equipment is lacking, the laboratory exercises may be performed as demonstrations. The field exercises are to be done by the instructor and class outside of the schoolroom. In the projects something is provided for each pupil to do individually outside of the laboratory. These projects have been divided into three groups: for the home, for the school, and for the community. They provide a vital kind of work because they connect the school work with actual life and provide opportunity for the pupil to do something on his own responsibility. It is suggested that a certain number of home projects be required of each pupil, who may be allowed to choose the ones he wishes to carry on. The pupils should be expected to present definite written reports of the projects and should be given school credit for the work done. A sufficient variety of projects has been given so that each pupil can find some suited to his circumstances:

The author believes that the pupils should make some written records of all the practical exercises. These records, kept in a notebook, should be brief and simple in form. It is suggested that each record may contain, first, a statement 
of the purpose of the exercise; second, a brief description of what was done; and third, a statement of the things learned or the conclusions drawn from the exercise.

Questions at the beginning of each chapter are given as problems to guide the pupils in their study. These, together with the questions at the end of the chapter, are suggested as a basis for the class discussions. It is believed that a few leading questions of this type will stimulate the pupils to independent thought and to organization of their knowledge.

In order to adapt the work to the individual interests and capabilities of the pupils, it seems desirable that students make reports to the class on some subjects of which they have made special study. As an aid in this line of work a few references are given at the close of each chapter.

The stress to be laid on the various chapters depends on the environment of the pupils, whether it is urban or rural. In accordance with this environment some chapters may be passed over lightly, while others should receive special attention. 


\section{TABLE OF CONTENTS}

\section{PART I. SCIENCE OF THE HOME}

SECTION A. HYGIENE OF THE HOME

CHAPTER

I. Heating the Номе

II. Ventilating the Home . . . . . . . 17

III. Lighting the Home • • . . . . . 33

IV. The Home Water Supply . . . . . 45

V. The Hygiene of the Dining Room • . 58

VI. Science of the Kitchen . • • . . . . 98

SECTION B. PLEASURE IN THE HOME

VII. Musical Instruments • • . . . . II8

VIII. Taking Pictures . . . . . . . . 126

IX. House Plants . . . . . . . . 138

SECTION C. ELECTRICITY IN THE HOME

X. Applications of Electricity . . . . . ${ }^{4} 48$

SECTION D. USE OF THE HOME GROUNDS

XI. The Ornamentation of the Home Grounds - i6I

XII. The Vegetable Garden . . . . . . I8o

XIII. The Fruit Garden . . . . . . . 203

XIV. Poultry Keeping and Bee Keeping • • . 214

XV. Attracting Birds around the Home . . . 226 
PART II. SCIENCE OF THE COMMUNITY

$$
\begin{gathered}
\text { SECTION A. MEANS OF TRAVEL } \\
\text { Group A. Travel on Land }
\end{gathered}
$$

XVI. The Locomotive . . . . . . . . . 243

XVII. The Electric Trolley • • • • • . 257 XVIII. The Automoвile . . . . . . . . . . . 266

Group B. Travel by Water

XIX. The Steamboat and Submarine . . . . . 284 Group C. Travel by Air

XX. Airships and Airplanes . . . . . . 300

SECTION B. MEANS OF- COMMUNICATION

XXI. The Telegraph $\quad . \quad$. . . . . . 318

XXiI. The Telephone . . . . . . . . 333

SECTION C. THE HEALTH OF THE COMMUNITY

XXIII. The Public Water, Milk, and Food Supply i... 347

XXIV. Contagious Diseases • • • • • . 365

XXV. Insects And Disease . . . . . . 394

XXVI. HeAlth OFFICERS . • • . . . . 417

XXVII. School Hygiene • . . . . . . • • . 426

SECTION D. COMMUNITY ENTERTAINMENT

XXViII. The Moving Pictures . • • • • . 444

SECTION E. CONSERVATION OF COMMUNITY RESOURCES

XXIX. Protection of Birds • • • . • • . . . . 459

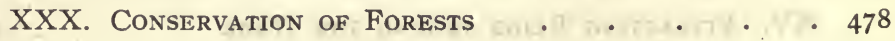


SECTION F. PROTECTION FROM WEATHER XXXI. The United States Weather Bureau . . . 503

SECTION G. RELATION OF EARTH TO THE OTHER HEAVENLY BODIES

XXXII. The Earth as a Part of the Solar System • 515

SECTION H. AN ENEMY OF HOME AND COMMUNITY XXXIII. Alcoholic Drinks . . • . . . 536

\section{APPENDIX}

Table of Relative Humidity • • . • . . 555

List of Apparatus . . . . . . . . . . 556

TABLE OF INVENTIONS . . . . . . . . . . 557 

PART I

SCIENCE OF THE HOME 
$1+51 / 49$

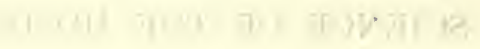




\title{
SCIENCE OF HOME AND COMMUNITY
}

\author{
SECTION A
}

Hygiene of the Home

\author{
CHAPTER I \\ HEATING THE HOME
}

I. In what ways are our present modes of heating better than those used in early times?

2. What advantages has each of the following methods of heating the home: hot air, hot water, and steam?

Early methods of heating. People have become so accustomed to the methods now used to heat their homes that they do not often stop to think that these same methods have not always been used and that a hundred years ago people did not have the same conveniences for heating that we now enjoy. Our present methods of heating, as well as numerous other conveniences, have come to us only gradually after many changes and improvements running back hundreds of years. Let us consider briefly the changes in methods of heating that have taken place from the very earliest times up to the present day.

The first method of heating used by primitive man many centuries ago was to build a fire on the earth floor of his crude hut and allow the smoke to escape through a hole in 
the top of the hut. As there was no chimney, the smoke was often blown down the opening and filled all parts of the hut. This method was probably used for thousands of years.

The primitive fireplace. When the first chimney was built the fire was moved to one side of the room, a hole was cut in the wall just over it, and a hood was made that projected out over the fire to collect the smoke. A little later this was improved by making a recess in the wall for the fireplace and building a separate chimney to carry off the smoke. By the end of the fifteenth century these fireplaces were in common use throughout the civilized world. For two hundred years after the settlement of this country by white people, they depended entirely upon the open fireplace to warm their homes during the cold winters. In the early days the churches were not heated at all.

Primitive stoves and furnaces. The next improvement in heating was the invention of the stove. At first it consisted of an iron box provided with openings at the top for the escape of the smoke, which passed out into the room. Charcoal was often burned in it, as that did not give off much smoke. The next step was to connect a pipe with this box to carry the smoke outdoors. The first stove of this type was made about two hundred years ago.

Stoves were first used in this country about fifty years before the Revolutionary War. About thirty-five years before this war (in I742) Benjamin Franklin invented the stove that was named after him. The Franklin stove was a box with metal sides and entirely open in front. It was set in the fireplace and connected with the flue of the chimney. This was a great improvement over the fireplace. Other improvements were continually made until the modern stove that we use to-day was developed.

The next great advance made in heating was the plan of placing a single large stove, called a furnace, in the 
cellar and heating the entire house by means of this. The first furnaces were used only about one hundred years ago.

Modern heating. The modern fireplace. Fireplaces are still frequently built into houses, both because they are ornamental and because the open fire is attractive. During the late spring and early fall, when it is not cold enough to start the furnace, these fireplaces serve a useful purpose in taking off the chill during the evening; but as a means of heating, the fireplace is ineffective and expensive. It is ineffective because it raises the air near it to an extremely high temperature, while the air in distant parts of the room is heated only slightly; it is expensive because so much heat is wasted in the heated air that passes up the chimney, and a large amount of fuel is required to keep the fire going. It is not adapted to cold climates.

The modern stove. The stove is a great improvement on the fireplace in that it warms the room more satisfactorily and requires less fuel. The stove heats the room by a process called convection. The heated air over the stove rises and circulates to other parts of the room, while the colder air rushes in over the stove and is heated. By this means a larger part of the air of a room is heated than would be possible by a fireplace. While in the fireplace the fuel is burned in the open, frequently filling the room with smoke, in the stove the fuel is burned in a closed firebox with a special pipe for carrying off the smoke. The stove has the further advantage that it is provided with dampers by means of which the fire may be controlled. When coal is first put into the stove, the back damper should be opened to allow the escape of poisonous gases that form, as otherwise these may be forced back into the room. Cook stoves are so built that the heated gases may be forced to pass around the oven, thus heating it before passing up through the pipe and chimney. 
The hot-air furnace. One disadvantage of heating by stoves lies in the fact that several stoves are needed to warm the whole house. Hence, systems are now very widely used in which the whole house is heated from one furnace located in the cellar, the heat being carried to the various

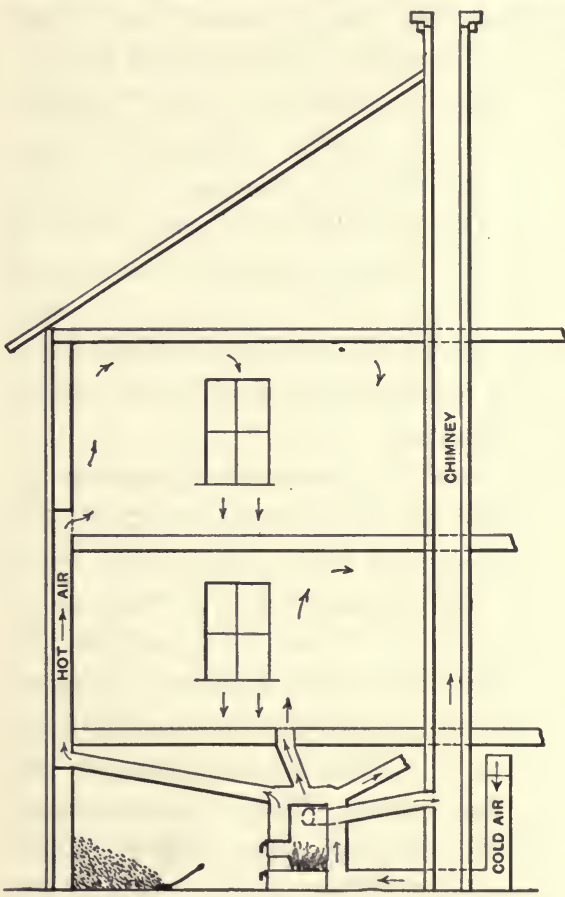

FIG. I. - Hot-air system. rooms by means of either hot air, or hot water, or steam. The hot-air furnace is a large stove surrounded with a metal jacket, with space between to allow air to circulate. Air is brought into this inclosed space by a duct leading from outdoors, from the cellar, or from the rooms above; and as it passes over and around the furnace it becomes heated. The furnaces are constructed so as to give a large heating surface. From the top of the air jacket, pipes lead to the several rooms to conduct the hot air through registers placed either in the floor or on the walls near the floor. Frequently these pipes are covered with asbestos to reduce the loss of heat. Each pipe usually has a damper near the furnace and a register in the room that may be opened or closed, by means of which the hot air supply may be shut off from one part of the house and sent to other rooms. 
The circulation of air through these pipes is maintained through the effect of heat on gases. When air is heated it expands and so becomes lighter, while the air coming in from outdoors is colder and heavier. When two gases of unequal weight are brought into contact, the tendency is for the heavier body to sink to the bottom and push the lighter gas up. So here the cold air rushes in under the warm air, which is thus forced upwards.

\section{DEMONSTRATION I}

Purpose. To study the principles applied in the hot-air furnace.

Apparatus. Flask, rubber stopper with a single hole to fit, glass tubing about a foot long, alcohol lamp or Bunsen burner, tumbler, chimney, touch paper or piece of cloth, candle.

Directions. I. Push the glass tubing through the hole in the stopper and insert the stopper in the flask. Fill the tumbler with water and place the end of the tube in it. Heat the flask gently and notice what happens at the end of the tube. What is the explanation? Remove the lamp but allow the end of the tube to remain in the water. Explain what happens.

2. Light a candle. On the table on each side of the candle put a match; on the matches place a lamp chimney. Light a joss stick or piece of cloth and hold at the lower end of the chimney near the matches. What do you notice inside of the chimney? What does this show?

3. How are the principles illustrated by these two experiments applied in the hot-air furnace?

The hot-water system. In the hot-water system the water is heated in the basement by the furnace and is then conducted through pipes to radiators situated in the various rooms. (See figure 2.) In the attic is placed a tank connected with this set of pipes. The hot water passes to this tank and to the radiators, and then back to the furnace, where it is reheated. 
The explanation of the circulation of the water is similar to that of the circulation of the air in the hot-air system. When water is heated, it expands and becomes lighter and is pushed up by the cold water, which descends to the furnace where it is reheated, thus keeping a constant circulation of

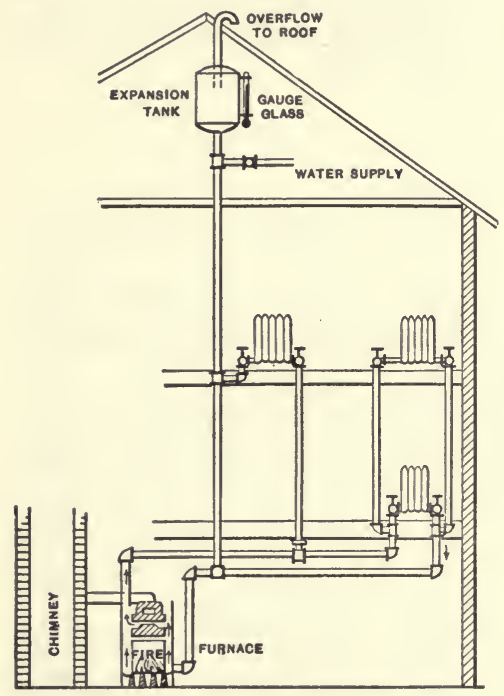

FIG. 2. - Hot-water system. water through the pipes. This is called the direct method of heating.

In another method of heating, the coils containing the hot water are placed in the basement, and fresh air from outside is drawn in and heated and then distributed to the various rooms by means of pipes and registers, as in the hot-air system. This is called the indirect method of heating. (See figure 5.) This system has an advantage over the direct method in that it provides better ventilation.

In still another system the radiators are placed in each room as in the direct method, and an opening from outside near the radiators brings in fresh air, which is heated by passing over the radiators. This is called the direct-indirect method. (See figure 6.)

\section{DEMONSTRATION 2}

Purpose. To study the principles applied in hot-water heating. Apparatus. Flask, stopper and tube used in previous experiment, two flasks with two-hole rubber stoppers, two pieces of glass tubing about ten inches long. 
Directions. I. Fill the flask with water and insert the stopper so that water stands in the tube about an inch from the stopper. Tie a colored string around the tube at the surface of the water. Heat the flask and watch the liquid in the tube. Remove the lamp and allow the water to cool. What happens to the water in the tube in each case? What does this show?

2. Secure two flasks, one a little smaller than the other. Break a hole in the bottom of the smaller one. Fill the larger flask with water and insert a rubber stopper with two holes. Through these holes push two pieces of glass tubing about ten inches long. Push in one tube until it just passes through the stopper. Push in the other tube about halfway to the bottom of the flask. Invert the other flask, insert a rubber stopper with two holes and push in the ends of the glass tubings. Add water until the upper ends of the tubing are covered. Add a few drops of red ink. Heat the lower flask and notice the circulation of the water.

3. How are the principles illustrated in these two experiments applied in the hot-water heating?

Steam heating. The method of heating by steam is similar to the hotwater method except that steam instead of hot water circulates. There is a similar system of radiators connected by pipes with the furnace. At the furnace the boilers are so arranged that the water is changed into steam, which

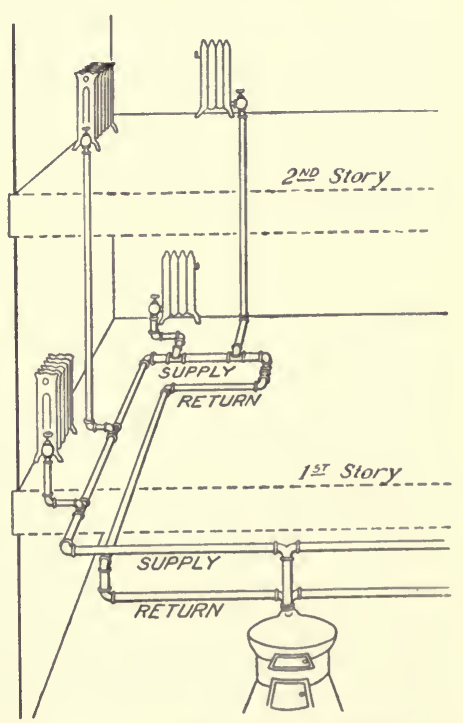

FIG. 3. - A steam-heating system. then circulates through the pipes. The same indirect method, as explained under the hot-water system, and like- 
wise the direct-indirect method explained above may be used.

The source of the heat in the steam is due not merely to the fact that the steam is hot, but largely to the fact that when steam condenses it gives off a large amount of heat. When water is boiled, it takes a large amount of heat to change it into steam. When we wish to measure the amount of heat, we use a standard called the calorie, as we use the pound to measure weight. A calorie represents the amount of heat necessary to raise the temperature of one gram of water one degree Centigrade. It requires over five hundred calories to change one gram of water into steam, that is, over five times the amount of heat needed to heat water from the freezing point to the boiling point. This heat is stored up in the steam, and when the steam condenses, the heat is given out to surrounding objects. It is the condensing of steam that furnishes most of the heat. Provision is made for pipes to take the water thus formed back to the furnace.

\section{Demonstration 3}

Purpose. To learn the source of heat in the steam-heating system.

Apparatus. Flask, rubber stopper with one hole, piece of glass tubing about eighteen inches long, beaker, ringstand, thermometer.

Directions. Bend the tubing twice at right angles so that the two arms are parallel and point in the same direction. One of these arms should be about three inches long, and the other arm about eight inches long. Fill the flask a third full of water and insert a rubber stopper with one hole. Push the short arm of the tubing through the hole in the stopper. Support the flask on a ringstand. Fill a beaker with cold water and place it so that the long arm of the tubing dips below the surface of the water in the beaker. Take the temperature of the water. Heat the water in the flask. After it has boiled five minutes, take 
the temperature again of the water in the beaker. How much has the temperature changed? What was the source of this heat?

The hot-water system has one great advantage over the steam system in that the water can be heated to any desired temperature and thus can be easily regulated in the mild weather; while in the steam system the water must be heated to the boiling point before any results are obtained, and in mild weather it is difficult to keep the temperature sufficiently low.

\section{Home Project I}

Purpose. To make a study of the heating system used in your home.

Directions. I. If your house is heated by hot air, steam, or hot water, make a careful study of the different parts of the system. Begin with the furnace and notice where the various pipes lead, and trace the circulation of air, water, or steam through the house and back to the furnace. Make a drawing of a section of the house from the garret to the cellar, showing the different parts of the system in their proper position.

2. Make a study of a cook stove when there is no fire in it, so that it can be taken apart. Make a drawing of a cross section of the stove. Label in the drawing the following parts: ash pan, grate, draft damper, oven damper, oven clean out. By means of black arrows show the path of the smoke and products of combustion around the oven and up the flue when the oven damper is up. By means of red arrows show the path when the damper is down. Notice how the stove may be cleaned out.

Heating by electricity. The latest improvement in heating is the use of electricity. This method is very convenient and does away with the smoke and dirt of stoves and furnaces. At present it is just in its beginnings and is now too expensive for common use. In the future, improvements will doubtless be made and electricity will be sold at 
a lower price, hence it is quite possible that a hundred years from now, electricity may be the common method of heating. As the stoves and furnaces of to-day have taken the place of the fireplaces formerly in common use, so in the future, electric radiators may take the place of stoves and furnaces.

The chemistry of burning. The source of heat in any of these systems, excepting electricity, is the burning of the fuel. In coal the chief element is carbon. In wood, too, this is found, together with other elements including a gas called hydrogen, which also burns. The burning of coal consists in the union of the oxygen of the air with the carbon, forming an invisible gas called carbon dioxid; and consists to a lesser extent in a union with hydrogen, forming water. In breathing we give off the same gas, which is formed in our bodies in a similar way, but not so rapidly, by the union of oxygen and carbon. This process of uniting with oxygen takes place in all ordinary types of burning, as in the candle and the kerosene lamp.

Fuels are of three kinds: solid, such as coal and wood; liquid, such as kerosene; and gaseous, such as illuminating gas. Coal and wood are the fuels most commonly used for heating purposes.

Coals are divided into two classes, the hard and the soft. The hard coal contains a larger per cent of carbon, and the soft coal a larger per cent of volatile substances that are driven off when the coal is heated. These substances are not completely burned, and as a result a large amount of smoke is formed. In order that the fire may continue to burn, the various products formed must be carried off through the chimney ; and a new supply of oxygen must be furnished. The fire is controlled by means of dampers which regulate the amount of air that enters. The important part of the air for the purpose of burning is oxygen. This constitutes about one fifth of the air. Experiments with pure oxygen 
show that substances burn much more vigorously in it than in air.

Before a substance will burn, it must be heated to a certain temperature called the kindling temperature. In kindling fires, substances are first used with a low kindling temperature, such as paper, then this sets fire to a substance with a higher kindling temperature, like wood, and finally the wood in burning heats up a substance like hard coal with a still higher kindling temperature, till it, too, burns.

\section{Demonstration 4}

Purpose. To prepare oxygen and study its properties.

Apparatus. Test tube, glass tubing about eighteen inches long, pneumatic trough, four wide-mouthed glass bottles, potassium chlorate, manganese dioxid, oxone, sulfur, iron picture wire, deflagrating spoon.

Directions. A. Preparation of oxygen. I. Fill the test tube half full of a mixture of equal parts of potassium chlorate and manganese dioxid. Insert a stopper with a hole. Bend. the glass tube about three inches from one end to make an acute angle, and at the same distance from the other end bend it to make an obtuse angle. Insert the end with the acute angle in the hole of the stopper, and put this in the test tube. Support the tube on the ring of a ringstand. Place the other end of the tube under the shelf of the pneumatic trough. Fill the trough with water to cover the shelf. Fill four wide-mouthed bottles with water and invert on the shelf.

2. Heat the test tube gently, allowing the first bubbles to escape. Then place one bottle with the mouth over the opening in the shelf so as to collect the gas. When the water has all been forced out, remove the bottle and put another in its place. In this way fill four bottles.

3. In place of potassium chlorate and manganese dioxid oxone may be used. The advantage of using this is that it is not necessary to heat the substance. It may be placed in a bottle and when water is added, oxygen is given off at once. 
B. Properties of oxygen. I. Invert one of the bottles and put in it a burning splint. How does the action compare with that in the air? Pour in a little limewater, shake the bottle. The white precipitate shows the presence of carbon dioxid.

2. Fasten a wire to a candle, light the candle and plunge it into a second bottle. Note results.

3. Put some powdered sulfur in a deflagrating spoon. Ignite it in a flame and then lower it in a third bottle. Note the difference between burning in air and in oxygen.

4. Wrap a small piece of cloth around the end of an iron picture wire. Roll this in powdered sulfur and hold it in the flame. When it has started burning, lower it into a fourth bottle of oxygen.

5. What conclusions do you draw from these experiments regarding the properties of oxygen and the difference between burning in air and in pure oxygen?

\section{LABORATORy Exercise I}

Purpose. To study the burning of wood, soft coal, and hard coal.

Apparatus. Ringstand, wire gauze, gas burner or alcohol lamp, small piece of wood, soft coal, and hard coal.

Directions. I. Place a small piece of wood on a wire gauze on a ringstand. Heat the wood. Place the gauze at such a height above the flame that the wood is heated without bursting into a flame. When the wood begins to smoke, hold a lighted match above it. The flame formed is due to the burning of the volatile substances driven off from wood by the heat. What change takes place in the wood?

The substance left is charcoal. Apply a flame to it and see if it will burn. How does the burning differ from that of the volatile substances?

2. In a similar way try soft coal, using a piece about as large as the end of your finger.

3. Repeat the experiment, using hard coal. What difference do you note in the burning of the two coals? The substance left after the first heating is coke. Will this burn? 
Means of starting fires. In the early times fires were kindled by rubbing two sticks together. A great improvement was made on this method when sparks were formed by striking a flint against an iron ore, called pyrites. This method was commonly used till a little less than a century ago, when matches were first made. When a match is drawn across a rough surface, the friction generates enough heat to set fire to the substance on the tip of the match, which then ignites the wood. Sulfur and phosphorus have been commonly used because they ignite at a low temperature. With these is usually mixed some compound that contains oxygen, so that the sulfur will burn more readily. Until recently yellow phosphorus was one of the substances commonly used to tip matches. This is a dangerous element to handle and has a very injurious effect on the people who make the matches,

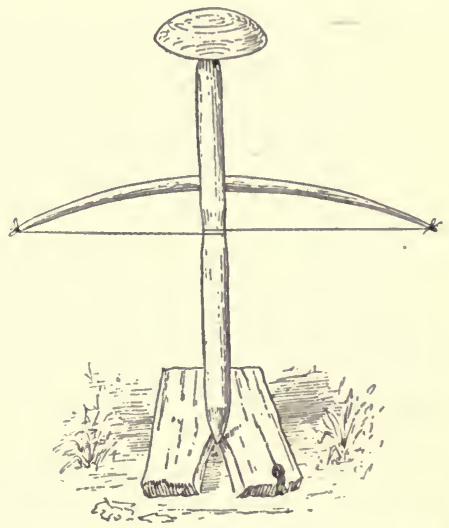

Fig. 4. - Primitive method of making fire by friction. causing a disease of the bones which usually proves serious. The use of this kind of phosphorus has been forbidden by law, and in its place a harmless compound of phosphorus is now used.

In safety matches the harmless red phosphorus is used. This is placed on a rough striking surface so that the match can be ignited only by rubbing it on this specially prepared surface. These are much less dangerous than the ordinary match, as there is less danger of accidental fires, such as may occur when mice gnaw matches and ignite them. While it may be a little more trouble to use safety matches, this is more than repaid by the lessened danger from fires. 


\section{LABORATORY EXERCISE 2}

Purpose. To compare safety matches and ordinary matches. Apparatus. Safety matches, ordinary matches.

Directions. Notice the parts of an ordinary match. How does a safety match differ? Light an ordinary match and note the order in which each part burns. Do the same with a safety match. Try to light each kind of match on an ordinary board surface. What difference do you find? What advantage has the safety match?

\section{SUPPLEMENTARY QUESTIONS FOR CLASS DISCUSSION}

I. Why are fireplaces still used?

2. What advantages has electricity as a means of heating ?

3. Why is the stove superior to the fireplace as a means of heating?

4. What principles of physics are applied in each of the methods used in heating. our homes?

5. What are the chief differences between the hot water and the steam methods of heating?

\section{REFERENCE}

Barber, First Course in General Science, Henry Holt and Company, New York City. Chap. 2. 


\section{CHAPTER II}

\section{VENTILATING THE HOME}

I. What are the essentials for a good system of ventilation?

2. From the standpoint of the ventilation provided which is the best heating system?

By ventilation is meant the keeping of the air in which we live in such a condition that it will be healthful to our bodies. The problems of heating and ventilating the home should be considered together, because the method of ventilation depends on the method of heating and should be arranged for at the time that the heating system is put in. Much can be done later to ventilate the house, however, even if no provision was made for it when the house was built.

\section{Demonstration 5}

Purpose. To study the composition of air.

Apparatus. Candle, cork, plate, tumbler, limewater.

Directions. I. Get a cork stopper a little larger than the diameter of a candle. Cut off a piece about half an inch thick from the large end. In the center cut a hole big enough to receive a short candle about an inch long. Float this in a plate full of water. The experiment can be seen better if a few drops of red ink are added to the water. Light the candle and after it is burning well, invert the glass tumbler over it. Allow to stand for a while after the candle goes out. Why does the candle go out? What happens to the water in the tumbler? The water rises to take the place of the oxygen used by the 
candle. The gas left in the tumbler is nitrogen. What are the proportions of oxygen and nitrogen?

2. To show the presence of carbon dioxid, pour some limewater into a dish and allow it to stand for an hour or two. The white coating that forms on the surface of the water shows the presence of carbon dioxid.

3. To show the presence of water in the air. Bring into the schoolroom a metal cup containing a mixture of ice and salt. What is the source of the water that condenses on the outside of the cup?.

\section{Demonstration 6}

Purpose. To learn how the air we breathe out differs from the air we breathe in.

Apparatus. Thermometer, limewater, straw, bicycle pump.

Directions. I. Breathe on the bulb of a thermometer and compare the temperature with that of the room.

2. Pour some limewater into a test tube and blow through it by means of a straw or glass tube. Pour limewater in another tube and force air through by means of a bicycle pump. Which solution gets the milkier? What does this show?

3. Breathe on a window pane. What do the results show?

4. Remove the covers of two quart canning jars. Allow one jar to stand outdoors. Have a pupil breathe into the other by means of a glass tube. Screw the covers on both jars tightly and let them stand in a warm place for a day or two. Just after the children have come in from outdoors, have the pupil who breathed into the bottle smell of the air in both bottles. What difference is noted? What does this experiment show?

5. What four changes have taken place in the air we breathe out?

Breathing. The air is made up of about one fifth oxygen, four fifths nitrogen, a small fraction of one per cent of carbon dioxid, besides minute quantities of other gases; and it also contains varying amounts of invisible water vapor. In the process of breathing, the air is taken into the lungs, and 
the oxygen is taken by the blood to all parts of the body. Here it unites with the food that has been digested and absorbed, and burning takes place slowly, in much the same way that coal and wood burn in the stove, only much less rapidly. As a result of this burning, the body is kept warm and power is given to use the muscles. In this process of burning, carbon dioxid is formed and carried back by the blood to the lungs, from which it is exhaled. As a result of this process of breathing, the oxygen in the air has been reduced from 2 I per cent to I 6 per cent, and the carbon dioxid increased from one twenty-fifth of one per cent to about 4 per cent; and there has been also an increase in the amount of water.

The ill effects of lack of ventilation. The ill effects of lack of ventilation, as frequently shown in crowded rooms and lecture halls, are well known. Drowsiness, fatigue, lack of attention, headache, and a general feeling of discomfort are the results. Frequent colds and similar ailments are the common results in winter of lack of proper ventilation. Likewise, the ill effects on those who are obliged to work for long periods of time in poorly ventilated rooms are shown on every hand, especially by contrast with those who work outdoors. There is a tendency toward a general undermining of the health, which may develop into tuberculosis and other lung troubles, while those who are much in the open are healthier and much less likely to contract these diseases.

Chemical causes of ill effects. In order to know how to ventilate properly, we need to know what are the causes of these ill effects, so that we may know what to seek and what to avoid. Two classes of causes have been proposed at various times, the chemical and the physical. As the air undergoes chemical changes in the process of breathing, the early theory was that the injurious effects of bad air were due to a lack of oxygen or to an excess of carbon dioxid. 
But experiments have shown that neither of these is the cause, since under ordinary conditions practically all air contains enough oxygen for breathing, and practically no air contains enough carbon dioxid to be injurious. Another explanation was that there were tiny organic particles given off in breathing which produced the ill effects; but experiments seem to show that these are not the cause; but disagreeable odors, due to particles given off from the body, from decaying teeth, and from clothing, render the air very unpleasant and may at times produce injurious results.

Physical causes of ill effects. The cause for the ill effects of poor ventilation is thus seen not to lie in the lack of chemical purity of the air, but must be sought in its physical conditions. Ventilation is not merely a matter of breathing alone, but also a matter of the reaction of the skin to the air with which it is in constant contact.

Recent experiments. seem to show that in seeking the essentials of ventilation, we should consider the effect of the air on our skin rather than the effect of the air we breathe on our lungs.

How the body controls its temperature. In order to understand what is needed for ventilation, one needs to know something of the part that the skin plays in the control of the heat of the body. Heat is produced in the body by the oxidation of food. The temperature of the body is kept constant, about 98 degrees, and the body is provided with means by which this temperature is automatically kept uniform. There are two methods by which the body loses heat, first by sending large quantities of blood to the surface of the skin, where it is cooled; and second, by the evaporation of water from the pores of the skin, in what is called perspiration. If the body is too warm, the arteries in the skin open wide and thus allow large amounts of blood to come to the skin, where cooling takes place; and the sweat glands increase their activity in evaporating water. On the other hand, if the 
body is too cool, the arteries contract and less blood is sent to the skin, and the activity of the sweat glands is lessened.

The ill effects of lack of ventilation are due largely to interference with this heat-regulating mechanism. Recent experiments show that these ill effects are due chiefly to four causes: (I) lack of air currents, (2) unpleasant odors, (3) too high a temperature, (4) too little or too much moisture in the air.

Essentials of ventilation. A proper system of ventilation should therefore do these things :

I. It should furnish a gentle current of air.

2. It should change the air so as to keep it free from disagreeable odors.

3. It should heat this air to the proper temperature, not to exceed 70 degrees.

4. It should add moisture to bring the air up to the proper degree of humidity, from 50 to 60 per cent.

Air currents. In order to meet the first and second conditions, each room in the house should have two openings, one by which the fresh air may enter and another by which the used air may leave. The inlet for fresh air may be provided by means of registers connecting with pipes which lead to the fresh air supply heated by the furnace. The outlet for the used air may be provided by means of a fireplace flue, with which each room may be connected by a short pipe, or the outlet may be provided directly by the open fireplace itself. A change of air may also be brought about through the use of windows and doors.

The common notion that drafts are injurious is a mistaken one, as they are essential to good ventilation. You do not take cold when out in the wind if you are properly clothed. When sitting indoors, it is well to guard against exposing a small part of the body to a very cold, strong draft; but some motion of air is essential to our comfort and health. If there is no movement of air, the layer of air next to the 
skin becomes warm and saturated, and so retards further evaporation and loss of heat, and the body becomes uncomfortably warm.

Colds and similar ailments, which are so common during the winter, are not due usually to exposure to drafts, as is often thought, but are caused generally by the unhealthful conditions that too often exist indoors during the cold season; hot, dry, motionless air. The remedy for these ills is to remove the conditions that cause them.

\section{Demonstration 7}

Purpose. To learn the conditions necessary for a change of air in ventilation.

Apparatus. Candle, lamp chimney with even top, two matches, cardboard.

Directions. I. Light the candle, place the chimney over it. Why does the candle go out?

2. Light the candle again. On each side, place a match. On the matches place the chimney and cover the top with the cardboard. Why does the candle go out now?

3. Repeat the previous experiment, except that the cardboard is not placed over the chimney. Why does the candle continue to burn?

4. What do these experiments show?

Temperature. If the temperature is too high, the body makes extra exertion by means of the sweat glands and blood vessels to lower the temperature. As a result the blood is drawn to the surface from other parts of the body, and even then the body temperature may not be kept down to the proper level. One of the most common causes of ill effects from poor ventilation is too high a temperature. It has been proved that the most healthful temperature for the living rooms is between 65 and 70 degrees. When the temperature becomes higher than 70 , it produces feelings 
of discomfort, and makes work more difficult. The temperature at which one feels comfortable depends on the humidity. With the low degree of humidity usually found in our houses, about 68 degrees is the best temperature. But if enough moisture is added to raise the humidity to 50 or 60 per cent, one will feel just as comfortable at 65 degrees. The best temperature also depends on the occupation and dress of the people living in the room.

Thermometer. The temperature may be easily watched by means of a thermometer. This consists of a glass tube with a very small bore and a bulb at one end filled with mercury, or some colored liquid, usually alcohol, which does not freeze at ordinary temperatures. In making a thermometer, the air is removed from the bore above the liquid, so that there is nothing left to interfere with the motion of the liquid. Heat causes the liquid to expand and rise in the bore, which is marked off into degrees. In the common Fahrenheit thermometer, the freezing point of water is marked 32 degrees and the boiling point 2 I 2 degrees, and the space between is divided into 180 degrees. In the Centigrade thermometer the freezing point is marked $\circ$, and the boiling point roo degrees, and the space between is divided into roo degrees. The Centigrade is much more convenient and is widely used in Europe for general purposes and for scientific work in this country.

\section{LABOratory EXERCise 3}

Purpose. To study and test thermometers.

Apparatus. Fahrenheit thermometer, Centigrade thermometer, beaker or tumbler, ice.

Directions. I. Make drawings side by side of a Fahrenheit and of a Centigrade thermometer. In each drawing mark the following points : the freezing point of water; the boiling point of water (this may not appear on some thermometers); the temperature of the body (hold finger on bulb or breathe on 
it - the result will be only approximate as the liquid will not rise quite to the body temperature) ; the proper living temperature of the schoolroom in winter.

Into how many degrees is the space between the freezing and boiling points marked on each scale? What advantage do you think the Centigrade scale has over the Fahrenheit? Do you see any disadvantage?

2. The thermometers found in houses are often incorrect. Bring yours from home so that you can test it. Place the end of the thermometer in a tumbler and fill the tumbler with cracked ice. Allow it to stand till the water from the melted ice covers the bulb, and the liquid in the thermometer falls no lower. Record the reading. The correct reading is 32 . Hang up your thermometer beside a tested chemical one furnished by the instructor. Note the difference. The average of this difference and of the error at the freezing point may be taken as the correction to be made in using your thermometer.

Humidity. If the air is too moist, evaporation in the skin takes place too slowly and the body becomes too warm. If the air contains too little moisture, evaporation takes place too rapidly. The lack of moisture in the heated air in our homes in winter has an injurious effect on the nose and throat. As this dry air passes over the membrane lining the nose and throat, it causes an excessive amount of evaporation from these surfaces, which become dry, parched, and irritated. As a result they afford a lodging place for germs, and we become more easily subject to colds and other diseases of the throat and nose. Furthermore, these membranes are not able to do so well their ordinary work of filtering the air of impurities.

This extreme dryness found indoors during the winter produces an artificial and unnatural condition because it is such a contrast to the natural condition found outdoors.

The amount of moisture in the air is measured in terms of per cent. When the air is saturated (that is, holds all it can, as just before a rain), the humidity of the air is said to 
be roo per cent. If it holds one half as much moisture as it could contain, the humidity is said to be 50 per cent. Outdoors the humidity ranges from 65 to 75 per cent or more. Indoors during the winter in the ordinary heated room, it is found that the humidity is very low, ranging from 20 to 30 per cent.

During the winter the air taken into the heating system from outdoors is very cold, and as it is heated, its power to hold more moisture increases rapidly, doubling for about each change of 20 degrees: thus air which at a temperature of 30 degrees may be half saturated, at a temperature of 70 degrees will be only about one eighth saturated, and hence be very dry and possess great absorbing power. This humidity may be raised by introducing water into the hotair chamber in the cellar. Many of the water pans often found in hot-air furnaces are worthless, because they do not add enough moisture to affect the humidity appreciably.

In order to furnish enough moisture for an ordinary house, from one to two quarts of water should be evaporated hourly. There are now being sold on the market instruments called humidifiers, which can be used to supply the necessary water.

\section{Demonstration 8}

Purpose. To find the humidity of the room.

Apparatus. Two thermometers, or a sling psychrometer.

Directions. I. Fasten a piece of soft muslin cloth around the bulb of one of the thermometers, and allow the other end of the cloth to hang in a bottle filled with water. Hang another thermometer beside this. Fan the bulbs vigorously for a short time, then look at the reading of the wet bulb. Continue to fan until the mercury in the wet bulb ceases to go any lower. Then take the reading of both the thermometers. A slight difference means a moist air. A large difference means a dry air. The per cent of humidity may be found from the table in the appendix, page 555. For example, if the difference between the two thermometers is 16 degrees, and the reading of the dry 
bulb is 70 degrees, the figure opposite 16 and under 70 gives the per cent of humidity, in this case 33 . Find the humidity of the air outdoors.

2. If a sling psychrometer is available, the test can be made more quickly and accurately.

Comparison of heating systems. We may now examine the various systems of heating with reference to the provision they make for ventilation. No system which fails to make some such provision should receive serious consideration.

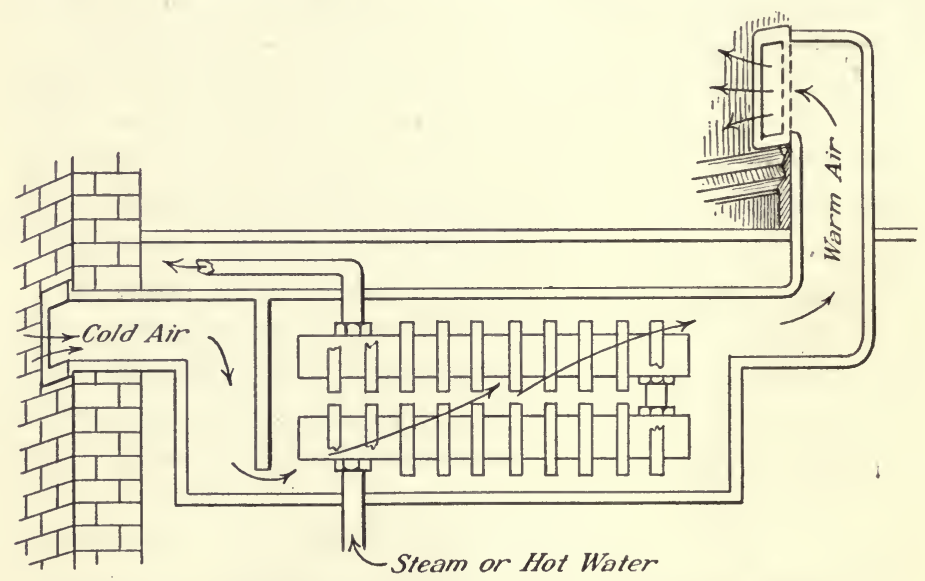

FIG. 5. - A method of ventilation in steam and hot-water systems.

The hot-water and steam heating systems, as ordinarily installed with radiators in each room, are the poorest, as no provision is made for change of air. The hot-air furnace, when fresh air is taken from outside, is preferable as it provides for a change of air. If only one opening is provided, - that is, the register where the hot air enters, - some ventilation is provided, since some air is forced out around the windows ; but in the best systems, another opening to a flue in the chimney is provided by means of which the used air is taken away. 
If properly installed, the hot-water system is probably the best. To provide for change of air, coils of pipe are placed in the basement. Fresh air is led from outdoors over these pipes, where it is heated. It can then be distributed to the rooms above by means of hot-air pipes, in a manner similar to that used with the hot-air furnace. This is superior to the hot-air furnace for two reasons: first, because the air does not become so intensely heated and dried, and second, because the temperature can more easily be controlled and kept down in the mild weather of late fall and early spring. It also has this second advantage over the steam system. Ventilation may also be secured by bringing the air directly from outdoors and allowing it to pass over a radiator. (See figure 6.) As ordinarily installed the hot-air furnace is the best from the standpoint of health, provided that air is taken from outdoors.

The open fireplace provides good ventilation, as air passes up the chim-

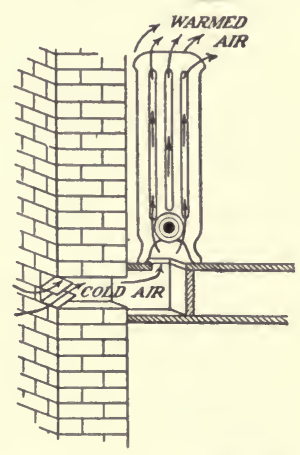

FIg. 6. - Ventilation at the radiator. ney and fresh air is drawn in from around the windows and doors. The stove provides ventilation in the same way.

Oil stoves and gas stoves are both unhealthful, as they draw the supply of oxygen from the air and give off all their waste products into the same room. As there is no provision for removing it, the air soon becomes filled with these products, some of which have a disagreeable odor.

\section{Home Project 2}

Purpose. To learn if your home is properly ventilated.

Directions. I. Is the air kept in motion? Light a piece of punk, or cloth, or a joss stick and hold it in various parts of the room and at different heights from the floor and notice the 
direction of air currents as shown by the smoke. Make a drawing of the room and show the direction of currents by means of arrows. Open some windows and test again for air currents. Find out which combination of open windows gives the best circulation of air.

2. Is a change of air provided? When you first come in from outdoors do you detect odors in the room? Are there any openings through which air enters the room? Does this air come from outdoors, from the cellar, or is it return air taken from the room? Are there any openings where the impure air can escape?

3. Is the room kept at the proper temperature (from, 68 to 70)? Read the thermometer several times during the day. Place it in different parts of the room and at different heights from the floor and take the readings. Make a record of all the readings in a table like the following.

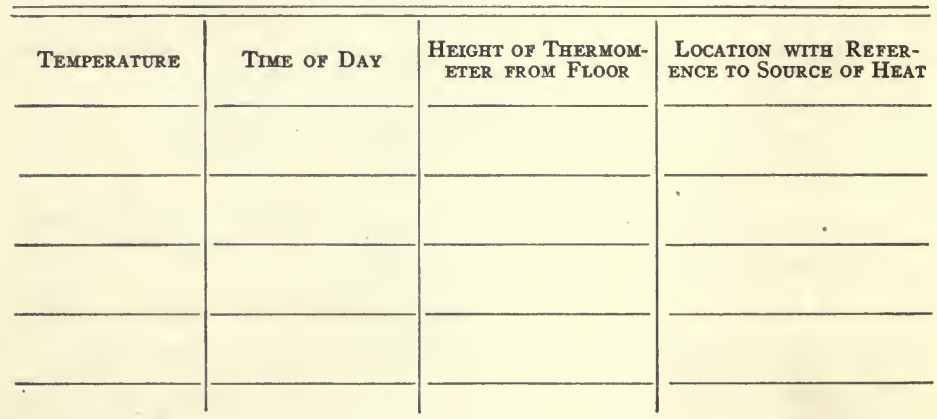

4. Is the proper degree of humidity maintained (from 50 to 60 per cent)? Determine the per cent of humidity, using the method explained in demonstration 8 . Find also the humidity outdoors.

5. Which of the four essentials of ventilation are provided in your home? Which ones are not provided? What can be done to provide those essentials that are lacking?

Ventilation by windows. Unfortunately in many of our homes no special provision was made for ventilation when the house was built, so we must plan our ventilation as best 
we can by means of doors and windows. A certain amount of ventilation takes place through the walls of houses and around the windows and doors. When a system of hot-air heating is used by means of which fresh air is forced into the room, other air must be forced out through these cracks and this provides some ventilation, sufficient perhaps for a small family but not enough for a schoolroom. In the hot-water or steam system, when radiators are placed in the rooms with no provision for bringing in fresh air, the amount of ventilation brought about by means of the cracks around the windows is inadequate. This is especially true of our modern houses which are made more completely air tight than formerly. Often too in northern climates
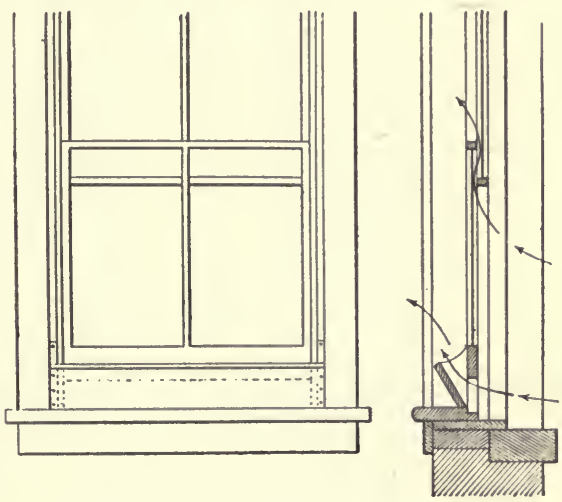

Fig. 7. - Ventilation by window. they are provided with storm windows, which tend to keep out the fresh air that might otherwise have entered.

Ventilation may be secured by opening windows on different sides of a room, and a board may be placed in front of a window to break the strength of the wind. One excellent way of providing ventilation without lowering the temperature of the room is to fit a frame to the lower window like a mosquito screen, so that the window may be lifted and the frame placed under it. This may be made any height, and covered with ordinary cotton cloth. This allows the fresh air to enter but prevents the room from being suddenly cooled, as the cloth does not lose heat much faster than the glass in the window. 
Ventilation of sleeping room. Special attention should be given to the ventilation of our sleeping rooms, even in the coldest weather. Fresh air should be provided by opening the windows wide, and in cold weather we may keep ourselves comfortable by extra blankets. In cold, windy weather, strong drafts may be avoided by placing a chair with a towel or piece of cloth over it in front of the window; or a board

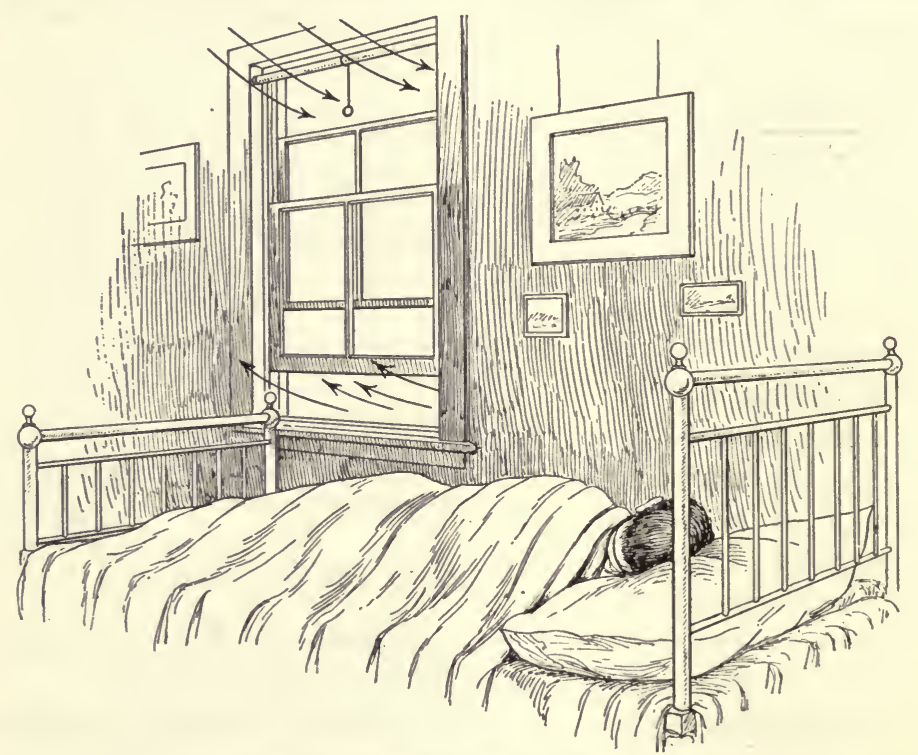

FIg. 8. - Getting fresh air at night.

may be placed across the bottom of the window in such a way that the air will strike this and be deflected over the top into the upper part of the room. Or a screen mentioned in the previous paragraph may be used. In order to get the full benefit of the ventilation furnished by the window in figure 8 , it would be better for the sleeper if he slept with his head at the foot of the bed, or if the bed were turned end for end. 


\section{Home Project 3}

Purpose. To make a ventilating screen.

Directions. Make a ventilating screen to fit your bedroom windows for use in cold weather. Follow the directions given on page 29. Try it and see if it proves satisfactory.

The sleeping porch is the best means for procuring perfect ventilation while asleep. Even after the house has been built, a sleeping porch can be easily added to it. In most sections of our country this can be used all the year round. And even in the northern portions it can be used three fourths of the year. From the standpoint of health, a sleeping porch is one of the most profitable investments that can be made.

\section{Home Project 4}

Purpose. To make a sleeping porch.

Directions. Talk the matter over with your parents and see if it is possible to arrange some place where you can sleep out at least during the warmer months of the year. There may be some porch that can be screened and fixed without much trouble. A small sleeping porch can often be added to the house at slight expense.

\section{SUPPLEMENTARY QUESTIONS FOR CLASS DISCUSSION}

I. How does the air we breathe out differ from the air we breathe in?

2. What theories have been advanced to explain the reason for the ill effects due to poor ventilation? Which is the correct one?

3. How does the body control its temperature?

4. Are the essentials of ventilation provided in your home? In the schoolroom?

5. What is the principle involved in the thermometer?

6. What is the relation of humidity to ventilation? 
7. Heated air contains the same amount of water that it did when cold. Why is the per cent of humidity so much lower?

8. How may ventilation be secured during the night while asleep?

\section{REFERENCES}

Barber, First Course in General Science, Henry Holt and Company, New York City. Chap. 6.

Fisher and Fisk, How to Live, Funk and Wagnalls, New York City. Chap. r. 


\section{CHAPTER III}

LIGHTING THE HOME

What advantages has each of the methods now used for lighting the home?

Early means of lighting. As we have already seen, methods of heating have gone through many changes, beginning with crude devices used by primitive people. In a similar way methods of lighting have undergone many changes, beginning with the simplest forms used thousands of years ago. Probably the first method of lighting was a torch made by setting fire to the end of a stick. This was the only means used for many hundreds of years. In time crude forms of candles appeared, and these were gradually improved until now we have our modern candle. At first candles were made by hand by dipping a string into melted tallow and allowing it to cool, and then dipping . again until the desired size was obtained. Today candles are made by machinery by pouring the melted paraffin into molds, through the center of which hang strings.

In our own country torches were frequently

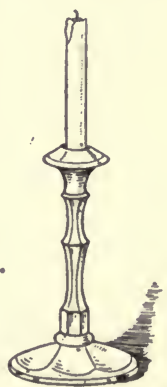

Fig. 9. - Candle in candlestick. used by the early settlers: Lincoln learned to read by the light of pine knots. The candle was very widely used even during the first half of the last century.

Early lamps. Another means of lighting used in early times along with the torch was a crude form of lamp. This 
consisted of some open receptacle like a shell, filled with oil, in which was placed a wick of some fibrous material. These lamps gave a very weak and flickering light and gave off much smoke. It was a long time before a chimney was invented. The first lamp with a chimney was made about one hundred twenty-five years ago by a Swiss named Argand.

Various kinds of oils have been used. During the first half of the nineteenth century whale oil was in common use in this country. This was later replaced by kerosene, which has been in use for only about fifty years.

The plan of lighting a house by gas carried to different rooms through pipes was first tried about one hundred twenty years ago. A little less than a hundred years ago gas was first used to light the streets of an American city.

Finally came the electric light. The arc lamp for street lighting was first used about forty years ago. A little later, for use indoors, appeared the incandescent lamp, which is so widely used to-day.

Burning of the candle. When the candle is first lighted the heat melts the paraffin, this liquid is drawn up the wick by capillarity, the heat then changes the liquid to gas, and the gas burns with a flame. The elements in the gas unite with the oxygen of the air, and gases are given off, chiefly carbon dioxid and water vapor. An ordinary flame consists of two parts, a bluish inner portion and a yellowish outer portion. This inner part consists of the unburned gas formed by heating the liquid. The outer part consists of the burning gases. The light of the flame is due to small particles of carbon which become intensely hot, and glow, thus giving off light. The yellowish color is due to the presence of small quantities of compounds of a metal called sodium, which is present in minute quantities even on the dust particles of the air. 


\section{LABORATORY EXERCISE 4}

Purpose. To study the burning of a candle.

Apparatus. Candle, piece of glass or cardboard.

Directions. I. Light the candle. After it is burning well, light a match, blow out the candle, and then quickly hold the lighted match about a half inch above the candle. Why does it light? Try several times to see how far above the candle you can hold the match and have it light.

2. How many parts do you see in the candle flame? What is happening to the paraffin near the wick? Blow out the candle flame and look quickly at the wick and feel of it. What does it contain?

3. Press a piece of glass or cardboard down on the flame and hold it so for a second or two. What is formed on the glass? How is it arranged?

4. Hold a match or toothpick across the middle of the flame till it begins to burn, then take it away and blow out the flame on the wood. Where does it begin to burn first?

5. What do the last two experiments show regarding the hottest part of the flame?

\section{LABORATORY EXERCISE 5}

Purpose. To find out what conditions are needed for a candle to continue burning.

Apparatus. Lamp chimney with level top, limewater, glass tumbler.

Directions. I. Light the candle. Invert a glass tumbler over it. Why does it go out? Light the candle again. Invert over it a canning jar. Does the candle burn any longer? Why?

2. Light the candle. On each side place a match and on these put the lamp chimney. Place a piece of cardboard on the top of the chimney. Why does the flame go out?

3. Light the candle and place it on a piece of blotting paper. Put the chimney over the candle and hold it down firmly on the blotting paper. Why does the flame go out? 
4. Light the candle and place a match on each side. On the matches place the chimney. Does the flame act any differently than in the previous experiments? Why?

5. What do these experiments show that a candle needs in order to keep burning?

6. To show what is given off when a candle burns, place a candle about an inch long in a glass tumbler. Light the candle and cover the tumbler with a piece of cardboard. After the flame goes out, quickly remove the candle and pour some limewater into the tumbler. Cover the tumbler and shake. The white substance formed shows the presence of carbon dioxid.

Kerosene lamps. The kerosene lamp marked a great advance over the candle as it gives a stronger and steadier light. Kerosene is obtained from petroleum, a thick liquid found in the earth. It contains a great variety of substances, which are separated from each other by heating the petroleum. As this is heated the various liquids present boil and are given off as gases which are caught and cooled till they condense to liquids again. . Those which boil at the low temperatures are given off first. These gases are caught in different vessels according to the temperature at which they are given off, and thus the various liquids are separated. Kerosene is one of the liquids that has a high boiling point. If the oil we burn in lamps should contain liquids that burn at a low temperature, there would be danger of explosion, so the government as a protection requires that kerosene shall have a flashing point of suffciently high temperature to be safe under ordinary conditions. The flashing point is the temperature at which a momentary flașh is formed when a flame is brought near the oil. The standard set is usually about i ro degrees. The temperature at which a continuous flame would be maintained is from 40 to 50 degrees higher. This is called the burning point. 
The principle involved in the burning of kerosene is the same as with the candle, except that the substance used is a liquid instead of a solid. The heat changes this liquid to a gas which burns and gives off heat and light. One feature which gives the kerosene lamp a great advantage over the candle is the use of a chimney. This creates a draft which furnishes a constant supply of fresh air to the wick, and insures a steady light. In some lamps the wick is made circular so that the air is supplied from the inside as well as from the outside. In one type of hanging lamp, the wick and chimney are placed on the side, so that the light is thrown downward.

Capillarity. The process by which the kerosene rises through the wick is called capillarity. Other illustrations of capillarity are seen in the absorption of ink by a blotter and in the rise of water through soils. When water stands in a dish, the water at the side is attracted by the dish and rises slightly, making a curved surface. If the container becomes so small as to be a tube, the water inside the tube rises higher than the surface outside, and the smaller the tube the higher the water rises. The spaces between the threads of the wick act like small tubes through which the kerosene rises.

\section{Demonstration 9}

Purpose. To study the structure and workings of a kerosene lamp.

Apparatus. Ordinary kerosene lamp, small tube, plate, two pieces of glass of the same size, rubber band, two tumblers, red ink, lump of sugar, blotting paper.

Directions. I. Study the structure of the parts of the lamp. What purpose does each part serve?

2. Light the lamp. After it burns for a minute blow it out and quickly hold a lighted match above the wick. Try several times to see how far above the wick the match can be held and still light the wick. What does this show? 
3. Light the wick and keep the chimney off. Fan the flame gently. Put on the chimney. What difference does it make in the flame? Fan the air near the chimney. How does the effect differ from that when the chimney was off?

4. Push a piece of cloth up under the burner and cover the small holes on the under side. What happens? Why?

5. The method by which the oil passes up through the wick is called capillarity. A few simple experiments will illustrate this. Put a small tube in water. Compare the level of the water inside with that outside.

Put some water in a plate and add a little red ink. Place two pieces of glass together and set them on edge in the plate. Separate the two at one edge and insert a piece of toothpick or match. Keep the opposite edges touching by means of a rubber band. Hold the pieces in this position and notice how the water rises between the plates. How do you explain the curve assumed by the water between the pieces of glass?

Put the edge of a piece of blotting paper in ink and see how far up the ink will rise. Hold the corner of a lump of sugar in water and note results.

Gas. The use of gas marks another advance in the methods of lighting. The mantle flames give a stronger light than the kerosene lamp; and the gas fixtures are much more convenient, as burners can be placed in each room and connected with a common supply of gas.

Two kinds of gas are commonly used, coal gas and water gas. Coal gas is made by heating coal in an inclosed retort so that it cannot burn. As a result combustible gases are given off. These are purified and finally stored over water in large tanks. Large pipes carry the gas to various parts of the city, and small pipes from these lead to each house. The pressure is kept up by the weight of these tanks, which rise and fall according to the supply of gas they contain.

Water gas is more commonly used. This is made by passing steam over heated coal. As a result hydrogen and cárbon monoxid are formed, both being gases which burn 
readily. The carbon monoxid is a very poisonous gas and great precaution should be observed in the use of water gas, to see that there are no leaks in the pipes and that the gas is not escaping at an unlighted burner.

As the gas enters the house, it first passes through a meter by means of which the amount used is measured. The pressure of the gas moves a disk back and forth, which is connected with a mechanism that rotates hands on a dial. There are several of these dials, one measuring small amounts, about 5 cubic feet, another I000 cubic feet, another I0,000,

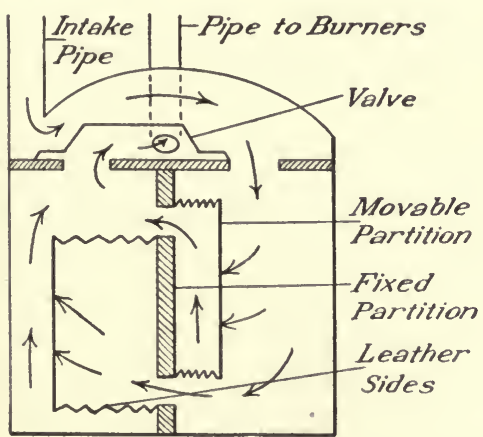

Section through meter

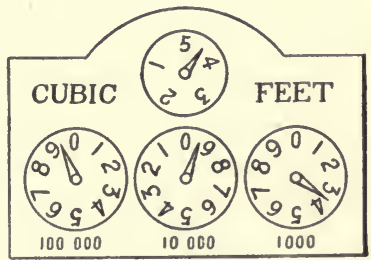

Dial

Fig. 10. - The gas meter.

and another 100,000. By subtracting the reading found at any previous date from the present reading, the amount of gas used can be determined.

One way of finding out whether the gas pipes leak in the house is to make a careful reading of the meter at night after the lights are turned out and then make another reading the next day just before the gas is lighted. The difference represents the amount of gas that has leaked out. Even if the expense involved is slight, the leakage may be dangerous to the health of the people living in the house.

At first, burners were used, at which light was given off directly by the burning of the gas. But a great improve- 
ment has been made through the use of mantles, which give a stronger light and use less gas. These mantles are made of substances which do not burn, but which when heated give off a bright light. Mantles must be replaced occasionally, as they are so fragile that they are very easily broken. In burners that are equipped with mantles a special arrangement is made for admitting a large supply of air so that more complete combustion takes place. This gives a higher temperature, which makes the mantles incandescent.

\section{Home Project 5}

Purpose. To read the gas meter and learn the cost of the gas used.

Directions. I. If you use gas in your home, make a reading of the meter. Make a drawing of the circles on the meter and indicate the pointer in each in the proper position. Record the reading of the meter. Notice how the gas can be turned off in case it should be necessary, as when gas escapes from a broken pipe. One week later, read the meter again and make another drawing. Subtract the first reading from the second to find how much gas was used in a week. Find the price of gas and compute the cost of the gas used in one week.

2. In order to find out whether the gas pipes leak, read the small dial called the test dial, just after the gas is turned off for the night. Read the dial again the next day just before the first burner is lighted. Any difference in the readings represents the amount of gas that has leaked from the pipes.

Acetylene. The chief advantage in the use of acetylene gas lies in the fact that it can be installed for isolated houses too far away from towns to use gas or electricity. The gas is made by adding water to a solid substance called calcium carbide. The generating apparatus is so arranged that the water and carbide are brought in contact, the gas is collected in tanks, and the amount of gas generated is regulated by pressure. The house is piped as for gas, and the pipes are 
connected with the tanks. Acetylene gas gives a very brilliant white light. Occasionally one hears of dangerous explosions from the use of these outfits.

\section{LABORATORY EXERCISE 6}

Purpose. To generate acetylene.

Apparatus. Test tube, calcium carbide.

Directions. Fill a test tube half full of water and place it on a test tube rack. Drop into the tube two or three small pieces of calcium carbide. Notice what happens in the water. Stand a little distance from the tube and apply a lighted match to the mouth. Note the appearance of the flame due to the burning of the acetylene.

Electricity. The latest advance made in lighting is the use of electricity, which is more convenient even than gas. When the current first enters the house it passes through a meter, which records the amount of electricity that is used in the house. This meter has several dials and looks much like a gas meter. A switch is usually provided so that the current may be disconnected. If an extra strong current should pass through the wires, they would become heated and might set fire to the house. To avoid this danger, a fuse box is provided where the current enters the house. The fuses are

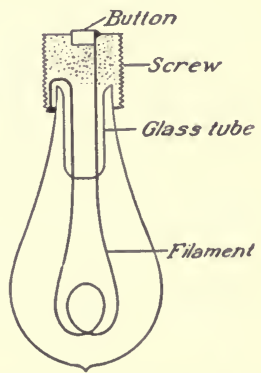

FIG. Ix.-Incandescent lamp. made of such materials that if too strong a current passes through them they melt. Thus the circuit is broken and the current does not pass through the wires in the house. In wiring the house, care should be taken to see that the wires are properly covered with some insulator, which, being a nonconductor of electricity, will not permit the current to pass through. 
The light in the bulb is due to the wires or filaments coiled inside, which offer so much resistance to the current that they become white hot and their glowing produces light. In the first lamps these filaments were usually made of carbon; but now other elements, such as tungsten, are being used in place of carbon. (See figures II and I2.) These

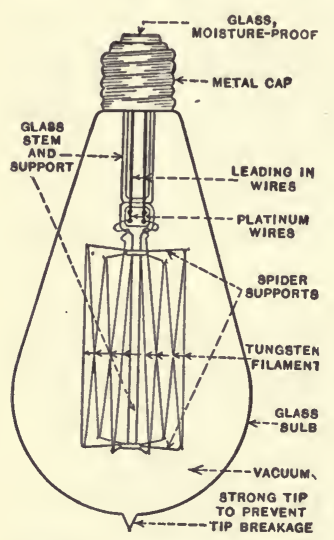

Fig. 12. - Mazda lamp.

lamps cost more than carbon filament lamps, but they are more economical as they use less electricity than carbon in giving the same amount of light. To prevent these filaments from uniting with oxygen and "burning up," the air is pumped out of the bulbs so that the interior of the bulb is a partial vacuum. This accounts for the loud report made when one breaks.

One pleasing method of lighting is called the indirect method, in which a large shade is suspended from the ceiling or fastened to the walls, with the lamps placed inside of it. The lamps cannot be seen and so do not dazzle the eyes; but the shades permit some diffused light to pass through, and some light is reflected from the ceiling.

\section{Home Project 6}

Purpose. To read the electric meter and compute the cost of electricity.

Directions. I. If you use electricity in your home, read the meter. Make a drawing of the circles showing the position of the pointers. Record the reading.

2. Notice how you could cut off the current if you should wish to. Can you think of any circumstances under which it might be desirable to do this? 
3. One week later, read again. How much electricity was used in one week? Find out the price of electricity and compute the cost for one week.

Comparison of lights. These different means of lighting may now be compared to see which is the best. From the standpoint of health one point to consider is the effect on the air of the room. In this respect the electric light is the best as it does not affect the composition of the air. All other forms of lighting take oxygen from the air and give off waste products into the air as a result of burning. In those lamps in which there is a complete burning, as the mantle gas lamp and acetylene, only carbon dioxid and water are given off. But in those cases where the burning is not complete, as with the kerosene lamp and ordinary gas burners, besides those gases there are given off others which are injurious in their effect on the health.

Another point to consider is the effect of the various lamps on the eye. Steadiness is an important requirement. From this standpoint, the electric lamp, the acetylene flame, and the mantle gas lamp are the best, as they give a steady light. Next comes the kerosene lamp, which is fairly steady; and poorest of all are the candle and ordinary gas burner, which give such a flickering flame as to tire the eye.

Glass and sunlight. To-day our houses during the daytime are brightly lighted by the sunlight that comes through the window panes. But before glass was made, houses were dark and dingy, because people used oiled paper and isinglass in their windows. Glass to-day is so common and cheap that we perhaps do not realize what a great help it is to us. Window glass is made of pure sand and compounds of the two metals, calcium and sodium, lime and soda being commonly used. These are heated together at a very high temperature and form liquid glass. As it cools, it becomes pasty and can be worked into various shapes. 


\section{SUPPLEMENTARY QUESTIONS FOR CLASS DISCUSSION}

I. What advantages has the kerosene lamp over all methods of lighting used previously?

2. In what ways are the burning of a candle and of a kerosene lamp similar? In what ways are they different?

3. Of how many illustrations of capillarity can you think?

4. In what ways is gas better than kerosene for lighting?

5. In what ways is electricity better than gas?

\section{REFERENCES}

Barber, First Course in General Science, Henry Holt and Company, New York City. Chap. I.

Holland, Historic Inventions, G. W. Jacobs, Philadelphia. Chap. I4. 


\section{CHAPTER IV}

\section{THE HOME WATER SUPPLY}

I. What care should be taken to see that wells and other sources of drinking water are kept pure?

2. What has the air to do with the working of a pump?

3. Which is the best method of getting running water in the home?

Kinds of wells. Dug wells. The water supply for the home that is not connected with a system of public waterworks may be obtained from wells, cisterns, springs, or brooks. The commonest type of well is the dug well, which may be either shallow or deep. The most important consideration is the purity of the water, and this is chiefly affected by the surroundings of the well. A well drains a region in the form of an inverted cone with its point at the bottom of the well and its sides extending out at varying angles. There should be no cesspools, sink drains, barn yards, or privies near enough so that the drainage from them can reach the well.

The soil acts as a filter, and impure water as it passes through the soil tends to become purified, but after a while the soil becomes clogged with the impurities which it collects, and so loses its power to purify water. When there is a constant source of impure water, like a cesspool, near the well, the soil between the two tends to become less effective as a filter the longer it is used. 
The conclusion to be drawn is that the well should be located so far from possible sources of impurities that there will be no danger of pollution. This distance varies with different conditions, such as kind of soil, the slope of the surface and of the rock strata, and the depth of the well. In general, however, the well should be a hundred feet from sources of impurities. If the slope of the surface is toward

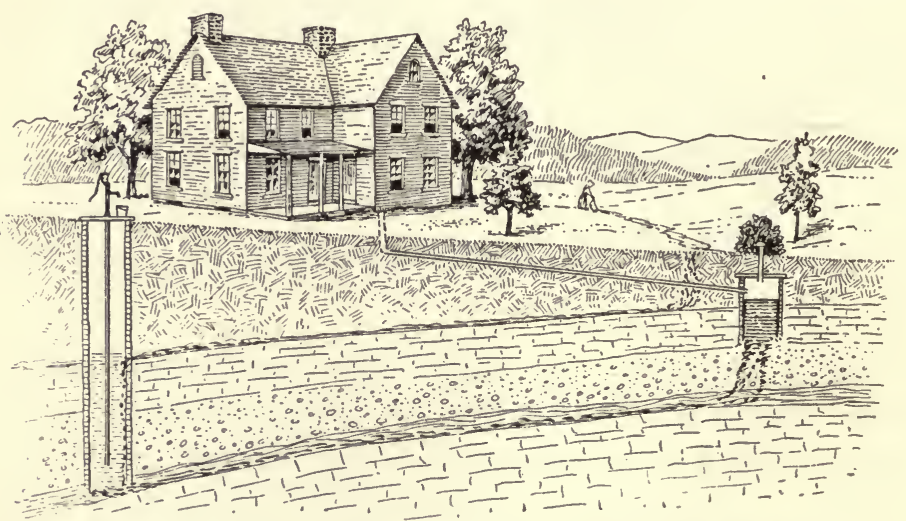

FIG. I3. - Danger of having cesspool and well too near together.

the well, the impurities are more apt to find their way into it. But even when the surface is level, the slope of the rock strata beneath may slant toward the well.

The well should be so constructed as to prevent surface water from draining into it. The top portion should be bricked down for six feet so as to be water-tight, and a casing of cement or brick should be raised about a foot above the surface. The covering over the well should be tight to prevent any impurities from falling through. A trough should be provided under the pump spout to carry off the overflow when the pump is used. Care should be taken to see that dirt is not tracked on to the well covering. 

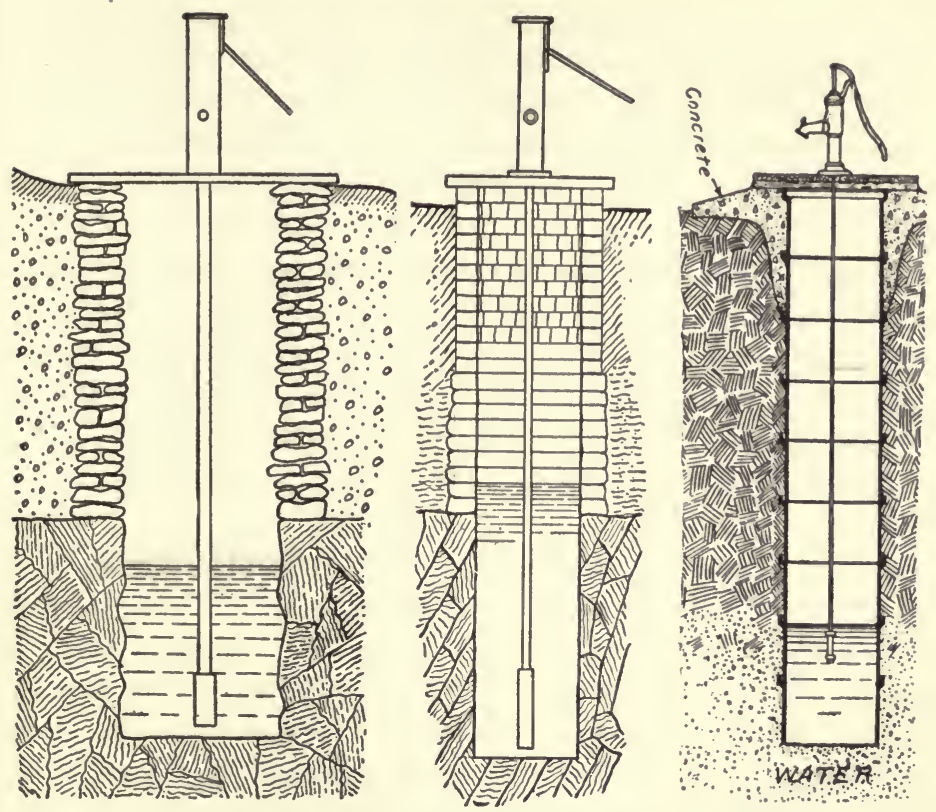

Fig. I4. - The two figures on the right show the right way and the figure on the left shows the wrong way to construct a well.

\section{Demonstration io}

Purpose. To test the purity of drinking water.

Apparatus. Distilled water, samples of drinking water from several sources, solution of potassium permanganate, nitric acid, solution of silver nitrate, two beakers, test tubes.

Directions. I. To test for decaying vegetable matter. Pour some distilled water into a beaker. Pour the same amount of drinking water into another beaker. Add to each beaker one drop of potassium permanganate solution. Boil the drinking water for a few minutes and allow it to cool. Compare the colors in the two beakers. If the color of the drinking water is very different from the pinkish tint. of the distilled water, vegetable impurities are present. 
2. To test for animal impurities. To the sample of water to be tested add a few drops of nitric acid and a few drops of silver nitrate and stir. If the water becomes milky, animal impurities are present. This is not an infallible test, because the presence of chlorides in the water will also give a white precipitate.

Bored wells. Sometimes bored wells are used. This is really a convenient way of digging a small well. Soil augers are used. The soil is removed for a considerable depth and the hole lined with tiling. The same precautions should be observed with reference to this well as for the dug well.

Driven wells. To make a driven well, a pipe with a hard point is driven into the ground till a layer of soil is reached that has a constant supply of water. The pipe is removed and the driving point is replaced with a filtering point covered with a sieve, which allows the water to enter but prevents the dirt from filling the pipe. The pipe is then driven down again. Under favorable conditions these wells may prove satisfactory. The chief objections are that the amount of water that can be pumped at one time is small and that the pipe may get clogged with dirt, especially if the soil is very fine.

Drilled wells. On the whole the drilled well is the most satisfactory. By means of drills and machines, a hole is drilled in the ground and a pipe driven down the hole as fast as it is drilled. Wells of this type may be drilled to a great depth, and the water thus obtained is pure, if care is taken that the pipes do not leak.

Springs. Occasionally springs are so located that they may furnish a satisfactory source of water. The chief consideration here, as with dug wells, is the cleanliness of the surroundings. If there is no source of impurity near, the spring will furnish a supply of good water. But care should be taken to prevent surface pollution. It is well to build up a casing about a foot above the ground the same as with a well. 
Brooks. It may sometimes happen that a house is so situated that water from a brook may be piped to the house. But generally such sources of water are undesirable. They are open to many sources of contamination and during the summer they are apt to dry up altogether.

Cisterns. Cisterns are sometimes used as a source of drinking water. If proper precautions are taken, these may be fairly satisfactory. The cistern should be water-tight to prevent impurities from entering. Various kinds of impurities gather on the roof, and therefore arrangements should be made so that the first washings from the roof during a rain may be conducted away, and then the later washings turned into the cistern.

Pumps. After the purity of the water is assured, the next question to consider is the method by which the water is brought into the house and distributed. One of the most common methods, especially for cisterns, is the pump. The ordinary cistern or suction pump consists of a cylinder $C$, with a piston $P$ that works inside the cylinder. This piston has a leather washer so that it fits the cylinder tightly. In the center of the piston is a weight or valve $V$ so arranged that pressure from above closes it tight, while pressure from below opens it. At the top of the pipe $T$, where the pump is fastened, is a similar valve $S$ which opens up and lets the water through, but which closes down and prevents the water from going back. A pipe $T$ connects the cylinder with the well or cistern.

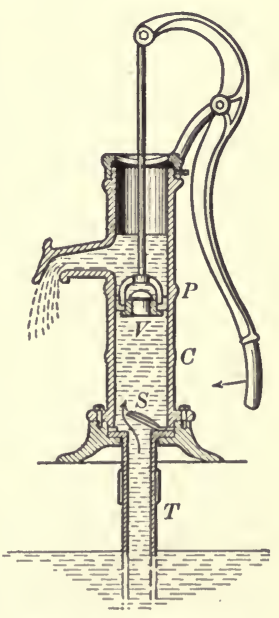

Frg. 15. - A suction pump.

How the pump works. In order to understand how the pump works, let us suppose that the cylinder is full of water and that the pump handle is down. When the handle is 
lifted, the valve $V$ in the piston opens and the water passes through while the piston is being pushed down to the bottom of the cylinder. When the handle is pressed down, the piston $P$ is lifted, the valve $V$ in the piston closes and the water above is lifted and flows out through the spout. At the same time the lower valve $S$ is opened upwards and the water enters and fills the cylinder; and then the operation is repeated as before.

It is easy to understand how the piston and its valve works, but what causes the lower valve to open and the water to rise? To push water up in this way requires some force and we are curious to know what this force is. It is the weight of the air pressing down on the surface of the well which forces the water up the pipe.

Weight of air. Perhaps you do not realize that the air has weight, but it has been proved by experiment. By means of an air pump the air has been pumped out of airtight vessels and the vessel weighed before and after removing the air. The second weight is found to be less than the first, the difference being the weight of the air. Air is very light but it extends up so high, perhaps twenty-five to fifty miles or more, that the total weight of air bearing down on any surface is very great.

Experiments have shown that the air bearing down on each square inch of surface weighs fifteen pounds, so that the air bearing down on your hand weighs about three hundred pounds. How, then, can you hold your arm out straight with all this weight on it? It is because the air that touches the back of your hand pushes up with the same force that the air on the palm of your hand pushes down, so that the two balance and you do not feel the weight. Likewise the air exerts an equal pressure sidewise, thus keeping its weight balanced in every direction. It is only when by a machine, such as an air pump, the air is removed from some space, that the unbalanced pressure shows its tremendous force. 
The weight of air presses down on the water in the cistern and the pressure is exerted all through the water, so that, at the opening of the pipe, water is forced up the pipe and into the cylinder of the pump. When the piston of the pump is raised, a vacuum is formed in the cylinder and water is forced up to fill this space by the weight of the air on the surface of the water in the cistern.

As there is a limit to the weight of air, so there is a limit to the height to which water may be pumped by the common suction pump. This limit is the height of a column of water which is one inch square and weighs fifteen pounds. This height is found to be about thirty-two feet. Air will not force water higher than this, because the weight of this height of water is just balanced by the weight of air extending up as high as it goes.

\section{DemONSTRATION II}

Purpose. To show that air has weight.

Apparatus. Air pump, bell jar with open top, rubber membrane.

Directions. Tie a piece of rubber membrane over the open top of a bell jar. Place the bell jar on the stand of an air pump and remove the air by means of the pump.

\section{LABORATORY EXERCISE 7}

Purpose. To show that air has weight and hence exerts pressure.

Apparatus. Test tube, glass tubing about six inches long, glass tumbler, piece of paper, rubber tubing about a foot and a half long, pint milk bottle, hard-boiled egg with shell removed.

Directions. I. Fill a test tube with water. Place your thumb over the end and invert it in a dish of water. Remove your thumb after the end of the tube is under water. Why does the water stay in the tube?

2. Put a piece of glass tubing in water till it is submerged. Place your finger over the upper end and remove the tube from 
the water. Why does the water remain in the tube? Remove your finger. Why does the water fall?

3. Fill a tumbler with water. Over the top place a piece of paper and press it down firmly on the rim. Hold the paper on with one hand and invert the tumbler with the other. Remove the hand from the paper. What keeps the paper up?

4. Submerge a piece of rubber tubing about a foot and a half long in a dish of water till the tube is full of water. Pinch one end of the tube with the thumb and finger and bring it out over the edge of the dish into another empty dish placed a little lower than the first. Remove the hand. What makes the water flow? Raise the second dish higher than the first, keeping the end of the tube under water and note what happens. A tube used in this way is called a siphon.

5. Light a piece of paper and drop it into a pint milk bottle. After the flame goes out, put a hard-boiled egg with the shell removed in the mouth of the bottle. How do you explain what happens?

6. Do these experiments help you to explain the working of a fountain-pen filler and why it is possible to drink soda water by means of a straw?

\section{LABORATORY EXERCISE 8}

Purpose. To show how a pump works.

Apparatus. A small cistern pump or a glass model of a lift pump.

Directions. Operate the pump and note carefully how it works. Take it apart and examine the various parts. Make a drawing of the pump and explain how each part works.

Lift pump. If the well is deeper than thirty-two feet, a lift pump is used. In this kind of pump, both valves are in a movable cylinder, which may be placed in a large pipe, within thirty-two feet of the surface of the water. The pressure of the air forces the water up to the cylinder, and from here it is lifted by means of a rod attached to the cylinder at one end and to the pump handle at the other. 
Frequently the cylinder is kept below the surface of the water in the well.

Force pump. If water is to be forced higher than the spout of the pump, a force pump is used. The lower part $S$ and $T$ is like the ordinary pump. The spout instead of being open is a water-tight pipe which connects with an air dome $A$. As the pump is worked, water is forced into this dome and compresses the air there, which in turn forces the water out through another pipe, giving a steady flow of water.

Running water in the house. It is easier and less expensive than is commonly thought to have running water in the house, and the convenience is worth the expense many times over.

Gravity system. One of the best systems is the gravity system,

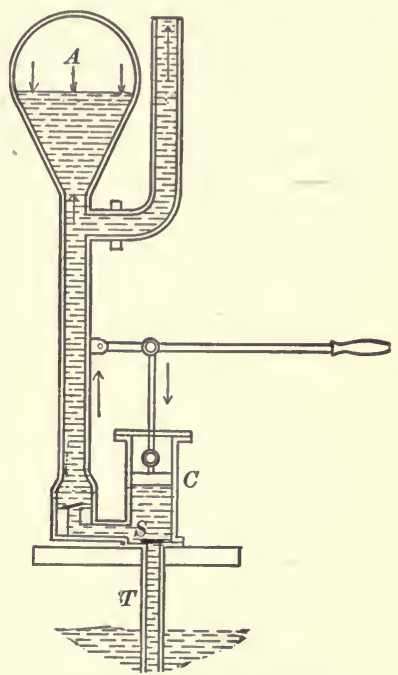

Fig. I6. - A force pump. when conditions are such that it can be used. For this purpose the stream or spring must be high enough above the house so that the water may be piped directly from the source of water supply into the house. This system is cheap and reliable, but the necessary conditions are found only occasionally.

Hydraulic ram. When the source of water is below the level of the house, some kind of pump and power to work it must be used. The cheapest method is the hydraulic ram, which requires a running brook with sufficient fall to furnish the needed power, and a very liberal supply of water, as the machine wastes about seven times as much water as it pumps. The principle involved is that some of the energy 
of the running water is used to compress air and this compressed air forces water through the pipes. The ram may pump the water from the brook that operates it, or it may pump water from a separate source. The advantages are that it is very cheap to operate and requires no one to attend to it. Its disadvantages are that there may not be enough fall of water or stream flow to operate it, and that the accumulation of air in the summer and the formation of ice in the winter may interfere with its operation.

Windmill. Another cheap source of power is the windmill. The wheel of the windmill is made of strong blades

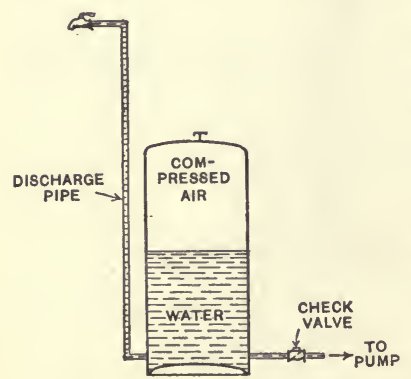

Fig. I 7. - Pneumatic tank. of wood or steel, curved or flat, and set at such an angle that the wind blowing against them causes the wheel to rotate. The wheel must be kept at right angles to the wind in order to be turned by it and it is kept in this position by a fan-like tail which works like a weathervane. When it is desirable to stop the wheel, this tail can be turned by means of a wire so that it is parallel with the wheel, which then turns its edges toward the wind and ceases to rotate. On the axle is a cogwheel that fits into another cogwheel to which is fastened a crank. This moves the piston of the pump at the base of the windmill up and down. A serious objection to the windmill is that the time of its operation cannot be controlled. There may be long periods of calm, and a large tank must be provided to allow for this possibility. Water may be piped directly from the elevated tank to the house.

An objection to the outdoor tanks in the northern states, by whatever method filled, is the danger of freezing during the severest weather. Tanks are sometimes placed in the attic of the house, but there is always the danger of leakage 
or that the weight of the tank when full may prove too great a strain for the house.

Pressure tanks. . On the whole, one of the most satisfactory devices is the pressure or pneumatic tank. (See figure 17.)

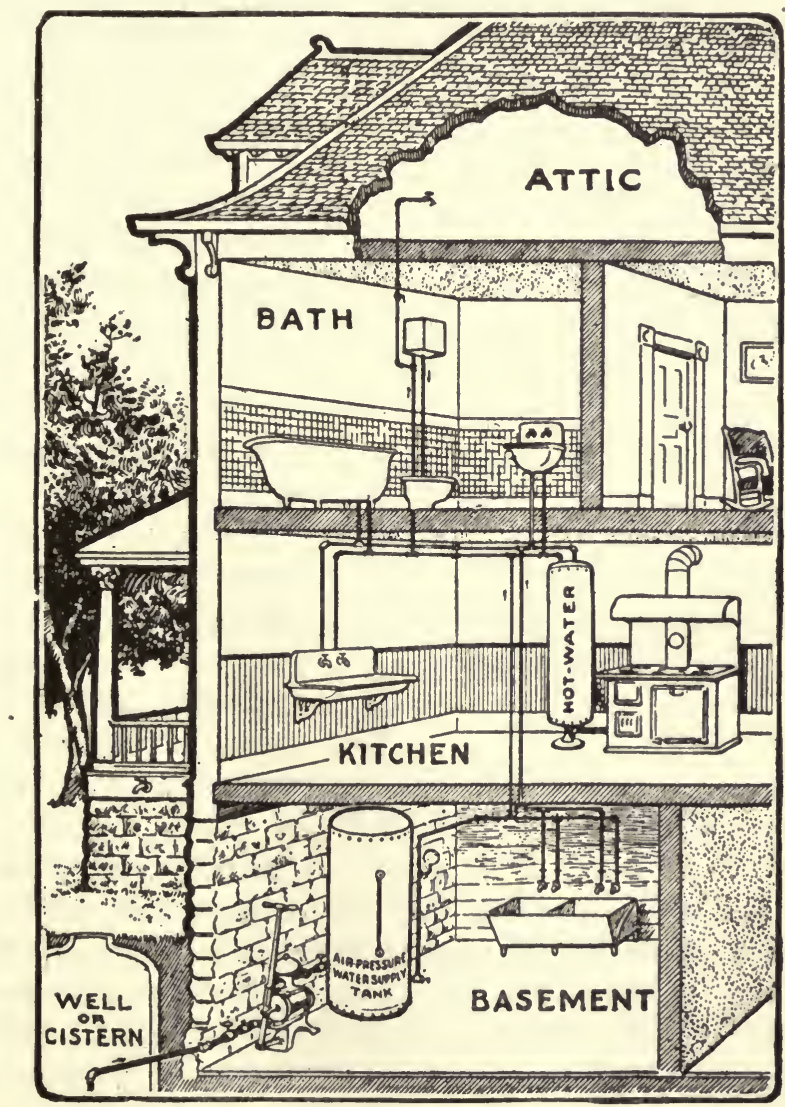

Fig. 18. - Pneumatic tank system of water supply for country houses.

This is an iron cylinder, which may be located in the cellar or sunk in the ground below frost line. This is connected with 
the well and by means of a pump the water is pumped into the tank. At the same time the pump compresses the air above the water in the tank, and this compressed air forces the water from the tank up through the pipes leading to the various parts of the house. Arrangements are made to pump new air into the tank to take the place of that dissolved by the water. The pumping may be done by hand, by windmills,

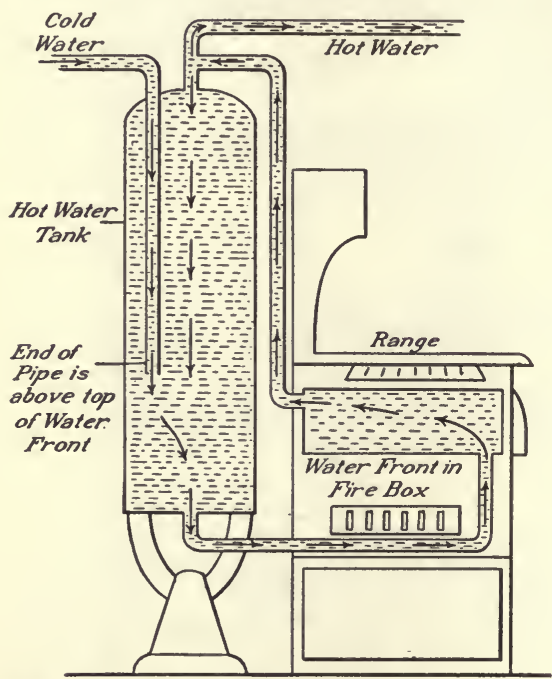

Fig. 19. - Hot-water tank and water front in range. by gasoline engines, or by electric motors. Where electricity is available, the motor is the most convenient, as it may be arranged to work automatically according to the air pressure, both to start and to stop.

Hot-water tank. Running water in the house allows of a constant supply of hot water during the cold weather when the fires are burning. The cold water is first brought into the hot-water tank by means of a pipe extending nearly to the bottom of the tank. The water is heated by passing through coils of pipes that are placed in the stove or furnace. From here it passes back to the tank, where it accumulates in the upper half and is drawn off from the top and circulates through the house. 


\section{Home Project 7}

Purpose. To read the water meter and compute the weekly cost of water.

Directions. I. If you have connections in your home with a supply of running water, read your water meter. If you have the straight reading register, copy the figures found there. If you have a dial-reading register, make a drawing in your notebook of your meter. Draw each circle, copying the figures, and draw in the pointer in its proper place with reference to the figures. Bring the drawing to school so that the teacher may explain how to read the meter.

2. One week later, make another reading and subtract the first reading from the second. Find the price charged for water and estimate the cost of one week's supply.

\section{SUPPLEMENTARY QUESTIONS FOR CLASS DISCUSSION}

I. Which is the best type of well?

2. How do the lift pump and force pump differ from the cistern pump?

3. What are the advantages of having running water in the house?

4. Of how many facts can you think which show that air has weight?

\section{REFERENCES}

Bashore, Outlines of Rural Hygiene, F. A. Davis Co., New York City. Chap. I.

Lynde, Home Water Works, Sturgis and Walton, New York City.

Harper's Machinery Book for Boys, Harper Bros., New York City. Chap. 6 (Windmill). 


\section{CHAPTER V}

\section{THE HYGIENE OF THE DINING ROOM}

How may we know what kinds of food we should eat and how much in order to keep our bodies in the best health?

In considering the matter of foods, two questions arise: first, what kind of foods should be eaten, and second, how much food should be eaten. The first question may be looked at from two standpoints, from that of health and from that of cost.

Uses of foods. In order to answer these questions, we must first understand the uses of foods in the body. Foods serve three purposes: first, they furnish material for the growth and repair of the parts of the body; second, they supply the body with fuel, which yields heat to keep the body warm and furnishes power by which the muscles work; third, they regulate some of the processes of the body, such as the beating of the heart, the digestion of food, and other activities that are constantly taking place in the body. The body may be likened to a furnace. As the fuel is burned in the furnace and furnishes heat and energy, so food is used for maintaining life in the body. There is nothing, however, in the work of the furnace which corresponds to the first use of foods, for the furnace cannot build and repair its parts as the body can.

Kinds of nutrients. Studies that have been made of foods show that while we have a great variety of foods, yet the kinds of substances in them that actually nourish the body may be divided into a few groups of nutrients. The five 
kinds of nutrients are proteins, fats, carbohydrates, water, and mineral matters. All of our foods contain one or more of these nutrients. In selecting foods we are concerned chiefly with the first three nutrients. Examples of protein are white of eggs, the lean part of meats, and the gluten of flour; examples of carbohydrates are sugar and starch, such as is found in vegetable foods; examples of fats are butter and the fatty portions of meats.

\section{LABORATORY EXERCISE 9}

Purpose. To test foods for different kinds of nutrients.

Materials. Various kinds of foods, iodin, nitric acid, ammonia.

Directions. I. To test for starch. Heat a little corn starch in water and allow it to cool. Then add a few drops of a dilute solution of iodin in alcohol. A blue color shows the presence of starch. In a similar way test a number of common foods.

2. To test for proteins. Add a little nitric acid to a piece of meat in a test tube and boil. Pour out the acid, rinse the meat in water, and add ammonia. The yellow color is a test for proteins. Test a number of foods for proteins.

3. To test for fats. Place a piece of butter on a sheet of writing paper and warm over a flame till it melts. Then rub off the butter and notice the change that has taken place in the paper. This effect in making the paper transparent is a test for fat. Test other foods for fat.

4. Put records in the form of the following table.

\begin{tabular}{l|l|l|l}
\hline KIND OF Food & Srarch & ProteIN & Fat \\
\hline & & \\
\hline
\end{tabular}

Put the names of the foods in the first column and put a check opposite each food in the proper column to correspond with the tests. 
Uses of nutrients. The only kind of nutrient which can build tissue is protein, hence a certain amount of this kind of food is absolutely necessary for the maintenance of the body; but the amount needed is less than was formerly considered necessary. Proteins also serve as fuel in the body, but it is better that most of this fuel be obtained from other foods. Carbohydrates and fats cannot build tissues, but they serve the purpose of foods in yielding fuel to keep the body warm and to furnish energy for the muscles. Mineral matters aid in forming bone and other tissues and help to regulate some of the activities of the body. Water supplies the body tissues with fluid and carries nutrients in solution.

Vitamines. Recent studies of foods have shown that in addition to the five nutrients mentioned above there are other substances, called vitamines, that are important for a proper diet. These substances serve a very important purpose in regulating some essential body processes, such as the contraction of the muscles and the absorption of food from the intestines. When these vitamines are lacking in the diet serious results to health follow. It is known that there are two classes of these substances, one of which is soluble in water and the other in fat. The one soluble in water is found in many foods, including milk, eggs, meat, the bran and germ of cereals, succulent vegetables, legumes, and probably in all fruits. The one soluble in fat is found less widely distributed and more care is necessary in planning the diet to see that it is included. This is found in green leaves, such as lettuce, in eggs, liver, and the fat of milk. It is found to a lesser extent in meats, especially in the organs of the body and the fat near them.

Digestion of food. Before the nutrients can be used in the body they must go through the process of digestion, the purpose of which is to change foods into a soluble form so that they can be absorbed into the blood and used by 
U. S. Department of Agriculture Office of Experiment Stations

A. C. True: Director
Prepared by

C. F. LANGWORTHY

Expert in Charge of Nutrition Investigations

\section{COMPOSITION OF FOOD MATERIALS.}

\section{IIIIIIIII}

Protein

LAMB CHOP

EDIBLE PORTION

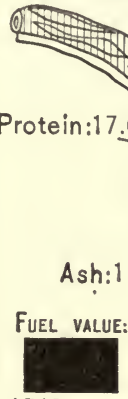

1540 CALORIES

PER POUND
Water:53.1
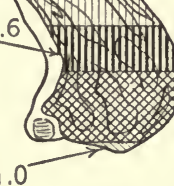

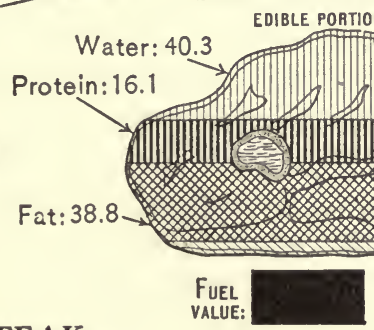

BEEF STEAK

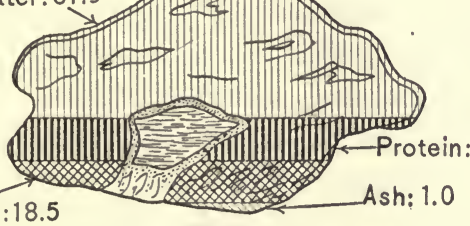

EDIBLE PORTION

Water: 61.9
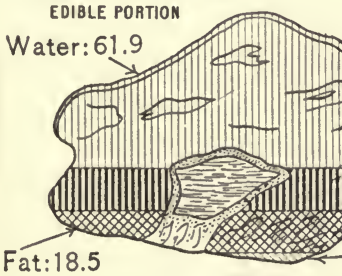

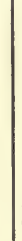

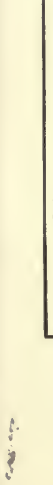

SMOKED HAM
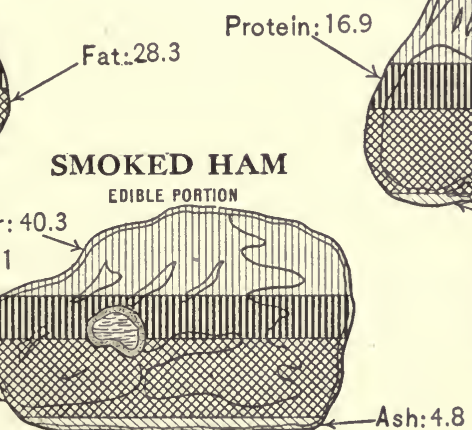

1940 CALORIES

PER POUND

\section{DRIED BEEF}

CDIBLE PORTION
PORK CHOP

EDIBLE PORTION

52.0

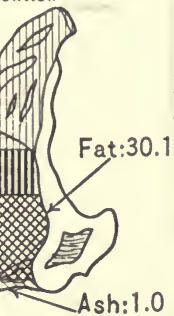

Fuel value:

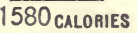
PER POUND

Protein:
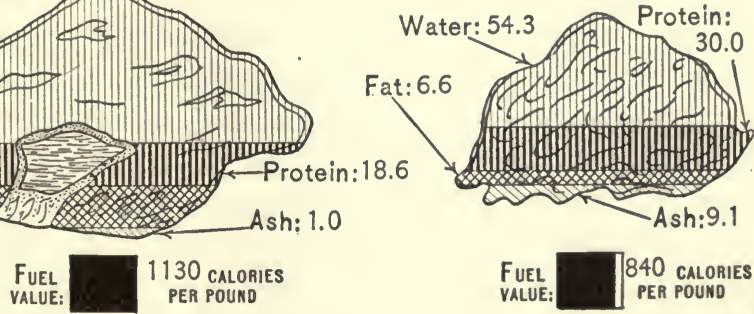

FIG. 20. - Composition of meats. 
the body. The process of digestion begins in the mouth, where the saliva acts on the starches, changing them into sugars. In the stomach the gastric juice acts on the protein, changing it to a soluble form known as peptone. The food is thoroughly worked over here and reduced to a fine semi-liquid state before it passes on to the small intestines. Just after the food leaves the stomach it comes in contact in the small intestines with the pancreatic juice, which has the power of digesting all three kinds of nutrients. It finishes the work begun by the saliva in digesting the starches, and that begun by the stomach in digesting the proteins, and in addition, with the aid of bile, it digests the fats.

Absorption of foods. After the foods are digested, they are absorbed through the walls of the intestines and carried by the blood to the various parts of the body, where they are used. The waste products resulting from the oxidation of foods are given off by the various excretory organs of the body. The carbon dioxid and some of the water resulting from the burning of the food pass off through the lungs.

Exercise and digestion. The subjects of exercise and digestion are closely related. One of the chief values resulting from exercise lies in the beneficial results which it has on the process of digestion. It is a well-known fact that those people who are doing heavy muscular work are less afflicted with digestive troubles than those who secure little muscular exercise. People who change their occupations or habits to those which require less muscular effort often find that their general health is much poorer. It is specially important for those living a sedentary life that some form of exercise should be taken regularly to insure the proper working of the digestive system as well as of the other systems of the body.

Our first answer to the question as to what kinds of food we need is that we must have foods which furnish enough of the proteins to build up and repair our body tissues and 
enough of the fats and carbohydrates to keep our bodies warm and to furnish energy for the muscles. So we next inquire from what foods we can best secure these proteins, fats, and carbohydrates.

Sources of proteins. Protein is an important constituent of meats, fish, beans, peas, cereals, and nuts. (See figure 2I.)

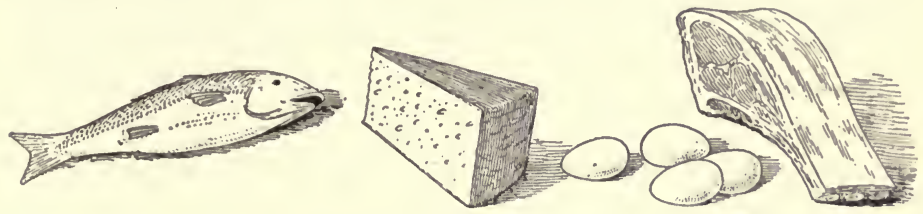

FIG. 21. - Protein foods.

It comprises about one tenth of cereals (see figure 28 ), one seventh of meats (see figure 20), one fifth of dried beans and peas, and one fourth of cheese. (See figure 26.) Nuts vary greatly in composition, peanuts containing about one twelfth. Fruits and vegetables contain only small quantities of protein. (See figure 25.)

Source of fats and carbohydrates. The chief sources of fats are nuts and the animal foods. (See figure 22.) The carbohydrates are obtained almost entirely from vegetable foods (see figure 23), milk and liver being the only animal foods that contain any appreciable

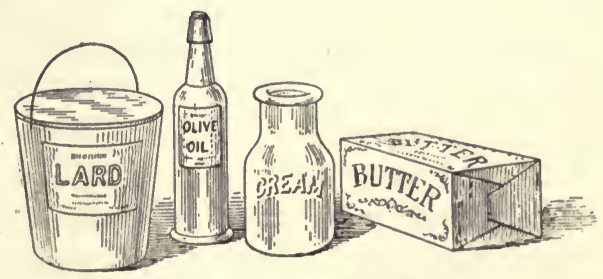

Fig. 22. - Fat foods. quantity. The carbohydrates make up about two thirds of peas and beans, three fourths of the cereals (see figure 28), and a large proportion of the nutrients of vegetables and fruits. It is thus seen that animal foods contain large proportions of 
protein and fat with small proportions of carbohydrates, while vegetable foods, excepting nuts, contain large proportions of carbohydrates, but little fat, and some contain large proportions of protein.

Water. Water forms a large proportion of nearly all foods. The amount varies greatly. Vegetables and fruits contain the largest proportion, ranging from eighty to ninetyfive per cent. (See figure 25.) Nuts and dried foods, like peas, beans, wheat, and corn contain the smallest proportion, ranging from five to fifteen per cent. (See figure 28.) Meats contain a medium amount, ranging from fifty to seventy per cent. (See figure 20.)

Mixed diet. In selecting food to furnish the protein which we must have, we may choose from meats, fish, beans, peas, cereals, and nuts. The carbohydrates we get almost entirely from vegetable foods, and the fats largely from animal foods, and to a minor extent from nuts. It will be seen from this that it is possible to obtain all the nutrients that the body needs from vegetable foods alone. There are some people, called vegetarians, who maintain that this is a more healthful diet than one composed of both animal and vegetable foods. The agitation aroused by these people has undoubtedly had beneficial results in showing that people generally use more animal food than the body requires and that a diet with a larger proportion of vegetable food and a smaller proportion of animal food would be more healthful. But the consensus of common experience and of medical advice is that for most people a mixed diet is preferable to a vegetarian diet. A mixed diet allows a greater variety of foods and makes it easier to select foods containing the proper proportions of nutrients. (See figure 24.)

Fruits and vegetables. (See figure 25.) In the foregoing discussion little mention has been made of fruits and vegetables. While these do not contain large proportions of solid nutrients and are not among the cheaper foods, they are 
among the best foods and should occupy a place in every diet. They are composed largely of water. Of the nutrients present, carbohydrates are the most common. These carbohydrates help to furnish a well-balanced diet when used in

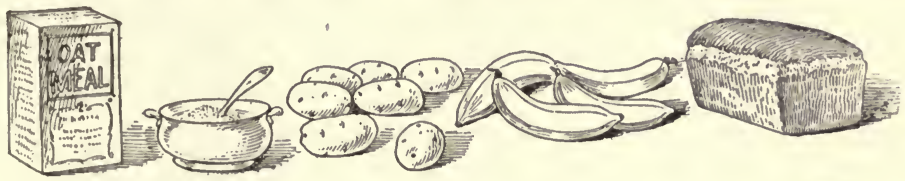

Fig. 23. - Carbohydrate foods.

connection with the protein foods. But in addition to their direct food value, they serve other important uses. The pleasant flavors of fruits and vegetables serve to make other foods more palatable and so aid in their digestion. They furnish also some of the mineral salts needed by the body, and, by the bulk of material which they contain, they assist in the proper working of the digestive organs. Fruits and vegetables are valuable also because they contain small quantities of substances called vitamines, which are essential to the well-being of the body. Cooking either diminishes or

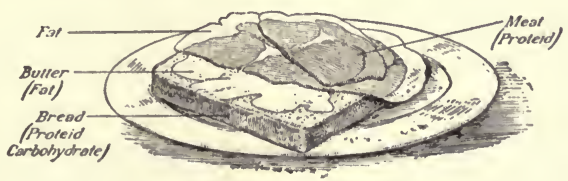

Frg. 24. - Food clements in a sandwich.

destroys these vitamines, and some uncooked fruits and vegetables should be eaten.

Fruits and vegetables can be easily raised in the home garden at slight expense and with but little labor. This is especially true of vegetables which can be raised from seed in one season. The fruits, excepting fall strawberries, require longer to mature, varying from two to ten years. Vegetables have good keeping qualities, and, of the surplus 
raised in the summer, many kinds may be stored or canned for winter use.

Nuts. Another kind of food of which mention should be made is nuts. The value of these and the place they should occupy in our diet has been largely misunderstood. As regards their composition, nuts are among the most concentrated foods we have, the edible portions containing only a small per cent of water (five to seven per cent). The important characteristic of nuts as food is the large proportion of protein and fat which they contain; they rank with meats and cereals in the proportion of protein and greatly exceed the meats in the amount of fats.

Mistakes in the use of nuts as food have arisen from failure to understand these two facts ; first, that nuts contain large amounts of protein, and second, that they are very concentrated. Their proper place is as a substitute for other protein foods such as meats and beans, and not as an addition to a hearty meal. Nuts have had the reputation of being indigestible, but this has resulted largely from the way in which they have been used. They should not be eaten at the end of a hearty meal when sufficient protein food has already been eaten. It is much the same as though a course of meat should be served at the end of a hearty dinner.

One precaution should be noted in eating nuts: they should be thoroughly masticated, because they are such concentrated foods. Failure to do this has undoubtedly been another cause of the ill effects felt after eating nuts. When they occupy the proper place in our diet and are thoroughly masticated, nuts may form an important and healthful article of food. Those people who prefer a vegetable diet may make nuts one of their chief sources of protein.

Special mention should be made of peanuts on account of their cheapness. Nuts as a class are a rather expensive food, but peanuts as a source of both protein and energy are much cheaper than meats and of equal value with cereals 


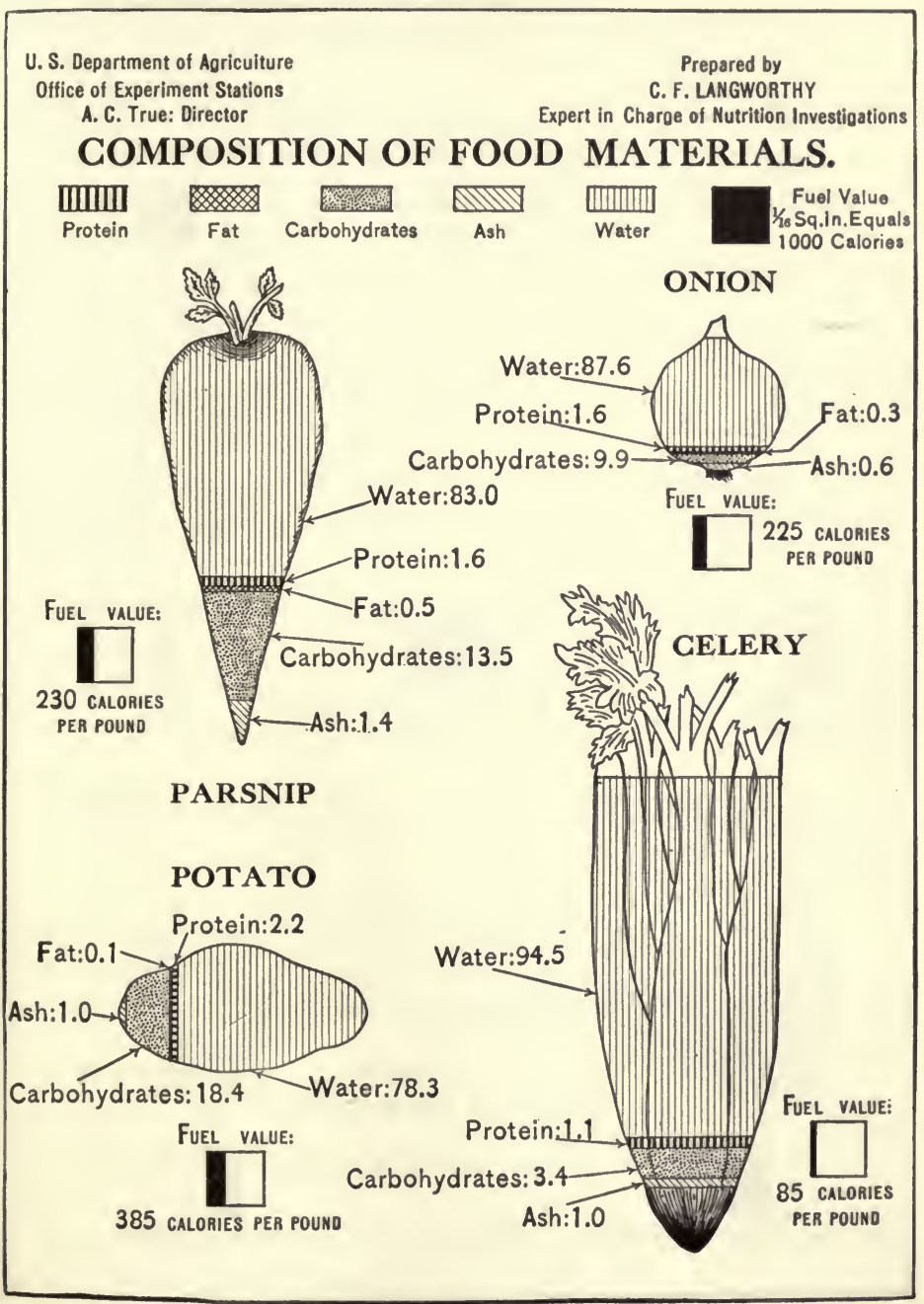

FIG. 25. - Composition of vegetables. 
U.S. Department of Agriculture Office of Experiment Stations

A. C. True: Director
Prepared by

C. F. LANGWORTHY

Expert in Charge of Nutrition Investigations

\section{COMPOSITION OF FOOD MATERIALS.}

\section{[IIIIIIIIIII \\ Protein \\ WHOLE EGG \\ Carbohydrates}

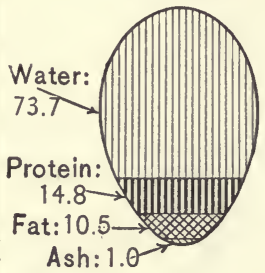

Fuel value of

WHOLE EGG:

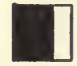

700 CALORIES

PER POUND

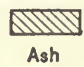

Ash

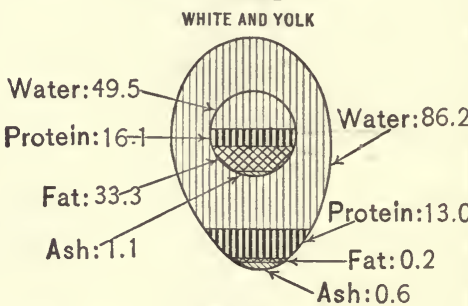

Fuel value of yolx:

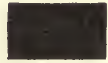

1608 CALORIES

PER POUND
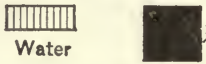

Fuel Value 16 Sq.In. Equals 1000 Calories

EGG

WHITE AND YOLK

Fuel value of white:

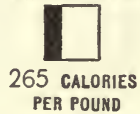

\section{GREAM CHEESE}

COTTAGE CHEESE

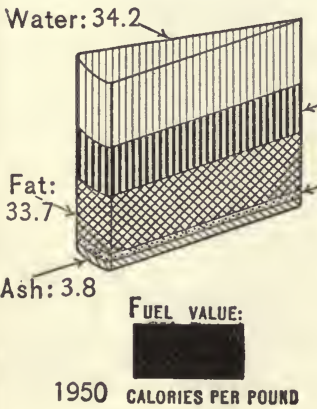

Protein: 25.9 Water: 72.0

Carbo.

hydrates: 2.4

\section{Carbo.}

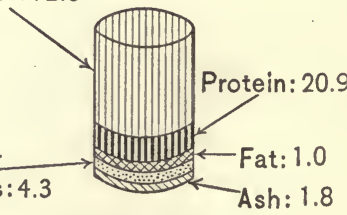

hydrates: 4.3

Fuel value:

510 CALORIES PER POUND

Fig. 26. - Composition of eggs and cheese. 
in this respect. The edible portion contains a larger per cent of protein and fats than meats and cereals contain.

Milk. Milk is one of the very best of all our foods. For children it is almost a necessity. It is well-balanced in the proportions of nutrients that it contains as is shown in the table given below. Milk serves all three purposes of foods. It furnishes energy at a moderate price in comparison with other foods ; it is a cheap source of protein ; and it is one of the most important sources of those substances called vitamines, which are so essential in regulating the body activities. It is the richest of all the common foods in lime, a substance necessary to build bones.

In these times when so much stress is being laid on the economical use of foods, special attention is called to the fact that skimmed milk is almost as good a food as whole milk. Reference to the table given below shows that the chief difference is that the skimmed milk contains less fat, but the proportions of the other nutrients are the same. Skimmed milk is sold at such a low price that it is one of the cheapest foods.

\begin{tabular}{|c|c|c|c|c|c|}
\hline & & WATER & ProteIN & FAT & CARBOHYDRATES \\
\hline $\begin{array}{l}\text { Whole Milk . } \\
\text { Skimmed Milk . }\end{array}$ & $\begin{array}{ll}\cdot & \cdot \\
\cdot & \cdot\end{array}$ & $\begin{array}{l}87 \% \\
90.5 \%\end{array}$ & $\begin{array}{l}3.3 \% \\
3.4 \%\end{array}$ & $\begin{array}{l}4 \% \\
.3 \%\end{array}$ & $\begin{array}{l}5 \% \\
5.1 \%\end{array}$ \\
\hline
\end{tabular}

\section{LABORATORY EXERCise IO}

Purpose. To compare foods as regards their nutritive value.

Directions. Answer the following questions from the study of the table given on page $7 \mathbf{I}$.

I. Which foods contain the larger per cent of proteins, animal or vegetable foods? Which of carbohydrates? Which of fats? 
2. Among the animal foods, which three contain the largest per cent of protein? Which one the least?

3. Among the vegetable foods, which three contain the largest per cent of protein? Which two the least?

4. Which two foods contain the largest per cent of carbohydrates? Which one the least?

5. Which four foods contain the largest per cent of fats? Which three contain the least? Which four have the largest fuel value?

6. Which kind of nutrient do we get almost wholly from vegetable foods alone? Which kind chiefly from animal foods alone? Which kind from both animal and vegetable foods?

7. Which five kinds of foods contain the largest per cent of proteins arranged in order? Which five of fats? Which five of carbohydrates? (See Io below.)

8. Which five foods have the most refuse? Which have none?

9. Which five have the largest per cent of water? Which five the least?

I0. Put your answers giving foods with the largest per cents of the various nutrients in the following tabular form. Under each heading put the five foods that come first, arranged in order.

\begin{tabular}{l|l|l|l|l|l}
\hline \hline Protetn & Fat & Carbohydrates & Water & Refuse & Fuel Value \\
\hline & & & & \\
\hline & & & & \\
\hline
\end{tabular}

I I. The members of the class may coöperate to make colored charts showing the composition of foods. Secure six large pieces of heavy paper. Copy on these pieces the outlines of the foods in figures $20,25,26,27,28$, and 30 , on an enlarged scale. Indicate the proportions of the nutrients by different colors, using either water colors or colored crayons. 
Table Showing Composition of Foods as Purchased

\begin{tabular}{|c|c|c|c|c|c|c|c|c|c|}
\hline & & & & \multicolumn{5}{|c|}{ Per Cent of } & \multirow{2}{*}{$\begin{array}{c}\text { Fuel Valde } \\
\text { PER Pound } \\
\text { Calories }\end{array}$} \\
\hline & & & & Protein & Fat & $\begin{array}{c}\text { Carbo- } \\
\text { hydrates }\end{array}$ & Water & Refuse & \\
\hline \multicolumn{10}{|c|}{ Animal Foods } \\
\hline Cheese . . & - & - & . & 29 & 36 & $\cdot 3$ & 32 & o & 2055 \\
\hline Fowl . & - & - & $\cdot$ & I 4 & 12 & o & 47 & 26 & 765 \\
\hline Halibut. . & . & - & . & I 5 & 4 & o & 62 & I 8 & 475 \\
\hline Lobsters . & 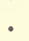 & - & . & 6 & .7 & .2 & $3 I$ & 62 & 145 \\
\hline Eggs . . & . & - & $\cdot$ & 13 & 9 & o & 66 & I I & 635 \\
\hline Milk. . . & . & . &. & 3.3 & 4 & 5 & 87 & o & 325 \\
\hline Pork chops & . & . &. & .13 & 24 & o & 42 & 20 & 1245 \\
\hline Lamb (leg) & . & . &. & I6 & 20 & o & 50 & 14 & I 130 \\
\hline Round steak & . & - & . & I9 & 13 & o & $6 I$ & 7 & 890 \\
\hline Sirloin steak & - & - & $\cdot$ & 17 & I6 & o & 54 & 13 & 975 \\
\hline \multicolumn{10}{|c|}{ Vegetable Foods } \\
\hline Apples . & . & . & . & .3 & $\cdot 3$ & I I & 63 & 25 & I90 \\
\hline Beans (dried) & . & - & . & 23 & 2 & 60 & I3 & o & I 520 \\
\hline Beets . & . & . & . & I & .I & 8 & 70 & 20 & 160 \\
\hline Corn meal. & . & . & . & 9.2 & 2 & 75 & 13 & 0 & I 655 \\
\hline Grapes . . & . & . &. & I & I & 14 & $5^{8}$ & 25 & 335 \\
\hline Lettuce & . & . & . & I & .2 & 3 & $8 \mathrm{I}$ & I 5 & 65 \\
\hline Oranges & & . & . & .6 & II & 9 & 63 & 27 & 150 \\
\hline Peanuts & & . & - & 20 & 29 & I9 & 7 & 25 & I 775 \\
\hline Potatoes & . & . &. & 2 & .I & I5 & 67 & 20 & 295 \\
\hline Strawberries & . & . & . & .9 & .6 & 7 & 90 & 5 & 180 \\
\hline Wheat flour & . & - & . & I I & I & 75 & 12 & 0 & I635 \\
\hline
\end{tabular}

Cost of foods. Now that we have determined what foods contain the nutrients the body needs, the next problem is to ascertain what foods give the largest amount of nutrients for the least cost. This cannot always be determined by comparing the price per pound or quart, for we must know also the proportions of nutrients that the foods contain.

People are often misled by the idea that the higher the price paid, the better the food. This idea is entirely wrong as applied to foods. The price of foods is not determined by the nutrients they contain, but largely by other factors 
U.S. Department of Agriculture

Office of Experiment Stations

A.C. True: Director
Prepared by

C.F. LANGWORTHY

Expert in Charge of Nutrition Investigations

\section{COMPOSITION OF FOOD MATERIALS.}

[I] IIIIII)

Protein COD

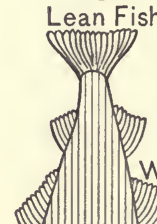

Water:82.6

Fuel value:

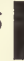

325 CALORIES

Protein: 15.8
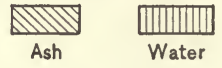

Water

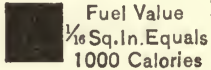

SALT COD

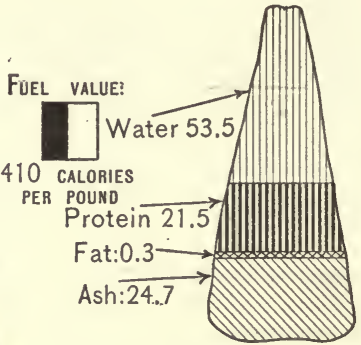

MACKEREL Ash: 1.2

Water:86.9

OYSTER

$\mathbb{N}$

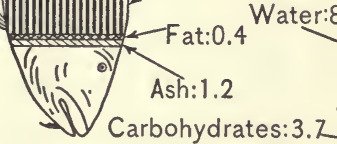

SMOKED HERRING<smiles>FC(F)C1CCCC1</smiles>

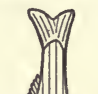

Water:34.6
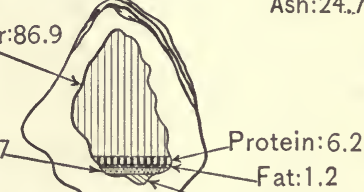

FuEL

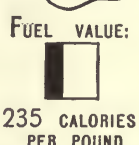

Ash: 2.0

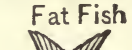

Water: 73.4

Protein:18.3

Fuel value:

Fuel value:

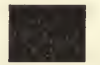

1355 CALORIES

PER POUND

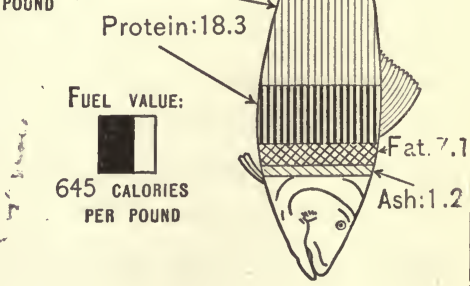

Ash:13.2 if

FIG. 27. - Composition of fish. 
such as rarity, appearance, tenderness, flavor, or cost of production, factors which influence only slightly the real value of foods. For illustration, take the case of sirloin and round steaks. Sirloin costs more, chiefly because it is more tender, and yet it contains more waste and less protein ; and hence it is really not so valuable a food as round steak.

If we compare fresh codfish with oysters, we find a much higher price is charged for oysters largely on account of the flavor and rarity; yet if the same amount of money be invested in both, twice as much food material and three times as much protein will be obtained in the codfish as in the oysters.

A man who made a careful study of portions of food served in restaurants in New York City found that five cents invested in a roast-beef sandwich bought $35^{8}$ calories, while five cents invested in raw oysters bought only ig calories. That is, the sandwich furnished I 8 times as many calories as the oysters, and yet they both cost the same.

The following table shows the difference in cost of 100 calories for various kinds of foods :

\section{Cost of ioo Calories}

Corn meal (6 cts. 1b.) . . . . . . $\frac{3}{8}$ cent

Dried beans (Io cts. 1b.) . . . . . . $\frac{2}{3}$ cent

Milk ( I I cts. qt.) . . . . . . . I $\frac{3}{5}$ cents

Cheese (40 cts. lb.) . . . . . . 2 cents

Almonds ( 35 cts. lb.). . . . . . . $3^{\frac{1}{2}}$ cents

This table shows that for any given sum of money one can get nine times as many calories from corn meal as from almonds.

The foods which furnish protein, arranged in order of cost beginning with the cheapest are : dried beans, cereals, peanuts, meats, fish. From the standpoint of the second purpose of foods, that is to furnish the body with fuel, the 
U. S. Department of Agriculture

Office of Experiment Stations

A. C. True: Director
Prepared by

C. F. LANGWORTHY

Expert in Charge of Nutrition Investigations

\section{COMPOSITION OF FOOD MATERIALS.}

[ाIIIIIIII

Protein

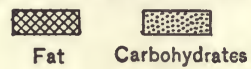

GORN

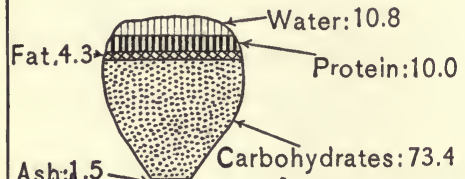

Ash:od.5

Fuel value:

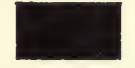

1800 CALORIES

PER POUND

OAT

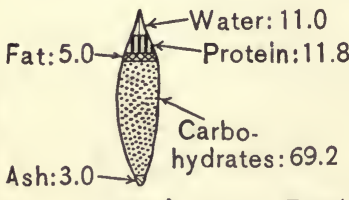

Fuel value:

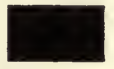

1720 CALORIES RER POUND

\section{BUCKWHEAT}

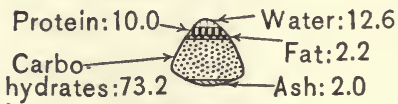

Fuel value:

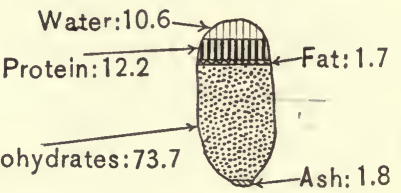

Fuel value:

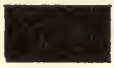

1750 CALORIES PER POUND

\section{RICE}

1600 Calories Water: 12.0 PER POUND

RYE
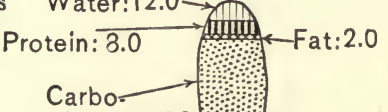

hydrates: 77.0

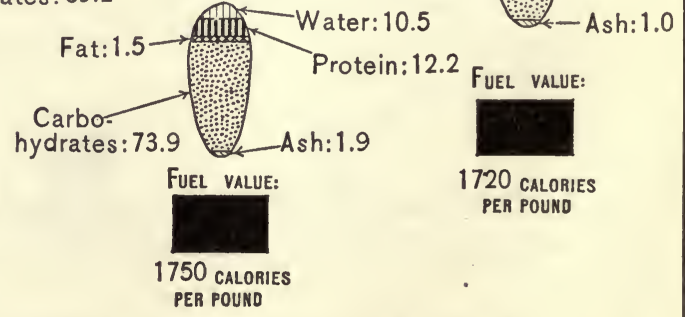

Fig. 28. - Composition of cereals. 
foods arranged in order of cheapness are : cereals, dried beans, potatoes, peanuts. It is thus seen that cereals and dried beans are the cheapest foods from both standpoints.

\section{LABORATORY EXERCISE II}

Purpose. To find out which are the cheapest foods and which are the most expensive.

Directions. I. Find the price per pound of the various foods given in the table on page 7I. If some, like oranges, are sold by the dozen, weigh a few and from this compute the price per pound.

2. From these figures showing the price per pound, compute for each food: $(a)$ the cost of a pound of protein; $(b)$ the cost of 1000 calories fuel value. For example, if the price of round steak were 25 cents, divide 25 cents by .i 9 the per cent of protein. This gives \$I.3I the cost of a pound of protein. To find the cost of 1000 calories, divide the figure given in the last column by 1000 and then divide the price per pound by this number. For example, taking round steak again: $890 \div 1000$ $=.89$. 25 cents divided by $.89=28$ cents, the cost of 1000 calories.

3. After you have worked out these results for all the foods, answer the following questions from a study of the figures.

Which are the seven cheapest protein foods?

Which are the seven most expensive foods? Write them down in order in the table given on page 76 .

4. Which are the seven cheapest foods for fuel value? Which are the seven most expensive? The remainder may be called medium-priced foods.

5. In general which are the cheaper foods, animal or vegetable?

6. Are there any foods which are found in both lists of cheapest foods? Are there any found in both lists of most expensive foods?

7. Record your answers to the above questions in the following tabular form, showing relative cheapness of foods. 


\begin{tabular}{c|c|c||c|c|c}
\hline \multicolumn{2}{c||}{ Cost of Proter } & \multicolumn{3}{|c}{ Cost of Fuel Value } \\
\hline Cheap & Medium & Expensive & Cheap & Medium & Expensive \\
\hline & & & & & \\
\hline
\end{tabular}

Economy of cooking. Proper methods of cooking may aid much in food economy. Frequently the more costly cuts of meat are more expensive simply because they are more tender, and yet they are not more nutritious than the cheaper meats, which by proper methods of cooking may be made as tender and palatable. Another means of economy has to do with the treatment of food after it is purchased. The bones and trimmings of meat contain appreciable amounts of nourishment, and these may be used in soups and stews instead of being thrown away, as is so often done.

Storing eggs. Another means of economy is to buy foods when they are abundant and cheap and store them for later use. This may easily be done with eggs. These are most abundant and cheapest during the spring and early summer. They may be secured then and stored for winter use. A number of methods of storing have been tried, but the waterglass method has proved the best. This is used in the proportion of one part of water glass to ten parts of water. The water should first be boiled and allowed to cool. A quart of water glass will make enough mixture to cover from I5 to 20 dozen eggs. The cost of the mixture averages about three cents per dozen eggs, not counting the cost of the container. Earthenware crocks or wooden pails are the most satisfactory containers. The solution may be poured into the container and the eggs added as they are collected. 
Only fresh, clean eggs should be used. The container should be covered and stored in a cool, dry cellar.

These eggs, of course, do not compare with fresh eggs for table use, but they are very satisfactory for cooking purposes. They compare favorably with the average egg bought at the store during the winter. It has been found that they keep in good condition for six or eight months. When the eggs are to be boiled, stick a needle through the shell at the large end of the egg to prevent the shell from breaking.

\section{Home Project 8}

Purpose. To store eggs for winter use.

Directions. Consult with your parents about the matter and if they are willing, try storing some eggs at your home as explained above. A pint of water glass (costing about 25 cents) will preserve from 8 to Io dozen eggs.

\section{Home Project 9}

Purpose. To distinguish fresh from stale eggs.

Directions. I. By candling. Secure a large shoe box and remove the ends. Cut a hole about the size of a half dollar in one side. Place the box over a lamp or electric bulb and darken the room. Hold the egg with the large end up, before the opening in the box. Good eggs look clear and firm. The air cell should not be larger than a dime, and the yolk may be seen dimly. If the air cell is large and the yolk looks dark, the egg is stale. If

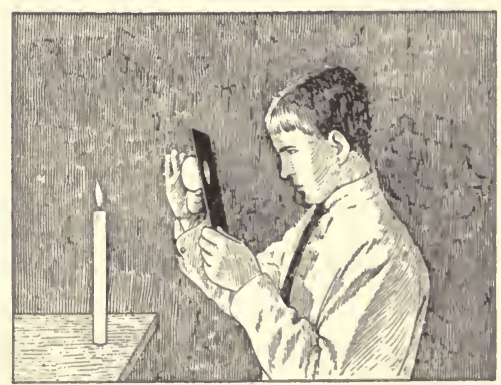

FIG. 29. - Candling eggs. the shell contents appear very dark, the egg is unfit for food. 
2. By the use of salt solution. Make a ten per cent salt solution. Place an egg in it. If it floats it is stale.

Amount of food needed. Our next question as to how much food a person should eat is a practical one that concerns us at every meal. In answering this question we may look at it from two standpoints ; first, with reference to the number of calories the body needs, and second, the amount of protein it needs.

Number of calories needed. The number of calories used under varying circumstances has been accurately measured by means of a calorimeter. 'This is an apparatus so arranged that it will measure the amount of heat given off by the various activities 'of a person confined in a small room. When a person is at rest, the activities of the vital organs (heart, lungs, etc.), require a certain number of calories. This is found to be about twelve calories a day for each pound of body weight, or about 1800 calories for a man weighing I 50 pounds. This is the fundamental basal requirement for every diet. All voluntary muscular work requires additional food in order to furnish extra calories.

The number of calories required during a day by a person depends on weight, activity, and age. The larger a person, the more food he needs if the weight is due to.tissue and not to excessive fat. The number of calories depends very noticeably on the muscular activity of the person. It increases rapidly as the work done becomes more severe. Exercise is often classified into four groups : light, moderate, active, and severe. Men of sedentary occupation, such as teachers and bookkeepers, take light exercise; mail carriers and carpenters, moderate exercise; farmers and blacksmiths, active exercise ; and soldiers and lumbermen, severe exercise. The following table shows how the number of calories depends on the exercise. 
Kinds of Activity

Sleeping

Sitting quietly

Standing

Light exercise

Moderate exercise

Active exercise

Severe exercise
Calories per Pound per Hour

.5
.6
.75
I
I.25-1.5
I.75-2
3 or more

The number of calories needed by persons under varying conditions of activity has been closely determined, and there is quite general agreement on the essentials for the heat requirements. This is shown in the following table.

Daily Calorie Requirements

\section{- For Adults}

\begin{tabular}{|c|c|c|}
\hline OCCUPATION & $\begin{array}{c}\text { CALORIES PER POUND OF } \\
\text { WEIGHT }\end{array}$ & $\begin{array}{c}\text { TOTAL FOR MAN OF } 150 \\
\text { PoundS } \\
\text { (Approximate) }\end{array}$ \\
\hline Sedentary (Professional man) & 17 & 2500 \\
\hline Moderate exercise (Carpenter) & 20 & 3000 \\
\hline Active (Farmer) . . . . . & 24 & 3500 \\
\hline Severe (Soldier) & 27 & 4000 \\
\hline
\end{tabular}

For Boys and Girls

I4 years old

I5 years old

I6 years old

I 7 years old

24

22

20

I 8

A person may find his calorie requirement by multiplying his weight by the appropriate figure in the above table. Women usually require less than men because they weigh less and perform less vigorous work. 
More calories in proportion to the weight are needed for children than for adults. For the two-year-old child about 40 calories per pound are required. This number gradually decreases to about 20 at the age of 16 .

In old age the number of calories needed is less than during middle age. This decrease runs from ro per cent at 60 years of age to 30 per cent for those over 80 years of age.

Protein requirements. Having noted the heat requirements of the body, we may next ask how much protein food the body needs. While protein as well as fats and carbohydrates furnishes energy, it is better to meet these heat requirements through the use of fats and carbohydrates, and to provide protein only for the repair of the body tissues. We have seen that the calorie requirement of the body depends on weight, age, and activity. The protein requirement depends on weight and age, but not on activity. A man when he is doing severe muscular work has the same protein requirements as when he is doing light work.

While there is quite general agreement among authorities regarding the number of calories needed by the body, there is a difference of opinion regarding the amount of protein needed. There are two schools, one favoring a low protein diet, and the other favoring a high protein diet. The standard set by the first school for a man of I 50 pounds' weight is 60 grams (about 2 ounces) daily: the standard set by the second school is about too grams (about $3 \frac{1}{2}$ ounces).

Chittenden's experiments. Professor Chittenden of Yale University is an exponent of the first school. During 1903 and 1904 he carried on a series of experiments to test the effect of a low protein diet. He selected for this purpose men representing a variety of occupations: soldiers, college athletes, and college professors. The experiment lasted for 6 months. During the first month the foods were gradually changed so as to include smaller quantities of proteins, until during the last 5 months the diet contained less than half 
as much protein as did the diet to which they had been accustomed. During this period the men retained their bodily weight, improved in general health, and showed a remarkable gain in strength.

The following table showing how much of certain foods will furnish two ounces of protein is taken from Professor Chittenden's report. Of course it would be very unwise to use only one kind of food to furnish this protein, but the table will show the relative value of different foods in furnishing protein. The foods are arranged in the order of the proportion of proteins, those containing the most being placed first.

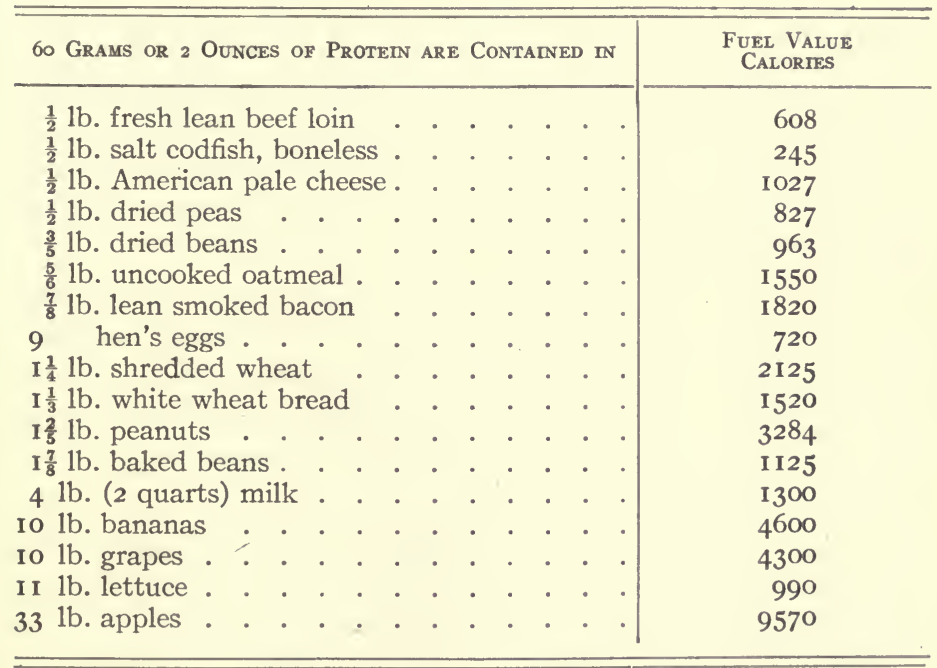

From this table it will be noted that the foods in the first part of the table which furnish the largest proportion of protein have a low fuel value; while the foods in the latter part of the table, which have a high fuel value, furnish only small quantities of protein. Here again we may see the need of including a variety of foods in our diet. 
Fisher's experiments. Another set of experiments was carried on at Yale by Professor Fisher. His purpose was to test Mr. Fletcher's claim that thorough mastication combined with obedience to appetite leads naturally to the selection of the proper amounts of food. The results have a bearing on the question of the protein requirements. Nine students took part in the experiment, which lasted 5 months. Two rules were followed: first, to masticate the food thoroughly, and second, to follow the appetite regarding the amount and kinds of food eaten. At the end of the experiment it was found that they were eating only one half as much protein as they had been accustomed to eat. Tests of endurance were made both at the beginning and end of the experiment, and it was found at the end that there was an enormous increase in the power of endurance. The men noticed, too, a general improvement in health and mental ability.

These experiments show that men can live on a low protein diet and remain in good health or even improve in health and physical condition.

The other school, which favors a high protein diet, points to the dietary studies which have been made in many countries which show that these people are living on a high protein diet. And they claim that while a person can live on a low protein diet, it is dangerous to health to continue to do so for long periods of time.

General conclusions. As far as the author has studied the question it seems to him that the low protein school has the better of the argument. It points out that these studies of dietaries simply show what people prefer to eat, but do not show what is best for them to eat. Young children would prefer to live largely on candy if allowed to follow their inclinations, but this does not prove that this is the best diet for them.

There seems to be a general tendency to take a position midway between these extreme views, to avoid on one hand 
the possible danger of a lack of sufficient protein, and on the other to avoid the dangers from an excessive use of proteins as evidenced in a too free indulgence in meat. Between the two extremes of 60 grams and roo grams as the daily requirement of protein, a standard is being set of 75 grams for a man of 150 pounds' weight, that is, one half a gram of protein for each pound of weight. So that an adult may find his protein requirement in grams by multiplying his weight by one half.

Children, on account of the formation of new tissues, require a larger proportion of protein. This ranges between one gram and three quarters of a gram for each pound of weight.

Determination of adequacy of diet. After a standard has been set as to how much protein and how many calories a person needs daily, how may one know whether his diet approximates this standard? This may be determined in three ways, by one's weight, by one's appetite, and by the use of food tables that have been prepared for this purpose.

Use of food tables. A person first makes out for one day a list of the kinds of foods eaten and the approximate quantities in terms of common servings. By studying the food table given on pages 85 and 86 one may determine the weight of protein and the number of calories in each serving of food. These may be added and thus the total obtained for the day. Such changes in the diet may be made as are needed to bring it more closely in accord with the standard. It is well to make such a study of one's daily food several times a year.

The following sample diet is given as showing the method of working out the food value. This is a sample of a low protein diet used by Professor Chittenden in his experiments, to which reference has already been made. 
BREAKFAST

\begin{tabular}{|c|c|c|c|c|}
\hline SERVING & & WEIGHT & ProtenN & CaJories \\
\hline One shredded wheat biscuit & . & 30 grams & 3.I 5 grams & 106 \\
\hline One teacup of cream. : & - & I 20 grams & 3.12 grams & 206 \\
\hline One water roll $\quad . \quad . \quad . \quad$. & . . & 57 grams & 5.07 grams & I65 \\
\hline Two one-inch cubes of butter & & 38 grams & 0.38 gram & 284 \\
\hline Three fourths cup of coffee & & Ioo grams & 0.26 gram & - \\
\hline One fourth teacup of cream & . . & 30 grams & 0.78 gram & $5 \mathrm{I}$ \\
\hline \multirow[t]{2}{*}{ One lump of sugar . } & & Io grams & & 38 \\
\hline & & & I 2.76 grams & 850 \\
\hline
\end{tabular}

\section{LUNCH}

One teacup home-made chicken soup

One Parker-house roll

Two one-inch cubes of butter.

One slice lean bacon

One small baked potato

One rice croquette

Two ounces maple sirup

One cup of tea with one slice lemon

One lump of sugar

I 44 grams

38 grams

38 grams

Io grams

60 grams

90 grams

60 grams

Io grams
5.25 grams

60

3.38 grams

0.38 gram

2.14 grams

I.53 grams

3.42 grams

I6. Io grams
I IO

284

65

55

I 50

I 66
38

928

DINNER

One teacup cream of corn soup. One Parker-house roll . . . One-inch cube of butter

One small lamb chop, broiled, lean meat

One teacup of mashed potato

Apple-celery-lettuce salad with mayonnaise dressing . . . .

One Boston cracker, split, 2 inches diameter

One half-inch cube American cheese .

One half teacup of bread pudding

One demitasse coffee.

One lump of sugar
I30 grams

38 grams

I9 grams

30 grams

I67 grams

50 grams

12 grams

12 grams

85 grams

Io grams
3.25 grams

3.38 grams

0.19 gram

72

I 10

I 42

8.5I grams

3.34 grams

92

I 75

0.62 gram

75

I.32 grams

3.35 grams

5.25 grams

\begin{tabular}{|c|c|}
\hline & - \\
\hline 29.2 I grams & 9.51 \\
\hline 58.07 grams & 2729 \\
\hline
\end{tabular}


The following table gives the protein and fuel value of a few common foods as served on the table.

Table of Food Values

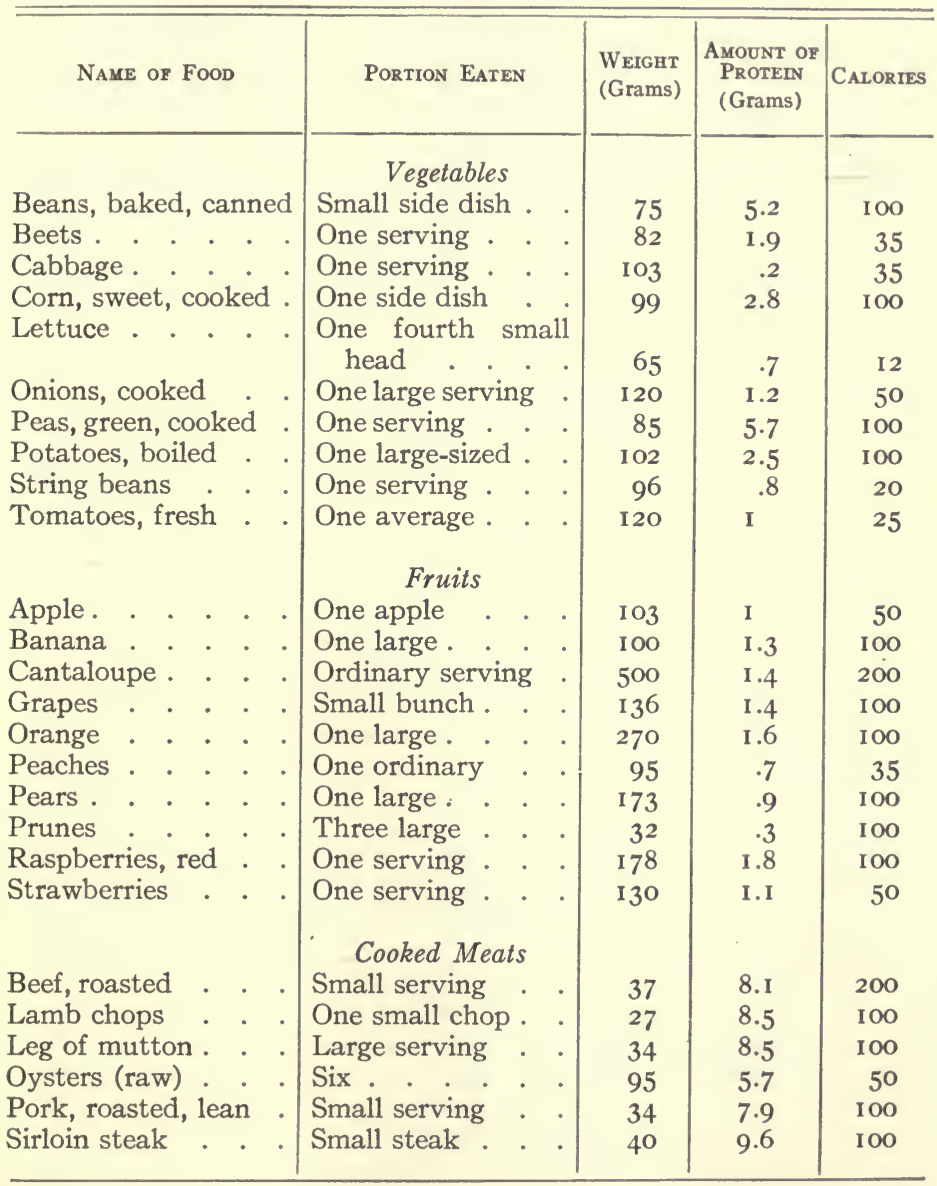




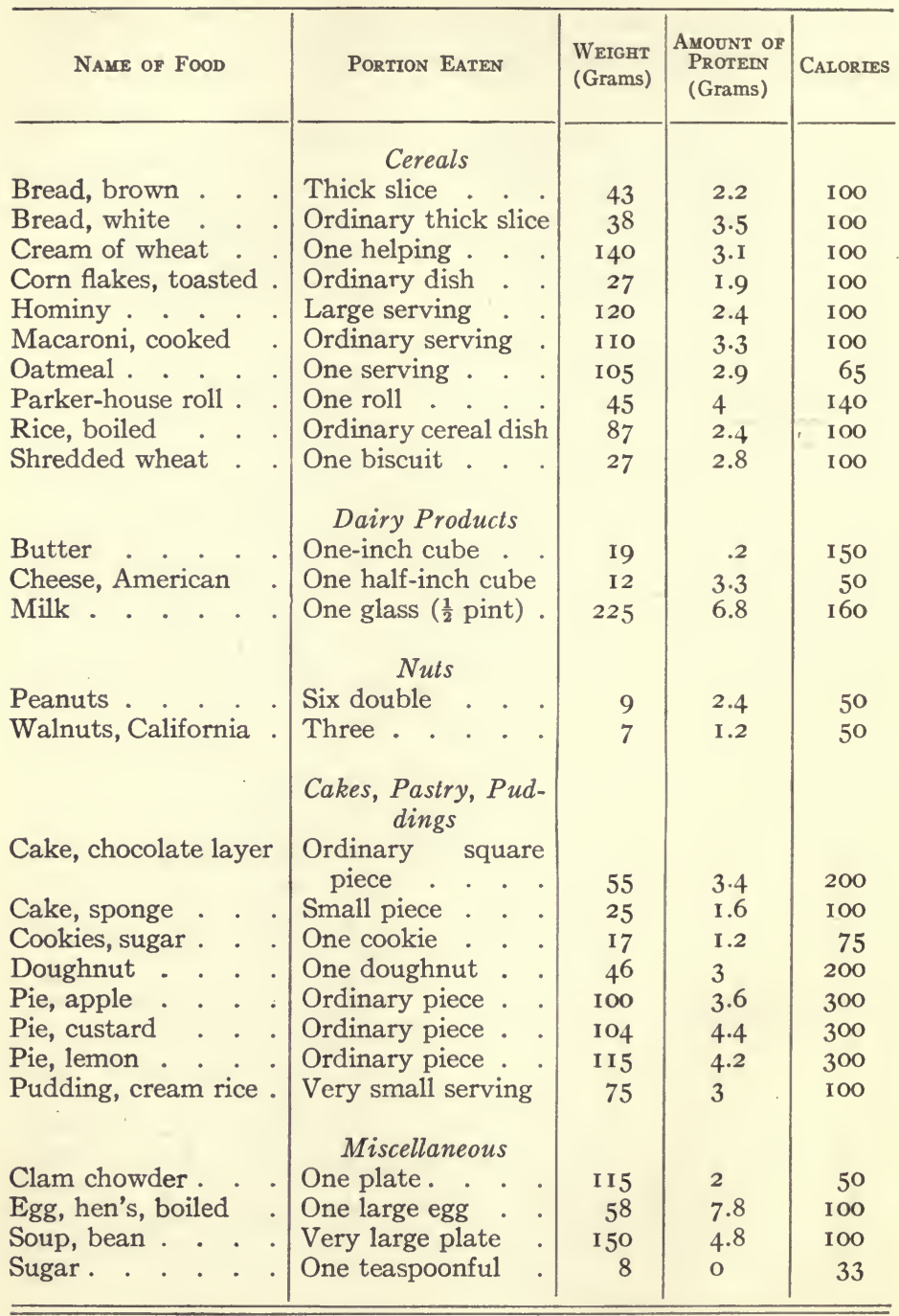




\section{Home Project io}

Purpose. To find out if you are eating the right kinds and amount of food.

Directions. I. Keep a careful record for one day of the kinds and amounts of food that you eat for each meal. In recording the amounts use the terms found in the second column of the table on pages 85 and 86 . Bring these figures to school and by the help of the instructor work out the following directions.

2. By means of the table find $(a)$ the weight of protein and (b) the fuel value in calories of each portion of food eaten. Record them in the following tabular form which should be copied in your notebook. (See page 84.)

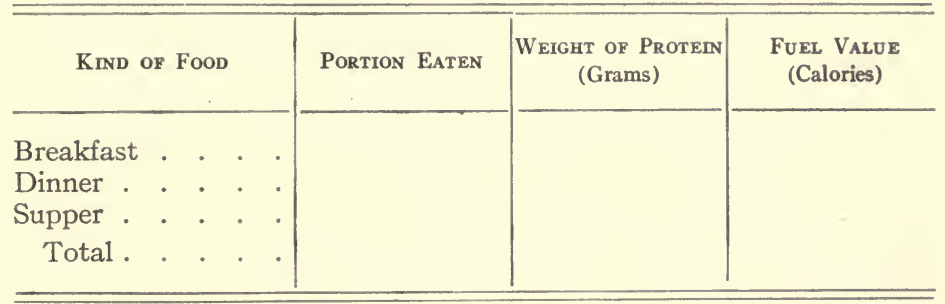

3. To find the number of grams of protein required daily by your body, multiply your weight by three quarters.

4. To find the number of calories needed, multiply your weight by the number given on page 79 to correspond with your age.

5. Compare these two results with the two found above. What changes can you make in your diet to make it conform more nearly with the standard given?

6. Using the table on pages 85 and 86 make out a diet for yourself for the three meals for one day that shall meet the standard you require. Make the record in the same form as above. Make several diets each of which meets your requirements.

7. Also, compare your weight with the average for your height.

Appetite as a guide. The common method of determining the amount of food we need is to eat till the appetite is 
satisfied. Is the appetite a safe guide? We can be sure that it is not always so, because we think at once of children who eat excessive amounts of candy and of drunkards who drink excessive amounts of alcoholic liquors. Many people have acquired an unnatural appetite for various kinds of foods that is not to be trusted. In the main a natural appetite is a safe guide to follow. If a person has not such an appetite, one way of securing it is to practice thorough mastication of food. This means that the food should be chewed till it becomes so fine that it naturally passes down the throat without conscious effort of swallowing, At first this will require thought to overcome a habit of hasty eating, but with a little attention the habit of thorough mastication may be acquired. When this point is reached, it may be said in general that a person may then allow himself to be governed by his appetite both as regards the amounts and kinds of foods to be eaten. But even under these conditions a person should keep in mind some general principles regarding the kinds and amounts of foods that the body needs.

It is the experience of many people who follow this practice that they naturally choose a low protein diet. Even when one has acquired the habit of thorough mastication, it is well to make an occasional study of one's diet by means of a table as previously explained.

Weight as a guide. Another method that gives some indication of the correctness of the diet is to note a person's weight in comparison with the average for the given height and age. If one is storing up a large surplus of fat, this shows that he is eating too much food. A reduction in weight should be brought about gradually and under the advice of a physician.

Failure to store up fat does not necessarily mean that the person's diet is correct, because protein food is not stored up, but the excess of nitrogen is eliminated through the kidneys. 
People may eat meat to excess and yet not show it by storing up fat.

Balancing the diet. The following table taken from a recent government publication will be helpful in planning a well-balanced diet.

\section{Food Elements}

Eat something from each of these five groups every day:

Group I. Foods for mineral matter, acids, and body regulators.

Group II. Protein foods.

Group III. Starchy foods.

Group IV. Foods for sugar.

Group V. Foods for fat.

\section{Group I}

Eat vegetables and fruits for mineral matter, acids, and body regulators.

Apples

Apricots

Asparagus

Bananas

Lima beans

Beets

Blackberries

Cabbage

Carrots

Cauliflower

Celery
Canned or

Green corn

Cucumbers

Grapes

Lemons

Lettuce

Muskmelon

Onions

Oranges

Parsnips

Peaches
Pears

Green or

Canned peas

Pineapple

Rhubarb

Spinach

Squash

Strawberries

String beans

Tomatoes

Turnips

\section{GROUP II}

Eat these foods for protein.

$\begin{array}{clll}\text { Beans } & \text { Cottage cheese } & \text { Lamb } & \text { Peanuts } \\ \text { Soy } & \text { Eggs } & \text { Skim milk } & \text { Peas } \\ \text { Lima } & \text { Fish } & \text { Mutton } & \text { Pork } \\ \text { Navy } & \text { Fowl } & \text { Nuts } & \text { Rabbits } \\ \text { Beef } & \text { Game } & \text { Oysters } & \text { Veal }\end{array}$

American cheese 
Group III

Eat these foods for starches.

Barley

White bread

Cake

Green or

Canned corn

Corn flakes

Corn meal

Soda crackers
Graham crackers

Cream of Wheat

Farina

Wheat flour

Hominy

Macaroni

Oatmeal

Rolled oats
White potatoes

Sweet potatoes

Rice

Rye

Tapioca

Wheat breakfast foods

\section{Group IV}

Eat these foods for sugar.

Dried apples

Cane sirups

Corn sirup

Dates
Honey

Maple sirup

Molasses

Dried peaches
Prunes

Raisins

Sorghum

Sugar

\section{Group V}

Eat these foods for fat.

Bacon

Butter

Chocolate

Cocoa
Corn oil

Cream

Lard

Oleomargarine
Olive oil

Peanut butter

Peanut oil

Salt pork

Method of eating. Mastication is the first step in the digestive process, and as this influences the later stages of the process, it is essential that food should be thoroughly and completely masticated. This mastication prepares the food for swallowing : it breaks it up into small particles so that the digestive juices of the stomach can act upon it more readily ; it increases the flow of the gastric juice; and it mixes the saliva with the food so that the process of digesting the starch begins. Since this process stops soon after the food reaches the stomach, it is important that the food should 
U.S. Department of Agricuiture Office of Experiment Stations

A. C. True: Director -
Prepared by

C. F. LANGWORTHY

Expert in Charge of Nutrition Investigations

\section{COMPOSITION OF FOOD MATERIALS.}

\section{IIIIIIIIII}

Protein
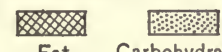

Carbohydrates

WHITE BREAD
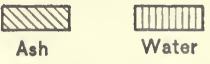

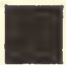

Fuel Value 16 Sq.In. Equals 1000 Calories

\section{WHOLE WHEAT BREAD}

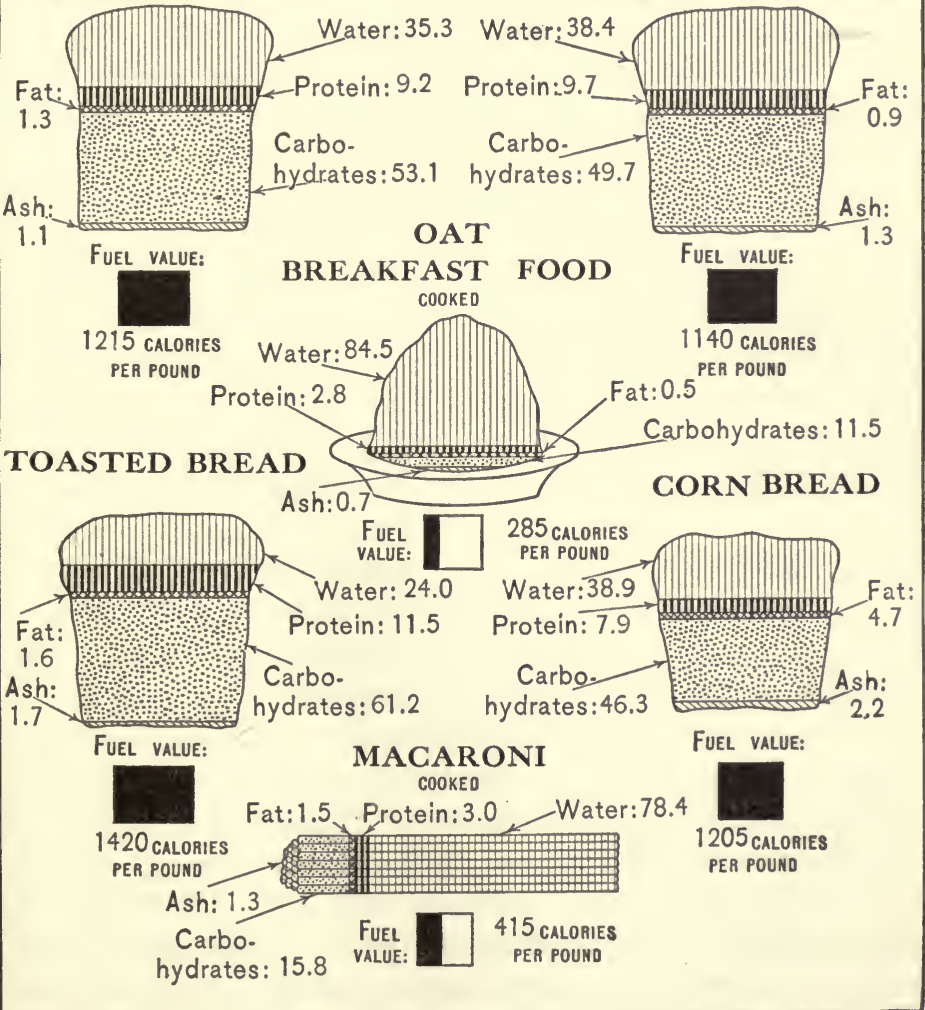

FIG. 30. - Composition of bread. 
remain in the mouth long enough for the process to get well started. We have seen, furthermore, that thorough mastication helps one to develop a natural appetite that serves as a guide in eating.

Overeating. Overeating and mastication are closely related, because insufficient mastication tends towards overeating and one of the chief reasons for emphasizing thorough mastication is to avoid the ills resulting from overeating. Many digestive ills are due to eating more food than the body needs; this is especially true in the cases of those people who lead a sedentary life, which involves little muscular exercise.

As a result of taking too much food into the -stomach, that organ is not able to take care properly of its contents, so that the food remains a long time in the stomach. There it may begin to decay and give off gases that may cause stomach trouble. The whole digestive system, - stomach, intestines, and the organs connected with them, - is overworked to get rid of the excess of food. Those systems which care for the food after it is digested and used, the absorptive and excretory systems, are overtaxed so that they become weakened. The kidneys in particular are strained by the extra work required in throwing off the excess of nitrogenous waste matter, due to eating too much protein food. The working of the whole machinery of the body is hindered by the excessive work demanded of it, and its action is clogged by the excess of food. As a result, the general efficiency of the body is lowered and the health impaired.

Sir Henry Thompson, a noted English physician, says, "I have come to the conclusion that more than half the disease which embitters the middle and latter part of life is due to avoidable errors in diet, and that more mischief in the form of actual disease, of impaired vigor, and of shortened life accrues to civilized man in England and throughout Central Eurnpe from erroneous habits of eating 
than from the habitual use of alcoholic drink, considerable as I know that evil to be."

The point to be emphasized in this quotation is that these diseases are due largely to avoidable errors in diet; that is, these diseases might be largely escaped by proper methods of eating. The ills resulting from improper methods do not show themselves all at once but accumulate gradually through years as the digestive system becomes weakened, so that, as noted in the statement above, these diseases are specially prevalent in the middle and latter part of life. On account of these slowly accumulating ills, it is very easy for one to overlook them for a while; but for this very reason it is very important that one should guard against them in youth before it is too late. Some of these diseases which are so prevalent but which might be largely avoided by proper eating, are: dyspepsia or indigestion in its many forms, jaundice, gout, colic, cholera morbus, constipation, and appendicitis. Statistics show that the death rate in this country for people over forty is increasing. Mistakes in eating undoubtedly constitute one cause for this increasing death rate.

Care of the teeth. As thorough mastication of food is such an important factor in its effect on. health, we can understand how important it is that the teeth should be well cared for, so that they may be preserved in good condition to perform the work of mastication. There are three factors concerned in the decay of teeth: first, the food particles that lodge between the teeth; second, the bacteria that act on these food particles ; and third, the acid produced as a result of this action. These acids act on the teeth and produce decay. To prevent this decay, a person should see to it that particles of food are not allowed to lodge between the teeth. The first step in the care of the teeth is thorough mastication, which leaves the teeth cleaner than does insufficient mastication. The larger pieces of food may 
be removed by means of toothpicks or dental floss, but the smaller, tiny particles require the use of a toothbrush. The best time to brush the teeth, if it is done but once a day, is after the evening meal. Otherwise the food particles would remain in the teeth during all the night, thus allowing a long time for the action of the bacteria in producing decay. But while the teeth should be cleaned at least once a day, the best care requires another cleansing after the morning meal. The value of a toothpowder lies in the fact that it contains substances which help to neutralize the acids that cause decay, and it also acts as an antiseptic on the bacteria.

Sources 'of food. All of our food is made either directly or indirectly by the action of plants. Some of our food consists of the flesh of animals, but these animals have fed on plant food, so that this brings us back to plants as the final source of our food. Starch is made by the green matter in plants known as chlorophyll, generally found in the leaf. This chlorophyll takes water and carbon dioxid, and from this, in the presence of light, manufactures starch. The water comes up from the roots through the stem and the carbon dioxid passes from the air through small openings in the leaf. This starch is one of our commonest foods. Later, some of this starch is united in the plant with substances that come up through the roots from the soil, and by this process proteins are formed, which constitute, as we have seen, another important food for mankind.

Summary. The whole matter of the hygiene of foods may be briefly summarized by saying that a thorough mastication of foods will help develop a natural appetite, which will decide for us both what to eat and how much to eat. One should also occasionally compare his weight with that of the average for his height; and compare his daily diet with standards that have been set as a result of experiments, so that he may know whether he is approximating these standards. As general guides these suggestions may be 
given : Avoid large amounts of meat foods. Use milk, fruits, and vegetables freely.

Drinking water. Water should be drunk freely many times a day. Recent experiments have shown that drinking water during the meals really helps the process of digestion instead of hindering it, as has sometimes been thought. Water should not be taken, however, when the mouth contains food and used as a substitute for mastication to wash down foods that are only partially masticated. Under ordinary conditions a person needs about two glasses at each meal, and two glasses between meals, or eight glasses a day, which is equal to about two quarts. Other drinks such as milk, tea, and coffee furnish a part of the needed water.

Some misnamed foods. There are some drinks which are very commonly used at the table that have sometimes been carelessly called foods, namely coffee and tea. These are not foods in any sense of the word. Both are stimulants that act as a spur on the nervous system to increase its activities. This stimulative effect is due to a drug called caffeine in coffee and theine in tea, the two being almost identical. Both also contain tannic acid, which is very harmful to the membrane of the stomach. The tannic acid does not dissolve in water as readily as the theine, and the effects of tea are less harmful if the water is not allowed to boil after the tea is made and dissolve the tannic acid.

Neither tea nor coffee serves any necessary function in the body, and their use is to be looked on as an indulgence. The effect of these drinks on adults varies greatly with different people. Some people are distinctly harmed by their use, while others seem to use them without any apparent injury. One of the worst features attending the use of tea and coffee is the possibility that one may acquire an appetite which he cannot control and thus become a slave to tea and coffee. But whatever may be said about their effect on 
adults, all authorities agree that their effect is injurious on growing boys and girls, who will be better off if they leave these drinks alone.

\section{SUPPLEMENTARY QUESTIONS FOR CLASS DISCUSSION}

I. Which is better, a mixed diet or a vegetable diet?

2. To what extent should cost be considered in buying foods?

3. How may economy be practiced without injuring the health?

4. How did Professor Chittenden's experiments differ from Professor Fisher's?

5. To what extent are their conclusions similar?

6. How may these experiments help us in determining our food habits?

7. What is the chief value of thorough mastication of food?

8. What bearing on health does the care of the teeth have?

9. How does overeating injure health?

\section{Home Project iI}

Purpose. To practice daily the proper health habits.

Directions. Copy the following table in your notebook. Try each day to follow out the habits here suggested. At the end of each day fill in the blank spaces, giving yourself the credits you deserve according to the faithfulness with which you have practiced each of these habits. At the end of the week have your father or mother sign the report. Then hand it to your instructor as a part of your regular class work for which you will receive school credit. 
Table of Health Habits for the Week Ending (date)

\begin{tabular}{|c|c|c|c|c|c|c|c|c|}
\hline & $\begin{array}{c}\text { DAILY } \\
\text { CREDIT }\end{array}$ & Sun. & Mon. & Tues. & WED. & Thurs. & FRI. & SAT. \\
\hline $\begin{array}{l}\text { Clean teeth } \\
\text { Sleep with window } \\
\text { open } \\
\text { Retire by } 9.30^{1} \cdot \\
\text { Abstain from use of } \\
\text { coffee and tea. } \\
\text { Exercise I hour out- } \\
\text { doors } \\
\text { Bathe once a week. }\end{array}$ & $\begin{array}{r}19 \\
19 \\
19 \\
19 \\
19 \\
5\end{array}$ & & & & & & & \\
\hline Total . . . . & 100 & & & & & & & \\
\hline
\end{tabular}

I believe that the above record is a truthful account of my child's health habits for the week.

(To be signed by parent.)

\section{School Project I}

Purpose. To form a League of Modern Health Crusaders.

Directions. Write to the National Association for the Study and Prevention of Tuberculosis, I05 East 22d St., New York City, for information as to how a league of modern health crusaders may be formed. Circulars will be sent giving full particulars.

\section{REFERENCES}

Conley, Nutrition and Diet, American Book Co., New York City.

Fisher and Fisk, How to Live, Funk and Wagnalls Co., New York City.

1 The time will vary according to the age of the child. 


\section{CHAPTER VI}

\section{THE SCIENCE OF THE KITCHEN}

I. In what ways are our modern methods of cooking better than the methods used in early times?

2. What advantages has each of the following methods of preserving foods over the other: drying and canning?

Purposes of cooking. Man in his early history ate his food uncooked; but to-day civilized man finds that cooking foods serves three important purposes: first, it destroys parasites and disease germs; second, it renders the food more palatable; and third, it makes the food more digestible.

Sometimes bacteria and parasites that cause disease, such as typhoid fever and trichinosis, are found in foods; but the high temperature used in cooking kills these dangerous forms and thus renders them harmless. Many foods are made more agreeable to the taste through cooking, and this has an important effect on the digestion of the food, as it is found that foods which we enjoy are digested better than foods that we dislike.

Many foods are rendered more digestible by cooking. Much of the starch found in vegetable foods is inclosed in cellulose walls, upon which the digestive juices cannot act. Cooking bursts these walls, thus allowing opportunity for the digestive juices to act on the swollen starch granules. Cooking softens the tough, connective tissues of some meats, and this renders them more tender and easily digested. 
Effect of heat on foods. Heat hardens or coagulates protein foods such as the white of an egg. Fats are little effected by low temperatures, except to be melted; but at high temperatures they are decomposed and form irritating substances which hinder digestion. The chief effect of heating starch in water is to cause a swelling of the starch granules. Dry heat changes the starch into dextrin and glucose, as seen in the crust of bread.

Making bread light. One important quality of good bread and similar foods is that they shall be light and porous. This is brought about by mixing some gas with the dough; for as the dough is cooked these gases escape and leave the bread porous. Sometimes this result is produced by mechanically forcing air into the dough by beating. Eggs are sometimes added to render the dough more capable of holding the air. But usually something is put with the dough to produce a gas, which rises through it and makes it porous. Gas is produced in dough by using baking powder or yeast. In both cases the same gas is produced, carbon dioxid.

A baking powder is a mixture of two compounds of such a nature that when water is added the two chemicals act on each other and carbon dioxid is formed. One of these compounds is usually baking soda, the other may be cream of tartar, phosphate, or alum. With these a little starch is usually mixed to prevent the powder from becoming moist. In place of baking powder, soda and sour milk may be used.

Yeast is, also used to make bread light. Yeast is a very small plant; a single one is too small to be seen by the eye without the aid of a microscope. As a result of the action of the yeast on the dough, carbon dioxid is formed and acts in the same way as that formed by baking powders in making the bread light. At the same time alcohol is formed, but in the oven this passes off from the bread. When war breads were being made by the use of substitutes for wheat, it was frequently found that the bread was heavy and un- 
palatable. Wheat contains a sticky substance called gluten, which keeps the dough porous after the gases pass through it. Barley and other wheat substitutes do not contain this gluten, and so it is necessary to mix a certain amount of wheat with the other flours in order to furnish enough gluten to make a light bread.

\section{LABORATORY EXERCISE I2}

Purpose. To study the action of baking powder and yeast.

Materials. Baking powder, baking soda, cream of tartar, and vinegar.

Directions. I. Mix dry baking soda and cream of tartar. Add hot water and note what happens. Add vinegar to baking soda. Put a little baking powder into water and note what happens. Dissolve baking soda and cream of tartar separately in cold water, then pour one into the other. Try again, using hot water, and note the difference.

2. Make a paste of flour and water. Mix with this a small piece of yeast cake. Allow to stand for a while in a warm place and notice what happens.

3. Put in each of two test tubes or small bottles a teaspoonful of molasses and ten of water. Mix a small piece of yeast cake with water and add a half to each bottle. Place one in a cool place, as in an ice chest, and the other in a warm place. At the end of a day notice any difference in the two.

Methods of cooking. Water is an essential factor in cooking. Many foods are cooked in boiling water. This insures an even temperature as water always boils at the same temperature, 2 I 2 degrees, with slight variations due to the atmospheric pressure. In the double boiler the outer dish holds boiling water and the inner dish the food to be cooked. So long as the outer dish contains water the food will not burn. Sometimes, as in stewing, foods are cooked in water which is kept just below the boiling point. 
In cooking meats, if it is desired to keep the juices within the cut, the piece is put directly into boiling water, which coagulates the outside and so forms a coating that retains the juices inside. If it is desired to extract the juices from the meats, as in soups, the meat is first put into cold water and heated gradually, and thus many of the juices dissolve in the water.

Some foods are cooked in hot fat, since fat can be heated to a temperature much higher than that of boiling water. It should be so hot that when the food is placed in it, the outside is heated quickly, forming a coating which prevents the fat from entering the inside. When the fat mixes with all portions of a food, a mass is formed which is difficult to digest.

It is seen that these various methods of cooking involve different temperatures. In stewing, foods are cooked at a temperature below $2 \mathrm{I} 2$ degrees; in boiling water, at a temperature of $2 \mathrm{I} 2$ degrees; in hot fat, at a temperature higher than this ; and in baking, at a still higher temperature.

Early methods of cooking. It is interesting to note the changes that have occurred in the methods of cooking since the very earliest times. At first, cooking was carried on over the open fire by broiling, or by roasting in hot ashes. Later on, crude kinds of kettles were suspended over the fire and the food was cooked by boiling or stewing in these. Then the open fireplace indoors was used, and movable ovens, open at one side, were placed in front of it. Machines were used to turn meats which were roasted in front of open fires. Then various kinds of closed ovens were made. Even within the history of our own country, open fireplaces and brick ovens were the common means of cooking. In more recent times have appeared stoves and the gas range; and now cooking is being done by electricity. In the future, improvements will doubtless be made along this line, and electricity may be made so cheap that it can be commonly 
used in cooking, thus doing away with the dust and inconvenience of coal and wood stoves.

Fuels used in cooking. One of the most common means of cooking is the wood or coal range. This is so constructed that the heated gases are forced around the oven before escaping up the chimney. Gas ranges are very widely used in towns and cities. The heat can be started, controlled,

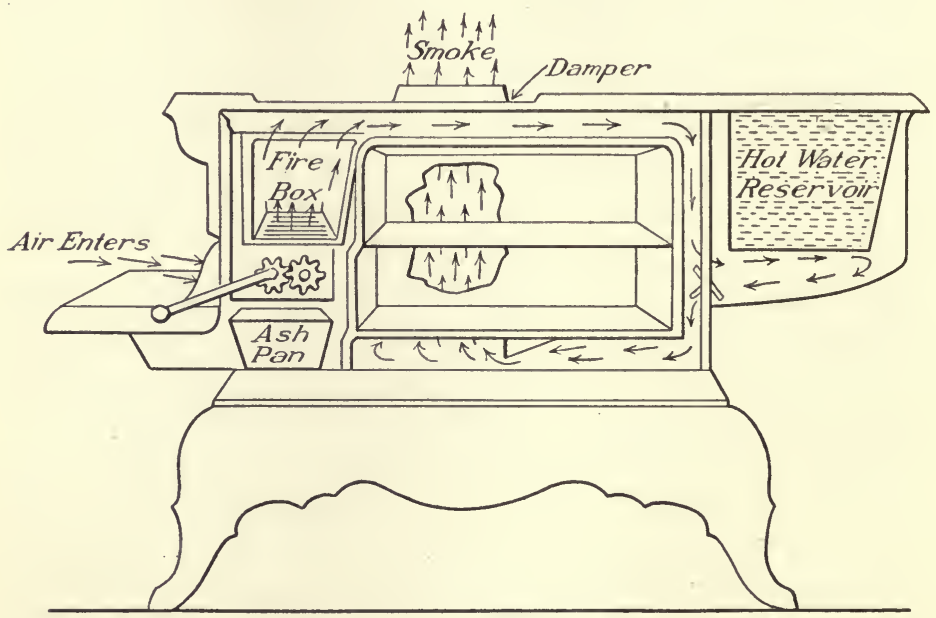

FIG. 31. - A kitchen range.

and shut off at will, and the gas range is especially advantageous during warm weather. The burners are so arranged as to mix air with the gas, thus producing a complete burning, which gives a very hot, blue flame. Usually these burners are adjustable, so that the proper amount of air may be admitted to give the hottest flame.

\section{LABORATORY EXERCISE I3}

Purpose. To study the working of a Bunsen burner.

Directions. The burners on a gas range work on the same principle as the Bunsen burner. Take a burner apart, noting 
the various pieces. Put it together and light it. Cover the air holes completely and then leave them wide open. What difference does it make in the flame? Cover the hole partially. How should the burners on a gas range be regulated?

Fireless cooker. The fireless cooker is another device for cooking. It consists of a box with a tightly fitting cover, in which are placed several receptacles separated by some material which conducts heat slowly, such as hay or excelsior. The foods to be cooked are first brought to boiling on a stove, then placed in these compartments and tightly covered. As there is little opportunity for the heat to escape, the foods continue to cook, and if suffi-

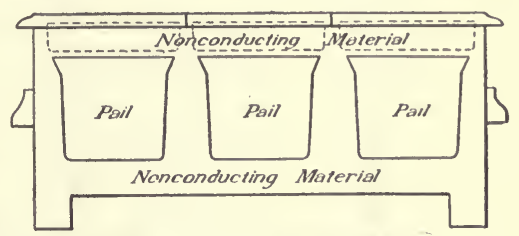

Fig. 32. - Fireless cooker. cient time be allowed, they are cooked enough for eating. Pies and bread may be baked and meats roasted. For this purpose heavy plates are heated and placed in the bottom of the compartment and the food placed on these. If one has access to a gas range or a kerosene stove by which water can be quickly heated, the fireless cooker has two great advantages, comfort during the warm weather, and the saving of fuel. It is claimed also that food cooked slowly and for a long time is more palatable than when cooked by the ordinary method.

Thermos bottle. The thermos bottle, in which liquids may be kept either hot or cold for a long time, is made on somewhat the same principle. It is virtually two bottles, one inside the other separated by a vacuum, through which heat cannot pass readily in either direction. The outer surface is made of a bright, smooth material which reflects the heat rays instead of allowing them to pass through. 
Refrigerator. In order to keep foods from decaying in warm weather, the refrigerator is now widely used. The bacteria which cause decay do not thrive at low temperatures ; hence food may be kept for some time in refrigerators. Melting ice remains at a temperature of 32 degrees till all is melted. The air around the ice is cooled and being heavier

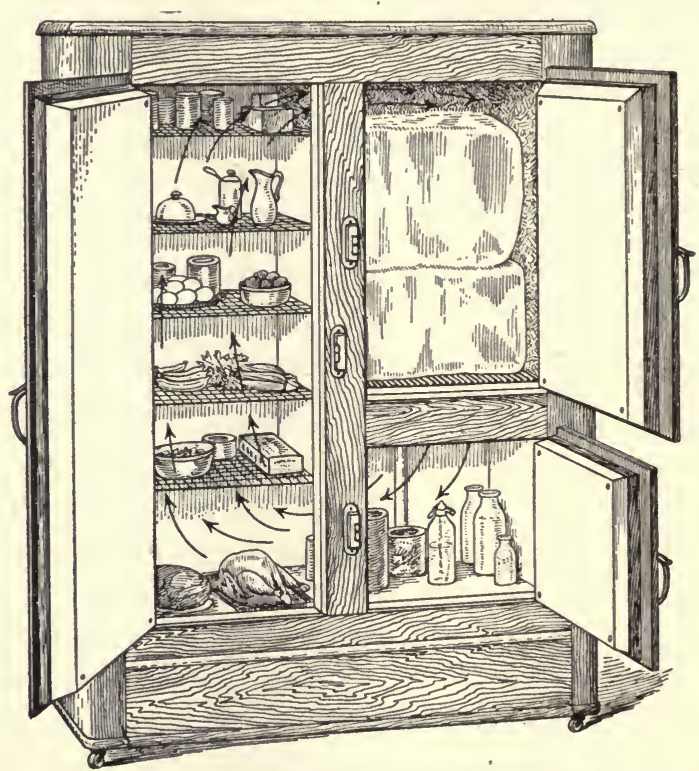

Frg. 33. - Circulation of air in a refrigerator.

sinks, and the warm air in the refrigerator comes in to take its place. Thus there is a circulation of air in the refrigerator similar to that which takes place in a room heated by hot air. The walls of the refrigerator are made of materials which do not conduct heat easily from the outside, and air spaces are usually left in the walls, as air is a poor conductor of heat.

Ice cream freezer. The freezing of cream and other liquids in the preparation of desserts is accomplished in an ice cream freezer. A freezing mixture surrounds the vessel 
that contains the substance that is to be frozen. It consists of ice and salt, about three parts of ice to one of salt. Salt has so great an affinity for water that when it is placed in contact with ice it causes the ice to melt. It requires heat to melt ice, and thus heat is taken from the surrounding bodies. A temperature may be obtained as low as 25 or 30 degrees below the freezing point, that is, almost down to zero Fahrenheit. The brine formed does not freeze because its freezing point is much lower than that of pure water.

\section{LABORATORY EXERCISE I4}

Purpose. To study the principles involved in freezing ice cream.

Materials. Salt, ice, tumbler, thermometer, test tube, tin cup.

Directions. I. Put a mixture of salt and crushed ice in a tumbler. Put in this the bulb of a thermometer and record the temperature. Try different proportions of ice and salt and find which gives the lowest temperature.

2. Put a test tube containing water into the mixture of ice and salt.

3. Fill a tin cup with snow. Place the cup on a board covered with a layer of water. Stir some salt into the snow. What happens to the water on the board and bottom of the cup? Why?

Causes of decay of foods. One common problem in the home is to keep foods from decaying. The decay of foods is caused chiefly by two kinds of small plants, molds and bacteria. Molds may be seen with the naked eye as threadlike plants growing upon various kinds of food. On these threads appear little stalks, each bearing a ball. These are filled with a powder called spores, which scatter and grow into new plants. These molds have no green coloring matter and so cannot make their own food like ordinary plants, but must live on food already made by other means. 
Bacteria are the smallest plants known and can be seen only with a microscope. They multiply very rapidly, so that a few may develop in a short time into an enormous number. Both molds and bacteria require moisture and warmth in order to grow; therefore very common means of preserving foods are drying and cold storage.

\section{DEMONSTRATION I2}

Purpose. To study the activities of bacteria and some means of controlling them.

Materials. Test tubes, raw meat, beans, boiled potato, white of egg, salt, vinegar, formalin.

Directions. I. The action of bacteria in causing decay.

$a$. Place in a test tube a small piece of raw meat; half cover with water. Set in a warm place for two or three days. Note the appearance of both meat and water. This change has been caused by bacteria.

$b$. With a knife heated in a flame, cut a boiled potato in two parts. On one half of the potato put some dust; leave the other half untouched. Cover them both and allow them to stand for several days. Note any difference.

2. Effect of drying on their activities.

In one tube place a bean, in another a bean half covered with water. Allow them to stand for a week and note any difference between the two.

3. Effect of freezing and boiling.

Put a small piece of raw meat in each of three test tubes; nearly cover with warm water. Boil the water in one tube. Plug all three tubes with cotton batting. Place one of the tubes that has not been heated outdoors where it will freeze, and keep the other in the schoolroom by the side of the one that has been heated. On the next day bring in the tube from outdoors and allow all three tubes to stand in the schoolroom for several days. Note any differences. What is shown about the effect of high and low temperature on the growth of bacteria? 
4. Effects of disinfectants:

Mix the white of an egg with about ten times its bulk of water. Pour some of this into each of five test tubes. Allow the first tube to remain as it is ; to the second add a little salt, to the third a little sugar, to the fourth some vinegar, and to the fifth three drops of formalin. Allow to stand side by side for several days and note any differences in the effect of the substances in preventing decay.

Preserving foods. Many methods of keeping foods for long periods of time are used; among the more common are drying, smoking, the use of preservatives, and canning. Drying was one of the earliest methods used and is quite common. Bacteria and molds that cause decay require a certain amount of moisture in order to live and by drying foods the amount of water may be reduced to such a limit that these forms cannot exist. Many foods are already dried as we harvest them, such as the various kinds of grains, peas, beans, and corn; and the food obtained from these by grinding, such as flour and meal, can be safely kept. In other cases artificial drying is used. For some uses even milk is evaporated and reduced to a dry powder that may be kept for a long time.

Drying fruits and vegetables. Many kinds of vegetables and fruits can be easily dried in the home. This gives an opportunity to save many vegetables that are commonly wasted, either because they are allowed to go to waste in the garden or are left over while preparing meals.

The general principle involved in drying is that enough water is removed by evaporation so that bacteria and molds cannot live on the product, and it can therefore be stored and kept. The food to be dried is first cut into thin slices, or in the case of corn the kernels are cut from the cob. These may be dried in three ways : in the sun, over a stove or other source of artificial heat, or before an electric fan. For holding the substances shallow trays of any convenient 
size may be used. The bottom should be porous so as to allow a free circulation of air. For this purpose laths may be used with spaces between them, or the bottom of the tray may be covered with a small-mesh, galvanized wire netting. Sun drying is the simplest but requires the longest time, varying from two to three days according to the weather. The food should be protected from insects and dust. When dried over the stove, the process may be finished in from two to five hours. The temperature should not be allowed to go

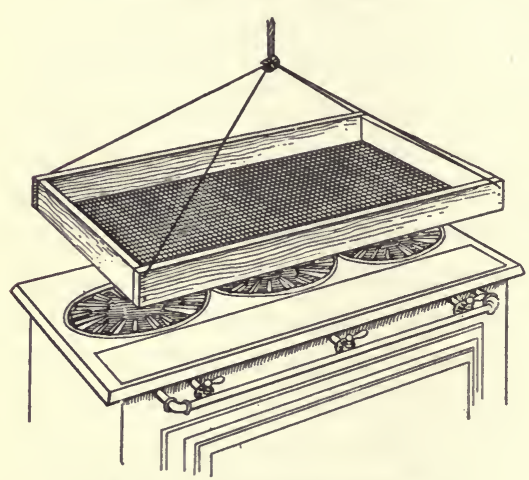

Fig. 34. - Home-made drier. above 140 or I 50 degrees. Instead of using heat, a motion of air may be employed to hasten evaporation. A number of trays may be put one on the other and an electric fan operated in such a way as to force a current of air to pass over them. Sometimes insects lay their eggs on the drying substances, especially if the drying be done in the sun, and these eggs may hatch later and the larvæ eat the food. To avoid this difficulty, the product may be heated for a short time in an oven at a temperature of about 140 degrees. This kills the eggs.

The dried products should be stored in receptacles that will protect them from insects, mice, and rats. Stout paper bags and pasteboard boxes with tight covers serve the purpose well. The products must be protected from moisture and they will keep best in a cool, dry, well-ventilated place.

Where it is desired to use the dried products, they are soaked for several hours in water so as to restore the amount that was lost by evaporation. They are then cooked in about the same way as fresh fruits and vegetables. 


\section{Home Project i2}

Purpose. To dry fruits and vegetables at home.

Directions. Send to the Department of Agriculture, Washington, D. C., for Farmers' Bulletin 84I on Drying Fruits and Vegetables in the Home. Dry some fruits or vegetables at home, following the directions given in this bulletin.

Preservatives. Some foods are preserved by the use of salt or sugar. Oftentimes preservatives are used in connection with the process of drying, - salt with meats, and sugar with fruits and berries, such as raisins and prunes. Smoking of meats such as hams is often accompanied by two other processes, drying and salting. Another harmless preservative that may be used is vinegar, the acid quality of which prevents the growth of bacteria that produce decay. Sometimes spices are used to help preserve foods, as in mince meat and sausages.

Canning. One of the most recent and widely used methods of preserving foods is canning. This is now such an important industry that most of our common fruits and vegetables can be bought canned. Canning has proved a great blessing to mankind, since foods which keep for only a short time in the fresh state can now be obtained at any season of the year. It is also a means of economy in the home. Vegetables can be raised in the garden and then canned for winter use. This may be done at slight cost and one is sure of the quality of the products canned.

The decay of fruits and vegetables is due to the action of. small plants : yeasts, molds, and bacteria. In canning, two principles are involved: first, all these plants present in the fruits and jars must be killed; and second, the cans must be sealed in such a way that no others can enter.

Killing the bacteria. The most difficult plants to kill are bacteria. The method usually employed in the home to 
kill these bacteria is to heat the jars at the temperature of boiling water for a period varying from fifteen minutes to three hours, depending on the product to be canned. In addition to the active forms in which bacteria are generally found, some exist in a dormant state, known as spores. The active form is easily killed by a short boiling, but in order to kill the spores, a longer boiling is necessary. Fruits are easily canned; vegetables require more care. Lack of success in canning vegetables is often due to failure to boil long enough to kill these spores.

Cold-pack method of canning. The process of canning has now been made so simple that it can be carried on in the home with inexpensive apparatus. The first steps are the preparation of the products to be canned and the cleaning of the containers. It is better to can the products within a few hours after they are picked. For home use glass jars are best. The jars should be thoroughly cleaned and kept in a dish of hot water.

In the cold-pack method, there are five steps: (I) blanching, (2) cold dipping, (3) packing, (4) processing, and (5) sealing. Blanching consists in putting the products into boiling water and allowing them to remain for a few minutes. This time varies from one to fifteen minutes, depending on the kind of product. The purpose of blanching in some cases is to loosen the skins, as with tomatoes, in other cases to reduce the bulk of the vegetable. The products may be placed in a piece of cheesecloth or a wire basket made for the purpose. Blanching is omitted in canning berries and soft fruits.

The cold-dip serves three purposes: (I) to harden the pulp under the skin so that the skin can be removed, (2) to set the coloring matter, and (3) to make it easier to handle the products in packing.

The products are then packed in hot jars. Sirups are added to fruits and hot water to vegetables. For seasoning, a level teaspoonful of salt is added to each quart of vegetables. 

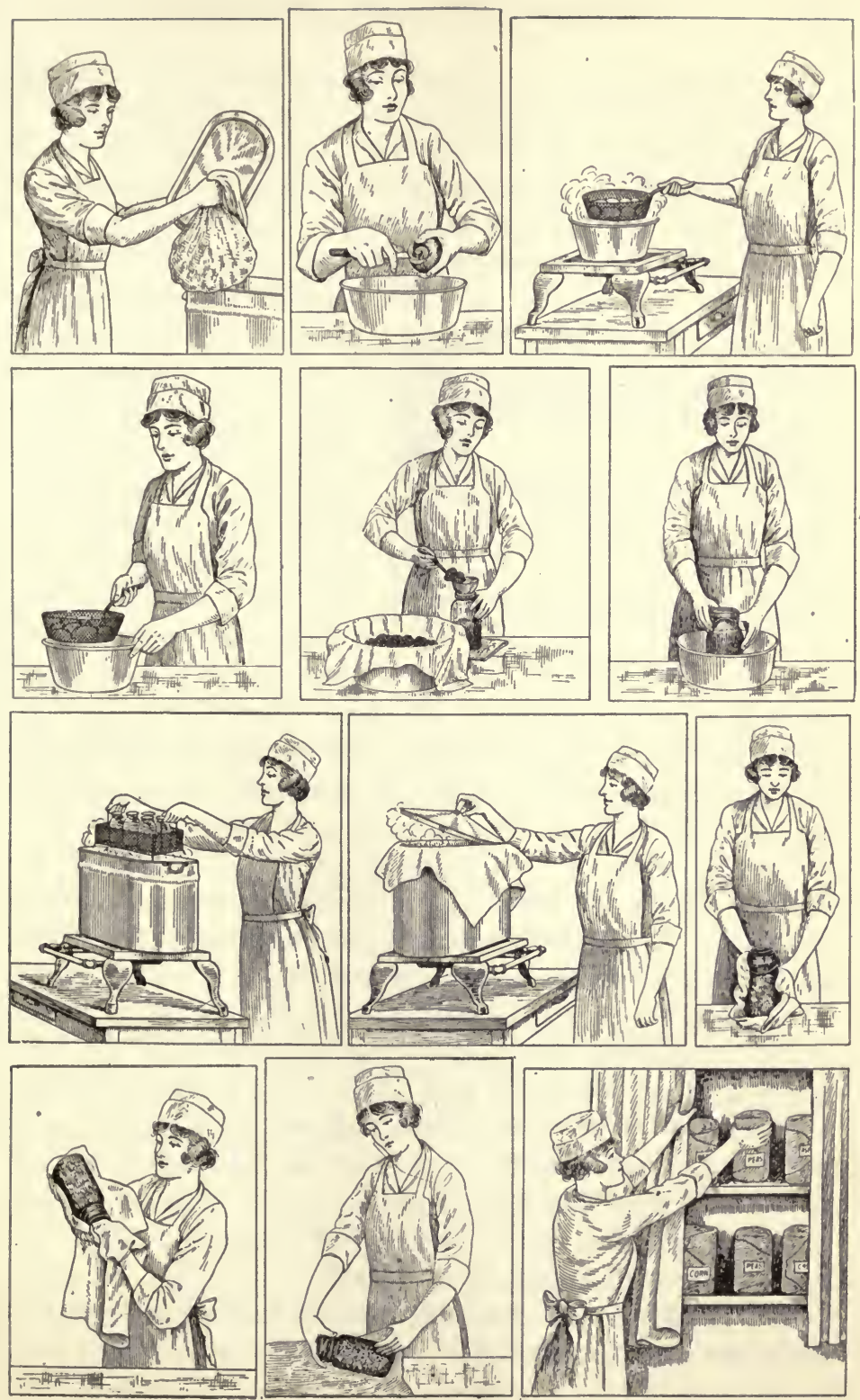

FIG. 35. - Steps in canning. 
The covers are put on and partially closed and the jars are then placed in some vessel for processing. This consists in heating the jars so as to kill bacteria. The time depends on the kind of product and the temperature. The simplest device for home use is the hot-water bath outfit. This consists of any receptacle in which water can be boiled. It must be deeper

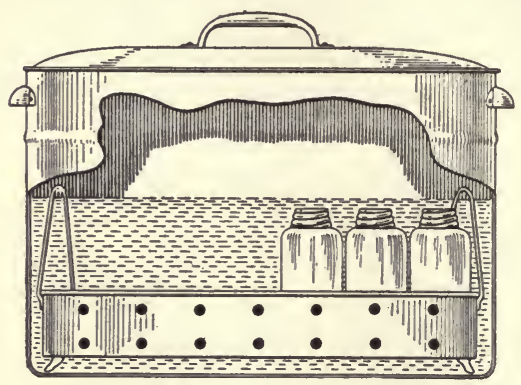

Fig. 36. - Boiler for canning. than the height of the jar so that the jar may be completely covered with water. Such utensils as wash boilers, lard pails, and tin pails can be used. Some kind of perforated platform should be placed on the bottom of the dish so as to permit the free circulation of water around and under the jars. The water should cover the tops of the jars by at least an inch. The receptacle should have a tightly fitting cover. After the processing is finished the jars are removed and sealed tightly at once.

Canning tomatoes. As a definite illustration of how the method is used, the following directions for canning tomatoes are given. The tomatoes are put into a piece of cheesecloth and placed in boiling water for one and one half minutes. They are then dipped into cold water and the skins are removed. They are then packed into hot glass jars and a level teaspoonful of salt added to a quart. The rubbers and caps are put on, but the cap is not fastened tight. The jar is put into hot water in the wash boiler and allowed to remain 22 minutes after the water begins to boil. The jar is then removed and the cap fastened down securely. The jars may be inverted to test for any leaks.

The following table shows the time of scalding and processing a few common vegetables and fruits. 
Time Table for Blanching and Sterilizing Vegetables and Fruits

\begin{tabular}{|c|c|c|c|c|c|c|c|}
\hline \multirow{2}{*}{\multicolumn{4}{|c|}{ VEGETABLES }} & \multirow{2}{*}{ BLANCHING } & \multicolumn{3}{|c|}{ STERILIZLNG } \\
\hline & & & & & $\begin{array}{l}\text { Hot Water } \\
\text { Outfit }\end{array}$ & $\begin{array}{l}\text { Steam Pressure } \\
\text { 5-10 Pounds }\end{array}$ & $\begin{array}{l}\text { Steam Pressure } \\
\text { I0-15 Pounds }\end{array}$ \\
\hline & & & & (Minutes) & (Minules) & (Minutes) & (Minules) \\
\hline Asparagus & . & . & . & I 5 & 120 & 60 & 40 \\
\hline Beans, wax & - & . & & $5^{-10}$ & 120 & 60 & 40 \\
\hline Beets . . & . & . & . & 5 & 90 & 60 & $40^{--}$ \\
\hline Corn, sweet & . & . & . & 5 & 180 & 90 & 60 \\
\hline Peas . . & . & . & . & $5-10$ & I 80 & 60 & 40 \\
\hline Spinach . & . & . & ${ }^{\circ}$ & I5 & 120 & 60 & 40 \\
\hline Squash & . & . & . & 3 & I 20 & 60 & 40 \\
\hline Tomatoes. & . & . & . & $I \frac{1}{2}$ & 22 & I 5 & Io \\
\hline Fruit & & & & & & & \\
\hline Apples . . & . & ${ }^{\circ}$ & & I $\frac{1}{2}$ & 20 & 8 & 6 \\
\hline Cherries . & . & . & & & 16 & 10 & 5 \\
\hline Peaches & . & . & $\cdot$ & $I-2$ & I 6 & IO & 5 \\
\hline Pears . . & . & . & & I $\frac{1}{2}$ & 20 & 8 & 6 \\
\hline Plums . . & . & . & & & 16 & IO & 5 \\
\hline Raspberries & . & . & ${ }^{\circ}$ & & 16 & IO & 5 \\
\hline Strawberries & . & . & . & & 16 & 10 & 5 \\
\hline
\end{tabular}

\section{Demonstration I 3}

Purpose. To show how to can fruits and vegetables.

Directions. Send to the Division of Publication, U. S. Department of Agriculture, Washington, D. C., for Farmers' Bulletin 839, "Home Canning by the One-Period Cold-Pack Method." Following the directions there found, demonstrate before the class the hot-water method of canning. Can at least one fruit and one vegetable.

\section{Home Project I3}

Purpose. To can fruits and vegetables at home.

Secure the Bulletin mentioned above and can some fruits or vegetables at your home. 
Canning under pressure. Canning is also done by steam pressure outfits. Pressure raises the boiling point of water. Under a pressure of five pounds, the boiling point is 228 degrees, and under a pressure of fifteen pounds it is 250 degrees. When the products are heated at these high temperatures they are sterilized in a shorter-time. Under a pressure of ten pounds only one half to one third as long a period is required as with the hot-water outfit. In commercial canneries these pressure outfits are used altogether. Small outfits for home use can be obtained at prices ranging from $\$$ I $_{5} .00$ up.

Chemistry of the kitchen. The chemicals used in the kitchen may be divided into three classes, - acids, bases, and salts. Examples of acids are vinegar and the juices of fruits. An acid has a sour taste and turns blue litmus paper red. A base has a soapy taste and turns red litmus blue. Ammonia and baking soda are common examples. Litmus paper is used to test for acids and bases. When an acid and base are mixed, it is possible to reach a stage where the mixture will affect neither blue nor red litmus paper. The two substances are said to have neutralized each other. If this solution be evaporated, a new substance will be left which is called a salt. The particular kind of salt formed depends on the acid and the base used. Common salt and cream of tartar are examples of salts.

\section{LABORATORY Exercise I 5}

Purpose. To study the action of some substances used in the kitchen.

Materials. Red and blue litmus paper, vinegar, ammonia, limewater, and lemon.

Directions. I. Pour a little vinegar into a dish. Place in it a small strip of blue litmus paper. What change takes place? This is the test for an acid.

2. Pour a little ammonia into a dish. Place in it a small 
strip of red litmus paper. What change takes place? This is a test for a base.

2. Dissolve some salt in water. Put in this a piece of red and also one of blue litmus paper. Does any change occur? This is said to be a neutral substance.

4. Get as many common substances as you can from the kitchen, such as lemon, orange, limewater, sugar, sour milk, sweet milk, buttermilk, baking soda, cream of tartar, baking powder, tomatoes, an apple, any fresh fruit, tea, coffee, washing soda, soap, gold dust, wood ashes, drinking water.

Test each one of these with both red and blue litmus paper. Test the juices of the fruits. Dissolve the powders in water. After letting the ashes stand, pour through a filter paper. Steep the tea and coffee in hot water. Place the name of each substance under one of the following headings in your notebook.
ACID
BASE
Neutral

Soaps. Soaps are made by the action of fats on alkalies. One called caustic soda makes hard soaps; another called caustic potash makes soft soaps. The cleansing action of soaps is due to the fact that they unite with the fatty substances that hold the dirt, thus freeing it, and allow it to be washed away. Washing soda also acts on grease, and most washing powders are mixtures of this soda and powdered soap.

Hard water. Some hard waters contain chemicals in solution which interfere with the action of the soap, since the soap acts on these chemicals before uniting with the grease around the dirt. Sometimes this hardness can be overcome by boiling, as when the chemical is calcium bicarbonate. This is called temporary hardness. Another kind, not so easily remedied, is called permanent hardness. Enough soap must be used to counteract all the chemical before the soap will have any cleansing power; and the sub- 
stance thus formed is an insoluble chemical which further interferes with the cleansing. Whe drinking water is hard, another supply of soft water is frequently provided in cisterns. This water may be pumped by hand or it may be made to circulate throughout the house by means of pressure tanks as already explained in Chapter IV.

\section{LABORATORY EXERCise io}

Purpose. To learn the effect of soap on hard water.

Materials. Soap, test tubes, calcium sulfate, soft water, washing soda.

Directions. I. To procure hard water, add calcium sulfate to some water. Shake and filter. Make a soap solution by heating a little soap in soft water in a test tube.

2. Take a little of the hard water and add to it a measured quantity of soap solution. Shake the test tube. Take the same quantity of soft water and add the same amount of soap solution as in the previous experiment. How do the results differ from those in the previous experiment? Why is hard water not satisfactory for cleansing purposes?

3. To hard water, add a little washing soda and shake the mixture. Then add some soap solution. What was the effect of the soda on the hard water?

Removing stains. A stain may usually be removed by one of the following methods : by dissolving it; by bleaching it; by neutralizing it ; or by absorbing it. The following table shows what may be used to remove various stains.

Kind of stain

Grease .

Fresh paint

Grass

Iron rust

Mildew

Lemonade

\section{How removed}

Dissolved in naphtha.

Dissolved in turpentine.

Dissolved in alcohol.

Weak hydrochloric acid for cotton or linen. Oxalic acid for silk.

Bleach with Javelle water.

Neutralize with ammonia. 
Naphtha works better if placed in a bowl of warm water, but it is easily inflammable and forms dangerous explosions when brought near a flame, and great care should therefore be taken when using it.

\section{SUPPLEMENTARY QUESTIONS FOR CLASS DISCUSSION}

I. In what ways may cooked foods be more healthful than uncooked foods?

2. How does the action of yeast differ from the action of baking powders as they are used in baking bread?

3. What are the essential differences in the various methods of cooking?

4. What advantages has the fireless cooker?

5. In what way is the construction of a refrigerator similar to that of a fireless cooker?

6. What principles involved in hot-air heating are found also in the refrigerator?

7. What are the essential differences in the various methods of preserving foods?

8. Why is hard water unsatisfactory for cleansing purposes?

9. Which is the best of the three methods of drying foods?

I0. How does the method of canning corn differ from the method of canning strawberries?

\section{REFERENCES}

Conn, Bacteria, Yeasts, and Molds in the Home, Ginn and Co., Boston.

Dodd, Chemistry of the Household, American School of Home Economics, Chicago.

Richards and Elliott, Chemistry of Cooking and Cleaning, Whitcomb and Barrows, Boston. 


\title{
SECTION B
}

\author{
Entertainment in the Home
}

\section{CHAPTER VII}

\section{MUSICAL INSTRUMENTS}

What advantages, as a source of pleasure in the home, has each of the following instruments as compared with the other two: phonograph, piano, violin?

The phonograph. Musical instruments furnish a pleasant means of home entertainment. The phonograph is coming to be very widely used. Its advantages are evident. It does not require years of practice before one can play it, but any one can learn in a few minutes to run the machine. Another great advantage is the great variety of selections that can be played upon it, representing all kinds of musical instruments and combinations of human voices. Not only can one listen to a great variety of music, but one can hear the very best, as many of the most famous singers and musicians are having records made of their performances.

The phonograph is one of the wonders of the last twentyfive years. It opens great possibilities for the future. Records of the songs of the great singers and of the speeches of great orators and famous men may be preserved to be used long after these people have died. We may get some conception of what this will mean if we suppose that to-day we had records of the farewell address of Washington or of 
the Gettysburg address of Lincoln, so that we could listen to the voices of these great men.

The phonograph was invented by Thomas A. Edison in 1877. The first machine consisted of a mouthpiece, across which was stretched a thin membrane, to the under surface of which was attached a sharp point. Just beneath this was a cylinder covered with tinfoil, which was rotated by hand. As one spoke into the mouthpiece, the membrane with the point attached vibrated and the point made indentations on the tinfoil beneath. These holes varied according to the intensity of the sound. A loud sound made a relatively deep indentation, while a soft sound made a shallow indentation. When the record on the tinfoil was finished, the point on the membrane was set back on the first part of the groove and the cylinder turned by hand. As this point followed these indentations, it reproduced the same vibrations in the membrane that had made the indentations; and it thus reproduced the same

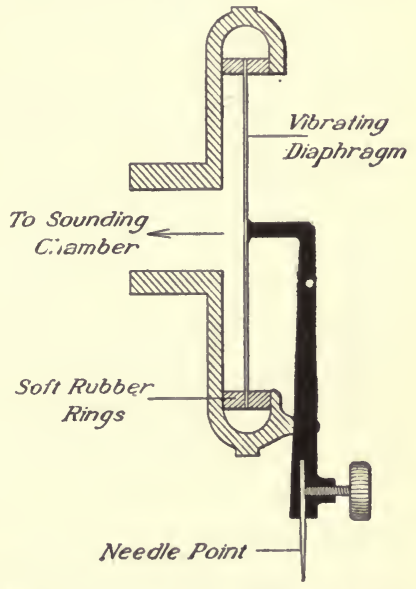

Fig. 37. - Section of a phonograph. sounds that had been spoken into it. The words first spoken into the mouthpiece by Mr. Edison and first reproduced by the phonograph were the lines of the poem, "Mary had a little lamb."

Since that time a great many improvements have been made in the phonograph, but the essential principles are the same as those used in that first crude machine. The modern phonograph has a device by which the record is kept rotating. This is usually done by means of a spring which is wound up by a crank on the side of the machine. It is necessary 
that the speed should be uniform, and this is controlled by means of a governor consisting of balls attached to wires and all rotating with the machine. The faster this rotates, the more these balls are thrown out by centrifugal force; and this brings a disk on the axle into contact with a friction pad, so that the speed is lessened. The speed may be regulated by means of a screw which controls. the position of these pads.

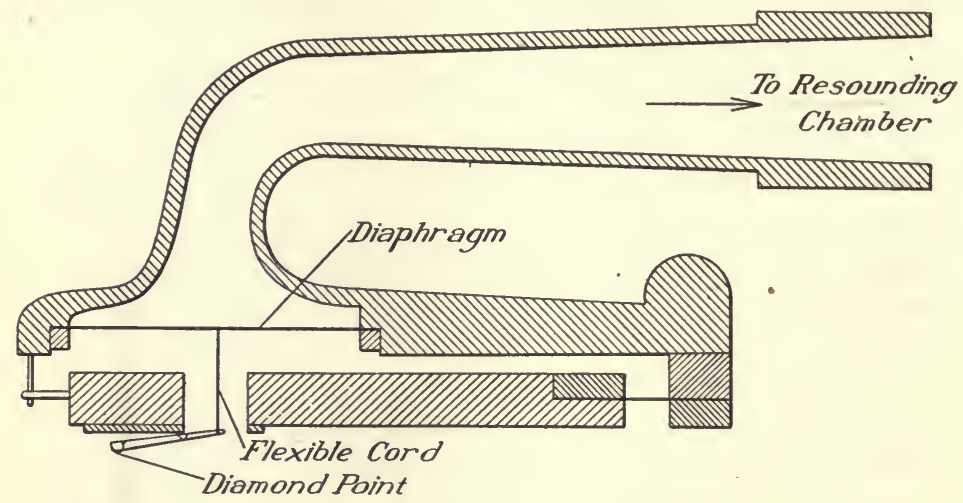

Fig. 38. - Section of a phonograph.

The tones are strengthened by means of horns. Sometimes these are visible and attached on the outside; in the box form the horn is hidden by the sides of the box.

The making of records is now a large industry. Two kinds of records are in use, the cylinder and the disk. The original records for the cylinder are made in wax, from which a sharp point cuts out a thin shaving, leaving the record engraved on the wax. The groove thus formed is very shallow, varying from .or inch in depth to .0०I or even less. In order that many copies of records may be made from this original, it is electroplated with gold and copper and from this mold many copies are made in wax. 
For the disk records a different method is used. A plate of zinc is covered with a thin coating of acid-proof fat. The stylus is arranged to work from side to side and traces a line through this fat. This is treated with acid, which etches out the line followed by the stylus. A mold is made by electrotyping, and from this many copies may be made on ebonite plates.

Although the use of the phonograph in the home as a source of enjoyment is the most common use now made, it is being used for other practical purposes, and will doubtless be so used even more in the future, as its various applications are perfected. A few of these uses will be merely mentioned. The dictaphone is coming to be commonly used by the business man. He dictates his letters into the mouthpiece of a recording instrument. This dictation is later copied by a typist. In learning new languages, records may be used to obtain the correct pronunciation. Mr. Edison has recently perfected an invention called a telescribe by means of which a telephone conversation may be recorded on a phonographic cylinder. A phonographic clock has been devised which calls off the hours and the quarter hours.

Types of musical instruments. The more common musical instruments may be divided into two groups: the stringed instruments, such as the piano and violin, in which the sound is produced by vibrations of strings; and the wind instruments, like the cornet and flute, in which the sound is produced by vibrations of columns of air. There is also a third group called the percussion instruments in which the sound is produced by the vibration of a membrane or metal disks, as the drum and cymbals.

There are three types of stringed instruments : first, those in which the strings are set in motion by hammers, as in the piano; second, those in which the strings are set in vibration by bowing, as in the violin; and third, those in which the strings are set in vibration by the fingers, as in the guitar. 
The piano. The essential sound-producing portion of the piano consists of three parts: the strings, whose vibrations produce the sound, the keys for setting the strings in vibration, and the sounding board. (See figure 39.) The purpose of the sounding board is to increase the volume of the sound. The volume of sound given out by the wires alone would be too small to make a satisfactory instrument.

If one looks at the strings on a piano, he will find that they differ in three ways, - in length, in size, and in material. There is another difference which one cannot see, namely,

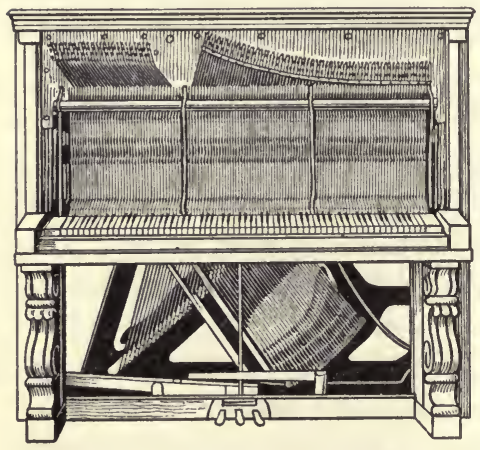

FIG. 39. - Piano.

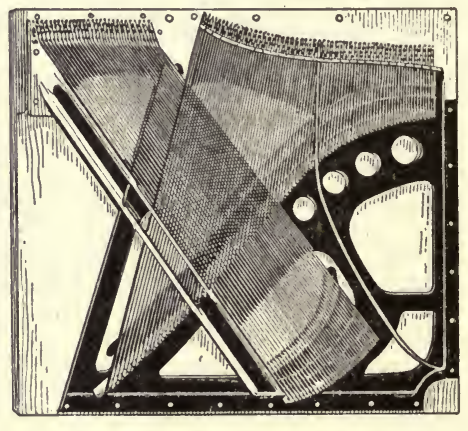

in tension. The different tones are produced by various combinations of these differences. Large strings, long strings, strings under small tension, and heavy strings tend to produce notes of low pitch; while small strings, short strings, light strings, and strings under a high tension tend to produce notes of a high pitch. The strings in a piano are attached at one end to screws which may be turned; thus the strain on the strings may be changed. By this means a piano is tuned, as this difference in tension affects the pitch.

The mechanism which sets the strings in vibration is a system of levers so arranged that by pressing down a key a hammer strikes the wire. Usually several wires are struck 
for each note. As soon as the strings are struck, a damper falls on them to check their vibration so as not to interfere with the succeeding notes of other strings. Pressing the loud pedal raises all these dampers, and thus increases the loudness of the sound. The soft pedal may operate in several ways: it may press a special damper against the strings, it may move the hammers nearer the strings so that they deliver a lighter blow, or it may allow the hammers to strike only a few of the wires which are used for the same note.

The quality of a tone given out by a string is affected by the place where the hammer strikes it. While the string is vibrating as a whole, it is at the same time vibrating in parts, - in halves, thirds, fourths, etc. Each of these vibrations gives out a certain tone called an overtone, and these all combine to give the note characteristic of a certain string. A large number of these overtones is desirable, as they help to make a more pleasing sound. The overtones given off are affected to some extent by the place where the string is struck, as certain desirable overtones may be destroyed if the string is struck at a particular place. In order to allow these desirable overtones to appear and to eliminate the objectionable ones, it has been found best to have the hammer strike the string at a distance of from one seventh to one ninth from the end of the wire.

Other stringed instruments. In the violin the vibration is produced by a bow instead of a hammer. The pitch of the strings in the first place is controlled by means of size, materials, and tension; and the violin is tuned by changing the tension through turning the keys. After the violin is once tuned, the pitch of the various notes is controlled by varying the length of the strings, by pressing the strings against the board with the fingers.

The method of controlling the pitch of the notes in the guitar and banjo is similar to that in the violin. The strings 
are set in vibration by the fingers instead of by the bow, and the sounding board of the banjo is made of membrane instead of wood.

\section{Demonstration I4}

Purpose. To study some of the principles underlying the use of musical instruments.

Apparatus. Tuning fork, sonometer, violin, or guitar.

Directions. I. Set a tuning fork in vibration. Hold it firmly on the box of a violin or guitar, or on any ordinary box. What difference is there in the sound? What is the use of sounding boards?

2. Fasten on the sonometer two strings of the same material but different diameter. Place them both under the same tension. Strike them both and note the difference in pitch.

3. Fasten two strings of the same size and under the same tension, but of different materials. Strike them and note the difference in pitch.

4. Use two strings of the same size and material. Put one under greater tension than the other. How do they differ in pitch? Fasten two strings of the same size and material under the same tension, but have one wire about twice as long as the other. How do they differ in pitch?

5. Upon what factors do these experiments show that the pitch of a string depends?

Wind instruments. In wind instruments the sound is produced by the vibration of air columns. The air may be set in vibration in several ways. In the flute it is set in vibration by blowing across a hole; in the clarinet by means of a vibrating reed; and in the cornet by means of the vibrating lips of the musician. The pitch is controlled in a variety of ways : by changing the length of the vibrating air column, as in the pipe organ; by blowing gently or hard, as in the clarinet; by breathing fast or slow, as on the cornet; or by a combination of several means, as in the flute. 


\section{SUPPLEMENTARY QUESTIONS FOR CLASS DISCUSSION}

I. What is the most valuable use made of the phonograph?

2. What circumstances might make the phonograph a more desirable instrument to have in the home than a piano?

3. If phonographs had been in use for a long time, so that records made 50 or 100 years ago could be obtained now, of . what use would they be to us?

4. How is the phonograph able to reproduce the human voice?

5. How is the pitch of the tones determined and controlled in each of the following instruments: piano, violin, guitar, and the various wind instruments?

6. How do stringed instruments differ in the methods by which the strings are set in motion?

7. How do wind instruments differ in the ways in which the air is set into vibration?

\section{REFERENCES}

Baker, Boy's Book of Inventions, Doubleday Page and Co., New York City. Chap. 7 (Phonograph).

Williams, How It Works, T. Nelson and Sons, New York City. Chaps. I4-I6. 


\section{CHAPTER VIII}

\section{TAKING PICTURES}

I. What must one know about a camera in order to take good pictures?

2. What are the different ways in which films may be developed and prints made?

History of photography. The process of taking pictures is now a very simple matter, and any one who wishes may easily learn to take them." But it has not long been so simple. Like other applications of science, photography has gone through many changes, starting from crude beginnings and improving till it has reached its present perfected state. Before photography was possible, two inventions or discoveries were necessary, first, the discovery that certain salts are affected by sunlight, and second, the invention of a device by which rays of light from an object could be focused to form an image.

The first photograph was made in about 1800 ; but the man who made it was not able to keep the picture after it was taken, because the sun blackened it. About twenty years later a liquid was discovered which made permanent the image formed on the sensitive salts by exposure to light. The first real portraits from life were made about I $\delta 40$ by the daguerreotype process, the picture being taken on a metal plate. A few years later glass was used.

The first pictures on glass negatives were taken by the wet-plate process, in which it was necessary to have the plate 
wet while it was being exposed in the camera. About $185^{\circ}$ the dry plate was invented, and this marked a great advance in photography. The next great improvement was the use of films in place of glass for the negatives. Meanwhile great improvements were made also in the construction of the camera.

The camera. An ordinary focusing kodak (see figures 40 and 4I) consists of the following parts: a light-proof box, which may be drawn out in the form of a bellows, a lens in the front end of this, which focuses an image on a film or plate placed at the back of the box. In front of the lens is the diaphragm with an adjustable open-

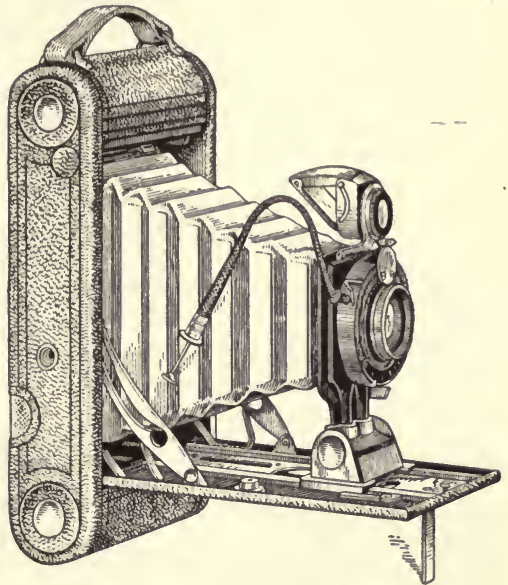

FIG. 40. - Folding camera. ing in the center through which the light passes, and the shutter by means of which the exposure is made. On the front is a finder by means of which those objects that will appear in the picture may be seen.

\section{DEMONSTRATION I 5}

Purpose. To show how a camera forms images.

Apparatus. Convex lens, cardboard, camera.

Directions. I. Hold a piece of cardboard on the side of a convex lens away from a window. Move the cardboard back and forth until a distinct image of the window is formed on it. How does the image differ from the object?

2. Take a camera apart and notice the use of each part in taking a picture. 
Loading the camera. Cameras may be loaded in three ways - with glass plates, with a roll of film, or with a film pack. If plates are used, the loading is done in a dark room. As ordinarily used, the film is done up in rolls having from 4 to 12 exposures. This is covered by a strip of black paper. This film may be loaded in the daylight. It is mounted on a spool, which is placed in slots at one side of the camera. It is then unwound and passed around the back of the camera to a spool on the other side. The camera is then closed and the spool is turned by means of a key on the outside of the camera till the figure I on the back of the film is seen through a little window of red glass on the back of the camera.

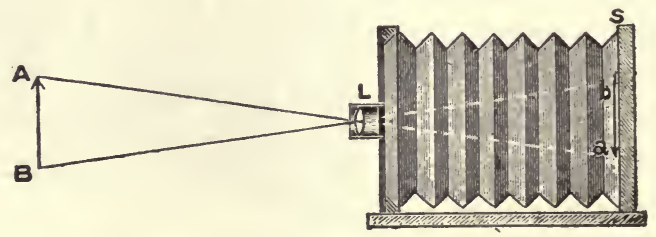

FIG. 4I. - Principle of camera.

Making the exposure. Three things need to be considered in making the exposure : first, focusing the camera; second, the size of the stop to be used; and third, the time of the exposure.

Focusing. Two methods of focusing are used, one by throwing the image on a ground glass, and the other by judging the distance of the object and setting the lens of the camera to correspond. In the first method a piece of ground glass is set in the back of the camera in the position to be occupied by the plate on which the picture is to be taken. The camera is pointed at the object, the shutter is opened, and a door at the back is opened to expose the focusing glass. The operator throws a cloth over his head to exclude the light, and by looking at the image on the glass determines 
when the object is in focus; meanwhile he moves the lens or the back of the camera back and forth by means of a screw, till the image on the glass shows distinctly. This image is inverted.

Rising and sliding front. As an aid in focusing, some cameras have a rising and sliding front. By means of a screw and a lever the lens may be moved either up or down, or from side to side. This enables one to easily cover the portion of the object that is to be included in the picture, by simply moving the lens, instead of moving the whole camera as would otherwise be necessary.

In the other method of focusing, the camera is tested before leaving the factory, and the positions at which an object will be in focus for certain distances are marked on the camera. The person estimates the distance of the object and sets the lens accordingly. When

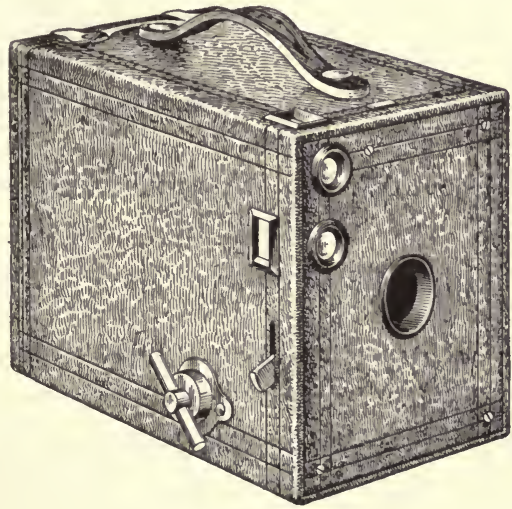

Fig. 42. - Box camera. this method of focusing is used, there is attached to the camera a finder, in which appear the objects that will show in the picture. In the box type of kodaks, there is no focusing arrangement, as the camera is made so that any object, within ordinary limits, will be fairly well focused.

Setting the diaphragm and the shutter. After the camera is focused, the next steps are to set the diaphragm for the size of the hole, and the shutter for the time of exposure. These depend on several factors, such as the nature of the object being taken, the kind of day, and the time of day. The time of exposure also depends on the size of the diaphragm. 
As the size is decreased, the time of exposure must be increased.

In what are called snapshots, the stop is set for a short exposure, from $\frac{1}{25}$ to $\frac{1}{50}$ of a second. The largest stop should be in position. This kind of exposure is best made on bright days. One motion of the lever opens and closes the shutter. While making the exposure, the camera should be held level and steady.

In what are commonly called time exposures, the camera must be placed on some solid support like a tripod. The stop may be set at any desired size and the time of exposure arranged accordingly. The brighter the day, the smaller the stop that may be used and the shorter the time of exposure in comparison with the same objects on cloudy days. The shutter is so set that it can be held open for any desired time, as determined by a watch.

The time of these exposures usually varies from $\frac{1}{2}$ second to 5 seconds, according to the stop used and the brightness of the day. For exposures outdoors the small stop may be used, but a longer time of exposure must be given. The time required for an exposure depends on the time of day and on the kind of day. Anything that causes a change in the intensity of light affects the time of exposure.

For interior exposures much more time is needed than for outdoor exposures. The time varies according to the time of day, the number of windows in the room, and the color of the walls and hangings.

Flashlights. By means of flashlight powders, it is possible to obtain pictures in the evening which are nearly as good as those obtained in the day. The flash powders are now sold in the form of sheets, which can be easily lighted. The sheet is pinned to a piece of cardboard and should be placed two or three feet behind the camera and two or three feet to one side. It should be placed at the same height, or a little higher than the camera. Just before the picture is to 
be taken, the shutter is opened, the largest stop being in position, and the flash paper is lighted; then after the flash the shutter is closed at once. The time occupied by the sheet in burning is about one second.

Autographic camera. In the autographic camera, there is a spring door on the back covering a slit. After the exposure of the film, this spring door is opened and one may write on the red paper back of the film any explanation of the picture he wishes, using a hard-pointed stylus. This is then exposed to the sky or to artificial lights for a time varying from two to sixty seconds. The door is then closed. When the film is developed, this writing appears on the edge of the picture.

\section{Demonstration i6}

Purpose. To show how to use a camera.

In order to show the various steps in taking a picture, take a group picture of the class indoors, explaining the things that must be done in focusing the camera, setting the stop, and making the exposure.

Developing. After the film is exposed, if it is taken into a dark room and examined by a red light, it will be found to look just the same as before exposure. The changes that have occurred are not of such a kind that they can be seen with the eye. But there have been some very complex chemical changes produced by the light that struck the film. We are all familiar with the fact that light produces changes in some substances. When some kinds of cloth are exposed to light, they fade. Likewise some wall papers fade after a few years, as do carpets and rugs. Even an ordinary newspaper changes color when exposed to light for a long time.

Some substances are much more sensitive to light than others. Compounds of silver with the elements iodin and bromin are very sensitive to light, and photography is based on this property of these compounds. The film or glass 
plate on which the picture is to be taken is covered with a thin coating of gelatin in which these compounds are embedded. When these are exposed to light, chemical changes take place, the amount of change depending on the intensity of the light. A white object will produce more effect on the plate than a black object; and so by this difference in the action of light from different objects, changes are produced which can later be made visible and reproduced as a picture.

\section{LABORATORY EXERCISE I 7}

Purpose. To show the effect of light on certain salts of silver.

Materials. Silver nitrate, sodium chlorid, and potassium bromid.

Directions. Dissolve a little silver nitrate in water in a test tube. Add an equal quantity of a solution of sodium chlorid. Filter and expose the filter paper to sunlight. What change takes place? Repeat the experiment, using potassium bromid in place of sodium chlorid.

In order to make these changes in the film visible, the film is treated with a certain chemical called a developer. This developer acts on the film in such a way that metallic silver is deposited in those portions of the film which have been acted on by the light. In those parts that have been most acted upon, the largest amount of silver is deposited; and where there has been the least action, the least silver is deposited. Light objects, therefore, appear in the negative as very dark because there is the most silver, and dark objects very light, because there is the least silver. The plate at this stage is called a negative because the shadows are reversed.

Fixing solution. If this negative were taken out into the light, the silver salts which had not been acted upon would be affected by the light, and the negative would be spoiled. 
So the negative is placed in a solution of hypo, which is called the fixing solution. This dissolves the silver salts which have not been acted on. That which remains on the plate is permanent and it may now be taken into the light.

Developing in dark room. There are two methods of developing, the dark-room method and the tank method, which can be carried on in daylight. In the dark room all ordinary light must be excluded, but it is found that red light has very little effect on the plates, and so a red light is provided by means of which the work can be done. The developers are usually bought in the form of powders which are dissolved in water and poured into a tray. Two other trays, one with water and one with hypo, are provided.

The plate is first immersed in water in one of the trays and then placed in the tray containing the developer. In a short time lights and shadows begin to appear, and then the outline of the objects. The stage of development may be watched by holding the plate up to the red light. Only experience can tell one when to stop the development. The plate is then placed in water to remove the excess of developer. Then it is placed in hypo where it is allowed to stay till the salts that have not been affected by the light are dissolved. This takes about fifteen minutes. The plate is then washed for about an hour in running water, or it may be left to soak for five minutes each in five changes of water. The plate is then taken out and dried.

Films may be developed in the same way. They may be cut and developed separately or the whole film may be developed.

The glass plates may be developed also in the dark room in a tank in which a number of plates can be developed at once. The developer is poured into the tank, and the plates are put in and allowed to remain a certain length of time according to the strength of the solution and its temperature. When the time is up, the developer is poured out, the plates 
are washed with water, and the hypo is added. In this process one does not look at the plates at all while developing.

Kodak film tank. Films may now be developed without a dark room by using the kodak film tank. (See figure 43.) This consists of a wooden box, a light-proof apron, a transferring reel, and a metal cup. At one end of the box the film is fastened, and at the other end is placed the light-proof apron wound around an axle. Between the two is the transferring reel. The ends of both the film and the apron are fastened to this reel. The cover is put on, and then by means of a

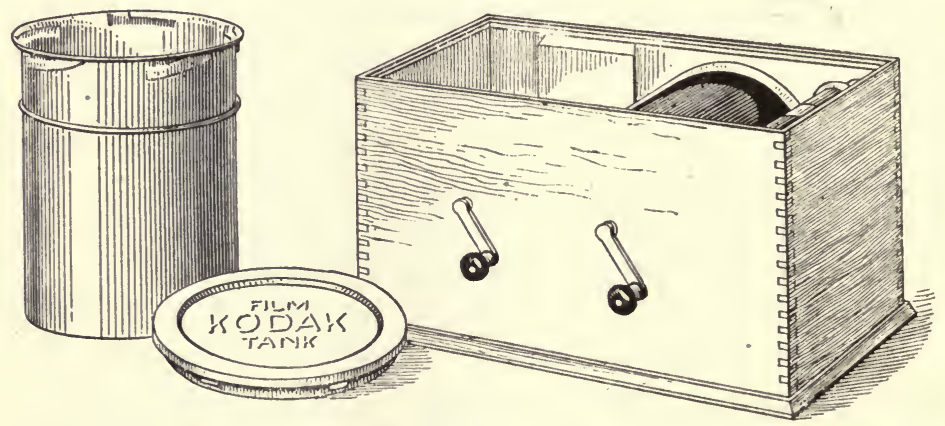

FIG. 43. - Kodak film tank.

handle on the outside of the box the film and apron are wound together on the same reel.

The box is opened and the reel is taken out and put into the metal cup, into which the developing solution has been poured. The apron surrounding the film is perforated with many small holes through which the solution reaches the film. It is allowed to stay in the solution twenty minutes. If two powders are used, it is developed in ten minutes. The time also varies according to the temperature, more time being required for low temperatures. The developer is then poured out, and the reel is rinsed several times in water. The reel is then taken out, and the apron and film unwound. The film is separated from the red paper and 
then placed in the hypo. light of an ordinary room. and then hung up to dry.
This may be done in the subdued After fixing, it is washed in water

\section{DEMONSTRATION I 7}

Purpose. To show how to develop films in the kodak film tank.

Apparatus. Kodak film tank, roll of exposed films.

Directions. Follow the directions that come with the tank and develop a film before the class. Pupils who have a camera may be invited to bring a film to school and develop it themselves at such time as can conveniently be arranged.

Printing. As we have already said, the lights and shadows are reversed in the negative. When a print, or positive, is made from this, we get the lights and shadows in their true relations. The printing paper contains salts of silver, like the negative, only they are not so sensitive to light. This paper is put in contact with the negative and exposed to light. Where shadows are heaviest on the negative, the least light will pass through, and so under this the positive will be light; while those parts of the negative that are lightest will allow the most light to pass through, and here the positive will be dark. Thus the conditions in the object from which the negative was made are reproduced.

There are two types of paper, the developing and the printing out. In the first type, of which velox is a common example, no image appears till the paper is developed. In the second type, of which solio and blue prints are examples, the images appear during the process of exposure.

Developing paper. The action and treatment of the developing paper is much like that of the film. The paper is placed in contact with the negative and exposed to some light, such as gas or electricity. The time depends on the kind of paper, the light used, and the distance the paper is 
held from the light. For holding the negative and paper, a printing frame is used. The paper should be handled in a room with subdued light and brought near the source of light only at the time of exposure. After exposure the paper is placed in a developing solution till the printing has reached the desired stage, then it is dipped in water and placed in hypo, as was done with the negative. The paper is then placed in running water for a few minutes or in five or six changes of water, and is then taken out and dried.

Blue prints. The blue print is an example of a printing out paper. It is one of the easiest papers to use because it does not require any special chemicals, water being the only thing needed. The chemicals on this paper are compounds of iron instead of silver. This paper requires a long time to print. The picture shows during the process of exposure, and the process may be watched by opening one half of the back of the printing frame.

Mounting. The prints may be mounted by using a dry mounting tissue, which comes in thin sheets and may be applied by pressing with a hot flatiron. Or the prints may be soaked in water and then mounted by using starch paste.

\section{DEMONSTRATION I8}

Purpose. To show how to print pictures.

Apparatus. Developed films, printing frame, blue-print paper, some developing paper like velox and the necessary chemicals for using it.

Directions. I. Make a print with blue-print paper, following the directions that come with the paper.

2. Also make a print from the same negative, using a developing paper and following the directions that come with it. Use one of the slow printing papers. This may be done during the daytime in the schoolroom, if the curtains are pulled down and if the paper is put into the frame in a drawer or closet that is partly darkened. 
3. Pupils who have a camera may be invited to bring films from home and print pictures for themselves.

4. The method of mounting prints may also be shown.

\section{SUPPLEMENTARỴ QUESTIONS FOR CLASS DISCUSSION}

I. In what ways is the camera similar to the eye?

2. How does the process of taking pictures used to-day differ from that used fifty years ago?

3. What advantages has the film over the glass plate?

4. What kind of camera would you prefer to have?

5. Which is the better of the two methods of focusing?

6. On what does the time of exposure depend?

7. Which is the better method of developing, the dark room method or the tank method?

8. What effect does the developer have on the plate or film?

9. Why must a fixing solution be used?

I0. In what ways is the treatment of a developing paper like the treatment of a film?

I I. Which is the better paper to use, the developing paper or the printing out paper?

\section{REFERENCE}

How to Make Good Pictures, Eastman Kodak Co., Rochester, N. Y. 


\section{CHAPTER IX}

\section{HOUSE PLANTS}

I. What plants are suitable for growing in the house and what care do they require?

Window boxes and pots. The receptacles used in raising house plants may be either flowerpots or window boxes. If flowerpots are used the smaller sizes should be avoided

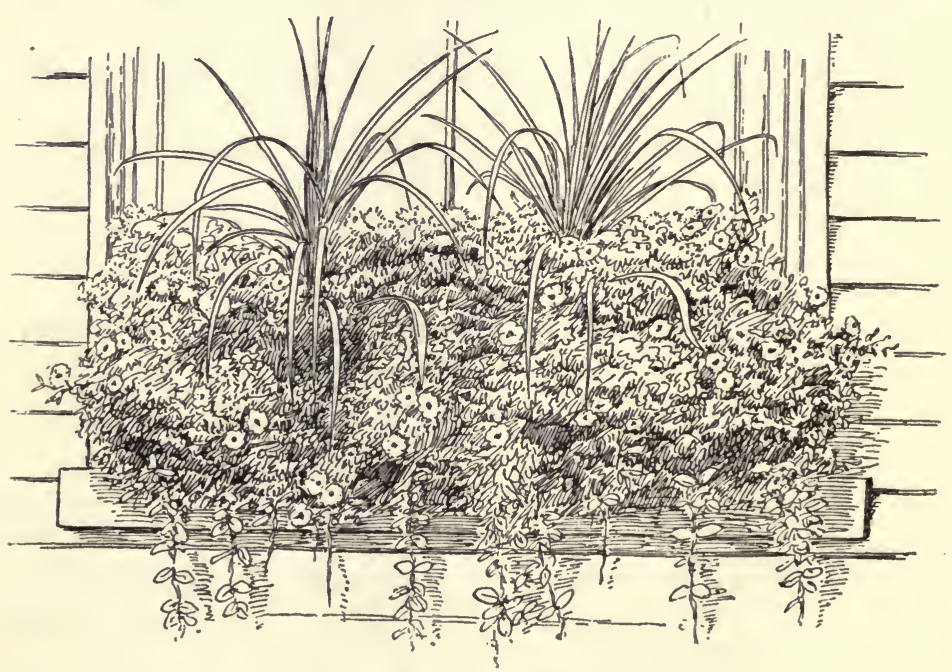

Frg. 44. - A window box.

as they dry out quickly. The five- and six-inch pots are the most convenient size. Very satisfactory window boxes of a size to suit conditions can be made out of boards. Holes 
should be bored in the bottom to allow the excess of water to escape, which may be collected in a zinc tray placed beneath the box. Before the soil is put into the receptacles, pebbles or clinkers or other coarse material should be placed in the bottom to provide for good drainage.

There is a "self-watering flower box," which is made entirely of metal and has a double bottom. The upper bottom is perforated by two holes, in which are fitted sponges, and it is pierced by a tube that leads to the top of the box. Through this tube water is poured into the bottom of the receptacle and is drawn up by the sponges and passed to the soil. In this way one watering insures that the soil will be kept moist for a week. The various receptacles may stand on a table or plant stand in front of the window, or they may be placed on the sill or on shelves or brackets in the window.

Plants to select. In deciding on which plants to select, one should first note the light conditions of the room in which the plants are to be kept, whether it is sunny or shaded during most of the day. If sunny, a great variety of plants may be grown; but if shaded, care must be taken to select plants that do well in such situations. Ferns are among the best plants for shaded rooms; other plants that will thrive fairly well in the shade are asparagus sprengeri, aspidistra, begonia, English ivy, oxalis, and primroses. These will also do well in the sun. Others that are well adapted for a sunny location are geraniums, heliotropes, wandering Jew, fuchsia, and bulbous plants. In general it may be said that the plants that thrive best in the shade are those that are raised for their foliage rather than for their flowers. Illuminating gas interferes with the growth of plants, so that if this is used in the house the kinds of plants that can be successfully raised will be limited.

Care of the plants. The chief consideration in the care of the plants is to supply them with the right amount of 
water. The soil should not be allowed to become dry, nor on the other hand should it be saturated. One can tell by

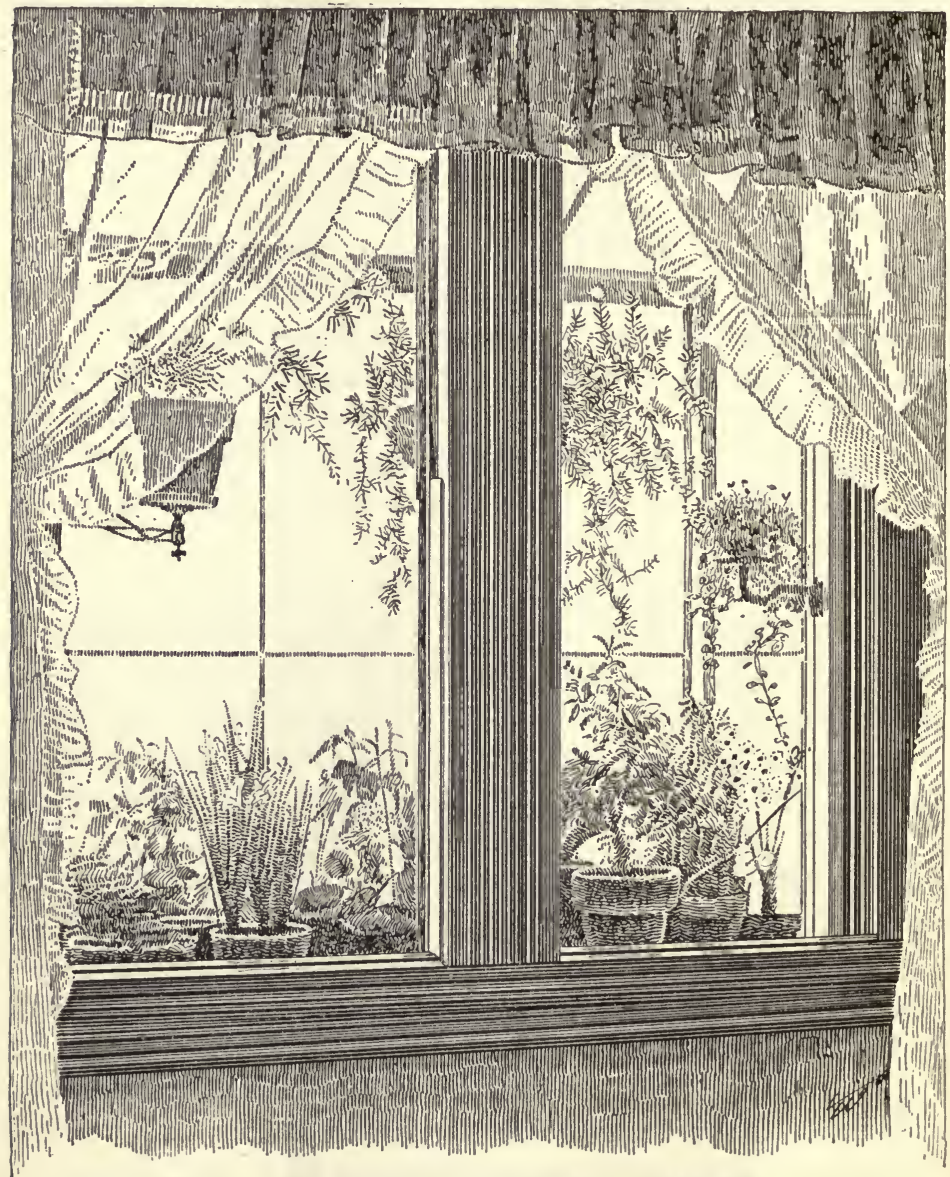

FiG. 45. - Window made attractive with house plants.

the appearance of the soil and its feel to the fingers when it is dry enough to need watering. When the plant is watered, the work should be done thoroughly until water runs into the 
drainage pan or saucer. The water that collects in this should be thrown away. No more water should be given until the soil becomes dry on top.

During the cold weather, care should be taken that the plants are not exposed to a low temperature.

As the roots live in such a small amount of soil, some fertilizer should be added occasionally. Different kinds may be bought that are specially designed for house plants.

Insect enemies. The more common insects that may occasionally attack house plants are plant lice, mealy bugs, and scale insects. Plant lice, either the green or the brown species, are the most common pests. One remedy is to sprinkle tobacco dust on the leaves while they are moist, allow it to remain a few days and then wash it off. The mealy bugs appear as tiny tufts of cotton on the leaves and in their axils. Both of these may be removed with a stiff brush or washed with a solution of whale-oil soap, or sprayed with kerosene emulsion. The red spider is a very small animal found with its web on the under side of the leaf. It may be removed by spraying with water.

\section{Home Project i4}

Purpose. To beautify the home by means of house plants.

Directions. Talk the matter over with your parents and if they are willing and the conditions are favorable, start some house plants in your own home. Follow the directions given in this chapter. Plant some bulbs as explained in the latter part of the chapter.

\section{School Project 2}

Purpose. To make the schoolroom attractive by means of house plants.

Materials. Flowerpots, window boxes, house plants.

Directions. Early in the fall the class should make plans to keep some house plants in the schoolroom during the year. 
The boys can make the window boxes, or flowerpots may be used. Doubtless plants will be donated by various members of the class; or if not, the class may plan some method for securing the needed plants. Some bulbs should be started as explained in the latter part of the chapter. The class may be divided into committees, each to look after the plants for a certain period.

Propagation of house plants. A number of house plants may be raised by means of soft-wood cuttings, which are made from the growing parts of the stem. If only a few

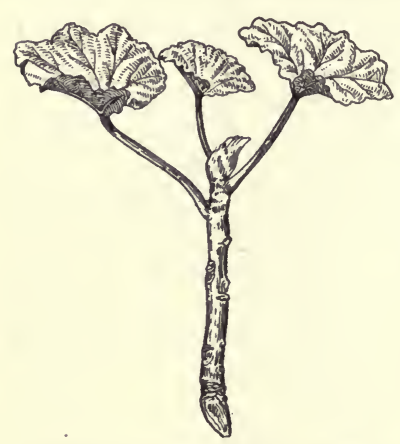

FIG. 46. - Geranium cutting. cuttings are to be raised, an ordinary flowerpot may be used. If a larger number is desired, one will need a box six or seven inches in depth and as long as desired. These receptacles should be half filled with clean, moist sand, well pressed down. To make the cutting, a growing tip two to four inches long is cut just below a joint. The lower leaves are removed so as to leave at least an inch of free stem; and to reduce still more the leaf surface, it is well to cut off about half of each of the remaining leaves. An incision is made in the sand by means of a knife, and into this the cutting is inserted for about an inch and the sand is pressed firmly about it.

To prevent too great evaporation, a tumbler or pane of glass is used as a cover, leaving a little crack for the entrance of air. The sand should be kept moist but not saturated. The cutting should be left until new leaves begin to form, which with a hardy plant like a geranium, will take about three weeks. This is evidence that new roots have formed, and now the plant may be transplanted. Geraniums and wandering Jew may be easily raised in this way and also 
begonia, carnation, chrysanthemum, coleus, rose, and fuchsia. Cuttings of the wandering Jew and of some geraniums may be successfully started in water, and then transplanted after the roots have formed.

Leaf cuttings. The rex begonia may be propagated by means of leaf cuttings. The leaf is cut into triangular pieces, each containing a bit of the leaf stalk. The tip is inserted into the sand, as with soft-wood cuttings, and the same care is given.

\section{School Project 3}

Purpose. To raise cuttings to take home.

Materials. Window box, sand, piece of glass, cuttings of various house plants.

Directions. I. Secure a window box and fill it two thirds full of clean sand. Obtain cuttings of the plants you desire to raise. Plant these cuttings and care for them, following the directions already given in the text. Members of the class should take turns in caring for the plants.

2. When they are ready for transplanting, members of the class are invited to bring flowerpots from home. The cuttings are transplanted from the window box into the flowerpots, which are then taken home by the pupils.

Bulbs for indoor blooming. Flowers may be easily obtained in the winter by planting bulbs in the fall. Roots are formed in some cool, dark place and the plants are then brought into the house, and by means of warmth and watering they are forced to bloom earlier than they would have done if left outdoors until the warmth of spring started their growth.

Outfit needed. Ordinary flowerpots may be used for holding the bulbs, or a shallow, wooden box with holes for drainage may be made. In the bottom of the pot there should be placed a flat stone or piece of broken pot over the hole, and on this a few more pieces of coarse material to allow good 
drainage. On this a little soil should be placed and then the bulb, which is covered with enough soil to just conceal the tip. More satisfactory results will be obtained if several bulbs of the same kind are placed in one pot about an inch apart. Three bulbs the size of a Roman hyacinth may be placed in a five-inch pot, and about six the size of the

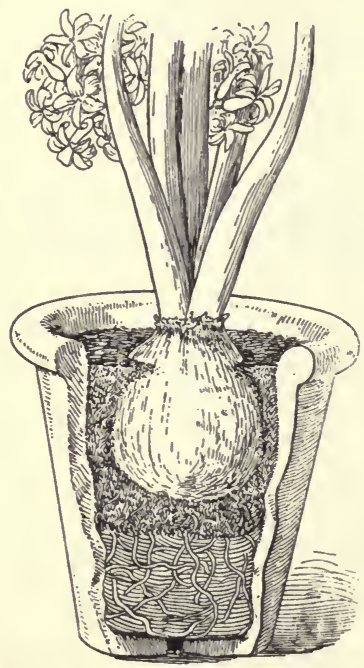

FIG. 47. - Hyacinth bulb that formed roots while it was in the dark. crocus. The pot should not be filled to the brim, as room should be left for watering.

Care of the bulbs. The pots should then be placed in a' dark, cool place and allowed to remain until the root system has well developed. If there is a part of the cellar not affected by the furnace heat, the pots may be placed there and covered to keep out the light. They should be watered occasionally. The bulbs may be set away at any time from the middle of September until the middle of November, but in general October is the best time.

On the whole the simplest method for the hardy bulbs is to put the flowerpots outdoors on boards and cover them with leaves or manure to exclude the light. If the covering is well moistened, the bulbs will not need any further care until they are taken indoors.

The first three bulbs given below in the table will not stand freezing and so must be kept at a temperature above 32 degrees. The other bulbs will stand a temperature below freezing.

When the plants are first brought in they should be kept for a few days in dim light and at a low temperature 
and then gradually brought into the bright light and high temperature of the living room. In order to secure a continuous succession of bloom, different varieties of bulbs may be chosen, or the same variety may be brought in at different times. The plants should be kept well watered.

In this table are given some results with a few kinds of bulbs based on actual experience.

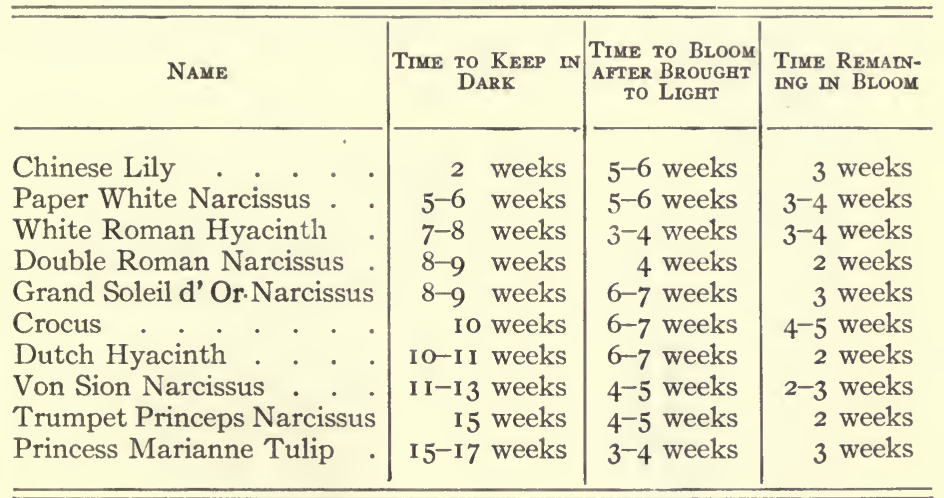

Growing bulbs in water. The Chinese lily, Paper White narcissus, and the Roman hyacinth may be raised in water. Special glasses are sold for this purpose. The water should just touch the bottom of the bulb. The glass should be set away in a cool, dark place until the roots develop, when it may be brought into the light. (See figure 48.)

These same bulbs may also be grown in a dish containing pebbles and water. The Chinese lily blooms very successfully when treated in this way. A shallow dish is half filled with pebbles and the bulbs are placed among the pebbles so that they will be partially supported by them. Water is added till it touches the bottom of the bulb. This is kept in a dark closet for a week or two, till the roots begin to form, 
and then brought to the light. Water should occasionally be added so as to keep the base of the bulb wet.

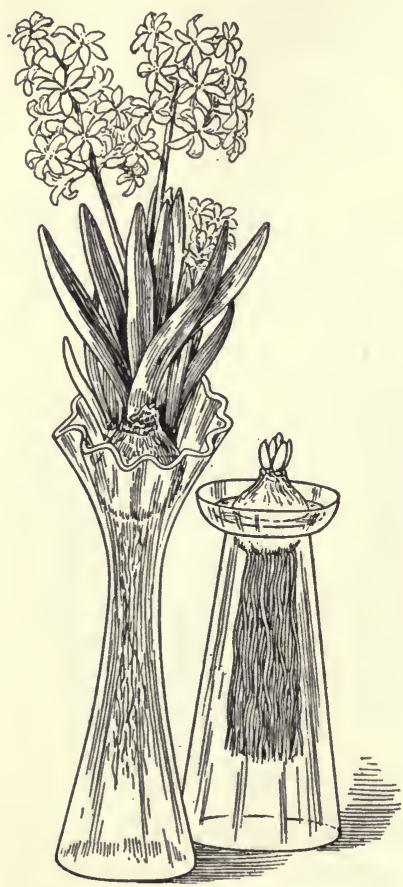

Fig. 48. - Roman hyacinth.

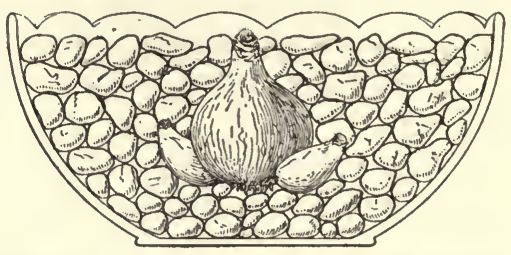

Fig. 49. - Section of a dish showing method of planting bulb of Chinese lily.

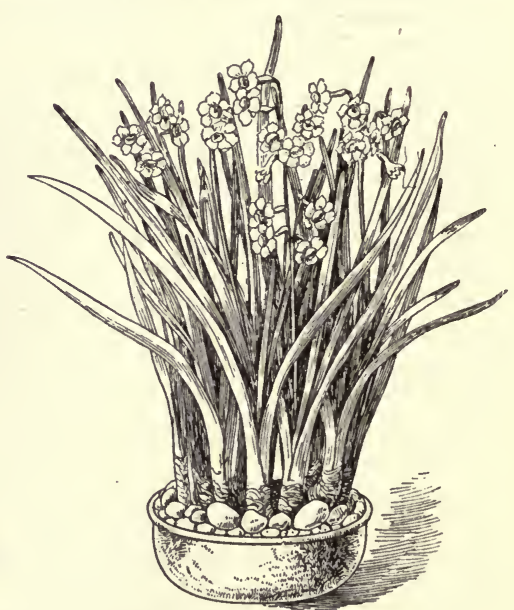

FIG. 50. - Chinese lily.

\section{School Project 4}

Purpose. To supply the rooms in the school with flowers during the winter.

Materials. Flowerpots, bulbs.

Directions. I. The planning for providing the various schoolrooms with flowers during the winter should begin in the early fall. If a good supply of bulbs cannot be secured in town, send to some reliable firm for a catalog. Plans should be made regarding the kinds and number of bulbs to plant. The Chinese 
lily bulb should be started as early as it can be obtained in the fall so as to secure the bloom before the Christmas vacation. The other bulbs may be started any time before November. The first may be brought in just after the Christmas vacation.

2. Follow the instructions already given in the text in caring for the bulbs. Special care should be taken to see that the plants do not freeze between Friday and Monday. The responsibility for doing the work may be divided among the different members of the class.

3. The particular purpose for which the flowers are to be raised may be changed to adapt it to local conditions. In some cases they might be raised for the hospitals. ,

\section{Home Project I 5}

Purpose. To raise a Chinese lily for a Christmas present.

Materials. Shallow glass dish, pebbles, Chinese lily bulb.

Directions. A novel and very pleasing Christmas present may be made for a friend by starting a Chinese lily bulb about six weeks before Christmas. At the end of that time it will be just about ready to blossom. Follow the instructions given in the last paragraph of the chapter preceding School Project 4.

\section{SUPPLEMENTARY QUESTIONS FOR CLASS DISCUSSION}

I. What things must be taken into consideration in selecting plants suitable for growing in the house?

2. What are some of the difficulties to be met in raising house plants?

3. What are the advantages of propagating house plants from cuttings?

4. What advantages do bulbs have as a means of obtaining flowers?

5. Of how many places can you think where the proper conditions for keeping bulbs exist?

\section{REFERENCES}

Dorner, Window Gardening, Bobbs Merrill Co., Indianapolis, Ind. Bailey, Manual of Gardening, Macmillan Co., New York City. 


\section{SECTION C}

\section{Electricity in the Home}

\section{CHAPTER X}

SOME APPLICATIONS OF ELECTRICITY IN THE HOME

Outside of lighting, which do you consider the most valuable use that can be made of electricity in the home?

One very common use now made of electricity in the home is for lighting, as we have seen in a previous chapter. When once the electric current has been brought into the house, there are many other uses to which it can be put. The purpose of this chapter is to explain some of the uses of electricity in the home besides lighting. It can be used for cooking, for heating, and for cleaning, and motors may be used to run fans and sewing machines. At present the cost of the electric machines and of the electricity to run them is high, but doubtless in the future these will be made cheap enough so that many people can afford to use them.

Cooking by electricity. Electricity finds many applications in cooking. Among the more common appliances are the following: electric toaster, coffee percolator, waffle iron, gridiron for cooking griddle cakes, broiler for cooking steaks, frying pan, kettle for boiling water, and oven for baking. Many of these can be used directly on the dining table at the time of the meal, such as the toaster, coffee percolator, and egg boiler. These may be connected to an 
ordinary electric light socket by unscrewing the lamp and inserting a plug with a wire fastened to it, or a special socket may be installed in the side wall.

In these various appliances electricity is made to produce heat. In order to do this, elements are used which give off heat without much light and thus transfer the heat to the apparatus. These elements are made of substances which are not good conductors; and when electricity passes through them they offer great resistance and so convert the electricity into heat. Wires are very commonly used; and the smaller and longer the wire, the greater the resistance and heat. Long coils of small wire are wound in a small compass and placed near the object to be heated. The amount of heat also depends on the strength of the current. By using different combinations of lengths and diameters, different temperatures can be obtained. A wire of nickel alloy is very frequently used. Wires of iron and german silver have also been tried. In some appliances these wires are visible, as in the toaster; in others they. are covered, as in the percolator. In other elements, instead of wires, thin coatings of certain metals, such as gold and platinum, which have been deposited on a piece of mica are used. These various elements are made into the shapes which will most conveniently fit the appliance for which they are intended.

Toaster. Some advantages of the electric toaster are that it may be kept on the dining table and the toast can be kept hot. The heating element is composed of a series of coils of wire exposed to view. In some toasters the coils are placed horizontally; in other toasters they are placed vertically.

Coffee percolator. The top portion of these percolators is made on the same principle as other percolators, but at the bottom is a heating element that boils the water. This lower part is a disk stove over which the upper part fits closely. The heating element is a long wire in the form 
of a spiral, embedded in enamel. This enamel is baked to the under side of the top plate. It requires about ten minutes to make the coffee, starting with cold water. In one form of percolator the top may be removed and the bottom part be used for boiling eggs.

The small disk stoves for heating a small quantity of water for boiling eggs, or any other purpose, are made in much the same way as the bottom part of the coffee percolator.

Electric kettle. The electric kettle is a convenient device for heating water. The construction of the lower part in some kettles is similar to that of the coffee percolator. In others the heating element is in the form of a band placed around the outside. In still another form, the heating unit is in the form of a small cylinder, which is immersed in the water. Some kettles are mounted on feet so that they can be placed on the table, without heating the table cover.

Electric oven. Many kinds of electric ovens have been made. These usually have two iron grids, one at the top and one at the bottom. Each of these has fastened to it pieces of enamel, in which are embedded coils of wire. The heated wires transfer the heat through the enamel to the grid, and then to the air in the oven. These ovens have two walls separated by some substance which does not conduct heat readily.

Cleaning by electricity. Electricity may be put to many house-cleaning uses. For this purpose we find the electric vacuum cleaner for cleaning carpets and upholstered articles, the electric washing machine and wringer for washing clothes, the iron for ironing them, and the dish-washing machine.

Electric vacuum cleaner. In the electric vacuum cleaner a motor is arranged to run a fan, which sucks up the dirt through a nozzle which rests on the surface that is to be cleaned. Particles of dust and dirt are picked up and collected in a bag attached to the machine. The cleaner is 
easily guided to any part of the room. It raises no dust and may be used to clean not only floors, but also furniture, books, walls, and draperies. Electric connection may be made with any lamp socket.

Washing machine. The electric washing machine consists of a tub in which the clothes are washed, a wringer, and a motor which may be connected with either the tub or wringer.

Electric iron (see figure 52). The value of the electric iron is widely appreciated and it is in general use. It maintains

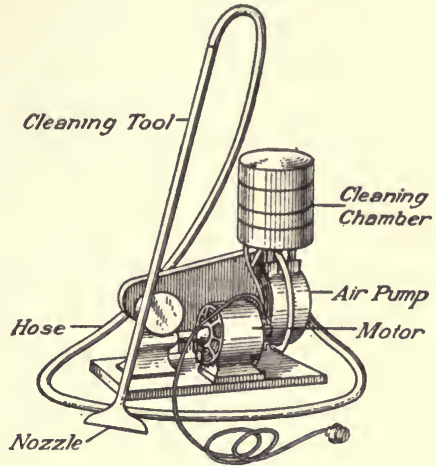

FIG. 5I. - Electric vacuum cleaner. an even temperature; and it is especially valuable during the warm weather, as it is much more comfortable to use than the old type of iron, which required proximity of a hot fire. The heating element in some irons is a coil of wire
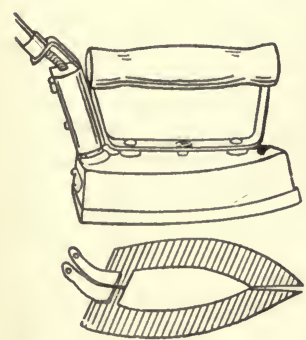

Fig. 52.- Electric flatiron, and resistance wire. wound over the flat strips of mica laid close to the bottom of the iron. In other irons the heating element consists of films of alloys of several metals on a mica base. Some irons have a device so that three degrees of heat may be obtained, high, medium, and mild. This is regulated by changing the position of the asbestos plug at the back, which comes in contact with three pins connected to the heating elements in the iron.

Electric dish-washer. The dishes are placed in a basket on a revolving plate, and hot water is sprayed against them with such force that they are quickly cleaned. They are then rinsed in clean hot water and allowed to dry. The 
power for turning the dishes is furnished by a motor. The water may be heated either by electricity or by a fire.

Electricity for heating. One means of heating is the luminous radiator. This consists of a frame in which varying numbers of lamps may be screwed. These are usually inclosed in a bulb of frosted glass. The filaments in the lamp give off their heat by radiation to objects near. Such a radiator may be moved from one room to another and may be used like a fireplace to take the chill off a room in the late fall and early spring.

Another form of heater is the convector. The principle involved here is the same as in appliances for cooking. Various forms of heating elements are used. These heat the air and cause a circulation, the warm air rising and the cooler air coming near to be heated. The amount of heat may be controlled by means of switches. In another type of convector the elements become red hot and give off a glow like the luminous radiator.

Electric fan. The electric fan is operated by a motor. Its use in summer for cooling purposes is well known, but it has other uses. It may be used in the winter to help heat the house. For this purpose it may be placed in the cold-air inlet of a hot-air furnace, it may be placed over a register, or it may be placed in front of a steam or hot-water radiator and a current of air directed against it. In each case the room is heated more quickly. Fans may also be used in drying fruits and vegetables.

Other uses of the motor. Other uses of the motor besides those which have already been mentioned are to run a sewing machine, turn an ice cream freezer or coffee grinder, and work a pump.

Sewing machine motor. Small motors may now be attached to the table of a sewing machine which will run the machine by means of a belt. The stopping and starting of the motor and the control of the speed may be regulated 
by the foot, so that both hands are left free to guide the work. More work can be done, because more stitches per minute may be taken when the motor is used than can be taken when the machine is driven by the foot.

A motor may be used to operate a pump. If one has the pneumatic-tank system of supplying water to the house, the motor may be attached to the pump and arranged to start and stop automatically according to the pressure in the tank.

Electric bell. One very common application found in many homes is the electric bell. This illustrates the ap-

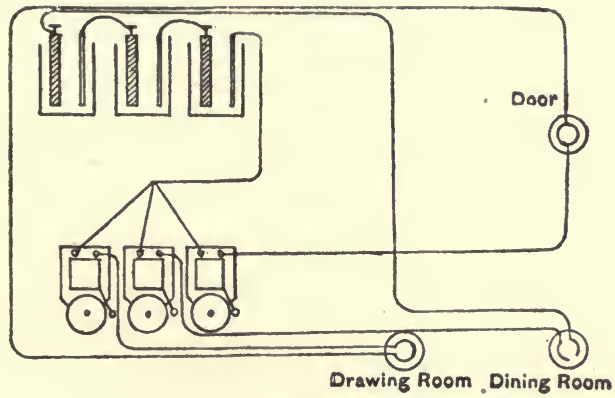

Fig. 53. - Bell circuits.

plication of two electric appliances, the bell itself and the cell that operates it. By pushing a button, the circuit is closed and the current from the battery operates the bell. When the finger is taken off the button, the circuit is broken and the bell stops ringing.

The most important part of a bell is a special kind of magnet called an electromagnet. Magnets may be formed in several ways. There are found in nature natural magnets called lodestones, which attract iron. Magnets may also be made by rubbing a piece of steel with another magnet, or by bringing iron or steel under the influence of a current of electricity. If a number of coils of wire are wound around 
a bar of soft iron, and a current of electricity is sent through the wire, the bar becomes a magnet and will pick up iron. This is called an electromagnet. The strength of the magnet may be increased by increasing the number of turns of the wire or by increasing the strength of the current.

This form of magnet is very useful because it can be controlled. If an ordinary bar magnet is brought near some

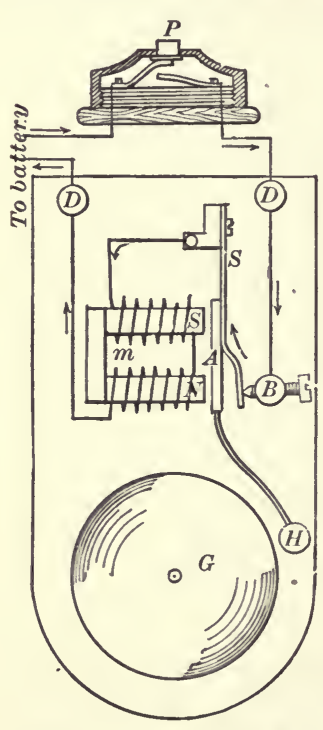

Fig. 54. - Electric bell. iron nails, they are taken up by the magnet and remain there unless shaken off. If an electromagnet is brought near iron nails, they are taken up by the magnet and stay there only as long as the current passes through the wire. If the current is broken, the nails drop off at once. So the power of the electromagnet may be controlled simply by opening and closing the circuit.

We may now refer to figure 54 to see how the electromagnet works in the electric bell. It is bent into the form of a horseshoe, $S N$. When the button $P$ is pushed down and a current of electricity passes through the wire, the magnet becomes magnetized and draws down the iron bar, $A$, called the armature, to which is fastened a clapper $H$. When this is drawn down, it strikes the bell. At the same time that the armature is drawn down, the electrical connection at the point $B$ is broken, and so no current passes through the electromagnet. It ceases to be a magnet and so no longer holds down the iron bar, which is then brought back by the spring $S$ to which it is attached. As soon as this happens, the contact is made again, and thus the operation is repeated. 


\section{LABORATORY EXERCISE I8}

Purpose. To study the working of an electric bell.

An electromagnet is an important part of the electric bell, so in order to understand how this works we will first study magnets.

\section{A. The Magnet}

Apparatus. Two bar magnets, horseshoe magnet, pieces of metal, such as iron, steel, tin, zinc, a dime, a copper, a nickel, piece of glass, iron filings, darning needle, blue-print paper.

Directions. a. Magnetic substances. I. Take a magnet and try a great many substances to see which it will attract. Find the greatest distance that a piece of iron is attracted. Put the end of the magnet in a box of tacks. By trying various portions of the magnet see which is the strongest part. Put the magnet in iron filings.

2. Test needles, pins, pens, etc., to see if they are made of iron or steel.

b. The magnetic field. I. Place a bar magnet on the table and put over it a sheet of paper. Sprinkle iron filings over this paper. Make a drawing showing the way the filings arrange themselves. Put two like poles of two bar magnets about an inch apart. Over these put a piece of paper and on it sprinkle the iron filings. Draw. Do the same with two unlike poles. Draw. What is the difference in the arrangement of the filings? Place a horseshoe magnet under the paper and sprinkle the filings.

2. To make blue prints of the magnetic field. Repeat the previous experiments, only instead of the ordinary paper, use a piece of blue-print paper over the magnets. Place in a shaded part of the room and sprinkle filings on the paper. Carefully place a piece of glass on the filings and put magnet and all in the sunlight and allow to stand till the paper becomes bronze. This will take from five to twenty minutes, according to the light. Then shake off the filings and wash the paper in several changes of water and then dry.

c. How to make magnets. Rub one end of a needle on one end of a magnet, rubbing several times in the same direction. 
Then rub the other end of the needle on the other end of the magnet. See if the needle will pick up tacks. The blade of a jackknife may be magnetized by rubbing over a magnet. Try bringing another needle near a pole of a magnet, but not quite touching it. See if the needle becomes magnetized.

\section{B. The Electromagnet}

Apparatus. Large nail or bolt about six inches long, about twenty feet of insulated wire, tw்o dry cells, tacks, magnet.

Directions. I. An electromagnet is an important part of an electric bell. It can be made as follows. Wind about ten feet of insulated wire around a large nail or bolt as thread is wound on a spool. Place the end of the nail in a pile of tacks. Is it a magnet? Connect the wire with a dry cell. Is it a magnet now? Withdraw the nail and see whether the coil will pick up fewer or more tacks. Disconnect the cell. What happens? Connect the cell again. See if a needle can be magnetized by rubbing against the nail.

2. Wind five feet of wire around the nail and see how the number of tacks it lifts up compares with the number when ten feet of wire were used. Try twenty feet and note the difference. Try two cells and compare with the number of tacks lifted when one cell was used with the same length of wire. In what ways do these experiments show that the strength of an electromagnet may be increased?

\section{The Electric Bell}

Apparatus. Electric bell, push button, cell.

Directions. Connect the bell and push button with the cell. Push on the button and notice what parts of the bell move. Make a drawing showing the connections of the bell, button, and cell. Make a careful drawing of the bell. By means of arrows show through what parts of the bell the current passes.

Cells. A very simple cell may be made by putting strips of copper and zinc, with a wire attached to each, into a weak solution of sulfuric acid. If the wires are brought together, 
a current is formed, as may be shown by holding the wire over, and parallel to, the needle of a compass. The needle will be turned from its north and south position. The cause for this current is the difference between the action of the acid on the two metals, the zinc being acted on more than the copper. If the cell is watched, bubbles of gas will be seen to form around the zinc and, passing across, gather on the copper. These are bubbles of hydrogen, which are poor conductors of electricity. After a while so many bubbles collect on the copper that the current cannot pass through, and so the cell ceases to give any current.

In order to make a cell that will be of practical use, it is necessary to find some way of preventing the accumulation of this gas on the metal. This is generally done by putting in the cell a second chemical, which unites with the hydrogen before it collects on the metal. A number of different chemicals may be used. In one cell copper sulfate is used, which causes copper to be deposited on the copper strip. In other cells a compound is used which gives off oxygen, and this unites with the hydrogen.

Classes of cells. Two types of cells are commonly distinguished, the wet and the dry. The Leclanché cell is a type of wet cell sometimes used for door bells. (See figure 55.) Carbon and zinc are used and

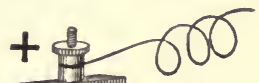

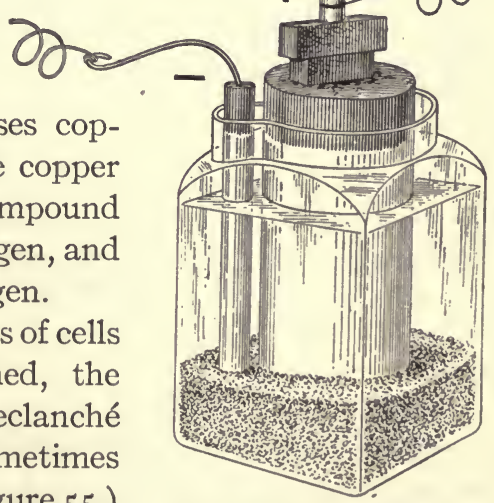

Fig. 55. - Leclanché cell. placed in a solution of sal ammoniac. The carbon is placed in a porous cup and surrounded with a compound which oxidizes the hydrogen.

Dry cells. The dry cell (see figure 56 ) is now largely replacing the wet cell on account of its greater convenience for 
handling. It is not really a dry cell but a moist cell, as the chemicals are brought into contact in the form of a moist paste. Most of these dry cells are modifications of the

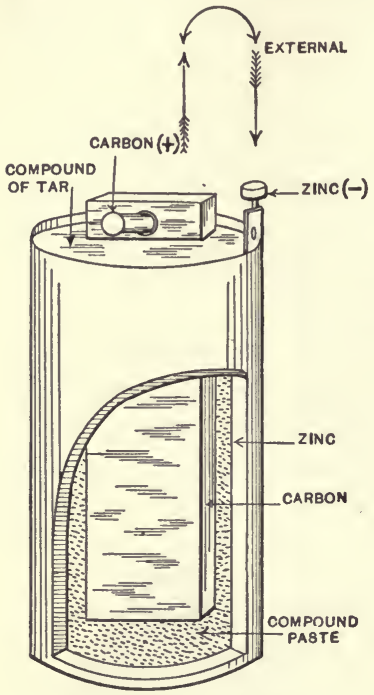

Fig. 56. - Dry cell.

Leclanché cell. The elements used are carbon and zinc, and the chief chemical is sal ammoniac. The outer shell of the cell is made of zinc. Inside this is a mixture of sal ammoniac and plaster of Paris to make a stiff paste. In the center is a rod of carbon surrounded with manganese dioxid. The two chemicals are separated by blotting paper. After the cell is moistened, it is sealed with pitch to prevent the water from evaporating. If the cell really did become dry, it would be worthless.

\section{LABORATORY Exercise I9}

Purpose. To learn how the cell used to operate the electric door bell is made.

Apparatus. Strip of sheet zinc, strip of sheet copper, each with a wire attached. Sulfuric acid, compass, tumbler, sal ammoniac cell, dry cell sawed lengthwise into two equal parts.

Directions. I. A simple cell may be made as follows. Fill a tumbler about two thirds full of water, add to this about one twelfth as much sulfuric acid. Put the strip of copper and zinc in this solution in such a way that they do not touch. Notice what takes place on the surface of each metal. Connect the two wires and see if there is any difference in what happens on the surface of the two metals. Hold the wire north and south and place a compass directly over it. What happens to the needle?

2. The sal ammoniac cell is very commonly used to operate 
door bells. Set up the cell, noting the different parts. Make a drawing of a longitudinal section through the cell.

3. Sometimes dry cells are used to operate the electric bells. Make a drawing of a dry cell cut in two lengthwise. Label the parts and explain the use of each part.

\section{Home Project i6}

Purpose. To study the parts of an electric door bell outfit, and to fix it if it gets out of order.

Directions. I. If you have an electric door bell in your home, study it to see how the different parts are connected. Make a drawing showing the bell, push button, wires, and cell. Notice the kind and number of cells. If more than one is used, show in your drawing how they are connected.

2. If your door bell is out of order, see if you can fix it. First test the bell by connecting it directly with the battery. Then look at the cells. They may need either a new zinc, more sal ammoniac, or simply more water to take the place of that which has evaporated. Look at the binding posts and see if the contacts are tight. Scrape all contacts to free them of non-conducting materials that may have accumulated. If the trouble is not with the cell, look at the push button to see if the contact here is all right. Examine the bell to see if the connections with the binding posts are secure, and if the vibrator makes proper contact. Very rarely it might happen that the wire was broken somewhere.

\section{SUPPLEMENTARY QUESTIONS FOR CLASS DISCUSSION}

I. What is the principle involved in the various instruments used for cooking by electricity?

2. What are the advantages of using electricity in the home?

3. What uses can be made of the motor in the home?

4. Explain how the electric bell works.

5. How do cells generate electricity? 
I60 SCIENCE OF HOME AND COMMUNITY

\section{REFERENCES}

Harpers' Electricity Book for Boys, Harper Bros., New York City. Chap. 2 (Cells).

Kaister, Electricity for the Farm and Home, Sturgis and Walton, New York City.

Lancaster, Electric Cooking, Heating, and Cleaning, D. Van Nostrand Co., New York City. 


\section{SECTION D}

\section{Use of the Home Grounds}

\section{CHAPTER XI}

\section{ORNAMENTATION OF HOME GROUNDS}

What steps should be taken in order to beautify the home grounds?

A large amount of pleasurable and profitable work in growing plants is possible in the home grounds by a little careful planning. The possibilities in this line are not generally appreciated and improved. Even in the small city lot, with only its back yard available, a great deal can be done: while as the size of the yard increases, the possibilities increase accordingly. The flower garden may serve to beautify the grounds; the vegetable and fruit gardens will furnish a source of foods of the best kind at low cost; both give opportunity for healthful outdoor exercise and furnish a source of pleasure to the one who cares for them and watches their development through the seasons. If one has a large yard, the vegetable and fruit gardens may yield some financial return, as well as keep the home table supplied with vegetables.

The plan. Before beginning the actual work of planting, it is much more satisfactory to make, first, on paper, a general plan of the grounds. This may be done in late winter before any work can be done outdoors. One should then send to 


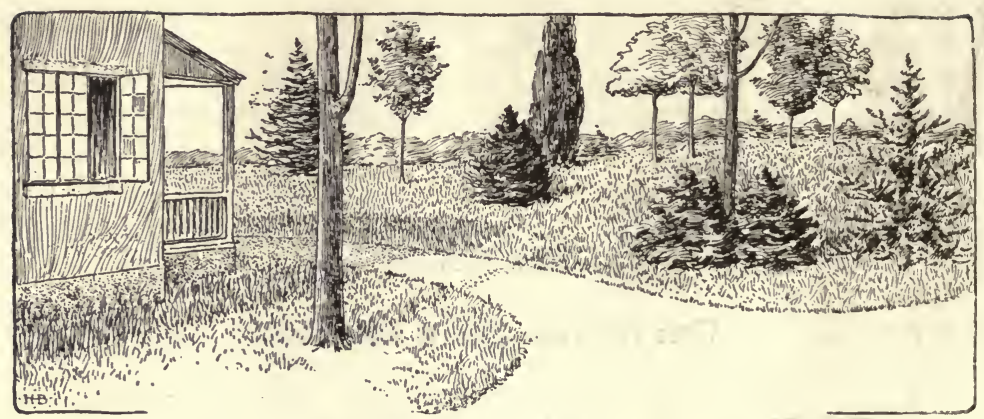

Fig. 57. - A meaningless back-yard planting, and an unnecessary drive.

the seed houses and nurserymen for catalogs. This general plan should consist of a map of the grounds drawn to a proper scale, showing the location of the buildings, walks, and boundaries (fences, hedges, etc.) and any trees, shrubbery, vines, or other things already planted. Then on this plan should be arranged such other plants, in the desired locations, as one may wish to set out. It is well also to make separate plans of the flower and vegetable gardens on a larger scale, showing exactly what is to be planted and where. These plans will enable one to work to better advantage in the spring and to secure more satisfactory results.

A. B. C. of landscape gardening. In planting to beautify the grounds, some general suggestions may be given with which practically all gardeners will agree. Three essentials should be kept in mind, which some one has called the A. B. C. of landscape gardening. First, the shrubs and flowers should be placed around the edge and borders of the lawns, and not in the center, which should be kept free and open. This open center forms an important part of the general effect and also tends to make the area seem larger than when the shrubs are scattered over the lawn. Second, the plants should be grouped in masses. If one wishes to plant three shrubs, instead of placing them so far apart that each stands 


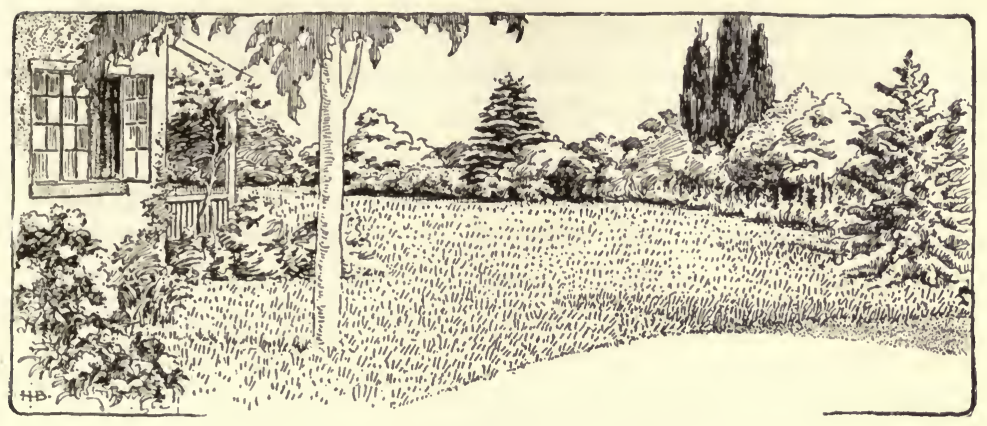

FIG. 58. - Suggestions for improving Figure 57.

out by itself, he should place them near enough to each other so as to give the effect of one mass. Likewise flowers should be planted close enough to give a mass of color. Third, do not plant in straight lines. This applies especially to shrubs. If a border is to be made of these plants, they should be arranged in a curving line. This rule does not apply so closely to flower gardens, especially in small gardens; for very good effects are to be obtained from placing flowers in a straight border. In large gardens, however, this rule may well be applied by having the border follow a broad curve.

Shrubs. Shrubs furnish one of the best means of ornamenting the grounds. Some results will be obtained the first year of planting, but it requires two or three years' growth to produce the best effects. The quickest returns will be obtained by purchasing from a nurseryman the shrubs partly grown. There are, however, many desirable wild shrubs which may be taken up and planted in the home ground. Some shrubs may be grown from cuttings, but these require a year or two longer to mature than when they are obtained partly grown.

The shrubs may be transplanted either in the fall or early spring, the fall being usually the better time except in the most northern states. When the plant is put in the ground, 
the hole should be made larger than the expanse of roots so as to furnish soft soil in which the new roots may grow. If the soil is poor it should be enriched with manure or fertilizer.

Where to plant. Shrubs form an important background for the yard and continue to grow for many years, improving each year in their decorative effects. Not only may they be planted along the borders, walks, and driveways,

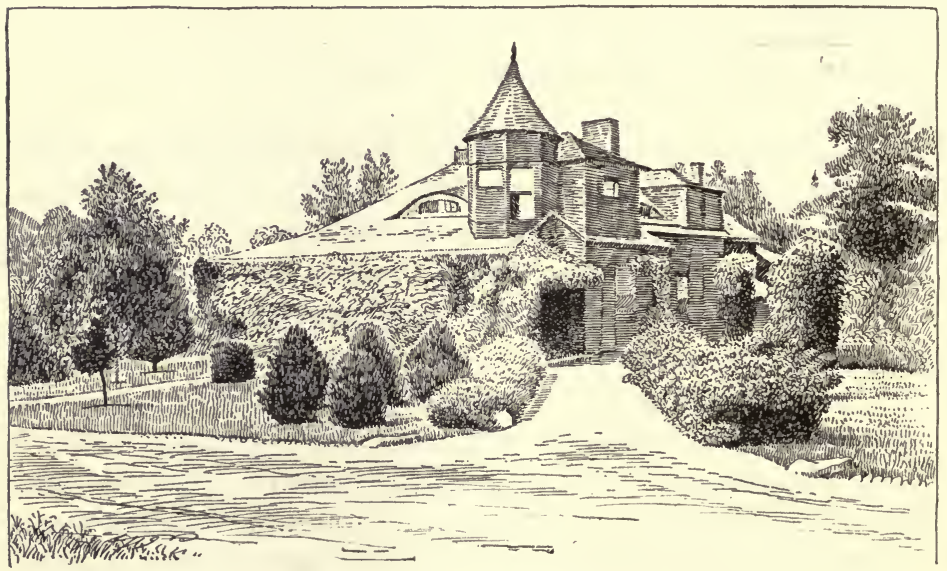

FIG. 59. - Planting of shrubbery.

but in front of porches and buildings, especially at angles and corners, thus helping to soften the hard lines of the buildings. Shrubs may often be used as a screen to shut off the view of some unsightly object.

What to plant. In deciding what shrubs to plant one should consider hardiness, size, time of bloom, and color of flower. In the northern tier of states hardiness is the first factor to consider, as many shrubs that thrive farther south cannot withstand the northern climate. In these northern sections it is well to plant liberally of native shrubs. 
The size of shrubs must be adapted to the size of the yard, only the smaller shrubs being planted in small yards. In larger yards, several tiers of shrubs may be planted, the tallest in the background and the smaller ones in the front. By proper selection of shrubs, one may have some in bloom all the season. Even in winter their decorative effects may be enjoyed if shrubs are planted which carry their fruit through the winter. These will also serve as a means of attracting birds.

The following table is given for reference to show the chief characteristics of a few of the more common shrubs.

Small Shrubs

\begin{tabular}{|c|c|c|c|}
\hline NAME & HeIght & $\begin{array}{c}\text { TIME OF } \\
\text { FLOWERING }\end{array}$ & COLOR OF FlOWER \\
\hline $\begin{array}{l}\text { Flowering almond . } \\
\text { Japanese barberry . } \\
\text { Deutzia gracilis. }\end{array}$ & $\begin{array}{r}4 \text { feet } \\
3-4 \text { feet } \\
3-4 \text { feet }\end{array}$ & $\begin{array}{l}\text { May } \\
\text { June } \\
\text { June }\end{array}$ & $\begin{array}{l}\text { Rose } \\
\text { Red and yellow } \\
\text { Rose white }\end{array}$ \\
\hline
\end{tabular}

Medium-sized Shrubs

\begin{tabular}{l|r|l|l}
\hline Golden bell .. . & 8 feet & April & Yellow \\
Panicled dogwood . & 8 feet & April-May & White \\
Hydrangea paniculáta & 6 feet & Aug.-Sept. & White \\
Spirea Van Houttei & 6 feet & June & White \\
Japanese snowball . & $7-9$ feet & May & White \\
Weigelia candida . & $6-7$ feet & All summer & Pink \\
\hline
\end{tabular}

\section{Large Shrubs}

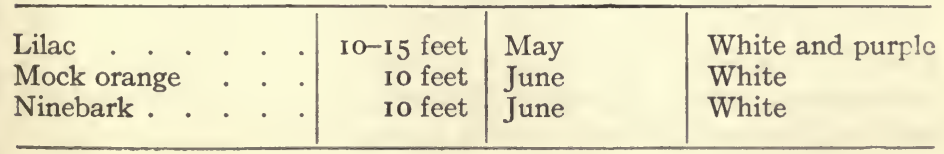


Native Shrubs Suitable for Transplanting

\begin{tabular}{|c|c|c|c|}
\hline NAME & HeIGHT & $\begin{array}{c}\text { TIME OF } \\
\text { FLOWERING }\end{array}$ & COLOR OF Flower \\
\hline $\begin{array}{l}\text { Barberry . } . \\
\text { Clethra } \\
\text { Red osier dogwood } \\
\text { Smooth sumac } \\
\text { Maple-leafed viburnum } \\
\text { Witch hazel . }\end{array}$ & $\begin{array}{r}6 \text { feet } \\
4-6 \text { feet } \\
3-6 \text { feet } \\
\text { 10 feet } \\
6 \text { feet } \\
\text { 12 feet }\end{array}$ & $\begin{array}{l}\text { March-April } \\
\text { August } \\
\text { June-July } \\
\text { June-Aug. } \\
\text { May-June } \\
\text { November }\end{array}$ & $\begin{array}{l}\text { Yellow } \\
\text { White } \\
\text { White } \\
\text { Yellowish green } \\
\text { White } \\
\text { Yellow }\end{array}$ \\
\hline
\end{tabular}

Perennial vines. Vines form an essential feature for the decoration of the home grounds, as they help to cover the bare side of a building with a wall of verdure. They are specially valuable for buildings of stone, brick, or concrete. The Virginia creeper and Boston ivy are both self-sustaining, as they develop little suckers which cling to the support on which they are growing. Vines occupy so little space that they may be grown in even the smallest yard. They may be trained on the main walls of the house or around the piazza. It is well to have them trained on some removable support such as wires or wire netting, which will keep the vines away from the woodwork and enable them to be taken down when the house is painted. Among the more desirable vines are clematis, Boston ivy, honeysuckle, climbing roses, trumpet vines, wisteria, Virginia creeper, and for the northern states, Engelmann's ivy.

\section{Field Exercise i}

Purpose. To study those shrubs and vines that are adapted for growing in the home grounds.

Directions. I. Visit parks, private grounds (if permission can be obtained), and thickets where wild shrubs grow in order to identify some of the common shrubs and vines that have ornamental value. The flowering effects of most of the common shrubs can best be observed in the spring. 
2. Notice to what extent the principles explained in this chapter are carried out in the location and arrangement of the shrubs.

3. Make a study of the different kinds of shrubs to note their attractive features, and to see how they can be identified. For each shrub studied, record the following points in your notebook.

A. Name of shrub.

$B$. Leaves.

a. Arrangement (opposite or alternate).

b. Kind (simple or compound).

c. Margin (entire, toothed, or lobed).

d. Draw leaf.

C. Flowers (brief description).

$D$. Fruit (brief description).

E. Height.

$F$. Features that make it adapted for planting in the home grounds.

G. Chief characters by which identified.

4. A similar outline may be used for vines. Note also the method of climbing and the support on which the vine grows.

5. Draw plans of some attractive yards and write down the names of the shrubs found growing there. The location of the shrubs on the plan may be indicated by small circles with figures in the center to represent different kinds of shrubs.

\section{LABORATORY EXERCISE 20}

Purpose. To make a plan for the ornamentation of the home yard. (Late winter or early spring.)

Directions. I. On a sheet of unruled paper make a plan of your home yard, on as large a scale as the paper will allow. Try ten feet to an inch. On this represent the buildings and sidewalks. Also indicate by means of small circles shrubs and vines already planted.

2. Plan first for the shrubs. Consider the kinds to select, their location and arrangement, following the suggestions already given in this chapter. Use small circles to represent 
shrubs and put figures in the center to show the different kinds. On one corner of your paper explain what each circle represents.

3. Next, select vines and indicate their location on the plan by means of circles.

4. Indicate the location of the flower garden.

The flower garden. Location. The flower garden may be placed as a border around the edge of the yard, bordering the walk, next to the fence, in the front of the porch or house, or in front of the shrubbery, but it should not be placed in the center of the lawn. Most plants grow better in the direct sunlight, so that if the garden is placed near the porch it should be in a sunny location. In selecting the seeds to be planted one needs to know three things about the flowers: their color, time of blooming, and height. If the border can be made wide enough so that two rows can be planted, the taller should be planted behind, and the shorter ones in the front. By noting the month when flowers are in bloom, one may make a selection so that the garden will have some flowers in bloom during the entire season. Such combinations of colors may be made as each individual prefers.

Perennials. Perennials are plants which live several years. The tops die down in the fall; but the underground parts live during the winter and send up new stalks each spring, and so require little care. Each year they increase in size, making large clumps, and pieces of the root may be cut off and used to start new plants. On account of their permanency, perennials may well form an important part of the flower garden. Seeds may be planted in April and will bloom the second summer. They may also be sown in August and September, in which case many will flower during the following summer. The seeds are rather slow to germinate and require good care. Plants may also be bought and set out in the spring. 
Table of Perennials

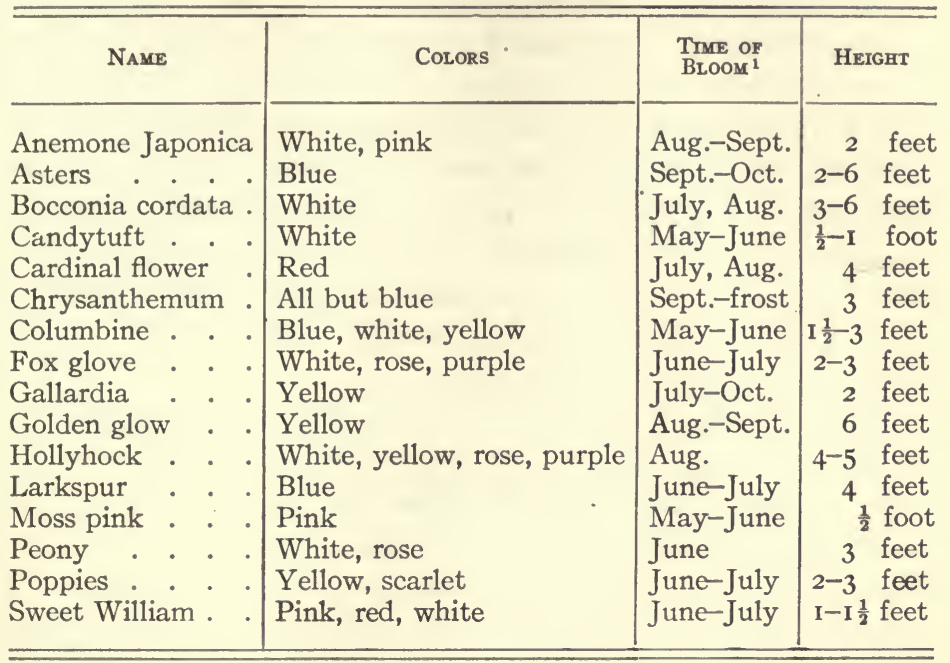

Perennials for shady places: anemone Japonica, bluebell, bugleweed, columbine, polyanthus, shooting star, lily of the valley, fox glove, lilies, German iris.

Bulbs. It is very easy to raise flowers from bulbs. The labor of planting them is small, and after they are once set out, they require little'subsequent care. Most of the fall bulbs may be allowed to remain for several years in the same situation, where they will bloom each year. Some will do better, however, if they are taken up and transplanted every few years.

Fall bulbs. Bulbs may be divided into two groups in accordance with the time of planting, fall bulbs and summer bulbs. Fall bulbs are planted in the fall and blossom during the spring and summer. This group includes most of the common bulbs, such as the crocus, hyacinth, tulip, narcissus, and lily. Summer bulbs are planted in the late spring and

1 For latitude of New York City. 
early summer and blossom during the summer and fall. Gladiolus and tuberose are examples of this class.

When to plant. The fall bulbs may be set out from the first of October until the middle of November. About the middle of October is the best time for the latitude of New York City. After the bulbs are set out, they develop a root system before the ground freezes and thus they are able to start into growth as soon as the warm spring days begin. Bulbs may be set out up to the time the ground freezes, but to get the best results this should be done earlier so as to allow the roots time to develop.

Where to plant. The bed for the bulbs may be located in a great variety of places, but they should not be set where water is apt to stand, as the bulbs may decay. One of the best locations for bulbs is a border. This border may be along walks and drives, in front of shrubbery and fences, or along the house or porch. Groups may be set between shrubs, and crocuses may be scattered irregularly over the lawn. Most bulbs do fairly well under trees and in other shaded places. In many cases the bulb starts growth so early in the spring that the flowers appear before the trees are in leaf. Beds of definite geometric shapes, such as circles or stars are better adapted to parks and large estates than to small yards.

What to plant. In deciding what bulbs to select and how to arrange them, one needs to consider three things: the height of the plant, the color of the flower, and the time when the plant is in flower. The plants which blossom at the same time may be so arranged according to color as to suit each one's taste. With reference to the time of blooming, the bulbs should be selected so as to give a continuous succession of flowers from early spring until summer. This may easily be done as there are some bulbs in flower during all this season, beginning with the snowdrop, which blossoms in March, often before the last snow disappears, followed 
by the other March flowers such as the crocus, glory of the snow, and scilla. The hyacinth appears in April, the tulips and daffodils in April and May, and the lilies from June to August.

As a matter of convenience for reference, some of the characteristics of a few common bulbs are given in the following table. They are arranged approximately in the order in which they flower. The times of blooming are for the latitude of New York City.

TABLE FOR BULBS

\begin{tabular}{|c|c|c|c|c|c|c|c|}
\hline \multicolumn{2}{|c|}{ NaMe } & $\begin{array}{l}\text { DEPTH } \\
\text { To Plant } \\
\text { (Inches) }\end{array}$ & $\begin{array}{c}\text { Distance } \\
\text { AparT } \\
\text { (Inches) }\end{array}$ & $\underset{\text { BLOOM }}{\text { MONTH IN }}$ & $\begin{array}{c}\text { LENGTH } \\
\text { OF } \\
\text { BLOOM } \\
\text { (Weeks) }\end{array}$ & CoLor & $\begin{array}{l}\text { HEIGHT } \\
\text { (Inches) }\end{array}$ \\
\hline Snowdrop & . . . & 2 & 2 & March & 3 & White & $3-4$ \\
\hline Glory of th & le snow & 2 & 2 & March & 2 & Blue & $6-9$ \\
\hline Scilla & .. & 3 & 4 & March & & $\begin{array}{l}\text { Blue } \\
\text { White }\end{array}$ & $4^{-6}$ \\
\hline Crocus . & . . . & 3 & 3 & March & 2 & $\begin{array}{l}\text { Blue } \\
\text { White } \\
\text { Yellow }\end{array}$ & $6-8$ \\
\hline Hyacinth & .. & 5 & 6 & April & 3 & $\begin{array}{l}\text { Red } \\
\text { Blue } \\
\text { White } \\
\text { Yellow }\end{array}$ & $8-18$ \\
\hline Tulip. . & $\cdot \cdot$ & 4 & 5 & $\begin{array}{l}\text { April } \\
\text { May }\end{array}$ & 3 & $\begin{array}{l}\text { Yellow } \\
\text { White } \\
\text { Red }\end{array}$ & $10-18$ \\
\hline Narcissus & $\because$. & 5 & $4-5$ & $\begin{array}{l}\text { April } \\
\text { May }\end{array}$ & 4 & $\begin{array}{l}\text { White } \\
\text { Yellow }\end{array}$ & 12-I 8 \\
\hline Lily of the & valley & $3-4$ & 6 & April & 3 & White & \\
\hline Lilies . & - . . & $4-10$ & I $2-24$ & $\begin{array}{l}\text { June } \\
\text { July } \\
\text { August }\end{array}$ & $4^{-8}$ & $\begin{array}{l}\text { White } \\
\text { Yellow } \\
\text { Red }\end{array}$ & $12-48$ \\
\hline
\end{tabular}

How to plant. Before setting out the bulbs, the soil should be thoroughly spaded to a depth of a foot or a foot and a half. Like other plants these will do better in a rich soil, 
but very satisfactory results may be obtained in ordinary garden soil. Soil may be enriched by adding fertilizers or decayed manure.

The depth at which the bulb should be planted depends upon the size of the bulb, the larger ones being set deeper; this depth varies from two inches for small bulbs like snowdrop, to twelve inches for some lilies. The depths for the various bulbs are given in the table on page I7I. A general rule is to coyer bulbs one and a half times their own diameter, with the exception of lilies, which should be covered about three times their own diameter. For the more northern latitudes it is well to protect the bulbs by means of a mulch of leaves or straw. This should be placed on the bed after the ground is frozen and then removed in the early spring.

\section{Home Project I7}

Purpose. To plant bulbs in the home yard so as to get flowers during the spring.

Directions. Find some place in your yard suitable for planting bulbs. During the fall spade it thoroughly and plant some bulbs, following the suggestions given in this chapter.

Summer bulbs. The more common kinds of summer bulbs are gladiolus, cinnamon vine, dahlia, and tuberose. Gladiolus may be planted from the middle of April until the last of June. The corms, as these underground parts are called, should be planted about four inches deep and six inches apart. The flowers have a great variety of colors. The cinnamon vine is valued for the rapidity of its growth, reaching a height of from ten to thirty feet in a single season. It may be set out the latter part of April. The dahlia is one of the most popular flowers, blooming in August and September. The part planted is really a root instead of a bulb, but it may be considered here. The roots may be planted from the middle of May until the first of July. 
They should be set about three inches deep. Tuberose bulbs may be set out the last of May, and they should be covered about an inch. The last flowers appear during the latter part of September.

All these summer bulbs are tender and must be taken.up in the fall and stored during the winter. After being dug up, they should be left in the sun and air for a few days to cure, and then they should be stored in a cool dry place where they will not freeze.

Annuals. Annuals live but one season. The seeds are planted in the spring, the plant develops rapidly and dies on the approach of cold weather. Among the annuals are a number of vines which grow to a great height during the season and make a very effective screen for a porch. The morning glory is one of the best and it sows itself, that is, some of the seeds which fall from the vines during the summer germinate the following spring, so that although the plant dies each season, other plants come up from the seeds formed. Among the low-growing vines, climbing nasturtium is one of the best.

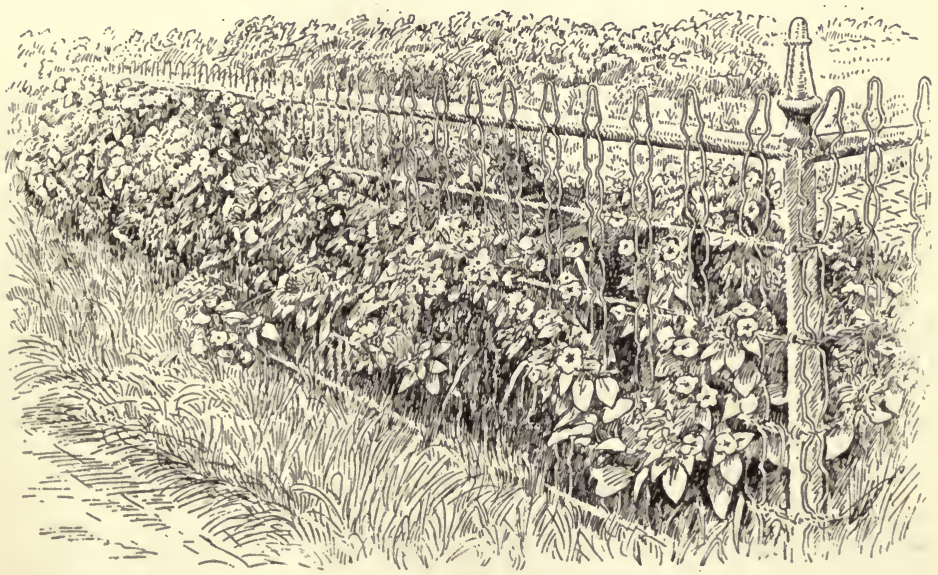

Fig. 60. - Border of four o'clocks. 
Table of annuals. Some annuals are hardy, such as the sweet pea, and may be planted as soon as the ground thaws in the spring; while others, such as the portulaca, are tender and cannot be planted till danger from frost is past. Some of the characteristics of a few common annuals and details regarding the planting of the seeds are given in the following table. The dates given are for outdoor planting. The seeds may be started in the house before this and then transplanted. In this way the flowers may be secured several weeks earlier. These dates are for the latitude of New York City; for other localities allow six days difference for each hundred miles in latitude; north, the dates for planting and time of bloom are later; south, they are earlier.

Table of Twenty-five Common Annuals Arranged in the Order in Which Seeds May be Planted

\begin{tabular}{|c|c|c|c|c|c|c|}
\hline NaMe & $\underset{\text { (Feet) }}{\text { HEIGHT }}$ & COLOR & $\begin{array}{c}\text { TrME oF } \\
\text { BLOOM }\end{array}$ & $\underset{\text { Plame to }}{\text { Trant }}$ & $\begin{array}{l}\text { DAYS RE- } \\
\text { QUIRED TO } \\
\text { COME UP }\end{array}$ & $\begin{array}{c}\text { Distance } \\
\text { To Thrn } \\
\text { OUT } \\
\text { (Inches) }\end{array}$ \\
\hline Sweet pea. & $4^{-6}$ & $\begin{array}{l}\text { Purple } \\
\text { Scarlet } \\
\text { White } \\
\text { Yellow } \\
\text { Pink }\end{array}$ & June-Oct. & March & $7-20$ & 4 \\
\hline $\begin{array}{c}\text { Poppy, Cali } \\
\text { fornia }\end{array}$ & I & $\begin{array}{l}\text { Scarlet } \\
\text { Yellow }\end{array}$ & July-Aug. & April I & 12 & 6 \\
\hline Nasturtium & $\mathrm{I}-6$ & $\begin{array}{l}\text { Orange } \\
\text { Red } \\
\text { Yellow }\end{array}$ & July-Oct. & April I 5 & 10 & 6 \\
\hline Alyssum . & $\frac{1}{2}$ & White & July-frost & April I 5 & 7 & 6 \\
\hline Candytuft & $\frac{1}{2}$ & $\begin{array}{l}\text { Red } \\
\text { White }\end{array}$ & June-Sept. & April I 5 & $4-9$ & 6 \\
\hline Phlox : & I & $\begin{array}{l}\text { Scarlet } \\
\text { Pink } \\
\text { White }\end{array}$ & Sept.-Oct. & April I 5 & IO & 6 \\
\hline Mignonette & I & Greenish & July-Oct. & April I5 & IO & 6 \\
\hline Pansy . . & $\frac{1}{2}-I$ & $\begin{array}{l}\text { Purple } \\
\text { White }\end{array}$ & Sept.-Oct. & April I 5 & $10-30$ & 6 \\
\hline
\end{tabular}


Table of Twenty-five Common Annuals - Continued

\begin{tabular}{|c|c|c|c|c|c|c|}
\hline NAME & $\begin{array}{l}\text { HEIGHT } \\
\text { (Feet) }\end{array}$ & Color & $\begin{array}{l}\text { TIME OF } \\
\text { BLOOM }\end{array}$ & $\begin{array}{l}\text { TiME TO } \\
\text { PLANT }\end{array}$ & $\begin{array}{l}\text { DAYS RE- } \\
\text { QUIRED TO } \\
\text { COME UP }\end{array}$ & $\begin{array}{l}\text { DISTANCE } \\
\text { TO THIN } \\
\text { OUT } \\
\text { (Inches) }\end{array}$ \\
\hline Zinnia . . & I $\frac{1}{2}-2$ & $\begin{array}{l}\text { Red } \\
\text { Scarlet } \\
\text { Yellow }\end{array}$ & July-Oct. & April I 5 & 5 & 6 \\
\hline Verbena . & I & $\begin{array}{l}\text { Purple } \\
\text { Red } \\
\text { White }\end{array}$ & June-Sept. & April I5 & $14-30$ & -8 \\
\hline Ageratum . & $\frac{1}{2}$ & Blue & Aug.-Sept. & May I & 7 & 6 \\
\hline Cornflower & $1-2$ & Blue & July-Sept. & May I & 5 & 6 \\
\hline Forget-me-not & $\frac{1}{2}$ & $\begin{array}{l}\text { Blue } \\
\text { White }\end{array}$ & June-Aug. & May I & 5 & 6 \\
\hline Four o'clock. & $2-3$ & $\begin{array}{l}\text { Crimson } \\
\text { White } \\
\text { Yellow }\end{array}$ & July-Oct. & May I & I 2-I 4 & 24 \\
\hline Morning-glory & $15-20$ & $\begin{array}{l}\text { Blue } \\
\text { Red } \\
\text { White }\end{array}$ & Aug.-Oct. & May I & $5^{-6}$ & 6 \\
\hline Sunflower. & $5^{-8}$ & Yellow & Aug.-Oct. & May I & 5 & 24 \\
\hline Aster . & I & $\begin{array}{l}\text { Blue } \\
\text { Red } \\
\text { White }\end{array}$ & Sept.-Oct. & May Io & $5^{-10}$ & 6 \\
\hline Balsam. . & $I-2$ & $\begin{array}{l}\text { Pink } \\
\text { Red } \\
\text { White }\end{array}$ & July-Aug. & May io & 8-10 & 8 \\
\hline Coreopsis . & $\mathrm{I}-2$ & $\begin{array}{l}\text { Yellow } \\
\text { Brown }\end{array}$ & Aug.-Nov. & May I 5 & $10-15$ & 8 \\
\hline Cosmos & $4-6$ & $\begin{array}{l}\text { Pink } \\
\text { Red } \\
\text { White }\end{array}$ & Oct.-Nov. & May I5 & $5^{-10}$ & I $2-24$ \\
\hline Marigold . & $1-2$ & Yellow & Aug.-Oct. & May I 5 & 5 & 8 \\
\hline Petunia & $1-2$ & $\begin{array}{l}\text { Magenta } \\
\text { White }\end{array}$ & Sept.-Oct. & May I5 & $10-30$ & I0 \\
\hline Stock, ten weeks & I & Pink & July-Aug. & May I5 & $4^{-8}$ & 8 \\
\hline Salvia . . . & $2-3$ & Scarlet & Sept.-Oct. & June I & $7-14$ & $18-30$ \\
\hline Portulaca . & $\frac{1}{2}$ & $\begin{array}{l}\text { Red } \\
\text { White }\end{array}$ & July-Sept. & June I & $5^{-15}$ & 4 \\
\hline
\end{tabular}

Annuals for shady places : Clarkia, forget-me-not, godetia, madia, musk-plant, nemophila, pansy, torenia. 
Comparison of annuals and perennials. Annuals and perennials each have their advantages. The chief advantage of the annual is that one gets much quicker returns, as the flowers are obtained the same season that the seeds are planted. This is an important consideration to people who do not own their homes but rent them for a year at a time. It is possible to obtain a greater variety of combinations from year to year. Since the garden is started entirely anew each year, any new combinations or varieties can be tried. With the perennials, it is much more difficult to make changes after the plants are once established: The seeds of most of the annuals germinate more quickly than those of the perennials, and so the annuals are more easily raised from seed.

The chief value of the perennial, as the name implies, is that the plant is established for many years, and after it is once started it requires less care than the annuals. With the perennials it is possible to make the flowering season nearly twice as long, since some of the perennials begin to bloom in the early spring and from this time on a continuous succession can be obtained till late fall. The first of the annuals do not begin to bloom till well on into the summer. There is a greater variety of ways in which perennials may be started, as either the seeds or plants may be used, and the seeds may be planted either in the spring or late summer.

The ideal arrangement is to have a combination of both annuals and perennials. The perennials may make the chief background of the garden, and spaces may be left between for the annuals which may be changed from year to year as one wishes.

\section{LABORATORY EXERCISE 2I}

Purpose. To make a plan of a flower garden. (Late winter or early spring.)

Directions. I. On a sheet of unruled paper make a plan of a flower garden to scale. Select some portion of your yard. 
2. In selecting the flowers take into account: $a$, the duration (whether annual or perennial); $b$, the height; $c$, the time of bloom; $d$, the color.

3. Select the flowers from the lists given in the chapter, following the suggestions given. In considering color, put together those colors that will best harmonize.

4. Write on the plan in the proper location the names of the flowers selected, and after each name write: $a$, the height; $b$, the time of bloom; $c$, the color; $d$, time of planting.

\section{Field Exercise 2}

Purpose. To identify some of the cultivated flowers and to note their attractive features. (Fall and spring.)

Directions. I. Visit parks and private grounds when accessible, and study the flowers found there. For each plant studied record the following points in your notebook.

A. Name.

B. Flowers.

a. Colors.

b. Size and shape.

c. Arrangement.

d. Odor (strong or weak, pleasant or offensive).

C. Leaves (record the most conspicuous features).

$D$. Height of plant.

E. Kind (annual, biennial, or perennial).

$F$. Chief characteristics by which identified.

2. After you have finished your study of a number of flowers, select the ten that you like best.

Care of garden. As a general thing one will not need to water the garden except during a very dry spell; but when it is watered, the ground should be thoroughly soaked for a depth of several inches. A mere sprinkling of the surface is useless and sometimes injurious to the plants because it tends to bring the roots towards the surface. It is especially important that the germinating seeds should have a supply of water. 
When the seedlings have reached a height of two or three inches, they should be thinned out to the distances given in the table, and if it is desired, the plants pulled up may be transplanted. This should be done on a cloudy day or late in the afternoon. If the flowers are kept picked, the plant will continue to bloom longer than if the flowers are allowed to remain. A few may be allowed to go to seed so that they can be saved for planting the next year.

Wild flower and fern garden. A very interesting section of the flower border may be made by reserving a portion for wild flowers and ferns. These may best be transplanted from the wild in the late fall or in the early spring, although they may also be transplanted in mid-season if done carefully. Notice the conditions under which the plants grow in nature, and put them in that part of the flower bed which most closely imitates those conditions. In a few years an interesting collection of wild flowers may be brought together. Ferns are among the most beautiful foliage plants, and most of them will thrive on the shady sides of the house, where it is difficult to get anything else to grow. In collecting these wild flowers be careful not to destroy plants needlessly, and to avoid exterminating rare plants.

\section{Home Project I8}

Purpose. To beautify the home grounds by growing ornamental plants.

Directions. I. Talk the matter over with your parents, and if they are willing, do some ornamental gardening in your home yard. You can at least have a flower garden. Perhaps you can do something in planting shrubs and vines. There may be an opportunity to earn money by selling flowers.

2. As far as feasible try to follow the plan you have made. Study the chapter carefully to find out the ways of doing things.

3. Make a plan of your flower garden; also make a record of plants raised, filling in the following table. 


\begin{tabular}{|c|c|c|c|c|c|c|c|}
\hline $\begin{array}{c}\text { NAME of } \\
\text { FLOWER }\end{array}$ & $\begin{array}{c}\text { Date } \\
\text { SeEd } \\
\text { Planted }\end{array}$ & DATE UP & $\begin{array}{c}\text { DATE OF } \\
\text { FIRST } \\
\text { FLOWER }\end{array}$ & $\begin{array}{l}\text { DATE OF } \\
\text { LAST } \\
\text { FLOWER }\end{array}$ & $\begin{array}{l}\text { TIME IN } \\
\text { BLOOM }\end{array}$ & COLORS & $\begin{array}{l}\text { Height } \\
\text { of Plant }\end{array}$ \\
\hline & & & & & & & \\
\hline & & & & & & & \\
\hline
\end{tabular}

\section{School Project 5}

Purpose. To beautify the school grounds.

Directions. If the school grounds have not been planted with shrubs, vines, and flowers, and if there is an opportunity to do something along this line, the class may work together to help ornament the school grounds. Permission should first be obtained from the school authorities. A plan of the ground should be made. Then means should be discussed of obtaining the needed plants. Native shrubs and vines are available without expense. A border of bulbs may be set out in the fall. If flowers are planted, those should be chosen that are in bloom during the school session. The various things to be done may be divided among committees. The work of digging and planting may be done by the boys.

\section{SUPPLEMENTARY QUESTIONS FOR CLASS DISCUSSION}

' $r$. Why. is it better to begin gardening by making a plan?

2. What should be taken into account, $(a)$ in selecting the kinds of plants for ornamentation, $(b)$ in setting them out?

3. What is the special value of vines?

4. Which would you rather have, a flower garden of annuals or one of perennials? Why?

5. Why are bulbs specially desirable to plant?

6. How should bulbs be planted and cared for?

7. What care does the flower garden require?

8. What are the chief values of gardening?

\section{REFERENCES}

Baker, Yard and Garden, Bobbs Merrill Co., Indianapolis, Ind. Bailey, Manual of Gardening, Macmillan Co., New York City. 


\section{CHAPTER XII}

\section{THE VEGETABLE GARDEN}

What are the things to be done in order to have a successful vegetable garden?

Reasons for gardening. There are at least three reasons for having a garden - profit, pleasure, and health. From the practical side, a garden may make a great saving in the cost of living by furnishing food that must otherwise be bought. A good-sized garden can furnish vegetables not only for the summer but for the winter as well, because the excess may be stored or canned. A vegetable garden also furnishes a means of earning some money during the summer, as fresh vegetables can usually be sold to the stores or to people who have no garden. There is also the possibility of canning vegetables for sale.

Profitable gardening. The following instances taken from various publications show to what extent it is possible to make even a small garden furnish vegetables for a family. One man in Illinois reports that the produce grown on a small, city, back-yard garden ( 28 by 25 feet) was nearly all that was needed from May 15 to November for a family of three, and part of the time for six. Another from New Jersey reports that a suburban garden ( 22 by 34 feet) was made to supply all the vegetables necessary for a family of three. Another man from Minnesota reports that for four years a small garden of $\frac{1}{19}$ acre - that is, a plot about the size of an average city lot ( 25 by roo feet) - kept a family 
of six adults abundantly supplied with vegetables all the year, with the exception of potatoes, celery, and cabbage.

In order to show what can be done in small gardens, the following records of what has actually been accomplished have been taken from various publications and put in tabular form. The values given represent the total value of the products and not the profits. Allowance must be made for expenses to estimate the profits. These returns are not those obtained from the average garden, they are much better than the results generally secured; but they show the possibilities under proper care. These instances are not taken from skilled gardeners, but some of the best returns are taken from school gardens worked by children from I 2 to 16 years of age.

Table Showing Value of Produce Raised

Small Gardens

\begin{tabular}{|c|c|c|c|c|}
\hline SIzE OF Garden & $\begin{array}{c}\text { NUMBER } \\
\text { SQUARE FEET }\end{array}$ & TOTAL & $\begin{array}{c}\text { VALUE of Produce } \\
\text { PER SQUARE FoOT } \\
\text { (Cents) }\end{array}$ & $\begin{array}{l}\text { RATE } \\
\text { PER } \\
\text { ACRE }\end{array}$ \\
\hline $\begin{array}{l}\qquad \times 30 \\
\text { (Average for } 250 \text { school } \\
\text { gardens) }\end{array}$ & 240 & $\$ 5$ & 2 & $\$ 850$ \\
\hline $10 \times 20$ & 200 & 5 & $2 \frac{1}{2}$ & 1050 \\
\hline $22 \times 34$ & 748 & $29 \frac{1}{2}$ & 4 & 1700 \\
\hline $25 \times 25$ & 625 & 32 & 5 & 2100 \\
\hline
\end{tabular}

Large Gardens

\begin{tabular}{c|r|r|r|r}
\hline $100 \times 220$ & 22,000 & 70 & $\frac{1}{3}$ & 150 \\
$100 \times 225$ & 22,500 & 100 & $\frac{1}{2}$ & 200 \\
(Average for 56 gardens) & & & & \\
$100 \times 150$ & 15,000 & 110 & $\frac{4}{5}$ & 325 \\
$100 \times 50$ & 5,000 & 43 & 1 & 425 \\
$100 \times 25$ & 2,500 & 41 & $1 \frac{3}{5}$ & 700 \\
$100 \times 45$ & 4,500 & 138 & 3 & 1500 \\
\hline
\end{tabular}


One of the secrets of success in these cases was the practice of double cropping, which is explained on page I86.

Gardening and health. Gardening has a beneficial effect on health in two ways : first, it furnishes a means for outdoor exercise, which is an essential to the best health; and second, it furnishes an abundance of the best kind of fresh food. It

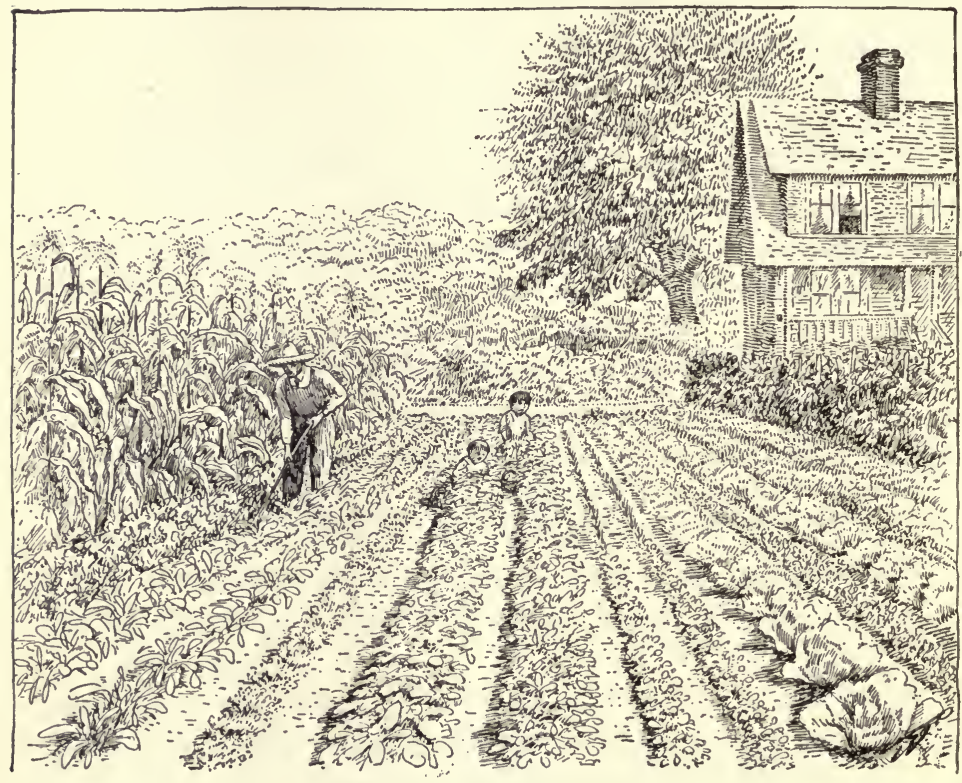

Fig. 61. - A home garden.

is undoubtedly more healthful to eat freely of vegetables and fruits in place of meats, especially during the summer, and fresh vegetables just picked from the garden are better than vegetables that have been kept for a while.

Pleasure in gardening. There is a great amount of pleasure in gardening. Many people find this one of their most delightful hobbies. It is interesting to watch the wonderful changes that take place from the time the first seedling ap- 
pears above ground till the fully matured product is obtained. This interest is increased by the work one does in helping the plants grow, through the killing of weeds and the cultivation of the soil. Another very attractive feature is the fact that gardening takes one out in the open amid pleasant surroundings at a time of the year when nature is at her best.

And furthermore a well-kept garden is in itself an attractive feature to be compared in some ways with the flower garden. The foliage effect of many plants is attractive. This is especially true of the carrot with its fern-like leaves. Some garden plants like peas and pumpkins have attractive flowers, and the corn plant with its erect tassels and drooping silks is an attractive feature of the garden.

The plan. During the late winter or early spring before the planting is begun, a map of the garden should be drawn on paper. The vegetables to be planted should be decided upon and the names written in the proper places on the paper; and the number of rows of each kind of vegetable and the distance between the rows should be indicated. This will first require that the dimensions of the garden be measured and recorded on the plan.

Kind of vegetables. In deciding upon the vegetables to be planted several considerations will need to be taken into account, such as the size of the garden, the time required for the vegetables to mature, and the succession of crops. If the garden is small, those vegetables should be avoided which require a very large area for the returns yielded. Among these are melons, pumpkins, winter squashes, and potatoes.

Varieties. It is important to consider the matter of the most suitable variety of each vegetable planted; that is, the different kinds of peas, corn, etc. Varieties differ in yield, taste, size, time required for maturing, and character of growth, such as climbing peas and beans and the dwarf 
20 feet

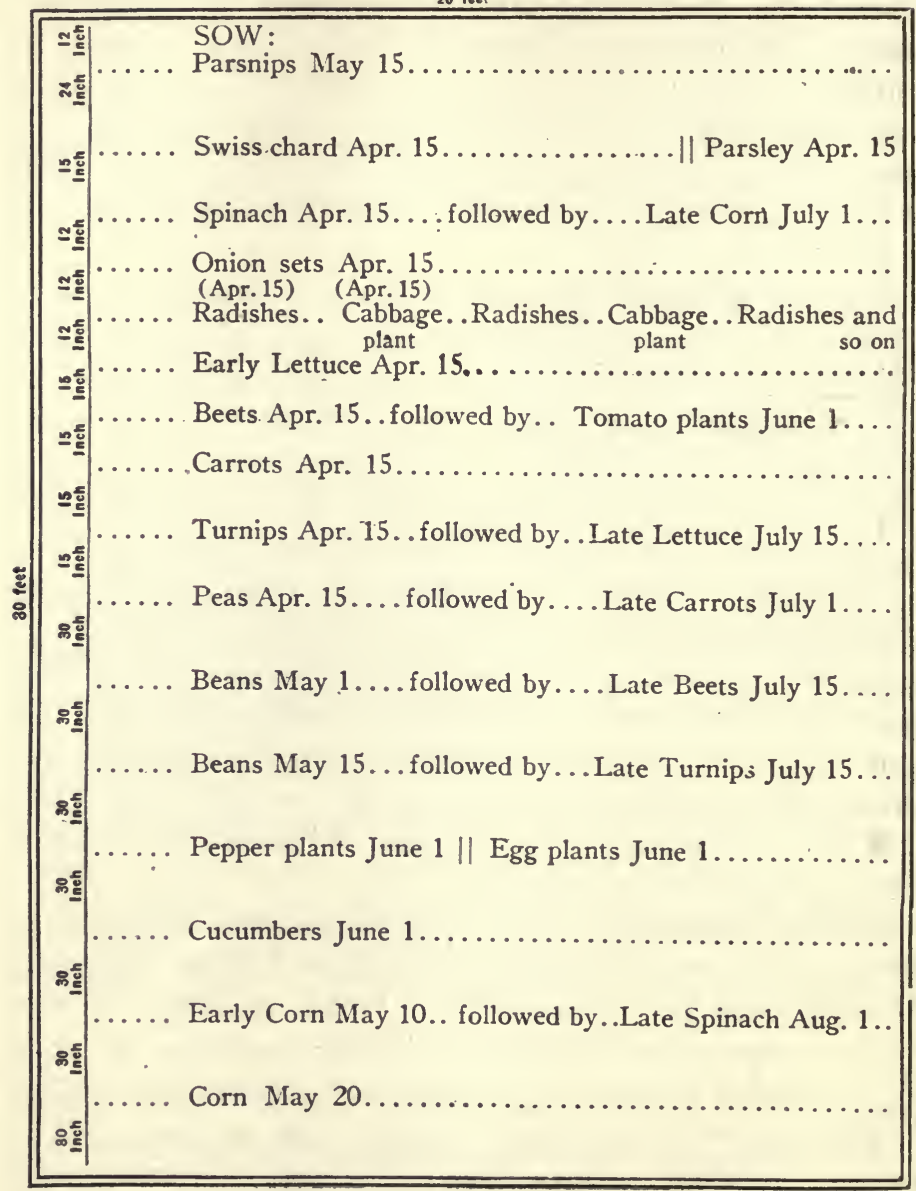

Fig. 62. - Plan of a vegetable garden.

or bush varieties. There are early peas and late peas, early corn and late corn. There may be a great difference in the yield of different varieties. The author tried an experiment with peas one season to compare the yield of different varie- 
ties. Nine varieties were planted side by side in the same length of row and all given the same care. A careful record was kept of the peas picked from each row.

The following table shows the result of the trial.

\begin{tabular}{|c|c|c|c|c|c|c|c|}
\hline VARIETY & & & & & $\begin{array}{c}\text { Total YIELD } \\
\text { (Quarts) }\end{array}$ & $\begin{array}{c}\text { Time to MA- } \\
\text { TuRe } \\
\text { (Days) }\end{array}$ & $\begin{array}{c}\text { TrMe IN BEAR- } \\
\text { ING } \\
\text { (Days) }\end{array}$ \\
\hline $\begin{array}{l}\text { Nott's Excelsior } \\
\text { Alaska . } \\
\text { Laxtonian . } \\
\text { Little Marvel . } \\
\text { Sutton's Excelsior } \\
\text { Advancer . } \\
\text { Dwarf Telephone . } \\
\text { Dwarf Champion . } \\
\text { Prince Edward }\end{array}$ & $\begin{array}{l}\dot{ } \\
\dot{.} \\
\dot{ } \\
\dot{ } \\
\dot{ } \\
\dot{ } \\
\dot{ } \\
\text {. } \\
\text {. }\end{array}$ & • & $\begin{array}{l}\dot{ } \\
\dot{ } \\
\text {. } \\
\text {. } \\
\text {. } \\
\text {. } \\
\text {. } \\
\text {. }\end{array}$ & $\begin{array}{l}. \\
. \\
. \\
. \\
. \\
. \\
. \\
.\end{array}$ & $\begin{array}{l}\text { I I } \\
\text { I6 } \\
\text { I9 } \\
20 \\
23 \\
24 \\
29 \\
35 \\
41\end{array}$ & $\begin{array}{l}62 \\
66 \\
63 \\
63 \\
63 \\
67 \\
71 \\
73 \\
71\end{array}$ & $\begin{array}{r}4 \\
6 \\
6 \\
3 \\
5 \\
4 \\
12 \\
10 \\
5\end{array}$ \\
\hline
\end{tabular}

It is seen that the best yielded nearly four times as many as the poorest. It must not be supposed, however, that this same difference would always hold with reference to these varieties, because it would vary according to climate, soil, and season. But this illustrates the fact that there is a great difference between varieties for any given situation. One interesting feature about gardening is the opportunity to try experiments with the different varieties and find which are best adapted to one's particular garden.

Among the best varieties of corn for flavor and tenderness is the Golden Bantam, which seems to be a general favorite. As the name implies the ears are small and the kernels yellow. It is a medium early variety.

It is interesting to try one or more new kinds of vegetables each year. Among these may be found some that are just as valuable as the common kinds more generally grown.

Parts of plants eaten. In accordance with the part of the plant used for food, vegetables may be divided into the 
following groups : $\mathbf{I}$. those whose root we eat, such as beet, carrot, parsnip, radish, and turnip; 2. those whose stems we eat, such as potato and onion; 3. those whose leaves we eat, such as cabbage, celery, lettuce, parsley, and spinach; 4 . those whose seeds we eat, such as peas, beans, and corn; 5. those whose fruit we eat, such as cucumbers, melons, pumpkins, squash, and tomato; 6 . those whose flowers are eaten, such as the cauliflower.

Double cropping. Succession cropping. In order to raise the most on a certain area, the ground should be kept in use all the time. Raising two crops on the same area is called double cropping. There are two kinds of double cropping, succession cropping and companion cropping. In succession cropping, as soon as one kind of vegetable has matured and been harvested, something else is planted in the same place. For example, radishes and lettuce may be followed by late corn; early beets by cauliflower or eggplant; peas by summer lettuce; early corn by cabbage plants, or spinach.

Companion cropping. In companion cropping the two crops occupy the ground at the same time, one being planted between the rows of the other. Those plants must be selected which mature at different parts of the season, one early and the other late, so that the early crop may be gathered and the plants pulled from the soil before they shade the second crop. Thus corn or tomato plants may be planted between rows of early peas, and when the peas have been picked, the vines are pulled from the soil to give room for the other crops. Other examples of companion cropping are radishes between the rows of beets or carrots, the radishes maturing before the beets or carrots need the room; squashes, pumpkins, or climbing beans planted in the hills of corn; early onions with cabbage. Giving attention to double cropping is one of the secrets of success in raising large crops of produce on small areas. 


\section{LABORATORY EXERCISE 22}

Purpose. To make a plan of a vegetable garden.

Directions. I. On a piece of unruled paper make a plan to scale of some part of your yard that could be used for a garden.

2. Follow the suggestions given in this chapter on garden making. Plan for a succession of crops and for double cropping.

3. Select the vegetables you wish to grow from the table on page 198. Draw lines on the paper to represent rows. On each line write the name of the vegetable to be grown, and after it (I) distance between rows, (2) date of planting. Use all the space and make the sum of the distances between the rows equal the width of the garden.

Outfit. The tools absolutely required are few in number, the threemost essential being the hoe, rake, and spade, or spading fork. In addition, however, a flat file for sharpening the hoe, a trowel, and a garden line will prove very useful. Two strong, pointed stakes should be provided to use with the line. If one has a large garden, it will pay to secure a wheel hoe. It

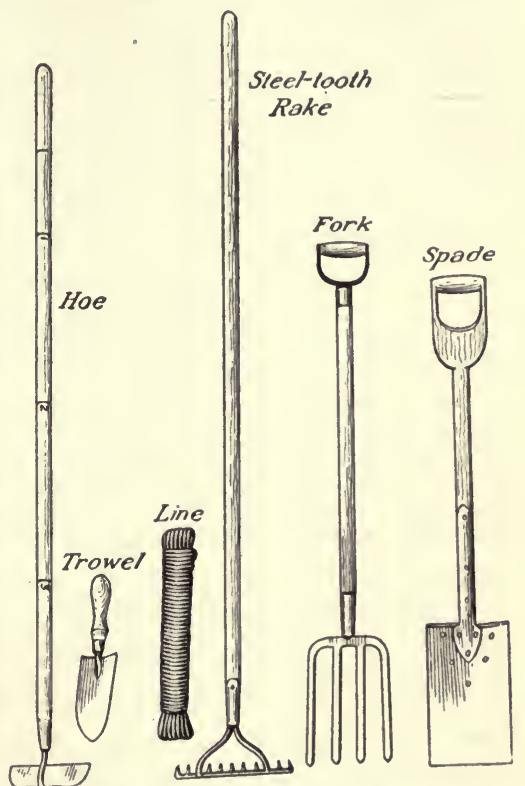

Fig. 63. - Garden tools.

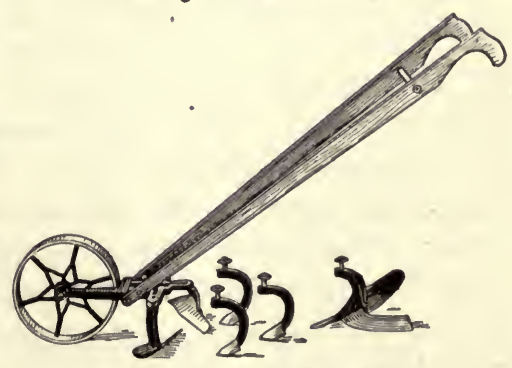

Fig. 64. - Wheel hoe. 
saves many backaches and enables one to do the work of caring for the garden in very much less time and with much more pleasure. The two most important attachments are the hoes and the cultivator teeth.

Preparation of soil. In order to get the best results, the soil should be enriched with manure or fertilizer. It should be plowed or thoroughly. spaded as soon in the spring as it can be worked. Special attention should be given to the preparation of the soil where seeds are to be planted. It should be gone over with a rake, the lumps taken out, and the top soil left in fine condition.

Planting the seeds. The garden line should be used to lay out the rows straight. The garden should be planted in long rows rather than in short beds, as this makes the work of cultivating the garden much easier, especially if a wheel hoe is to be used. If one row is more than it is desired to plant with one kind of seed, then the remainder of the row may be planted with some other seed which requires about the same space between the rows. In planting seeds, three things need to be considered, the depth, time, and distance.

Depth. The depth of planting depends chiefly on the size of the seed, the larger seeds being planted at a greater depth. A general rule is to plant a seed at a depth of two or three times its smaller diameter. The depth of planting a few common seeds is given in the table on page r98.

Time. The time of planting the first seeds depends upon the hardiness of the seedlings to frosts. This time varies with the latitude and with the season, according to whether the spring is early or late. The average time for a few seeds in the latitude of New York City is given in the table. Vegetables may be divided into two groups; hardy and tender. The hardy vegetables, like radishes and peas, can stand the light frosts of spring and so may be planted as soon as the soil is in good condition to work. The tender vegetables, like cucumbers and tomatoes, are killed by the 
frosts and so cannot be planted till the danger from frost is past, usually about three or four weeks after the hardy vegetables are planted. In setting out tender plants like tomatoes, it is well to wait until about a week after the time when the seeds of the same vegetable could be planted.

Distance. The distance of planting seeds depends on the size of the mature plant. Space enough should be allowed so that the plants will have room enough to grow without crowding. Some seeds like peas are scattered along the rows in drills, while others like corn and potatoes are planted in hills at certain stated distances.

\section{LABORATORY EXERCISE 23}

Purpose. To test the seeds you are going to plant in your. garden.

Apparatus. Two plates, pieces of cloth, and blotting paper.

Directions. I. Secure your seeds early enough so that you can test them before the time of planting outdoors arrives. If any of them should prove poor, you will still have time to get some more seeds.

2. For large seeds like peas secure a piece of cloth and fold into four thicknesses a little smaller than the plate. Moisten the cloth, put it in a plate, and put the seeds between the folds. Cover with the other plate.

3. For medium seeds like radish, use four folds of blotting paper and put the seeds between the folds.

4. For small seeds like lettuce, use two folds of blotting paper and place the seeds on top of the paper.

5. Keep a record of the number of seeds put in the tester. Keep the seeds in a fairly warm place and see that the cloth and paper are kept moist. At the end of two weeks, count the number of seeds that have germinated and compute the per cent that this number is of all those planted. If the per cent is very low, below 50, it will pay to secure new seeds.

Thinning. It is very important that the young plants should be thinned out when they are two or three inches high. 
The distance to which they should be thinned is given in the table. When the plants are crowded together, there is not room for all to develop, and the result is a large number of poor, small specimens instead of several good, large specimens. If desired, the plants pulled up may be transplanted.

Succession of crops. If the garden is large enough, arrangements should be made for a succession of crops; that is, the same kinds of seeds should be sown at intervals of a week or two, so that when the plants from the first seeds have stopped bearing, then those from the second will be maturing. This succession may be arranged with those vegetables which mature quickly, such as radish, lettuce, peas, beets, corn, and beans. Another way to secure a suc- cession is to buy varieties which require different lengths of time to mature and plant them all at the same time. Some vegetables require the whole season to mature so that generally only one crop is raised; such are parsnips, salsify, melons, and pumpkins. Seeds of beets and turnips, that are to be stored for the winter, should be planted about the middle or latter part of the summer.

How to get early vegetables. Early vegetables may be obtained through the use of hotbeds, cold frames, and seed boxes. A hotbed is a shallow box covered with glass. It may be placed on the surface of the ground, but it is better to have it sunk into the ground for a part of its width. The dirt inside is taken out and a thick layer of fresh horse manure is placed in the bottom. This is then covered with soil. The decaying manure furnishes heat, which keeps the hotbed up to a high temperature. In this such plants as cabbage, lettuce, celery, and tomato may be started from one to two months earlier than they could be planted outdoors. The bed must be carefully watched. The cover must be shut down at night to prevent the young plants from freezing, and opened during the day to allow ventilation. The bed must also be watered. These plants are later transplanted 
to a cold frame, where they are gradually hardened, and then they are set out in the garden. If one has a large enough frame, some plants like lettuce may be allowed to mature in the hotbed.

A cold frame is made in the same way as a hotbed, only no manure is put in to furnish artificial heat. Besides being used to harden the plants started in the hotbed, it may also be used to start seedlings, on the same principle as the hotbed, but later. Seeds can be planted in the cold frame three or four weeks earlier than they could be in the garden. A simple cold frame can easily be made. A box of any desired size may be partly sunk into

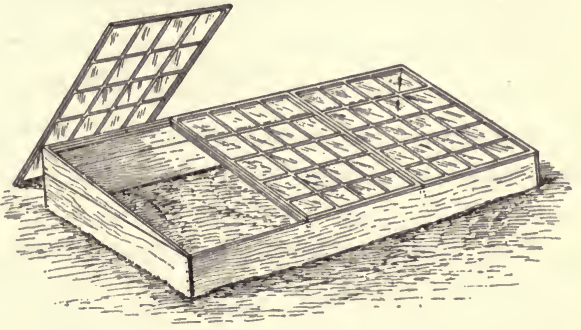

Fig. 65. - Cold frame. the ground in a sunny location, tipping toward the south, and then covered with panes of glass.

A seed box is a shallow tray in which seeds may be started indoors. These boxes may be placed in a sunny window, and three or four weeks' time may be gained on the season in this way. Plants like corn, melons, and cucumbers that are grown in hills may be planted in strawberry boxes indoors early in the season. When danger from frost is past the bottom of the box may be cut off and the whole box sunk in the ground.

Transplanting. Transplanting is best done on a cloudy day or late in the afternoon. It is well to water the plants a few hours beforehand, so that when they are taken out some dirt will adhere to the roots. If the ground is very dry, the plants should be watered after they are set out. Not only may plants be transplanted from the hotbed and cold frame, but when plants like beets and lettuce are thinned out, the extra plants may be set out. 


\section{Home Project ig}

Purpose. To raise some early vegetables.

Directions. Early vegetables sell at good prices. They are also very desirable for the home table. If you care to raise them for either of these reasons, study up all you can about hotbeds and cold frames in some book like Bailey's Manual of Gardening. Follow the instructions you find there, and make and plant a hotbed or cold frame. Keep an account of the value of the plants raised. An expense account may be kept, like that suggested on page 201 .

\section{School Project 6}

Purpose. To raise seedlings of some vegetables in the schoolroom so they may be taken home and planted in your gardens.

Directions. Those who are interested can work together to raise seedlings of some plants like lettuce, cabbage, and tomato in boxes in the schoolroom. For this purpose shallow flats can be made and the seeds planted in them. Care should be taken to see that the plants do not freeze between Friday and Monday. When it is time to set the plants outdoors, they may be divided among the members of the class and taken home.

Cultivation of soil. After the plants have once got started, the essential point in caring for them is to hoe the ground around them often. This serves three purposes, it keeps down the weeds, it mixes air with the soil for the roots to use, and it helps retain the moisture in the soil. During the winter and early spring the ground becomes soaked with water, and then as the warm weather comes on the water evaporates and the soil becomes dry. There is usually enough water in the soil in the spring to last the plants nearly all summer if it can only be kept from evaporating and thus retained in the soil where the roots can use it. The water at first sinks down deep into the earth and then gradually rises to the surface, where it evaporates. Between the particles of soil are small pores through which the water rises by 
capillarity in much the same way the oil rises through a lamp wick.

Now if something can be done to break up these pores at the surface, the water will be kept within the soil. If the soil is stirred the pores are too large and discontinuous to carry the water to the top. Thus the loose soil on top (mulch, it is called) forms a blanket which keeps the water in the soil. When the ground becomes hardened, as after a rain, the soil packs again, so that the garden should be hoed as soon after a rain as the soil becomes dry, and in general it may be said that the soil should be stirred about once a week. It is literally true that one of the best ways to water a garden is to hoe it. It is seldom necessary to pour water on the garden except in the very driest times.

Enemies of the garden. Weeds. In nearly every garden there are two enemies that one must meet, weeds and insects. Most soil is filled with seeds of weeds, some of which may

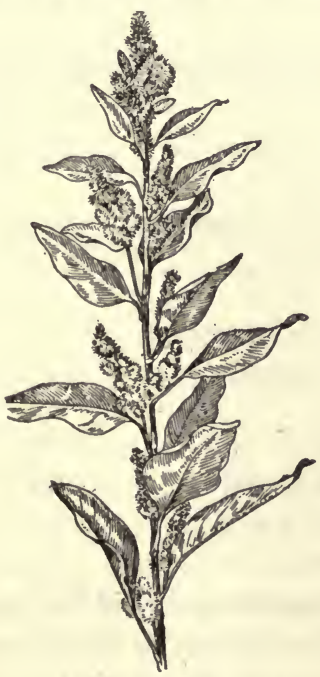

Rough pigweed

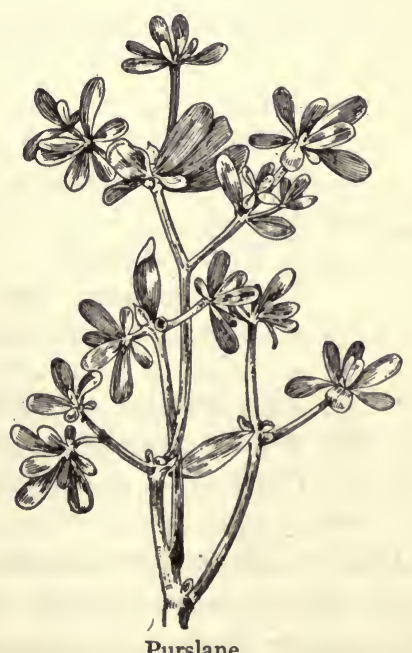

Purslane

FIG. 66. - Two common weeds of the garden. 
live in the soil for many years and then germinate. Some have been known to live as long as fifty years. It is a common thing for seeds to live ten or fifteen years. So when the conditions for seed germination arrive in the spring these seedlings spring up in the garden. If these are allowed to grow, they reduce the yield of the garden, because they rob the garden plants of water and plant food in the soil, and they deprive the plants of sunlight above ground. Weeds also make the garden look unsightly, and one of the important things to do in caring for a garden is to keep down the weeds by hoeing.

\section{Field Exercise 3}

Purpose. To identify the most common weeds found growing in vegetable gardens.

Directions. I. During the fall a trip may be taken to some gardens in the vicinity in order to identify some of the more common weeds.

2. For each weed studied record the following points in your notebook.
$A$. Name.
$B$. Height.
C. Character of growth (erect or prostrate).
D. Leaves.

a. Size and shape.

b. Arrangement (opposite or alternate).

c. Margin (entire, toothed, or lobed).

$d$. Make drawing of leaf.

E. Flower (brief description).

$F$. Fruit and seeds (brief description).

$G$. Chief characters by which identified.

Insects. Insects are another common enemy of the garden. Some plants grow without much interference from insects, while other plants are almost always attacked by them. Insects can be divided into two groups according to their 
method of doing harm, the biting insects and the sucking insects. The biting insects, like the potato beetle, devour the solid tissues of the plant, usually of the leaf; the sucking insects, like the squash bug, suck out the sap from the plant.

The following table is taken from Farmers' Bulletin 818. It lists the insects most likely to appear in the vegetable garden and furnishes information in regard to the plants attacked and the treatment recommended.

\begin{tabular}{|c|c|c|}
\hline INSECT & Plants Atracked & TREATMENT \\
\hline Eating type: & & \\
\hline Tomato worm . & Tomato . . . & $\begin{array}{l}\text { Hand pick or spray with } \\
\text { arsenate of lead. }\end{array}$ \\
\hline Cabbage worm & Cabbage group. & $\begin{array}{l}\text { Hand pick or apply arsen- } \\
\text { ate of lead. }\end{array}$ \\
\hline Cucumber beetles & Cucumber . . & $\begin{array}{l}\text { Cover with frames. Ap- } \\
\text { ply tobacco dust or spray } \\
\text { with Bordeaux mixture } \\
\text { or arsenate of lead. }\end{array}$ \\
\hline Potato beetle. . & $\begin{array}{l}\text { Potato, eggplant, } \\
\text { and tomato . . }\end{array}$ & $\begin{array}{l}\text { Hand pick and apply arsen- } \\
\text { ate of lead. }\end{array}$ \\
\hline Sucking type: & & \\
\hline Squash bug. . & $\begin{array}{l}\text { Squash, pumpkin, } \\
\text { melons, etc. . }\end{array}$ & $\begin{array}{l}\text { Hand pick; spray with } \\
\text { kerosene emulsion or } \\
\text { nicotine sulfate. }\end{array}$ \\
\hline Aphids (plant lice) & $\begin{array}{c}\text { Cabbage group and } \\
\text { other plants. }\end{array}$ & $\begin{array}{l}\text { Spray with kerosene emul- } \\
\text { sion, a solution of hard } \\
\text { soap, or nicotine sul- } \\
\text { fate. }\end{array}$ \\
\hline
\end{tabular}

To destroy the sucking insects, the plants are sprayed with some poison like kerosene emulsion, which kills the insect by contact or by smothering it. To destroy biting insects the plants are sprayed with some poison like lead arsenate, which is the best poison for this purpose. Paris green is also frequently used. The insects eat this with the leaf and are poisoned. For small quantities three teaspoonfuls of lead arsenate or one of Paris green are used 
with a gallon of water. In small gardens the insects may be hand picked by knocking off the insects with a stick into a dish containing kerosene. When setting out plants, like tomatoes and cabbages, they may be protected from cutworms by putting tin cans or a collar of heavy paper around them. A simple way of combating the cucumber beetle found on vine crops is to plant an abundance of seeds (IO-I5) in each hill. The harm is done chiefly to young plants. The beetles will not usually kill all of this number, and after the plants have become larger and the danger is past, they may be thinned out to three or four plants. Young plants can also be protected by setting over them a frame covered with cheesecloth.

\section{LABORATORY EXERCISE 24}

Purpose. To study the activities of some garden insects.

Apparatus. Insect breeding cages, garden insects.

Directions. I. Simple breeding cages may be made out of shoe boxes by cutting a hole in the cover and fastening over it a piece of mosquito netting. Or a lantern globe may be placed in a flowerpot filled with moist sand. Any glass receptacle such as a canning jar may be used.

2. Secure insects from the garden, bringing in also a piece of the plant on which they are feeding. Keep them in a breeding cage and bring in fresh leaves each day to feed them. Secure also some beneficial insects like the lady beetle and larva of the lace-winged fly.

3. Study the various insects, noting in each case: $(a)$ general appearance by which it may be identified; $(b)$ nature of harm or good done; $(c)$ stages in which harmful or beneficial; $(d)$ method of eating; $(e)$ chief methods of locomotion.

4. If desired the insects may be mounted as explained in Hodges, Nature Study and Life, Chapter IV.

Storing vegetables for winter. If the garden is large enough, the family may be supplied with vegetables not 
only during the summer, but in the winter as well. Many vegetables may be stored in a cool, dry, well-ventilated cellar where the temperature does not fall below freezing. A cellar containing a furnace will be too warm and dry and vegetables stored in it will wilt. If the cellar is warmed, a corner may be partitioned off for storing these vegetables and ventilation procured through a cellar window.

Some vegetables such as parsnips and oyster plant may be frozen without injury, indeed they may be left outdoors all winter and dug up when needed. Other vegetables such as potatoes, beets, carrots, and turnips require a temperature above freezing, from 35 to 45 degrees, and the last three will keep better if buried in moist sand. If the cellar has a dirt floor, a very simple way of storing root crops is to dig a shallow, broad trench and place in it beets, carrots, turnips, parsnips, and salsify, and then cover them with the dirt that has been excavated. Potatoes will keep better if placed in the dark.

Vegetables, like pumpkin and squash, will keep better at a slightly higher temperature than that required for root crops, about 50 degrees, and the air should be moderately dry.

To store celery secure boxes about a foot wide and as deep as the celery is high. Cover the bottom with two or three inches of wet sand. Dig up the celery plants, roots and all. Stand them on the sand, packing them close together. Cabbages and onions may also be stored in a cool cellar. Even tomatoes may be kept here for a few months. Just before the time for heavy frosts pick the largest green tomatoes and place them on straw in the cellar.

Cleaning up the garden. In the fall when the products have all been harvested, the weeds and old plants should be pulled up and buried, so that the garden is all ready for the next spring. This gives the garden a neater appearance and kills some insects found on the weeds that might make trouble in the garden next season. 
The following table gives in condensed form some of the more important facts regarding the raising of a few common vegetables. The dates for sowing seeds are for the latitude of New York City. They indicate the times for the first and last sowing.

\begin{tabular}{|c|c|c|c|c|c|c|c|c|c|}
\hline \multicolumn{3}{|c|}{ NAME } & \multirow{2}{*}{$\begin{array}{c}\text { SEEDS FOR } \\
\text { IOO FEET } \\
\text { OF ROW } \\
\text { I oz. }\end{array}$} & \multirow{2}{*}{$\begin{array}{c}\begin{array}{c}\text { DATE To } \\
\text { Sow }\end{array} \\
\text { Apr. I5 } \\
\text { Sept. I }\end{array}$} & \multirow{2}{*}{$\begin{array}{c}\text { DEPTH TO } \\
\text { PlanT } \\
\text { (Inches) } \\
\frac{1}{2}\end{array}$} & \multirow{2}{*}{$\begin{array}{c}\text { Rows } \\
\text { APART } \\
\text { (Feet) } \\
\\
\end{array}$} & \multirow{2}{*}{$\begin{array}{c}\begin{array}{c}\text { Plants } \\
\text { IN Rows } \\
\text { (Inches) }\end{array} \\
I-21\end{array}$} & \multirow{2}{*}{$\begin{array}{c}\text { DAYS RE- } \\
\text { QUIR ED TO } \\
\text { COME UP } \\
\\
4\end{array}$} & \multirow{2}{*}{$\begin{array}{c}\text { Trme to } \\
\text { MATuRE } \\
\text { (Days) }\end{array}$} \\
\hline Radish & . & . . & & & & & & & \\
\hline Lettuce & . & . . & $\frac{1}{2} \mathrm{oz}$ & $\begin{array}{l}\text { Apr. I } 5 \\
\text { Aug. I5 }\end{array}$ & $\frac{1}{4}$ & I & $4-6^{1}$ & $4-8$ & $60-90$ \\
\hline Onion (se & ets) & . & I qt. & $\begin{array}{l}\text { Apr. I5 } \\
\text { May }\end{array}$ & 2 & I $\frac{1}{2}$ & 3 & $\dot{-}$ & $90-120$ \\
\hline Peas & . & . . & I-2 pt. & $\begin{array}{l}\text { Apr. I5 } \\
\text { June I }\end{array}$ & 3 & $2 \frac{1}{2}$ & I & 7-10 & $40-80$ \\
\hline Beets . & - & . . & $2 \mathrm{oz}$ & $\begin{array}{l}\text { Apr. I } 5 \\
\text { Aug. I }\end{array}$ & I & I & $3-4^{1}$ & 6 & $60-80$ \\
\hline Cabbage & & . . & $\frac{1}{1} \mathrm{OZ}$ & $\begin{array}{l}\text { Apr. I5 } \\
\text { July I }\end{array}$ & $\frac{1}{2}$ & 2 & I 8 & 6 & $90-130$ \\
\hline Parsnip & . & - . & $\frac{1}{2} \mathrm{oz}$ & $\begin{array}{l}\text { Apr. I } 5 \\
\text { June I }\end{array}$ & $\frac{1}{2}$ & I $\frac{1}{2}$ & $3-4^{1}$ & $12-15$ & $125^{-1} 60$ \\
\hline Carrot & . & . & I oz. & $\begin{array}{l}\text { Apr. I5 } \\
\text { June I }\end{array}$ & $\frac{1}{2}$ & $1 \frac{1}{2}$ & $2-3^{1}$ & $8-9$ & $75^{-1} 10$ \\
\hline Turnip & - & . . & $\frac{1}{2} \mathrm{OZ}$ & $\begin{array}{l}\text { Apr. I5 } \\
\text { Aug. I }\end{array}$ & $\frac{1}{2}$ & $I \frac{1}{2}$ & $3-4^{1}$ & 4 & $60-80$ \\
\hline Potato & . & . & $5 \mathrm{lb}$. & $\begin{array}{l}\text { Apr. I } 5 \\
\text { June I }\end{array}$ & $3-5$ & 2 & $15-18$ & 20 & $80-140$ \\
\hline Corn . & . & . & $\frac{1}{4}$ pt. & $\begin{array}{l}\text { May I } \\
\text { July ro }\end{array}$ & $2-3$ & $2 \frac{1}{2}$ & $30-36$ & 8 & $60-100$ \\
\hline Beans (b & ush & a) & I pt. & $\begin{array}{l}\text { May I } \\
\text { Aug. Io }\end{array}$ & 2 & $1 \frac{1}{2}$ & $2-3$ & 8 & $40-65$ \\
\hline Beans (li & ima) & ) & I qt. & $\begin{array}{l}\text { May I5 } \\
\text { July I }\end{array}$ & 2 & $2 \frac{1}{2}$ & 3 & 14 & $90-120$ \\
\hline Muskmel & & . & $\frac{1}{2} \mathrm{oz}$. & $\begin{array}{l}\text { May I5 } \\
\text { June I }\end{array}$ & I & 7 & 72 & 8 & $120-150$ \\
\hline Cucumbe & & . & $\frac{1}{2} \mathrm{Oz}$ & $\begin{array}{l}\text { May I5 } \\
\text { July I }\end{array}$ & $\frac{1}{2}$ & 5 & 60 & $4^{-I I}$ & $60-80$ \\
\hline $\begin{array}{l}\text { Squash } \\
\text { (summ }\end{array}$ & & & $\frac{1}{2}$ oz. & $\begin{array}{l}\text { May I5 } \\
\text { July I }\end{array}$ & I & 4 & 48 & II & $60-80$ \\
\hline $\begin{array}{l}\text { Tomato } \\
\text { (young }\end{array}$ & $\mathrm{pl}$ & ants) & - & $\begin{array}{l}\text { May } 20 \\
\text { June } 15\end{array}$ & - & 3 & 36 & - & $100-140$ \\
\hline
\end{tabular}

1 Distances to which plants should be thinned. Seeds should be planted much closer. 
Table Showing Months of Planting Seeds and Using Products (For latitude of New York City)

( $\mathrm{P}$ represents the months seeds may be planted: $\mathrm{E}$ represents the months the products may be eaten)

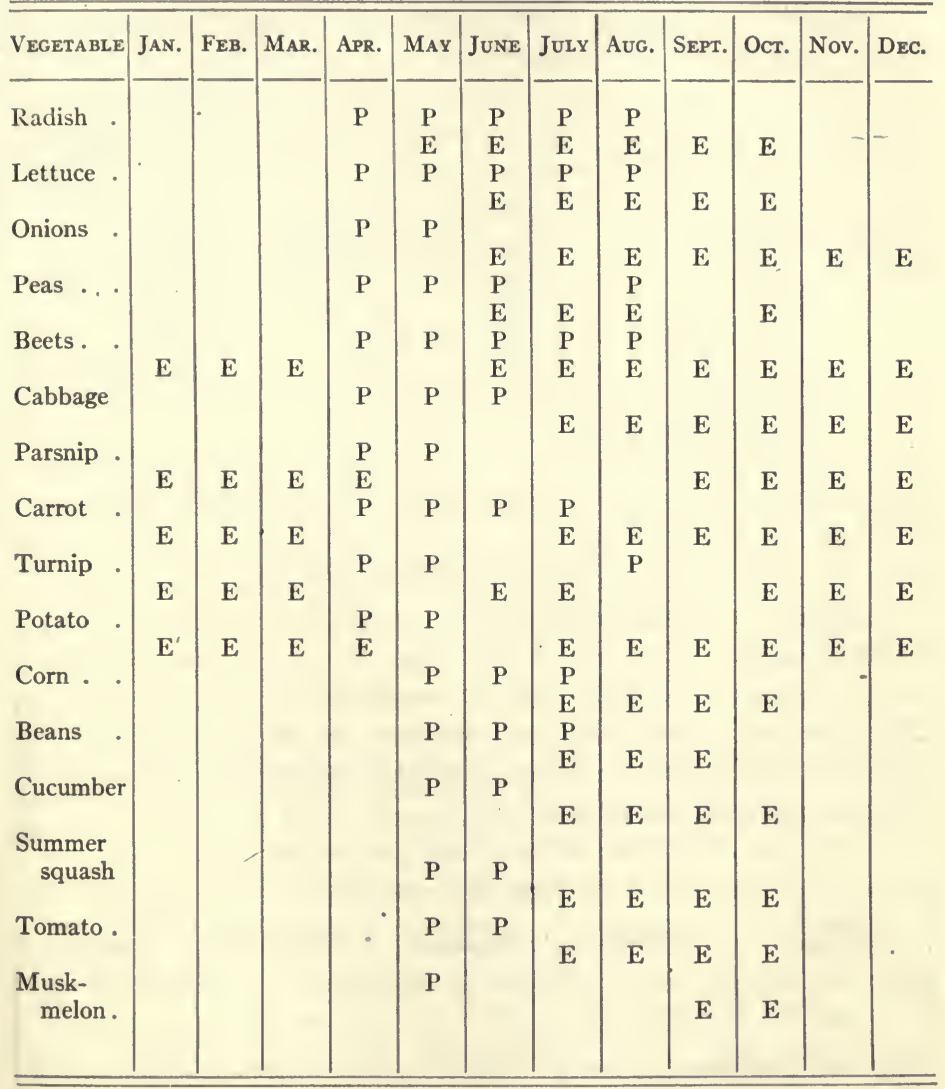

In the preceding table the months during which the various seeds may be planted in the garden are shown by the letter " $\mathrm{P}$ " in the upper half; the months during which the products may be eaten are shown in the lower half by 
the letter " E." This supposes that some vegetables are stored in the cellar. The table does not take into account the possibilities when using the hotbed and cold frame. If these are used, some vegetables can be planted and harvested earlier.

Vegetables may be grouped as follows according to the time it takes them to mature.

\begin{tabular}{|c|c|c|c|c|}
\hline 4-8 WeEks & 8-12 WeEkS & I 2-I6 WEEKS & I 4-20 WEEKS & I7-2I WEEKS \\
\hline $\begin{array}{l}\text { Cress } \\
\text { Radish } \\
\text { Spinach }\end{array}$ & $\begin{array}{l}\text { Beans } \\
\text { Beets } \\
\text { Carrot } \\
\text { Corn } \\
\text { Cucumber } \\
\text { Lettuce } \\
\text { Peas } \\
\text { Squash (summer) } \\
\text { Turnip }\end{array}$ & $\begin{array}{l}\text { Cabbage } \\
\text { Onion sets } \\
\text { Parsley } \\
\text { Potato }\end{array}$ & $\begin{array}{l}\text { Eggplant } \\
\text { Pumpkin } \\
\text { Tomato }\end{array}$ & $\begin{array}{l}\text { Celery } \\
\text { Melons' } \\
\text { Onions (seeds) } \\
\text { Parsnip } \\
\text { Salsify } \\
\text { Squash (winter) }\end{array}$ \\
\hline
\end{tabular}

\section{Home Project 20}

Purpose. To raise vegetables.

Directions. I. If you have room in your home yard and your parents are willing, start a vegetable garden. It may be either to raise vegetables for home use or to sell. First make a plan of the garden. Show it to the instructor to see if he has any suggestions to offer on it.

2. Keep a record something like the following.

\begin{tabular}{|c|c|c|c|c|}
\hline $\begin{array}{c}\text { Name of } \\
\text { Vegetable }\end{array}$ & Variety & $\begin{array}{c}\text { Date of } \\
\text { Planting }\end{array}$ & Lengte of Row & $\begin{array}{c}\text { Date Above } \\
\text { Ground }\end{array}$ \\
\hline & & & \\
\hline
\end{tabular}

\begin{tabular}{|c|c|c|c|}
\hline $\begin{array}{c}\text { Date First Crop } \\
\text { Picked }\end{array}$ & $\begin{array}{c}\text { Date Last Crop } \\
\text { Picked }\end{array}$ & Total Yisld & $\begin{array}{c}\text { Valoe at } \\
\text { Market Prices }\end{array}$ \\
\hline & & \\
\hline
\end{tabular}


3. Figure out the total value of all the produce raised, and then find the value of the produce per square foot of the garden.

4. Keep an expense account in accordance with the following outline.

\begin{tabular}{|l|c|c||c|c|}
\hline & $\begin{array}{c}\text { Amount } \\
\text { PaId OUT }\end{array}$ & Date & $\begin{array}{c}\text { AMount } \\
\text { RECEIVED }\end{array}$ & Date \\
\hline Totals.. & & & \\
\hline $\begin{array}{c}\text { Amount } \\
\text { earned }\end{array}$ & & & & \\
\hline
\end{tabular}

\section{Home Project 2 I}

Purpose. To test different varieties of some one kind of vegetable.

Directions. Secure the seeds of as many kinds or varieties of one kind of vegetable as you can, and see which are best suited to your garden and which you like the best. Send to seedsmen for catalogs. For instance, if radishes were chosen, a record like the following could be filled out.

VARIETIES OF RADISHES

\begin{tabular}{|c|c|c|c|c|c|c|c|c|}
\hline $\begin{array}{l}\text { NAME OF } \\
\text { VARIETY }\end{array}$ & $\begin{array}{l}\text { Date of } \\
\text { Planting }\end{array}$ & $\begin{array}{c}\text { Date of } \\
\text { FIRST CROP }\end{array}$ & $\begin{array}{l}\text { DAYS To } \\
\text { MATURE }\end{array}$ & Size & Shape & COLOR & Flavor & YiedD \\
\hline
\end{tabular}

\section{Home Project 22}

Purpose. To raise tomatoes for canning.

Directions. Perhaps some of you would like to raise tomatoes for canning. If so, write to the Division of Publications, U.S. Department of Agriculture, Washington, D. C., and ask for Farmers' Bulletin 521, "Canning Tomatoes at Home and in Club Work." It is sent free. This bulletin gives a number of recipes for tomatoes and explains how girls may earn money by selling canned tomatoes. It gives a number of records showing how girls have made from $\$ 23.00$ to $\$ 78.00$ in a season. 


\section{SUPPLEMENTARY QUESTIONS FOR CLASS DISCUSSION}

I. Of what value is the vegetable garden?

2. What things should be considered in deciding on the kind of seeds to plant?

3. How may the most be raised in a small area?

4. What are the advantages of cold frames and hotbeds?

5. What things must be considered in planting seeds?

6. What care does the vegetable garden require after the seeds are planted?

7. How may one have vegetables in the winter?

8. Which would you rather have, a flower garden or a vegetable garden? Why?

\section{REFERENCES}

Bailey, Manual of Gardening, Macmillan Co., New York City. Bennett, The Vegetable Garden, Doubleday, Page \& Co., New York City.

Rockwell, The Home Vegetable Garden, J. C. Winston Co., Philadelphia.

Maynard, The Small Country Place, J. B. Lippincott Co., Philadelphia. 


\section{CHAPTER XIII}

\section{THE FRUIT GARDEN}

How may fruits be raised in a small garden?

Fruits have not been grown in small yards as generally as have vegetables because the latter mature in a single season, while the former require one or more years to mature after first being set out. On the other hand, fruits have the advantage that they bear for years and do not need to be started anew from seeds each season. They form such a valuable portion of our diet that it is well worth while to raise them at home so that they may be obtained fresher and at less cost than when purchased in the market.

Kinds of fruits. The fruits grown in northeastern United States are divided by the fruit grower into the following classes : the tree fruits, such as the apple, pear, peach, plum, and cherry; the small fruits, such as strawberries; the bush fruits, such as blackberry, raspberry, currant, and gooseberry; the vine fruits, such as the grape.

Plants to select. In deciding on the kinds to plant, one needs to take into account the following considerations: the size of the yard, the size of the mature plant, the number of years before the plant begins to bear, and the month in which the fruits are ripe. Some fruits may be grown in even the smallest yards. Grapevines require very little space, as they may be trained on fences, porches, or buildings, if there is not room for a separate grape arbor. Strawberries also require little space and are well adapted to. 
small areas. The bush fruits require more room, and yet at least one row can be set along the fence or walk. In medium-sized yards a few of the smaller tree fruits may be raised, such as the peach, cherry, and plum; while in large yards room may be found for a few apple and pear trees.

In Farmers' Bulletin I 54, "The Home Fruit Garden," published by the U. S. Department of Agriculture, is given the following list of fruit-bearing plants that can be grown on an area of 60 by 80 feet. It comprises 474 plants distributed among 9 kinds of fruit as follows : 32 grape vines, I 8 dwarf pear trees, 6 peach trees, 6 cherry trees, 6 dwarf apple trees, 6 plums, 20 plants blackberries, 40 blackcaps, 40 red raspberries, and 300 strawberry plants.

From the same publication is taken the following list of varieties for a city lot, the varieties being chosen with special reference to northern Ohio. This list requires $\mathrm{I} 30$ plants, divided among I 2 kinds of fruits :

Apples, 4 trees - I Red Astrachan, I Golden Sweet, I Baldwin, I Fallanater.

Peaches, 4 trees - I Early Canada, I Yellow Rareripe, I Early Crawford, I Late Crawford.

Pears, 2 trees - I Bartlett, I Duchess (dwarf).

Plums, 2 trees - I Wilder, I Lombard.

Quinces - 2 Champion.

Apricots - I Motezumet.

Grapes, Io vines - 5 Concord, 5 Niagara.

Raspberries, 20 bushes - Io Gregg, Io Cutbert.

Blackberries, 20 bushes - Io Taylor, Io Agawam.

Currant, Io bushes - 5 Victoria, 5 White Grape.

Gooseberries - 5 Downing.

Strawberries - 50 Brandywine.

Time to mature. The time required for plants to come into good bearing varies from one to ten years. Fruits may be divided into four groups, according to the time before they bear good crops: the strawberry, in two years; 
the grape and bush fruits in three years; the peach, cherry, and plum in five years; and the apple and the pear in ten years. In each case some fruits will be borne earlier than this.

Succession of fruits. Another thing to consider is the season of the year when fruits are ripe, so that one may select the proper fruits and varieties to furnish a succession of fresh fruits during the whole season. The same kinds of fruit may mature at different times according to the variety, so that by selecting both an early and a late variety, the time of fruit bearing may be extended. The fruits may be divided into three groups, according to the time when they ripen: the early fruits, including the strawberry and cherry; the midsummer fruits, such as the currant, gooseberry, raspberry, blackberry, and peach ; and the late fruits, such as the grape, pear, and apple.

In the following table are given a few facts in brief form for reference.

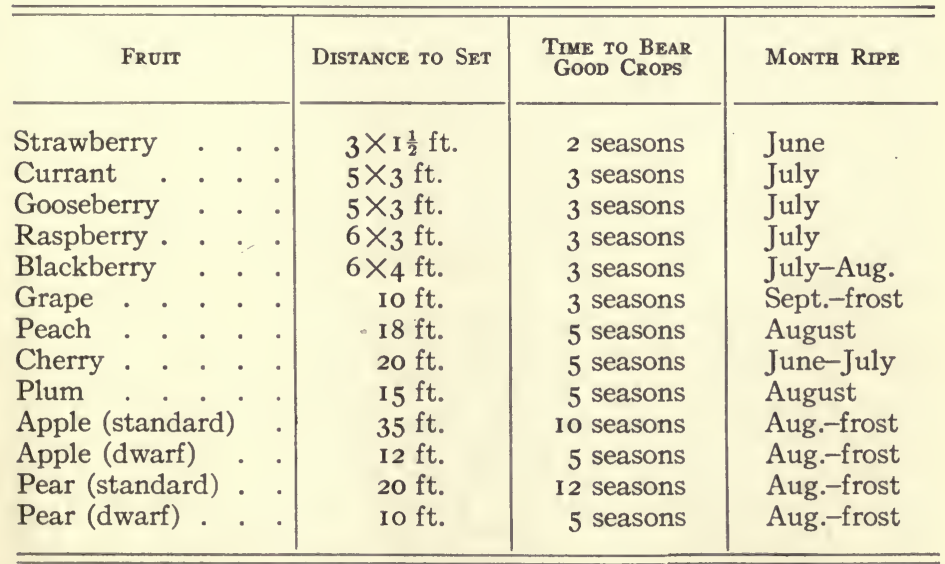

The distances here given are those used in large orchards, but for the home garden these distances can be made con- 
siderably less, thus allowing a larger number of plants to be grown. To compensate for this crowding, the soil will need larger amounts of fertilizers and thorough cultivation.

Fall or everbearing strawberries. One of the most interesting developments in the fruit world during recent years has been the appearance of the fall, or everbearing, strawberry. This has the great advantage that it bears fruit the same year it is planted. It is set out in the early spring at the time the first seeds are planted in the vegetable garden, and in about three months it begins to bear fruit, at about the time we get our first corn and tomatoes. It continues bearing till the heavy frosts of the fall kill the blossoms. Every garden can have its fall strawberries as easily as it has peas and corn.

The plants should be ordered during the winter from some reliable nurseryman. They cost more than ordinary strawberries, but after the first expense the gardener can raise his own plants, as explained later in the chapter. Among the best varieties are Progressive and Superb. The best variety will be different for different localities. In southern Minnesota the author tried three varieties side by side and found that the Progressive yielded six times as many berries as Americus, and twelve times as many as Superb. In other localities the results would be different, but one can soon learn after one or two trials the variety best adapted to his conditions.

The plants should be set in the spring as soon as the ground can be worked. Two systems have been used for growing strawberries, the hill system and the matted-row system. In the hill system the runners are all kept cut off; in the matted-row system, they are allowed to grow and form a mat. (See figure 67.) For the fall strawberries the hill system is better. In a small garden where the cultivation is to be done by hand, the plants may be set from 18 to 24 inches apart each way. For horse cultivation, they will need 


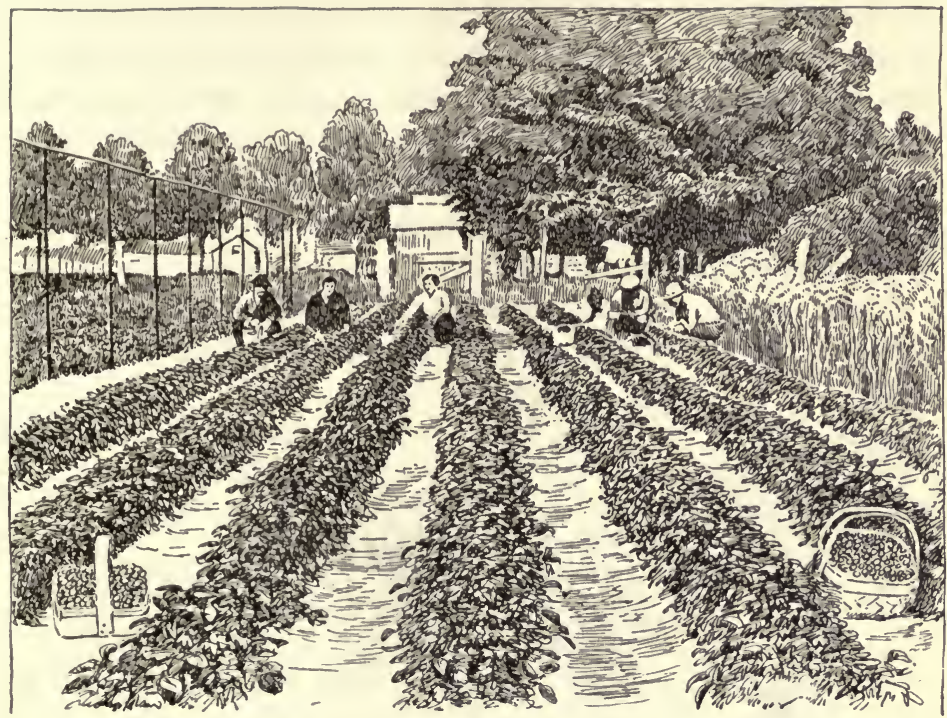

FIG. 67. - Matted row system of raising strawberries.

to be set 30 inches apart. In setting out the plants care should be taken not to set the plant so shallow as to have some of the roots exposed, nor on the other hand should it be set so deep as to cover the growing part of the plant. (See figure 68.)

The soil should be hoed frequently the same as for any plants, and the blossoms that appear in the spring should be picked off. If these blossoms are allowed to develop, the berries will not be worth picking; whereas if the flowers are picked, more nourishment goes to the roots and they become stronger and better fitted for the work to be done later in the season. The runners should be cut off with a sharp hoe or a pair of scissors. As a result larger and better berries are obtained. It is also much easier to keep out the weeds.

During the middle of the summer, blossoms appear again and these may be allowed to grow. In about three months 
from the time of planting, the first berries may be picked. If they are offered for sale, they are usually put in pint boxes, and will bring about twice as much as the spring berries. If one plans to sell the berries it is well to put some straw between the rows to keep the berries clean. But this straw has the disadvantage that it interferes with cultivation and so enables the weeds to grow.

These plants will also bear the following spring if given proper care. In the late fall they should be covered with

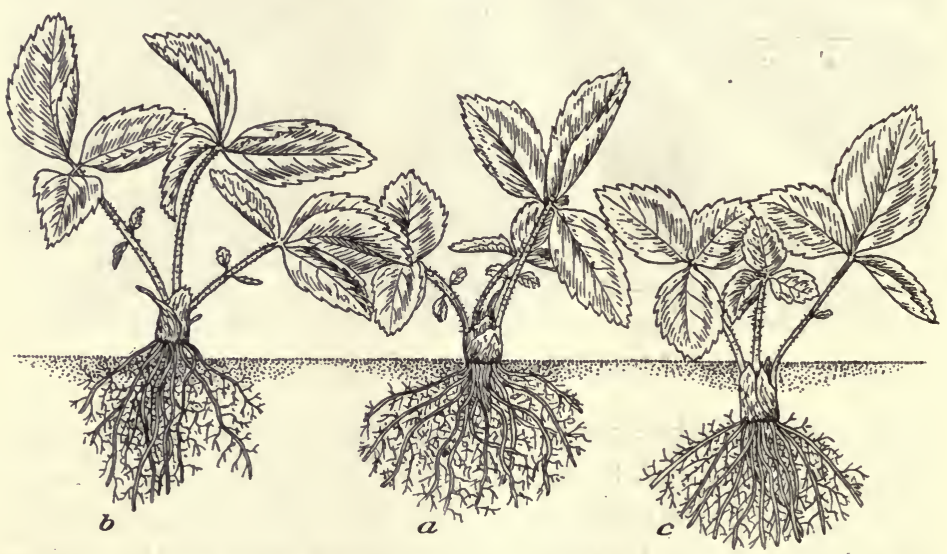

FIG. 68. - Setting out strawberry plants. $b$, too shallow; $c$, too deep; $a$, just right.

straw to a depth of two or three inches. This protects them from the alternate thawing and freezing of the winter and early spring that injures the roots. In the spring, about the time that the gardens are planted, the plants are uncovered. The danger of uncovering too early is that the late frosts may kill the blossoms. If the strawberry patch is small, the straw may be taken off and the bed cultivated till the berries are nearly ripe, then the straw should be placed back to keep the berries clean. If the patch is too large to remove all the straw, that over the plants may be parted and placed between the rows. 
These same plants will also bear again the following fall, making three crops in two years. After the spring crop is harvested, the straw should be entirely removed from the bed and the soil cultivated. The runners should be cut the same as the first season.

Propagation bed. After one has decided on the variety he wishes to grow, he can raise his own plants without any expense. A small corner may be used for a propagation bed. The plants should be set out about three feet apart and the blossoms picked off during the entire season. All the runners should be allowed to grow. In the late fall the bed should be covered with straw. In the early spring the straw is removed and the plants dug up and set out as already explained. A single plant

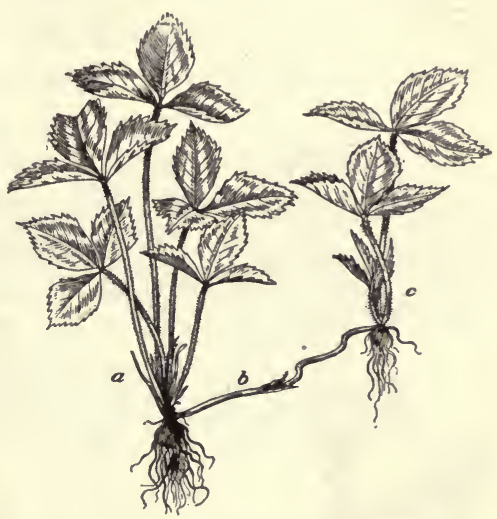

Fig. 69. - Runner of strawberry plant. may develop. from 20 to 50 runners. One great advantage of raising one's own plants, besides the saving of expense, is the fact that a larger per cent of the plants will live, and they get a better start than when shipped from a distance.

\section{Home Project 23}

Purpose. To raise fall strawberries.

Directions. If you have room for a garden in your home yard, try a small bed of fall strawberries. Send off during the winter and get the catalogs of several reliable nurserymen, and pick out the varieties that seem best adapted to your locality. It is well to try at least two kinds. When the plants come, heel them in at once, that is, open the bunches and set the plants in a trench 
and cover the roots with soil. They will keep this way for a week or two if necessary. When setting them out, put a few in a propagation bed, so that you will have some plants to set out next year. Follow the directions given in this chapter in caring for the plants.

Keep a record of the results in the following table.

\begin{tabular}{|c|c|c|c|c|}
\hline $\begin{array}{l}\text { NAME OF } \\
\text { VARIETY }\end{array}$ & $\begin{array}{c}\text { DATE of } \\
\text { IST PICKING }\end{array}$ & $\begin{array}{c}\text { DATE OF } \\
\text { LAST PICKING }\end{array}$ & $\begin{array}{l}\text { TrME IN } \\
\text { BEARING }\end{array}$ & $\begin{array}{l}\text { YIELD } \\
\text { (Pints) }\end{array}$ \\
\hline & & & & \\
\hline & & & & \\
\hline
\end{tabular}

Spring berries. The method of raising spring berries is much the same as the fall berries. Different varieties are used to start with. The blossoms are picked, the runners cut

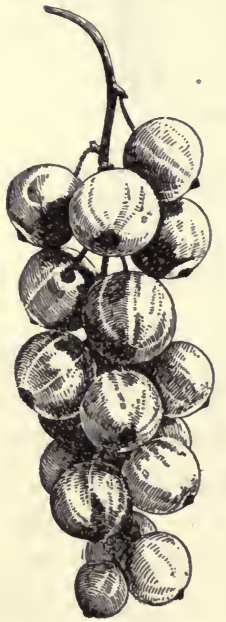

Frg. 70. - Perfection currant.

off if the hill system is used, and the plants are covered in the fall. In the spring the plants are uncovered in the manner already explained for the fall berries. After the fruit has been picked, the bed may be renewed by cutting off the tops of the plants and raking off the straw. The soil between the rows is cultivated thoroughly and most of the old plants cut out, leaving a few to send out a new set of runners. Thus another crop is obtained the next season. Some people prefer to use the bed only one season and then plow it up.

Bush fruits. The bush fruits, that is, raspberry, blackberry, currant, and gooseberry, are midsummer fruits which bear well the third season. In many yards room may be found for at least one row of bush fruits next to the fence. These should be planted about three feet apart.

The grape. The grape is especially well adapted for growing in a small yard. The plant itsêlf occupies little space and 
may be trained on any upright support, such as a fence, arbor, porch, or wall of a building. If a building is to be used for support, it is well to attach a strip of woven wire to the wall and fasten the vines to this. In addition to furnishing a supply of fruit, it has an ornamental value as a vine to cover bare places, or furnish shade for a porch. When the young plant is being trained, it should be cut back the first two years so as to form one main stem with two branches. These branches are brought down into a horizontal position extending in opposite directions and attached

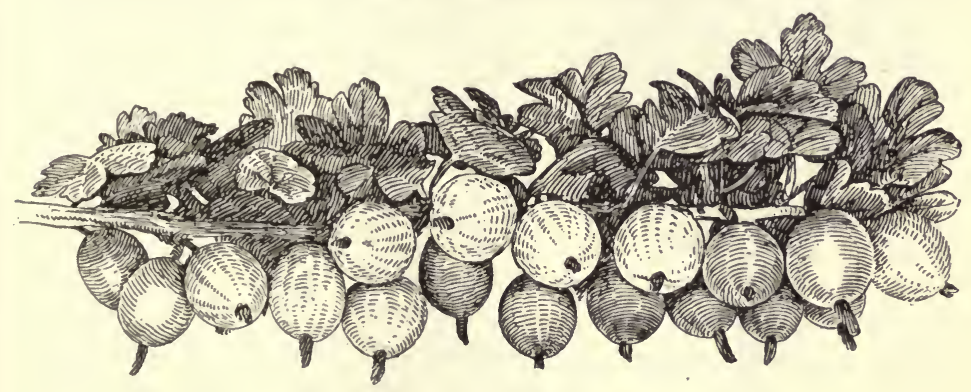

FIG. 7 1. - Downing gooseberry.

to wire or other support. From these are allowed to develop vertical branches on which the fruit is borne.

Tree fruits. The fruit tree, on account of the time it requires to mature and because it grows large, is not so well adapted to the small garden as those already mentioned; but a few of the small tree fruits, the peach, plum, and cherry, may well find a place in the medium-sized yard, and the apple and pear in larger gardens. While waiting for these fruits to mature, one can utilize the space between with small fruits and vegetables.

Dwarf trees. Dwarf trees of the apple, pear, and peach are often raised. These are much smaller than the ordinary kinds; they require fewer years to come into bearing; and they are easier to care for. For these reasons they are 
especially adapted for planting in small yards. Some kinds of peaches, apricots, nectarines, and pears may be trained like vines on arbors and buildings. These are much more expensive than the common kinds, but they can be grown where there would be no room for the ordinary fruit tree. Another device which may be used in small yards is to

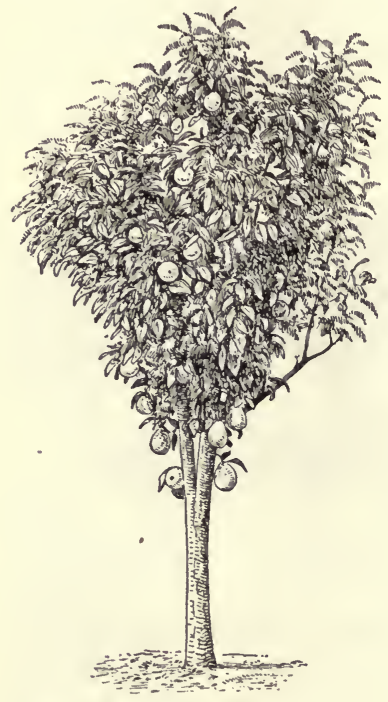

Fig. 72. - Dwarf pear tree. graft a number of varieties on one tree, so that it is possible to make a single apple tree bear different kinds of apples.

Propagation of fruits. In starting the fruit garden, one will generally get more satisfactory results by purchasing a few plants from the nurseryman; later, as they mature, new plants may be grown from them.

Runners. The strawberry is propagated by means of runners, which grow out from the plant in abundance and take root and form a new plant. The connection with the old plant may be cut and the new one transplanted. In one year a large number of plants may be raised from a small beginning. (See figure 69.)

Cuttings. The currant, gooseberry, and grape may be propagated by means of cuttings. In the autumn, after the leaves have fallen, stems of the last season's growth are cut into pieces six inches long, containing at least two buds. These may be set out at once in mellow soil in the garden, so that the top bud is just below the surface. Or, the cuttings may be tied together in bundles with the lower ends together, and placed in a trench in the garden with the butt ends up, and covered to a depth of three or four inches with soil. 
The cuttings may also be stored in a cool cellar in sand or sawdust. In the spring they are taken up and planted three or four inches apart with the top bud just at the surface of the ground. In the fall, after the roots have formed, the cuttings may be transplanted to their permanent location. Cuttings of currants may be made in the spring and planted at once.

Layering. The grapevine may also be propagated by layering. In the spring or early summer a branch of last season's growth is bent down and buried in the soil. Roots form at this place; and the next spring the stem may be separated from the main vine and the plant dug up and transplanted.

\section{Home Project 24}

Purpose. To raise fruits in the home yard.

Directions. If you have room in your garden, set out a few fruit plants. Room can usually be found for a grapevine, and a row of bush fruits can often be planted along by the fence or border of the yard. Dwarf fruit trees require only a small space and give returns quickly.

\section{SUPPLEMENTARY QUESTIONS FOR CLASS DISCUSSION}

I. What does one need to consider in deciding on the kinds of fruits to be raised in a small garden?

2. What are the advantages of dwarf fruit trees?

3. What steps are necessary to raise fall strawberries?

4. How may the grape be raised in the small yard?

5. How may fruits be propagated in the home garden?

\section{REFERENCES}

Bailey, Manual of Gardening, Macmillan Co., New York City. Maynard, The Small Country Place, J. B. Lippincott Co., Philadelphia.

Rockwell, The Home Vegetable Garden, Part 3, J. C. Winston Co., Philadelphia.

Rockwell, Making a Garden of Small Fruits, Macbride Nast and Co., New York City. 


\section{CHAPTER XIV}

\section{POULTRY KEEPING AND BEEKEEPING}

What are the differences in the care required for keeping poultry and keeping bees?

\section{Poultry Keeping}

Extent of industry. The real extent of the poultry industry in this country is not appreciated because it is divided among so many people, each doing only a small business; but the aggregate is large. The value of the annual poultry product on farms alone was estimated in 1890 to be about $\$ 300,000,000$; and the amount for the entire country must have been considerably more. At the present time the value of the annual products may be said to be approximately a half billion dollars.

Use of small areas. While but few people devote their entire time to poultry keeping as a business, it is an industry which can be adapted to almost any requirements, from the small yard which will allow the keeping of only a few hens to the large poultry farm. It may be made a source of food for the family or of income under many conditions where only a small amount of time can be devoted to it. The business can be started on a small scale with little outlay of capital and gradually be increased to whatever extent one desires. In fact, it is better to begin on a small scale till one acquires experience. Successful poultry raising demands experience and attention to details rather than strength for most of the work, so with a little assistance for the heavier work it may easily be managed by girls and women.

A good market at profitable prices can always be found 
for fresh eggs in cities and large villages. Under an intensive system a large number of fowls can be kept in a small space. The smaller the flock, the greater the returns usually are per capita.

Breeds. The various breeds of fowls may be grouped under three, classes: the meat breeds, the egg breeds, and

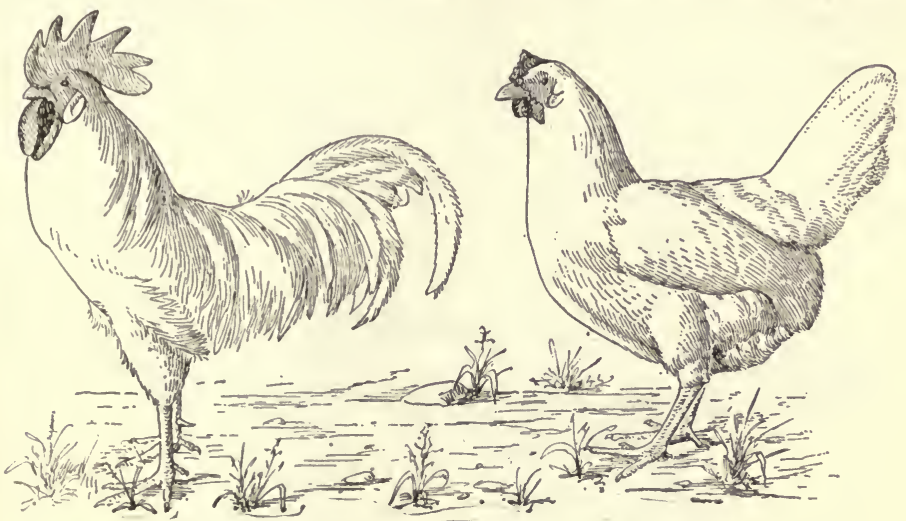

FIG. 73. - Single-comb White Leghorns. An egg breed.

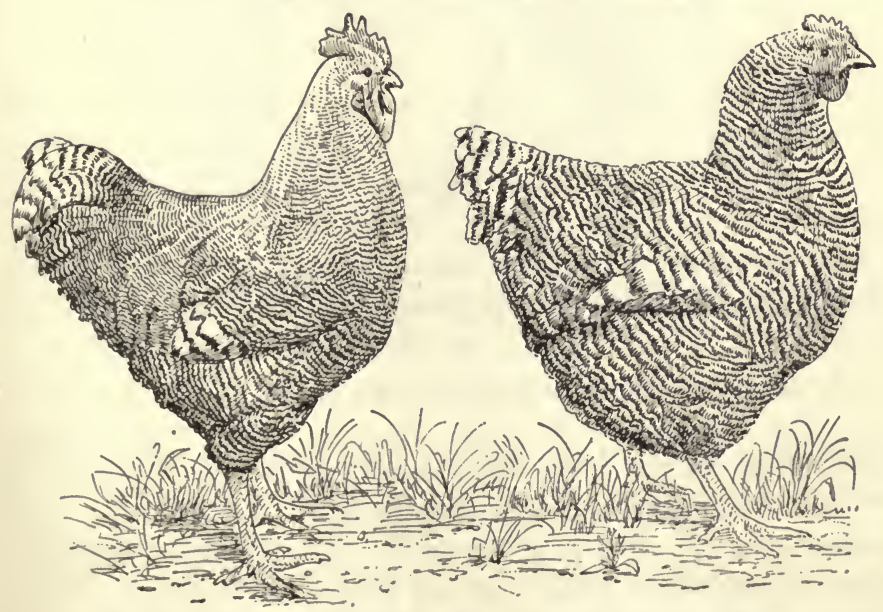

FIg. 74. - Barred Plymouth Rocks. A general-purpose breed. 
the general-purpose breeds. The Brahmas are an example of the first, the Leghorns of the second, and the Wyandottes and Plymouth Rocks of the third. Under average conditions the best breed will probably be one of the generalpurpose fowls, those which are well adapted for both meat and egg production. It is more profitable to raise purebred stock, even though the first cost_be a little more.

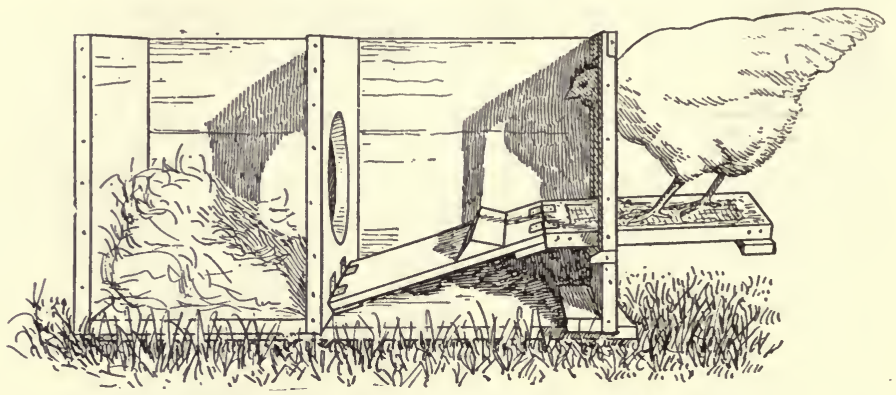

Fig. 75. - Trap nest. Hen entering.

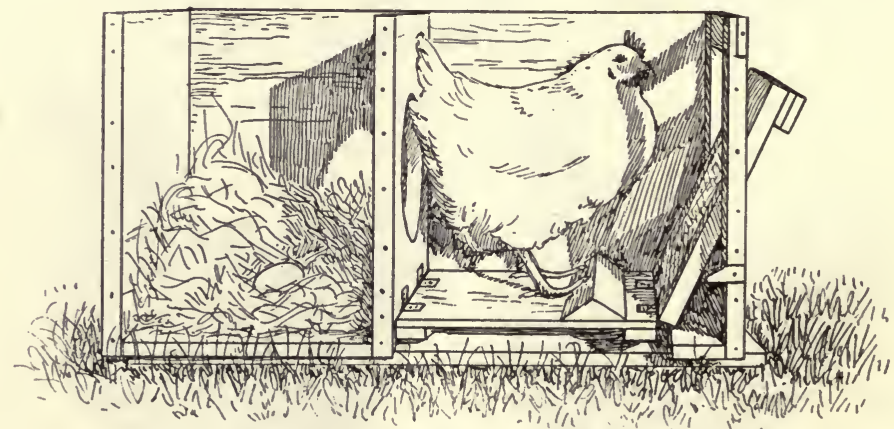

Fig. 76. - Trap nest. Hen trapped.

Selection of the best stock. One essential to profitable poultry keeping is the selection of the best chickens for egg production. In every flock there are usually some hens which do not lay enough eggs to pay for the cost of feeding them. This selection may be brought about in two ways. 
As the chickens are maturing, the most active and vigorous and the largest may be selected as those which will probably be the most productive. Another method is the use of the trap nest. This is a nest so constructed that as a hen enters a nest, she is shut in and kept there until released. By putting numbered leg bands on each pullet, the number of eggs which each lays in a certain time may be determined, and so the best layers may be selected. These nests, however, require close attention and must be visited several times a day to release the hens and keep an account of the eggs laid; but they are the only means of determining the exact number of eggs laid. Even if they are used for

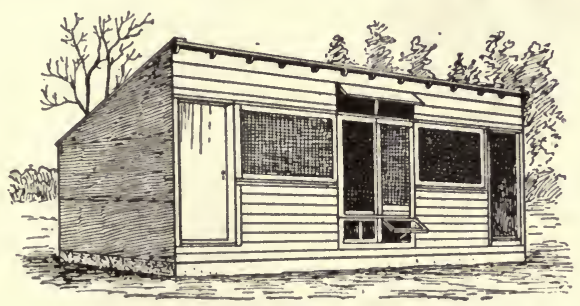

Fig. 77. - Front view of henhouse.

only a few weeks at a time during various seasons of the year, they may be a great aid in the selection of the best layers.

Hatching the eggs. The question of whether the eggs shall be hatched by hen or incubator depends largely on the number of chickens to be raised. Small numbers can be raised very satisfactorily by using hens; large numbers require an incubator. While this and the brooder that is required after the eggs are hatched are rather expensive, there is the advantage that they can be used at any time and large numbers of chickens can be raised.

Poultry house. Many types of poultry houses are in use. The essential points are that they shall be so arranged as to keep dry, receive sunshine, and be well ventilated. 
Many poultry men are providing ventilation by leaving a part of one side entirely open, protected in cold and stormy weather by a cloth screen.

Care of poultry. The essential points in the care of hens may be briefly summarized under the following heads : clean water at least once a day, grit, oyster shell, a dust box to keep the fowls free from vermin, and the proper amounts and kinds of food. The matter of food is one of the details

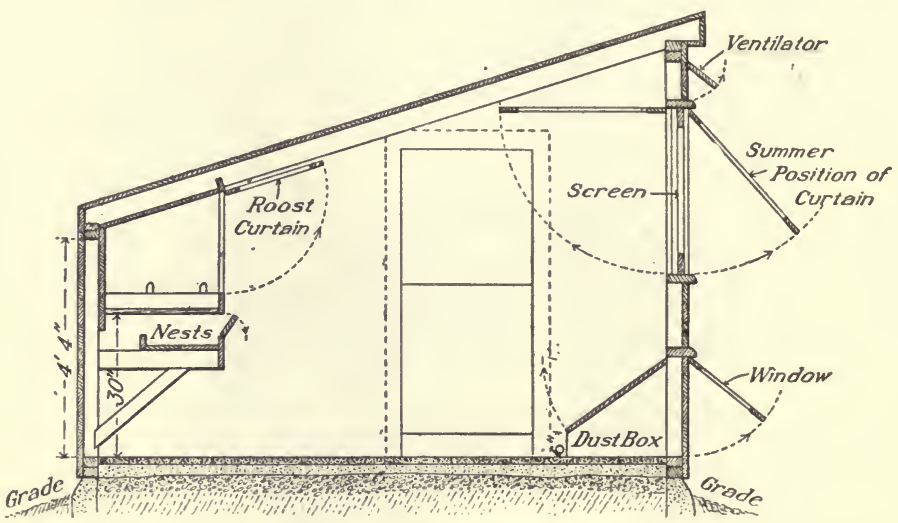

Fig. 78. - Cross section of henhouse shown in figure 77.

on which experts do not agree. Indeed there is no one method of feeding which is best, for there are many combinations of foods, all of which are good. The essentials in which these all agree are that in connection with the grains there should be fed some form of meat food, such as beef scraps and some green vegetable food, such as cabbage or beets. The mixture of foods, known as mash, is given dry by some and mixed with water by others. It has been the custom to give the mash wet, but in recent years experiments made with dry mash kept constantly before the fowl in hoppers have given very satisfactory results, both as regards egg production and the saving of labor in feeding. 
Another essential generally recognized is that some of the food should be given in such a way as to require exercise on the part of the fowl to obtain it. This is brought about by throwing grain in a litter of straw or other material, which the fowls are obliged to scratch over in order to obtain the food.

\section{Home Project 25}

Purpose. To take charge of a small flock of chickens.

Directions. I. If some one at your home keeps chickens, perhaps arrangements can be made for you to take entire charge of a small flock. Or perhaps you

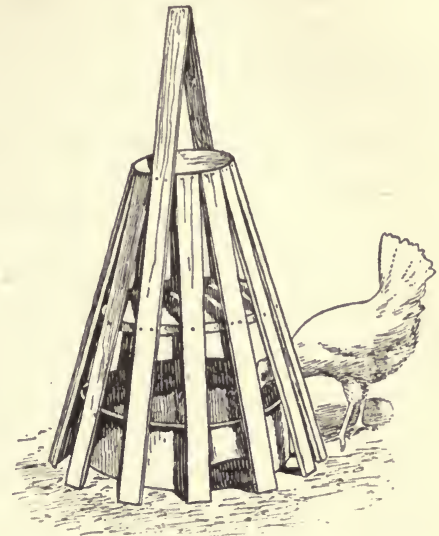

Fig. 79. - A method of keeping drinking fountain clean. can start anew. Either fall or spring is a good time to begin. In the spring one may start with a few setting hens and raise chicks. In the fall a small flock of pullets may be secured. It pays to get good stock even if it costs a little more. Look up some good book on poultry and try to care for the flock in the very best way. Try a trap nest for at least one month in the winter. Make special effort to get eggs in the winter, for that is the time when they are worth the most, and the ability to get winter eggs is one of the tests of successful poultry keeping.

2. Two types of records may be kept: one a careful description of the steps taken in caring for the poultry; such points as breed, number to start with, shelter provided, method of feeding, raising young chicks, total number of eggs each month, average number for each pullet. A second record should be kept giving a statement of receipts and expenses. This may be kept in some such form as the following. 
Monthly Financial Account

\begin{tabular}{|c|c|c|c|c|c|}
\hline AMOUNT PaID & Our & & Date & AMount Recerved & Date \\
\hline $\begin{array}{l}\text { Total for month } \\
\text { Gain or loss }\end{array}$ & $\dot{\cdot}$ & $\begin{array}{l}\cdot . \\
\cdot\end{array}$ & & . & - \\
\hline
\end{tabular}

\section{BeEkeEPING}

Keeping bees is another of those home activities which one may undertake on a small scale for the triple purpose of furnishing the tables with a fresh supply of wholesome food, of securing some financial return, and of finding a source of wholesome recreation in studying the wonderful life of those insects. The number of hives kept should be determined by the conditions, but it is wise for the inexperienced to make a small beginning. From caring for one hive for a season, one may secure the experience needed to care for a larger number the following season.

Kinds of bees in colony. Honey bees have been cared for by men for centuries for the honey and wax they produce. Some of these colonies have escaped from hives and are now found wild, making their homes in hollow trees. These bees illustrate the high type of development made possible through instinct. Honey bees are social insects; that is, a large number live together in a community, each bee having a work to perform for the benefit of the whole colony. Three kinds of individuals are found in a hive: one queen, several hundred drones, and from fifteen to thirty thousand workers. The queen lays the eggs, some of which are fertilized by the drones; and upon the workers fall all the other tasks of the colony.

Combs. The combs are made of wax, which the bees form into six-sided cells. This wax is secreted by some of the workers, which gorge themselves with honey and then 
hang motionless until the wax appears on the outer surface of their bodies and is taken off by the other workers. Cracks in the hive are filled by means of a kind of cement, called propolis, which is secured from the buds of trees.

Care of the young. The queen lays the eggs, one in each cell, and may lay two kinds, fertilized and unfertilized. The first kind develops into drones, and the other into either workers or queens, according to the kind of feed given them. The larvæ that hatch from these eggs are fed by the workers on a rich food called bee-jelly, and then with honey and bee bread, after which the cells are filled with food and capped with wax. In about two weeks more, the adult bees emerge from the pupal state and gnaw their way through the wax cap. In three weeks from the time the eggs are laid, the adult bees come from the cells. They then take up their duty of feeding the larvæ, which is the work of the newly hatched bees. This is the method by which drones and workers are reared, but to produce queens a different plan is followed. A larger cell is made by tearing down the partitions between several cells and preserving only one fertilized egg. When this hatches, the larva is fed entirely on bee-jelly during all of this stage, and as a result a queen is developed instead of a worker.

Swarming. In order that the number of colonies may be increased, there occurs occasionally during the summer what is known as swarming, when a part of a colony leaves the old hive and starts a new colony. Ordinarily there is but one queen in a hive, but before a swarm is to go out another queen is allowed to hatch; thereupon the old queen goes away with a part of the colony, leaving the new queen in the old hive.

Food. The food of the colony consists of nectar and pollen. The work of gathering this is performed by the older workers. The nectar is sucked up into a honey sack, where it is made into honey and then thrown out to be 
stored in the cells. Pollen is gathered from flowers and carried on the hind legs in pollen baskets, which are concave segments fringed with hairs. From this pollen, bee bread is made, which is fed to the larvæ.

Flowers visited by bees. The first requisite for successful beekeeping is the presence, within a radius of a mile, of proper kinds of flowers from which nectar and pollen may be gathered. Hives may be kept even on roofs in cities, if parks and the right kind of shade trees are near. Of the trees commonly planted along the streets, the red maple, tulip, locust, horse chestnut, and linden invite the bees, I

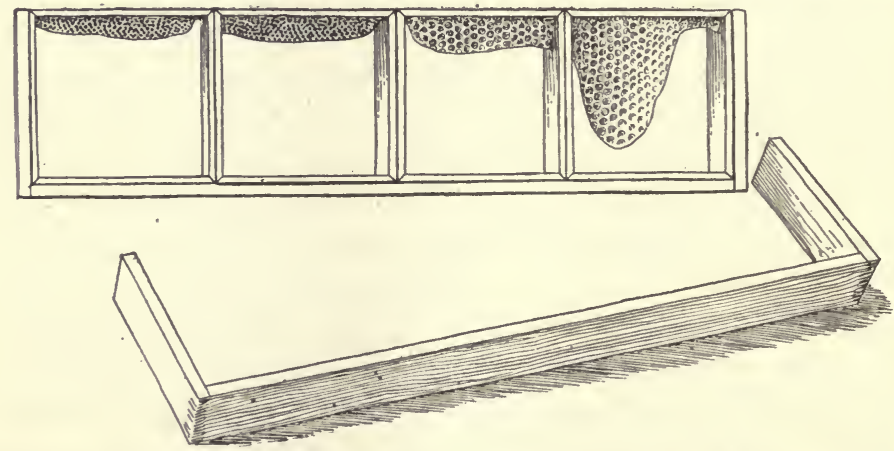

Fig. 8o. - Below, an empty section holder; above, one fitted with section-boxes, in which are foundation starters; two of these have been added to by the bees.

- especially the linden, which is one of the very best of all honey-producing plants. Other valuable flowers are those of fruit trees, clover, buckwheat, raspberry, and of many wild flowers, such as the sweet clover and goldenrod. The blossoms of many plants in both the vegetable and flower gardens are visited by bees.

Annual yield. A colony of bees may be expected to yield annually an average of from 25 to 30 pounds of comb honey, or 40 to 50 pounds of extracted honey. In the former case the comb in which the honey is stored in the hive is taken 
with the honey. In the latter case the liquid honey is extracted from the combs by means of a centrifugal machine.

How to begin. Spring is the best time of the year to begin beekeeping. It is best for the inexperienced beekeeper to procure from some reliable dealer a first-class colony of Italian or Carniolan bees in a good frame hive. The cost will be from $\$ 10.00$ to $\$ 20.00$. While bees can be secured at less cost, in the end the better equipment will prove more satis-

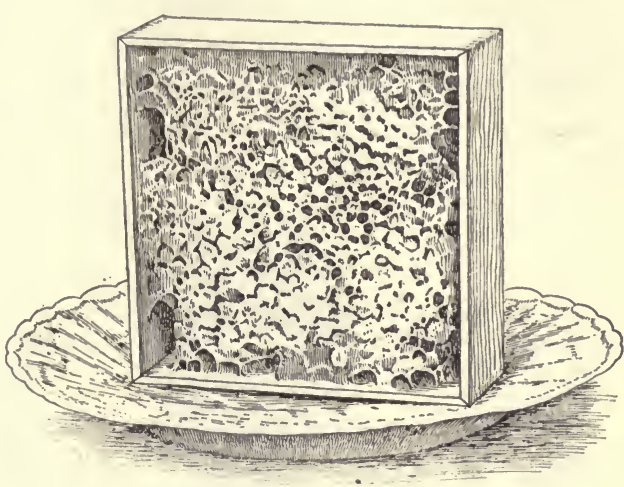

Fig. 8I. - A section-box filled with honey. factory. If one begins in the spring, there is the probability of an opportunity to increase the number of colonies through

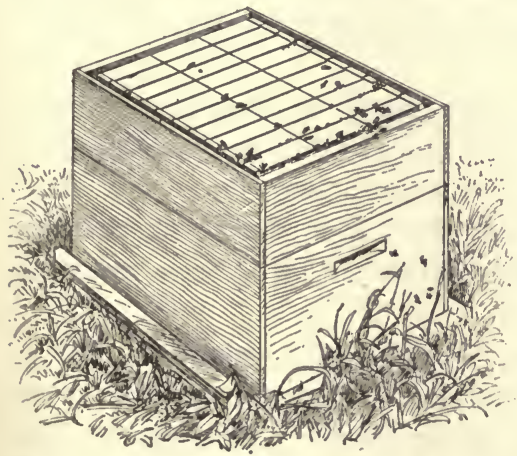

Fig. 82.- - One and a half story hive for combhoney; the super is filled with section-boxes. swarming. If they are watched, they may usually be induced to occupy another hive by proper handling. This swarming takes place in May and June.

The hive. . A hive consists of two parts. The lower portion, known as the brood chamber, contains the brood combs, in which the young bees are reared. The upper story is the super, in which are placed sections where the excess honey is stored. When these are 
filled (see figure 8I) they are sold as comb honey and replaced by other empty sections (see figure 80 ) or the honey may be extracted and the same section replaced. The hives should be placed where they are partially shaded. If no shade trees are near, artificial shade may be provided by erecting a wooden roof over the hives.

Wintering bees. The simplest way to winter bees is to use a chaff hive and allow them to remain outdoors. This hive has double walls separated by a few inches, the inter-
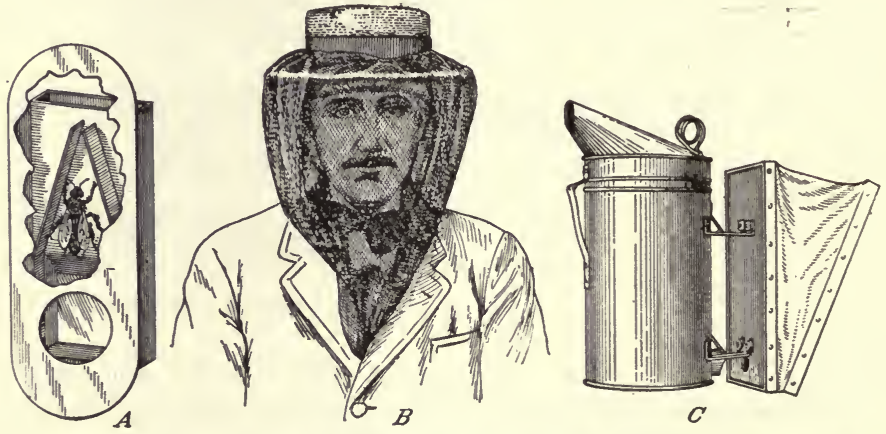

FIG. 83. - Appliances for keeping bees: $A$, bee-escape; $B$, veil; $C$, smoker.

vening space being filled with chaff or similar material. This tends to keep the hive warm in winter and cool in summer. The bees must also have sufficient honey or sirup stored in the combs to furnish them food during the winter. In the most northern states, however, the bees must be wintered indoors.

Kinds of bees to choose. With the improved strains of bees now used and with modern appliances there is very little chance of being stung while working with bees. The nervous and warlike black bees, which were formerly kept, have now been largely replaced by the much gentler Italians and Carniolans. So gentle are these that many beekeepers never use any protection while handling them. But one 
may handle any bees with no danger of being stung if he is provided with bee-gloves, veil, and smoker.

One of the returns from beekeeping is the opportunity afforded to study the interesting life of bees. This is even greater if an observation hive is used, which contains panes of glass set in the side, through which the activities of the bees may be watched. A door is arranged to cover this glass when the interior is not under inspection.

\section{SUPPLEMENTARY QUESTIONS FOR CLASS DISCUSSION}

I. What care do poultry require?

2. Which require more care, bees or poultry?

3. Which is more interesting, keeping poultry or keeping bees?

4. Which is better adapted to a small yard?

5. What habits of bees make them interesting to watch ?

\section{REFERENCES}

Maynard, The Small Country Place, J. B. Lippincott Co., Philadelphia.

Valentine, How to Keep Hens for Profit, Macmillan Co., New York City.

Comstock, How to Keep Bees, Doubleday Page Co., New York City. 


\section{CHAPTER XV}

\section{ATTRACTING BIRDS AROUND THE HOME}

I. Why is it desirable to have birds about the home?

2. What may be done to attract them there?

One thing that helps to make the home attractive is the presence of birds in the trees and on the lawn. If the conditions are favorable, some birds will come to the yard without effort on our part; but it is possible to increase very largely the number of birds around our homes by offering special inducements.

Reasons for attracting birds. There are two reasons why it is desirable to attract birds to our houses: first, because of the pleasure which they give on account of their attractive colors, pleasing songs, and interesting nesting habits; and second, because the birds will help destroy the injurious insects that attack the plants of the garden. The food of birds consists largely of insects, and if the birds are nesting in our yards, they will obtain these insects chiefly from the plants found growing there.

Bird music. Bird songs are attractive on account of their great variety and the melody of their tones. Some songs consist of a few simple, unmusical syllables, which so strongly resemble certain words that the birds have been named from them: such as the chickadee and bobwhite. On the other hand, some birds are wonderful songsters, and it is worth while to make an effort to hear them, just as one plans to attend a concert to hear a wonderful musician. Some 
of the birds which deserve special mention on account of the pleasing character of their songs are the house wren, the brown thrasher, the goldfinch, the song sparrow, the wood thrush, and the hermit thrush. Most bird students agree that the thrushes are the best songsters.

Spring is the season of bird song. The chorus begins in the early spring when the first birds return, and the climax is reached about the middle of May; and then the birds gradually stop singing so that the season is nearly over by the first of July.

The birds begin to sing at the earliest daybreak and the climax is reached at about sunrise; then the singing gradually becomes less till the morning chorus is over by the middle of the forenoon. There is another shorter period of singing in the late afternoon shortly before sunset.

\section{Field Exercise 4}

Purpose. To see how many birds you can recognize from their songs.

Directions. I. Some morning in May is the best time to study bird songs. Notice how the songs of birds differ. Which ones are especially musical? See how many birds you can recognize from the songs.

2. Note some of the following points for each song: $(a)$ whether varied or monotonous, $(b)$ loud or soft, $(c)$, high or low pitch, $(d)$ musical or unmusical.

3. Write the names of all the birds whose songs you know in the order of their attractiveness, putting the most pleasing first and the least pleasing last.

Nesting habits. The nesting habits of birds are so interesting that it is a pleasure to have birds around our home. The nests themselves are made of a great variety of materials and are found in a great variety of locations, on the ground, in bushes, in trees, in barns, and even in chimneys. It is interesting to notice the method by which birds build and 
shape their nests. The Baltimore oriole weaves its nest with its bill; the robin uses its breast to mold the shape of the nest.

Usually from three to six eggs are laid in the nest, and these hatch in about two weeks in the case of most of our common birds. The period that follows the hatching of the young is a most interesting time. One of the most remarkable features about the rearing of the young is the frequency of feeding. It is worth while to watch a nest for an hour and see how many times the young are fed. Another

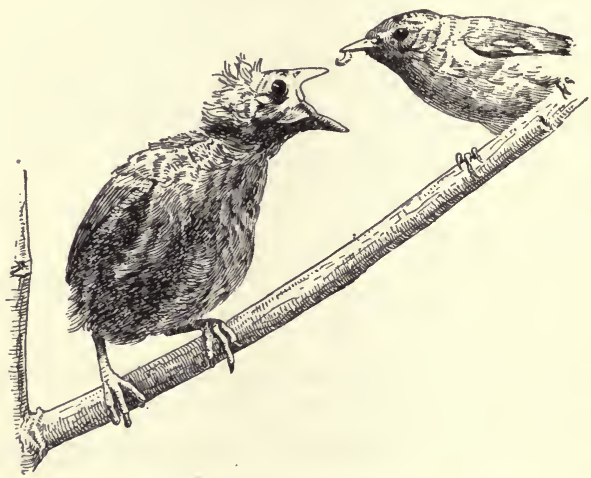

FIG. 84. - Redstart feeding young cowbird. interesting feature is to watch the parent birds teach the young birds how to fly and to feed themselves after they leave the nest.

The cowbird has the peculiar habit of laying her eggs in the nests of other birds. When these hatch they are reared by the foster mother the same as her own young. It is a curious sight to see a little mother feeding a young cowbird bigger than herself. (See figure 84.)

Four things may be done to attract birds : first, provide nesting boxes; second, feed the winter birds; third, provide fountains for drinking and bathing; and fourth, plant shrubs which bear fruit that is eaten by birds. The first is done in the spring, the third in the summer, and the second in the winter, so something can be done in almost every season of the year.

Providing nesting boxes. Some kinds of birds will build their nests in artificial nesting boxes put out for them. 
Whether any particular bird will do this depends on its natural nesting site; if it nests in a hollow $\operatorname{limb}$, there is a possibility that it may use a nesting box. A great many kinds of birds have been known to occupy these houses. The author has been able to list twenty-nine kinds of birds which have positively been known to use these boxes somewhere in the United States. The kinds which use them most commonly are the bluebirds, wrens, martins, tree swallows, and flickers. The martins have now become so accustomed to these artificial houses that they seldom nest anywhere else.

Houses to suit the birds. A great variety of houses can be made, all of which will attract birds. Wood is most commonly used. This may be ordinary boards or old weather-beaten boards. If new boards are used, they should be painted or stained green or brown, or else rubbed in mud so as to take off the new look. Pieces of slabs with the bark on make good material. Sometimes sections of hollow limbs may be found in the woods, or sections of small trees may be cut and the center hollowed out with augur or chisel. Tin cans, roofing paper, pottery, cement, and gourds may also be used.

The houses are made in a great variety of shapes. Sometimes attempts are made to imitate man's houses, but the ordinary box shape is probably as good as any. The size of the house depends on the bird that is to occupy it.

Birds may be conveniently classed in three groups according to the size of the house and entrance hole needed, as small, medium, and large. To the small group belong such birds as the wren and chickadee, which can use a hole too small for the English sparrow. To the medium group belong such birds as the bluebird and the tree swallow, which can use a hole too small for the starling. To the large group belong such birds as the flicker and red-headed woodpecker, which require an entrance of from two to three inches. 


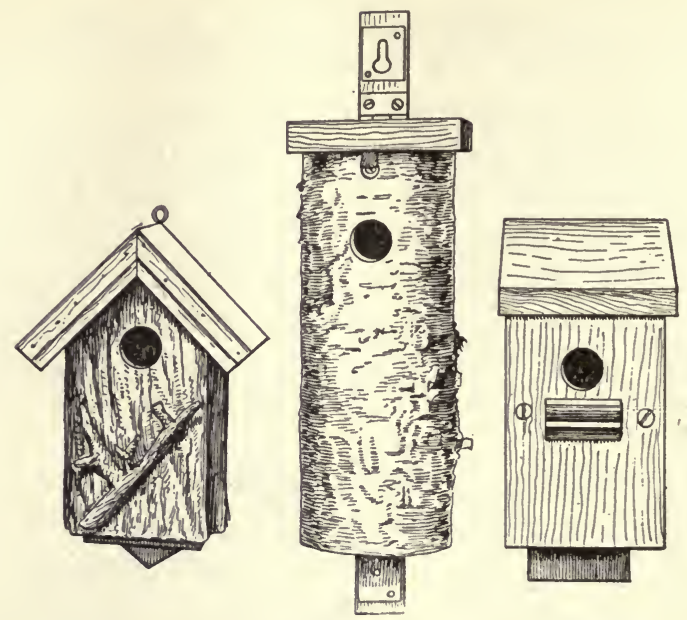

Fig. 85. - Three types of nesting boxes.

The following table gives a few essential points regarding the size of bird houses.

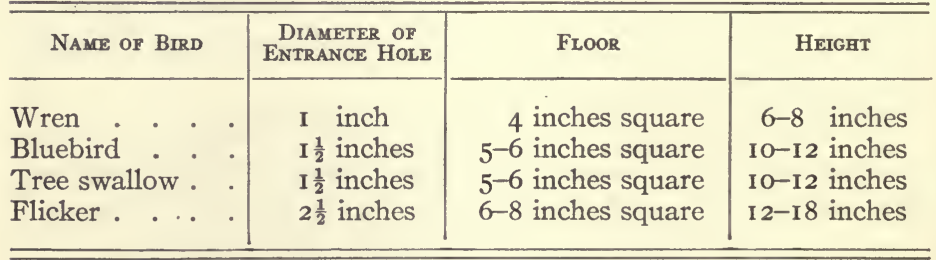

Bluebird. Below are given directions for building a house for a bluebird. This house seems to be the best type, although other types are frequently used by birds. The long dimension of the house should run up and down vertically. For the floor use a piece of board 6 inches square, for the back a piece 12 inches long, for the front a piece Io inches long, and for the sides two pieces $1 \mathrm{I} \frac{1}{2}$ inches long on one edge and $9 \frac{1}{2}$ inches long on the other edge. When 
these sides are nailed to the front and back, a space of $\frac{1}{2}$ inch is left at the top for ventilation. For the roof use a piece 9 inches long, so that it will project well out over the entrance. This roof should be fastened at the back with hinges and in front with a clasp. The entrance hole should be one and a half inches in diameter and should be bored in the front (the ro-inch board) 2 inches from the top. No perch should be provided.

The reasons for building the house this way are these. The purpose of having the long axis vertical, of having the hole near the top, and of having the overhanging roof, is to protect the young birds from cats. Cats climb up to boxes and try to claw out the young birds by reaching down through the hole. In this type of house, it is almost impossible for a cat to reach down to the young birds. Moreover, this style of house prevents the young from leaving the house till they are well matured, and better able to care for themselves and to escape such enemies as cats and squirrels. If the hole is too low down, the young birds may fall out before they are old enough to leave the nest. The house should be made with a movable roof, so that each spring all the material in the house may be cleaned out, and in case English sparrows begin to use the house, their eggs may be removed. The perch is omitted because the native birds do not need it, and it furnishes an opportunity for the English sparrow to stand and fight the birds that are using the house, even when the hole is too small for the sparrow to enter.

House wren. The house wren will use a great variety of boxes. The entrance should be $\mathrm{I}$ inch in diameter. A very satisfactory house can be made from an old tomato can. In the open end is fastened a circular piece of wood with an opening of I inch in the upper third. The author kept one of these houses in his yard for four successive seasons, during which time five broods of wrens were reared in it. 
Martin. While most birds prefer a house with a single apartment, the martins prefer to live together in colonies; so that for them houses are made with a number of rooms. Each dimension of the room should be 6 to 7 inches. The

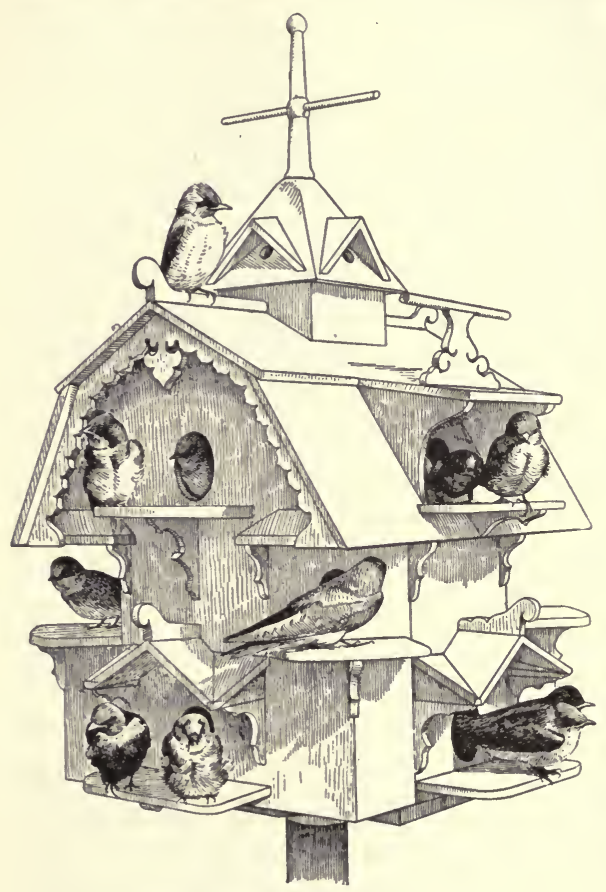

Fig. 86. - A martin house. opening should be about $2 \frac{1}{2}$ inches across.

Putting out the house. In putting out the house one needs to consider five things: the time, the location, the height, the method of fastening, and the protection from enemies. The house should be put out early in the spring just before the bird is expected to return. Bluebirds and wrens both rear two broods; so that houses put out in the late spring may be in time for the second brood.

Houses should be placed out in the open, for birds will not use them so frequently if they are placed in the dense shade. Telephone poles and grape arbors make good situations. Houses may also be placed on trees if they stand out by themselves, separate from other trees. The best height for the house is 8 to I 5 feet. The house should be fastened so that it is secure against the winds, but so that it can be easily taken down and cleaned. Some have a 
screw eye, a loop of wire, or hole in the back, which can be placed over a hook; some have an extension of the back by means of which it can be screwed or nailed up; and others are suspended by wire so as to swing in the wind.

Protection from cats. Two enemies of our birds are unfortunately very common, the cat and the English sparrow. The birds can be protected from the cat to some extent in

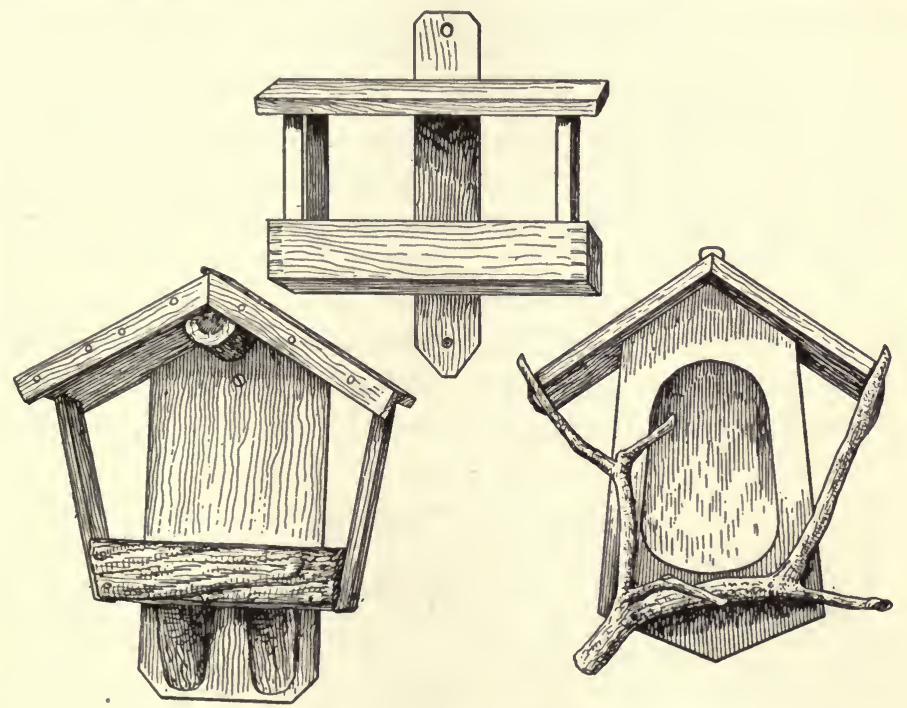

Fig. 87.- Open nesting boxes.

the construction of the house, as already explained. Still further protection may be given when the house is put up. A piece of zinc or tin about 2 feet wide may be wrapped around the tree or post 4 feet from the ground and fastened. Another method of protection is to fasten the boxes to the top of posts by means of iron bands two feet long.

Protection from English sparrows. The wren may be protected against the English sparrow by making the hole so small ( $I$ inch) that the sparrow cannot enter. In the 
case of houses for the bluebird, which have a hole large enough for the sparrow, the best thing to do is to make the house with a movable cover and remove the sparrow's eggs about once a week. Oftentimes this will drive sparrows away.

Open houses. Other birds which do not nest in cavities will sometimes build their nests in a box, open on three sides like a porch. (See figure 87.) These houses consist of a floor from 6 to 8 inches square with a roof held up by posts at the corners, or the back may be a solid board, leaving three sides open. Birds which have been known to occupy these houses are the robin, phœbe, song sparrow, and catbird. These houses should be put up in locations where these birds usually nest.

All types of houses referred to can be easily made with the simplest tools; but if one wishes to buy these houses they can be procured from various dealers at prices ranging from 50 cents to 2 dollars apiece.

\section{LABOratory Exercise 25}

Purpose. To study some types of bird houses.

Apparatus. Collection of types of bird houses showing adaptations to different birds.

Directions. I. For each house studied notice (a) size, (b) shape, (c) size and location of entrance hole, $(d)$ means of fastening. Make a drawing of each box.

2. Taking the boxes together as a group, notice the chief differences. Are there any respects in which all agree? Which do you consider the best house? Why?

\section{Home Project 26}

Purpose. To make a nesting house to put in your home yard.

Directions. I. Find out which birds that use nesting boxes are most common around your home, and make a nesting box for them. Look up-some bird books so as to find the kind of 
house best adapted for this particular bird. Then put it up in the most suitable place in your yard.

2. If the house is occupied, the following observations may be made: bird using box, date nest begun, date young hatched, date young left nest, number of times young fed in an hour, time of day birds begin to feed young, time of last feeding, kind of food brought, division of work between father and mother.

\section{School Project 7}

Purpose. To put up nesting boxes in the school yard.

Directions. If the schoolhouse is so located that birds are found there, and if there are good opportunities for putting up bird houses, the class may arrange to build a few houses and put them on the school ground.

Providing nesting material. Still other birds may be attracted around our homes by putting out materials that birds use in making their nests. Among the best materials to put out are yarns (in pieces about a foot long), strings, horsehair, small strips of cloth, cotton batting, and shoemaker's flax. Such birds as the oriole, chipping sparrow, robin, and others may use them.

Feeding winter birds. During the winter when snow covers the ground, it is difficult for birds to obtain food. If food is plàced out for these birds, they will come very close to the house, even to the window sill, where they can be watched from just inside the window. Among the more common birds which come around the house to feed are the woodpeckers, the chickadee, the nuthatch, the bluejay, the junco, and tree sparrow. These birds, especially the chickadee, often become sufficiently tame to foed from the hand.

Kinds of food. Birds may be divided into two groups according to their food, into seed-eating and insect-eating birds, although many eat both seeds and insects. The best 
food for the insect-eating bird is suet. The best foods for the seed-eating birds are sunflower seeds, hemp, millet, nuts, grains, and crumbs.

Methods of offering the food. Food may be put out in a great variety of ways: on the ground, on shelves, in suet
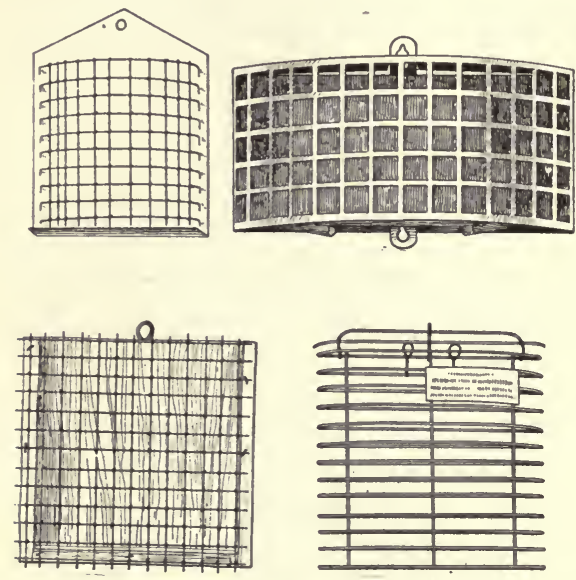

FIG. 88. - Suet baskets. baskets, in automatic hoppers, on a moving counter, or in Audubon and weathercock food houses. One of the simplest ways to put food out is to trample down a spot in the snow and scatter out crumbs and grains.

Various kinds of shelves may be used. They may consist simply of a board, with a narrow strip around the edge, which may be fastened to a tree or post, or be placed on the window sill. A suet box can easily be made. A piece of board 5 or 6 inches square serves as the back. Around two sides and the bottom of this are nailed strips about $\mathrm{I} \frac{1}{2}$ inches wide. Over this is fastened a piece of hardware cloth or of poultry netting with small meshes. This may be suspended by means of a screw eye at the top. Suet may also be fastened on a branch by tying a string around it.

Automatic feeders on the principle of poultry hoppers can be bought or easily made. (See figure 89.) The large hopper is filled with seeds and grain, which come out of a small opening at the bottom leading to a shelf. As fast as the seeds are eaten, others fall down to take their place. 
A moving counter may be arranged on a pulley running on a wire, which may be fastened between a second story window and a neighboring tree. A string may be fastened to this so that it can be kept in any position desired.

Dealers in bird appliances sell what are known as the weathercock and the Audubon food houses. The first is a box open on one side and placed on a pivot so that it swings with the wind, keeping the open side away from the wind and thus protecting the birds. The Audubon food house has panes of glass around the sides to protect the birds from storms and an en-

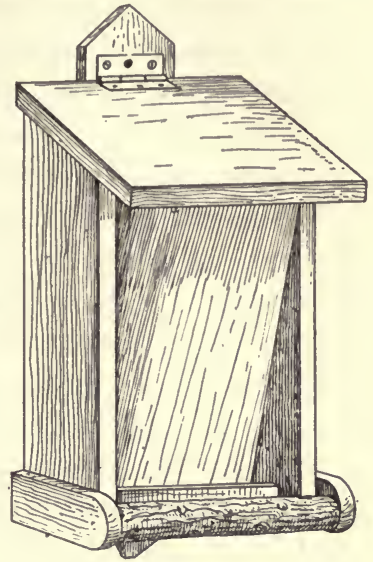

FIG. 89. - Bird feeder. trance from underneath by which the birds come to the food placed behind the glass.

\section{Home Project 27}

Purpose. To feed the winter birds.

Directions. I. If winter birds are found around your home, begin in the late fall to provide them with food. A suet box, as explained in this chapter, can be easily made, also a feedery can be made out of wood similar to the automatic hoppers used for poultry. See that these devices are kept constantly supplied with food.

2. Interesting studies of the birds that come to feed may be made in accordance with the following outline.

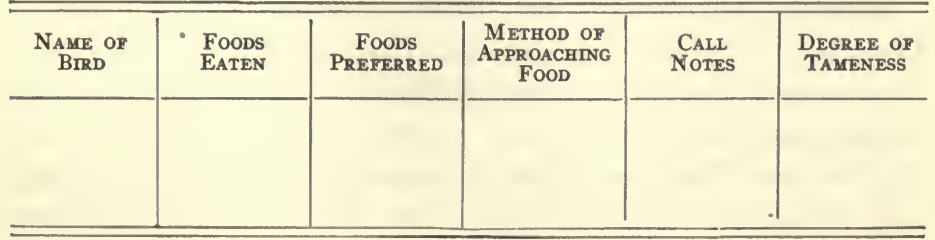


Bird fountains. Birds use water for two purposes: for drinking and for bathing. In constructing a fountain, two things should be kept in mind: first, the edge and bottom should be made of roughened material, so that the bird will not slip; second, the water should be shallow, not exceeding three inches. Simple bird baths may be made of such receptacles as large flowerpot saucers and ordinary pans.

The fountain should be placed in such a location that no cats can lurk near in shrubbery to jump out at the birds. The fountain may be raised on a pedestal.

One of the most successful types of fountain is made of cement and sunk in the ground. A hole about 3 feet across is dug out, gradually sloping from the edge to a depth of about 5 inches in the center. This is plastered over with a mixture of Portland cement and sand, thick enough to leave the center 3 inches deep and slope gradually from there to the edge. If it is impossible to supply running water, these fountains may be cleaned out once a week with a broom and new water added.

\section{Home Project 28}

Purpose. To provide water for the birds.

Directions. If there are no opportunities for birds to find water around your yard, a fountain may be the means of attracting many birds that you will enjoy watching. This will afford opportunity to see birds during the summer when they are quiet and retiring. As already explained in this chapter, very simple devices, such as ordinary pans, may be used. The water should be changed occasionally so as to keep it clean and cool.

Planting shrubs for the birds. Shrubs furnish nesting sites for birds, and many bear fruit which the birds eat. In planning the home grounds, some shrubs may be used which bear these fruits; and as some hold their fruit during the winter, they serve too as a means of ornamentation. The birds which feed largely upon wild fruit are the cedar 
waxwing, robin, catbird, fox sparrow, flicker, grosbeak, and bluebird; and there are a number of others which feed to a lesser extent on wild fruit. The fruits most commonly eaten are those of the elder, mulberry, dogwood, wild cherries, bayberry, and Juneberry. The mulberry is one of the best plants to set out and this serves as a protection to cultivated fruit, as some birds eat the mulberry in preference to cultivated fruit that may be growing near.

Domestication of wild birds. Considerable progress has been made in recent years in the domestication of wild birds. The greatest success has been achieved in rearing the mallard duck, bobwhite, and pheasant. Some strains of the mallard duck have been thoroughly domesticated and the rearing and selling of these birds is coming to be an industry somewhat similar to poultry raising. In many states there are game farms on which wild birds are reared.

\section{SUPPLEMENTARY QUESTIONS FOR CLASS DISCUSSION}

I. What things must one take into account in building a bird house?

2. Which is the best type of house?

3. How should a house be put out?

4. How may birds be protected from the cat and from the English sparrow?

5. Which method of attracting birds will give the greatest pleasure?

6. Which is the best way of putting out food for the winter birds?

7. What should one consider in making a bird fountain?

8. What benefit will the birds derive from the things we can do to attract them around our homes?

\section{REFERENCES}

Baynes, Wild Bird Guests, E. P. Dutton Co., New York City. Trafton, Bird Friends, Houghton Mifflin Co., Boston. Chaps. 



\section{PART II}

SCIENCE OF THE COMMUNITY 

SECTION A

Means of Travel

\section{CHAPTER XVI}

\section{THE LOCOMOTIVE}

I. What part do locomotives play in the life of the community?

2. How is a locomotive constructed and how does it work?

Travel in early days. When the white settlers first came to this country, there was no need nor any means of travel outside of their little village. Later, horses were brought over from England, and, as different colonies were established, travel by horseback became common. Still later the paths were widened to roads, and the stagecoach became the means of fast travel. Finally this was replaced by the locomotive.

Uses of locomotive. The locomotive plays a very important part in our daily life. Not only does it enable us to travel quickly and comfortably from one place to another, but it brings to us most of the necessities of our daily life. Many of our foods are brought from long distances by means of the locomotive. Oranges are brought from California, early strawberries from Florida, sugar from the southern states, flour from the flour mills of Minneapolis, meat from the stock yards of Chicago. If we should make a complete list of all the kinds of foods we eat, we should find that the 
great majority, excepting a few fruits and vegetables raised locally near our towns, have been brought to us in some part of their journey by means of the locomotive.

It is the same with reference to our clothing. The wool, after being sheared from the sheep, was first taken by locomotives to factories, where it was spun into cloth; it was then taken again by locomotives and carried to other factories, where it was made into clothing; then brought to our town, where we finally bought it. Our cotton clothing was made from cotton which was carried from the cotton fields in the south to the mills by the locomotive. It was made into cloth, and then taken to factories where it was made into various articles which were brought to the store and put on sale. The locomotive played an important part several different times during this process.

The coal that keeps us warm in the winter has been brought to us from the coal fields by the locomotive. The newspapers, magazines, and books, that are so important in our life, are brought to us by the locomotive. On the payment of two cents for a postage stamp, a letter is carried for us across the continent by the locomotive, and in a few days an answer is brought back.

Indeed if we think over carefully the things that enter into our daily life - the house in which we live, the rugs upon the floor, the furnishings inside, the piano, the phonograph, and other necessities and pleasures of life - we shall find it difficult to name anything which the locomotive has not either directly or indirectly helped bring to us.

Locomotives and suburban homes. Another benefit of the locomotive lies in the fact that it has increased greatly the distance that a man may live from his place of business in the great cities. In great centers of population, like New York and Chicago, thousands of business men may do their business in these cities and at night return to their homes, miles away in small suburban towns. This enables 
a man to combine the advantage of country life for himself and family with the advantages of a central location for his business office.

Locomotives and growth of the United States. The locomotive has had a tremendous influence on the development of the United States. As we think of the vast reaches of plains and the great chains of mountains extending across our country, we can readily appreciate how slow must have been the growth of the country without the aid of the locomotive. Many parts of the country which now support a prosperous population would not even be open to settlement had it not been for the locomotive.

Locomotive and travel. The locomotive has made travel easy and cheap, so that while a century ago few people traveled beyond the confines of their own town, to-day it is common for people to travel over all parts of the United States. The knowledge gained of how other people live has a broadening influence and tends to produce a feeling of toleration for others, and travel thus results in more harmonious coöperation between different sections of the country.

History of steam engine and locomotive. The steam engine and locomotive play so important a part in our lives to-day that it is difficult to see how we could get along without them; and yet the railroads in this country have all been developed within the last hundred years. It will be interesting to look at the history of the steam engine and locomotive and see the changes through which they passed while developing their present form.

The first steam engine was made in I 20 B.c. by Hero of Alexandria in Egypt. This was so arranged that steam in escaping from small tubes on a flask caused it to rotate in much the same way that a lawn sprinkler revolves when water is forced from it. The device was only a toy, and no useful application was made of it. 
It was a long time after this, about I 700 years, before any further thought was given to the principle of steam engines. In 1629 an Italian named Branca described an engine which was driven by steam driving directly against paddles on a wheel, something like a water wheel. In 1663 , a real steam engine was built in England, which was actually made useful in lifting water from the mines. About seventeen years after this the first safety valve was invented.

Newcomen's engine. In I705 Thomas Newcomen constructed a steam engine that was a great improvement on anything that had so far been made. It consisted of a steam boiler and a cylinder in which moved a piston head. The steam forced this head to one end of the cylinder, and then, by turning a valve by hand, a spray of cold water was led into the cylinder. This condensed the steam and formed a vacuum, and the atmospheric pressure forced the head back. Thus the pressure of the steam forced the piston head in one direction and the weight of the air forced it back. This machine had to be watched and the valves turned at the end of every stroke. It has sometimes been called an atmospheric engine.

James Watt. The next great improvement was made by James Watt during the latter half of the eighteenth century. He invented a device by which the motion of the engine adjusted valves automatically in such a way that the steam was taken in turn to each end of the cylinder, so that the piston head was moved in both directions by steam pressure instead of in only one direction as in the Newcomen engine. The steam engine of to-day is essentially in principle the same as the one invented by James Watt, except that there is now being used for some purposes a different type of engine called the turbine. But in the locomotive the Watt type of engine is still used.

First locomotive. The first locomotive was invented by an Englishman named George Stephenson. In I8I4 he 
made a successful trip hauling coal cars at the rate of four miles per hour. The first commercial railroad to carry passengers and freight was built between Stockton and Darlington, England; and on the day of its opening, in 1825 , the

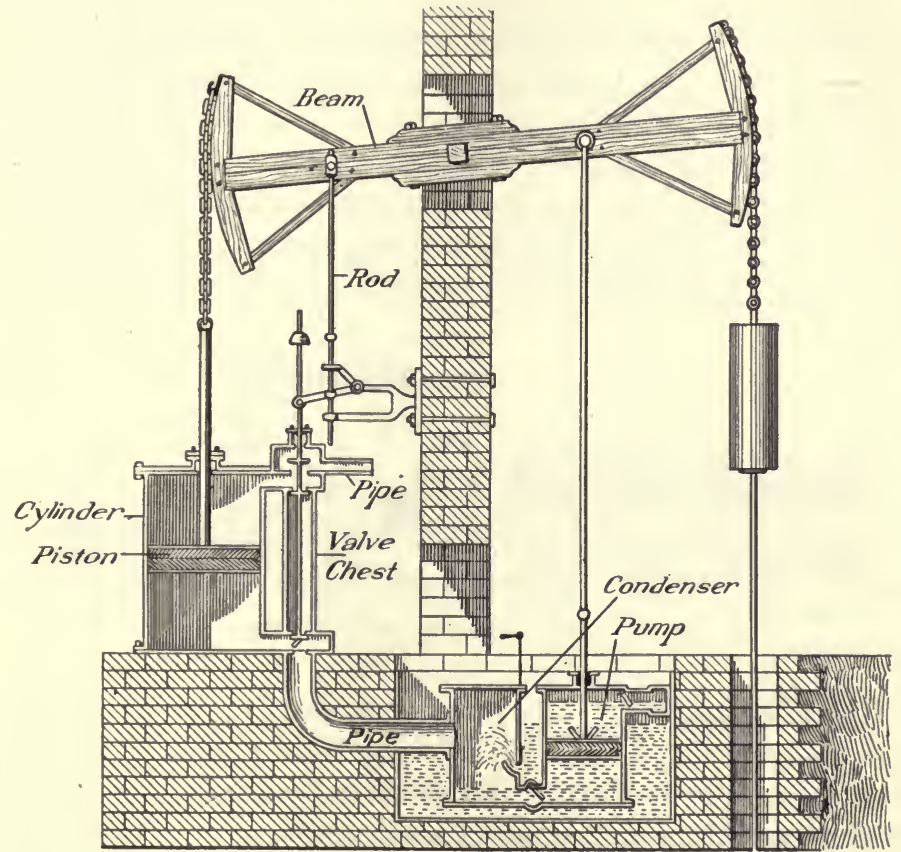

FIG. 90. - Watt engine.

engine was driven at the rate of 15 miles an hour. From this date the future of the locomotive was assured.

The first locomotive was used in this country in 1829 . After that railroads developed very rapidly in the United States, many miles being built each year. In 1849 the first continuous line between New York and Boston was completed. In 1869 the first line connecting the Atlantic and Pacific coasts was finished, and now the railroads form a 
network over the whole country. The older forms of travel, by horseback and stagecoach, have gradually become of less importance, and the railroad has now become the chief means of long distance travel.

Having learned something about the important part that the locomotive plays in everyday life and something of its history, let us now study a modern locomotive to see how it is built and how it works.

Parts of a locomotive. The locomotive consists of three essential parts: first, the fire box and boiler, that generate power; second, the cylinders and their valve gear, that use the power; and third, the wheels on which the locomotive moves.

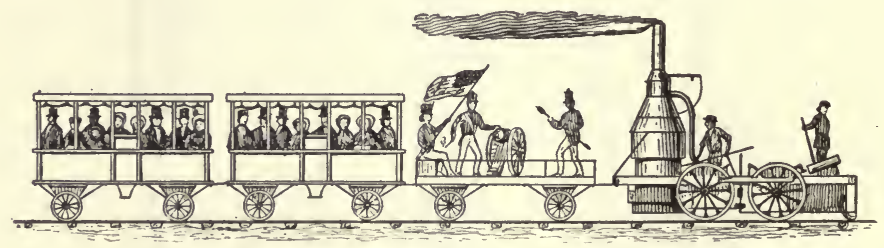

FIG. 9r. - First locomotive in United States.

Boiler and fire box. The purpose of the fire box and boiler is to convert large amounts of water into steam in a short time. In order to do this, there must be a large amount of heating surface, with heat on one side and water on the other, so that large quantities of water will be in contact with the heated surfaces. There is a direct heating surface on the boiler immediately over the fire box, and in addition to this there is the indirect heating surface made by using small tubes about two inches in diameter, to carry off the heated gases from the fire box to the smokestack. About 200 of these tubes run through the boiler and are surrounded with water. By means of these tubes a heating surface of 2500 square feet may be obtained, that is, equal to an area 50 feet square. 
Water gauge. The boiler has attached to it a water gauge, a steam gauge, a safety valve, and an injector. The water gauge is a glass tube placed on the outside of the boiler, so that the height of water may be determined by looking at this gauge.

Steam gauge. The steam gauge is a device for recording the pressure of the steam in pounds. It is so arranged that as the pressure increases, a hand on a dial rotates, much like the hands on a clock; and the pressure is read from the figure to which the hand points.

Safety valve. The safety valve is a device for allowing the steam to escape when a certain pressure is reached, so

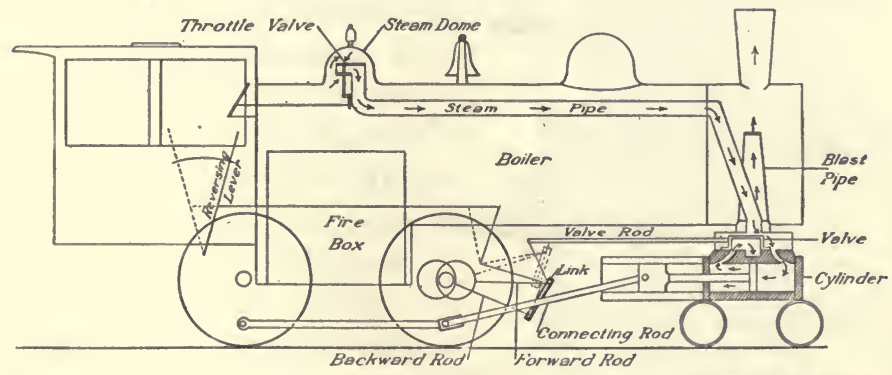

Courtesy of Harper \& Brothers

Fig. 92. - Parts of a locomotive.

as to prevent the possibility of an explosion occurring in the boiler. This valve fits into a hole in the boiler; it consists of a tight-fitting plug, which is kept in place either by a spring or by a lever with a weight attached to it. The tension of the spring or the weight can be adjusted to allow the steam to escape at any desired pressure.

The injector is a device which fills the boiler with water; this is operated by steam pressure.

Fuels. Coal is the fuel generally used. The draft is increased by allowing the exhaust steam to pass into the smoke box; and as this is under considerable pressure, it rushes out of the box, creating a partial vacuum. As a result, 
air is drawn in through the pipes and fire box, thus making a draft. Some engines are so built that they use liquid oil instead of coal. This is forced in the form of a fine spray into the fire box, where it burns quickly.

Cylinder and valves. The parts so far described are used to convert water into steam. The rest of the engine converts the energy into the motion of the wheels. The steam is led from the boiler into the steam chest $S$ (figure 93). From here two openings $p$ and $p^{\prime}$, called ports, lead to the

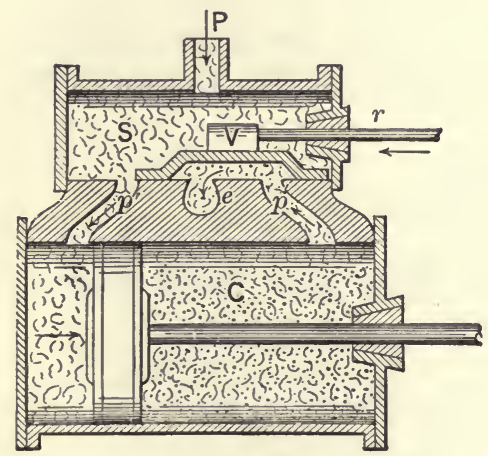

FIG. 93. - Cylinder and steam chest of steam engine. cylinder $C$. Over these openings is the slide valve $V$, with its under surface hollowed out. This valve is connected with an eccentric. In the cylinder is a piston connected on the outside by means of a connecting rod with the drive wheel of the locomotive.

When the steam enters the chest $S$, it passes through $p$ or $p^{\prime}$ and enters the cylinder $C$, pushing the piston to the other end of the cylinder. This turns the wheel, which moves the eccentric, and this moves the valve $V$ in such a way that the port $p$ is closed and the port $p^{\prime}$ is opened. Thus the steam enters through this opening and pushes the piston back, and the steam in the other end of the cylinder is forced out through the opening $p$, and then through the exhaust $e$ to the outside.

Eccentric. The eccentric consists of a circular plate mounted on the crank shaft. The opening in this plate is not at the center, but at one side, so that as the shaft revolves, it gives a slight motion to the eccentric rod, similar to that given by a small crank, and this rod in turn moves 
the slide valve. These parts are so adjusted that the slide valve covers and uncovers the openings at just the right time to allow the steam to enter each in turn. Two eccentrics are provided for each valve, one for the forward motion when the locomotive is going ahead, and another for the backward motion when the locomotive is going backward. The link. (See figure 92.) One very important part of the mechanism is the link, which consists of a curved piece of steel, the ends of which are connected with the eccentric rods. This serves two important uses, it enables the engineer both to reverse the engine and to control the amount of steam that enters the cylinder. When the engineer wishes to reverse the engine, he throws over a lever which is connected with the link, and this moves the slide valve in such a way that its position is quickly changed, so that the piston is made to move in the opposite direction.

Another purpose served by the link is to enable the en-

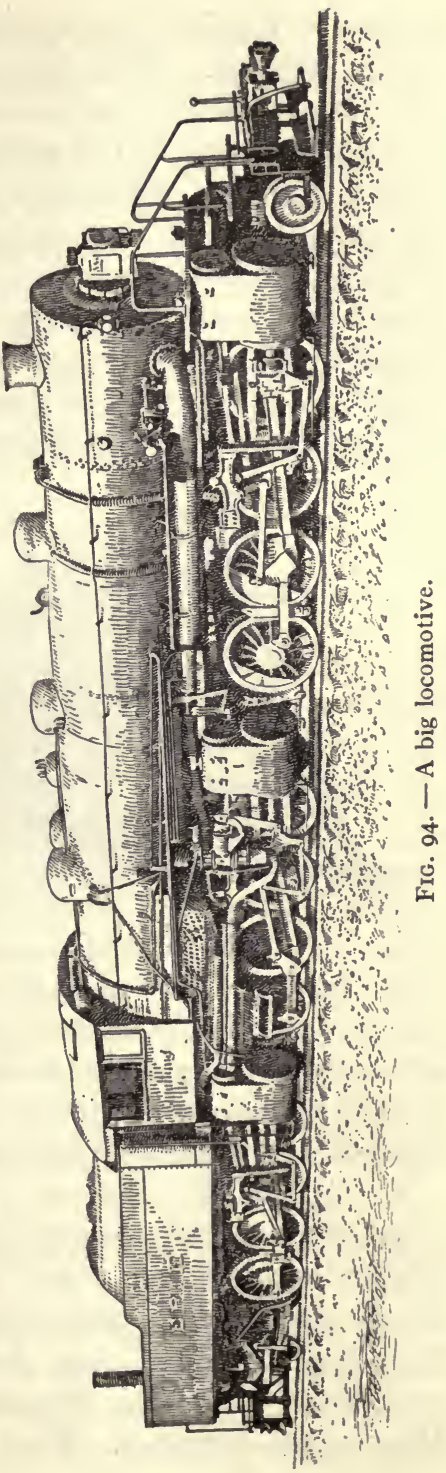


gineer to regulate the amount of steam that is admitted to the cylinder. When the train is starting, a large amount of power is needed, and so steam is admitted during nearly the whole length of the stroke of the piston. As the train gets under way, the steam is admitted for a shorter and shorter portion of the stroke, until when under full headway only a small amount of steam is admitted. When the lever is set in the center no steam at all is admitted to the cylinder; then the locomotive goes on its own momentum.

The most common method of controlling the motion of the link is by means of a lever in the cab, which is worked

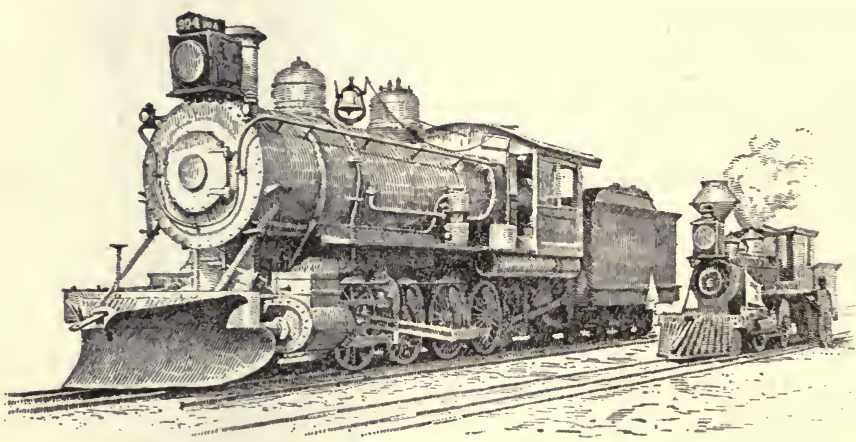

Fig. 95. - Thirty years in locomotive building.

by hand and held in place by means of a spring clip fitting into notches. In some locomotives a wheel and screw gear is used in place of the lever. In still other cases the reversing gear is operated by means of compressed air.

Driving wheels. The motion of the piston rod is communicated to the locomotive by means of large driving wheels, varying from 5 to 7 feet in diameter. In the first locomotives built, a single pair of drivers was used; but in later types two and even three driving wheels are used on each side, these being joined by means of a shaft so that they rotate together. This gives more points of contact 
with the rail, and so there is less slipping when the train starts. This allows better time to be made when there are frequent stopping places.

When the piston rod is in line with the center of the driving wheel, it has no driving force and is said to be at dead center. The wheels on the two sides of the locomotive are so arranged that when those on one side are at dead center, those on the other side receive the maximum driving power of the piston. Speeds of more than a mile a minute have been maintained for a period of eight hours. For short distances, rates of over 90 miles an hour have been made.

\section{LABORATORY EXERCise 26}

Purpose. To study the parts of a steam engine.

Apparatus. Model of steam engine or toy engine.

Directions. Operate the model and notice carefully how each part works. Make a drawing and label the parts. By means of arrows show the path of steam. Explain the use of each part.

\section{Field Exercise 5}

Purpose. To see how the locomotive works.

Directions. I. If there are locomotive shops in town, arrange with the superintendents to visit them with the class. Or arrange with some engineer or fireman to explain to the class the working of the locomotive (during the stop of the locomotive at the station). Notice also the operation of the brakes. Have some of the station men explain the operation of the block signals.

2. It may be possible also to visit a stationary steam engine in some power house in town.

Brakes. Modern trains are supplied with powerful brakes, which make it possible to stop the train quickly. One of the most common types is the Westinghouse brake, which is worked by compressed air. On the engine is a tank kept filled with compressed air under high pressure. Under each car is a smaller tank connected by a pipe with the main tank 
in the engine. On each car connected with the tank is a cylinder provided with a piston which connects with a brake. The engineer is able to control the working of all the brakes, and by turning a cock the compressed air is caused to enter each cylinder, pushing out the piston which sets the brakes.

Railway signals. In order to lessen the possibility of accidents various systems of signals are used so that the engineer may know whether any other trains are near his. The railroad tracks are divided into blocks, or sections, of a few miles in length. At the beginning of each block are signals, used to indicate whether any train is in that block. No train is supposed to enter a block till the previous train has left it. Levers are attached to posts by the side of the track, and by their position they indicate whether a train is in the block. These levers may be operated by signal men, or automatically by electricity. The weight of the train on the rails closes a circuit, which operates the signal. On a double-track road, the engineer is concerned only with those trains which are going in his direction, but on the single-track road, he is also concerned with those coming from the opposite direction.

Train dispatcher. The trains are controlled by a train dispatcher, who is connected by telegraph with every railroad station. He keeps a careful record of the position of every train. The telegrapher at each station informs the dispatcher when each train leaves his station. Ordinarily the trains run on a scheduled time, and each engineer and conductor knows where he is expected to be at any given time and what right of the road he has. But when a train becomes delayed, the schedule is interfered with, and the trains are then run by special word from the dispatcher, who sees that proper places are assigned for meeting other trains, with as little danger and loss of time as possible. These orders for the trainmen are telegraphed to the telegraphers at the stations and given by them to the conductor. 
Uses of the steam engine. We have referred to one common application of the steam engine, that is, in the locomotive. But we are also indebted to the steam engine for many other services. The great dynamo which generates electricity for lighting our homes and streets and for running the electric cars is usually turned by a steam engine.

Other applications of the steam engine are seen in factories, where it is used to run the machinery. The great majority of the common things that enter into our everyday life are factory made. Our clothing is made from thread woven or knit in mills. Many of our foods have passed through some process in a factory. The shingles and boards in the hou'ses that furnish us shelter have been prepared in mills run by steam engines. The furnaces and stoves that warm our homes have come from the factory. The furniture in our homes, the rugs on the floor, and the curtains at the window have, somewhere in their process of manufacture, been fashioned by machinery run by a steam engine. The books and magazines that we read and the paper that comes to our doors daily have been printed on presses operated by the steam engine.

In some cases water falls and electricity furnish the power to run the machines of the factory; but in most cases, the electricity is generated by steam power, and the steam engine is by far the most common source of power used in factories.

\section{SUPPLEMENTARY QUESTIONS FOR CLASS DISCUSSION}

I. What do you consider the most important use of the locomotive?

2. Compare the methods of traveling from Boston to Washington used roo years ago with the methods used now.

3. What was Watt's contribution to the steam engine?

4. What are the methods used for generating steam in a locomotive? 
5. How is the energy of the steam converted into the motion of the wheels?

6. What are the uses of the link?

7. What precautions are taken to prevent accidents on railroads?

\section{REFERENCES}

Cressey, Discoveries and Inventions of the Twentieth Century,

E. P. Dutton, New York City. Chap. I2.

Doubleday, Stories of Inventors, Doubleday Page Co., New York City. Pages $5 \mathrm{I}-67$.

Harpers' Machinery Book for Boys, Harper Bros., New York City. Chap. 7.

Howden, Boys' Book of Locomotives, McClure Co., New York City.

Williams, How It Works, T. Nelson and Sons, New York City. Chaps. I and 2. 


\section{CHAPTER XVII}

THE ELECTRIC TROLLEY

What part does electricity play in the running of the trolley?

Uses of electric cars. One of the most recent developments in modern means of travel is the electric trolley and it has grown rapidly in popularity. Almost every city now has its system of electric cars, and in the more thickly settled portions of the country, a network of these lines connects the larger cities. The trolley is taking the place, to some extent, of the steam cars. It has one great advantage over the steam cars in that no special roadbed need be constructed, as the rails can be laid up hill and down, on roads already constructed or across country. This makes the cost of construction very much less. In some localities trolleys are being constructed through regions of beautiful scenery, and the trolley is a source of much pleasure during the summer months, as well as an important business necessity at all times of the year. Like the railroad the electric car widens the residential area about a big city and enables business people to find pleasant homes in the suburbs.

History of electric cars. Crude forms of electric cars were made many years before they became a practical success. In 1835 Thomas Davenport of Vermont constructed a small circular railway at Springfield, Mass., on which he operated a car driven by a motor. This was probably the first electric car ever built. Following this, other inventors at various times made different forms of 
electric cars; but the first practical electric locomotive was made by Doctor Siemens. This was exhibited at the Industrial Exposition in Berlin in 1879. - It attracted a great deal of attention, and inventors from various parts of the world began to devote more time to perfecting an electric car; so that from this may be said to date the development

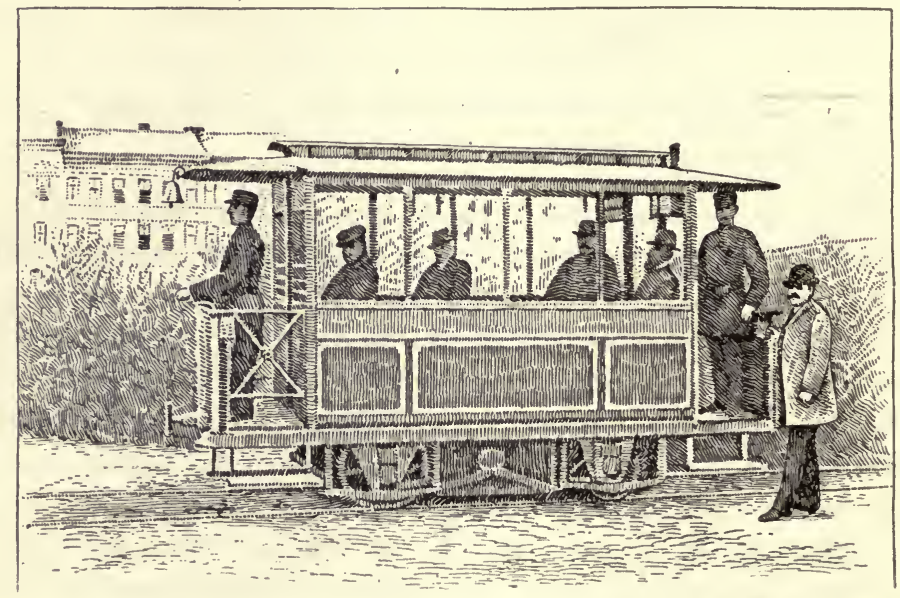

Courtesy of Harper \& Brothers

Fig. 96. - The first electric railway.

of the modern electric car. Improvements in the dynamo and motor have made the perfection of the practical trolley car possible.

First electric car. Shortly after this Exposition, the first commercial electric railway in the world was constructed in Germany between Berlin and Lichterfelde, a distance of about a mile and a half. For this purpose an old horse car was used and converted into an electric car by mounting a motor between the axles.

Electric cars in America. In this country special attention was given to electric cars by Stephen Field and Thomas Edison. In I88 I each constructed a short electric railway, 
Field in Stockbridge, Mass., and Edison in Menlo Park, N. J. In 1883 an electric railway was constructed at the Chicago Railway Exposition. The electricity was conveyed to the motor by means of a central rail. The first commercial electric street railway in this country was constructed in $188_{5}$ between Baltimore and Hampden, Md., a distance of two miles. Since that time many improvements have been made in the electric car, and it has advanced with rapid strides, until now the trolley is a common sight in all parts of the United States. A few figures will give some idea of this wonderful growth. In 1885 there was one electric railway in the United States; in 1890 there were 144 ; in I9I5 there were 1027 electric railway companies, 46,500 miles of track, and 79,000 passenger cars.

The mechanism of the trolley car. We may now attempt to understand some of the principles that underlie the working of the trolley car. If we take into account all the details, it is a very complicated piece of mechanism, but some of the simpler facts regarding it can be easily understood. As electricity is needed to run the trolley car, let us first notice how this electricity is made. This takes us first to the power house.

Dynamo. The dynamo is the machine by means of which electricity is generated. It consists of two essential parts, an armature and a pair of field magnets. The armature consists of a coil, or series of coils, of wire and is placed between two field magnets. The armature is so mounted on an axle that it rotates between the magnets. Magnets have power to attract iron, and if iron filings are scattered over a bar magnet they will arrange themselves in regular lines. When the armature revolves between the magnets, it is cutting across the lines of force running out from these magnets, and as a result an electric current is set up along the wire. By means of proper connections this current may be led out and carried away by wires. Two kinds of current 
may be produced by these dynamos, the alternating current and the direct current. In alternating currents the direction in which the electricity is passing changes with each half revolution of the coil of wire. In direct currents the current is passing in the outside circuit in the same direction all the time.

In order to produce strong currents, very powerful electromagnets are used with many coils of wire in the armature. It does not matter whether the magnets are stationary and the armature revolves, or whether the armature is stationary and the magnets revolve. Dynamos of both forms are used.

\section{Demonstration ig}

Purpose. To illustrate the principle of the dynamo.

Apparatus. Galvanometer, bar magnet, primary and secondary coil (the inner one removable), wire.

Directions. Connect a coil of wire with a galvanometer. Thrust a bar magnet into the center of the coil and watch the needle. After the bar comes to rest, is there any current? Remove the magnet and notice the needle. Connect a primary coil of wire with a cell. Thrust this coil into the center of the secondary coil used in the previous experiment. Watch the needle. Remove the coil. Under what conditions is a current generated in the secondary coil of wire?

Power to turn dynamos. Some power must be used to turn the dynamos. For this purpose, water wheels, steam engines, and gas engines are used. Water is the cheapest of these and is very widely used. The power plants at Niagara Falls are the best-known examples of the use of water power. The electricity here generated may be carried many miles to points where it is used. The electric current is taken from Niagara a distance of 154 miles to the city of Syracuse, where it is used to drive the street cars. In other localities it is being carried even longer distances than this. At the present time the most common means used for turn- 
ing the dynamo is the steam engine. In some places the gas engine is used.

How the current is conducted to the car. From the power house the electricity is conducted by means of wires to the trolley cars. In the system most commonly used, the electricity is conveyed by a wire suspended over the tracks. The electricity passes from this to the car through the trolley pole. Powerful springs at the base of the pole push the pole and the little wheel at its end upward and in constant contact with the wire. From the trolley base the current is conducted to the various parts of the car, and returns by means of the rails on which the car runs. In order to complete the circuit, the ends of the rails are either connected by wires or else welded. In order to supply enough electricity to all parts of the system, different wires, known as feeders, are run from the main supply of the current, and connect with various parts of the system.

Controller. As we watch the motorman running the car, we notice that he controls the car by means of three handles, one for the brakes, and two on a boxlike structure called the controller. When he wishes to start the car, one of the handles is turned a notch at a time till a place is reached where it is allowed to remain stationary. When he wishes to stop, the handle is turned back again and the brakes applied. If he wishes to make the car go backwards, he moves another handle and then turns the first handle as before.

This controller serves three purposes: first, it connects the motor with the circuit, so that the car can be started or stopped; second, it regulates the amount of electricity which passes to the motor, so that the speed of the car can be controlled; and third, it governs the direction in which the car goes, so that it can be made to go either forward or backward.

If the full current were turned into the motor suddenly, it would cause the car to start with an unpleasant jerk and 
it might injure the motor. In order to avoid this, resistance coils are connected with the motor, so that when the handle is turned to the first notch, the current passes through both the coils and the motor, and thus the motor at first receives only a portion of the full strength of the current. As the handle is turned still further around, these resistance coils are cut out, till finally the motor receives the full strength of current and runs at full speed.

Circuit breakers. In order to protect the parts of the machinery on the car from being injured by too strong a current, circuit breakers and fuses are provided. These circuit breakers are so arranged that when too strong a current passes through them they automatically open the circuit. Sometimes when riding on the trolleys, one hears a noise like an explosion which is due to the working of this circuit breaker. If you watch the motorman, you will see that he reaches up and turns back a handle connected with the circuit breaker, thus making a connection again.

Fuse. A fuse serves the same purpose. This is composed of certain metals which melt when a strong current passes through them, thus opening the circuit and preventing the current from passing through the remaining portions of the machinery.

Motor. The machine which actually makes the wheels of the car turn is the motor, which is placed under the car on the axles. The motor is constructed the same as a dynamo; that is, it is a reversible machine. If it is turned by some outside power, it generates electricity; if electricity is conducted through it, the parts begin to revolve. So the same machine can be used for either a dynamo or motor. As a matter of efficiency, however, it is found better to make machines intended for motors somewhat different from those intended for dynamos.

The motor has the same essential parts as the dynamo, that is, an armature and two magnets. When two magnets 
are brought together, if the north end of one is brought near the south end of the other, they will be drawn towards each other. (See figure 97.) If the two north ends or the two south ends are brought together, they will be pushed apart. This can be well illustrated by means of a bar magnet and a compass, which is a magnet mounted so that it can rotate. If the south end of the magnet is brought near the north end of the needle, the needle will turn around till its north end points towards the south end of the magnet. If the magnet be constantly moved, the needle may be kept in constant motion. When an electric current is passed through a motor, the field magnets and armature both become magnets and on account of the attraction of unlike poles and the repulsion of like poles, the armature is caused to revolve. This is so constructed as to make the motion continuous as long as the current passes through the motor. The motor is

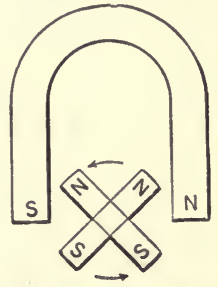

FIG. 97. - Illustrating principle of electric motor. connected with the axles of the car by means of gears, and thus the wheels are made to rotate and the car to move.

Thus the long story that began with the burning of coal in the fire box of an engine at the power house, is now completed when the energy thus generated is made to move wheels of a trolley miles away.

\section{LABORATORY Exercise 27}

Purpose. To see how the motor works.

Apparatus. Two bar magnets, wire, two long nails, small motor, two cells.

Directions. I. In order to understand the principles involved in the motor, we will first study the action of two bar magnets towards each other. Make a stirrup of a piece of wire and suspend a bar magnet in this by means of a string. Bring the north pole of the other magnet near the north pole of the 
suspended magnet. Bring it near the south end. What difference in action do you note? Bring the south end of the magnet near the south end and then near the north end of the suspended magnet. What is the law governing the action of magnets towards each other?

2. Make two electromagnets by winding six or seven feet of insulated wire around a long nail. Connect each electromagnet with a cell. Suspend one the same as was done with the magnet in the previous experiment. Bring the ends of the other electromagnet in turn near the ends of the suspended magnet. What happens?

3. Connect a small motor with a cell and notice how the parts work. How does the previous experiment help you to understand what takes place?

Brakes. Some of the smaller cars are stopped by means of hand brakes, but most of the larger cars are fitted with brakes operated by compressed air and similar to those used on railway trains. The air is compressed by means of a motor which works automatically, always keeping the pressure up to a certain point. We often hear this machine whirring while we are riding on the trolley; it suddenly stops when a certain air pressure has been reached, and then starts again when the motorman has used the brakes and the pressure has been lessened.

Lighting and heating. The cars are lighted and usually heated by current taken from the trolley wire. The electric heaters are usually placed at intervals on both sides of the car.

In many cars there is a system of electric buttons, connected with a bell near the motorman for signaling. When a person wishes the car to stop, he pushes a button and this causes the bell to ring as a signal to the motorman.

Electric locomotive. There are conditions in which the smoke of the ordinary locomotive is very offensive and in fact unsafe. To insure safety in tunnels and to avoid the 
danger of smoke and sparks elsewhere the electric locomotive is now taking the place of the steam locomotive. In I9I 5 there were 2250 miles of steam railway tracks in the United States that had been changed to electric operation, and some railroads are extending its use to great sections of their lines. The electric locomotive can also be made of much smaller weight than the steam locomotive. But it has to be heavy enough so the drivers will not slip if equally heavy trains are hauled. It is run by motors similar to the ordinary trolley car, but more powerful, and a single engine may draw a whole train of passenger or freight cars.

\section{SUPPLEMENTARY QUESTIONS FOR CLASS DISCUSSION}

I. What advantages has the trolley over the locomotive?

2. What parts do the dynamo and the motor play in running the trolley?

3. In what ways are the dynamo and motor alike?

4. How does the motorman control his car?

5. What provision is made on the electric cars for protection from accidents?

6. How is the electricity produced that runs the cars?

7. How does the motor change electricity into action?

\section{REFERENCES}

Cressey, Discoveries and Inventions of the Twentieth Century, E. P. Dutton Co., New York City. Chap. I3.

Harper's Electricity Book for Boys, Harper Bros., New York City. Chap. Io. 


\section{CHAPTER XVIII}

\section{THE AUTOMOBILE}

What should a person know about an automobile in order to run one successfully?

Uses of automobiles. Automobiles now seem to be used for almost every purpose that any type of vehicle has ever served. They began as pleasure cars. Now they are put to a great variety of commercial uses: delivery wagons, motor trucks, plows, and jitney busses. In the great European War they were used to propel gun carriages and to transport soldiers and supplies. The battle of the Marne was won by the French and Verdun was saved through the use of automobiles. Moreover, the service of the automobile seems to be only in its beginning. It doubtless has an even greater future before it, when it will take the place to some extent of locomotives and street electric railways. For lines of business that require a person to travel short distances the automobile is a great time saver, enabling him to do a larger amount of work in a day.

History of the automobile. The first carriage to be propelled by an engine was built in 1769 , by a Frenchman named Cugnot. This carriage was propelled by a steam engine placed on the frame of the carriage. It was a very clumsy affair mounted on three wheels. It traveled only three or four miles an hour, it had to stop every ten minutes to get up steam, and it could carry only three persons. Compare this with our modern automobile! 


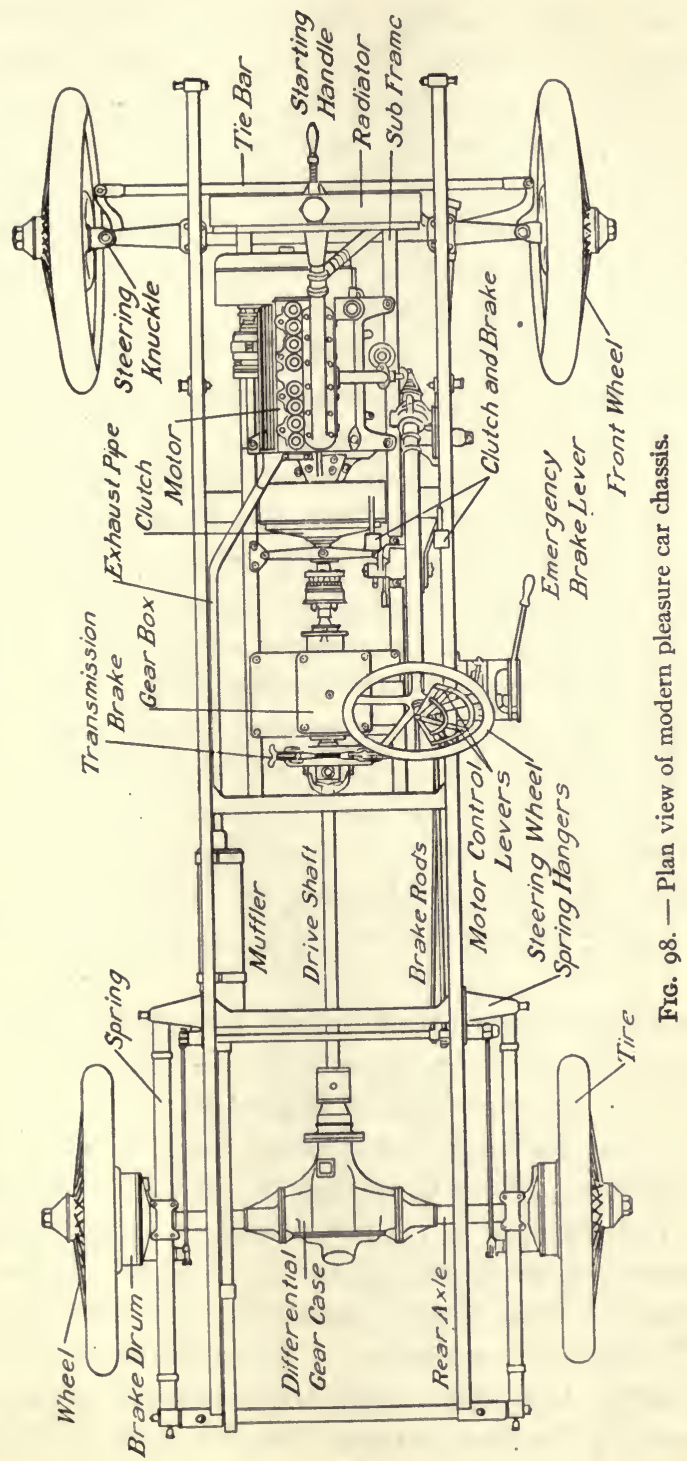


The next steam carriage was made in England in I80 I by Richard Trevithick. The use of these carriages so frightened the horses that a law was passed requiring a man to walk ahead of the steam carriage with a red flag to give warning of its approach. Later they were prohibited from using the highways altogether, because they interfered with the horse traffic. It was not until I896 that the "Red Flag Act" was repealed.

During the year 1895 in the city of Chicago, when one of the first automobiles was passing along Michigan Avenue, the driver was stopped by a policeman and told that horseless carriages were not permitted on the streets.

No great progress was made in the development of power-

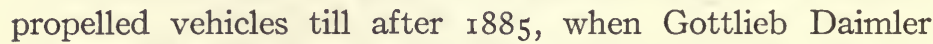
invented the high-speed gasoline engine. But it was not until the beginning of the present century that the automobile began to make rapid development. No machinery or invention for travel has ever made such rapid strides as has the automobile during the past fifteen years. In I895 the first automobile race was held in this country. The winning car was driven by a four horse-power engine. It traveled at the rate of $7 \frac{1}{2}$ miles an hour. About twenty years later racing cars had reached a speed of 120 miles per hour.

In 1898 there were probably not 100 automobiles in the entire United States; by the end of I9I 8 there were approximately 6,000,000 cars and trucks registered in the United States, or one for every I 8 persons, that is, about one for every 4 families. This is an increase of 20 per cent over the number registered in I9I7, and nearly six times as many as there were seven years previous in I9I I. In the states of Iowa and Nebraska there is one automobile for every seven persons. The entire population of these states can be carried in their cars. One third of the total number in the country is registered in the five states of New York, Ohio, California, 


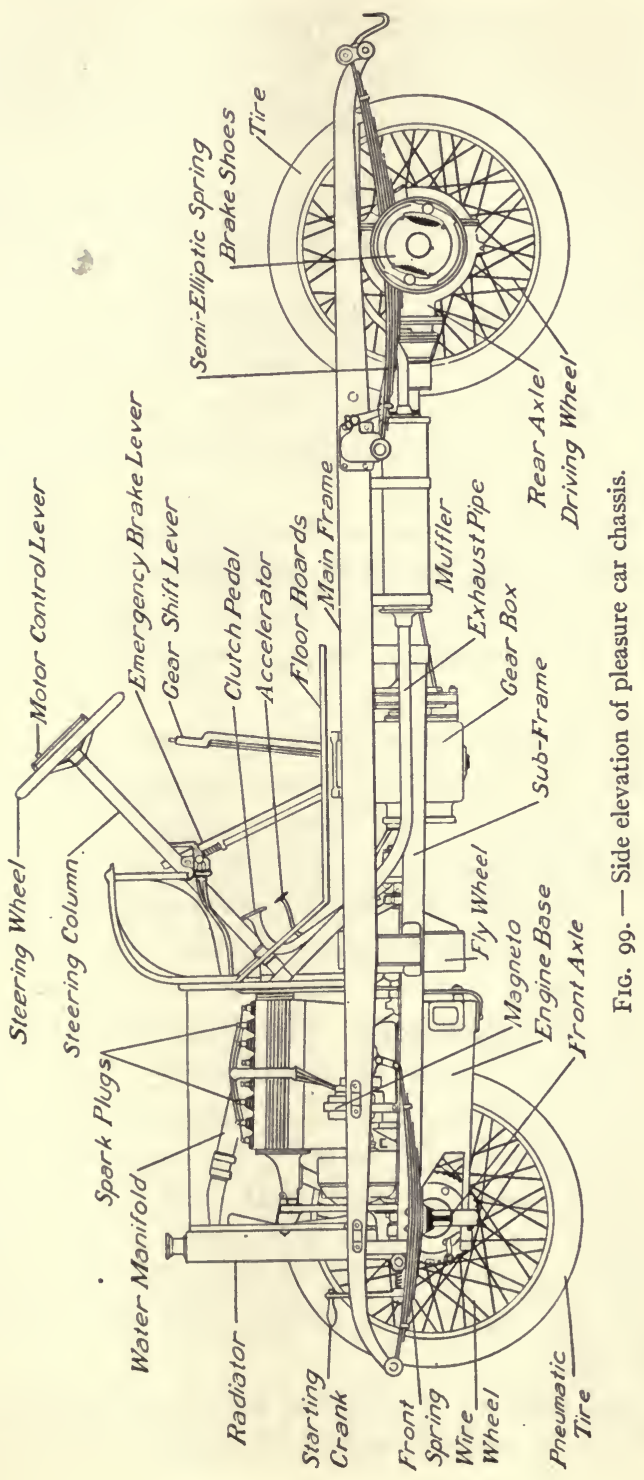


Pennsylvania, and Illinois. There are ten states in which the number registered in each is over 200,000 . Besides the five nentioned above these include Indiana, Iowa, Michigan, Minnesota, and Texas.

In 1904 there were made in this country II,000 cars; in $1909,125,000$; in 1915, almost 900,000 ; and in 1917, nearly $2,000,000$.

Types of automobiles. Automobiles may be divided into two types, according to the power used to run the machine, - the electric car and the gasoline car. Steam also has been used, but its disadvantages were so many that it has been largely abandoned.

Comparison of gasoline and electric cars. Each type of car has its advantages and disadvantages. The advantages of the electric car are that it is more simple in construction and more easily managed, and it is without odor, vibrations, or noise.

The advantages of the gasoline car are that it is. lighter and cheaper; it can travel over a larger range of country, as gasoline can now be obtained in almost every village, and the supply. of gasoline can be pumped into the tank in a few minutes. When everything is considered, the gasoline car has more advantages than the electric car and so is much more widely used.

Parts of an automobile. The gasoline automobile is a very complicated piece of mechanism. For the sake of simplicity, we may say that it is composed of the following parts : I. the axles and wheels; 2 . the supporting frame and springs; 3 . the body or part that carries the load; 4 . the power plant; 5 . the clutch and gear box; 6. the power transmission system; 7. the lighting system; and 8 . the mechanism by which the driver controls the car. (See figures 98, 99.)

Axles and wheels. The front axle is attached solidly to the frame and is not pivoted at the center, like the axle of a 
carriage. At the end of this axle the wheel is mounted on a short axle pivoted in such a way that it can be moved, so as to turn the vehicle in any desired direction. The spindles carrying the wheels are connected by a tie bar, so that both front wheels move together. The motion of these wheels is controlled by 'a steering wheel, whose motion turns a lever connected with the spindle on which the wheel revolves. (See figure Ioo.) The rear axle not only helps support the weight of the car, but it is here that the power of the engine

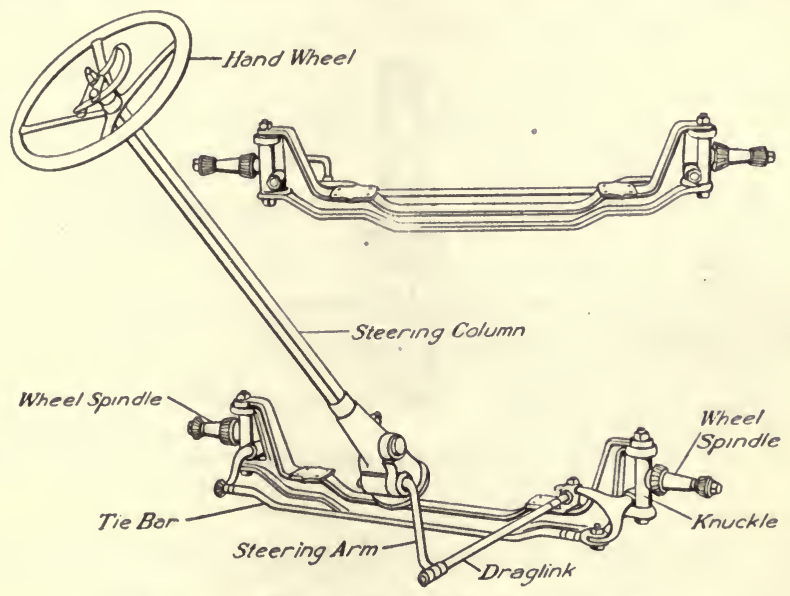

Frc. 100. - Front axle and steering mechanism.

is transmitted to the axle so as to move the car. (See figure ror.)

Wheels and tires. The spokes of the wheel are made either of wood or wire. On large motor vehicles used for carrying heavy loads, solid rubber tires are frequently used; but for the ordinary car, pneumatic tires are used. These consist of a tough outer casing which comes in contact with the road, and inside of this and protected by it from wear is a tube of rubber which is air tight. This is filled with air under pressure by means of an air pump. In order to pre- 
vent skidding, the outer casing is made with a roughened surface, and in wet weather chains are attached to the tires. To reduce friction, the wheels are mounted on the axles by means of antifriction ball or roller bearings.

Frame and springs. The frame supports most of the weight of the car, connects the axles, and carries the springs. The frame is usually made of steel; and the lightness and strength of the modern automobile are due largely to the new varieties of steel that have been introduced in recent

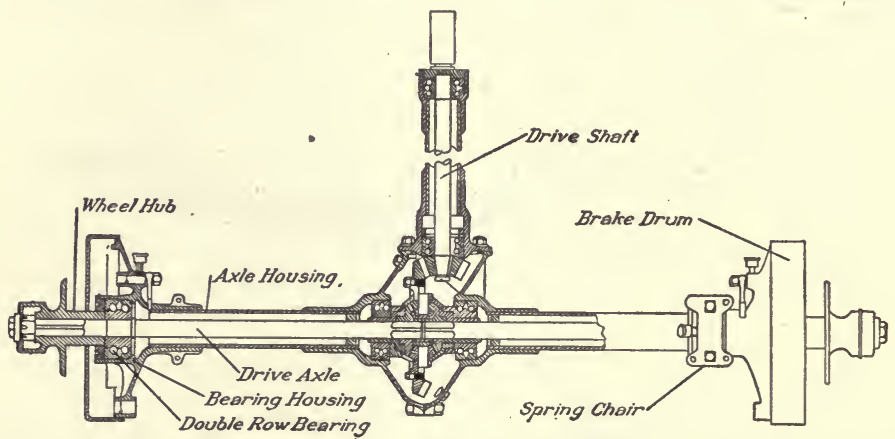

FIG. I0I. - Semi-floating automobile rear axle construction with shafts and gearing mounted on double row ball bearings.

years. The frame is supported on the axles by means of springs.

Body. A number of types of bodies are made, according to their use. The following are among the most common: the roadster, coupé, touring, limousine, and truck. These may be made of either wood or metal. In order to reduce the air resistance, which is especially noticeable at high speeds, some bodies are made in a torpedo shape with gradual curves and unbroken sides. These bodies are of either the closed, open, or semi-closed type. Nearly all types have a transparent wind shield to protect the operator from dust and cold wind. Either celluloid or glass is used for this shield. 
Power plant. The power plant consists of the following parts: a gas engine, a carburetion system, an ignition system, a lubrication system, and a cooling system.

How the gas engine works. The gas engine is known as an internal combustion machine, because the fuel is burned inside the cylinder and the explosion thus formed forces back the piston. Before entering the cylinder, the gasoline is changed to a gas and mixed with air in the carburetor. The mixture is set on fire by means of an electric spark.

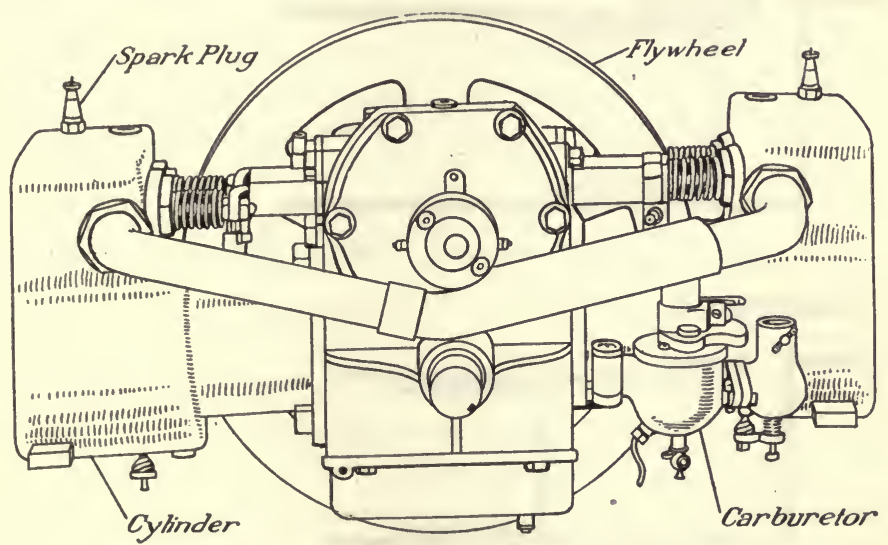

FIG. 102. - Simple two-cylinder opposed water-cooled motor.

The common gas engine is spoken of as a four-cycle engine, as there are four distinct steps in the action of the piston. The first stroke of the piston sucks in the mixture of air and gas from the carburetor into the cylinder. The second stroke compresses this mixture. At the beginning of the third stroke, the explosion of the gases takes place and the piston is forced back. On the fourth stroke the burned gases are forced out of the cylinder through a valve. These strokes are called respectively suction, compression, combustion, and exhaustion. (See figures 103-106.)

Only once in four strokes, therefore, is the motive power 


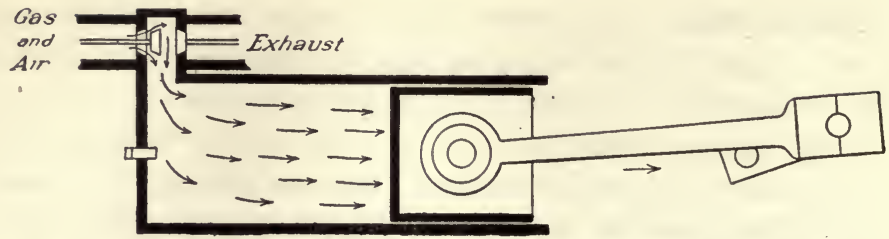

Fig. 103. - First stroke (suction). - Gas and air admitted to cylinder.

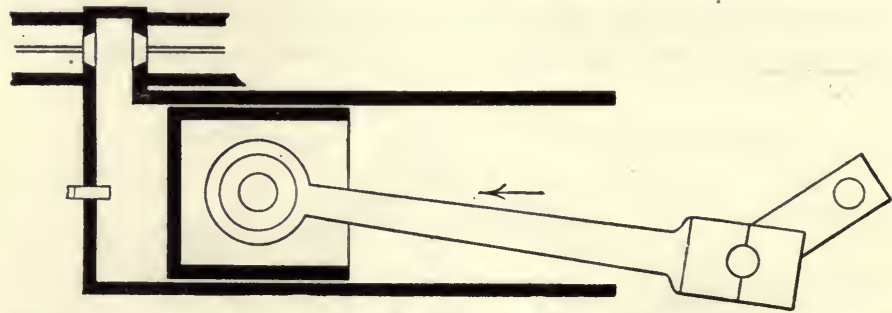

FIG. 104. - Second stroke (compression). - Mixture of gas and air compressed.

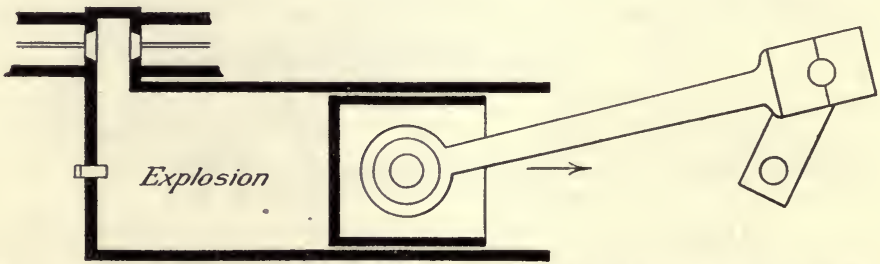

Fig. 105. - Third stroke (combustion). - Mixture is exploded and expands, driving the piston forward.

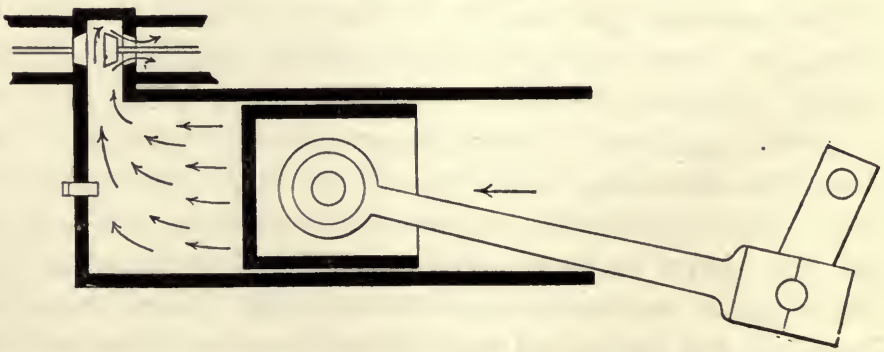

Courtesy of Harper \&o Brothers

Fig. I06. - Fourth stroke (exhaustion). - The burned-out mixture of gas and air expelled from the cylinder.

The Four-cycle Gas Engine. 
applied to the piston. In order to keep the piston running during the other three strokes, a heavy flywheel is provided, whose momentum keeps the axle rotating until the next explosion.

In order to give a more even application of power, automobiles are now furnished with engines of four, six, eight, or even more cylinders. A four-cylinder engine would be so arranged that the driving gear would receive an impetus four times as frequently as it would from an engine of one cylinder.

Starting. In order to start the engine, some power must be used to give the piston a few strokes till an explosion occurs. In some cars this is done by hand, by means of a crank attached to the front of the car. Other cars have electric starters, in which the power to start the piston is furnished by a motor, driven by electricity from a storage battery. This is controlled by pressing a button or lever.

Comparison with steam engine. The gas engine differs from the steam engine in a number of ways. In the first place the fuel is burned inside of the cylinder instead of in a fire box. In the four-cycle engine the propelling force is applied only once in four strokes, and on only one side of the piston; while in the steam engine it is applied at every stroke, alternating on the two sides of the piston. A steam engine will start as soon as the steam is admitted to the cylinder; while in order to start a gas engine, the crank shaft must first be rotated by some external means. A steam engine can begin to do work at once as soon as the steam moves the piston head, while a gas engine must be started first without connection with the axle of the automobile, and then the load is gradually applied by means of a clutch.

Carburetion. Before the gasoline is allowed to enter the cylinder, it is changed to a gas and mixed with air, so that it will explode in the cylinder. The machinery which does 
this is called the carburetion system. The most common kind of carburetor is the spraying type. The gasoline is

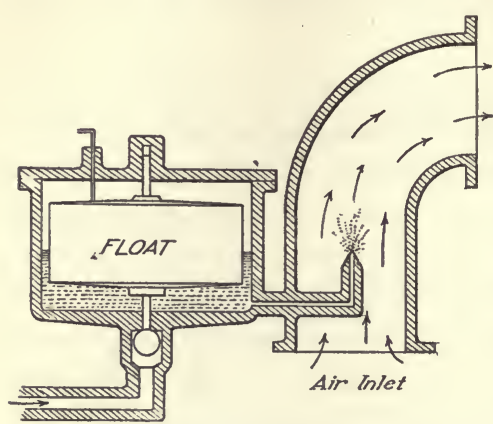

F1G. 107. - Defining elements of simple float-feed carburetor. forced under great pressure through small openings, forming a spray which quickly changes to a vapor. At the same time, it is mixed with air in the proportion of about one part of gasoline vapor to six or seven parts of air. This mixture is led into the cylinder and put under pressure before it is exploded.

When the gases escape from the engine after the explosion, they emit a very loud noise. In order to silence this, a muffler is used. This is cylindrical in shape and is made up of several compartments, separated by partitions in which is a series of holes; through these holes the gases pass, so that they finally leave the muffler with only a slight hissing noise.

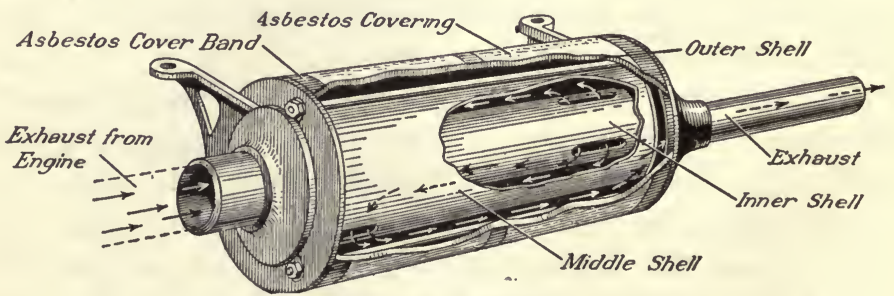

Fig. ro8. - Muffler.

The amount of gasoline needed to run the engine varies with the make of the car. Some cars will run from 20 to 25 miles on a gallon of gasoline, while others will run only ten miles. 
Ignition system. The purpose of the ignition system is to explode the gases in the cylinder at the proper time, so that the piston may be forced down. The heat to ignite the gas is furnished by an electric spark. The source of electricity may be either dry cells, storage batteries, or magnetos; or a combination may be used. The switch that regulates the time of explosion is controlled by contact with the camshaft, which is so set that the explosion occurs at the proper time. A part of the ignition system is an induction coil, which is a device by means of which a current of sufficient strength is formed to cause a spark in the cylinder. The spark plug is composed of two points separated by a short distance, across which the current jumps, producing the spark that sets fire to the gases.

Lubricating system. In order to prevent friction from wearing out the parts of the engine, they must be kept supplied with oil. The lubricating system commonly used consists of a tank for storing the oil, a kind of pump to force the oil to the bearing parts, and piping to take the oil from the tank to the pump and from the pump to the engine. The tank is large enough to hold one or two quarts of oil, and the pump is worked automatically by connection with the crank shaft or other part of the engine.

Cooling the engine. The combustion of gases in the cylinder produces a large amount of heat, and the cylinder would soon become heated to such a high temperature as to interfere seriously with the working of the engine. So some device must be used to keep the cylinder from getting overheated. This is accomplished by the use of either air or water. The air-cooled engines are constructed in such a way as to expose a large surface for cooling. In most cases fans or some other device are used for forcing drafts of air against the cylinder.

The air system of cooling has the advantage of simplicity and is much easier to operate, especially in winter when 
there is danger that water will freeze. On the whole, however, the air system is much less effective than the water system. To avoid the danger of overheating, nearly all makes of cars use the water system.

In the water system of cooling, the cylinder is surrounded by a jacket kept filled with water. The circulation of this water is maintained in either of two ways, the natural system or the pump system. In the natural system, the water circulates as in a hot-water heating system, described on page 7 , the hot water rising and the cold water flowing in to take its place. In the other system, the water is forced around through the tubes by means of pumps operated automatically by connection with some part of the engine. The water is cooled by passing through radiators exposed to air and containing many tubes which give a large cooling surface. The air is forced against these radiators by means of fans. In winter alcohol is added to the water to prevent freezing.

\section{DEMONSTRATION 20}

Purpose. To show how the gas engine works.

Apparatus. Two large-mouth bottles, pan, coffee pot, Bunsen burners, small gas engine or model of one, induction coil, cells.

Directions. 1. To show the need of a mixture of gases to cause an explosion. Fill an ordinary pan about a third full of water. Fill one large-mouth bottle with water and another half full. Invert them both in the pan of water. Connect a piece of rubber tubing with the gas jet. Put the other end over the edge of the pan and under the mouth of the bottles. Then turn on the gas till the water is forced out of the bottles. Then turn off the gas. Take out the bottles and put a piece of cardboard over the mouth of each. Bring a lighted match to the mouth of the bottles after taking off the covers. What is the difference in the action of the two? What does this show? Partially fill the bottles again with water to see what proportion of air and gas give the loudest explosion. If illuminating 
gas is not available, hydrogen gas may be generated by using zinc and hydrochloric acid.

2. To show that this explosion has the power to do work. Cut a hole in the side of a coffee pot near the bottom big enough to admit the end of a Bunsen burner. Halfway up on the side make a small hole. Turn on the gas and bring a lighted match near the small hole. Why does the cover fly back? Close the cover and see how many times it can be made to fly back. Turn off the gas and clean out the products of combustion from the pot. Then try the experiment again. What do the results show?

3. To show how the gas is ignited. Set up an induction coil and cells and show the formation of the spark.

4. Run a small gas engine with illuminating gas. Notice carefully how each part works. Or make a study of a model. Make a drawing and explain the use of the various parts.

Other devices. Clutch. The clutch is a device by means of which the engine may be allowed to run alone without moving the wheels of the automobile. This serves two purposes. When starting the car, it is necessary to allow the engine to get full speed before putting on the load; then after the engine is once started, the clutch may be gradually thrown in and the car starts. And again, when it is desired to stop for a very short time, the clutch may be thrown out and the engine need not be stopped; this saves starting the engine again. The most common kind of clutch is the friction type, in which the parts are held so closely together by springs that they rotate together. The tension of the springs is released by means of a foot pedal, thus allowing the parts to operate separately.

Gear box. The gear box is a mechanism by means of which the speed and driving power of the engine may be changed. These are spoken of as the high and low gear. When climbing a hill, it is desirable to increase the power and lessen the speed. The gear box contains different 
combinations of gears, which are controlled by a lever. The mechanism for reversing the engine is also located in the gear box.

Power transmission. Power may be transmitted from the gear set to the wheels by means of sprockets and chains, or by means of a shaft and gears on the rear axle. The chain drive is often used on large motor vehicles, but the gear drive is used largely on the ordinary cars. This has the advantage over the chain drive that it is inclosed and so can easily be kept lubricated and free from dirt.

Lights. Three means of lighting automobiles have been used: kerosene, gas, and electricity. In the gas systems, a tank containing acetylene gas under pressure is attached to the car. Electricity is now most commonly used. This has the advantages of cleanliness, reliability, and ease of operation, the lights being turned off and on by operating a switch.

Three types of electric lighting systems are in use: that using the dynamo or magneto; that using the storage battery; and that using both the dynamo and storage battery. In the last system, the current to the lamps is furnished by the battery, but the dynamo keeps the battery charged. This combination system is the one most commonly used.

Means of controlling automobiles. The engine is started either by hand or by electricity. At first the clutch is thrown out by means of a foot pedal and then allowed to come back after the engine starts. The direction of the car is controlled by the stearing wheel, which connects with the two front wheels. The speed is controlled by means of two levers on the steering wheel, one of which controls the supply of gas given to the engine, and the other controls the time of sparking. In some cars the supply of gas may also be controlled by a foot pedal. The speed may also be controlled by changing the lever in the gear box. The rate of 
speed is indicated by a speedometer, and the distance traveled is registered on a cyclometer.

The average car has an engine of from 25 to 50 horse power, enabling one to attain a speed of 30 miles an hour or more. On racing cars, engines of tremendous horse power are used. Speeds have been attained exceeding that of the locomotive. Special racing cars have traveled at the rate of a mile in less than half a minute.

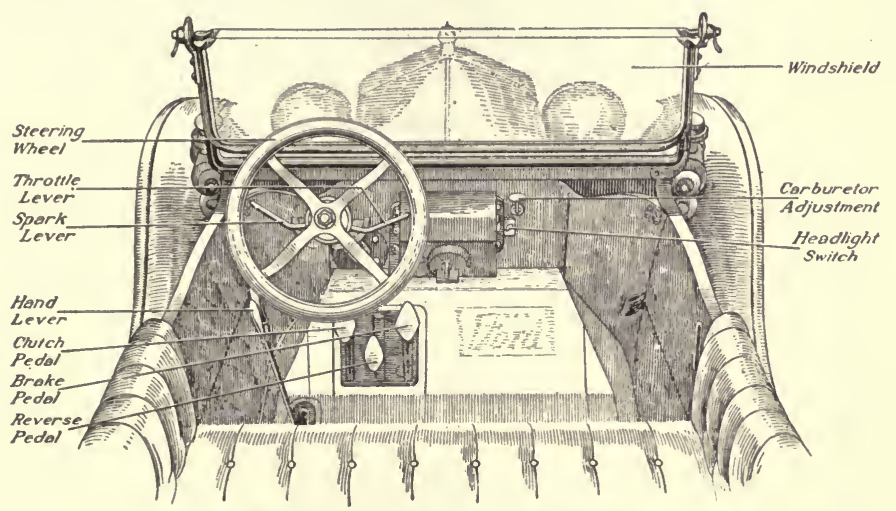

FIG. 109. - Control of automobile.

Stopping the car. There are several means used to stop the car: shutting off the supply of gasoline, throwing out the clutch, and applying the brakes. The most common kind of brake is a band brake, which works on the hub of the rear wheels. This is operated by means of a foot pedal. The brake may also be attached to a drum on the driving shaft. Frequently another brake is provided, known as the emergency brake. This is usually operated by hand by moving a lever.

Warning signals. Warning signals may take a great variety of forms; but the most common types are the bulb horn operated by hand, the exhaust whistle, which is attached to the exhaust pipe and operated by the escaping 
gas, and the electric horn, operated by electricity. In the electric horn a membrane is caused to vibrate by means of a cam provided with many points and rotated by a motor.

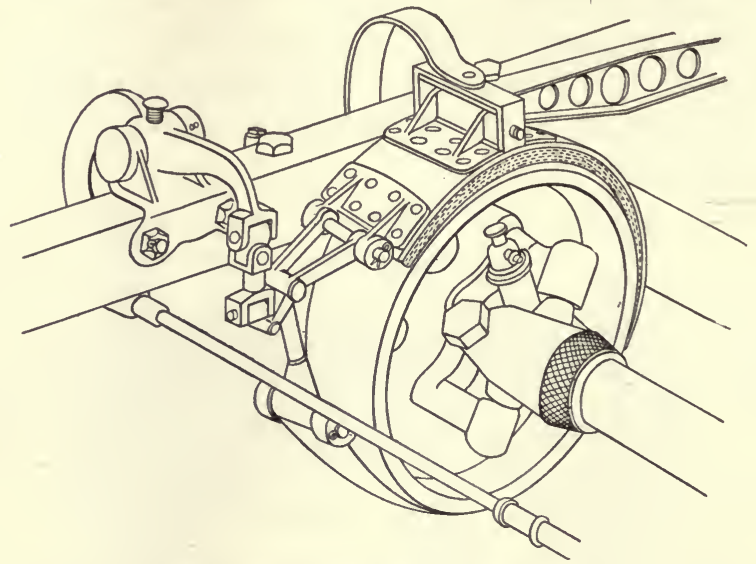

Fig. IIo. - Shaft brake of band form.

Field Exercise 6

Purpose. To study the parts of an automobile and see how it is run.

Directions. I. Arrangements should be made with some mechanic in a garage to have the class visit the shop when an auto is being taken apart to be fixed. The uses of the various parts can then be explained to the members of the class.

2. Arrangements can also doubtless be made with some of the parents of the members of the class who own an auto, to take small groups on an auto ride and explain the method of running the car.

\section{SUPPLEMENTARY QUESTIONS FOR CLASS DISCUSSION}

I. Name all the uses that you have seen made of automobiles.

2. Which is more useful, the auto or electric trolley car? 
3. Which has more advantages, the electric auto or the gasoline auto?

4. How does the gasoline engine differ from the steam engine?

5. What purpose does each of the following systems serve in the auto: the carburetion system, the ignition system, and the cooling system?

6. Explain how the engine works.

7. Which is the best method of lighting the auto ?

8. How does the chauffeur control the car?

9. What devices are provided for preventing accidents?

\section{REFERENCES}

Baker, Boy's Book of Inventions, Doubleday Page and Co., New York City. Chap. 4.

Cressey, Discoveries and Inventions of the Twentieth Century, E. P. Dutton Co., New York City. Chap. I4.

Darrow, The Boys' Own Book of Great Inventions, The Macmillan Co., New York City. Chap. I2.

Doubleday, Stories of Inventors, Doubleday Page Co., New York City. Pages 67-85.

Harper's Machinery Book for Boys, Harper Bros., New York City. Chap. I 8.

Holland, Historic Inventions, G. W. Jacobs Co., Philadelphia. Chap. 16.

Maule, Boys' Book of New. Inventions, Grosset and Dunlap, New York City. Chap. Io.

Williams, How It Works, T. Nelson and Sons, New York City. Chap. 4. 


\section{CHAPTER XIX}

\section{THE STEAMBOAT}

I. In what ways are the means of travel on water now in use better than they were when Columbus discovered this continent?

2. How is the submarine made so that it is able to travel under water?

Early types of boats. Probably the first boat used by primitive man was a log, which may have been propelled by using a branch for an oar. From this two types of boats developed. One was the dugout, made by digging away the center of a log. Improving on this type, men later con-

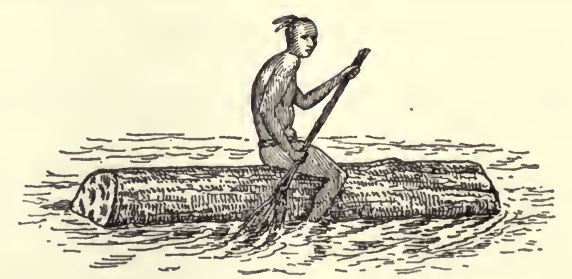

FIG. III. - The first boat.

structed canoes made of bark or other light material. The other early form was the raft, made by fastening several logs together. At first the rafts were propelled by hand; later, sails were attached to them.

Eventually the raft developed into a large boat, made by fastening planks and logs together to give it a spoon shape. These early boats were propelled by both oars and sails. At first there was no rudder. About I I ०० B.c. the first rudder 
appeared in the form of an oar projecting from the stern of the boat. This type of rudder was used for many hundreds of years.

The best type of boat of ancient times was the Roman galley. Some of the galleys of this time, about Ioo A.D., were 400 feet long. Oars were depended on chiefly for propelling the boat. In some of the large boats several hundred rowers were employed. Sometimes there were three tiers of oars, one above the other.

During the next few centuries little progress was made in boat building. Gradually less reliance was placed on oars and more on sails, until the sails replaced the oars entirely; so that the boats of this time could be called sailing ships. The rudder was improved and fastened to the boat and worked by means of a tiller.

About the middle of the thirteenth century the compass was first used as a guide for steering the boat. Before this, sailors had steered at night by the north star. In cloudy weather they were easily lost. The use of the compass enabled the sailors to undertake much longer journeys than they had ever dared to try before. Without the aid of the compass probably the. New World would not have been discovered at the time it was by the people of Europe.

The first steamboat. The next great development was the application of steam power to the propulsion of boats. The first boat to be propelled by steam was made by an American named James Ramsey. In 1786 this boat was driven at the rate of five miles an hour. This was propelled by means of a piston working in a cylinder. When the piston was raised, the cylinder was filled with water, and when the piston was pushed down the water was forced out, and the reaction of this against the water in the river caused the boat to move ahead.

In 1787 another American, named John Fitch, made a boat in which the oars were worked by a steam engine. A 
speed of three or four miles an hour was attained. Both of these were interesting experiments, but neither was a success commercially.

Robert Fulton's "Clermont." The first really successful steamboat was built by Robert Fulton. In I807 his steamboat, the Clermont, made a trip on the Hudson from New York to Albany - a distance of I50 miles and return in 62 hours. This trip was regularly made by sailing packets in about four days. The Clermont was propelled by means of paddle wheels, which were fifteen feet in diameter, one on each side of the boat, and turned by a

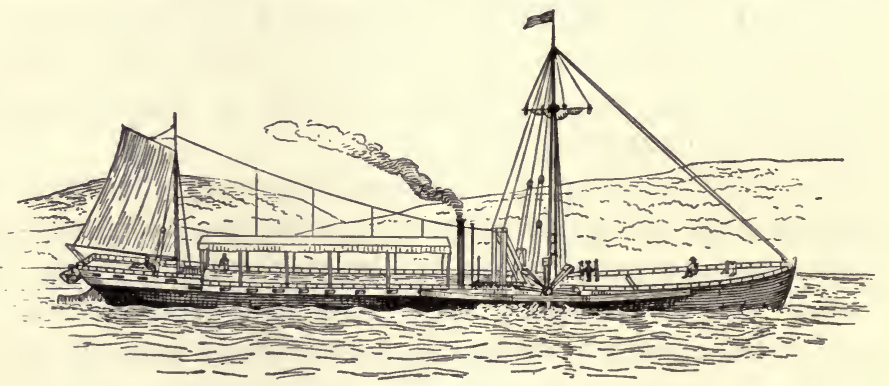

Frc. Ir2. - Fulton's Clermont, the first stcamboat.

steam engine. The boat was r 30 feet long. The Clermont continued to make regular trips between these cities and to take passengers.

Trans-Atlantic steamboats. Other steamboats were soon built in other sections of the country, and twelve years later the steamship Savannah, using both steam and sails, crossed the Atlantic Ocean in 26 days. The first steamboat to cross the Atlantic using steam all the way was the Royal Williams, which crossed from Nova Scotia to the Isle of Wight in I7 days.

The next great improvement in the steamboat was the invention by John Ericsson of the screw propeller. This is a wheel entirely immersed in water and fastened at the 
stern of the boat. Its blades are placed in such a way that as they rotate and push against the water they force the boat ahead. The first steamboat using a screw propeller crossed the Atlantic in I839. Since that time, there have been many wonderful improvements in the ocean steamship.

The first ocean steamers were made of wood. Later iron was used. The first iron steamboat crossed the Atlantic in I850. About 25 years later, steel took the place of iron, and to-day our great Atlantic steamships are made entirely of steel.

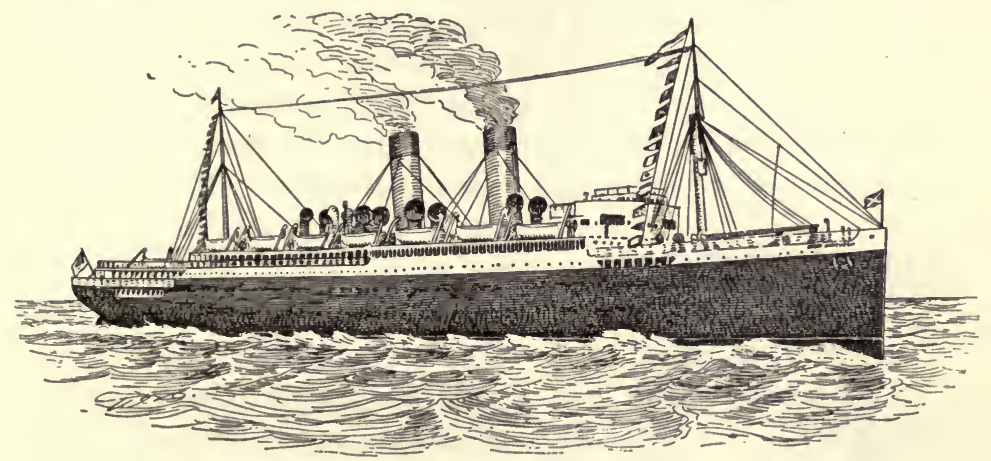

FIG. II3. - A modern steamship.

Lusitania. Such improvements have been made in the modern trans-Atlantic steamships that they are floating hotels with all the comforts and conveniences that are obtainable on land. Some have such conveniences as drawing rooms, smoking rooms, reading and writing rooms, veranda cafés, and even gymnasiums and swimming pools. One of the largest of these, the ill-fated Lusitania, that was sunk by a German submarine, was 790 feet long and 88 feet wide. It was provided with engines of a total horse power of 70,000 , which gave the steamer a high rate of speed. She held the record for speed, having made 632 knots in 24 hours, an average of 26 knots or 30 .miles in an hour. She 
made the entire voyage across the Atlantic in 4 days, 20 hours, and 22 minutes, averaging 28.5 miles per hour. Accommodations were provided for several thousand people.

Provisions for a trip across the ocean. Some idea of the preparations necessary for a trip across the ocean may be obtained from the following figures showing just a few items of food needed by this ship for a round trip: 80 boxes of oranges, rooo pounds of tea, I800 pounds of coffee, ro, 000 pounds of sugar, 2 Io barrels of flour, 8000 pounds of cereals, 3000 gallons of milk, 40,000 eggs, 28 tons of potatoes,' 2000 chickens, 5500 pounds of butter, 17,000 pounds of mutton, 45,000 pounds of beef. This food was cooked in kitchens provided with steam ovens and electric heating devices.

Steam turbine. In recent years there has been developed a new type of steam engine called the turbine, that is being

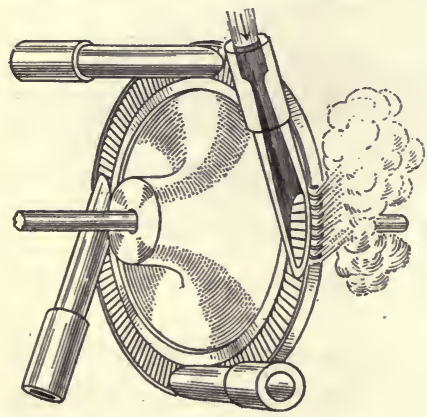

FIG. II4. - Steam turbine with one set of nozzles. much used on steamships. It is much like a water wheel, which is turned by the force of the water striking against its paddles. In the steam turbine the steam is led through small nozzles and caused to strike against many blades on a revolving drum. The steam is under enormous pressure, and as it strikes against these blades it causes the drum to revolve at a tremendous speed (figure II4). There are several series of these blades, so arranged that the steam rebounds from one set to the next, the steam being used repeatedly.

These turbines are now being used on such large steamships as the Mauretania, as it is found that they have the following advantages over the ordinary steam engine: (I) There is no vibration, thus allowing the boat to travel smoothly without unpleasant jarring. (2) They occupy. 
less space. (3) They are more economical at high speeds. (4) They are more easily tended and require fewer repairs.

\section{Demonstration 2 I}

Purpose. To make a simple steam turbine.

Apparatus. Flask, rubber stopper with one hole, glass tubing, toy windmill.

Directions. I. To make a toy windmill, take a piece of paper about 6 inches square and cut from each corner inward nearly to the center. Fold over every other point. Pass a pin through these four points, through the center of the paper, and then into a wooden handle.

2. Heat a piece of glass tubing and draw it out nearly to a point. Break it off, leaving a very small hole. Put this tube in the hole of the rubber stopper and then insert the stopper in a flask so that the small point is uppermost. Fill the flask a third full of water. Heat the flask till the water boils vigorously. Then hold the windmill over the glass tube where the steam is escaping.

Change in a century. About one hundred years after the Clermont had made its first trip at the rate of 5 miles an hour, another boat, a yacht called the Arrow, traveled a mile over the same course in I minute and 32 seconds, which is at the rate of 46 miles an hour. From 5 miles an hour to 46 miles an hour represents the progress made in one hundred years.

How vessels are guided. Compass. In the earliest times men did not dare to venture far from land but steered by landmarks, by the sun, and perhaps by the flight of birds, and on clear nights by the stars. The compass was first used as a guide in steering ships between I 100 and I 200 A.D. In its first form it was a needle in a straw floating on water. About 1360 the needle was mounted on a pivot and inclosed in a box as it is now used. A compass is a magnet mounted so that it can turn easily, and it always takes a north and south 
position. The power of a magnet to take this position was not known till the end of the eleventh century, and then only to a few learned men. They did not think it safe to tell the common people about its use in steering ships, for fear they would be considered magicians, so it was a long time after, probably over a hundred years, before the compass was in common use.

The tendency of the compass to point north and south is explained by saying that the whole earth acts like a huge magnet with its two magnetic poles near the geographic poles. The compass points to the magnetic north pole and not to the geographic north, so that for most sections of the earth a certain number of degrees must be added to or subtracted from the reading of the compass, to get the true north. As one passes east or west these corrections vary. Since in recent years so much steel has been used in the construction of steamships, it is found that the compass is influenced by the mass of iron near it. For these two reasons, therefore, some substitute for the compass in guiding ships has been sought.

\section{LABORATORY EXERCISE 28}

Purpose. To study the action of the compass.

Apparatus. Compass, two darning needles, knitting needle, cork, magnet.

Directions. I. Magnetize a knitting needle by rubbing an end of the needle on one end of the magnet, and the other end of the needle on the other end of the magnet. Fold a piece of paper about one inch square, diagonally. Place the needle at its middle in the crease of paper and suspend the paper by means of a fine thread. In what position does the needle come to rest? Compare with the compass. Move the needle and try several times. Does it always come to rest in the same position?

2. Magnetize a large darning needle by rubbing the point on the north pole of a magnet and the eye end on the south pole. 
Magnetize another needle by rubbing the point on the south pole and the eye end on the north pole of the magnet. Cut two thin pieces of cork from a stopper. Float the corks in a pan of water. Put a needle on each cork. In what position do the needles come to rest? Do the points of both needles point in the same direction? Can you explain?

3. Set the compass on a level table and notice the direction in which the needle points. Place pieces of iron and steel on the table near and see if the needle is affected. Try a magnet.

Gyro-compass. Recently there has been invented a new type of compass, called the gyro-compass, which is being

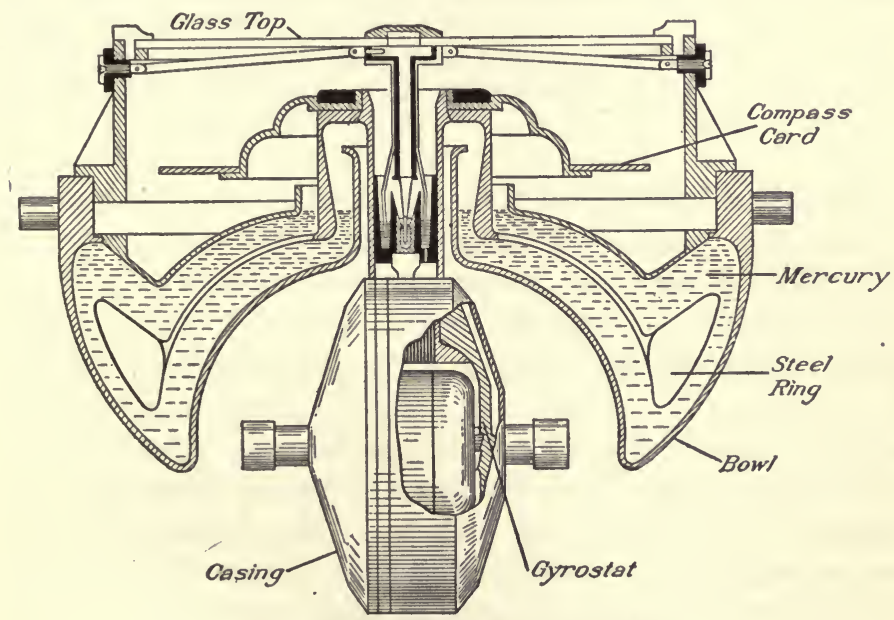

FIG. II5. - Section of gyro-compass.

used commonly, especially on battleships. The gyroscope is a wheel mounted on an axle inside of a frame, which tends to rotate in the same plane in which it started. If the wheel is a large one, the strength of a man is not enough to change its plane of rotation. In the gyro-compass the wheel is caused to rotate in a north and south plane at a high rate of speed by means of a motor. The gyroscope is floated in a bowl containing mercury, so that the wheel keeps rotating 
in a north and south plane regardless of any motion of the ship. The top is covered with glass, and on this is a dial showing the points of the compass. Other dials may be placed in any part of the ship and by means of electrical connections with the gyroscope the true readings are indicated on these dials.

\section{Laboratory Exercise 29}

Purpose. To see how a gyroscope works.

Apparatus. Toy gyroscope.

Directions. Set the gyroscope spinning by means of a string. Try placing the gyroscope in a great many positions, as on the edge of a tumbler, on a string, on the tip of a pencil, on the end of the finger with the axis horizontal. How could this be used to guide vessels?

Protection from accidents. In order to assure the safety of the large ocean ships, they are provided with a number of separate water-tight compartments, so that if by accident water should enter one, it cannot flood the others. As a protection against icebergs, an instrument called a frigidometer is used. This consists of a special thermometer placed near the forward end of the ship, in a vessel through which sea water passes. The lowering of the temperature may indicate the presence of icebergs. This thermometer is connected with an indicator on the bridge. This can be so set that when a certain temperature is registered by the thermometer, an electric gong rings and a red light shows as a warning to the one on watch. Protection from fire is assured by the use of steel instead of wood in the construction of the ship.

Protection from rocks. Protection from dangerous rocks and coasts is assured by signals conveyed under water. A bell is submerged under water over the dangerous rocks and the strokes are controlled from a shore station or from a lightship by means of electricity or compressed air. The 
different bells ean be distinguished by the varying number of strokes and the interval between. The receiving apparatus consists of water tanks about two feet square fastened to the ship below the water line. Each tank contains a microphone which is connected by means of wires with a telephone in the pilot house. By this means the pilot can hear the strokes of the bell and can tell from their number and intervals the exact locality. These signals operate up to fifteen or twenty miles. They operate regardless of fog or any other conditions of weather. They have already been the means of saving many lives and thousands of dollars' worth of property.

Why a boat floats. When a boat is made of wood it is not difficult to understand why it floats; but when boats are made of a heavy substance like steel, it is not so easy to understand. Whether a body will float or sink depends on its specific gravity, which means the weight of a body compared with water. A body that weighs the same as an equal volume of water is said to have a specific gravity of $\mathrm{I}$. If it weighs twice as much, it has a specific gravity of 2 ; if half as much, a specific gravity of .5 .

A body that has a specific gravity of less than I floats; one that has a specific gravity of more than I sinks, when placed in water. Now when a piece of steel is so much heavier than water, how is it that a boat made of steel floats? The explanation is that a large amount of air is inclosed within the steel sides of the boat, and the specific gravity of the steel and air combined is less than $\mathrm{I}$; that is to say, the whole volume is lighter than an equal volume of water.

\section{LABORATORY EXERCISE 30}

Purpose. To learn why a boat floats.

Apparatus. Spring balance, stone, overflow can, catch bucket, wooden cylinder to fit overflow can, egg, salt, shot, test tube. 
Directions. I. To show the buoyant force of water on a sinking body, tie a string to a stone and weigh it in air by means of a spring balance. Submerge the stone in water and weigh it. How much has it lost? To what is this loss due?

2. To show the buoyant effect of water on a floating body, fill the overflow can as full of water as possible. Weigh the catch bucket. Weigh the wooden cylinder. Place it on the surface of the water in the overflow can and catch the overflow in the catch bucket. Find the weight of the water in the catch bucket. How does this compare with the weight of the block of wood?

3. Put some shot in a test tube and float the tube in a dish of water. Glass and shot are both heavier than water. Why then does the tube float? Why do steel ships float? Catch the overflow as in the previous experiment and compare with the weight of the tube and shot. Add more shot. What happens to the tube? Remove some shot. What happens? What fact does this illustrate about the loading and unloading of a boat?

4. To show the difference in the buoyant force of fresh and salt water, put an egg in a dish of fresh water. What happens? Put the egg in a strong solution of salt and water. What happens? What causes the difference? In which body of water would a boat sink deeper, in the Great Lakes or the Atlantic Ocean? Why?

Submarines. During the European War our attention was specially called to submarines on account of the destructive use to which they were put. This use of the submarine was especially brought home to the American people when the Lusitania was sunk in I9I5, killing more than a thousand people, including many Americans. Some German submarines crossed the ocean and came to an American port bringing merchandise, The use that has been made of these submarines shows how well perfected they have become. It is a possibility of the near future that one may travel across the ocean in a submarine submerged all the 
way, and may thus avoid the dangers and inconveniences of storms. It will be interesting to go back a number of years and trace the history of the submarine from its early stages.

Submarines in the Revolutionary War. During the Revolutionary War, David Bushnell made an attempt with a submarine to blow up a British frigate in New York harbor. He actually succeeded in getting under one of the warships with a magazine of powder; but in trying to fasten this to the vessel by means of a screw, he struck it against a bar of

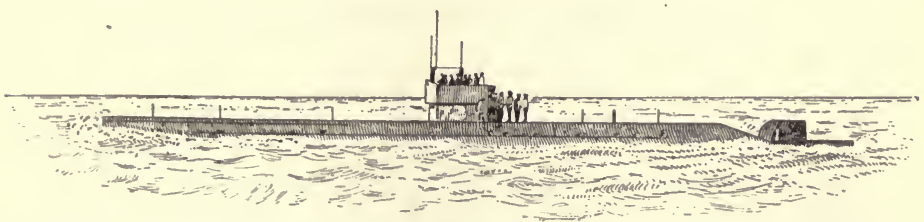

FIG. II6. - A modern submarine.

iron. While trying to find another place, he drifted away from the ship and could not find it again.

Robert Fulton directed his attention to submarines about the year I800. His experiments were partially successful for he constructed a submarine which descended to a depth of twenty-five feet and remained three hours. $\mathrm{He}$ also showed how it was possible to use a submarine to blow up other boats in time of warfare.

Submarines in the Civil War. We hear again of submarines during the Civil War, when the Confederates constructed submarine boats called "Davids." One of these was successful in sinking ore of the United States steamships, the Hoosatonic, by means of a torpedo. The submarine itself, however, was disabled by the explosion and sank to the bottom with its crew.

Holland submarine. The first really successful submarines were built by Mr. Holland during the nineties. In 1892 the 
United States Government made an appropriation to be used for the construction of submarines for the navy, and decided to adopt the Holland type. The first Holland was completed as a torpedo boat in I900. These have been greatly improved and have been adopted by the more important navies of the world.

How they rise and sink. Submarines are now made so that they can run either on the surface or submerged. They are made to sink by admitting water to tanks, and can be made to dive by the action of the propeller and a horizontal rudder. They are made to rise again by pumping out the

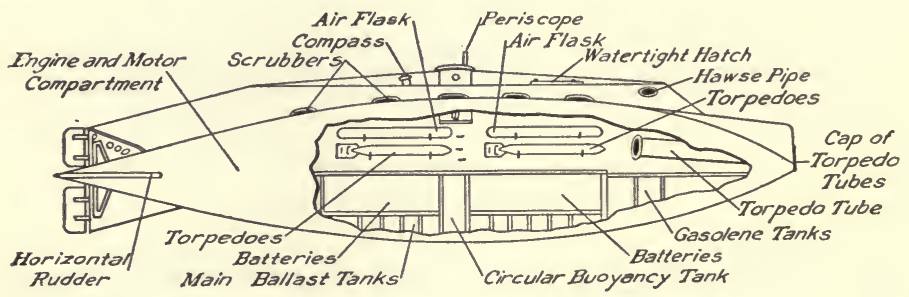

FIG. II7. - Sectional view of submarine (Holland type).

water. The depth to which they sink is indicated by means of gauges. The shell of the boat is made of strong steel so as to withstand the tremendous pressure of the water far below the surface.

\section{Demonstration 22}

Purpose. To see how the submarine is made to rise and sink. Apparatus. Large-mouth bottle, rubber stopper with two holes, glass tubing, and rubber tube.

Directions. Fill the bottle with water. Push a piece of glass tubing through one of the holes in the rubber stopper. Push one end of the rubber tubing over the glass tube. Put the stopper in the bottle and put the bottle in a dish of water. Blow through the rubber tubing till the water is forced out of the bottle. What happens to the bottle? Why? Fill the 
bottle again with water and put it in the dish. What happens? Why?

Some of the latest submarines are several hundred feet long. They can travel when submerged in knots an hour, and on the surface I 7 knots; they are able to travel I40 miles under water and 5000 miles on the surface. One type is 2 I feet wide, has accommodations for $27 \mathrm{men}$, and carries provisions to last 30 days. During the European War great improvements in submarines were made by the Ger-

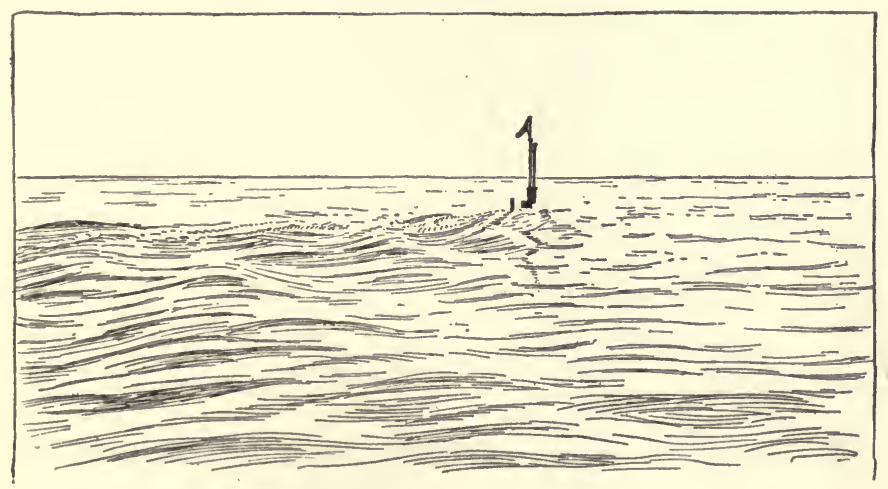

FIG. 118. - Submarine diving.

mans, but the exact details of construction are not yet generally known.

How the submarine is propelled. Two sources of power are used for propelling the boat. When the boat is on the surface, a gasoline or oil engine is used to run the boat, and this also runs a dynamo which charges a storage battery. When the boat is under water, the gasoline engine is shut off, and the propeller is turned by a motor run by electricity from the storage battery. This also furnishes electricity for lighting the boat and for cooking. 
In order to supply air for the passengers, tanks of compressed air are carried. In submarines used for war pur-

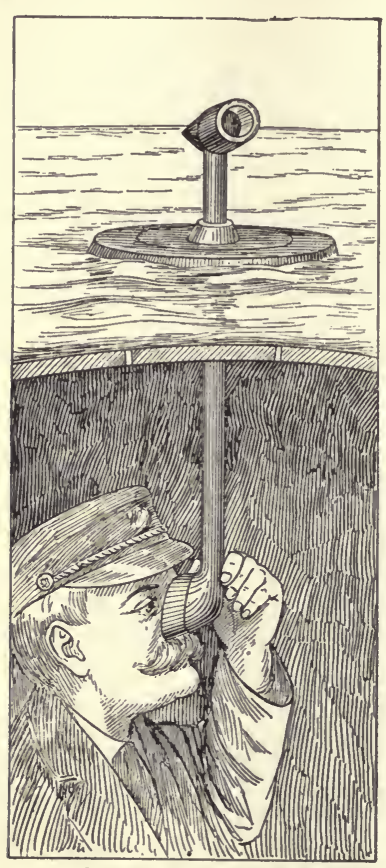

Courtesy of Harper \& Brothers

FIG. II9.--Periscope of submarine. poses compressed air is also used to work machines to discharge torpedoes. These are arranged so that they can be discharged at an enemy's ship a long distance away.

Periscope. To enable the people in a submarine to see the surroundings on the surface of the water, a periscope is used. This consists of a long tube reaching to the surface of the water and containing mirrors so arranged that one looking through a telescope in the boat is able to see what is in front of the periscope. It can be turned so as to face any part of the horizon.

\section{SUPPLEMENTARY QUESTIONS FOR CLASS DISCUSSION}

I. Summarize briefly the changes that have taken place in the steamboat during the last hundred years.

2. What conveniences are found on a modern trans-Atlantic steamship?

3. How does the steam turbine differ from the ordinary steam engine used on the locomotive?

4. Why is the gyro-compass taking the place of the ordinary compass as a means of guiding ships?

5. What provisions have steamships as a protection against accidents?

6. What uses can be made of the submarine boat in times of peace? 
7. What features are found on the submarine that are not found on the ordinary boat?

\section{REFERENCES}

Cressey, Discoveries and Inventions of the Twentieth Century,

E. P. Dutton Co., New York City. Chap. I 5 and pages 328333 (Submarines).

Darrow, The Boys' Own Book of Great Inventions, Macmillan Co.,

New York City. Chapter Io (Submarines).

Doubleday, Stories of Inventors, Doubleday Page and Co.,

New York City. Pages 85-97 and I53-I8I (Submarines). Holland, Historic Inventions, G. W. Jacobs Co., Philadelphia. Chap. 7 .

Howden, Boys' Book of Steamships, McClure Co., New York City.

Johnson, Modern Inventions, F. A. Stokes Co., New York City. Chap. 2 (Submarines).

Maule, Boys' Book of New Inventions, Grosset and Dunlap, New York City. Chap. 8 (Turbines). 


\section{CHAPTER XX}

\section{AIRSHIPS AND AIRPLANES}

I. What progress has been made in the last twenty years in the development of air navigation?

2. How do the airship and the airplane differ in their construction and the method by which they are kept in the air?

During the European War frequent references were made in the newspapers to the use that was being made of airplanes and airships, especially of the Zeppelins in their air raids on England. Some idea of the distance these airships can travel is given by the fact that frequent raids were made on London, showing that these ships can travel from Germany to London and return without alighting.

In our own country, the United States Government is authorized by Congress to spend $\$ 300,000$ annually for carrying mails by air routes. During the Mexican disturbance, when American soldiers were camping in Mexico, mail was taken almost daily from Columbus, New Mexico, to General Pershing's headquarters, a distance of over 400 miles.

During the summer of 1918 a regular aërial mail route was established between New York and Washington, and between New York and Chicago. (See figure 120.) Regular trips are made each way daily except on Sunday. The trip from New York to Washington (225 miles), which is made by the trains in 6 hours, is made by the airplanes in two and a half or three hours. The trip between New York and Chicago (850 
miles), which is made by the fastest trains in $2 \mathbf{I}$ hours, is made by the airplanes in 9 hours. Plans are being made to extend this service to other cities.

It has been suggested that further application of airplanes may be made by using hydroplanes along lakes and rivers to patrol forests so as to enable the foresters to more efficiently control forest fires.

Let us notice the early attempts that were made to navigate the air and see what progress has been made up to the

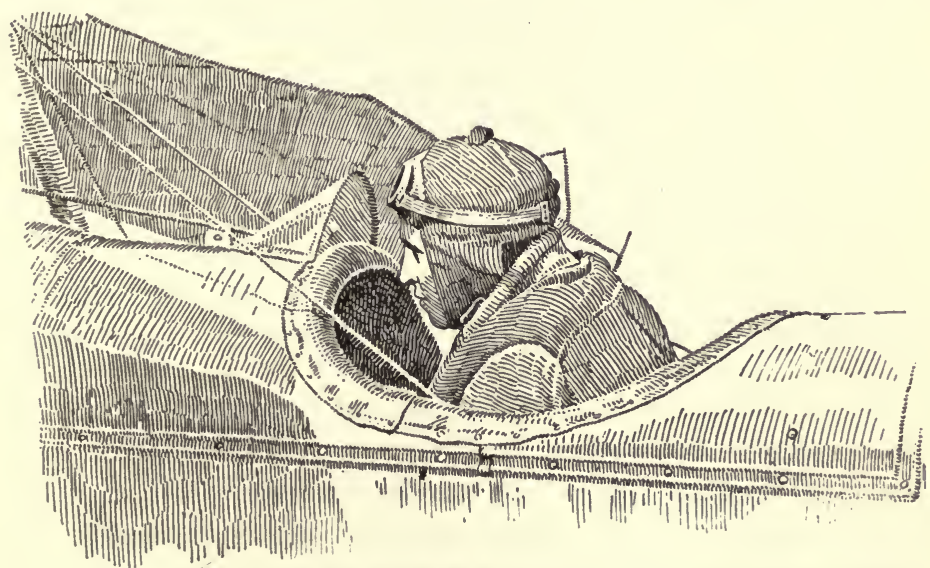

Fig. 1 20. - One of Uncle Sam's new aërial postmen, Lieut. Culver, who started from Washington during the summer of 1918 in the first aërial mail flight.

present time, especially the very remarkable progress within the last ten years.

Early history of balloons. The first experiments with balloons were carried on in France. The first man to ascend in a balloon was M. de Rozier, who in ${ }^{7} 78_{3}$ rose to a height of about 84 feet, the balloon being held captive with ropes. This was made to rise by building a fire on a grate situated at the bottom of the balloon, and as the air became heated the balloon rose bearing with it M. de Rozier, who 
kept the balloon in the air for about five minutes by throwing straw and wood on the fire.

About a month later another ascent was made by two men, and the balloon was allowed to go free with the wind. The men descended about five miles from the starting place, the journey taking about 25 minutes.

In less than a month after this, another ascent was made by two other Frenchmen in a balloon filled with hydrogen gas. The journey lasted about an hour and a half and the men landed about thirty miles from the place from which they started. The first ascent in America was made during the last of December of the same year. After this, experiments were carried on in other countries and many improvements were made.

Why a balloon rises. The principle involved in the rise of the balloon is similar to that in the floating of a boat. It is much the same as though a diver in the water should set free a block of wood. It would at once rise to the surface because it is lighter than water. The balloon rises till it weighs the same as an equal volume of air around it, the air being lighter the higher up one goes. The balloon continues to float at this height and is carried by the wind till some of the gas escapes, and then the balloon gradually falls to the ground. When the balloonist wishes to rise higher, he throws out sand bags which have been placed in the basket of the balloon; this makes it lighter, and hence it rises. If the balloonist wishes to descend, he pulls a line that opens a valve which allows the gas to escape, and so the balloon sinks.

\section{Demonstration 23}

Purpose. To illustrate the principle of the balloon.

Apparatus. Large-mouth bottle, rubber stopper with two holes, thistle tube, zinc, hydrochloric acid, rubber tubing.

Directions. Put some granulated zinc in the bottle. Bend a short glass tube at right angles and push one end in one of 
the holes in the stopper. Put a thistle tube through the other hole. Put the stopper in the bottle. Push down the thistle tube nearly to the bottom of the bottle. Add water till it rises to cover the end of the thistle tube. Push one end of a rubber tubing over the end of the right angle tube. Make some soapsuds in warm water. Dip the end of the rubber tubing into the soapsuds. Add hydrochloric acid through the thistle tube. Hydrogen will be generated and will pass out through the tube into the soapsuds. Remove the tube from the suds and allow a bubble to form on the end of the tube. Shake it off. Why does it rise? This same gas is often used to fill balloons. Apply a lighted match to a floating bubble.

Balloons for military purposes. Balloons were used for military purposes during the Civil War, serving as a vantage point from which the enemy's works could be seen. Since that time all the large countries have made some use of balloons as a part of their military equipment.

Dirigible balloon. The next great step in the development of air navigation was the appearance of the dirigible

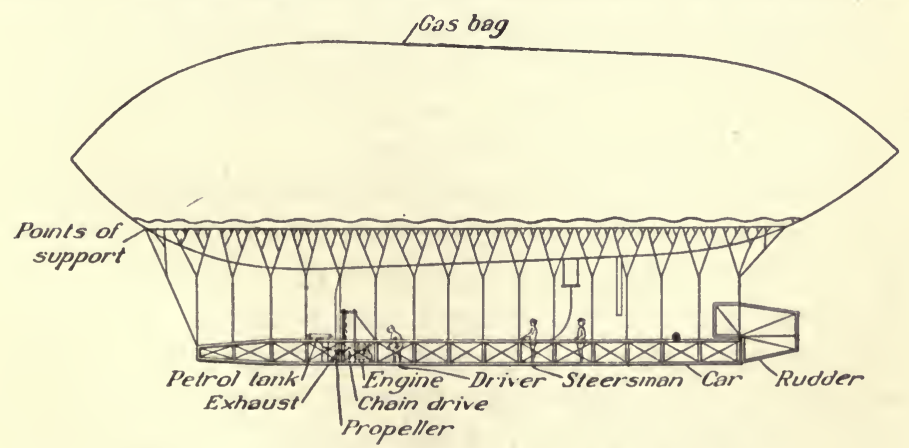

FIG. I21. - Longitudinal view of typical dirigible balloon.

balloon, or airship. This was propelled by artificial means and steered by a rudder. The first attempts were not very successful on account of the great weight of the engines used, and it was not until light engines of great horse power 
were developed that much progress was made in air navigation.

The first successful journey in a dirigible balloon was made in France in I884. Although this was a short journey of only two or three miles and return, it showed the possibilities that there are in this kind of airship. During the last fifteen or twenty years great strides have been made in the development of airships, France and Germany taking the lead.

Santos Dumont. Santos Dumont was the first man to attain any great success with airships. He was a Brazilian by birth, but he carried on most of his experiments in France. He began his experiments about 1898 and his many remarkable successes attracted much attention. One of the chief of these was his trip around the Eiffel Tower and return to his starting place.

Zeppelins. Modern airships are of three types, - rigid, non-rigid, and semi-rigid. The best known of the rigid type are those of Count Zeppelin of Germany, who began experimenting with airships about I898. The success he has attained since then is well known the world over. He began the construction of airships of a gigantic size, much larger than had ever before been attempted.

The framework of the Zeppelin is made of aluminum, and it is divided into separate compartments, each of which contains a gas bag filled with hydrogen gas. Suspended from this frame are two boat-shaped cars between which is a weight running on a rail, by which the balance of the ship fore and aft can be adjusted. The ship is driven by means of four propellers, ten feet in diameter, each with three blades. These are turned by two powerful engines of I Io horse power, one in each car.

At the rear end are two planes, which give greater stability when the airship is traveling rapidly. Steering up and down is effected by means of elevating planes, and steer- 
ing to the right and left is controlled by a triple rudder placed at the rear. The entire ship is about the size of an ocean steamer, being 500 feet long and about 50 feet in diameter. It weighs about ten tons and can carry six tons in addition to fuel, cargo, and passengers. It can travel at a speed of thirty miles an hour. Before the war a regular passenger service was kept up in Germany; and in seven months 183 journeys were made, carrying all together nearly 4000 passengers. These airships were capable of carrying twentyfour persons and were fitted with a cabin and restaurant.

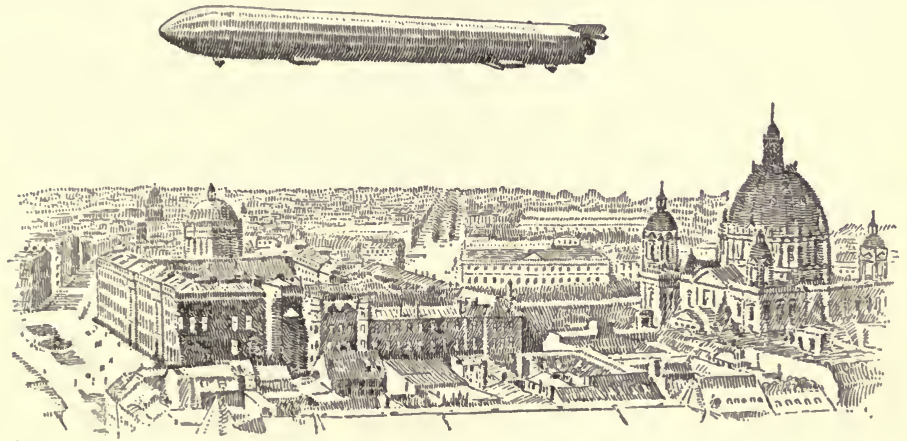

FIg. 122. - A Zeppelin airship over Berlin.

Later forms of the Zeppelins have three cars and eight engines, with a total of 820 horse power. These have attained a speed of 75 miles an hour and can stay aloft for four days and nights.

History of airplanes. Leaving the subject of balloons and airships, we now come to a study of airplanes, machines that are heavier than air, and use no gas to hold them up. For thousands of years men have tried to devise means of flying. The first crude attempts were made to imitate the shape and motion of a bird's wing.

In I886 Mr. Wenhane constructed a machine, which contained a number of surfaces arranged in tiers one above 
the other; for he believed that a single surface large enough to support a man could not be controlled on account of its great size. He performed some interesting experiments, but he was not able to accomplish a flight.

About twenty years later Otto Lilienthal, in Berlin, carried on experiments in gliding or soaring. He used large wings, and starting from a height of fifty feet or less he would glide with the wind. In one of these flights he was killed.

Langley's experiments. Professor Langley of Washington, D. C., carried on some successful experiments about twenty years ago which contributed much to the progress of flying machines. He built a small model of a flying machine not large enough to carry a person. It was provided with two sets of wings about twelve feet wide and the whole machine was about sixteen feet long. It was driven by a propeller turned by a small steam engine. It was steered by a rudder which worked automatically. After several years of experimenting, the machine made a successful flight in 1896 , remaining in the air for a minute and a half. This was the first flying machine ever made that actually propelled itself through the air driven by an engine. It is amazing to think of the progress that has been made in the twenty years that have elapsed since then.

Wright Brothers. In our own country the Wright brothers carried on successful experiments in gliding during I900 and the years following. They found that a vertical rudder in the rear was the best method of steering to the left and right, and that a horizontal rudder in the front was the best means of guiding the machine up and down. In I902 they accomplished a glide of 300 yards. In I 903 they attached an engine to one of their machines and made their first successful flight. Two years later they made a flight of 24 miles and landed in safety.

In I908 Wilbur Wright took his machine to France and demonstrated the practical value of the airplane. He re- 
mained in the air more than two hours, and carried passengers at a height of 400 feet. From this time on very rapid progress was made in the development of the airplane.

Crossing English Channel. A prize of Iooo pounds was offered by an English newspaper to the first man who should cross the English Channel in an airplane. Several attempts were made to win this prize. The first attempt was made by a young Frenchman, M. Hubert Latham; but he was unsuccessful, for his engine stopped after he had started across the Channel, and he was obliged to descend to the water by a series of long glides. His machine floated, however, and

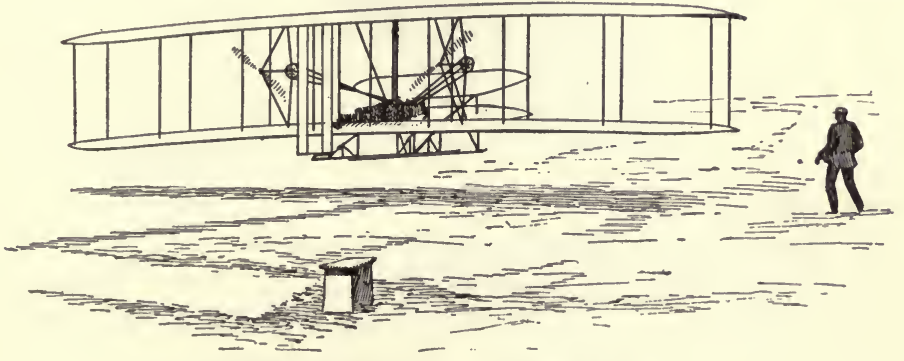

FIG. I23. - First Wright plane.

he was rescued. The next attempt was made by another Frenchman, Louis Bleriot, who successfully flew across the Channel from France to England on July 25, 1909, and thus won the prize.

In August of the same year the first aviation meet was held at Rheims. Here many wonderful feats were performed in a great variety of airships and airplanes. A prize was offered for the one making the greatest speed, and another for the one attaining the greatest height. The prize for height was won by a Frenchman, M. Latham, who reached a height of 500 feet. The prize for speed was won by an American, Glenn H. Curtiss, who flew at the rate of 47 miles an hour. 
Since then tremendous progress has been made in air navigation in the distances covered, in the speeds attained, in the heights reached, and in the number of passengers carried.

Distances. During the latter part of I909, Wilbur Wright flew with a passenger for an hour and a half. Henry Farnam remained in the air four hours. In I9 Io Paulhan flew from London to Manchester, a distance of I83 miles, with only one stop, and won the prize of I0,000 pounds offered by the Daily Mail of London. In America, Curtiss flew from Albany to New York, a distance of I 50 miles, with only one stop. In I9I I long flights, varying from 800 to Ioo0 miles, were made in various parts of Europe. During the latter part of I9r6 an American woman, Ruth Law, made a continuous flight from Chicago to Hornell, New York, a distance of 590 miles. The entire trip from Chicago to Governor's Island, near New York City, a distance of about 900 miles, was made in a little less than nine hours at an average speed of about roo miles an hour. In I916 Lieutenant Marchal made a non-stop flight of 8 r 2 miles from France to Poland. And now some of the experts prophesy that a trans-Atlantic flight will be made in the near future.

Speed. There has also been a wonderful gain in the speed attained. In I9I2 a speed of 72 miles an hour was reached. In I9I6 in America, Mr. Carlstrom traveled a distance of 3 I 5 miles at the rate of 137 miles an hour, or more than two miles a minute. From 47 miles an hour to 137 miles is the progress made in seven years. Army airplanes are reported to have traveled at the rate of more than I50 miles an hour. In January, I9I8, two men in a plane driven by liberty motors were reported in the newspapers to have traveled from Dayton to Cleveland, Ohio, a distance of 2 I 5 miles, in I hour and ${ }_{5}$ minutes. This is at the rate of 172 miles an hour. 
Other lines of progress. Each year sees a new record established in the height attained by airplanes. In I9I9 Captain Schroeder of the United States Army Air Service ascended to a height of 28,900 feet. This is about the same as the height of Mt. Everest, the highest mountain in the world. Still more recently an Englishman is reported to have reached a height of 30,000 feet.

Greater weights are being carried, and airplanes are now made to carry a number of passengers. A Curtis seaplane

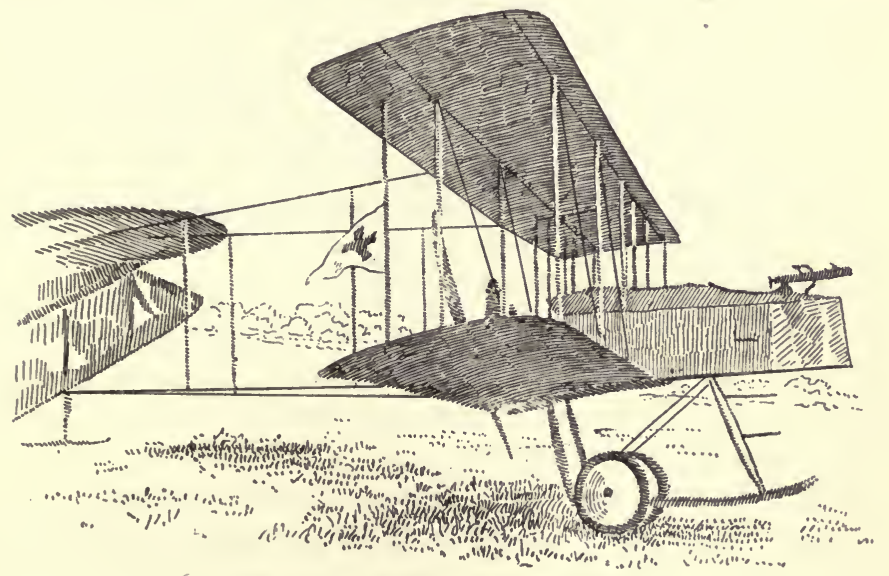

FIG. 124. - English military biplane.

recently carried 50 passengers. Some airplanes can carry Io,000 pounds in excess of their own weight.

Progress is also being made in safeguarding air travel. The serious accident, excepting with war planes, is now the exception. The Aero Club in France made an investigation, which showed that during I9I2 only one fatal accident occurred for every 92,000 miles flown.

Airplanes in war. Even before the great European War, the leading nations had spent large sums of money on airplanes, and the airplane branch was an important adjunct 
to the army. During this war airplanes have served an important purpose as scouts, to examine the enemies' redoubts, to take photographs, to detect movements of soldiers, and to direct the artillery fire.

Several distinct types of airplanes have been devised for war purposes, such as the scouting plane, the fighting plane, and the bombing plane. The crew of a scouting plane consists of a pilot and observer. It can travel at great speed and was used to report movements of the enemy, to take photographs, and to direct artillery fire by means of the wireless outfit with which it is provided. The fighting plane carried one person and was built to climb quickly and fly faster than any other type of plane. (See figure I 25.) This was equipped with a machine gun which could be fired straight ahead, between the propeller blades, without hitting them. The bombing planes have been well called the dreadnaughts of the air. (See figure I26.) They are large and powerful and so constructed that they can carry between one and two tons of explosives. These were used to drop bombs on vital portions of the enemies' lines such as supply depots and railway junctions.

During this war such tremendous strides have been made in the art of flying there seems little doubt that flying machines and airships will soon be common throughout the civilized world, and will be used for commercial purposes to transport passengers and cargoes. Doubtless more rapid development in air navigation was made during the four years of war than would have been made in fifteen or twenty years in peace times.

How the airplane is kept up. Having traced the development of the airplane from its crude beginnings to its present perfected state, we may next inquire how it is constructed and on what principle it works. The balloon is kept up because the gas which it contains is lighter than air; but the airplane is heavier than air and is kept up by a different 
principle. It is very much like the principle illustrated in the flying of a kite. In the first attempts that were made to fly, efforts were made to imitate the flapping action of a bird's wing; but to-day airplanes are made in accordance with the principles governing the soaring bird and the kite. If a person holding the string of a flying kite runs against the wind, the kite rises. There are three forces acting on the surface of the kite: the wind, the string, and the weight of the kite. In the airplane, the pull of the string is replaced by the motion of the propellers, which urge the air-

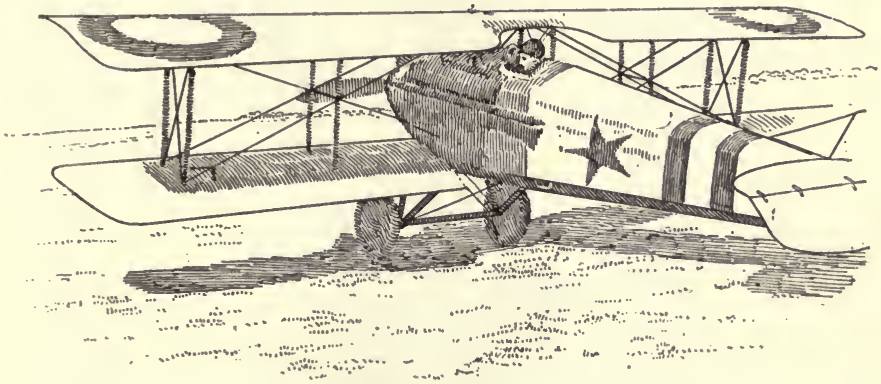

FIG. 125. - French fighting airplane, known as the S.P.A.D.

plane onward until a sufficient wind is generated to lift the airplane.

Shape of planes. Experiments have shown that the best shape for a plane is a long, narrow surface, with the long edge at right angles to the direction of flight. Some birds have wings that are fourteen times as long as broad. These planes are now made with a slightly curved surface, as it is found that these have greater lifting power than those with flat surfaces.

Stability. While flying, the planes encounter many cross currents of air, which tend to make the airplanes unstable. In order to give the plane more stability in a longitudinal direction, in which the plane is traveling, one or two hori- 


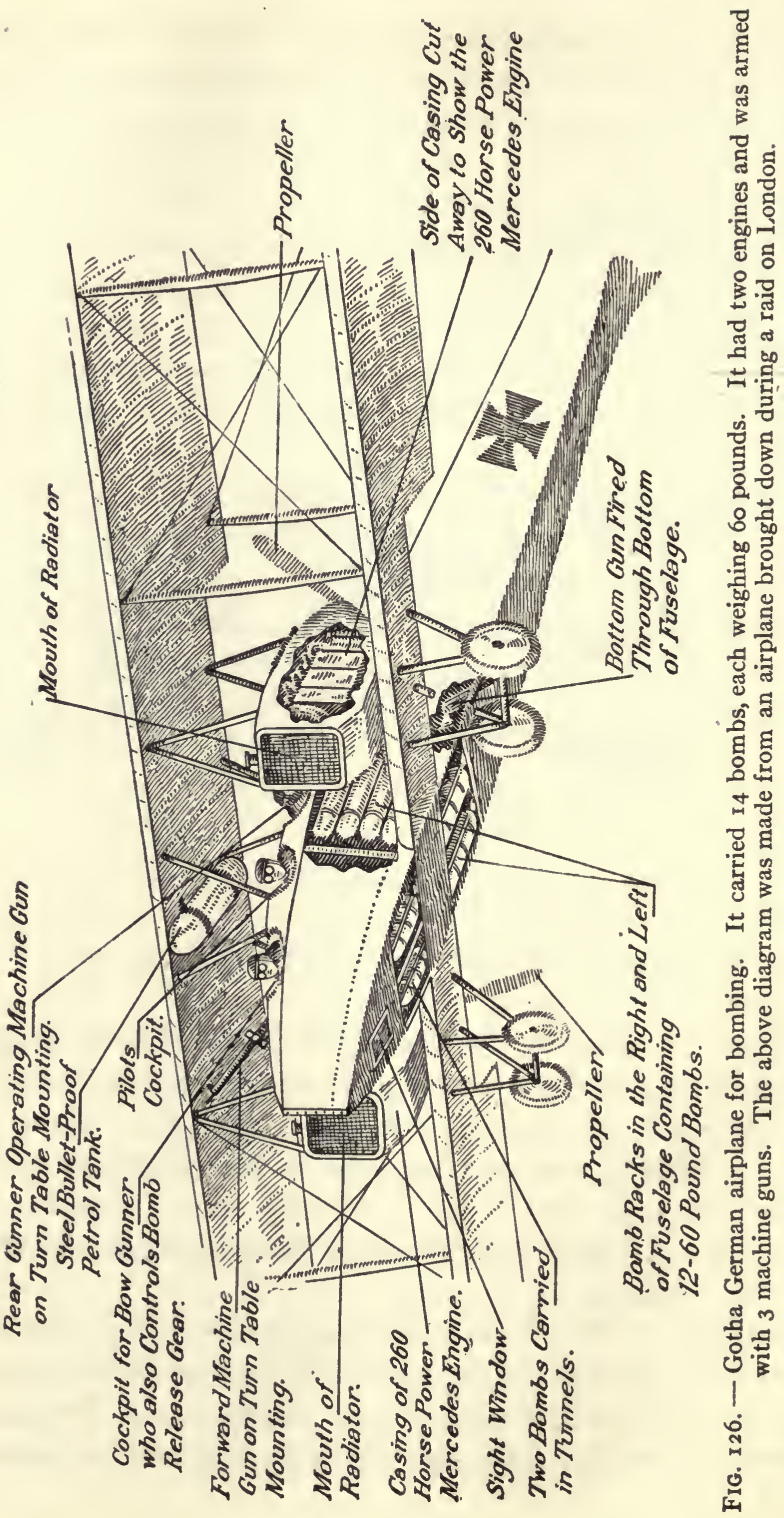


zontal planes are attached to the rear. To give stability in a lateral direction, several devices are used. In the Wright biplanes, flaps hang down from the main planes, which can be raised or lowered. Another method often found on monoplanes is a warping of the tips of the planes. Experiments have been made with automatic devices to keep the plane stable, such as a pendulum or gyroscope; but so far with little success.

Power. Gasoline engines are used to furnish the power to propel airplanes, because they are light and powerful. Engines of great horse power are being used. The propellers are commonly two bladed and from five to ten feet in diameter. They may be placed either in front or behind. They may be single or double.

Starting the airplane. In order that an airplane shall glide through the air, it must have an initial motion given it before it is launched. The Wright brothers in their first experiments started their machine by means of a heavy falling weight, which drew the machine along a track. Modern machines are mounted on wheels, and the motion is started by the propellers, which force the machine over the ground. The same wheels that serve for starting also serve for alighting. Sometimes these are provided with brakes, and sometimes the machine has skids, on which it alights and stops in a short distance. Hydroplanes are now made which can start from the water and alight on it. The wheels are replaced with floats, which keep the machine on the surface of the water.

Running the airplane. For steering there must be two sets of rudders, one to guide the plane up and down, and one to guide it to the right and left. The horizontal plane used for the first purpose may be placed either in front or at the rear. The vertical plane for the second purpose is placed at the rear. These planes are both controlled by levers within easy reach of the aviator. 
The direction of flight depends on the speed of the machine and on the angle that the planes make with the direction in which the machine is being driven. An increase in the angle or in the speed tends to make the machine rise, a decrease to make it fall, so that by the proper adjustment of speed and angle the machine may be made to go in a horizontal plane. As the direction of the wind is constantly changing, the aviator must change the angle of the planes to correspond.

Airplanes easily tip from side to side on account of the variation in air currents on the two sides. This tendency

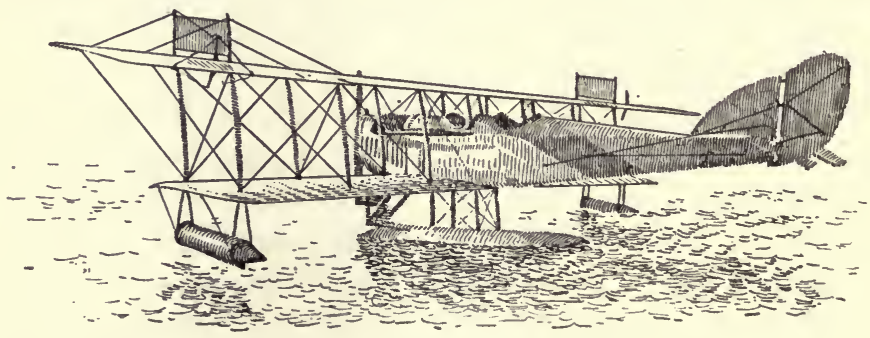

Fig. I27. - Seaplane scout, a submarine chaser of the air.

to tip must be neutralized in some way by the aviator. This is most frequently done by warping the tips of the planes, or through a motion of small flaps attached to the main planes. These are controlled by means of a lever, which connects with the tips by means of wires. They are so arranged that as the tip on one side is warped up, the tip on the other side is warped down. They can be so manipulated as to check the tendency of the machine to rock from side to side.

In making a turn, the part of the machine on the outside of the curve travels faster than the part on the inner side and so tends to rise. This tendency is controlled by warping the tips of the planes just as in keeping the machine balanced in ordinary flight. In the first planes the aviator was ex- 
posed to the weather, but in the later ones inclosed cabins are made.

Types of airplanes. Two types of airplanes are being commonly used, the monoplane and the biplane. And in recent years triplanes are being made. The monoplane has one large plane on each side; while the biplane has two planes on each side, one above the other. Biplanes are slower than monoplanes, but they can carry heavier loads. A brief description will be given of one of each of the first two types.

Bleriot monoplane. The Bleriot monoplane, which is made to carry two passengers, is $27 \frac{1}{2}$ feet long and has a span from

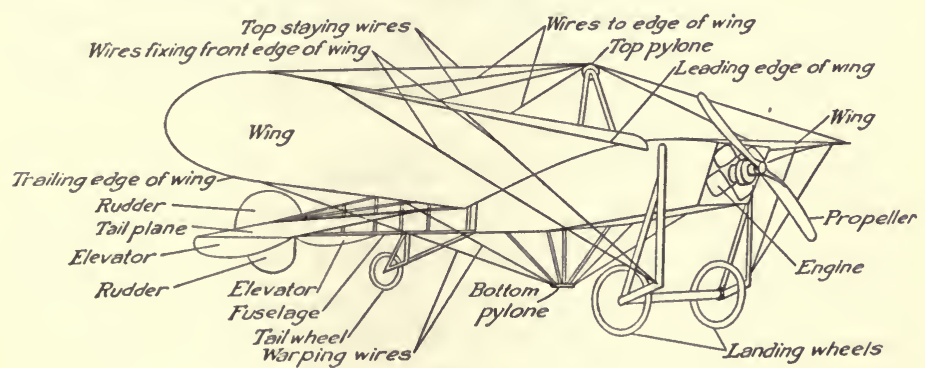

Fig. I28. - Bleriot monoplane.

tip to tip of 36 feet. The area of the main plane is 263 square feet. The whole machine weighs 700 pounds, and it is driven by a gasoline engine of 50 horse power. One lever, moved by hand, controls the warping of the wings when moved in one direction, and governs the lifting tail when moved in another. The rudder is controlled by a foot pedal.

Wright biplane. The Wright biplane has two canvas-. covered wings arranged one above the other about 6 feet apart. Each wing is 40 feet wide and $6 \frac{1}{2}$ feet long. The total area of these wings is 500 square feet. In the first machines there were placed in front two smaller horizontal planes, with an area of about 60 square feet, which could be 
warped so as to steer the machine up and down. In the later machines these planes are mounted in the rear. At the rear also there are two vertical rudders for steering the machine to the right and left. The balance is maintained by warping the rear corners of the wings, which are made movable. A single lever controls both the warping of the wings and the action of the two vertical rudders.

On the frame between the two main wings are carried the engine and the seats for the operator and passenger. The machine weighs 900 pounds and is driven by a 25 horse power gasoline engine, which turns two twin-bladed propellers in opposite directions at the rate of 400 revolutions a minute. If anything should happen to stop the engine while in the air, the machine can glide to the ground and land safely. The later machines are provided with wheels for starting and alighting.

Comparison of airship and airplane. In comparing the airship and airplane, we find that each has its advantages. The airship is safer, can carry a much greater weight, and can stay in the air longer. On the other hand, the airplane can travel faster and is much smaller and cheaper to make. We might perhaps compare the airship with the freight train that carries heavy loads and the airplane with the express train that carries lighter loads and travels faster.

There seems little question that within a short time regular passenger routes by means of airships and airplanes will be established in this country, and that we may soon have the novel sensation of traveling through the air faster than the express train travels. And all the time we shall be enjoying a magnificent view of the country over which we are passing.

Shortly after the signing of the armistice in November, I918, there was established an air passenger service between London and Paris. The journey takes only $2 \frac{1}{2}$ hours. Dur- 
ing two months I 200 passengers were carried across the Channel.

\section{SUPPLEMENTARY QUESTIONS FOR CLASS DISCUSSION}

I. Which seems to have greater possibilities for the future, the airship or the airplane?

2. How does the airman control his airplane?

3. How are airplanes kept from tipping?

\section{REFERENCES}

Cressey, Discoveries and Inventions of the Twentieth Century,

E. P. Dutton Co., New York City. Chap. I6.

Darrow, The Boys' Own Book of Great Inventions, Macmillan Co.,

New York City. Chaps. 8-9.

Delacombe, Boys' Book of Airships, F. A. Stokes Co., New York City.

Johnson, Modern Inventions, F. A. Stokes Co., New York City. Chaps. 3, 4, 6, 7 .

Maule, Boys'. Book of New Inventions, Grosset and Dunlap,

New York City. Chaps. I-3.

Navigating the Air, by the Aero Club, Doubleday Page and Co.,

New York City. 


\section{SECTION B \\ Means of Communication}

\section{CHAPTER XXI}

\section{THE TELEGRAPH}

I. What are the essential parts of a telegraph system? how do they work?

2. How does the wireless telegraph differ from the ordinary telegraph?

Use of the telegraph in daily life. There are many wonderful machines, very important in our daily lives, to which we have become so accustomed that we hardly realize what they do for us. This is true of the telegraph. Let us stop for a moment to see how much we owe to this wonderful little instrument. We are apt to think of the telegraph only in connection with bringing the sad news of the death or sickness of a friend or relative. But this is only an occasional use. We receive the benefit of the telegraph every day of our lives, many times unconsciously.

Newspapers. Each day the newspaper brings to our doors news which has been flashed from every part of the world by the telegraph. We were able to follow the happenings of the great war in Europe from day to day, and to receive the news of a battle only a few hours after it was fought. When President Wilson makes a speech in any part of the United States or Europe, the next day's papers give the entire speech to all parts of the country. As one 
looks over the items of a daily newspaper, it will be found that the great majority of items have been sent in by telegraph.

Elections. On election day citizens in all parts of the country cast their ballots. By midnight of the same day returns are telegraphed into headquarters, and even in presidential elections by the next morning the whole country usually knows who has been elected president.

Baseball. During the World Series of baseball games between Boston and Brooklyn in I9I6, thousands of baseball fans were gathered together in all the large cities near the telegraph offices, and were able to watch the returns inning by inning as they were brought in by the telegraph, and only a few minutes after the fourth game was finished, these thousands of people knew that Boston had again won the world's championship.

Weather forecast. Each day's paper contains the weather forecast of the next day's weather. This is made possible because reports of weather conditions in two hundred localities are telegraphed to Washington and other cities, where forecasts of weather are made as a result of these reports.

Railroads. The telegraph is indispensable in the running of railroad trains. As explained in Chapter XVI, whenever a train arrives at a station, the news is telegraphed to a man called a dispatcher located at headquarters, who arranges the places where the trains shall meet and pass, thus avoiding accidents.

Clocks run by telegraph. Clocks may now be regulated by electricity. A certain accurate clock is taken as the standard; other clocks, connected with this, have a mechanism so that the minute hand is set forward or back, as may be necessary to keep the clock in unison with the standard clock.

Other uses. The telegraph is of great value to the business man in his ordinary business transactions. If he wishes to order some material which he needs at once, he can send a telegram and secure the order on the next train. If a 
great flood or fire devastates a city and leaves the people destitute and homeless, the telegraph sends out the news and relief comes back at once.

Compare the conditions to-day with those a hundred years ago, when there were no railroads nor telegraphs. The battle of New Orleans, in the War of I8I2, was fought after the treaty of peace had been signed, because the news traveled so slowly that the soldiers had not yet learned that the war was ended.

History of the telegraph. On May 24, I844, the now famous words, "What hath God wrought," were sent by

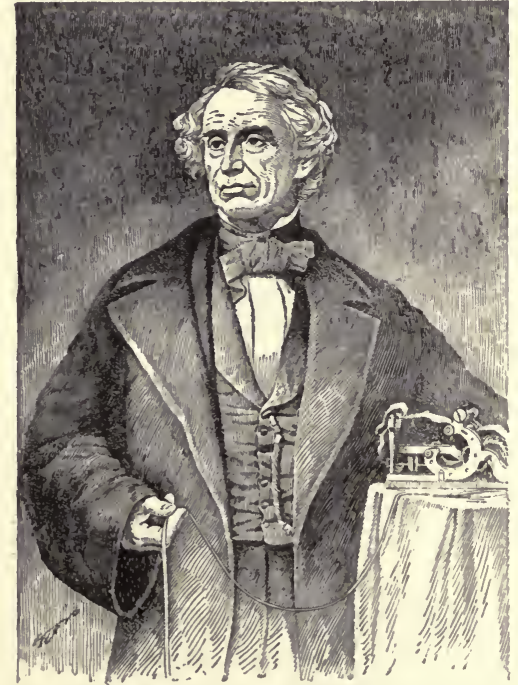

Fig. 129. - Morse and his first instrument. telegraph from Washington to Baltimore, a distance of forty miles. The credit for this achievement of being the first to send messages at this distance belongs to Samuel Morse. Back of this success, however, is a story of struggle, poverty, and persistence. Samuel Morse was a professor in the University of the City of New York, and he gave his spare time to a study of electricity. In $\mathrm{I}_{32} 2$ he conceived the idea of conveying signals at a distance by means of electricity. He worked for eleven years in perfecting his instrument, which was finally finished in 1843 . He then devised a system of dots and dashes for sending messages. During this period he underwent many deprivations in order to get enough money to carry on his experiments. 
Before this, many experiments had been tried in sending messages by electricity; some had been partially successful, but none of them had suggested any possibility of commercial success. Morse's success was made possible only through the inventions of other men, whose results he put together in the construction of the telegraph. Two of the most important of these were the invention of the electric magnet and of a constant battery to furnish electricity.

He made application to Congress for aid to build a telegraphic line between Washington and Baltimore. He was finally successful in his appeal and in 1843 received an appropriation of $\$ 30,000$. With this, a line between the two cities was constructed and the first message was sent.

This first line proved so successful that the telegraph was soon in use in all parts of the world. By I86 I a line had been built connecting New York with San Francisco.

To-day there is a network of telegraph lines extending over the whole country. In I9I4 there were 240,000 miles of line (equal to the distance to the moon) and $\mathrm{r}, 600,000$ miles of wire. In I9I 2 it was estimated that there were $90,000,000$ messages sent out, or nearly one for every person in the United States.

Atlantic cable. The next great step was the laying of the Atlantic cable in 1857 from Newfoundland to Ireland, so that messages could be sent across the ocean. The credit for this is due largely to Cyrus W. Field. After the cable had been used successfully for eighteen days, however, it ceased to work. At the close of the Civil War, Mr. Field determined to lay another cable. He started out in 1865 with 2300 miles of cable on board the Great Eastern, at that time the largest vessel in the world. About a thousand miles from starting, the cable parted and they were unable to find it. In the following year, I866, another attempt was made, which proved successful. From that time there has been telegraphic communication between America and Europe. 
How the telegraph works. Some improvements have been made in the telegraph since Morse's day, but in principle the telegraph in use to-day is the same as that invented by Morse. The telegraph consists of four parts, the sender, or key, the sounder, the relay, and the batteries. Figure I32

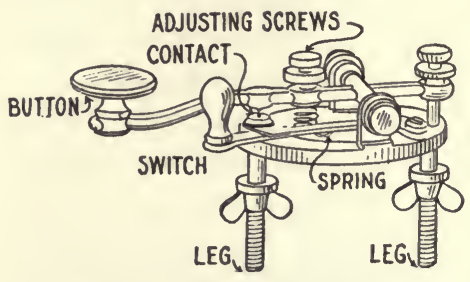

Fig. 130. - Telegraph key. shows how these various parts are arranged.

The key. The structure. of the sender, or key, is shown in figure 130 . This consists of a lever with a button at one end. On the under side is a point which makes contact with another point directly beneath it. These two points are ordinarily separated by a spring. When the key is not being used, the switch is shut so that the circuit is closed. When the key is to be used, the switch is opened. When the button is pushed down, the two points come in contact and the current passes through, thus affecting the relay and the sounder at the other end.

Sounder. The sounder is shown in figure $\mathrm{I} 3 \mathrm{I}$. This consists of two electromagnets, and over these a bar, pivoted at one end. Just over the electromagnets is

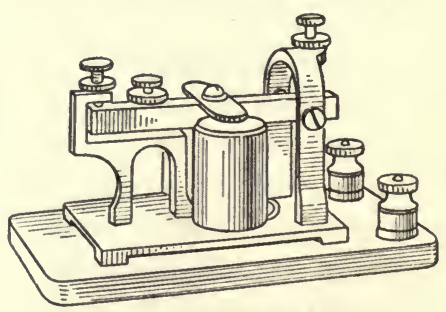

Fig. I31. - Telegraph sounder. the armature. Ordinarily the bar is kept back by a spring so that the armature does not touch the electromagnet. The distance that the bar can be pulled down is controlled by a screw. When the key of the sender is closed, the current passes through the coils of wire and the electromagnet becomes magnetized, thus pulling down the armature. When the key is open the current ceases to flow through the coils so 
that these are no longer a magnet, and hence the armature is pulled back by the spring. Thus two sounds are made, one when the armature is drawn down, and another when it is released by the striking of the bar against the screw.

Morse alphabet. When these two sounds come very close together, so that they seem as one, the signal is called a dot. Where they are separated by an appreciable time, so that two distinct sounds are heard, the signal is called a dash. The different letters are represented by various combinations of dots and dashes. The American code of the Morse alphabet is as follows: A - B - .. C . D - . E . F.—. G - C. H ... I .. J - C. K . - L $\mathrm{M}-\mathrm{N}-\mathrm{O} \ldots \mathrm{P} \ldots \mathrm{Q} \cdots \mathrm{R} \cdot \mathrm{R} \ldots \mathrm{T}-$

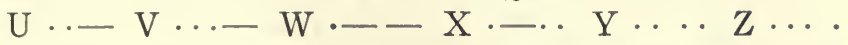

These dots and dashes may be recorded on a strip of paper run by clockwork, which passes under a point attached to the sounder. When the key is held down for a dash, a longer mark is made on the paper than when the key is held down for a dot. The telegraph operator can learn by practice to read the signals by ear and write them down directly as fast as they come in. This method is commonly used.

If the two stations are only a short distance apart, the sender, sounder, and batteries are all that are necessary for sending messages. But when the stations are long distances apart, the wire offers so much resistance that the sounder is worked only very weakly or not at all, so that no signals are transmitted.

Relay. To overcome this difficulty, a relay is used. The method of connecting this is shown in figure 132 . There are two distinct circuits, first, the long distance circuit which operates the relay, and second, the local circuit which operates the sounder. In the long distance circuit only one wire is needed as the ground serves as another conductor through which the current returns. The ends of the main 
line are attached to pieces of metal sunk in the ground so as to make good connections.

The relay (figures $\mathrm{I}_{32}$ and $\mathrm{I33}_{3}$ ) is somewhat like the sounder. It consists of an electromagnet and an armature.

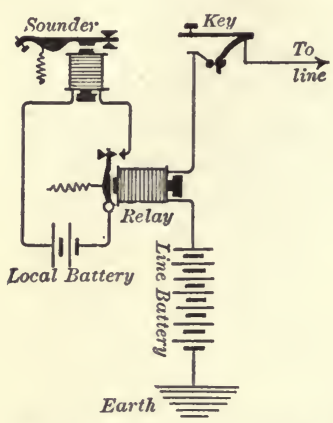

Fig. 132. - Diagram of relay telegraph circuit.

When a current passes through the magnet, the armature is drawn down and contact between two points is made. This closes the local circuit, and the local battery is brought into play, which operates the sounder. By means of these relays, telegrams may be sent long distances, even across the continent. The message may be sent to one city, as from New York to Chicago, and then the message can be repeated at Chicago and sent to San Francisco.

Duplex telegraphy. When the telegraph was first used, only one message could be sent at a time over the wire; but in a few years the system of duplex telegraphy was invented by means of which two messages could be sent at the same time in opposite directions. Then, later, diplex telegraphy made it possible to send two messages in the same direction at the same time on one wire. The next development allowed two messages to be sent from each end of the line

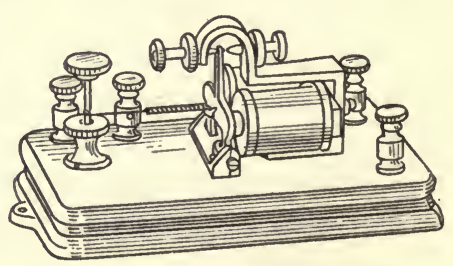

Fig. I33. - Telegraph relay. at the same time, or four in all. Now we have the multiplex telegraphy by means of which many messages can be sent in both directions at the same time. It has been found possible to send thirty-six messages in each direction at the same time. In actual practice, however, it has been found best to limit this to six in each direction. For this work twelve 
operators are needed at each end, six to send and six to receive; one line may thus employ twenty-four operators. For this there must be a separate key for each sender and a separate sounder for each receiver.

High speed telegraphy. When it is desired to transmit long messages for newspapers, the hand method of sending would be too slow. For this purpose machines are used which send messages with great rapidity. Several systems are able to send 400 words per minute. In one system words have been sent at rates varying from 1000 to 3000 words per minute. This is much more rapid than even the telephone.

The words of the message are first translated into the Morse alphabet, and perforations are made by a machine on a strip of paper to correspond to the dots and dashes of the alphabet. This is done by a machine much like a typewriter, each key of which makes the holes that correspond to the dots and dashes for that letter. This strip of paper is run through telegraphic instruments so arranged that the signals are transmitted to the other end.

Various means are used to receive these messages. One of the most common is an electrochemical receiver. Paper is covered with certain chemicals which are decomposed by the electric current and leave markings on the paper. One combination used is starch and potassium iodid. When this salt is decomposed, the iodin is set free, and when it comes in contact with the starch it produces a blue color. Machines are now in use which reproduce the message in typewritten form, ready for instant delivery and use. This machine has made a record of roo words a minute.

Facsimile telegraphy. Devices are now used which make it possible to transmit accurate copies of charts, diagrams, pictures, and signatures over a telegraph line. This is called facsimile telegraphy. If a person takes a pen in a telegraph office and writes a message, it is possible to reproduce it so accurately at the other end, that the handwriting may be 
recognized. Thus it is possible for a person to telegraph his signature to a check or other paper requiring a personal signature. This is called the writing telegraph or telautograph.

By means of the printing telegraph, messages may be sent so that they are received printed on a strip of paper. The stock ticker, which is one form of this, is very widely used among brokers.

\section{Demonstration 24}

Purpose. To show how a set of telegraph instruments work. Apparatus. Sounder, sender, relay, cells.

Directions. Connect the parts of the telegraph instruments including the relay, as shown in figure 132. Study each part carefully to see how it works. Make a drawing showing the connections. Try sending some of the letters of the Morse alphabet.

Wireless telegraphy. Use. If to-day a ship at sea is in danger of sinking on account of some accident, the operator of the wireless telegraph sends out the S. O. S. signal, the call for help. This travels in every direction for many miles, and some ship is almost certain to receive the message and will hasten then to the aid of the crippled ship. Thus many lives have been saved, and the sea is now robbed of many of its terrors by the wireless telegraph.

Nearly all the ocean liners are provided with wireless telegraph instruments, so that people on board can keep in communication with their friends on shore, and the business man can still direct his affairs. Daily newspapers are published on some of the larger boats, the news having been received by wireless.

History of wireless telegraph. The chief credit for the development of wireless telegraphy is due to Marconi, who was the first to develop a practical instrument. As is true of all inventions, this was made possible only through the 
work of many men before him, who had made discoveries which he used in constructing his instruments. While still but a young man of 2 I years, he transmitted signals without wires through a distance of two miles. This was in 1896 . In 1897 this distance was increased to 18 miles, and in 1899 messages were sent across the English Channel, a distance of 32 miles. He next directed his attention to telegraphing across the Atlantic Ocean; and in rgor, a signal was sent from England to Newfoundland, a distance of r 800 miles. These and other stations have been improved until now a number of companies are doing business in sending messages across the ocean. Messages are now sent more than 4000 miles.

Waves. If a stone is thrown into a pond, water waves are sent out and spread in every direction. In a similar manner light and electricity travel by wave motion. Scientists believe that all space is filled with a very thin substance which they call ether. (This has nothing to do with the ether used in medicine.) It is really no more wonderful that electricity should travel through this ether without wires than that light should come to us from the sun. It seems more strange because the light waves affect our eyes, and we are able to see objects by means of the light waves that come from them. Electricity travels by means of waves which we cannot detect through our senses as we can light waves; but instruments have been made which detect these waves.

Sender. A wireless outfit consists of a sending apparatus to send out electric waves, and a receiving apparatus to receive these waves sent out from another station. The connections of these parts are shown in figure 134. The sending apparatus consists of some source of current electricity such as batteries $B$, an induction coil $I$, Leyden jars, a spark gap, and a key $K$, to control the current. The induction coil is an instrument by means of which an electric current. 
of low voltage may be changed to one of high voltage. The Leyden jars serve to store up electricity till a heavy charge has

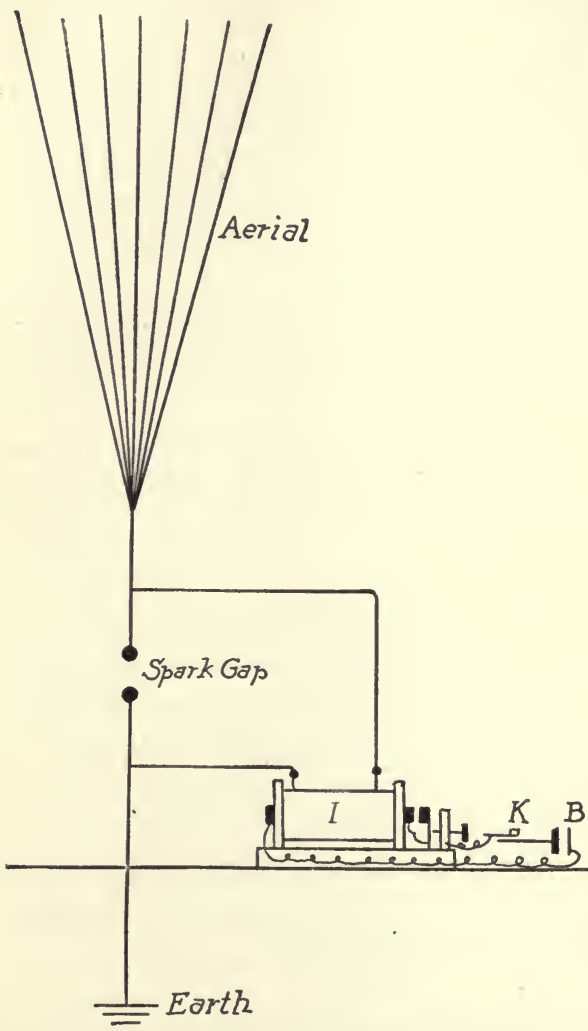

Fig. I34. - Wireless sending apparatus. accumulated. When sufficient electricity has been stored in the jars, it jumps across the spark gap with tremendous force, and this starts the electric waves, which are transmitted in every direction. In order to make these waves carry through long distances, long wires called antennæ are connected with the sending apparatus. In some stations wires 200 feet high are used. The waves thus sent out follow the curvature of the earth, so that the effect may be felt by instruments several thousand miles away.

Receiving apparatus. The most important part of the receiving apparatus is the detector, or coherer, as it is called. The purpose of this instrument is to detect the presence of the electric waves. Many different kinds have been devised. One that has been much used by Marconi consists of a small glass tube, plugged at each end, and having the 
intervening space filled with metal filings. Under ordinary conditions these filings do not conduct electricity, but when they are acted upon by an electric wave, they change their positions and arrange themselves in such a way that an electric current can pass through them. The connections for a receiving instrument are shown in figure 136 . When the filings become affected by the electric waves, the current from the battery $B$ passes through and this operates a relay $M$. When this relay is closed, a second circuit is brought

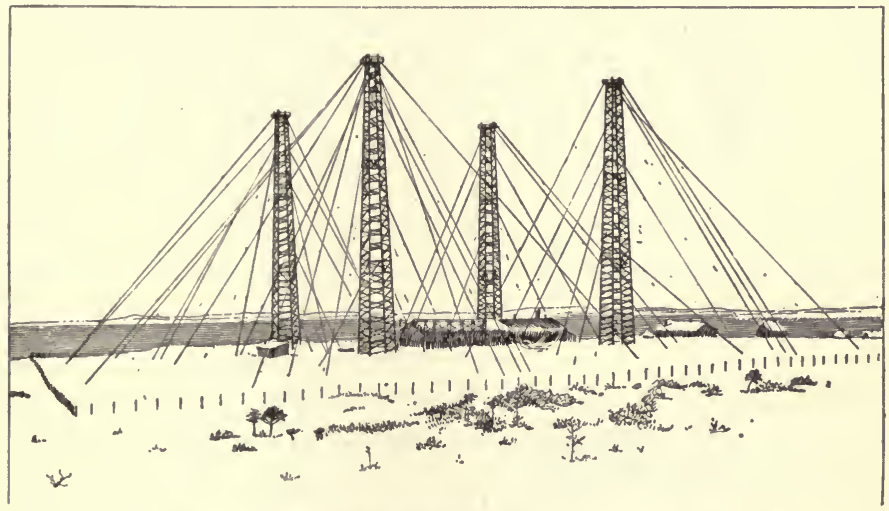

Fig. 135. - Wireless telegraph station at Glacé Bay.

into action, including the battery $b$, the tapper and the telegraph sounder. This tapper is called the decoherer because, when it strikes the coherer, it breaks up the regular arrangement of filings so that they cease to conduct electricity. The tapper works like an electric bell. In this same circuit is placed the recording instrument, which is similar to a regular telegraph sounder. In order that the sounds may be more easily heard, listening attachments are placed over the ear.

The Morse code of telegraph signals is used. In this case, however, the dash becomes a series of rapid dots very close 


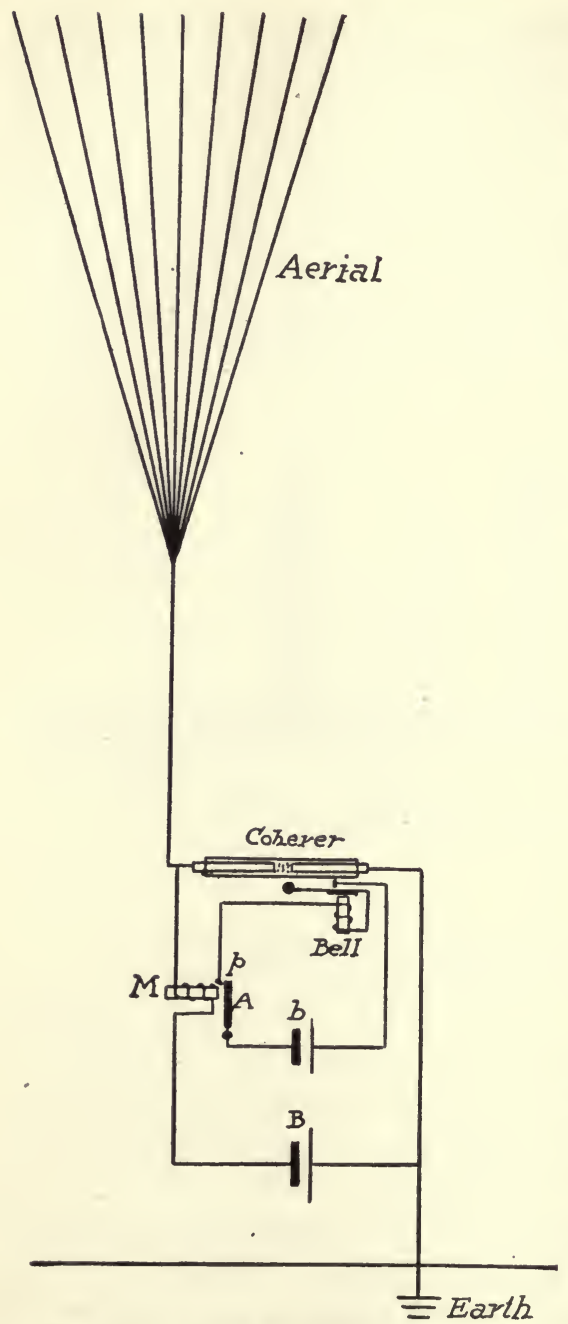

Fig. 136. - Wireless receiving apparatus.

together, because the action of the decoherer does not allow a dash to be made.

Tuning. After it had been found possible to send messages by wireless over long distances, one of the first difficulties that arose was how to do this in such a way that other instruments than the one for which it was intended should not receive the message. Many experiments have been tried and now this privacy is insured by a system of tuning, as it is called. This is done by regulating the wave length that is given out by a certain sending apparatus, so that it can be received only by an apparatus which is tuned to correspond to the same wave length. But in order to insure secrecy, codes are used which can be understood only by those who know the key to the code. A single word may stand for a whole sentence. 


\section{Demonstration 25}

Purpose. To show how the wireless telegraph works.

Apparatus. A small demonstration form of wireless outfit.

Directions. Set up the outfit following the directions that accompany it. Study carefully the working of the various parts. Make a drawing showing the parts and their connections. See how far apart the sender and receiver can be placed and still send and receive messages.

Comparison of wireless and ordinary telegraph. When we come to compare the wireless and ordinary telegraph, the first thing we note is the fact that wireless is much cheaper to construct, because no connecting wires are necessary. This is especially evident when we consider how much it cost to lay the Atlantic cable in order that we might telegraph across the ocean. And on land after the lines of wires are set up there is the expense of maintaining the poles and wires, which are often broken down by storms, and of replacing the poles as they decay.

For communication on water between boats or between boats and land, of course, only the wireless can be used. In certain mountainous countries, or in countries where heavy snowstorms are common as in Alaska, the wireless is much easier to install and operate. For regular service between points where the telegraph is already established, this is largely used in preference to the wireless. Whether the wireless will ever be a serious competitor for this trade it is difficult to say. But for long distance telegraphy over the ocean, there are a number of commercial stations of wireless running in competition with the cable service.

\section{SUPPLEMENTARY QUESTIONS FOR CLASS DISCUSSION}

I. What part does the telegraph play in our daily life?

2. What has been the history of the development of the telegraph? 
3. How can the parts of a telegraph system be used to send a message?

4. How are messages sent at high speed?

5. What advantages have the wireless and ordinary telegraph each over the other?

\section{REFERENCES}

Baker, Boys' Book of Inventions, Doubleday Page and Co., New York City. Chap. 3 (Wireless).

Cressey, Discoveries and Inventions of the Twentieth Century, E. P. Dutton Co., New York City. Chap. 7 (Wireless). Darrow, The Boys' Own Book of Great Inventions. Chaps. 2, 5, 6. Macmillan Co., New York City.

Holland, Historic Inventions, G. W. Jacobs Co., Philadelphia. Chaps. Io and 15.

Maule, Boys'. Book of New Inventions, Grosset and Dunlap, New York City. Chap. II (Wireless).

Massie and Underhill, Wireless Telegraphy and Telephony,

D. Van Nostrand Co., New York City. 


\section{CHAPTER XXII}

\section{THE TELEPHONE}

How does the telephone differ from the telegraph?

Of all the remarkable inventions of the last century, perhaps none quite equals the telephone. Probably none has become so directly interwoven with the daily life of so many people. In I9I 7 there were in this country about $10,000,000$ telephones, or one to every ten inhabitants, or one to every two families. In ten years the number has more than trebled. In I9I 5 there were in this country 670,000 miles of pole lines and $19,000,000$ miles of wire. It has been estimated that about forty million conversations take place every day over the telephone, that is, about thirteen billion yearly, or an average of $\mathrm{I} 30$ to every person in the United States. The telephone has revolutionized our way of living and doing business.

In New York City alone there were in I9I 7, 682,000 telephones. This city maintains 52 exchanges, employing 5000 girls. Between the hours of five and six in the morning, two thousand people are using the telephone, between seven and eight, 25,000 people, and by eleven o'clock, I80,000 calls per hour are being answered. Long distance conversations too are common. In I909, I8,000 conversations were held between New York and Chicago, or an average of 50 per day.

Uses of the telephone. The telephone finds use in almost every walk of life where the human voice is used, and makes 
it possible for all kinds of business to be done much more quickly. Large hotels are equipped with a complete system of telephones. Stores of all descriptions receive a large share of orders by telephone. When Benjamin Franklin was postmaster general at Philadelphia, it required at least three weeks to send a letter by mail to Boston and receive an answer. Now the two cities are connected by telephone, and one may in less than five minutes transact business which required three weeks, or 5000 times as long, a century ago.

Factories and mines are equipped with telephones which allow the work to be controlled from a central office. Some railroads are now using it in place of the telegraph in dispatching trains.

Many of the larger newspapers are equipped to gather news by means of telephone instead of telegraph. For every edition of the New York World there has been an average of 750 telephone messages. The United Press has devised.a method by means of which news is telephoned at one time over one wire to ten or twelve newspapers situated in as many different towns.

In emergencies the telephone is of special value, as in cases of sickness, fire, or burglary. In our large cities it is possible to reach the entire police force by use of a system of telephones. In times of war a string of telephone wires enables the generals to control the actions of their soldiers.

The telephones on farms. There has been a great increase of the use of the telephone on farms, and it is doing much to lessen the isolation of farm life. In igro there were 2,000,000 telephones in farmhouses. Every fourth farmer has a telephone which puts him in touch with his neighbors and markets. The telephone is of great aid to the farmer in marketing his produce, especially his perishable crops. It is of special value also in case of emergency in calling for help. For example, in 1909 a three million dollar fruit crop was saved in Colorado by use of the telephones. One spring 
when the trees were in flower the owners learned from the Weather Bureau through the telephone that a frost was coming that night, which would injure the blossoms. The farmers telephoned to the towns for help to come and assist in lighting smudge pots to ward off the frost. In this way the crop was saved.

Effect of the telephone. The telephone has had a most important effect on the development of the country and on the spirit of its people. It has helped to make a unity of feeling and maintain a spirit of coöperation that would not have been possible without it. It has helped to obliterate narrow state and sectional lines, and to develop a national spirit that makes us one people and one nation. It has a broadening and educative effect. It has been the climax of those recent inventions which have helped to bring people closer together. Railways and steamboats carry letters, the telegraph transmits messages instantly, but greatest of all is the telephone, which brings men practically face to face, carries speech over the electric wire, and makes message and answer both instantaneous.

History of the telephone. The inventor of the telephone was Alexander G. Bell. He was born in Scotland and moved to Canada when he was twenty-three years old. Two years later he moved to this country and became a professor in Boston University. For several years he worked on his idea of some method of direct communication by means of the voice at a distance. In 1876 he finally succeeded in making an instrument which would carry the human voice. He obtained a patent on this immediately and in the same year exhibited it at the Centennial Exhibition at Philadelphia. Here it received much praise and attention. At first it was generally regarded as a toy without practical application. In getting the telephone started as a commercial proposition Bell and his friends who were financing the proposition had considerable difficulty. 
The first public telephone line was installed in 1877 in the state of Massachusetts and by the end of the year there were 778 telephones. It was not until $\mathrm{I} 880$ that the Bell Telephone Company was well established. At first the telephone could be used only over short distances, but improvements were made so that it could be used over longer and longer distances. The first inter-city line was built between Boston and Lowell. A few years later Boston and New York were connected by telephone, in I893 New'York and Chicago, and still more recently conversation has been carried on between Boston and Denver, a distance of about
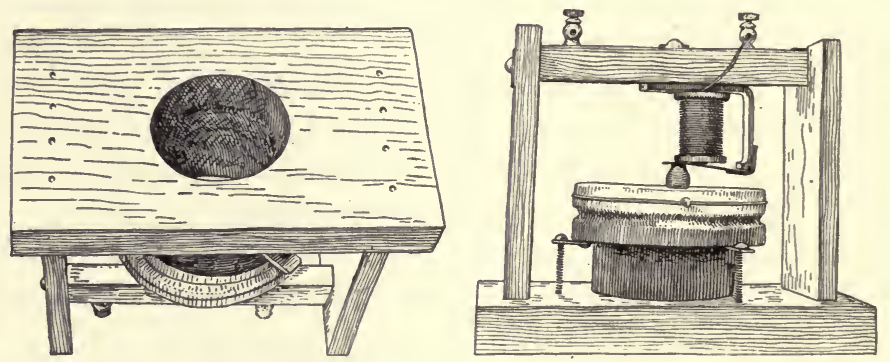

FIG. 137. - First Bell telephone.

2500 miles, and finally between New York and San Francisco, a distance of about 3500 miles. During all this time improvements have constantly been made on the telephone, and the Bell Company hires several hundred experts who devote their time to experimentation in order to find possible improvements.

Periods of the telephone. The history of the telephone may be divided into four periods. The first period from I 876 to 1886 was one of experiments. The instruments used were very crude and imperfect. Iron wire, poor transmitters, overhead wires, and boy operators were used.

The second period from I886 to 1896 was one of development. During this period great improvements were made 
and the telephone reached a high degree of efficiency. Copper wire, underground cables, long distance lines, and girl operators were innovations of this period.

The period from 1896 to 1906 was one of expansion. This was the period of business, when profits were made as a result of previous toil and investments. During this period there appeared the pay station, the farm line, and the private branch exchange.

The period from I906 to I9I6 was one of organization. During this period the telephone has reached out into ever broadening fields till it has become truly national in scope.

How the telephone works. Having seen something of the history and uses of the telephone, let us now try to understand how it is constructed and how it works. Like the telegraph it uses electricity, yet in principle it is quite different. In the telegraph the circuit can be opened and closed, and the signals sent in this way; but in the telephone the voice is not strong enough to do this. A current is passing through the wire all the time and the voice causes variations in the strength of the current.

In the telephone, it is not sound vibrations that travel along the wire, but an electric current.

With the telegraph, the earth can be used as a return wire, thus saving the expense of one wire, but with the telephone two wires are generally used, because the telephone is so sensitive that it would be interfered with by various disturbances that might develop in the earth.

Receiver and transmitter. In the simplest form of telephone first used, one piece of apparatus served both as transmitter and receiver. Figure $\mathrm{r} 38$ shows the construction of this. It consists of a U-shaped magnet which has around each pole a coil $C$ of many turns of very fine wire which is connected with the outside circuit. Just in front of the magnet is a thin diaphragm $D$ made of metal. As one speaks into the transmitter the air waves produced by the voice 
cause the diaphragm to vibrate back and forth. This vibration across the magnetic field of the magnet induces currents

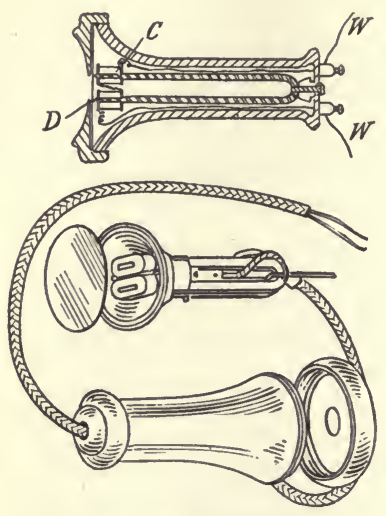

Fig. I38. - Bell telephone receiver. in the coil of wire, first in one direction and then another, the strength depending on the distance the diaphragm moves. These varying currents travel to the other end of the line and cause the magnet to attract the diaphragm and give it the same motions as those of the first diaphragm which started the variations in the current. In this way the second diaphragm makes the same vibrations as the first, and hence it reproduces the same sounds.

This form of telephone can be used for only short distances. The modern telephone has been modified in several ways. In the first place, another instrument has been introduced to serve as the transmitter. The receiver is about the same as that first used, except that a U-shaped magnet is used in place of a single magnet.

Carbon transmitter. The carbon transmitter is the form most commonly used (figure I39). Back of the diaphragm $D$ is some granular carbon $G$ in a little box $C$, and as the diaphragm vibrates, it causes a variation in the pressure upon the points of carbon. This produces a variation in the strength of the current that passes through the battery. This is connected with an induction coil Ic (figure I40), and

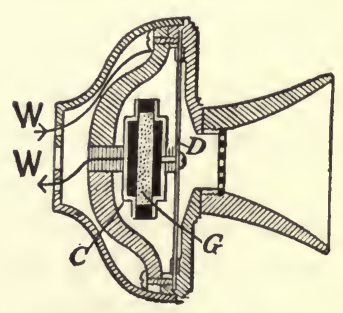

FIG. I39. - Carbon transmitter. produces in the secondary coil varying currents, which travel over the main line. These variations are reproduced in the 
receiver at the other end and produce corresponding variations in the vibrations of the diaphragm.

The induction coil just referred to is another addition to the original telephone. This is necessary in order to produce a current of sufficient force to operate over long distances. The current is usually furnished by a battery at the central stations, instead of by a local battery.

The telephone is a very sensitive instrument. In some cases the distance through which the diaphragm moves is

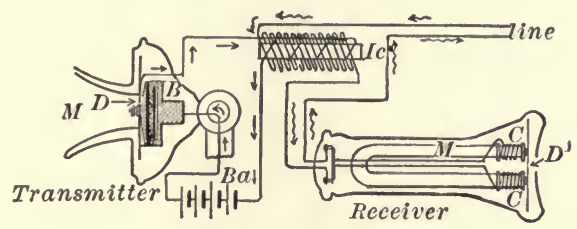

Fig. 140. - Local battery telephone system.

only one ten-millionth of an inch. To send a telephone message requires less than a hundred-millionth part of the current required for a telegraphic message. So small is the amount of current necessary to operate the receiver, that if all the work done in lifting the receiver off the hook one foot were changed into electric energy, it would furnish enough electricity to operate the receiver continually for 100,000 years.

\section{DEMONSTRATION 26}

Purpose. To study the working of the telephone.

Apparatus. Galvanometer, bar magnet, coil of wire wound in form of a spool. Demonstration form of dissectible telephone.

Directions. I. Secure a coil of wire wound on a spool and provided with binding posts. Connect these with a galvanometer. Place a bar magnet inside the coil. Bring a piece of soft iron near the magnet. Does the needle move? Take the iron away. Is any current generated? 
2. Make a study of the parts of a dissectible telephone. Make a drawing and explain the use of each part.

Central. One of the most interesting parts of a telephone system is the central station, where connections are made

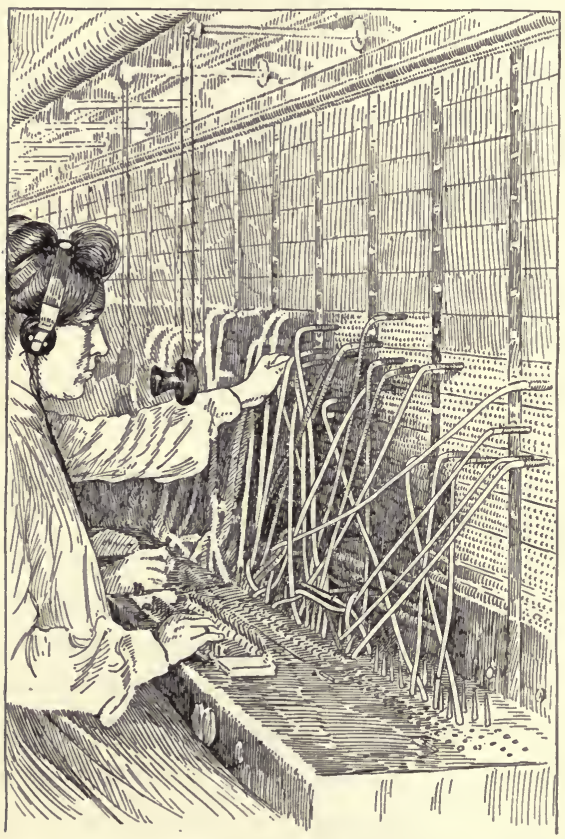

Fig. I4r. - Central making connections. Each dot on the board is a subscriber's connection. The cords connect one subscriber with another. The switches for operator's phone and the pilot lamps showing when a subscriber wishes a connection are set in the table. for different subscribers. When a subscriber takes his receiver from 'the hook, a little lamp glows opposite the hole that is marked with this person's number; this is a signal to the operator that some one wishes a connection made. The operator's receiver and transmitter are fastened to her head and neck, so that both her hands are free. She connects her wire with the subscriber's by means of a plug, and having found the desired number makes the necessary connections. This is done by inserting a plug connecting with the first subscriber's telephone into a hole connecting with the second subscriber's telephone. By pressing a button she causes a bell to ring on the second subscriber's telephone. When the second receiver is taken 
from the hook, a second light glows before the operator, and the two lights continue to glow as long as the telephones are being used. When the receivers are hung up, the lights go out; this is a signal to the operator, who then pulls out the plugs.

The cords containing the connecting wires are weighted and hung below, so that when a plug is taken out of a hole the wires fall back into their places automatically, out of the way and ready for the next call. Practice enables these girls to work with astonishing rapidity. In the best exchanges they answer a call in an average time of $3 \frac{1}{2}$ seconds.

For out-of-town calls, connection is made with "Long Distance," who makes the connection in much the same way as that already described. A record of the time occupied by the conversations is kept by means of an automatic time stamp. Charges are made according to the time that the line is in use.

\section{Field Exercise 7}

Purpose. To visit the central telephone office.

Directions. Arrangements can usually be made with the superintendent of the telephone exchange to allow the class to visit the central office. Here some one can explain the work of the operators and the construction of the central telephone outfit. At the next meeting of the class the points observed should serve as a basis for discussion.

Wireless telephone. Now, most wonderful of all, comes the wireless telephone, by means of which people may talk with each other at a distance without any wires between. The more recent development of the wireless telephone has been largely the work of Americans. In I900 the wireless was first successfully used for a distance of one mile, although the sounds reproduced were not satisfactory. The mechanism was gradually perfected so that it was used over longer distances, and the sound was reproduced more exactly, until 
it is superior to the ordinary telephone in the distinctness and fidelity with which sounds are reproduced.

Talking over long distances. In I907 speech was transmitted from Massachusetts to Washington, D. C., a distance of 400 miles. In May, 1915, this was increased to 1000 miles, the distance from Long Island to Georgia. Later in the year communication was made between Washington, D. C., and the Eiffel tower, Paris. The climax was reached in the same year when a message spoken into the telephone receiver at Washington was heard at San Francisco, a distance of 2500 miles and also at the Hawaiian Islands, a distance of 4900 miles. This is farther than conversation has been carried on by means of the wire telephone. Science had found a means by which a person speaking in an ordinary tone of voice could have this reproduced so that its owner could be recognized at a distance equal to one fifth the circumference of the globe. If the sound waves themselves could have traveled that distance, it would have required more than six hours, but the electric waves covered the distance in a small fraction of a second.

This message went out not only to the west but in every direction; so that any one within a radius of 4900 miles of Washington could have heard the message had he been provided with the necessary instruments. This message, then, could have been heard in all the great cities of Europe, - in Paris, London, Berlin, Rome, and Petrograd, and in Rio Janeiro in South America, or at the North Pole. It would have been possible for people in the United States to talk with their friends in the trenches in France, if both had been provided with suitable instruments.

Combination of common and wireless telephone. Another remarkable thing that has been accomplished is to connect up the wire telephone with the wireless so that they can both be used. A man in New York City talked into an ordinary telephone receiver as far as Washington by wire, 
and from there the waves were sent out into the ether and connection made with San Francisco by wireless. It is possible to have this taken up again by a wire telephone. So that the possibilities of the future are that a person living at Chicago, or some other inland city, may telephone directly to a person in Paris. The message will first travel by wire to some wireless station on the Atlantic coast, then by wireless to some coast station in Europe, and then by wire to Paris, without interruption.

Uses of wireless telephone. The possibilities that are thus suggested sound almost like fairy tales and fairly stagger the imagination. It does not seem probable now that wireless will take the place of the ordinary short-distance telephone, but will rather work with it and make it more effective. The two working together will make a universal telephone. The wireless telephone has certain special fields with which the ordinary telephone cannot compete. Chief among these is telephony from continent to continent across the ocean. Other fields are in telephony from ship to ship and between ship and shore. Battleships of navies and some airplanes are now provided with wireless outfits. In the near future it will doubtless be possible, as one travels on the ocean steamers, to keep in touch by telephone with his friends during the entire journey across.

Outfits on trains. Already these outfits have been installed on trains, and it is possible for one to telephone from a train while it is traveling at the rate of fifty miles an hour. In this way conversations have been carried on through a distance of fifty-two miles. But this device will be used chiefly for directing the movements of trains, which can by this means receive orders without stopping.

Advantages of wireless over ordinary telephone. For long distance transmission the wireless telephone has many advantages over the wire telephone. It is much cheaper to install, as there are no poles or wires. It costs less to main- 
tain it, as it requires fewer employees and there is not so much outfit to keep in repair. There would be fewer breakdowns, as there would be no wires to be exposed to storms, and the breakdowns that did occur could be more easily found and repaired. And furthermore, it transmits speech more distinctly and perfectly.

Disadvantage of wireless. The wireless telephone has one great disadvantage, however. It is found that the efficiency of its working varies from day to day, owing to natural electrical disturbances. This does not matter so much for short distances; but for long distances it is a serious matter, since unfavorable conditions may prevent the telephone from working at all. It is not possible now to use the wireless in cities where there are many telephones in close proximity. It does not seem probable that wireless will take the place of wire telephone for local use.

Construction and operation of wireless telephone. We may next inquire regarding the construction and method of operation of this wonderful instrument that can send the human voice across the ocean. There are three essential parts to a wireless telephone: first, a machine to start waves in the ether; second, a device by means of which the voice can control these waves; and third, a receiver for detecting the waves and changing them into sound.

There is the same difference between the wireless telephone and telegraph that there is between the ordinary telephone and ordinary telegraph. In both telegraphs the circuit is interrupted by means of a key. In both telephones there is a continuous current, and connected with this is a telephone transmitter.

A number of different devices have been used, but we will undertake to understand only the general principle. The human voice, by means of the air waves, sets the diaphragm of the telephone into vibration. As this disk vibrates, it causes a change in the current. This varying current is 
used to send out waves through the ether in every direction. These waves are picked up by a sensitive receiving apparatus, which sets in motion another diaphragm with vibrations corresponding to the sending diaphragm, and thus the original sound, with all its tones and quality, is reproduced.

Types of transmitters. A variety of transmitters have been devised for controlling the current. One is very much like the ordinary carbon microphone transmitter. In another form, called an audion, a flame is used as a part of the circuit, as it is found to be very sensitive to electric waves. Still another depends on the fact that the electrical resistance of selenium depends on the amount of light that strikes it. This is used in connection with an arc lamp.

The sending station has aërial wires like a telegraph station and may send out continuous electric waves; or it may send out a discontinuous set of waves caused by sparks, which vibrate so rapidly that they cannot be heard, and do not affect the telephone diaphragm. This vibration frequently may vary from 40,000 to 100,000 per second.

Tuning. The wireless telephone has the same problem of tuning as the wireless telegraph. This difficult problem has been partially solved, so that a receiving instrument can receive a message only when it is tuned to correspond to the sending instrument.

\section{SUPPLEMENTARY QUESTIONS FOR CLASS DISCUSSION}

I. Which is more useful to man, the telegraph or the telephone?

2. What has been the history of the development of the telephone?

3. How are the receiver and transmitter constructed?

4. How are the connections made at central?

5. How does the wireless telephone differ from the ordinary telephone? 
6. How does the wireless telephone differ from the wireless telegraph?

7. What are the possibilities of future uses for the wireless telephone?

\section{REFERENCES}

Carson, History of the Telephone, A. C. McClure Co., Chicago. Darrow, The Boys' Own Book of Great Inventions, The Macmillan Co., New York City. Chaps. 3, 4, 7.

Doubleday, Stories of Inventors, Doubleday Page and Co., New York City. Pages I 8I-I99.

Harper's Electricity Book for Boys, Harper Bros., New York City. Chap. 8.

Holland, Historic Inventions, G. W. Jacobs Co., Philadelphia. Chap. 13.

Johnson, Modern Inventions, F. A. Stokes Co., New York City. Chap. 14 (Wireless).

Massey and Underhill, Wireless Telegraphy and Telephony,

D. Van Nostrand Co., New York City. 


\section{SECTION C \\ The Health of the Community}

\section{CHAPTER XXIII}

\section{THE PUBLIC WATER, MILK, AND FOOD SUPPLY}

I. What may communities do to protect their water supply?

2. Why should the milk supply of a city be carefully inspected?

3. In what ways may foods be made unfit to eat?

Water supply. The first and most important duty to which a community should give its attention is the protection of its health. One of the first things to do is to obtain

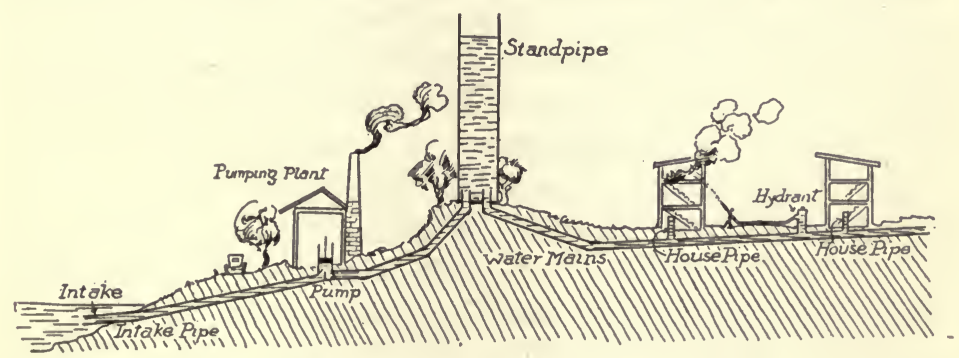

FIG. 142. - Water supply system for towns and cities.

a pure water supply. As all people in a city are using water from the same source, an impure water supply affects all the people in the community. The city water supply may be obtained from two sources, ground water from artesian 
wells, and surface water from lakes and rivers. The chief kind of impurity against which the water must be protected is the disease germ. One of the commonest of these germs found in water is the one that causes typhoid fever. Many cases of typhoid are due to impure water.

How it is made impure. Drinking water may be contaminated by typhoid germs in a number of ways. In every case some one with typhoid fever is the source of the germs, which are given off in the wastes of the body. Sometimes the sewage containing these germs may empty into a river, and then the water from this river may be used as drinking water by a city situated further down the river, as on the Merrimac River in New England. A city may discharge its sewage into a lake and take drinking water from the same lake near the sewer outlet, as was formerly done in Cleveland, Ohio. Even the water of an artesian well has been known to be contaminated through a leak in the water pipes, through which sewage entered when a flooded condition of the river brought the river water in contact with these pipes, as happened some years ago in Mankato, Minn. In Plymouth, $\mathrm{Pa}$., an epidemic occurred because a family living on the banks of the stream from which the town took its water had thrown the wastes from a typhoid patient on the snow near the stream. When this melted, the germs were carried into the stream.

All these cases go to show how important it is to prevent contamination of the water supply, because typhoid is a preventable disease, due to carelessness, and many cases may be avoided by keeping the water supply pure.

Purification by filter beds. When there is a possibility that water may be polluted, it can be made clean by filtering, and this is being done by many cities. Sand filters are the means which modern science has found for purifying water. These filters are four or five feet thick and are spread out over several acres. On top is a layer of fine sand, 
below this a layer of coarse sand and then layers of gravel, pebbles, and stones. Pipes are placed beneath to carry off the purified water. The filter beds are flooded with water, which soaks through and comes out below purified. Not only have the larger particles been filtered out, but what is of much greater importance, the water has been freed of bacteria and decaying organic material.

Strange as it may seem, the work of clearing the foul water of the injurious bacteria is done by other bacteria that are beneficial, which live on the small grains of sand and attack and destroy the harmful bacteria as they pass through the filter. In order that these bacteria may work to best advantage, they must have the oxygen found in the air, so that if the water is very foul, it is not allowed to

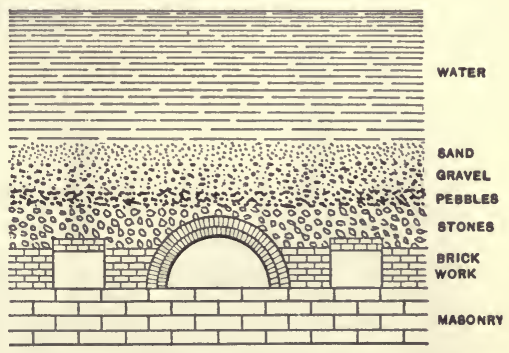

FIG. 143. - Cross-section of a sand filter. cover the filter beds all the time. But it is occasionally drained off so that the bed may be exposed and the bacteria given a chance to get oxygen in the air. The sand filter operates slowly and therefore many of the large cities now use rapid filter beds with alum and hypochlorite. Following are two instances in which large municipalities have found means of reducing the death rate by securing, under adverse conditions, a supply of pure water.

Cleveland, Ohio. Cleveland took its drinking water from Lake Erie and formerly emptied its sewage into the same lake not far from where the water was taken in. As the city grew larger, the number of cases of typhoid fever increased, till finally such an epidemic broke out that people became frightened and the city authorities saw that something must be done. Accordingly experts were called in to study the 
situation. They found that the currents of the lake were carrying some of the sewage, containing its typhoid fever germs, to the part of the lake from which water was taken for drinking. So the city had the inlet for the water extended miles out into the lake, and the outlet for the sewers placed at such a distance from the intake that the sewage could not reach it. As soon as this work was completed, the number of cases of typhoid fever decreased at once and

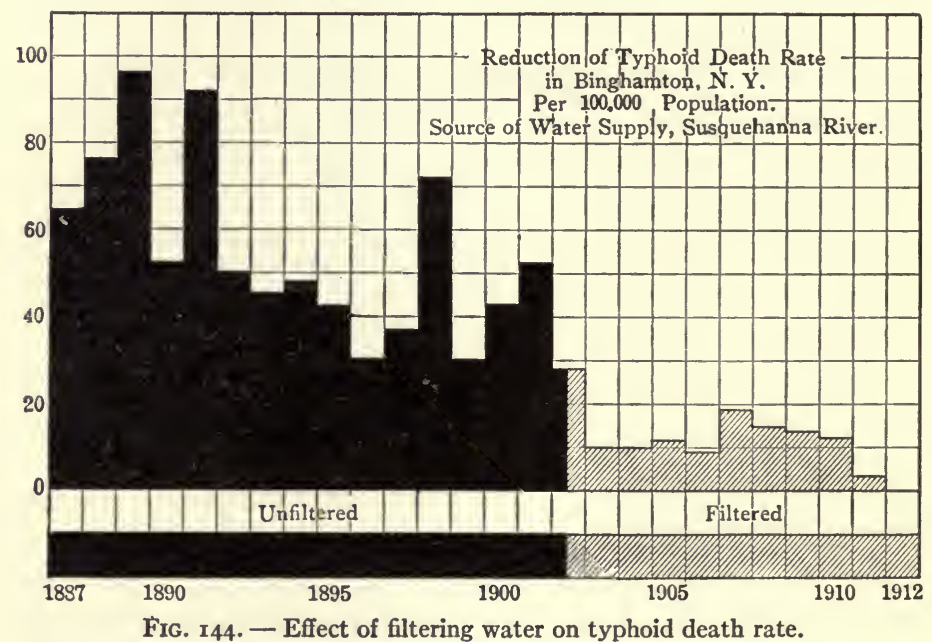

within a year the number of deaths was only one eighth as many.

Lawrence, Mass. Lawrence is situated on the Merrimac River. Nine miles above on the same river is the city of Lowell, and above Lowell are still other cities. Each of these cities takes its drinking water from the river above it and pours its sewage into the river below it. Thus each city gets in its drinking water some of the sewage of the cities above it. The lower cities on the river were especially subject to typhoid fever. Whenever Lowell had an out- 
break, one was sure to follow in Lawrence. People soon learned that the reason was that the bacteria from the sick people in Lowell were carried down the river into the drinking water of Lawrence. After a careful study of the situation, the people of Lawrence decided to put in large outdoor filters in order that the river water might pass through these

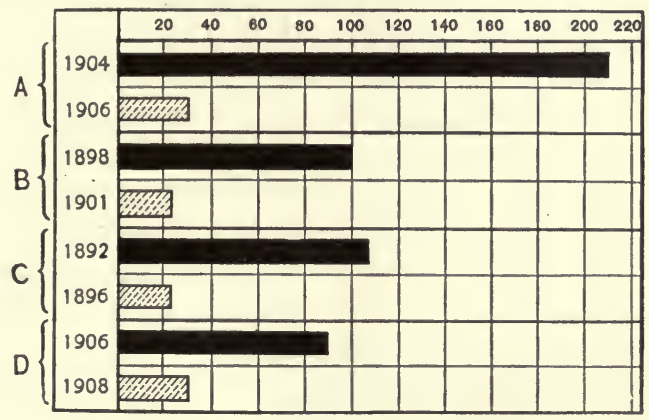

Fig. 145. - Cases of typhoid per 100,000 inhabitants before filtering water supply (solid) and after (shaded) in $A$, Watertown, N. Y. ; $B$, Albany, N. Y.; $C$, Lawrence, Mass. ; $D$. Cincinnati, Ohio.

and be purified before it was used by the people of the city. These filters worked so well in taking out the typhoid germs that only one fifth as many people died each year from typhoid fever as had formerly (see figure 145), and when the next epidemic of the disease appeared in Lowell, Lawrence was not affected.

\section{Demonstration 27}

Purpose. To see which kinds of water contain the fewest bacteria.

Materials. Sterilized test tubes containing culture medium, pipette, petri dishes.

Directions. I. The culture medium can be bought all prepared from dealers directly, or through drug stores. It can also be made as explained in Conn's Bacteria, Yeasts and 
Molds in the Home. It will be convenient to melt the culture and fill a number of sterilized test tubes about half full. Plug each tube with cotton batting.

2. Obtain several samples of water, some from the faucet, some from a well, some from bottled water, some from melted snow, some from a river, some from the street gutter.

3. Take as many culture tubes as the samples of water to be tested, place them in a dish of water and heat the water till the gelatin melts. By means of a sterilized pipette introduce I cc. of the samples of water into the various tubes, one tube for each sample. Shake the tubes so as to mix thoroughly the water and pour the culture medium from each tube into a sterilized petri dish, covering at once. Put a piece of gummed paper on each dish and label the source of the water.

4. Allow to remain at ordinary temperature for two or three days. Count the number of colonies which appear. This represents the number of bacteria in the cubic centimeter of water. Which sample contained the most? Which the least?

Milk. Milk is one of the best foods that we have. But it is also a medium most favorable to the growth of bacteria and great care should be taken to see that milk is clean. Milk is a common means of carrying disease germs and producing epidemics. An investigation made by the surgeongeneral of the army showed that at least 500 epidemics in this country had been traced to impure milk. Of these epidemics, 3 I 7 were of typhoid fever, I 25 of scarlet fever, and $5^{\text {I }}$ of diphtheria. Tuberculosis and tonsillitis germs also may be carried by milk. It is thought that one sixth of the cases of typhoid fever are due to unclean milk.

How milk may carry diseases. Cows may have tuberculosis, in a form similar to that found in man, and these cows may be a means of giving the disease to man directly through milk and meat. But most of the disease germs found in milk are introduced through carelessness after it is drawn from the cows. Some epidemics of typhoid fever 
have been due to the fact that the milk cans were washed in water containing the disease germs, which grew and multiplied in the milk. An epidemic of diphtheria in one city was traced to a man with a light case of diphtheria, who was working in the dairy. In another city an epidemic of typhoid fever was found to be due to the fact that three people living in the house connected with the dairy had the fever, and the dairy utensils were washed in the house and wiped on towels used by the people there. In some cases after people have recovered from typhoid they may continue for years to give off the bacteria causing the disease, and if they work in a dairy they may contaminate the milk.

Milk inspection. In cities and towns where many people get their milk from a few sources, inspectors should be appointed by the town to see that only clean milk is sold the people. The chief food of babies is

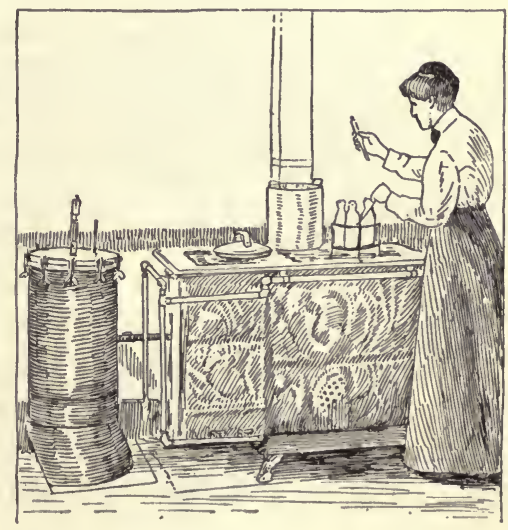

FIG. 146. - Pasteurizing milk.

(See page 38r.) milk, and many thousands die every yẹar on account of impure milk. In the city of Rochester, N. Y., nearly rooo children under five years of age died in 1892 . The city began an inspection of its milk supply, and as a result the number of deaths of young children decreased to less than 500 during 1896 , although the city had increased in population. Clean milk reduced the number of deaths one half and saved each year the lives of 500 children in this city alone.

Now let us see just what a city should do in order to get pure milk for its people. The best way to answer this is 
to explain what is actually being done by many cities. Inspectors are appointed who go into the country, examine the dairies, and require the owners to meet certain conditions of cleanliness before they are allowed to sell milk. If the owners do not meet these conditions, their licenses are taken away from them, or they are fined. It is vitally important that no person with a contagious disease be

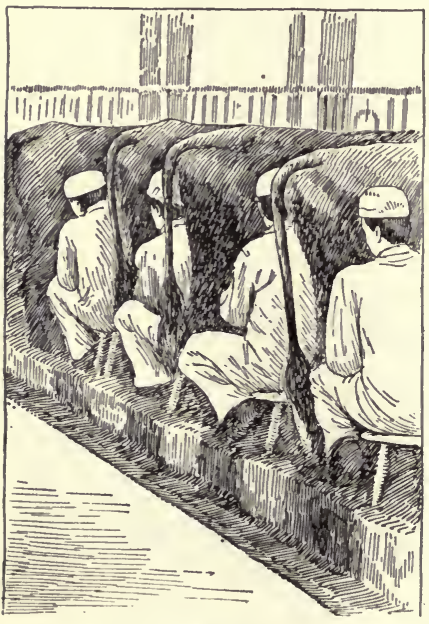

FIG. 147. - Sanitary milking. (Pail scalded, .cow groomed, milk bag wiped, hands washed.) connected with the dairy.

Clean milk. The barn must be clean, the cows must be cleaned before each milking, and the milkers must be clean. As soon as drawn, the milk should be put in a cool place so that it will keep sweet longer. It is found that the cleanliness of milk can be tested by the number of bacteria in it, because the more dirt in the milk, the more bacteria get in on the dirt. The numbers of bacteria increase if the milk is not kept cool, and they also increase with the age of the milk. Ordinary milk may contain as high as $10,000,000$ bacteria per cubic centimeter (about one fifth of a teaspoonful). Some idea of the cleanliness of milk and the care given it may be obtained by finding out the number of bacteria in it. Scientists have a way of doing this. The city of Rochester has set a standard of 100,000 bacteria per cubic centimeter and does not allow any milk to be sold that contains more than this. This leads the dairy men to keep their barns and cows clean and to be careful in handling the milk. 
Certified milk. Some dairies sell certified milk. This means that unusual care has been given to all the work in connection with the dairy, and as a result unusually pure

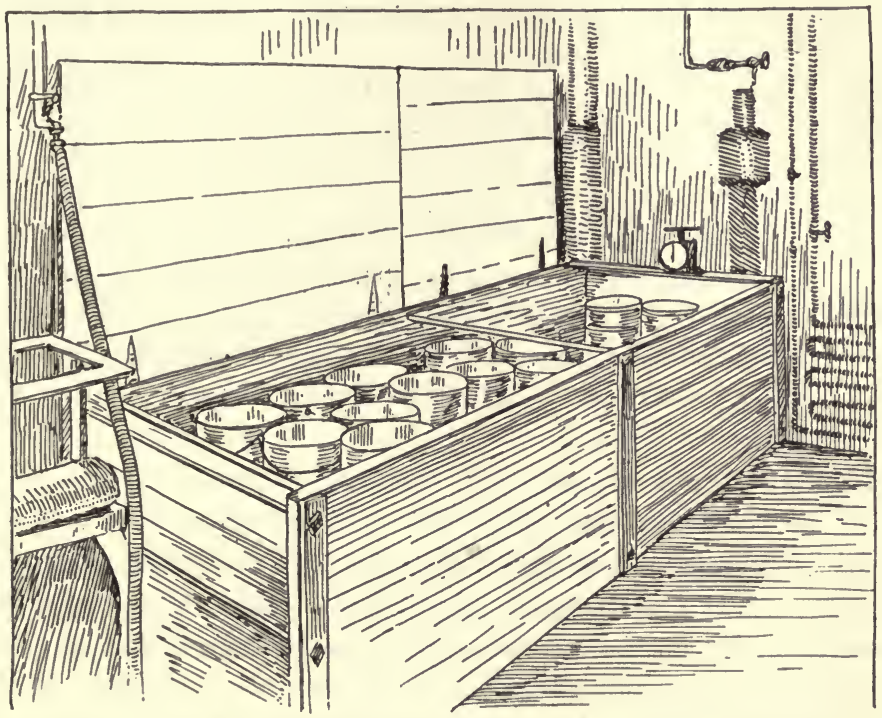

Fig. I48. - Cooling milk. This should be done as soon as drawn.

milk is obtained. This milk is certified by the inspectors and is sold at a higher price than ordinary milk. But every town should have inspected milk, which means clean milk, at the regular price.

\section{Demonstration 28}

Purpose. To compare the cleanliness of milk from different sources by estimating the number of bacteria in a cubic centimeter (cc.).

Materials. Several samples of milk. See demonstration 27 and read I under Directions. 
Directions. I. Pour Ioo cc. of water into a flask and boil for ten minutes. When the water cools add I cc. of milk and shake thoroughly.

2. Melt a tube of culture medium. Into this put one drop of the diluted milk. Shake it thoroughly. Pour into a sterilized petri dish and cover.

3. Allow to stand for several days and count the number of colonies. Each colony started from one bacterium. Estimate the number of bacteria in I cc. of the undiluted milk, remembering that about 15 drops. make a cubic centimeter and that I cc. of the milk was diluted with Ioo cc. of water.

4. Prepare several tubes and dishes, putting in milk from different sources. Also take milk from the same sample after it has stood for a day, because the number of bacteria depends on the age of the milk.

Foods. Most of our foods are bought from public supplies, so that it is not possible for each individual to determine for himself the conditions under which foods have been prepared. It is necessary, therefore, to have these matters controlled by laws, and foods examined by men who make it a business to inspect them.

Diseased foods. In order to know how best to protect our food, we must first know what some of the impurities are that are found in foods. Foods may be diseased or decayed. For example, if cattle that have had tuberculosis are killed and sent to market, the meat contains the germs and is dangerous as a food. In the preparation and marketing of foods, they may be contaminated with germs through exposure to dust and flies or by being handled by people who are diseased. Food may be kept so long before being sold to the consumer that it begins to decay; then there are formed certain poisons called ptomaines, which often cause serious sickness and even death.

Adulteration. Various kinds of adulterations are practiced but the three most commonly found are: first, the 
mixing of some cheaper material with the original substance; second, the addition of coloring matter; and third, the use of chemical preservatives to keep foods from decay.

Mixture. The substances used- in the first case are usually not harmful to the human system, but the objection to this method lies in the fraud thus practiced. Ground coffee may be adulterated with chicory, ground peas, beans, etc.; unground coffee is adulterated less frequently. Butter may be mixed with oleomargarine; water may be added to milk, or the cream removed; flavoring extracts and spices are frequently adulterated.

Coloring matter. There is a difference of opinion whether there are ill effects in the body from all of the materials used for coloring foods. But regarding the effect of many of them there is no doubt, as they are known to be injurious. There indisputably remains the fraud, as these colors are used to give a false appearance to the foods containing them. Coloring matters may be added to jellies made from cheap substances so as to give them the same appearance as those made from good fruits. They may be added to cucumber pickles and tomato catsup to bring back the original color which has been lost in the process of canning. Butter is frequently artificially colored. And chopped meats which are not fresh may have coloring matter added to give them the appearance of fresh meat.

Preservatives. The most dangerous kind of adulteration is the use of chemical preservatives, because most of those used are injurious to health. Among the more common kinds are formaldehyde, benzoic, boric, and salicylic acids, and their sodium salts, such as benzoate of soda.

Milk is sometimes treated with preservatives, especially in warm weather, to delay its souring. Formalin is the substance generally used for this purpose. Milk is the chief food of infants, and therefore it is specially important that it should be pure and wholesome. At that early time in 
life, these preservatives are particularly dangerous to health. Impure milk is an important factor in the large infant mortality in our large cities. An official of the Health Department of New York City said, "No doubt, if we could get pure milk, mortality of infants would decrease fifty per cent."

In recent years there has been considerable discussion regarding the effects on the body of benzoate of soda. The United States government has allowed this to be used in certain small quantities as a preservative, but there are serious doubts regarding the wisdom of this action. Dr. Wiley (in experimenting with his poison squad) found that this substance was injurious to the health of those taking it. The general consensus of the best scientific and medical opinion seems to be that the use of benzoate of soda as a preservative of foods should not be allowed.

One of the chief arguments against the use of all kinds of coloring matters and preservatives lies in the fact that their use makes it possible that substances be canned and sold which are entirely unfit for food. For instance, in the canning of tomatoes and catsups, if the substances are allowed to stand too long or are not cared for in a clean way, the mixture ferments and becomes unfit for food. But by the use of some preservatives, such as benzoate of soda, the fermentation may be stopped, and by adding coloring matter the original color may be restored; then the mixture may be canned and sold. To outward appearances it may seem like good clean food, while in reality it is entirely unfit to be eaten.

Condemned foods. Unfortunately the marketing of spoiled foods is much commoner than is commonly suspected. In the state of Missouri during the year I912, the food inspectors condemned and destroyed, as unfit for use, the following foods which were offered for sale: 20 pounds of candy, 80 cans of unwholesome milk, I25 pounds of spoiled beans, I 34 bottles of olives, I35 packages of break- 
fast food, 3 r 6 cans of decaying canned food, $58 \mathrm{r}$ bottles of impure patent medicines, 74I pounds of meat and fish, I 2,000 pounds of hominy, 1885 cans of bad fruits and vegetables, and 225,000 eggs.

In New York City in 1907, 362,795 pounds of groceries and canned goods were destroyed because they were unfit for use. In 1902 in the same city $12,000,000$ pounds, or 6000 tons, of unfit food were destroyed.

The Secretary of Agriculture estimated that in former years the sale of adulterated food in the United States amounted to over a billion dollars $(\$ 1,175,000,000)$ or about I 5 per cent of our entire commerce in foods. Probably the conditions are much better now.

\section{LABORATORY EXERCISE 3I}

Purpose. To test foods for adulterants.

Materials. Hydrochloric acid, iron alum, formalin, zinc, lead acetate, white woolen yarn, ammonia, iodin, foods to be tested.

Directions. I. To test milk for formalin.

In order to see what the test is, add a few drops of formalin to 5 or Io cc. of milk in a test tube. To this add an equal quantity of strong hydrochloric acid and a piece of iron alum about the size of a pinhead. Mix the liquids with a gentle rotary motion. Place the tube in a beaker filled with boiling water and allow to stand for five minutes. A purplish color of the mixture shows the presence of formalin. Try the test again without adding the formalin.

2. To test meat products such as sausage and chopped meat for sulfides.

Macerate the sample with water. Pour about $25 \mathrm{cc}$. in a flask and add pure zinc and about $5 \mathrm{cc}$. of $\mathrm{HCl}$. If sulfides are present hydrogen sulfide will be liberated. To test for this, dip a piece of filter paper into a solution of lead acetate and suspend it in the flask. A black precipitate on the paper indicates the presence of hydrogen sulfide. 
3. To test fruit products such as jellies, jams, and sirups for artificial coloring matter.

Place a few teaspoonfuls of the sample in water and boil to dissolve it. Place in this liquid a small woolen cloth or a few pieces of white woolen yarn. Boil for five to ten minutes, stirring occasionally. Remove the cloth and wash in hot water. If the cloth is brightly colored the presence of artificial dyes is shown. Natural colors give a dull pinkish brown tinge. To make the test more certain, place the cloth in a solution of dilute ammonia made by mixing Io parts of water with I part of ammonia. Boil for about five minutes and remove the cloth. The artificial coloring matter dissolves the ammonia. If this is colored, add $\mathrm{HCl}$ to it till the mixture is acid. Place in it a fresh piece of white woolen cloth and boil. Remove and wash in water. If the cloth is colored, the presence of artificial dyes is shown.

4. To test ground coffee for adulterations.

Place a few teaspoonfuls of ground coffee in a beaker half full of cold water and shake thoroughly and allow to stand. Most of the coffee will float, while the chicory and cereal adulterants sink, coloring the water with a brownish tinge.

5. To test spices for starchy adulterants.

Cloves, mustard, and cayenne contain practically no starch, so that the presence of starch is proof of adulteration. To test for starch boil in water for a few minutes, allow to cool, and add a drop of iodin. A blue color indicates the presence of starch and hence of some adulterant.

6. To test lemon extract.

To a test tube nearly filled with water add a teaspoonful of the extract. If real lemon oil is present, it will be thrown out of solution and will give a turbid appearance to the solution and will form a layer on top of the water. If the solution remains clear after diluting with water, very little or no oil of lemon is present.

United States Pure Food Law. When people realized the injury that was being done them through these impure foods, they took steps to protect themselves by law. In I906 the 
United States government passed what has been known as the Pure Food Law. This law does not forbid the use of all preservatives and coloring matters, but it requires preparations put up in bottles, cans, and other packages, intended for interstate shipment, to bear a label stating the materials contained and the proportions of each. One often sees the inscription on foods and drugs "Guaranteed under the United States Food and Drug Act, June 30, 1906, Serial No. - ." This inscription is often misunderstood to mean that the product has been examined by government inspectors and its purity and the correctness of the label guaranteed. It would be a splendid thing if this were so, but it is not. The statement on the label is merely the guarantee of the manufacturer, not of the government, under this act.

But this law was important in that it established the principle that the government has the right to regulate the manufacture and sale of foods. It enables one to know what is inside the package and is, of course, a check on many dishonest manufacturers. Under the federal act also, arrangements were made for the appointment of inspectors to examine meat in certain establishments. This federal meat inspection covers only meat intended for interstate shipments. State supervision is needed to look after meat intended for local consumption. Some steps have already been taken along this line and most of the states are passing and enforcing laws to protect us from impure foods.

United States Division of Foods. Much of the credit for these investigations into the purity of our food supply is due to the Bureau of Chemistry, which is a branch of the United States Department of Agriculture. About thirty years ago, Dr. Wiley, the former chief of this bureau, began an investigation of food adulteration. Since then this work has grown in importance, till about five years ago this food laboratory was made into a sub-branch of the Bureau of 
Chemistry, and called the Division of Foods, with a force of about twenty-five men devoted entirely to the study of foods. The results of the investigations made by the Bureau of Chemistry have instructed and awakened the people of the country and have thus helped to make possible the food laws which have been passed.

City ordinances. Many cities are passing local ordinances affecting the manufacture and sale of foods, by regulating sanitary conditions in the butcher shop and the bakeshop where bread and other foods are made or handled, and requiring the covering of fruits and bread with screens to keep off the flies. It is desirable to require that cooked foods be kept in dust-proof receptacles, for dust may be one means of transmitting disease germs. Under ordinary city conditions many dust particles fall on food left exposed. Culture plates exposed under a glass showcase in a bakery collected ${ }_{5}$ bacteria in ten minutes, while one exposed on the open counter collected 800 bacteria in the same length of time. A culture exposed on a sidewalk fruit stand collected Io,000 bacteria in ten minutes, nearly 700 times as many as under cover. Only those stores should be patronized which keep their food covered. Sometimes bread is wrapped at the bakery in paper and this helps to keep it clean. A bacteriologist who made an estimate of the number of bacteria on a loaf of bread, found an average of 7500 bacteria on a loaf of unwrapped bread and only 585 on a loaf of wrapped bread.

"White list." In some cities local organizations help to raise a high standard of cleanliness by keeping a "white list." Members of the organization visit and examine the stores, and if they find a store clean and sanitary it is put on the "white list." If it is not clean it is not put on this list. This stimulates the storekeepers to make greater efforts to keep their stores clean in order that they may be advertised as on the approved list. 


\section{Community Project I}

Purpose. To investigate local conditions with reference to water, milk, and foods.

Directions. I. The class may divide itself into three committees, a water committee, a milk committee, and a food committee. Each committee will investigate the local conditions with reference to its topic and report to the class. The water committee will collect information regarding the source of water supply, possibility of contamination, means taken to purify it or to prevent contamination, means of distribution, cost, measurement of water used, further steps needed to protect the water supply. If possible the committee may visit the filter plant, pumping station, or watershed.

2. The milk committee will collect information regarding the source of milk, sanitation of dairies, inspection given by city, conditions under which licenses are granted, need for further care on the part of the city. They may perhaps visit some of the dairies and report on the conditions found.

3. The food committee may investigate the source of the foods used in town, inspection given foods by federal, state, and local authorities, the local ordinances, care exercised by local dealers in handling food supply, other steps that should be taken to further protect the food supply.

4. In the class discussions of the reports after information on present conditions has been presented, special attention should be given to the things that still need to be done and to the ways in which the members of the class can help to bring these about.

5. It may be possible to make portions of a sanitary survey of a market, a bakery, and a dairy suggested in Hoag and Terman's, Health Work in the Schools, on pages 244 to 25 I.

\section{SUPPLEMENTARY QUESTIONS FOR CLASS DISCUSSION}

I. How may drinking water become impure?

2. How may it be purified?

3. What results follow from making the water supply pure? 
4. How may milk be a means of carrying disease germs?

5. What care is needed to get pure, clean milk?

6. Which is the worst form of food adulteration from the standpoint of health?

7. What has the national government done to help people get pure foods?

8. What is your locality doing to protect its water, milk, and food supply?

9. What more should be done?

\section{REFERENCES}

Coleman, The People's Health, Macmillan Co., New York City. Chaps. 3-5.

Hazen, Clean Water and How to Get It, J. Wiley and Sons, New York City.

O'Shea and Kellogg, Health and Cleanliness, Macmillan Co., New York City. Chaps. I2-I4. 


\section{CHAPTER XXIV}

\section{CONTAGIOUS DISEASES}

How are contagious diseases spread and how may they be controlled?

Bacteria and disease. Bacteria have a very important bearing on health because of the part they play in causing a number of common diseases. In some cases the bacterium which causes the disease has been discovered under the microscope and the cause of the disease is thus definitely
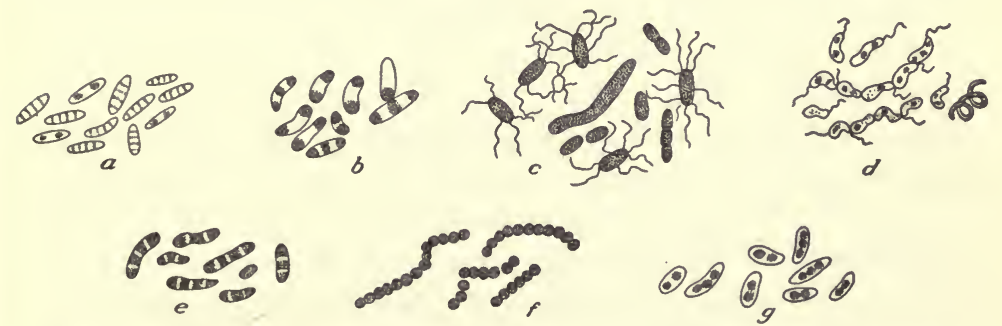

FIG. 149. - Types of disease bacteria : $a$, tuberculosis; $b$, diphtheria ; $c$, typhoid fever ; $d$, vibrio of cholera; $e$, anthrax; $f$, erysipelas; $g$, pneumonia.

known. It has been discovered for diphtheria, tuberculosis, typhoid fever, pneumonia, cholera, lockjaw, whooping cough, and blood poisoning. There are other diseases which are so similar to bacterial diseases in their general behavior that it is generally believed that they are caused by bacteria or other microörganisms, although the bacterium has not been discovered. Of this nature are scarlet fever, measles, mumps, and smallpox.

There is a great difference in people as to their susceptibility to the action of these bacteria. Several people exposed to the same disease may all take the bacteria into their 
systems, and yet while one person becomes sick, others may be unaffected, or very slightly so. One person may have disease germs in his system and not be affected by them, while another person may receive these germs from the first person and come down with the disease.

Characteristics of bacteria. In order to understand how these parasites cause disease and what may be done to control them, we need to know something about their general activities.

Size. Bacteria are the smallest living organisms that have been discovered with the microscope. They vary in size from a ten-thousandth to a hundred-thousandth of an inch in diameter. There are probably others so much smaller that they cannot be seen even with the aid of the microscope. It would take about $\mathrm{I}_{500}$ bacteria of average size placed end to end to reach across the head of a common pin. It has been estimated that a pint can would hold over two hundred billion bacteria. But although they are so extremely small, these little plants play a very important part in man's life on account of their frequent occurrence and power of rapid reproduction. While we cannot see bacteria without the aid of the microscope, the effect of their action in masses is evident all around us, as in the souring of milk, the spoiling of food, and the decay of refuse and other organic matter.

Multiplication. The great abundance of bacteria depends upon the remarkable rapidity with which they grow and form new bacteria. Their means of multiplication is a process called division. A bacterium divides into two similar parts, each part growing meanwhile till it is as large as the first bacterium. In a short time, sometimes in twenty minutes, these two divide to make four; in another twenty minutes these four divide to make eight, and so on, each division doubling the number of bacteria. At this rate, the descendants of a single bacterium would amount in ten hours to about a billion. Bacteria do not continue to grow 
at this rate indefinitely because the limit of their multiplication is soon reached through lack of food and through certain conditions unfavorable to growth. But it is this tremendous power of multiplication that makes them such a factor in man's life.

Occurrence and food. Bacteria are found in a great variety of places: in the soil, in the air, in water, in food, and in the human body. Some kinds are injurious to man, but the great majority are beneficial or harmless. Fifteen hundred kinds of bacteria are known to science but only about fifty to seventy-five produce disease. Although these little organisms are plants, they contain no chlorophyll and so cannot make their own food. Some bacteria feed upon the living bodies of plants and animals. These are called parasites. Others live on the dead bodies of plants and animals. They are called saprophytes.

\section{DEMONSTRATION 29}

Purpose. To see under what conditions air contains the fewest bacteria.

Materials. See demonstration 27 and read I under Directions.

Directions. I. Melt as many tubes of the medium as there are samples of air to be tested. Pour each into a sterilized petri dish and cover at once. Allow to stand till the gelatin hardens.

2. Following are suggested some of the various localities and times for testing the air: in the schoolroom before school, and after school; in the hall while classes are passing, and just after sweeping; outdoors on a windy day, and on a still day; on a street that is much traveled, on one that is little traveled.

3. In each of the cases to be tried remove the cover from the dish, keeping it off three minutes, then replace.

4. Allow the dishes to stand for several days, - note the appearance of colonies. If possible, count them. If too numerous for this, determine the relative number of bacteria found in the various localities. Or the experiment may be tried again with a shorter exposure so as to reduce the number of colonies. 
Conditions of growth. The most important conditions affecting the growth of bacteria are temperature and moisture. For the majority of bacteria the most favorable temperature is between 60 and roo degrees. The effect of lowering the temperature is to lessen their activity and they become dormant near the freezing point. At this point most kinds are killed, but some can withstand freezing for several weeks or months. Such are the bacteria that cause typhoid fever, which may be frozen in the ice for two months during the winter and when the ice melts some may renew their activities. All bacteria, however, are killed by boiling, and, if the heating is continued for an hour, they may be destroyed at a temperature of 160 degrees. There is one form in which bacteria exist, known as spores, the vitality of which is not destroyed by bringing it to the boiling point. Under certain conditions some bacteria may stop their activities and form themselves into a spherical mass surrounded by a thick membrane. These spores are dormant but are able to withstand adverse conditions, such as excessive drying and heat which would kill bacteria in their ordinary forms. But while spores are not destroyed by boiling a short time, if the boiling is continued for several hours, the spores will be killed.

Two other conditions favorable to the growth of bacteria are dampness and darkness. They cannot withstand drying and the action of direct sunlight, hence the need of having our houses well lighted and our windows unobstructed.

Relation to disease. The bacteria in their action within the body produce poisons, some of which are called toxins, which are absorbed into the blood and carried through the body, producing the ill effects characteristic of each disease. All of these diseases may be transmitted from one person to another; some, however, are more highly contagious than others. It is very important that everybody should know something about these diseases; how they are caused, how they may be carried, and how they may be avoided. Then every one will under- 
stand how to protect himself and his home, and to coöperate intelligently with the board of health and other organizations whose duty it is to look after the public welfare.

In considering the part that bacteria play in disease, we need to understand three things: first, how the bacteria leave the body of a sick person; second, how they are distributed from place to place; and third, how they enter the system of a well person.

How bacteria leave the body of a sick person. The disease bacteria leave the body in the following ways : in the sputum, in the excreta, in the urine, and in eruptions of the skin. Sometimes patients who have recovered entirely from a contagious disease may continue to give off disease germs from their body for several years, thus proving a source of danger to the community.

How bacteria are distributed. The chief ways by which these bacteria are distributed are by water, milk, food, flies, and contact. By contact is meant the transfer of fresh germs through short distances from patients to people near. This may be through mouth spray, clothing, eating utensils or by direct contact, as in kissing. One of the commonest means of transfer by contact is by the hands. These are carried to the mouth many times during the day, and if they have come in contact with moist germs, these germs find easy access to the mouth.

Formerly it was believed that the germs were carried by dust, books, letters, and other articles that had been touched by the patient; but to-day modern medicine is emphasizing especially the danger of direct contact with the patient through the hands and the sputum given off as a fine spray in coughing and in conversation. Experiments have shown that in ordinary conversation this spray may be carried three or four feet, and in coughing ten feet. This is believed to be one of the common means by which influenza is carried; hence the use of cloth masks.

Since drying and sunlight soon kill bacteria, it is not 
believed that dust is a very common means of carrying disease germs.

One way in which moist sputum may be carried is by shoes and rubbers. These carry the germs directly into the house on the carpets and rugs and may prove especially dangerous to babes playing on the floor.

The following table taken from Dr. Hill's The New Public Health shows the most common routes of infection.

The Chref Infectious Diseases of the Temperate Zone
Classified BY

Their Chief Routes of Infection

Typhoid fever (and other intestinal infections)

Tuberculosis (human)

Diphtheria, scarlet fever, measles,

German measles, mumps, whooping cough, smallpox, chickenpox Trachoma, cerebro-spinal meningitis, leprosy

Water, food, flies, milk, contact. Flies, milk, contact.

Milk, contact.

Contact.

From this it will be seen that water and food carry only the intestinal infectious diseases and that flies as carriers are limited to this group chiefly, as the amount of tuberculosis carried by flies is small. Milk carries the first three groups, while contact alone carries them all. In this chapter we are interested chiefly in the public means of transfer, food, water, milk, and flies.

How bacteria enter the body. The chief means by which bacteria may enter the body are through the mouth (in the food or drink), through the nostrils and mouth in breathing, and through wounds in the skin. The first two are the most common means.

The various ways in which these organisms may leave the body of the patient, how they may enter the body of another person, and how they may be carried from one to the other are shown in the following table. 
Table of Some Common Diseasés

\begin{tabular}{|c|c|c|c|}
\hline Disease & $\begin{array}{c}\text { How ORGaNISMS LEAVE } \\
\text { THE BODY }\end{array}$ & $\begin{array}{c}\text { HOW ORGanisms } \\
\text { ARE CARRIED }\end{array}$ & $\begin{array}{l}\text { How ORganisMS } \\
\text { ENTER THE BODY }\end{array}$ \\
\hline Diphtheria . . & $\begin{array}{l}\text { By coughing, in } \\
\text { sputum. }\end{array}$ & Milk, contact. & $\begin{array}{l}\text { By breathing, by } \\
\text { mouth through } \\
\text { food or drink. }\end{array}$ \\
\hline Tuberculosis & $\begin{array}{l}\text { In sputum, by } \\
\text { coughing. }\end{array}$ & $\begin{array}{l}\text { Milk, meat, } \\
\text { flies, contact. }\end{array}$ & $\begin{array}{l}\text { By breathing, } \\
\text { through wound } \\
\text { in skin, by } \\
\text { mouth through } \\
\text { food or drink. }\end{array}$ \\
\hline Typhoid fever. & In excreta. & $\begin{array}{l}\text { Contact, wa- } \\
\text { ter, ice, flies, } \\
\text { milk, food. }\end{array}$ & $\begin{array}{l}\text { By mouth } \\
\text { through food } \\
\text { or drink. }\end{array}$ \\
\hline Pneumonia. . & Coughing. & $\begin{array}{l}\text { Dust particles } \\
\text { in air, con- } \\
\text { tact. }\end{array}$ & By breathing. \\
\hline Lockjaw . . . & & $\begin{array}{l}\text { Soil and dust } \\
\text { particles in } \\
\text { air. }\end{array}$ & Wounds in skin. \\
\hline Smallpox . . & Eruption of skin. & Contact, milk. & $\begin{array}{l}\text { By breathing, } \\
\text { through mouth } \\
\text { in drink. }\end{array}$ \\
\hline Scarlet fever & $\begin{array}{l}\text { Sputum, discharg- } \\
\text { ing ears, and } \\
\text { nose and throat } \\
\text { discharges. }\end{array}$ & Contact, milk. & $\begin{array}{l}\text { By breathing, } \\
\text { through mouth } \\
\text { in food and } \\
\text { drink. }\end{array}$ \\
\hline Measles . . & Eruption of skin. & Contact, milk. & $\begin{array}{l}\text { By breathing, } \\
\text { through mouth } \\
\text { in drink. }\end{array}$ \\
\hline Whooping cough & Coughing. & Contact, milk. & $\begin{array}{l}\text { By breathing, } \\
\text { through mouth } \\
\text { in drink. }\end{array}$ \\
\hline $\begin{array}{l}\text { Grippe } \\
\text { Hydrophobia }\end{array}$ & Coughing. & $\begin{array}{l}\text { Contact. } \\
\text { Dogs. }\end{array}$ & $\begin{array}{l}\text { By breathing. } \\
\text { By wound. }\end{array}$ \\
\hline $\begin{array}{c}\text { Infantile paraly- } \\
\text { sis } . .\end{array}$ & $\begin{array}{l}\text { Throat discharges, } \\
\text { sputum. }\end{array}$ & Contact. & $\begin{array}{l}\text { Through mouth } \\
\text { in food or by } \\
\text { breathing. }\end{array}$ \\
\hline Trichinosis . & & Pork. & Eating pork. \\
\hline Malaria . & Blood. & Mọsquito. & $\begin{array}{l}\text { Injected by mos- } \\
\text { quito. }\end{array}$ \\
\hline Bubonic plague & Blood. & Fleas on rats. & $\begin{array}{l}\text { Flea bites a per- } \\
\text { son. }\end{array}$ \\
\hline Influenza & $\begin{array}{l}\text { Coughing, sneez- } \\
\text { ing. }\end{array}$ & Contact, air. & By breathing. \\
\hline
\end{tabular}


How to control diseases. The facts which we have learned in this chapter show that in order to control these diseases, the first step is to take such care of the sick persons that they cannot give the disease to others. In some cases this means that these patients must be isolated and others who may have been exposed must be quarantined in order to protect the health of other people. But this alone is not sufficient, because people may have mild forms of diseases without being seriously sick, and yet give off disease germs. Further, as already explained, some people may continue to give off germs for some time after they have recovered from the disease. So it is necessary to guard the public routes of infection by which the germs may be carried: water, milk, food, and flies. The methods of keeping water, milk, and food pure have been explained in a previous chapter, and the methods of controlling the fly will be discussed in a later chapter.

A few facts about the methods of controlling some of the more common and dangerous diseases will now be given, so that each one may do his part toward helping to do away with these diseases.

Smallpox and vaccination. It is a well-known fact that after a person has recovered from certain diseases, he is protected to some extent from contracting those same diseases again. In some cases this protection may be complete and last for years; in other cases the protection may last for only a short time. The principle involved in this is the one applied in vaccination as a protection against smallpox. This practice was discovered over a hundred years ago by an Englishman, Dr. Jenner. Cows are subject to a mild disease known as cowpox, which is somewhat similar to smallpox. In vaccination there is injected into a person's system some virus, which contains the living active principle of cowpox. This is obtained from calves raised especially for this purpose. If this " takes," it causes a very mild form of 
the illness; but as a result of this, the person is protected from the dangerous disease of smallpox.

When the virus that causes cowpox is injected into the blood, the body makes a substance, called antibody, which offsets the effect of the poison and the person recovers. This antibody, thus made, remains in the system and is effective in neutralizing the injurious effects of any smallpox microörganisms that may enter the body. The time that this immunity lasts varies with different people, the average time being about seven years, although some slight degree of immunity is afforded for a lifetime from a single vaccination.

Effect of vaccination on the death rate. Epidemics of smallpox are so rare in this country to-day that people are apt to become careless about the matter of vaccination, overlooking the fact that it is vaccination which has made this freedom from smallpox epidemics possible. Statistics furnish indisputable evidence of the great blessing that vaccination has proved to mankind in saving hundreds of thousands of lives.

Before the discovery of vaccination, smallpox was one of the most common diseases, even more common than measles to-day. The great majority of people at some time had the disease. In the city of Boston in $172 \mathrm{I}$, over one half the people had the disease and one thirteenth of the population died of it. Nine years later, there was another epidemic which was almost as severe. During the centuries past smallpox has been one of the greatest scourges throughout the world, sweeping off people by the thousands. It has been estimated that $60,000,000$ people died of smallpox in Europe during the eighteenth century.

Now an epidemic of smallpox is of very rare occurrence in those countries where vaccination is commonly practiced, and the number of deaths from this disease is very small. Records that have been kept of the deaths from smallpox show that on the average the percentage of those who die 
among people who have not been vaccinated is ten times as great as among those who have been vaccinated.

In five European countries in which vaccination is compulsory, the average number of deaths from smallpox per million of population is five; while in six European countries that do not have compulsory vaccination, the average death rate is four hundred, or eighty times as high.

When vaccination has been made compulsory in a country, the effect on the death rate has been very marked at once. In I874 Germany passed a compulsory vaccination law. As a result, the average number of deaths from smallpox for the ten years following was only two per I00,000 population, while for the ten preceding years it had been seventy-one. This meant a yearly saving of about twenty-five thousand lives, or of about two hundred and fifty thousand for those ten years in that country alone. During that same period of ten years, the death rate in the neighboring country of Austria, where vaccination was not compulsory, was sixty-two per hundred thousand of population as compared with two in Germany where it was compulsory. In Sweden, the rate of cases of smallpox per million inhabitants was two thousand before vaccination; it fell to five hundred when it was made optional, and to five when it was made compulsory.

Since the United States has taken charge of the Philippine Islands, vaccination has been introduced and as a result there has been a remarkable decrease in the number of deaths from smallpox. In the year I 897 about 40,000 people in the islands died of smallpox. In 1907 , after vaccination had been introduced, there were only 304 deaths, or less than I per cent as many as before vaccination.

One sometimes hears objections raised against compulsory vaccination, because occasionally it has been followed by serious results. But in most of those cases which have been carefully investigated, it was found that the ill effects were not due directly to the vaccine, but to bacteria which 
had entered the wound as a result of some one's carelessness, either in the preparation of the vaccine, or in the care of

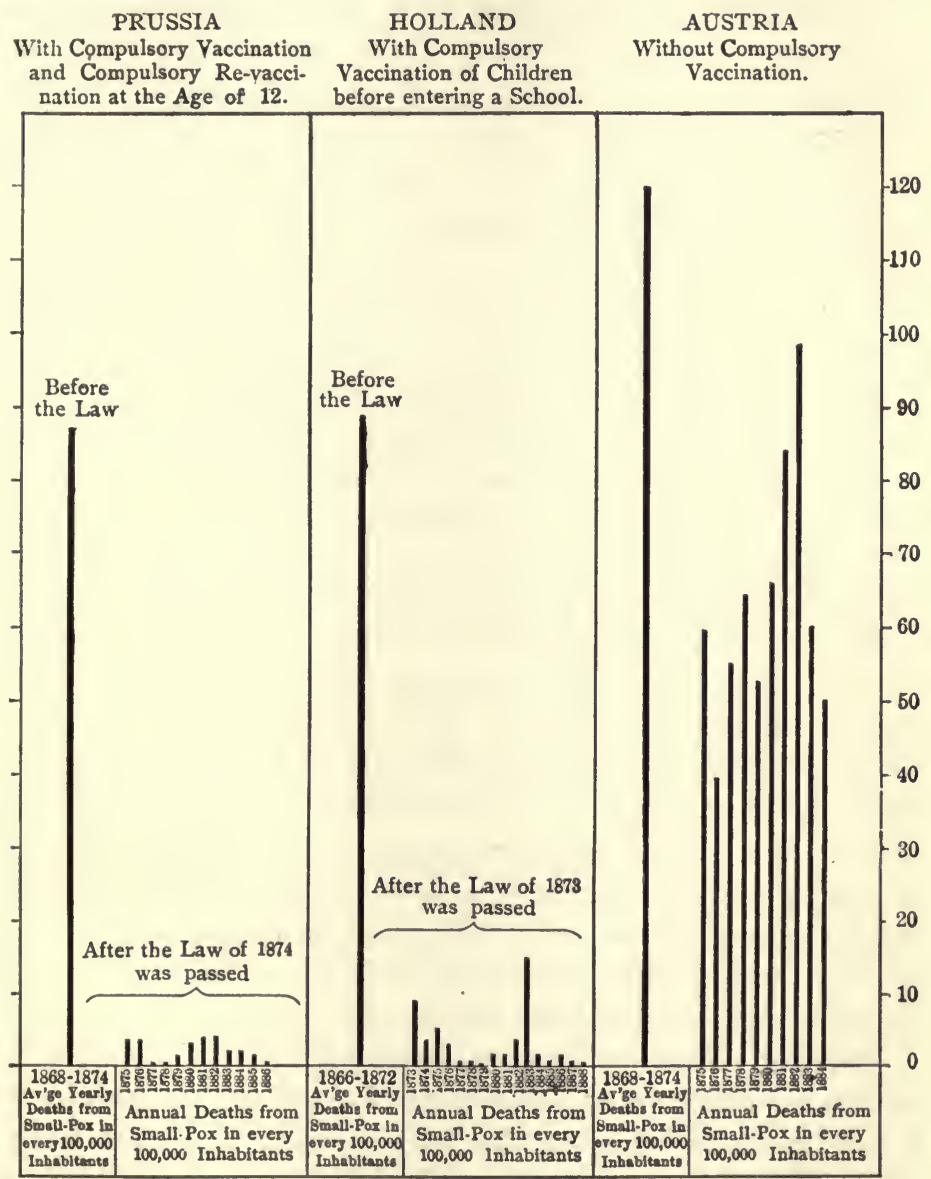

FIG. I50. - Showing effect of compulsory vaccination on death rate from smallpox.

the wound. Such extreme precautions are now observed that the possibility of danger from this source is very small indeed. It is doubtless true to-day that there is much less danger from 
smallpox than formerly, as the result of general improvement in all methods of sanitation. But still the fact remains that vaccination has been the chief means of controlling smallpox and saving thousands of lives, and it still remains the most effective means of preventing epidemics of smallpox.

Diphtheria antitoxin. One of the most wonderful discoveries of recent years is the antitoxin treatment for the cure and prevention of diphtheria. This remedy was announced by a German, Dr. Von Behring, in I89o. Horses are subject to diphtheria, but it is seldom fatal with them. Their bodies make antitoxins to offset the effects of the toxins produced by the bacteria. Accordingly horses are carefully kept for the special purpose of making antitoxin to be used with human beings. Strong, healthy horses are kept in clean stables and carefully looked after. They are first injected with the toxin, but not the bacteria, which causes diphtheria, as a result of which they make in their bodies antitoxin, and soon recover from the disease. After the horses are well, blood is drawn from their necks in an almost painless way, and in this blood is found the antitoxin. This is injected into the system of people suffering from diphtheria and has the same effect there in curing the disease as it did in the horse. Not only is this an almost sure cure for this disease if it is taken in the early stages, but it is also effective as a preventive when given to members of the family who have been exposed. This immunity, however, does not last long, usually not more than four weeks.

The chief difference between the principles involved in vaccination for smallpox and in the use of antitoxin for diphtheria is that in the former case the body makes its own antibody, while in the latter case, this antibody is made in the body of the horse and then injected into the human system.

Effect of treatment on the death rate. As a result of this treatment, diphtheria has passed from being one of the most dreaded diseases to one that is seldom fatal if taken in time. 
Statistics everywhere show a remarkable lowering of death rates where this treatment is applied. In New York City before this method was used, 40 per cent of those who had the disease died; now only 8 per cent die.

The following table shows the effect on the death rate from the use of antitoxin.

\begin{tabular}{|c|c|c|c|}
\hline LOCALITY & & $\begin{array}{l}\text { BEFORE ANTI- } \\
\text { TOXIN TREAT- } \\
\text { MENT }\end{array}$ & $\begin{array}{l}\text { AFTER ANTI- } \\
\text { TOXIN TREAT- } \\
\text { MENT }\end{array}$ \\
\hline $\begin{array}{l}\text { Chicago . } \\
\text { Boston . } \\
\text { New Jersey } \\
\text { Boston hospital }\end{array}$ & $\begin{array}{l}\text { Total number of annual } \\
\text { deaths } . \\
\text { Death rate per io,ooo . } \\
\text { Death rate per io,00o . } \\
\text { Annual death rate per } \\
\text { thousand cases . }\end{array}$ & $\begin{array}{r}1471 \\
14.5 \\
10.5 \\
\\
400\end{array}$ & $\begin{array}{r}85 \mathrm{I} \\
6.5 \\
3.7 \\
70\end{array}$ \\
\hline
\end{tabular}

This means an annual saving of more than three hundred lives in Boston and of five hundred and sixty-six lives in Chicago.

\section{LABORATORY EXERCISE 32}

Purpose. To observe the effect of the antitoxin treatment for diphtheria on the death rate in New Jersey.

Death Rate in New Jersey per io,000

\begin{tabular}{|c|c|c|c|}
\hline & Before Treatment & & AFter Treatment \\
\hline I 884 & 8.2 & I 898 & 5.25 \\
\hline I 885 & I I .7 & I 899 & 4.2 \\
\hline I 886 & IO & 1900 & 4.9 \\
\hline I 887 & I I .4 & 1901 & 3.5 \\
\hline I 888 & I 4.8 & 1902 & 3.75 \\
\hline I 889 & I I.2 & 1903 & 3.7 \\
\hline I 890 & I I & I 904 & $4 \cdot 5$ \\
\hline I 89I & I 1.75 & 1905 & 3.25 \\
\hline I 892 & I I. 75 & 1906 & 2.8 \\
\hline I 893 & 10.9 & 1907 & 3 \\
\hline
\end{tabular}


Directions. I. Starting with the third year of the first table put a dot opposite the death rate for that year in the column on this page with the figure 3 at the top. To show.how this is done the first two years have been filled out. Do the same for the remaining seven years. Connect adjoining dots with straight lines.

2. Begin with the third year of the second table and in the. same way complete the other eight years and connect the dots as above.

Figures at the left represent the death rate, those at the top, years.

Ist year $2 \mathrm{~d} \quad 3^{\text {rd }} 4^{\text {th }} 5^{\text {th }} 6$ th 7 th 8 th 9 th Ioth

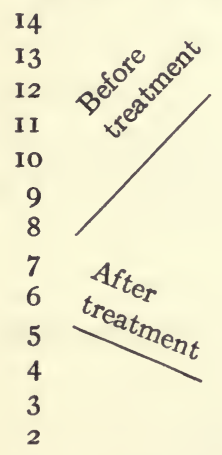

3. Reckoning the population of New Jersey as two million, how many lives have been saved during the last ten years in the state of New Jersey through the antitoxin treatment? To do this, first find the average death rate for the ten years before the treatment and then for the ten years after. Subtract these. The difference is the number of lives saved annually for each ten thousand population. From this work out the total number saved in New Jersey during ten years.

Hydrophobia. The treatment of hydrophobia is another application of the discoveries of modern science. After a 
person has been bitten by a mad dog, some time elapses before the symptoms of the disease appear. During this period the person is inoculated first with a weakened virus of hydrophobia which causes the body to form an antibody, then with increasingly stronger doses so that the body gradually becomes accustomed to these attacks, until by the time the effects from the dog bite would have been felt the body is able to overcome them entirely.

Typhoid fever. There are two diseases of common occurrence which are the cause of so many deaths that special mention should be made of them. They are typhoid fever and tuberculosis. They are due largely to people's carelessness and ignorance and hence are preventable diseases. Typhoid fever germs are often spread through drinking water. These bacteria live in the intestines of the patient and pass out from the intestines in the excreta, both the feces and the urine. They may pass directly with the sewage into some stream, or they may be deposited on the soil, from which they may sink down into the underground water and eventually find their way into wells. It frequently happens in the country that the well is located very near the place which receives the sewage, and the bacteria may pass into the well to be taken into the bodies of people who drink the water.

In cities which have a system of sewers, it sometimes happens that the sewers empty into a stream from which a city lower down takes its drinking water. When typhoid fever breaks out in the first city, the bacteria are carried to the second city, where another outbreak occurs. It is seen thus that the prevention of typhoid fever depends largely on two things, the proper disposal of sewage, and the purification of drinking water. Some facts about the purification of water were given in a previous chapter.

Recovered patients a source of infection. Another consideration which emphasizes the need of continual care in 
disposing of sewage and in the purification of water is the fact that even after a patient has recovered from the disease, he may continue to carry typhoid germs in his body for several years. These are given off in the excreta, which may thus be a means of spreading the germs. Thus such a person may be as dangerous to the health of a community as are typhoid patients. It is estimated that one person in every twenty-five who recovers from the disease continues to carry these germs, sometimes for as long a period as twenty years.

Household filters. If the water supply is suspected of being contaminated with typhoid germs, the surest protection is to boil for a half hour all water to be used for drinking purposes. This will kill all the germs and make the water safe. The great majority of the common small filters, which contain sand and charcoal and are attached to the faucet, are worse than useless. They do not remove the bacteria from the water, and the dirt which collects becomes a breeding place for bacteria. There are, however, filters which will remove the typhoid bacteria. Three types are on the market, the Pasteur, the Berkfield, and the Chamberlain filters, all of which embody the same principle. These contain unglazed porcelain through which water passes slowly. Even these require careful attention to insure safety. They should be thoroughly cleaned every day, and every fourth day should be boiled five minutes so as to kill the bacteria in the pores of the filter.

Ice. It is possible for typhoid germs to be carried even in ice. Freezing does not kill all the bacteria; some may lie dormant for several months frozen in the ice, ready to renew their activity when it melts. Whenever ice is to be used for cooling water, the cleanest and safest way is to put the ice around the receptacle containing the water instead of directly in the water. 


\section{Demonstration 30}

Purpose. To see if ice contains bacteria.

Materials. See demonstration 27 and read I under Directions.

Directions. Melt a piece of ice in a sterilized beaker. Take one cubic centimeter of the water and add it to a test tube containing melted culture medium. Shake and pour into a sterilized petri dish. Cover. Allow to stand a few days and see if any colonies appear.

Disposal of sewage. Besides the question of the purification of drinking water, the matter of the disposal of sewage must be considered in this connection. The details of this matter in cities must be left for experts to solve. There are, however, methods by which each city may dispose of its sewage without emptying it into streams. They may filter it by means of sand beds or burn it in cremating furnaces; the present method of contaminating our beautiful streams and rivers is unnecessary.

Pasteurization of milk. Milk may be a means of carrying the germs of typhoid fever, tuberculosis, diphtheria, and scarlet fever. In large cities it is usually impossible to know exactly the place from which the milk comes, and when it is fed to children it is safer to treat it in the home so as to destroy the bacteria. This may be done in two ways, by boiling or by pasteurization. The objection to boiling is that it so changes the character of the milk as to render it more indigestible.

In the process of pasteurizing, the milk is not heated to so high a temperature as the boiling point, only to about I6o degrees. This temperature is sufficient to kill the bacteria and does not affect the digestibility of the milk, and is, therefore, to be preferred to boiling. At this temperature the bacteria which cause milk to sour are destroyed also, and pasteurized milk will keep sweet longer. Pasteur- 
ization may be done in this simple way. (See figure I46.) A pail is partly filled with boiling water, and in this are placed the bottles of milk. The water should come nearly to the tops of the bottles. The bottles are allowed to remain here about a half hour and the milk should be stirred occasionally. The boiling water is cooled by the milk, and the amounts of water and milk can be so regulated that the final temperature of milk and water will be about the 160 degrees desired. When the milk has been heated enough, it should be cooled quickly. This may be done by allowing cold water to run into the pail. Inexpensive pasteurizing outfits may be bought in the market.

\section{Demonstration 3 I}

Purpose. To try the effect of pasteurization on the keeping quality of milk.

Materials. Beaker, test tubes, thermometers.

Directions. Fill the beaker half full of water, and the test tube half full of milk. Put the test tube in the beaker. Heat the beaker and put the thermometer in the water. Regulate the flame so as to keep the temperature between 160 and 170 degrees for about a half hour. Take out the tube and plug the mouth with cotton batting. Fill another tube half full of milk and plug with cotton. Allow the two tubes to stand side by side for several days and notice how long the milk in each keeps sweet.

Food. Three common ways in which typhoid fever germs may be carried have been explained, namely by water, milk, and flies. In addition to these means the germs may sometimes be carried in various articles of food, as on uncooked fruits and vegetables and on raw oysters. Epidemics of typhoid have occurred from eating uncooked oysters, which, it was later found, had been fattened in a bay into which had emptied the sewage from a house containing a typhoid patient. A wise precaution in the use of fruits and vegeta- 
bles is to wash them thoroughly before eating, and in the case of oysters to cook them.

Vaccination for typhoid fever. Modern science has found a means of preventing typhoid fever through vaccination. In times of war, typhoid has always been the scourge of armies. In the Spanish-American War, more soldiers died from this disease than were killed in battle. This idea of vaccination originated with Professor Wright in England, and was first tried on a large scale in the British army. As a result of these tests, it was found on comparing the inoculated regiments (about 9000 soldiers) with the uninoculated (about 7000 soldiers) that there were about ten times as many cases of typhoid among the latter regiments as among the former. In the inoculated regiments there were no deaths, while among the non-inoculated there were fourteen deaths.

During the Japanese-Russian War, in the Japanese army, where vaccination was practiced, there were practically no cases of typhoid fever; while in the Russian army, where this treatment was not employed, the efficiency of the army was greatly reduced through the large number of cases of typhoid.

Similar results have been obtained in the United States armies. Vaccination has now been made compulsory throughout the army. Before this treatment was given, there were 1037 cases of typhoid fever and 76 deaths during three years in the army and navy. During three years after vaccination was made compulsory there were only 50 cases and 5 deaths. The number of cases was reduced to one twenticth and the number of deaths to one fifteenth of what they had been formerly.

In a bulletin issued by the Department of Agriculture it is advised that well persons exposed to the dangers of field service be vaccinated. But it is not recommended for old people, very young persons, civilians who live at home, 
and for people in ill health. The need of applying this treatment as widely as possible is evident when we consider the fact that there are annually in this country about 200,000 cases of typhoid fever with about I 5,000 deaths.

Method of typhoid vaccination. The typhoid bacteria are first allowed to develop for a day on beef-tea jelly and are then killed by exposure to high temperature. This solution is then injected through a needle prick into the skin of the upper arm. Three doses are given at intervals of ten days. Only slight indisposition generally follows the inoculation, and even this usually disappears inside of two days. The effect of introducing this vaccine into the system is to increase enormously the antibodies in the blood, which are the body's means of combating this disease, so that when living typhoid germs do enter the system these antibodies are present in sufficiently large quantities to offset the effects of the poison which the germs produce. This immunity lasts for two years and in some cases longer.

The great white plague. Another disease which should be especially mentioned is tuberculosis of the lungs, or consumption, as it is called. One tenth of all deaths are due to this disease alone, the annual number of deaths in the United States being over I00,000. The number of deaths from this one disease equals the total number caused by the following eight diseases combined: smallpox, typhoid fever, scarlet fever, diphtheria, cancer, diabetes, appendicitis, and meningitis. The number of people in the United States constantly suffering from consumption is about 500,000 . If the present death rate continues, 5,000,000 people of those now living in this country will die of this disease.

These figures have been given so as to emphasize the next statement, that most of this terrible loss of life is unnecessary, because tuberculosis is a curable and preventable disease. As one looks back over the past it is a sad thing to think that most of those thousands of deaths might have been pre- 
vented, but on the other hand as one looks forward to the future, it is encouraging to think that this mortality may be very largely reduced through the spread of the knowledge of how consumption may be cured and prevented. It is the purpose of the next few pages to give some of the information which one needs in order to enable him to act his

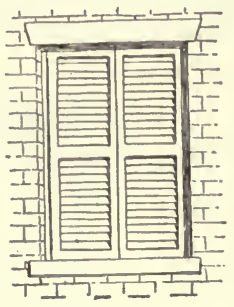

The closed window.

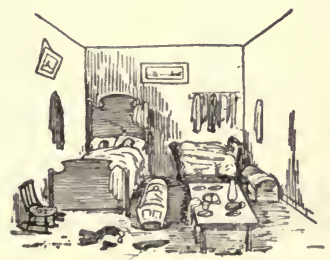

Crowded rooms.

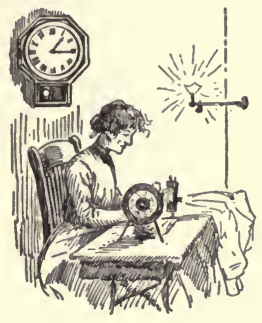

Overwork.

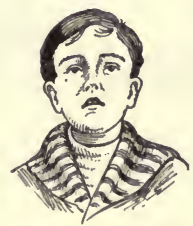

Mouth breathing.

Fig. 151. - Allies of consumption.

part as an intelligent citizen in the widespread movement to stamp out this disease.

How bacteria leave and enter the body. Tuberculosis of the lungs is caused by bacteria which live in the lungs, and cause little rounded bodies known as tubercles. The bacteria are passing constantly into the saliva of the patient and leave the body in the sputum. While the chief way in which they are thrown out is in the act of expectoration, they may also be thrown off in the mouth spray in the 
acts of coughing and sneezing. These may find entrance into another body in three ways: (I) by being breathed in through the mouth or nostrils, (2) by being taken in food or drink, and (3) by entering wounds. The first two are the most common.

Bacteria in foods. It is known that cattle are subject to tuberculosis and it seems now to have been definitely proven that through the meat and milk of diseased cows the bacteria of tuberculosis may be taken into the human system. On the other hand, cattle may take the disease from human beings by eating grass upon which the sputum of a sick person has been deposited.
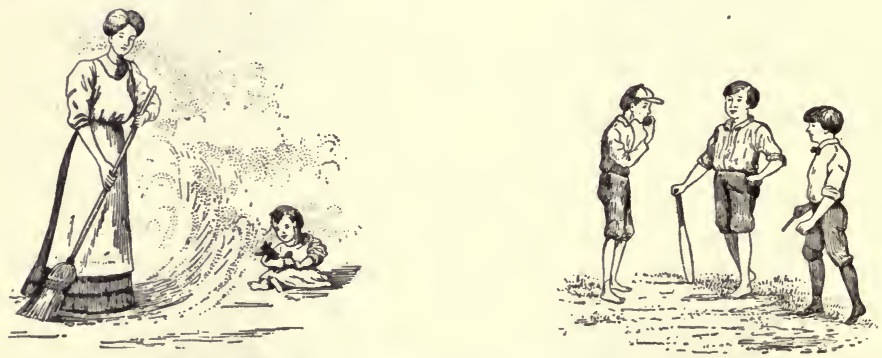

FIG. I52. - How the germs of consumption are carried from the sick to the well. By sputum.

By two people taking a bite from the same apple.

It has been found that young children are specially susceptible to the germs in milk from tuberculous cows. These bacteria may be found not only in the milk itself but in the products obtained from it, as cream, butter, and cheese; and in oleomargarine, sometimes used as a substitute for butter. Investigations made. in the city of Washington showed that $5 \frac{1}{2}$ per cent of the samples of milk tested contained bacteria of tuberculosis. It was found also that I 7 per cent of the cows examined in the neighborhood of this city were affected with tuberculosis. Investigations made in Europe indicate that the per cent of butter containing the tubercle bacilli is slightly larger than the per cent of milk. 
Public drinking cups. The public drinking cup is another means of spreading the disease. Tuberculous people use these cups, and in the saliva left on the edge are thousands of the bacteria, which are taken into the mouth of the next person using the cup.

Cure of tuberculosis. The cure of tuberculosis consists in the employment of three things : fresh air (night and day),

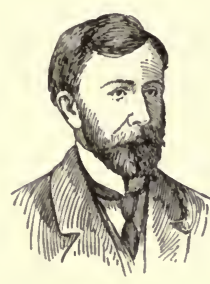

The doctor.

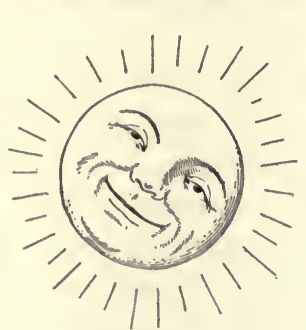

Sunlight.

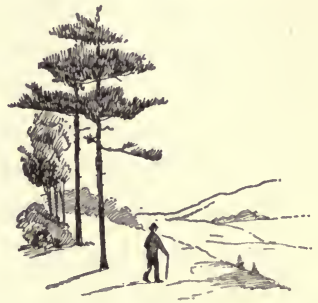

Out-door air.

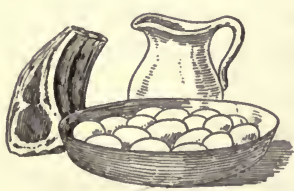

Good food.

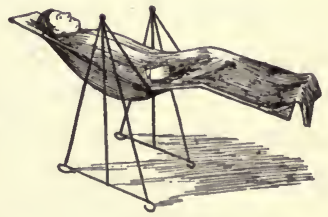

Rest.

Fig. 153. - Helps in the cure of consumption.

plenty of good, nourishing food, and rest. All medicines advertised as cures for this disease are useless and worse than useless, even when they are not actually harmful. It is not necessary for one to go to any particular climate, the essential thing being a location where a constant supply of pure, fresh air may be obtained.

Window tent. The window tent is an excellent device for use in winter to secure fresh air without cooling the room in which the patient is sleeping. This is simply a frame covered with canvas, resting on the head of the bed and so 
fastened to the window that little air can enter the room. In the lower part is an opening through which the head may pass into the inclosure which receives the air through the window. By this means the sleeper obtains a constant supply of fresh air for breathing, while his body is not cooled thereby. A serviceable home-made tent may be constructed out of stiff wire and canvas. This need be used only in the colder months, as at other times the windows can be kept wide open without any discomfort.

Prevention of tuberculosis. Care of sputum. The prevention of tuberculosis must look in the first place to the proper supervision of those who already have the disease. As the sputum of these patients is the chief means by which the disease is spread, the first care must be the proper disposal of this sputum. This should be deposited either in paper napkins, which should be burned, or else in covered metal cups which contain some chemical to kill bacteria. The bacteria are not carried in the breath of the patient. A careful patient is not dangerous to those with whom he associates. A tuberculous person should never expectorate in public places, where the sputum may become a source of danger to the public. As people often have the disease and do not know it, the general rule should be followed by every one not to expectorate in public places. The signs so frequently seen prohibiting expectoration are designed to prevent the transmission of tuberculosis through the expectoration of careless and thoughtless persons.

Protection of food. The bacteria in meat may be killed by a thorough cooking. Those in milk may be destroyed, by pasteurizing as previously described on page 382 . The presence of tuberculosis in cattle may be detected by what is known as the tuberculin test. There are laws regulating to some extent the kind of cattle that may be kept by dairymen, and sold as meat, and where these laws are rigidly enforced, the public is partially protected against this danger. 
Drinking cups. The public drinking cup should everywhere be abolished. Recently there has been invented a slot machine so constructed that if a penny is put into the slot, there drops out a clean cup made of waxed paper. In most schools sanitary drinking fountains are being used.

Antituberculosis movement. In recent years people have become so awakened to the fact that tuberculosis is our most fatal disease, and yet that it is curable and preventable,

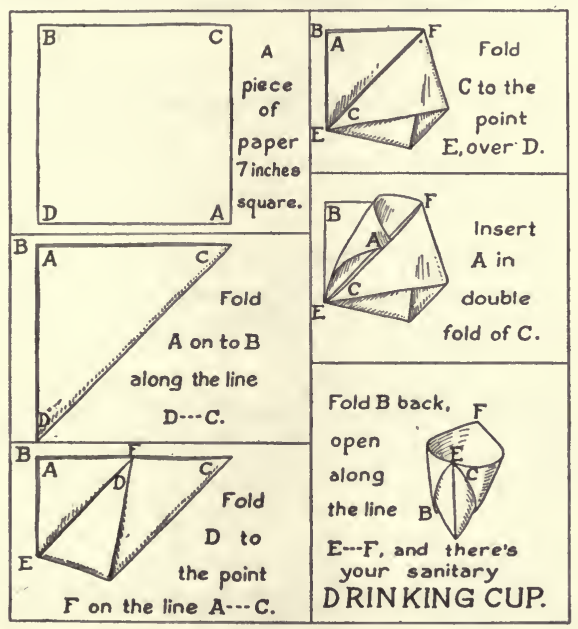

Fig. 154. - How to make a drinking cup.

that organizations have been formed throughout the world for the purpose of combating this disease. In this country there are at least sixty city committees devoted to this purpose, and fifteen state organizations; and a few years ago there was formed the American National Association for the Study and Prevention of Tuberculosis. The various nations have organized an International Tuberculosis Congress. These organizations are doing much in educating the people by means of exhibitions and the distribution of printed matter. 
Sanatoriums. Many states and cities have instituted sanatoriums where treatment may be given to consumptives. Some large organizations and private companies have planned sanatoriums for the benefit of the members and employees. Frequently neighboring counties unite in building a sanatorium.

Decrease in the death rate. Already statistics show a steady decrease in the number of deaths caused by, tuberculosis. Since 1880 the death rate in the United States has fallen more than 50 per cent.

19001901190219031904190519061907190819091910191119121913191419151916

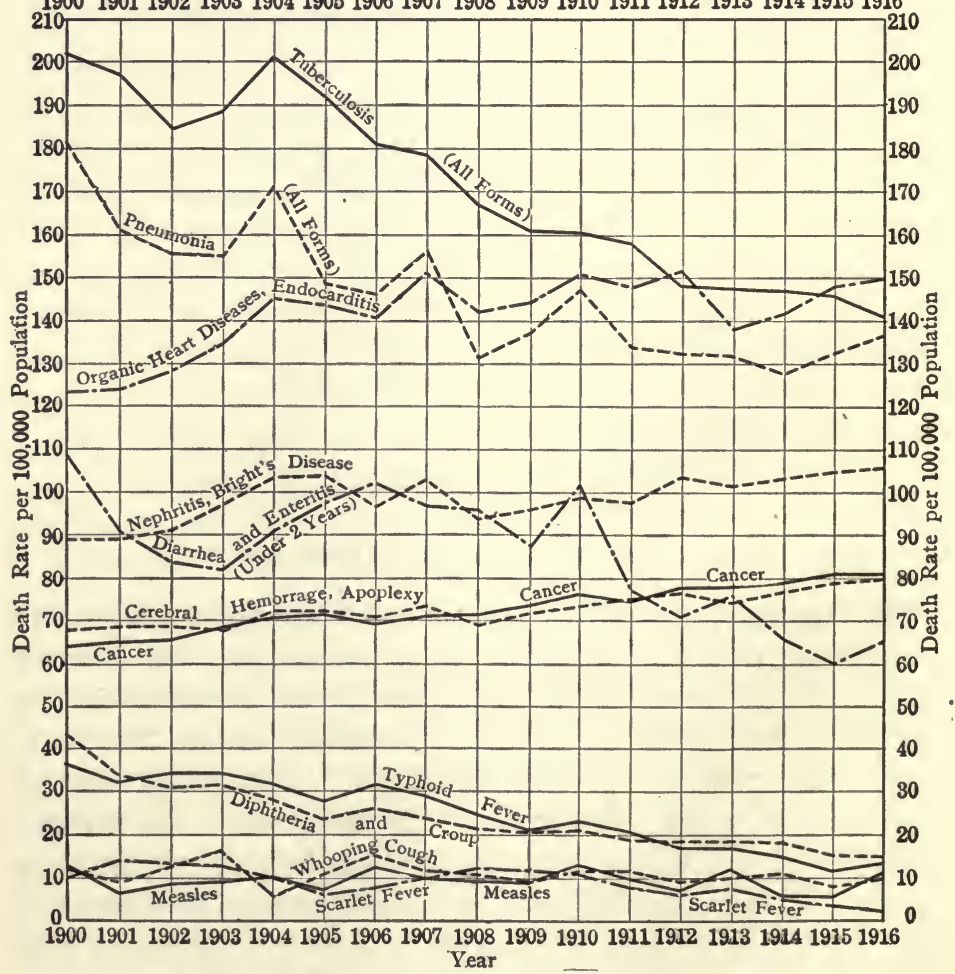

Fig. 155. - Death rates from important causes of death. 


\section{LABORATORY EXERCISE 33}

Purpose. To compare the death rates for various diseases. - Materials. Figures 150 and 155 .

Directions. I. In figure I55 notice which three diseases cause the greatest number of deaths. Which five the least.

2. Make a table like the following in your notebook.

\begin{tabular}{|c|c|c|c|}
\hline Disease & Death Rate & Number Who Die & $\begin{array}{c}\text { Per Cent of IN- } \\
\text { Crease OR Decrease } \\
\text { Since I900 }\end{array}$ \\
\hline & & \\
\hline & & \\
\hline
\end{tabular}

Fill in the figures for the first three columns for each disease for 1916, counting the population of the United States as 100,000,000. Put first the disease with the highest death rate and arrange the rest in order.

3. Beginning with diseases having the lowest death rate, add together the number of people killed till you get a total equal to the number killed by tuberculosis alone. How many and what diseases does it take to do this?

4. For which diseases has the death rate been decreasing? For which increasing? Compare 1916 with 1900 and work out for each disease the per cent of increase or decrease. Put the figures in the fourth column of the table above.

Are the diseases that are decreasing contagious or organic diseases? Which are those that are decreasing? See if you can find out, either by using books or by asking a physician, why there have been these changes.

5. Study figure 150 to notice the effect of vaccination on the death rate from smallpox. What does the figure show $(a)$ for Prussia, (b) for Holland, (c) for Austria?

6. In Prussia what was the average annual death rate for the six years before vaccination was made compulsory? What was it for the six years after? The population of Prussia for 1880 was 27,000,000. Compute the number of lives saved in this country 
through vaccination from the years 1875 to 1886 , taking the above figure as the average population for these years.

7. Do the same for Holland, whose population in 1880 was nearly $4,000,000$.

8. Estimate the number of lives that might have been saved in Austria from the years 1875 to 1884 if vaccination had been made compulsory as it was in Prussia. To do this first find the average annual death rate in Austria for the years I875 to I884. Subtract from this the average annual death rate in Prussia for the same years. What does this difference represent? The population of Austria in 1880 was about $22,000,000$. Remembering that the death rate means the number of deaths per 100,000 inhabitants, estimate the number of lives that might have been saved by vaccination during the years 1875 to 1884 , taking the above figure as the average population.

\section{Community Project 2}

Purpose. To study the death rate in your own state and locality for different diseases.

Directions. I. Secure the latest report of the state board of health. From a study of the statistics of deaths compute the per cent of deaths from the ten most common diseases. Arrange these in the order of the per cent of deaths.

2. Obtain the reports from the city health officer of the deaths in your city or county and work out the per cent of deaths from the ten most common diseases.

3. If possible get the figures from some neighboring city and rompare the two.

\section{SUPPLEMENTARY QUESTIONS FOR CLASS DISCUSSION}

I. How can such small organisms as bacteria have so much influence on human life?

2. What is the relation of temperature and moisture to the growth of bacteria?

3. What are the chief means by which disease bacteria leave the body?

4. How may they enter the body? 
5. What are the chief means by which disease bacteria are carried from one person to another?

6. How does the treatment for diphtheria differ from that for smallpox?

7. What are the evidences of the effectiveness of vaccination for smallpox and of the antitoxin treatment for diphtheria?

8. When is compulsory vaccination advisable?

9. What are the chief things to do in order to be protected from typhoid fever?

Io. Compare vaccination for typhoid fever with vaccination for smallpox.

I I. Where should the chief emphasis be laid in the control of contagious diseases?

12. What are the chief things to be done in the control of tuberculosis?

13. What can you do to help in the fight against contagious diseases?

\section{REFERENCES}

Hough and Sedgwick, The Human Mechanism, Ginn and Co., Boston. Chaps. 30-3I.

Ritchie, Primer of Sanitation, World Book Co., Yonkers-onHudson, N. Y. 


\section{CHAPTER XXV}

INSECTS AND DISEASES

How do the fly and mosquito differ as regards (a) the harm done, $(b)$ their life history, and $(c)$ the means to be used to control them?

It has been proved conclusively within recent years that certain insects are responsible for much sickness and many deaths because they carry the organisms which cause diseases. Mosquitoes are known to carry malaria and yellow fever and this is the only method by which these diseases are carried. It is known that house flies are one means of carrying typhoid fever, Asiatic cholera, dysentery, infantile diarrhea, and tuberculosis; and there is strong evidence that they may carry also smallpox, ophthalmia, and parasitic worms.

While mosquitoes and flies are the most dangerous insects as disease carriers in this country, there are other insects which carry disease. The "spotted" fever of the Rocky Mountain region is carried by a certain tick; pink eye in the southern states is carried by a small fly; the sleeping sickness in Africa is transmitted by flies; the bedbug may aid in the dissemination of disease; fleas found on rats are the means of spreading bubonic plague; and several diseases of domesticated animals are caused by insects.

\section{Harm Done by Mosquitoes}

Mosquitoes and Malaria. Malaria is caused by a microscopic animal which lives in the blood. These parasites 
enter the red blood corpuscles and grow till they occupy nearly the whole space, and then divide into a number of little spores, which, as the wall of the corpuscle bursts, pass out into the blood. It is at this stage that the chills which characterize malaria occur. These spores enter-other corpuscles and the process is repeated.

Some of these spores undergo a different kind of development. When these are sucked up with the blood by a malarial mosquito, they pass through certain stages of development in the body of the mosquito, and at the end of a little more than a week produce spores of another kind, some of which find their way into the salivary glands. When the insect bites a person, these spores are introduced into the blood of this person together with the fluid from the salivary glands, and begin the process of growth which brings on malaria. Thus it is seen that the relation of the parasite to the mosquito and human beings is a very vital one. It cannot undergo its complete development in either one alone, so that for the continuation of the disease both human beings and this mosquito are essential, one of which must be infected with the parasite.

It has been estimated that the annual financial loss in this country due to the agency of mosquitoes in carrying malaria is \$100,000,000. The United States Department of Agriculture has made a study of the economic loss sustained on the southern plantations on account of the sickness and deaths due to malaria. These losses are of two kinds, those due to loss in time and those due to reduced efficiency, at the season of the year when labor is most needed to work and harvest the crops. On one plantation it was estimated that $\$ 6500$ was lost in one year, $\$ 2200$ from actual sickness and $\$ 4300$ from inefficiency due to malaria.

In I9I6, the death rate per 100,000 in the United States was 3. This means that about 3000 people died that year of malaria. These deaths are all due indirectly to mosqui- 
Transmitted
bybite of
mosquito. Red
Corpuscle
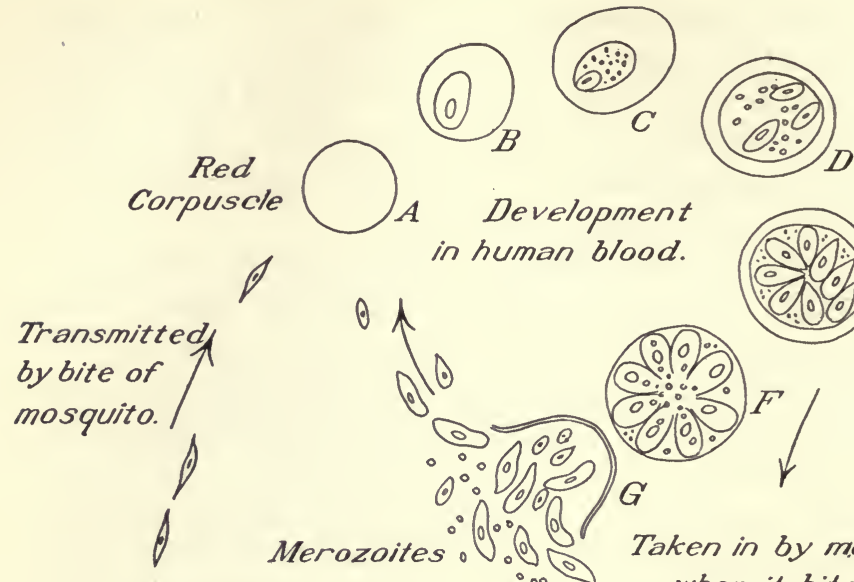

Development in human blood.
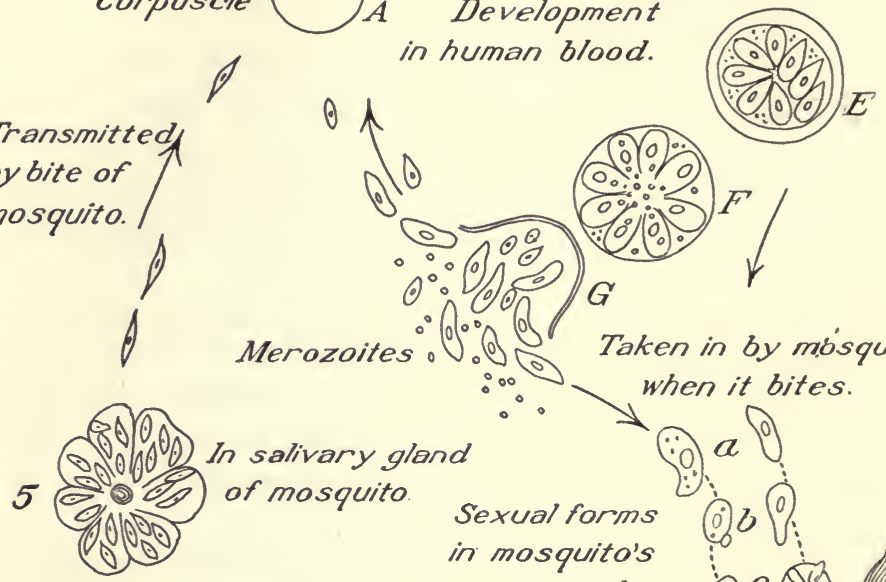

Merozoites:

0.0 sporozoites in

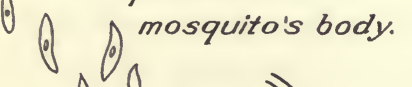

Fertilized cell. Sexual forms mosquito's stomach.
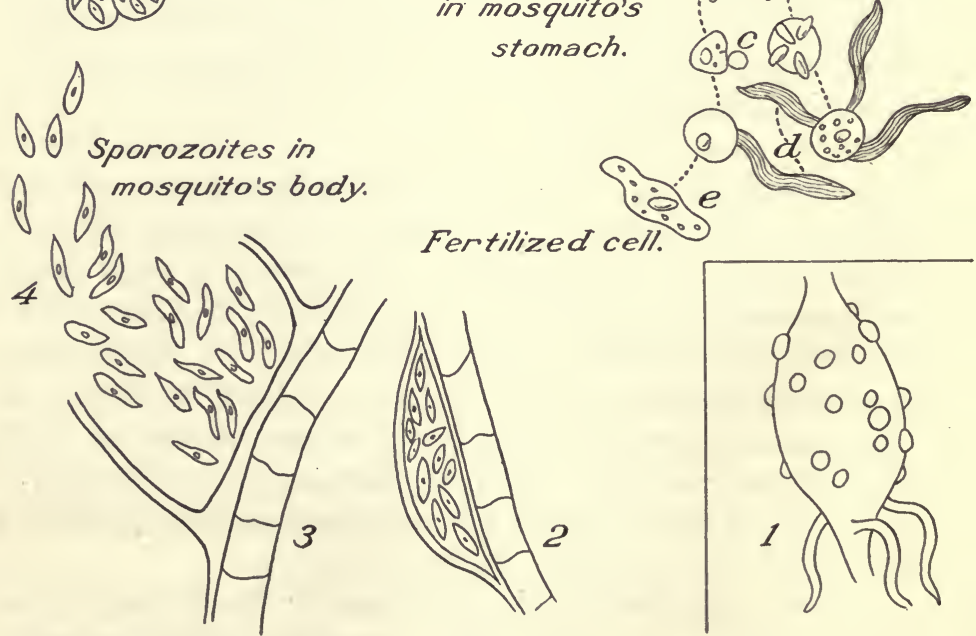

FIG. 156. - Life history of the malarial parasite in man and mosquito. I, 2, 3, parasites on outer wall of mosquito's stomach. 
toes, for without their agency the disease would not spread from person to person.

Yellow fever. Yellow fever is also carried by mosquitoes. The cause of this fever is believed to be an organism somewhat similar to that which causes malaria. The method by which mosquitoes carry the fever is similar. During the epidemic of 1878 , there were twelve thousand deaths from yellow fever in the United States. Since the part that the mosquitoes play in carrying this disease has become known, such effective measures have been taken to control the disease, that in I9ro there was only one death from yellow fever.

These diseases are not carried by all mosquitoes. Malaria is carried by only one genus, Anopheles, and yellow fever only by Stegomyia. The common mosquito (Culex), usually found around our buildings in the northern states, does not carry either of these diseases.

Financial loss due to mosquitoes. But even the common mosquito may be such a pest as to cause financial loss. Where they are especially abundant, they cause a depreciation of the value of the real estate and prevent the development of sections of the country which would otherwise be available for suburban homes, summer resorts, and agricultural pursuits. In some sections of southern New Jersey, herds of cattle have been so pestered by swarms of mosquitoes that dairying had to be abandoned.

As a minor matter, mention may be made of the expense involved in providing screens, which Dr. Howard estimates as amounting to $\$ 10,000,000$ annually.

In the northern United States where malaria seldom occurs mosquitoes are nevertheless a great pest, as they drive people indoors during the evening and deprive them of the use of the outdoors at the best time of the year, so that even in this section it is worth while to make an effort to get rid of them. 


\section{Life History of Mosquitoes}

In order that remedies looking toward the extermination of the mosquito shall be applied intelligently and successfully, it is necessary to know the life history and habits of the mosquito. The life histories of all kinds of mosquitoes

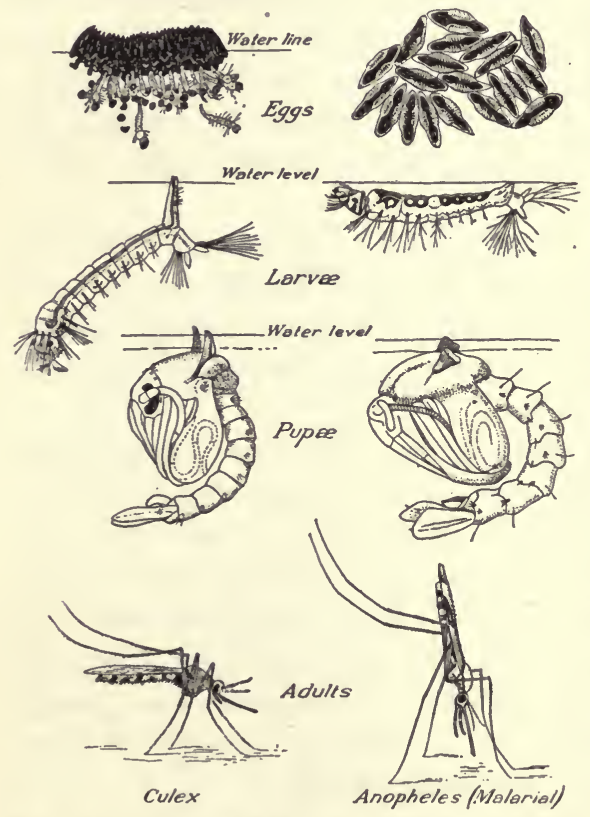

FIg. 157. - Life history of common mosquito (Culex) at left and of malarial mosquito (Anopheles) at right. Notice how they differ in each stage.

float upon the surface. Under favorable conditions these hatch on the same day. The larvæ grow rapidly, feeding upon minute organisms. When at rest the larvæ hang head downwards with the tip of the abdomen, which contains the breathing tube, thrust to the surface of the water where air 
is secured. When disturbed, the larvæ frequently sink to the bottom but can remain only a few minutes, being obliged to return to the surface for air.

The pupa, into which the larva develops, differs noticeably from the larva in form and possesses two breathing tubes situated on the thorax. The insect now rests with its head uppermost. The pupa is active, being an exception in this respect to the general rule among insects. The insect remains in the pupal stage only a few days; the skin splits and the adult emerges, resting on the old skin at the surface of the water until its wings become dry and hardened.

Under favorable conditions the whole life history may be completed in ten days, one day in the egg, seven days in the larval state, and two in the pupal state. During cool spells of weather this time may be greatly prolonged. The development of the malarial mosquito takes from fifteen to twenty-four days.

Several hundred eggs are laid in a single mass and as each may develop into an adult in ten days, it is clear that the possibilities of multiplication are enormous. Professor Hodge has calculated that the descendants from a single mosquito (on the supposition that one half are females and that each of these lives and lays two hundred eggs) might amount in one hundred and eighty days to a number represented by the figure two followed by thirty-nine ciphers. Of course this never actually happens, on account of the insect's enemies and the lack of food, but it suggests the possibilities of growth.

Breeding places. Mosquitoes breed in a great variety of places, such as rain barrels, tin cans in dump heaps, dishes, and almost any receptacle containing water, in pools of water, in ditches, depressions, footprints, in cesspools, hollows of trees, sewer catch basins, railroad ditches, swamps, and woodland pools. In fact they may breed in almost any stagnant pool of water that stands for a week or more. They 
may even breed indoors, in flower vases, unused water pitchers, and tanks. They may come from deserted cisterns or from sewer traps during dry spells when the sewers have not been flushed.

\section{Control of Mosquito}

Natural enemies of mosquitoes. In discussing methods for exterminating the mosquito, it is important to know

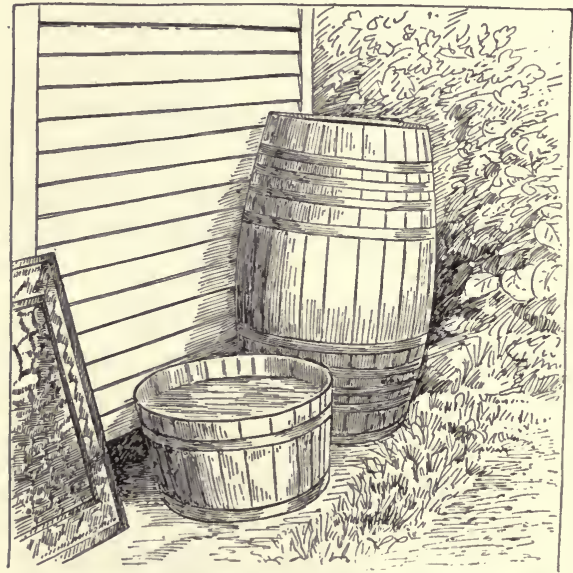

FIG. 158. - Rain barrels, breeding places for mosquitoes. Should be kept covered. what are its natural enemies and to encourage their presence. As the adults are chiefly nocturnal, their chief enemies will naturally be those which are active at night. Among the birds, the nighthawk and whippoorwill are night feeders and destroy many mosquitoes. The swallows, too, although not nocturnal, include mosquitoes in their diet. Twenty-four species of birds have been known to feed upon the mosquito. They are eaten also by frogs, toads, bats, dragonflies, and other insects, and many are caught in spider webs.

The larvæ and pupæ have many enemies. Nine species of shore birds are known to feed on the wigglers of mosquitoes. Hundreds of larvæ have been found in the stomach of a single killdeer. The larvæ are eaten in large numbers by fishes and many water insects. 
The remedies that man may use may be divided into two groups: first, those directed against the adult stage, and second, those directed against the water stages.

Remedies against Adults. Fumigants. Against the adults, three measures may be taken: fumigants may be used to kill them; repellants may be used to drive them away, and screens may be used to keep them out. The mosquitoes in the house may be killed by burning pyrethrum powder. This may be burned completely or heated on a shovel or tin pan. During the process the windows should be closed. The mosquitoes are overcome by the fumes and fall to the floor, where they may be swept up. Burning sulfur is very effective and is often used in fumigating houses which may contain disease-bearing mosquitoes. Special caution however must be taken in its use, as it injures certain household goods.

Repellants. To prevent mosquitoes from biting, certain substances may be used, the odor of which is unpleasant to mosquitoes. The best of these repellants is oil of citronella. This may be applied to the face and hands, or it may be placed on a cloth kept near one, as in sleeping rooms. When applied to the face, care must be taken that none enters the eye, as it causes intense smarting. Citronella may be used alone or with something else. Dr. Howard considers the following the most efficacious mixture that he has tried: One ounce of citronella, one ounce of spirits of camphor, and one half ounce oil of cedar. The effects of the citronella last about an hour. To retard the evaporation of the oil, four ounces of vaseline may be mixed with one ounce of oil.

One of the best remedies for the irritation produced by mosquito bites is moist soap. Other remedies which have been tried and found efficient are glycerine, ammonia, alcohol, or marking the puncture with naphthaline moth balls, indigo, or iodin. 
Remedies directed against water stages. Two kinds of remedies may be employed: first, the preventive, whose purpose is to prevent the breeding of mosquitoes, and second, the curative remedies whose purpose is to destroy those mosquitoes that may be breeding. The first remedy is the more important because it is lasting in its effects, but the second serves as a valuable temporary substitute.

Preventive remedies. Among the first class of remedies are the following: In large marshes draining by means of ditching is effective. Work of this kind on the salt marshes of California and New Jersey has been carried on over large areas with marked success. Not only has the mosquito nuisance been abated but the value of the land for agricultural purposes has been increased. Some ponds may be drained and small woodland pools may be filled with soil.

The breeding of mosquitoes in cisterns, tanks, barrels, etc., may be easily prevented by covering them with mosquito netting or boards.

Empty cans and bottles that accumulate in yards or dumps should be turned over so that they will not hold water. Better still, these should not be allowed to accumulate. There may be frequent community house-cleanings during which the cans are collected and buried.

Mosquitoes usually travel only a few hundred yards or rods, so that a community may generally find relief from the mosquito by destroying the breeding places found within the immediate vicinity. But there are a few species which breed on the coast marshes, as in New Jersey, that are borne inland by the wind to a distance of thirty miles or more.

Curative remedies. Fishes may be introduced into ponds to feed upon the water stages of the mosquito. The swampy margins should be deepened to allow the fishes access to all parts.

For small pools and ponds kerosene may be applied to the surface at the rate of one ounce to fifteen square feet. This 
stifles the larvæ and pupæ and also destroys many of the adults which come to lay eggs. To be most effective this must be applied frequently, as the film is easily destroyed by rain or wind.

\section{Successful campaigns} against the mosquito. Mosquitoes can be controlled and the injury they do largely prevented by the intelligent coöperation of the people of a community. There are numerous cases where efforts of this kind have met with remarkable success. Two of the most successful cases were those under charge of the United States government in Cuba and Panama. At the close of the Spanish War, the American soldiers under charge of Colonel Gorgas made a campaign against the mosquito in Havana and the immediate vicinity. As a result of this work, yellow fever was wiped out in Havana and the number of deaths from malaria was reduced to one half the first year and to one quarter the second year,

\begin{tabular}{|c|c|}
\hline YEAR & $\begin{array}{llllll}250 & 500 & 750 & 1000 & 1250 & 1500\end{array}$ \\
\hline 1871 & 991 \\
\hline 1872 & 515 \\
\hline 1873 & (124) \\
\hline 1874 & 145 \\
\hline 1875 & 1001 \\
\hline 1876 & 1619 \\
\hline 1877 & 1374 \\
\hline 1878 & 559 \\
\hline 1879 & 141 \\
\hline 1880 & 645 \\
\hline 1881 & 185 \\
\hline 1882 & IIs \\
\hline 1883 & 849 \\
\hline 1884 & 511 \\
\hline 1885 & 165 \\
\hline 1886 & 162 \\
\hline 1887 & 532 \\
\hline 1888 & $468=$ \\
\hline 1889 & 303 \\
\hline 1890 & 308 \\
\hline 1891 & 356 \\
\hline 1892 & 38 \\
\hline 1893 & 496 \\
\hline 1894 & 32 \\
\hline 1895 & 033 \\
\hline 1896 & 128 \\
\hline 1897 & 11S SYIIIN- \\
\hline 1898 & 18 \\
\hline 1899 & 10. \\
\hline 1900 & $310 \%$ \\
\hline 1901 & 18 Carrier of Yellow Fever Discovered \\
\hline 1902 & None \\
\hline 1903 & None \\
\hline 1904 & None \\
\hline 1905 & First Cuban Rule \\
\hline 1906 & 12 \\
\hline 1907 & 3 \\
\hline 1908 & 3 \\
\hline 1909 & None \\
\hline 1910 & None \\
\hline
\end{tabular}

Fic. 159. - Showing death rate from yellow fever in Havana before and after the discovery that mosquitoes carried the disease. 
and there has been a constant decrease each year since.

Previous to the digging of the Panama Canal, Colonel Gorgas was appointed sanitary officer of the canal zone. $\mathrm{He}$ employed similar methods against the mosquito there, with the result that yellow fever has apparently been eliminated and malaria greatly reduced. This work had a very important bearing on the building of the canal, which would undoubtedly have been seriously interfered with if this work of Colonel Gorgas in doing away with the mosquito had not first been done.

In San Antonio, Texas, the work of finding and destroying the breeding places of mosquitoes was taken up by the school children, and as a result the mortality from malaria was reduced seventy-five per cent the first year, and entirely eliminated the second year.

In the town of Crosset, Arkansas, with a population of two thousand, 60 per cent of the time of the doctors was taken up in treating malaria. During the year I9I7 a campaign against the mosquito was carried on costing $\$ 2500$, or $\$ 1.25$ per person. As a result the number of cases of malaria was reduced 82 per cent.

\section{Laboratory Exercise 34}

Purpose. To study the life history of the mosquito and to find methods of destroying it.

Materials. Mosquito wigglers in tumblers of water covered with mosquito netting, fish, tadpoles, water insects, kerosene.

Directions. I. Study the larva and note $(a)$ its method of breathing, $(b)$ its method of moving, $(c)$ position when at rest. What is the longest time that a larva stays away from the surface?

2. Compare the pupa with the larva in the three points given above.

3. When the adult emerges, notice its resting position. Describe the mouth parts. 
4. Place a counted number of wigglers in a dish of water with a fish. Notice how long before they are all eaten. In another dish put some wigglers with a tadpole and note results. Try various kinds of water insects and see which ones eat the wigglers.

5. In another dish containing larvæ and pupæ, pour a few drops of kerosene on the surface of the water. How long before you note any results?

\section{Community Project 3}

Purpose. To see what the class can do to help rid the locality of mosquitoes.

Directions. I. The class may be divided into groups, each to supervise a certain section of the city. Aid of other agencies in town such as newspapers, civic organizations, and health officers should be sought so that all may coöperate for the best results.

2. The class may first make a survey to see what breeding places there are in the locality and which of them contain wigglers. A map should be made to show this.

3. The next step is to apply remedies. Is it feasible to have any of the breeding places drained or filled? Which ones can be covered? On which can kerosene be used?

\section{Harm Done by Fly}

Method of doing harm. Until recently the house fly has been considered merely a nuisance, but investigations of the past few years, have proved that it is a positive source of danger as a means of carrying diseases. The method by which it carries these is very different, however, from that of the mosquito in carrying malaria and yellow fever. The kinds of diseases usually transmitted by the flies are those which may be taken into the system through food and drink. The fly breeds in filth and frequents filthy places. As it walks over these places, there adhere to its feet and the hairs on its body, small particles of filth which often contain those bacteria that cause disease; and still other bacteria may be 
sucked up through its proboscis and taken into its digestive system. The fly may then enter our homes or places where food is sold; and as it alights on the food or falls into the milk, it leaves some of these bacteria, either in the particles of filth that fall from its body, or in the fly specks deposited. When the food is eaten, these germs are taken into the human system and produce disease. Or, again,

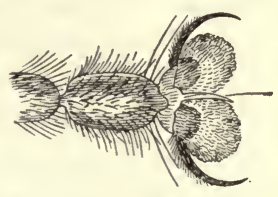

Fig. I60. - Foot of fly, a germ carrier. the fly may alight directly upon the face and fingers of human beings and leave bacteria, which may then be taken into the mouth. The evidence which is being gathered indicates that diseases are frequently spread by flies.

Evidence against the fly. Following is some of the evidence that flies are carriers of diseases.

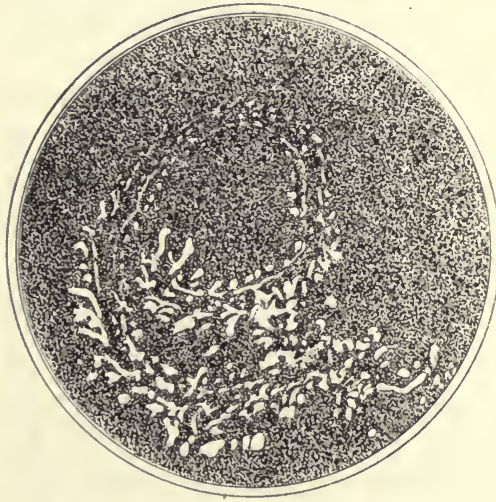

Fig. I6r. - Fly tracks on a culture.

I. It is the habit of flies to feed on filth of all kinds in which bacteria are abundant.

2. Bacteria are present in great numbers on flies. This has been shown by allowing a fly to walk on a medium in which bacteria will grow. After this had stood a few days, large numbers of colonies of bacteria developed in the culture.

The bacteriologist at the Connecticut Experiment Station devised a method for estimating the number of bacteria found on a single fly. Four hundred and fourteen flies were examined, and on each fly was found an average of a million and a quarter bacteria. Very few of these were the kind that produce disease, but 
these figures show the enormous possibilities of these insects for doing harm whenever injurious bacteria are exposed within their reach.

\section{Demonstration 32}

Purpose. To show that flies carry bacteria.

Materials. Two petri dishes, two tubes of culture medium.

Directions. Melt some culture medium and pour into a sterilized petri dish. Cover. When the medium hardens, place a fly under the cover and allow it to walk on the medium. Then let it escape and cover the dish. Prepare another dish of culture medium and cover, but do not allow a fly to walk on it. Allow the dishes to stand side by side for several days and notice any differences.

3. Some of the bacteria present on flies are the ones which cause diseases. At various times the bacteria which cause typhoid fever, tuberculosis, bubonic plague, and cholera have been found either on flies or in fly specks.

4. It is a fact only too well known that flies are abundant in houses and stores and that they frequently alight on food.

5. Investigations have been made which show a relation between the number of flies and the number of deaths caused by diseases which may be carried by flies. During the seasons of 1907 and 1908 a committee in New York City made a special study of the conditions found in that city with reference to typhoid fever and other intestinal diseases. To obtain some idea of the relative abundance of flies at different times of the year, fly traps were set in various parts of the city, and the number of flies caught each day was counted. Statistics were gathered regarding the number of deaths due to the diseases mentioned above. On comparing the records of the number of flies caught with these statistics (taking into account the time necessary for the diseases to develop), it was found that there were the most deaths during that part of the year when flies were present in largest num- 
bers, and that when the number of flies decreased on the approach of cold weather, the number of deaths decreased also. During the year 1908 , there were 5550 deaths due to these diseases. The committee which had charge of this investigation estimated that 4272 of these deaths were due to flies. An insect which is believed to cause over four thousand deaths in a single city in a single year is certainly to be considered a most dangerous animal. The following quotation is taken from Mr. Jackson's report for the committee : "Regarded in the light of recent knowledge, the fly is more dangerous than the tiger or the cobra. Worse than that, he is, at least in our climate, much more to be feared than the mosquito and may easily be classed the world over as the most dangerous animal on earth."

6. Epidemics of typhoid fever and other diseases occur, which can easily be explained on the supposition that the disease was carried by flies, but which cannot be explained in any other way.

7. In the city of Seattle, Washington, during the year I908, when a special crusade was waged against flies by the Board of Health, the death rate from typhoid fever was reduced one half.

Flies and typhoid fever. The fly is such a common carrier of typhoid fever that Dr. Howard, the United States Entomologist, has proposed that its common name be changed from house fly to typhoid fly. "The bacteria which cause typhoid fever pass out in the excretions of the patient. Whenever these are exposed the bacteria may be carried by flies and left on uncovered food and dishes. Five thousand American soldiers died of typhoid fever during the SpanishAmerican War. It is now believed that the epidemic was due largely to flies, which were thus responsible for more deaths than the Spanish bullets.

Flies probably rank next to impure milk and polluted water, as a means of spreading diseases. In those cities which 
have a pure water supply it is believed by some authorities that flies are the most common cause of transmitting this disease. One estimate states that the annual financial loss in this country due to typhoid fever is over $\$ 350,000,000$. The fly as one means of spreading this disease is responsible for a portion of this loss.

Flies and tuberculosis. Flies may also serve as a means of spreading tuberculosis. The sputum of patients contains large numbers of the bacteria that cause this disease. Whenever flies feed upon this sputum, so commonly deposited by careless persons on streets and sidewalks, the bacteria may be carried off and left in milk and on various articles of food.

Many diseases to which young children are subject are what are known as intestinal diseases, because they affect the intestines. The bacteria which cause these diseases are taken into the system through the food and drink. Flies are a common means of carrying these children's diseases.

Great as is the harm done by the fly, one fact stands out prominently; the house fly can be controlled and nearly all the sickness and death due to its activities can be prevented through the intelligent coopperation of the citizens of any community. That there have been so many preventable deaths due to ignorance and carelessness is a disgrace to our civilization, but on the other hand this very fact gives great hope for the possibilities of the future. In order that we may be able to apply the most effective remedies in the extermination of the fly, it is necessary that we should first understand the essential facts regarding its life history and habits.

\section{Life History of Fly}

The most important breeding place of flies is horse manure. They breed also in human excrement and in almost any decomposing animal or vegetable matter. Examination 
of manure piles has shown that on the average a pound of manure may have from 500 to Iooo larvæ in it. The fly in its development passes through the four stages of egg, larva, pupa, and adult. About one hundred and twenty eggs are laid at a time by one female and this may be repeated four times in a season. The eggs hatch in a day or less; the larval state, the maggots, lasts from five to six days; and the pupal state from five to seven days. Thus the entire period of development takes from ten to fourteen days, being more rapid in the warmer seasons and climates.

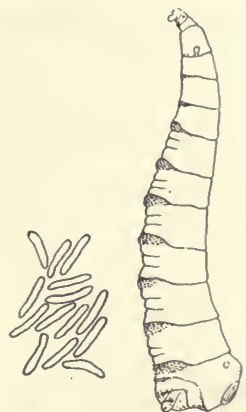

Eggs

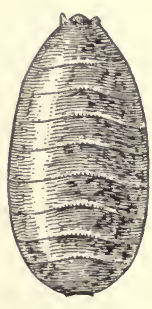

Pupa

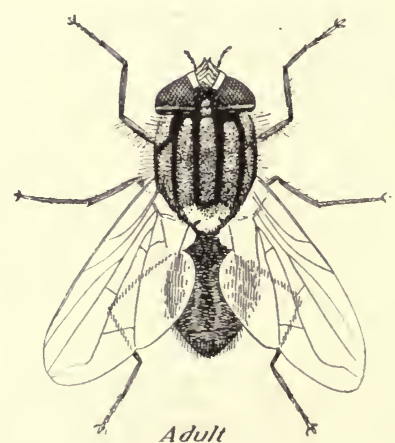

Adult

Fig. 162. - Life history of the house fly.

The females begin to lay eggs in from ten to fourteen days after emerging from the pupal state. Egg-laying begins in the spring and continues till the cold days of autumn. During this period it is possible to have from eight to twelve generations. It is thus seen that possibilities of increase during a single season are enormous. On the approach of cold weather most of the flies die, but a few hibernate for the winter, some as adults in cracks and crevices of buildings and a few in the puparium state.

\section{Control of Fly}

The most effective fly campaign requires the coöperation of citizens, health officers, and town authorities. It is 
naturally the duty of the health officials to take charge of the work; the aid of the city authorities is needed to furnish the appropriation to carry on the work; and the intelligent coöperation of the citizens is necessary in carrying out the ordinances of the health officials. Often the first steps may be taken by civic organizations. . The newspapers have always proved a great help in the campaign of education which is usually needed to arouse the citizens. The American Civics Association with headquarters in Washington, D. C., is ready to assist any local organizations in taking up this work.

Preventive measures. Remedial measures may be directed along two lines: first, to prevent the breeding of flies; and second, to furnish protection against the flies that do exist. The first might be called preventive, and the second, curative remedies. The more important remedies, because the most lasting, are those directed toward the first end. As horse manure forms the breeding place for from 90 to 95 per cent of the house flies, the chief thing is to prevent flies from breeding there. This may be done in two ways, by removing the manure frequently

DIARRHEAL DISEASE UNDER 5 YEARS

Total Days of Sickness.

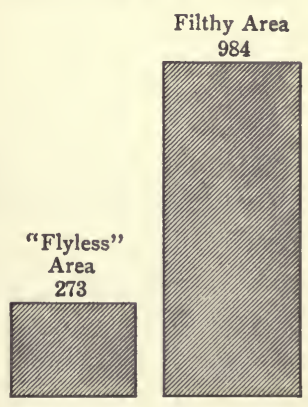

Total Disease Duration as an Index of Sanitation.

U.S. Public Health Service

FIG. I63. - Effect of doing away with flies on prevalence of this children's disease.

and by keeping the manure in tight bins or receptacles, covered or screened so the flies cannot enter. The bin should be emptied every week. For a single horse, a barrel 
with a tightly fitting cover serves as a good receptacle. In order, that this method should be most effective, it is necessary that all stables should take the same precautions. A single manure pile uncared for will furnish enough flies to infest a whole neighborhood, for flies will usually travel about a quarter of a mile from their breeding places. A covered bin does not entirely prevent flies from breeding in the manure, but it is better than an open manure pile.

Health departments. Much can be done by boards of health in making and enforcing ordinances relative to the destruction of breeding places. The health. department of the District of Columbia has issued orders to the effect that all persons owning a building where domesticated animals are kept shall provide for the storage of manure a bin so covered as to prevent flies from entering; and this manure must be removed from the city twice a week during the summer and once a week during the rest of the year.

In the country and in towns where there is no sewer connection, it is important that sanitary privies be used to prevent the access of flies to human excrement, and that the privies be screened. No filth of any kind should be allowed to accumulate about the buildings. Garbage cans should be tightly covered and frequently emptied.

Curative measures. Treating manure piles. Although preventive remedies are the more important, until they are in effective operation, much can be done through curative remedies. These may be directed along two lines: first, to kill the flies and the larvæ; and second, to screen one's self and one's food from the flies. Numerous experiments have been tried in treating manure piles with chemicals to kill the larvæ and pupæ. One of the best substances is borax. This is spread on the manure pile as a powder, and then the pile is sprinkled with water, which dissolves the borax. This solution kills the larvæ and pupæ. About a pound per week is required for one horse. Hellebore also has been found effective. 
Traps. For the catching of adult flies there has recently been devised by Dr. Hodge a new kind of trap. He lays emphasis on the fact that about ten days elapse after the emergence of the fly before egg-laying begins. Hence the most successful line of attack will be to catch the first flies that emerge in the spring before they lay eggs. Each fly caught then eliminates thousands of flies that might have descended from this one during the season. The general plan of Dr. Hodge's trap is much like the old-fashioned traps, but it is used in a different way. It is placed over a hole in the cover of a garbage can, the cover is slightly lifted so that the flies can enter the can, then when they seek to escape they are caught in the trap. One of these traps caught 2500 flies in less than an hour. The flies may be killed by submerging the trap in hot water. Dr. Hodge writes that a single trap has

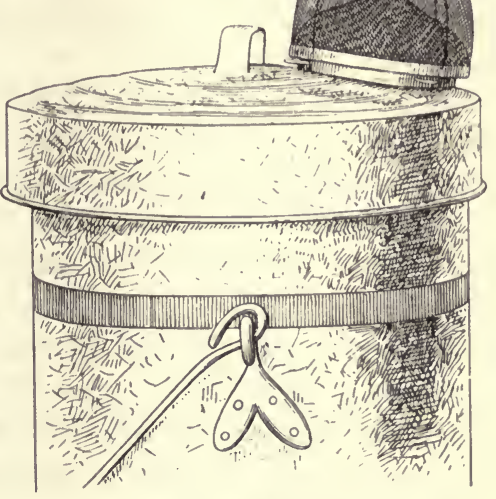

Fig. I64. - Hodge fly țrap.

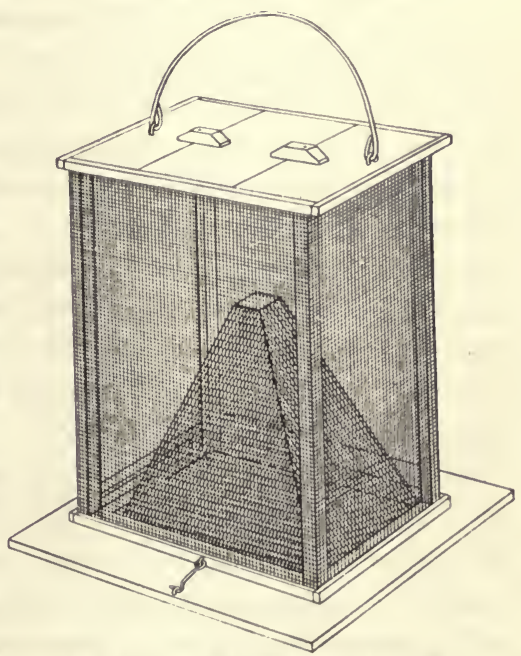

FIG. 165. - A fly trap easily made. worked so successfully that he has not found it necessary to put up screens on doors or windows. This trap is also 
provided with a base in which bait may be placed to attract the flies, so that the trap may be kept indoors. Bread and milk are most effective. Many kinds of large traps are being used which have proved effective, when properly baited and located.

Poisoning flies. It is possible also to poison flies. One of the best preparations for this purpose is formalin. The weak solution used is not dangerous to human beings, but is very effective in poisoning flies. A 2 per cent solution should be used, made by adding two tablespoonfuls of the solution as bought at the drug store to a pint of water, or water and milk. It will prove more attractive to the flies if sugar or bread and sugar are added to it. This may be placed in shallow vessels. A convenient way of having a constant supply is to fill a bottle with the solution, break a little nick.in the top of the bottle so that the liquid can flow out, and then invert it in a saucer. Flies cannot live long without something to drink and they naturally seek liquid early in the morning. If the liquids in the room are removed or covered up in the evening, the formalin will prove more effective. Some of this solution may be kept outdoors on the porch as well as indoors.

Screens. As a protection against the flies that are not killed, the doors and windows should be well screened. A piece of sticky flypaper placed on the outside of the screen door will catch many flies which otherwise would enter the house when the door is opened.

Protection of food. All food when not in use upon the table should be screened or placed where flies cannot reach it. Only those bakeries, fruit stands, and grocery stores should be patronized which keep the food offered for sale well screened from flies. Some cities have passed ordinances requiring that food exposed for sale shall be protected from flies and dust. The supervision of this matter is sometimes taken over by civic organizations. 
Fleas and bubonic plague. One of the most terrible scourges recorded in history is that of bubonic plague or "black death." This disease is caused by bacteria which attack rats as well as human beings. It has been shown that fleas are the means of carrying these bacteria from rats to human beings. The flea sucks the blood of the rat which contains thousands of bacteria ; later he may pierce the skin of a human being, thus permitting the bacteria to enter that cause the development of the disease. Not long ago when the plague broke out in San Francisco, it was successfully controlled by waging a warfare on rats, which were indirectly the means of spreading the disease through fleas that lived upon them. It was also found that ground squirrels were subject to the disease and that fleas might carry the disease from them as well as from rats.

\section{Community Project 4}

Purpose. To learn what the class can do to help control the fly nuisance.

Directions. I. The campaign may be started in the late winter or early spring. Encourage the free use of fly traps. Some members of the class may make fly traps to sell. Send five cents in stamps to the International Harvester Company, Harvester Building, Chicago, Ill, for a fly trap pattern. This gives detailed directions for making a fly trap in such a simple way that any boy or girl can make one.

2. For fifty cents there may be obtained from the same company, a set of twelve stencils, three feet square, of the house fly, giving drawings that may be reproduced on the blackboard, on paper, or on cloth. Cloth charts could easily be made by various members of the class. There might be opportunities to use these charts by giving talks to some of the rooms in the graded schools. Various members of the class may be assigned to give a talk on the different charts, which may be taken around to the rooms to be visited. The class might prepare a whole evening's entertainment on the fly to 
which friends and parents would be invited. This might serve as a good opportunity to organize a fly prevention campaign.

3. The specific things that the class can do should be discussed, and plans made to put these into effect. Attention may be given to the things that each member can do in his own home. The coopperation of all possible agencies in the locality should be sought.

\section{SUPPLEMENTARY QUESTIONS FOR CLASS DISCUSSION}

I. Which is the more dangerous animal, the fly or the mosquito?

2. What is the most conclusive evidence against the house fly as a carrier of disease?

3. Show why it is necessary to understand the life history of the fly and mosquito in order to fight them successfully.

4. What kind of measures against the fly and mosquito require the coopperation of all the people concerned?

5. What measures can be taken by each individual regardless of what his neighbors may do?

6. What are the best steps to be taken in a community in a campaign against the fly? What against the mosquito?

7. Against which insect can remedies be more effectively applied in the adult stage?

\section{REFERENCE}

Doane, Insects and Disease, Henry Holt and Company, New York City. 


\section{CHAPTER XXVI}

\section{HEALTH OFFICERS}

I. What are the duties of health officers?

2. What sort of ordinances should a city pass in order to protect the health of its citizens?

When people are living together in communities, it is necessary for all to coöperate in order to look after those matters that affect the public health. This work is intrusted to a group of men called the board of health, or to one man called the health officer.

Amount of money spent. Our American towns and cities have given altogether too little attention and money to the very important work of looking after the health of the com-. munity. The work of the boards of health is greatly handicapped by lack of funds. An investigation made of the amount of money spent by various cities in maintaining the work of the board of health showed that in cities of from 30,000 to 50,000 population, an average of only twenty-seven cents per capita was spent annually. This is altogether inadequate to provide for the maintenance of an effective health board; at least twice this amount should be spent. In cities of 20,000 population and over, one man should be employed to give his entire time to the work. And in the case of smaller towns, several towns may unite to employ a man.

Politics and health. One thing that greatly hinders the work of looking after the public health at the present time is the fact that the appointment of the officers is too often 
a matter of politics. Men are appointed on account of some political pull without reference to their fitness for the work. The selection of health officers should be taken out of politics and only specially qualified men should be appointed. A board of health should have at least one physician connected with it. It is desirable that the health officer should do no practicing.

Duties. The board of health has many important duties to perform. These may be divided into six groups : first, to collect vital statistics; second, to control communicable diseases; third, to reduce infant mortality; fourth, to look after water, milk, and food; fifth, to keep the town clean; and sixth, to control the fly and mosquito nuisances.

\begin{tabular}{|c|c|c|}
\hline St. Paul & 214,744 & $255^{8}$ \\
\hline Minneapolis & 301,408 & 3739 \\
\hline Milwaukee & 373,857 & 5205 \\
\hline Los Angeles & 319,198 & 4538 \\
\hline Cleveland & 560,663 & 8047 \\
\hline Rochester & 218,149 & $32 \times 5$ \\
\hline San Francisco & 416,912 & 6319 \\
\hline St. Louis & 687,029 & 10888 \\
\hline Kansas City & $248,38 r$ & 3966 \\
\hline Detroit & 465,766 & 7452 \\
\hline Indianapolis & 233,650 & 3824 \\
\hline Buffalo & 423,7 I 5 & 6940 \\
\hline Jersey City & 267,779 & 4401 \\
\hline Denver & $213,38 \mathrm{I}$ & 3533 \\
\hline Newark & 347,469 & 5784 \\
\hline Louisville & 223,928 & $375^{6}$ \\
\hline Boston & 670,585 & I I 562 \\
\hline Cincinnati & $363,59 I$ & 6319 \\
\hline Providence & 224,326 & 3980 \\
\hline Pittsburg & 533,905 & 9603 \\
\hline Baltimore & $55^{8}, 485$ & 10753 \\
\hline Washington, D.C. & 331,069 & 65 II \\
\hline New Orleans & 339,075 & 7250 \\
\hline
\end{tabular}

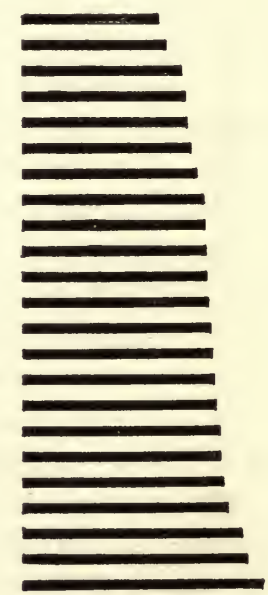

Fig. I66. - Annual death rate per rooo of the chief cities of the United States.

Vital statistics. The vital statistics are the records of all the births and deaths that occur, of the causes of the deaths, the age of the person deceased, and similar details. It is very important to know what per cent of deaths occur from each disease in order to know which are the most 
dangerous diseases against which special precautions should be taken. A comparison may be made with the average statistics from other cities; and if this shows that the death rate from some particular disease is unusually high, special attention may be given to controlling this desease.

Control of contagious diseases. One of the duties to which special attention is given is the prevention and control of

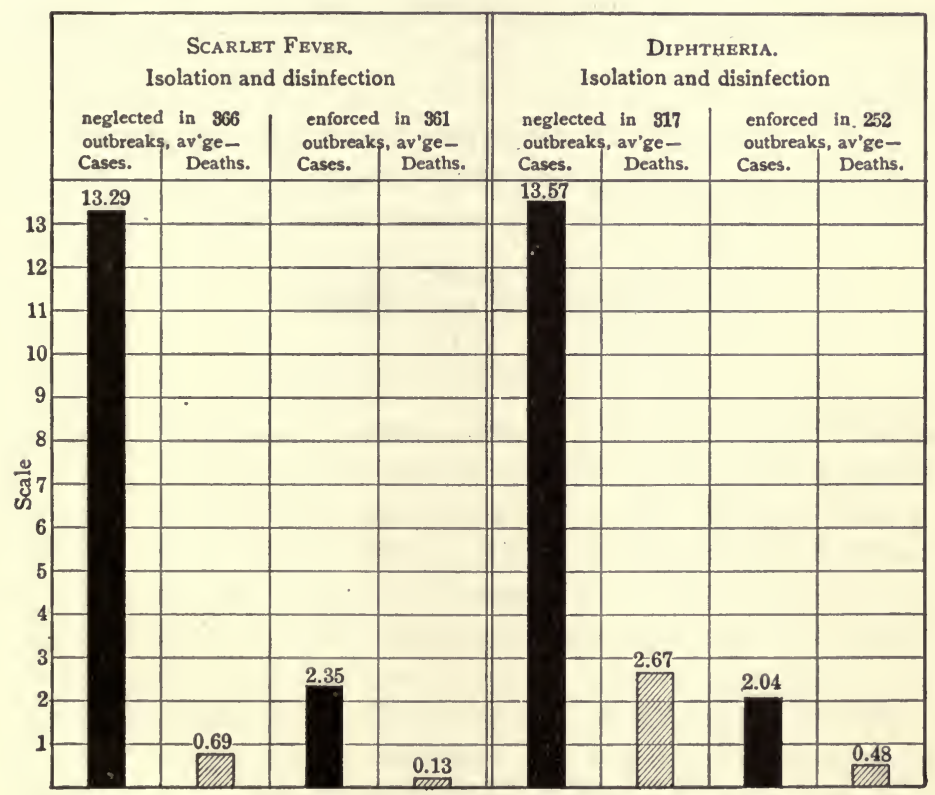

Fic. 167. - Effect of isolation and disinfection on scarlet fever and diphtheria.

diseases that may be carried from one person to another, such as diphtheria, smallpox, and tuberculosis. In protecting well people from unconsciously coming into contact with those who have the diseases, very strict measures must be taken, such as isolating the patient and quarantining people who have been exposed. Sometimes this may cause some inconvenience to the people concerned, but it is neces- 
sary in order to protect other people. Placards are placed on houses which contain patients with these diseases, as a warning to other people. After the patient has recovered, sometimes it is necessary to disinfect the house to kill the bacteria that cause the disease.

As a protection against smallpox, compulsory vaccination may be required sometimes; and the board of health may furnish free the virus for smallpox vaccination, the vaccine for vaccination against typhoid fever, and the antitoxin for diphtheria.

The board of health may visit the schools to examine the children for evidences of communicable diseases, and take measures to guard against an increased number of cases.

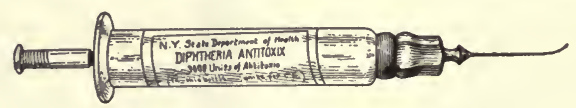

Fig. 168. - Antitoxin for diphtheria.

School inspection daily or semi-weekly by a school nurse is the best means of controlling infectious diseases.

Milk supply. Many of the deaths among infants can be avoided by furnishing visiting nurses and by careful inspection of milk. One tenth of the cases of consumption among children are believed to come from cow's milk that contains disease germs.

The milk supply of a town should be carefully inspected to determine, first, that it is free from disease germs ; second, that it is not adulterated; and third, that no chemical has been added to prevent it from souring. The first is by far the most important. All persons handling food or milk should be tested for and known to be free from tuberculosis and typhoid. Cattle should be tested for tuberculosis. The dairy farms should be carefully inspected, and if the necessary sanitary conditions are not found, the license to sell milk should be taken away till the conditions are remedied. Frequent inspection of these farms is necessary. 
Food supply. The public food supply should also be carefully guarded. The places where the food is cooked, the bakeshops, should be carefully inspected. The room where the food is cooked and handled should be kept clean and sanitary. No persons having contagious diseases should be allowed to work in these shops. The food, when exposed for sale, should be covered to protect it from dust and flies. The purity of the food should be guaranteed by state and national laws.

Butcher establishments, where animals are killed or where meat is sold, should be carefully watched. Inspectors should make sure that no animal with tuberculosis is sold for meat and that all meat is kept under sanitary conditions.

Water supply. The public water supply should be guarded with special care to see that no disease germs are allowed to enter it. If the water comes from lakes and rivers, the surrounding areas should be watched to see that they are not contaminated by disease germs that might enter from sick people living near. If the water is taken from a lake or river into which sewage flows, care should be taken to see that the inlet for the water is located a long distance from the outlet of the sewer. If water is taken from artesian wells, the pipes should be watched to see that no leaks allow disease germs from the sewer pipe to enter.

Keeping town clean. It is usually the duty of the board of health to see that the town is kept free from certain kinds of filth. Arrangements are usually made by them for the collection of garbage, ashes, rubbish, and manure.

Fly and mosquito control. Closely allied with the matter of cleanliness is the matter of fly control. The board of health should take measures to see that the breeding places of flies, chief among them the manure piles, are so frequently removed that flies have no opportunity to breed. Ordinances should be enforced relative to the protection of food from flies. 
In the southern states, where malaria and yellow fever are found, the board of health should take measures to control the mosquito nuisance. Some of the means by which this may be done have been explained in a previous chapter.

As an example of what is being done, the following quotations are taken from a list of city ordinances relating to public health, passed in a city of r०,000 population.

Purpose of the Department of Public Health. "Section 6. The department of public health shall exercise general supervision over the health of the city. It shall make such investigations and reports, and obey such directions concerning communicable disease, as the State Board of Health of the State of Minnesota may require or give, and under the general supervision of the State Board of Health, it shall cause all laws and regulations relating to the public health to be obeyed and enforced."

Duty of the People. "Section 8. Every person in the city of - shall observe and obey each and every special regulation and every order of the department of public health that is or may be made for carrying into effect any of the provisions of this or any other ordinance of said city relative to the health thereof, or any law of this state or otherwise, whether issued directly by such board, or promulgated by the health commissioner."

Duties of the Health Commissioners. "Section io. The health commissioner shall be president of the department and shall have and exercise a general supervision over the sanitary conditions of the city. He shall give the council and the department of public health all such professional advice and information as they may require, for the purpose of preserving the public health. He shall investigate the existence of any communicable or pestilential disease and adopt all measures necessary to arrest the progress thereof."

"He shall enforce all laws of the State, and ordinances of the city, in relation to health and sanitary conditions, and 
shall cause all nuisances as hereinafter defined to be abated or removed. He is hereby empowered and it is hereby made his duty and the duty of the health inspectors to enter any building in said city between sunrise and sunset, for the purpose of ascertaining if such building is in good sanitary condition."

CARE OF Food. "Section I7. No food, meat, fish, birds or fowl or vegetables, nor any milk, not being then healthy, fresh, sound, wholesome and safe for human food, nor any meat or fish that died by disease or accident, shall be brought within the City of — or held for sale at any public or private markets, as such food, anywhere in said city."

"Section 20. Every person being the owner, agent, lessee, or occupant of any room, stall or place where any food, meat, fish or vegetables designated or held for human food shall be stored or kept or shall be held or offered for sale, shall put or keep such room, stall and place and its appurtenances in a cleanly and wholesome condition, and every person having charge (or interested or engaged, whether as principal or agent) in the care, or in respect to the custody or sale of any food, meat, fish, birds, fowls or vegetables (designated for human food) shall put and preserve the same in a cleanly and wholesome condition, and shall not allow the same or any part thereof to be poisoned, infected, accessible to flies or rendered unsafe or unwholesome for human food."

Removal of Manure. "Section 28. Between the I5th day of April and the I 5 th day of October of each year, the owner, proprietor, agent or occupant of any stable or barn where horses, cows, or other domestic animals are kept within said city, shall not deposit, cause to be deposited or allow to accumulate within or about such premises for a longer time than twenty-four hours, any manure, animal bedding, or barn refuse, but shall provide a box of sufficient size for the reception of such manure, animal bedding or 
barn refuse, into which box shall be deposited or saused to be deposited all such manure, animal bedding or barn refuse, and said box shall be so constructed that the contents thereof is not accessible to flies, and shall be placed upon the premises owned, occupied or controlled by such person in a situation as remote as possible from any surrounding dwelling or street, and shall empty and cleanse the same as often as necessary and whenever directed to do so by the department of 'public health."

Expectorating. "Section 3I. No person shall spit, or expectorate or deposit or place any sputum, spittle, saliva, phlegm, mucus, tobacco juice, cigarette stumps or quids of tobacco upon the floor or stairway of any part of any public hall or building in the City of - or upon the sidewalk of any public street, avenue or highway in the City of or upon the floors or inside furnishings or equipments, or in any place upon the outside or upon the platform of any street car while the same is in use upon any of the streets or highways in the City of - or in any manner defile or pollute the floor, furnishings, equipments or platform of any street car while in use upon any of the streets or highways of said city."

Fines. "Section 38. Any person who violates, disobeys, omits, neglects, or refuses to comply with, or who resists, any of the provisions of this ordinance, or who refuses or neglects to obey any of the rules, orders or sanitary. regulations of the department of public health, or who omits, neglects, or refuses to comply with, or who resists any officer of the department of public health, or order or special regulation of the health commissioner, or of said department of public health, shall upon conviction thereof, before any court having competent jurisdiction, be subject to a fine not exceeding One Hundred Dollars $(\$ 100.00)$ and costs of prosecution or imprisonment in the city prison or county jail of - County for a term not exceeding ninety (90) days." 
Duty of all citizens. One point cannot be too strongly emphasized, namely, that all the people of a town must coöperate with the health officer in order to produce the best results. The citizens must not feel that they have done their entire duty when they have appointed a health officer. He is greatly handicapped unless he has the intelligent and hearty coöperation of the people. Every member of a community should cheerfully obey the health ordinances of the town. Cases of contagious diseases and instances of violation of health ordinances should be reported to the proper authorities. Each person should see that the conditions around his home are healthful and that nothing he does shall be a menace or a nuisance to his neighbors.

\section{Community Project 5}

Purpose. To study the duties of the local health officer.

Directions. I. Information should be obtained regarding the local health officers: who they are, how they were appointed, and what they are doing. A copy of the local health ordinances should be secured and discussed in class. The things that the members of the class can do to coöperate with the health officers should be emphasized. Find how much money per capita the town is spending each year to protect the health of the community. Compare with other towns.

2. Make a study of the parks and playgrounds. What bearing do these have on health?

\section{SUPPLEMENTARY QUESTIONS FOR CLASS DISCUSSION}

I. What should the people do to help the health officers?

2. How do the health officers control contagious diseases?

3. What can they do to keep the milk and food supply pure?

4. What can they do to control the fly and mosquito?

5. What are the health officers in your town doing?

6. What can you do to help the health officer in his work?

\section{REFERENCE}

Coleman, The People's Health, Macmillan Co., New York City. 


\section{CHAPTER XXVII}

\section{SCHOOL HYGIENE}

I. What should be done to make the school building a healthful place in which to stay?

2. What sort of physical defects are found among school children?

In recent years people have come to realize that it is most important that the school shall look after the health of the children, because success both in school and outside depends largely on health. So we find to-day special attention is being given to the health of school children. School doctors and nurses are employed to examine children and to remedy defects of eyes; ears, nose, throat, and teeth. In this chapter reference will be made to two lines of work being carried on in the interest of the children's health : first, the provision of sanitary schoolrooms in which the child works; and second, the medical inspection of children to find and remedy defects and sickness.

Lighting the schoolroom. In the construction of the schoolhouse, lighting is one of the important things to consider. Plenty of light in a room is necessary for the best health as well as for the cheerfulness of the room. Improper methods of lighting seriously injure the eyes. The following points need to be considered : first, the amount of light; second, the direction from which it comes; and third, the height of the window from the floor.

In general the amount of window space should be from one sixth to one fourth of the floor space. During the winter there is less light than in the fall and spring, and there 
should be enough windows to provide sufficient light during this season, as well as on cloudy days.

The direction from which the light comes is a second point to consider. It should not come from the front, because it would then shine directly into the children's eyes, and strain them. It should not come from the rear because the shadow of the body would be thrown on the desk. It should not come from the right because the shadow of the hand is thrown on the reading and writing. The best arrangement is to have the light come from the left.

The bottom of the window should be at such a height that it is above the level of the eyes of the children when they are seated. This should be from three and one-half to four feet. If it is lower than this, it strains the eyes more because the light shines directly into them. The top of the window should reach up well toward the ceiling, as the light from high up is better distributed throughout the room.

Heating and ventilating the building. The general principles involved in heating and ventilating the school building are the same as those involved in the home, which were discussed in the first and second chapters. But in the schoolroom more attention should be given to ventilation than is ordinarily done in the home, because a larger number of persons are gathered in one room.

Essentials of ventilation. As we have seen in Chapter II, good ventilation requires attention to the following matters; a constant supply of fresh air, a motion of air, the right degree of temperature, and the right per cent of humidity.

Fresh air and motion. To keep a constant supply of fresh air requires two openings in a room, an inlet where the fresh air enters and an outlet where the used air is removed. Experiments which have been carried on show that the best place for the inlet is about eight or nine feet from the floor and that the best place for the outlet is within a foot of the floor and on the same side of the room as the inlet. 
In securing this supply of fresh air, a motion of air is provided for at the same time.

Gravity system. Various methods are used to produce this circulation of air. One system is called the gravity

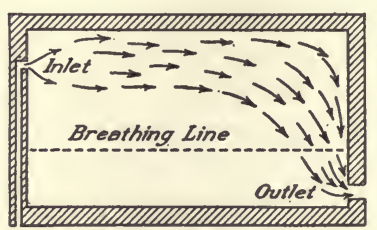

Air admitted an side.

Discharged near bottom.
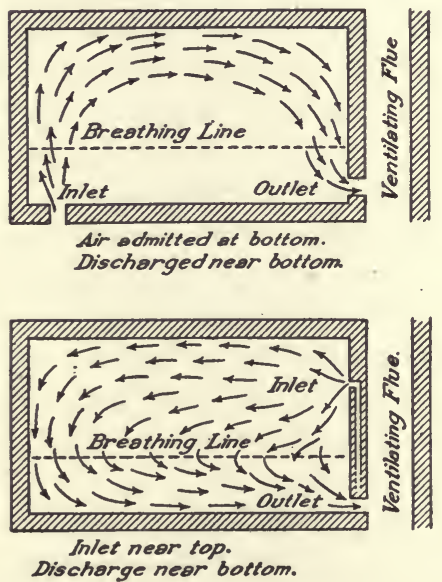

Fig. I69. - Inlets and outlets. system. In this system the motion is brought about through a difference in the weight of the air due to a difference in temperature. The foul air duct is connected with the chimney, and the air here being much warmer than the air outdoors rises, while the cold air is taken in at the basement and after being heated is led into the various rooms. This may work fairly well in cold climates during the winter where the air outdoors is much colder than that in the schoolroom. But in the fall and spring, when the difference in temperature is small, the system is not satisfactory.

Fans. In order to obtain the best circulation, fans are generally used. Two systems are used, the pressure and the exhaust. In the pressure system, the air is forced into the room by means of a fan located in the basement. In the exhaust system, the air is drawn out of the room by means of a fan which rotates in such a way as to suck the air out. If only one of these systems is used, it should be the pressure, as that is generally found to be better. Sometimes both systems are used. 
Sometimes two methods of heating are employed. Fresh air is forced into the rooms at about the desired temperature to provide ventilation, and the exact temperature is controlled by means of steam or hot-water radiators placed in each room. The temperature is controlled by means of thermostats which control the valves on these radiators. This combination makes a very satisfactory heating and ventilating system, when properly cared for.

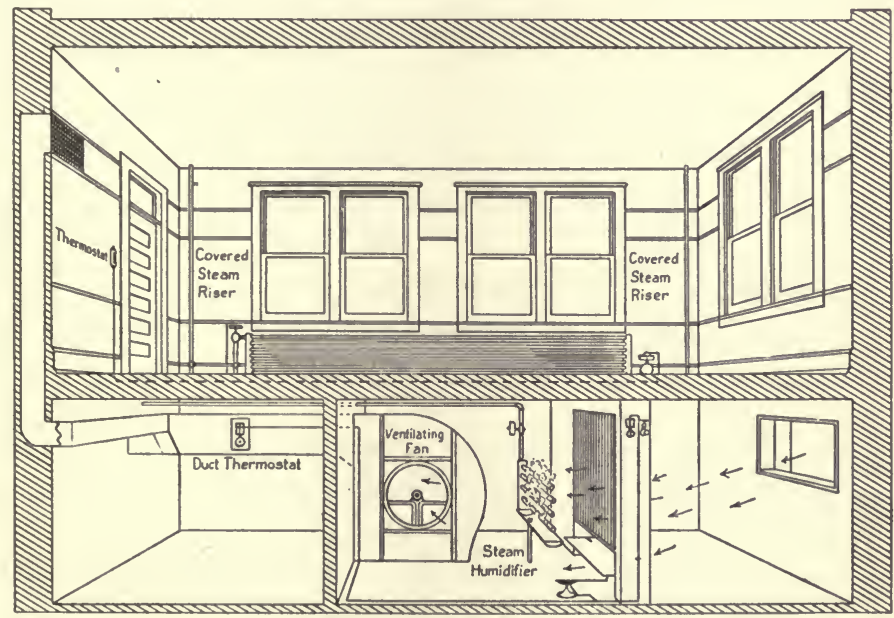

Fig. I70. - School ventilating system that supplies warm air of correct humidity.

Ventilating one-room schools. For heating small, oneroom, rural schools a jacketed stove is widely used. The stove is surrounded with a jacket of some sheet metal which extends down to the floor and is open at the top. Fresh air is brought in from the outside by means of a duct connecting with the jacket. As the air is heated, it rises and passes out into the room. The foul air is removed by means of an opening in the chimney near the floor or by means of a pipe connected with the chimney and extending down to within a foot of the floor. 
Amount of air needed. There is some difference of opinion as to just how much fresh air a child needs each minute. There is a requirement in some states that enough air should be brought into the room so as to provide each pupil with thirty cubic feet of air per minute. These figures were based on some theories which have been partly abandoned, and some authorities to-day say that pupils do not need this amount of fresh air. However, until we have more definite knowledge regarding this matter, we can well afford to be on the safe side of furnishing too much rather than too little fresh air. The nearer we can approach the outside conditions of abundant fresh air the better off we shall be. The air must be changed often enough to remove the unpleasant odor arising from small particles given off from clothing and bodies.

Temperature. The best temperature varies in accordance with a number of factors, such as the clothing worn by the children and the kind of school work being done, whether active or passive. It also depends on the humidity. In the dry atmosphere found in most school buildings the proper temperature is about sixty-eight degrees. If moisture is added to bring up the proper per cent of humidity, a temperature of sixty-five is sufficient. The temperature may be kept even by means of a thermostat. If the temperature runs too high, the thermostat shuts out the warm air and opens the cold air damper wider, and if the temperature is too low, the thermostat causes a reversal of this action. Sometimes the thermostat shuts and opens the valves controlling the steam entering the radiators.

Humidity in schoolrooms. During the colder portions of the year the humidity of our schoolrooms is too low. One great defect in our ventilating systems is that they do not have arrangements to increase the humidity. The average humidity of schoolrooms in winter ranges from twenty to thirty per cent. This is a very dry air and is detrimental 
to the health of those living in it, as explained in Chapter II. Experiments which were carried on at Yale University showed that when the air was kept at the proper humidity, the pupils were able to do better mental work, and were freer from colds than when the humidity was low. Experiments show that the proper per cent of humidity for the schoolroom is about fifty.

How humidity is determined. One may naturally ask at this point, "How can one tell what the per cent of humidity in a room is?" This is determined by an instrument called a psychrometer. This consists of two ordinary thermometers, one of which has a piece of wet cloth fastened over the bulb. We have often noticed that when our hands are wet on a cold day they are colder than when dry. This is because the water evaporates and when it does so, it makes things colder around it; that is, it requires heat and takes it from the surrounding bodies. On hot days sidewalks are often sprayed with water to cool off the surrounding air.

In a similar way, the water in the cloth on the builb of the thermometer evaporates and lowers the temperature of the thermometer, so that if the readings of the two thermometers are taken, the one with the wet cloth will be found to be lower. The difference between these two thermometers varies from day to day. The amount of water that evaporates, and hence the lowering of the temperature, depends on the amount of moisture in the air. If the air is saturated, no water will evaporate, and hence there will be no difference in the readings of the two thermometers. On the other hand, if the air is very dry a large amount of water will evaporate, and the reading of the wet bulb will be much lower than that of the dry bulb. In general, then, a small difference between the two bulbs means a high per cent of humidity, while a large difference means a low per cent of humidity. Tables have been worked out by which, if one 
reads the two thermometers, it is possible to find at once the per cent of humidity. (See Appendix.)

In order to get an accurate reading, the thermometers should be fanned for a few minutes, or even better they may be attached to a board which can be rotated in the hand by means of a handle. This is called a sling psychrometer.

Humidifiers. While many of the older buildings have made no arrangement for adding water to the air, a number of satisfactory systems have been devised and are being introduced into the better and newer build-

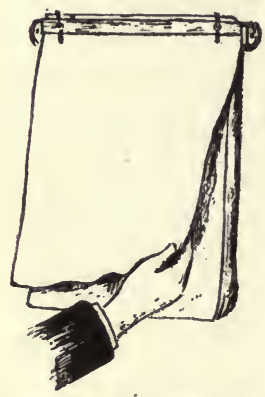

Fig. I71.- Paper towels, a sanitary substitute for the dangerous public towel. ings. In one system, steam is allowed to escape through small holes in pipes placed in the cold air duct. Instead of steam, water may be forced in as a spray through nozzles.

Another plan is to have large pans of steaming hot water in the cold air duct. In still another plan, a rotating cylinder is placed in the fresh air duct. This is covered with a coarse meshed cloth, and as the cylinder revolves the lower edge passes through a trough filled with water. Thus the cloth is kept moist and dripping all the time. As thermostats are used to regulate the temperature, so humidostats are used to control the humidity.

\section{Demonstration 33}

Purpose. To see if the ventilating system of your school furnishes the essentials of good ventilation.

Apparatus. Touch paper, down, two thermometers.

Directions. I. Amount of air entering the room. Throw a tuft of down in front of the air inlet and estimate how far it travels in a second. Try several times and take the average. Measure the dimensions of the air inlet. Find its area. Multiply this by the velocity of air just found so as to compute the 
number of cubic feet of air that enter the room each second; then find it for each minute. Multiply the number of pupils in the class by thirty, which has been set as the standard number of cubic feet that should be furnished each pupil per minute. How does the amount of air entering the room compare with this product?

2. Air currents. Light a piece of touch paper or a joss stick and hold in various parts of the room to determine the direction and strength of the air currents. Make a diagram of the room on the board and indicate the direction of the currents by means of arrows.

3. Temperature. Place a thermometer in different parts of the room and find the temperature. Try on several days. Compare with the standard of $68^{\circ}$.

4. Humidity. Test the humidity as explained in Demonstration 8, page 25. Compare with the standard of $50^{\circ}$ to $60^{\circ}$. Find the humidity outdoors.

5. Which of the four essentials of ventilation are provided in the schoolroom? Which are lacking? How may the deficiency be remedied?

Sanitary drinking fountains. The common drinking cup should be abolished from every school. It is one means by which such diseases as tuberculosis, diphtheria, mumps, pneumonia, and other common infectious diseases are transmitted. Even well children may serve as carriers of disease germs in their mouth, so that the common drinking cup is a public nuisance and a source of danger wherever found. An individual drinking cup may be made out of a piece of clean

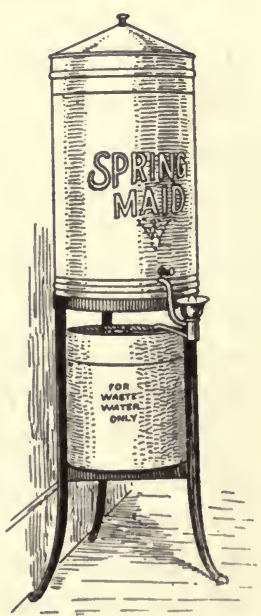

FIG. 172. - Fountain faucet. paper as shown in figure r54. With the many types of drinking fountains now available, there is no excuse for allowing the public cup to be used any longer. Even where 
running water is not available, there can be obtained water jars to which sanitary drinking fountains are attached.

Playground. A properly equipped school needs a large playground. One great defect of our schools in the country, as well as in the city, is the small size of the playground. Whenever a new building is being planned, provisions should be made for adequate playgrounds, with room for baseball grounds, tennis courts, and open spaces for other games. Play is an essential part of a child's life. It not only furnishes the physical exercise that the growing child needs, but it also has a distinct educational value in itself.

Open-air schools. During recent years open-air schools have been established for tuberculous and sickly children unable to attend the regular school. Sometimes these are entirely in the open, sometimes they are provided with a roof, and sometimes an ordinary room is changed into an open-air school by hingeing the windows at the top and opening them to their fullest capacity. For the colder seasons the children are provided with special clothing to keep them warm. These schools have proved almost universally successful in that the children have made great gains physically and are able to do better work in their school subjects. If these open-air schools are good for weak and sickly children, we are naturally led to inquire why they would not also be good for the ordinary child.

Defects in school children. Having seen that the conditions under which children study are healthful and sanitary, the next step in looking after children's health is to examine the child himself and see if he is handicapped by any physical defects that can be remedied. All over the country, children are now being examined and the results show that more than half of all children have some defects of the ear, eye, teeth, throat, or nose. In many cases neither the children nor their parents know that these defects exist. When these defects have been discovered, in most cases they can be 
remedied, and thus the children are made happier and better able to do their work. The results of the examinations of hundreds of thousands of children in all parts of the United States are shown in the following table in the first two columns. The last column is obtained by estimate through multiplying the number of school children in the United States (about twenty million) by the per cents obtained from those children who have been examined.

Table Showing Defects of Children

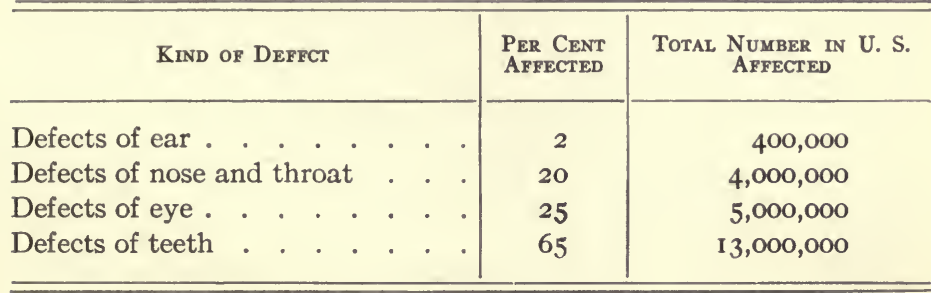

It is found that only about one third of the children are free from defects, about one third have defects of teeth alone, and the remaining third have defects of the teeth and in addition at least one other defect.

Defective teeth. The most common of all defects are those of the teeth. From two thirds to three fourths of all children are found to have defective teeth. This may include every stage from a small decaying spot to teeth which are almost entirely decayed. Of all teeth examined about one fifth are defective.

How defective teeth affect health. Defective teeth may prove injurious to health in three ways: first, the power of mastication of food is decreased; second, the pus from the decaying teeth when absorbed into the blood or taken into the stomach has an injurious effect; and third, decaying teeth may be the breeding place of bacteria that cause disease, such as rheumatism and heart disease. Some very 
remarkable cures of rheumatism have been effected by simply cleaning the teeth.

Purposes of mastication. Mastication serves many useful purposes as we have already learned in Chapter V. These uses may be briefly summarized as follows: first, mastication grinds the food into a fine mass and thus prepares it for the process of digestion which takes place in the stomach and intestines; second, the thorough mixture with the saliva begins the act of digestion of the starch; third, thorough mastication better enables one to determine how much food and what kinds he should eat; fourth, it provides the necessary stimulus for the normal growth of the teeth and jaw; fifth, thorough mastication helps to clean the teeth. When the teeth are defective, mastication is done less thoroughly, and hence these purposes are fulfilled less successfully.

Dental clinics. Dental clinics are now being introduced into many of our cities. The teeth of the children are examined and treated free by dentists hired by the school authorities. As teachers are hired to teach children how to read, so dentists are hired to look after the children's teeth. These clinics are very common in Europe, and are rapidly increasing in number in this country. Eventually these clinics will doubtless be found in every city and town. When a town is too small to afford it, several towns may join together to hire a dentist. One agricultural paper suggests that a new "R. F. D." be established, - " rural free dentistry."

Defects of the eye. About one quarter of all children are suffering from defects of the eye. In order to understand what these defects are, we shall need to examine the eye to see how it is constructed and how it works. We may compare it with a camera. The eyeball corresponds to the camera box, the lens in the eye to the camera lens, the iris and the pupil of the eye to the diaphragm of the camera, 
and the retina which lines the eye corresponds to the sensitive surface on the film or glass on which the picture is taken.

In the average good eye, rays of light pass through the eye lens and are focused on the retina, where an inverted image is formed in each eye. This causes impulses to pass along nerves to the brain, which give us the sensation of a single image right-side up. The brain inverts the images and causes us to see one image instead of two.

Kinds of defects. There are three common defects of the eye: nearsightedness, farsightedness, and astigmatism. In nearsightedness, the rays of light come to a focus before they reach the retina, and hence the image is blurred. In farsightedness, the rays would focus behind the retina if they could pass through this. In astigmatism, the curvature of the lens is not the same in all directions and while a ver-

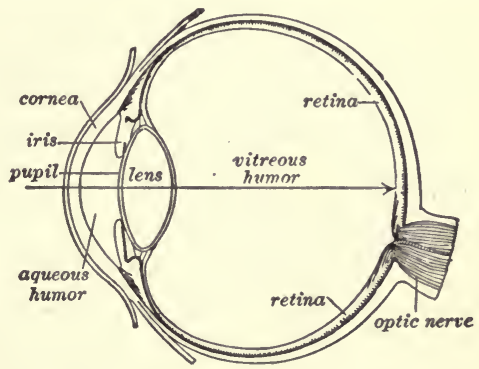

Fig. 173. - Section of the human eye. tical line may be clearly focused, a horizontal line is blurred. The eye attempts to remedy these defects by accommodation; but this involves a straining of the eye muscles, especially in farsightedness and astigmatism, and if carried too far, results in eye ache and headache.

Remedies. The remedy for nearsight is a concave lens. This helps to throw the focus further back on the retina. The remedy for farsight is a convex lens. This brings the light to a focus more quickly. The remedy for astigmatism is a lens with unequal curvature in different directions to offset the curvature of the eye lens.

The science of the oculist has developed so far that most of these common defects can be easily remedied by the use of spectacles. In the case of a very nearsighted person, a 
pair of spectacles brings about a most remarkable change in enabling him to see things he has never seen before, so that all life takes on a new aspect. Glasses should be fitted only by a competent oculist.

School work requires so much use of the eyes that care should be taken to reduce as much as possible the strain on the eyes. There should be the proper amount and kind of light in the schoolroom. The books used should be printed on good paper and the type should be plain and large, especially for growing children, larger than that required

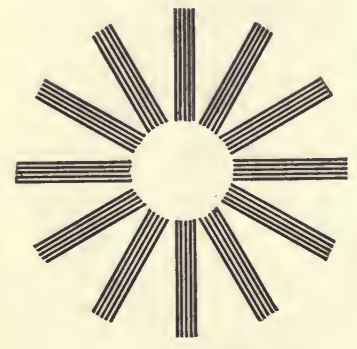

Fig. 174. - Lines to test astigmatism. for adults. An excessive amount of written and home work should be avoided.

Testing the eyes. Nearsightedness may be easily detected by means of the Snellen card. This is a card with a series of letters of different sizes showing the distance at which each size of the letter can be seen by the average eye. Each eye is tested separately, and if a person is nearsighted, it is shown by the inability to read the letters at the standard distance. Farsightedness may be tested by the same card, and is shown if a child can see a line of letters at a greater distance than that marked on the card. To test for astigmatism, a card is used containing a number of lines extending in different directions from a common center like spokes of a wheel. Astigmatism is shown if certain lines appear blacker than others.

\section{Demonstration 34}

Purpose. To test the eyes of the members of the class. Apparatus. Snellen's vision chart.

The eyes of the members of the class may be tested by using 
Snellen's vision chart. Follow the directions that accompany the chart.

\section{Demonstration 35}

Purpose. To illustrate the working of the eye.

Apparatus. Reading lens, cardboard, candle, concave lens, convex lens.

Directions. I. To show how the image is formed. Hold the reading glass and the cardboard in line with the window till images appear distinct on the cardboard. To what in the eye do the cardboard and lens correspond? How does the image differ from the object?

2. To illustrate the conditions for nearsightedness. Set a lighted candle on a table and place a piece of white cardboard about two feet away. Put the reading glass between the two in such a way that an image of the candle appears on the cardboard. To show nearsightedness, move the cardboard farther away from the lens till the image is blurred. To show the remedy, put a concave lens in front of the reading glass.

3. To illustrate the conditions for farsightedness. Set up the cardboard, candle, and reading glass as in the previous experiment, till the image is clear. Then move the cardboard nearer the lens till the image is blurred. This illustrates farsight. To show the remedy, place a convex lens in front of the reading glass.

Defects of nose and throat. Defects of the nose and throat are quite common. About two million children in the United States are suffering from obstructed breathing. The two most common defects are adenoids and enlarged tonsils. These tend to obstruct the nasal passages and cause mouth breathing. This is not as healthful as nose breathing because when air passes through the nose it is filtered of dust and bacteria, warmed, and humidified. In some cases these obstructions interfere seriously with the mental development of the child. Inflammation of the nose and throat often spreads to the ear through the eustachian tube and 
causes deafness. In many cases the difficulty may be remedied by a simple operation in which the tonsils or adenoids are removed.

Defects of the ear. A small per cent of children have defects of the ear. The chief cause of these defects is a diseased condition of the throat and nose. Hence it is important to give proper care to these troubles before they spread to the ear. Two other causes of defective hearing are infectious diseases and stoppage of the ear canal. The diseases which
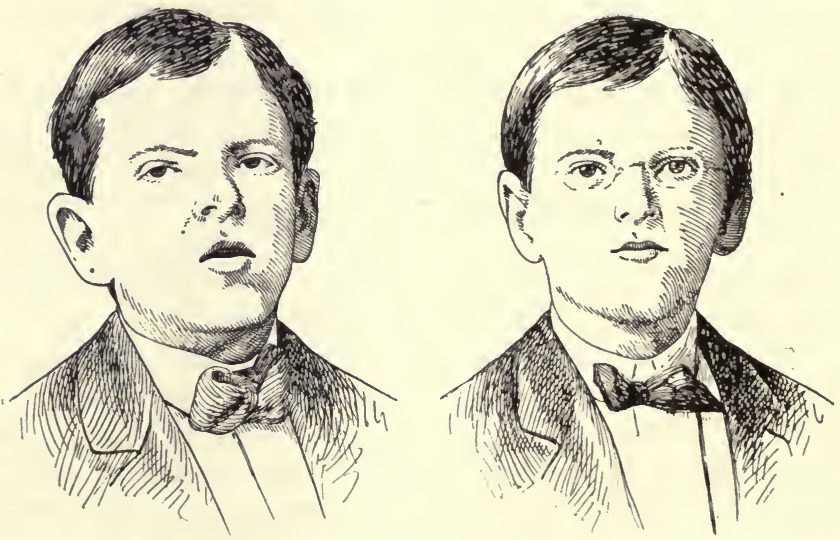

Fig. I75. - Before and after removal of adenoids.

are most apt to affect the ear are scarlet fever, measles, and diphtheria. Wax accumulations sometimes cause deafness. If taken in time, the wax may be easily removed. This should be done only by a doctor. It is dangerous to run hair pins and other objects into the ear in order to remove the wax, as some people carelessly do.

The ears may be tested by means of a watch. The person should be blindfolded and each ear tested separately. The watch is held at varying distances and the greatest distance at which it can be heard is ascertained. Meanwhile the other ear should be covered. 
Medical inspection of school children. The state requires the child to attend school until a certain age is reached. At school the child is exposed to some dangers that he would not encounter at home. Since the law compels a child to attend school, the law must protect his health while there. Compulsory medical inspection of schools must naturally follow compulsory attendance. In some states medical inspection is compulsory, and eventually this will doubtless be required in all states.

Medical inspection has two large purposes : first, to detect infectious diseases; and second, to detect and remedy any defects of eye, ear, etc., that interfere with the child's development. The school is the best place to detect and control infectious diseases, so that the other children and the entire community may be protected.

In the larger cities a corps of competent doctors and nurses should be hired to carry on this work. The chief work of the doctors is to discover the defects; the nurse follows up the cases and visits the home and tries to see that the parents give the child the needed treatment. In some cities clinics are being established where children are treated for their defects if the parents are too poor or too careless to have it done. It seems natural and logical not only to find out the defects, but also to remedy them.

In some smaller towns which cannot afford to hire both a doctor and a nurse, it is found that a nurse alone can do very effective work, and many of our towns and small cities are employing a school nurse, who is the most important single factor in the work of medical inspection because she is constantly on duty and visits the homes.

Advantages of medical inspection. Medical inspection is found to have the following advantages : first, it is a means of preventing the spread of infectious diseases; second, school work proceeds more successfully because there is a saving of time that might otherwise be lost on account of 
sickness and the children are able to do better school work because they are in better health; third, it makes the child happier and gives him a better chance in life; fourth, it is a means of educating the public on the matter of health.

Work of nurse and doctor. In working out a system of medical inspection the following things are done by the doctor or nurse. First, a thorough examination is made of every child when he enters school; second, a daily examination is made of all children reported as ill by the teacher; third, after a child has been out of school, he is examined when he returns; fourth, occasional examinations are made by the nurse of the eyes, ears, teeth, nose, and throat; fifth, frequent inspections are made to detect contagious diseases and these cases are referred to the board of health; sixth, the school nurse looks after the minor ailments and gives instructions in practical lessons in hygiene to the children; seventh, the school nurse follows up the cases when defects are reported, by.visiting the homes and encouraging the parents to have the children treated; eighth, in cases where the parents cannot or do not see that the child receives the necessary treatment, the school should have it done. This may be done through private means or at public expense.

\section{School Project 8}

Purpose. To make a sanitary survey of the school.

Direction. Procure a copy of Hoag and Termann's Health Work in the Schools, published by Houghton Mifflin Co., Boston. Make a survey of your school following the outline given on pages 246-248. As a result of this survey would you say that the sanitary conditions in your school are satisfactory? If not, what is lacking? What can be done to remedy these defects? 


\section{SUPPLEMENTARY QUESTIONS FOR CLASS DISCUSSION}

I. What are the proper methods of lighting the schoolroom?

2. What are the best ways of heating and ventilating the schoolroom?

3. Does the system used in your schoolroom furnish the essentials of ventilation?

4. In what ways may a circulation of air be maintained in the schoolroom?

5. How may the per cent of the humidity of a room be determined?

6. How may the proper amount of moisture be introduced into the room?

7. Why should the public drinking cup be abolished?

8. What is the purpose of medical inspection of schools?

9. Why is medical inspection of schools extremely desirable and almost necessary?

10. Why is the school nurse a very important factor in a system of medical inspection?

I I. What effect have defective teeth on health?

12. How may the defects of the eye be remedied?

13. What harm is done to health by adenoids and enlarged tonsils?

\section{REFERENCE}

Dresslar, School Hygiene, Macmillan Co., New York City. 


\section{SECTION D \\ Community Entertainment}

\section{CHAPTER XXVIII}

\section{MOVING PICTURES}

How are moving pictures made and how are they thrown on the screen?

No application of science during the last ten years has had such a rapid development and become used by so many people as the moving pictures. They are now found in all parts of the country, and almost every town has one or more moving-picture theaters. It has become in a very real way the people's theater. It is estimated that there are fifteen thousand moving-picture theaters in the United States, besides many halls where moving pictures have been established, and that these have an average daily attendance of fourteen million people who spend each day for admission fees over one million dollars. There are shown daily in all the moving pictures a total of about eighteen thousand miles of films, almost enough to encircle the earth.

Early attempts. Let us first notice some of the early attempts to make moving pictures, and the progress that has been made in recent years. In 1872 Edward Muybridge, a resident of San Francisco, conceived a plan of taking a series of pictures in rapid succession. His plan required the use of a large number of cameras that were set up side by side. About ten years later, Dr. Marey in France made 
improvements on the plan of Mr. Muybridge. He devised a plan by which all the pictures were taken by one camera by means of turning a handle. This was a great step forward, because it reduced the expense and took all the pictures from one viewpoint. This may be called the real forerunner of the modern moving picture camera. In 1886 he made a special exhibition of the results that he had obtained.

Developments in photography. Before any marked progress could be made in the development of moving pictures, two improvements in photography were necessary. These were, first, the substitution of films for glass plates, and second, the making of a more sensitive surface for coating the plate so that the pictures could be taken with a very short exposure.

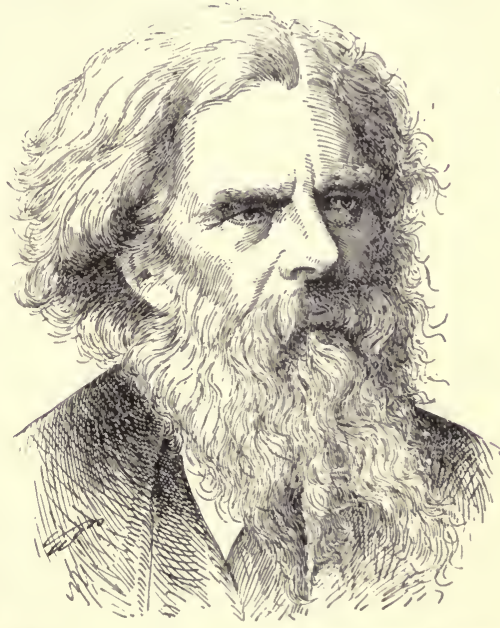

Fig. I76. - Muybridge, sometimes called the father of moving pictures.

Celluloid film. The development of a sensitive film to take the place of glass plates was made by Mr. Eastman of New York State. Experiments were made with many substances in the attempt to find one that was transparent, that could be made in thin sheets, and that was sufficiently pliable and strong to be wound around a roller. After many failures, Mr. Eastman made a celluloid film that met these requirements. These sheets of celluloid are coated with sensitive chemicals for making the negative. In 1889 the first long strips of film suitable for moving-picture work appeared. 
Edison's kinetoscope. While Mr. Eastman had been working to perfect a film, Thomas Edison had been working on a mechanism to show the pictures to the public. When the film was perfected by Mr. Eastman, it was used by Mr. Edison in the kinetoscope, the first moving-picture machine. This was on exhibition at the World's Fair at Chicago in I893, and attracted a great deal of attention. It was a box-

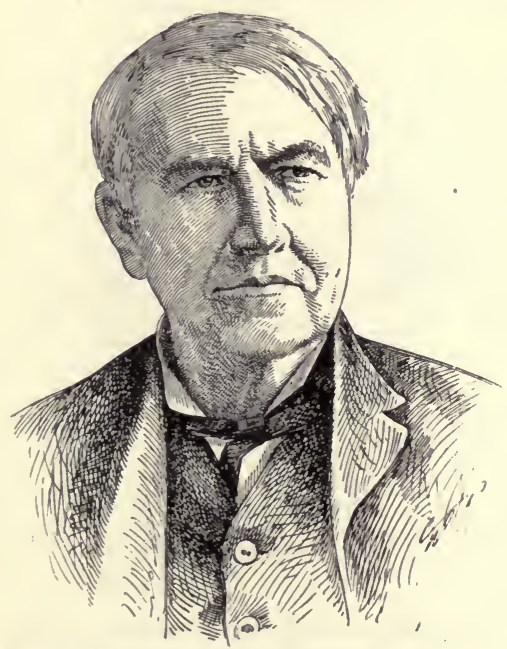

FIG, 177. - Edison, inventor of the kinetoscope and phonograph. like structure, containing a slot. When a nickel was dropped in the slot and the eye applied to the opening, pictures passed before the eye with such rapidity that they seemed to be alive. Within the box was a long film of pictures revolving around a series of spools. Just below the peep hole was a revolving shutter. A motor caused the film to move across the field of vision and the shutter to revolve in such a way that a series of pictures was presented rapidly to the eye. This was the first real moving picture.

Although this attracted much attention, it was looked upon at first only as a toy, and its commercial possibilities were not realized. It reminds one very strongly of the reception given the telephone at the Centennial Exhibition at Philadelphia in 1876 .

Animatograph. The first attempts to project moving pictures on a screen so that they might be seen by many people at the same time were made in England by Robert 
W. Paul. He called his machine the animatograph. He invented a device by which the film was brought into a fixed position for a very brief space of time, and thus enough light was allowed to pass through to make the images distinct. This was first successfully operated in London in 1895 . In the following year a public demonstration was given, and it proved highly successful. This animatograph was introduced at the Olympia, where it proved the most attractive feature. The Olympia, then, was the first moving-picture theater; and in Great Britain Robert Paul is called the father of the moving pictures.

Cinematograph. At the same time that Robert Paul was experimenting with his machine in England, Messrs. Lumière and Sons were working on the same problem in France. They perfected a camera for taking the pictures and a projector for throwing them on the screen. They called their machine the cinematograph. These proved successful, and were used in France about the time the Paul machines were first used in England. It was the French cinematograph which was introduced into America and laid the foundation for the development of moving pictures in this country. Although it was the invention of an American, Thomas Edison, which made the moving pictures possible, they were developed in both England and France before they were in this country. The first.moving pictures to appear in America were exhibited in 1896 at the Eden Musée.

Having noticed briefly the history of the moving pictures, we may consider more carefully how the pictures are produced and how they are thrown upon the screen.

Making the film. The Eastman Kodak Company alone manufactures about one hundred miles of film daily. In the manufacture of the film, such vegetable materials as flax and cotton waste are used. These are treated with acids, which change the materials to gun cotton. This is then dissolved in wood alcohol, which is spread out in a 
thin mixture over smooth surfaces, where it is allowed to dry. It is then coated with the sensitive emulsion. The sheet is then cut up into strips one and three eighths inches wide, which is the standard width for movie cameras and projectors. The materials of which the films were formerly made were highly inflammable and their use was attended with danger of fire. A kind of material has now been made, however, which is practically non-inflammable.

In order to have the film move steadily in the camera and projector, perforations are made along either side of the film by means of machines. The standard is sixty-four holes per foot. The success of the picture depends to a great extent upon the accuracy with which these perforations are made.

Moving-picture camera. The moving-picture camera consists of three parts, the camera proper, a box for the unexposed film, and a box for the exposed film. By means of a handle turned by hand, the film is unwound and brought before the shutter; there it is exposed, and then wound up in the other box. These boxes can easily be detached from the camera; and when one film is used, the box can be removed and another put in its place. The motion is given to the film by turning a handle attached to the side of the camera. This is so constructed that the film moves by jerks, so that the exposed section of the film is still for a fraction of a second while the picture is being taken. It requires practice to be able to turn the handle at the right speed. This should be done so as to make about sixteen exposures a second. Sometimes the handle is turned by a motor.

When the end of a series of exposures is reached, the operator pushes a film punch projecting from the camera, which makes punch marks on the film. The number of feet of film that has been used is indicated automatically on a dial, so that the operator may know when to change 
the film. The length of these films may vary from three hundred to five hundred feet.

When an object is to be taken which is moving both horizontally and vertically, like a flying machine, a special kind of tripod is used. This has two sets of gears and wheels, one of which moves the camera in a horizontal plane, while the other moves it up and down. This requires two men to operate it, one to turn the handle for taking the pictures, and the other to move the camera so that the object to be photographed is kept in the center of the field of vision.

Preparing the film. Special means have to be employed for handling long films in development. The films are wound around long wooden frames or reels. The principle involved is the same as that described in Chapter VII. The films for one subject are often developed in several parts and then are fastened together by means of a transparent cement. There is often great waste in the film, sometimes as much as twenty per cent being thrown away on account of imperfections.

In order to make a positive that can be used in the projecting apparatus another strip of perforated film similar to the first one is used, except that it is less sensitive to light. The principle is the same as that involved in making ordinary prints, only different devices must be used on account of the great length of film. 
Throwing pictures on the screen. For showing pictures on the screen, three essentials are needed: a projecting apparatus, a source of strong light, and a screen or white surface. This projecting apparatus is the same in principle as the stereopticon, or magic lantern, the chief difference being in the mechanism by which the film is passed through the machine.

Parts of a stereopticon. The essential parts of a stereopticon are shown in Figure I79. These consist of a source of

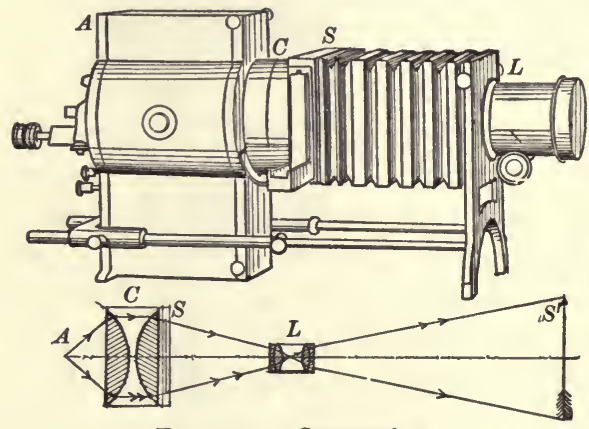

FIG. I79. - Stereopticon. light $A$; a set of condensing lenses $C$, which concentrate the light upon the lantern slide $S$. This is focused by the lens $L$ upon the screen $S^{\prime}$. This lens inverts the image so that the slide is placed in the holder upside down.

Projecting apparatus. The delicate part of the movingpicture lantern is the mechanism by which the film is passed through the machine. This film must have an intermittent motion, the same as in the camera, so as to stop for a fraction of a second to allow light to pass through and throw a distinct image on the screen. The film is mounted on a spool and led over a toothed sprocket, which fits into the perforations. A loop is then formed, and the film passes into the gate behind the lens. As the shutter revolves, shutting off the light from the picture, the film is given a jerk downwards, thus bringing the next picture into the gate, in exactly the same position as the previous one. The film is then connected with another sprocket and finally rolled up on another spool. The machine may be operated either by hand or by 
motor. These pictures are thrown upon the screen at the same rate at which they are taken, about sixteen per second. After the film has been used, it must be rewound on another reel, so as to bring the first picture into its proper position again.

\section{Field Exercise 8}

Purpose. To visit a moving picture theater to see how the projecting apparatus works.

Directions. Arrangements should be made with the manager of some moving picture theater to have the class visit the theater when it is not being used, in order to see how the projecting machine works. The operator can explain the details of the operation. At the next meeting of the class the points observed should be discussed.

Physiology of moving pictures. In order to understand the action of the moving pictures, we must not only understand the camera by which they are taken, and the projector by which they are thrown on the screen, but also the eye which sees them. The machine throws on the screen about sixteen pictures a second, which occupy a foot of film. The screen is darkened about half the time. Why do we not see these as so many distinct pictures, instead of as a continuous series of moving pictures? This is due to a peculiarity in the action of the eye. Rays of light pass through the pupil and are focused by the lens on the retina of the eye. This is lined with a network of sensitive nerves, so that when the image is formed here, impulses pass to the brain, and we have the sensation of sight. Even after the object is removed from view, the image still lingers in the brain for about one twenty-fourth of a second, just as though the object were in full view. In the movies the pictures are shown so rapidly that the second picture is shown before the image of the first leaves the brain. Thus the brain sees a continuous series of pictures without any breaks between, 
and this gives the appearance of motion. Moving pictures are really an illusion made possible through this peculiarity of the eye.

A picture is thrown on the screen and remains visible for about one thirty-second of a second; then the screen is darkened for about the same length of time by the passage of the shutter, which cuts off the light. Thus the pictures follow one another, one thirty-second of a second on the screen and then one thirty-second of a second darkened. As the image of the picture stays in the brain one twentyfourth of a second after the picture has left the screen, the brain retains this impression during the one thirty-second part of a second that the shutter cuts off the light. The image of the second picture is thus impressed on the brain before the first leaves it, so that the brain does not see the darkened screen at all. If the pictures were run through slowly, say at the rate of only five or six a second, then we could distinguish between the pictures and the darkened screen.

\section{LABORATORY EXERCISE 35}

Purpose. To illustrate why we seem to see a continuous set of pictures at the movies.

(The following exercise is taken from Rowell's Introduction to General Science.)

Directions. Obtain a piece of cardboard about three inches square. Punch a hole in each of two opposite ends. Pass through each a piece of string about fifteen inches long and tie the ends together, making a loop. On one side draw a man's head in colors or paste on it the picture of a man. On the other side draw straight vertical lines. Put a loop over each thumb and turn the cardboard till it winds up the strings. To put the "man in prison" pull the thumbs apart thus giving a rapid rotary motion to the cardboard. The man will seem to be behind prison bars. Explain the result. How does this principle hold in the movies? 
Science and moving pictures. Moving pictures have been used to illustrate many interesting things in nature. In order to show the opening of a flower or the entire growth of a plant from seed to blossom, the camera is focused on the object, and a picture is taken every half hour or so during the entire period. These pictures are then shown rapidly on the screen, and what really takes several weeks or months in nature is shown here in a few minutes. In a similar way, films show the development of caterpillars into butterflies, the development of the house fly, the development of the chick in the egg, and the breaking of the egg. A number of moving pictures of birds feeding their young have been made.

Through the use of the microscope moving pictures have been taken of such small objects as bacteria. In connection with the use of X-rays, pictures have been taken showing
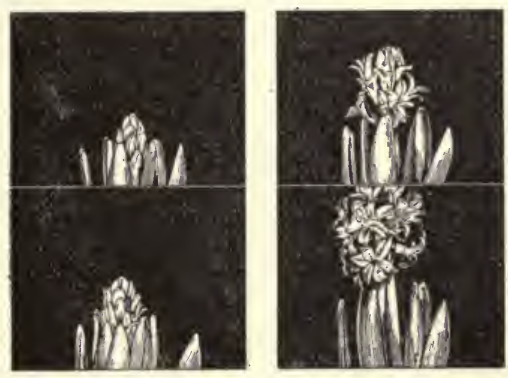

Fig. 180. - Birth of a flower. Film for movies showing growth on $2 \mathrm{~d}, 4^{\mathrm{th}}$, 6th and 8 th days. the motions of the stomach of a frog during the process of digestion.

"Animated newspaper." One of the more recent developments in moving pictures is the animated newspaper. This is edited and planned in a way similar to the ordinary paper. The purpose is to obtain moving pictures of the more important daily news items in various parts of the country. Operators are kept in various sections of the country to obtain pictures of news of special interest in these different localities. The films are sent to the main offices of the paper, where positive films are quickly made ready to send out to the subscribers. This work is done with great rapid- 
ity, so that if the original film is received by ten o'clock P.M., the positive films are ready to send out by two o'clock the next morning. These films can then be taken out by the early morning trains. These papers have regular subscribers among the showmen, to whom the films are sent regularly. Some of these papers are published weekly, some twice a week, and doubtless in the near future they will be published daily.

Moving pictures in the schoolroom. There is a great opportunity for the use of moving pictures in schoolrooms. Already some schools are being equipped with movingpicture outfits. Geography can be made much more real by means of moving pictures. Great mountains, lakes, and rivers are easily shown, as are the activities of people in various countries showing their costumes and habits. In fact there seems almost no end to the possibilities of moving pictures in geography. In elementary science many things can be realistically shown, such as the opening of a flower, the action of filings around a magnet, and the development of the house fly. There are also great possibilities in connection with literature.

Trick pictures. Many unusual effects, impossible in real life, are produced by tricks in the process of making and showing the pictures. In order to make people appear very large or very small, pictures are taken at different distances, thus giving different-sized images. Then these two films are printed one over the other so that the two images appear on the screen at the same time.

In picturing accidents the camera is stopped just before the accident occurs and a dummy is substituted for the real actor, and then the camera goes on taking pictures. Later the dummy may be removed and the actor come back again.

In order to show reversed action such as a pumpkin rolling up hill or smoke going down a chimney, the film is unrolled backwards, the last picture being shown first. 
To produce action of inanimate objects, such as a shoe lacing itself, a series of pictures is taken of the object in different positions and then these are thrown on the screen rapidly.

The apparent walking of a person up the side of the house is produced by taking pictures with a camera which is placed above the stage.

Animated cartoons. One of the more recent developments of the movies that has now become well established
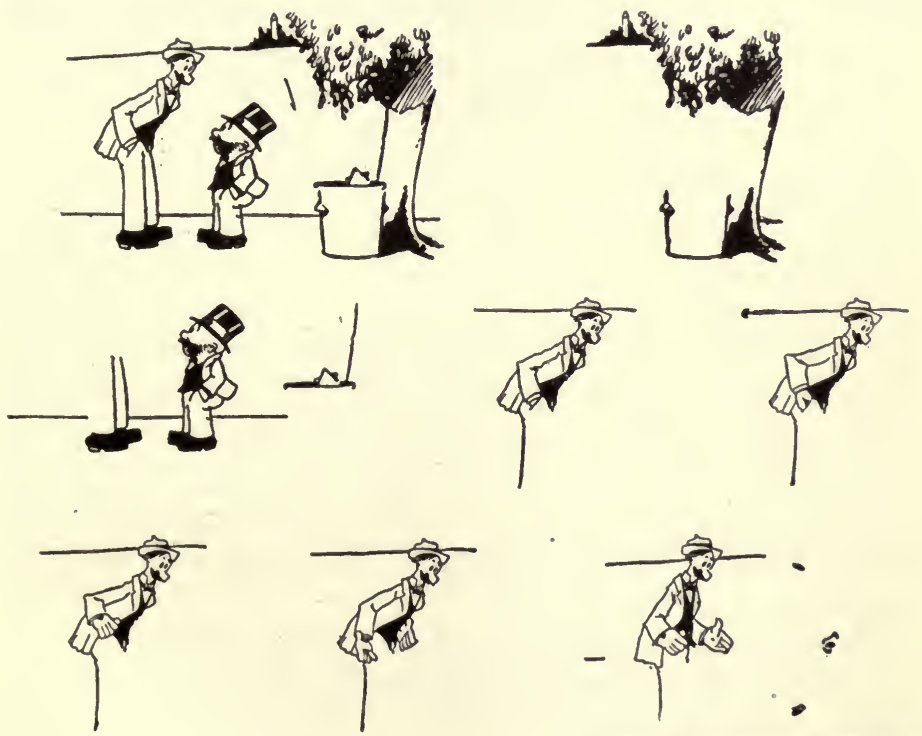

Courlesy of Everybody's Magazine.

FIg. 181. - Drawings for animated cartoons. These are the drawings required to show the whole process of withdrawing Mutt's hand and closing his eye.

is the animated cartoon. There is almost no limit to the ideas that may be worked out in this way. These cartoons are made by taking photographs of a series of drawings. One drawing is placed before a camera and a picture taken, than another drawing and another picture taken, and so on 
till pictures have been taken of all the drawings. The pictures made from these exposures are shown rapidly on the screen, so that a series of drawings that are seen by the audience in eight minutes took an artist five weeks to make. In order to procure a half reel (about 500 feet) of animated cartoons about 2000 drawings must be made. Some idea of the number of drawings required may be gained by explaining that in the Mutt and Jeff pictures it takes four drawings to show Mutt withdrawing his hand from his pocket and three drawings to show him winking his eye. In order to make the Mutt and Jeff drawings, sixty assistants are employed to help the head artist, who has general charge of the work.

Talking movies. Finally, we have the talking movies, which consists of a phonograph and a moving-picture machine working in unison. At first thought it might seem a simple thing, to start them both at the same time and let them run, but as a matter of fact it has proved very difficult to keep them exactly together. In recent years this has been worked on by Edison in this country and by Gaumont in France.

In order to get the best results, it is necessary that the records on the phonograph be taken at the same time that the camera is taking the pictures, and then that these be reproduced together.

The important part of the talking movies is the mechanism by which the phonograph and moving-picture machine are kept in exact unison. In some of the first machines made, this was controlled by the operator, who managed both machines by hand. A dial with hands, like the face of a clock, was provided for each machine and indicated the speed. The operator watched these dials and tried to operate the two machines so that the hands on the two dials maintained the same position. This proved a very difficult thing to do. In the later forms the machines are operated by motors. A mechanism is so arranged that the operator 
has to watch only one needle, and a device is provided so that the speed of the motors may be changed until the two machines work in unison. This has now been perfected to the stage where it works very satisfactorily, and these machines are now found in many of our large cities.

The talking movies have proven successful enough so that we can get some idea of their possibilities when we have seen and heard renowned men and women from distant parts of the country, sometimes after their death. It will be a wonderful thing for future generations to be able to see and hear the great men and women of to-day. How much it would be worth to us to-day if we could hear the voices and see the actions of the great men who stand out conspicuous in our country's history, like Grant and Lee, Washington and Lincoln!

\section{SUPPLEMENTARY QUESTIONS FOR CLASS DISCUSSION}

I. What were the first steps taken in the development of the moving picture?

2. What part did Thomas Edison play in the development of the moving picture?

3. What was the relation between the development of the movies and the development of photography?

4. How does the moving-picture camera work?

5. How is the film developed and the positive made?

6. How are the pictures thrown on the screen?

7. What peculiarity of the action of the eye makes the moving picture possible?

8. What are some interesting educational applications made of the movies?

9. What uses could be made in your school of moving pictures?

I0. How is the animated newspaper managed?

II. How are trick pictures produced?

I2. Watch carefully the movies you attend and notice what 
are trick pictures. How many kinds of trick pictures can you find?

I3. Which do you consider the most interesting trick pictures?

14. What are the special advantages of the talking movies?

\section{REFERENCES}

Cressey, Discoveries and Inventions of the Twentieth Century,

E. P. Dutton Co., New York City. Pages 360-373.

Dench, Making the Movies, Macmillan Co., New York City.

Doubleday, Stories of Inventors, Doubleday Page and Co.,

New York City. Pages I13-I3I.

Johnson, Modern Inventions, F. A. Stokes Co., New York City. Chap. I.

Maule, Boys' Book of New Inventions, Grosset and Dunlap Co., New York City. Chaps. 5-6.

Welsh, $A-B-C$ of Moving Pictures, Harper Bros., New York City.

Talbot, Moving Pictures, How They Are Made and Worked, J. B. Lippincott Co., Philadelphia. 


\section{SECTION E}

\section{Conservation of Community Resources}

\section{CHAPTER XXIX \\ PROTECTION OF BIRDS}

I. Why should birds be protected?

2. What is being done to protect birds?

There are in nature certain forms of life which are of such great value to man that they should be protected. Chief among these are birds and forests. In order to protect these adequately, the coopperation of all concerned is necessary. The work of just one individual or of a few without help from others will be of little avail.

The subject of bird protection will be treated under three headings: first, why birds should be protected; second, against what they need to be protected; and third, how birds are being and can be protected.

Reasons for bird protection. Birds should be protected on account of both their esthetic and economic value. Studies of the food habits of birds show that birds help man in three ways : by eating insect pests; by eating weed seeds; and by eating rodent pests, such as mice and rats.

In the government at Washington there is a branch of the Department of Agriculture, called the Bureau of Biological Survey. The purpose of this branch is to study the food habits of birds and to determine whether these birds are 
beneficial or injurious. In order to do this, specimens of birds are collected in different months and from different states. The experts at Washington open the stomachs of these birds and make a careful study. of their contents. From this study they are able to determine what food the birds have been eating. So far the Bureau of Biological Survey has examined more than sixty thousand stomachs, comprising over four hundred species of birds.

For instance, in order to find out about the food of the robin, 1236 specimens were collected in different months from forty-two states, the District of Columbia, and three Canadian Provinces. It was found that about one seventh of the robin's food was made up of things valuable to man, such as fruit and beneficial insects, one third was composed of injurious insects, and about one half was made of neutral elements, chiefly wild fruit.

Birds as insect destroyers. These studies have shown that insects form the chief food of birds, and that most of these insects are injurious to man because they feed upon the crops he is raising, or because they carry diseases. Birds help man because they keep these insects down to such a point that man is able to control those that remain. If man were to be deprived of the services of the birds, insects would increase to such an extent that man would have a terrible struggle to overcome them.

Amount eaten by birds. One thing that makes birds so helpful is the fact that they devour so many insects in the course of a day. Birds watched in the field have been observed to eat from two to ninety insects in a minute, depending on the bird and the kind of insect. In the studies made by the Biological Survey it was found that a single stomach of a bird contained a great many insects. For instance, the stomach of a grosbeak was found to contain fourteen potato beetles; a crow blackbird, thirty grasshoppers ; and a flicker, five thousand ants. 
It was also found that a single species of bird feeds on a great many kinds of insects. For example, the downy woodpecker was found to eat forty-three different kinds of insects ; the robin, two hundred twenty-three kinds ; and the night hawk, six hundred kinds.

It was further found that many different kinds of birds feed upon some one kind of insect. For example, twenty-six kinds have been found to feed upon the potato beetle, thirty-six kinds on the codling moth (the caterpillar of which is the worm of wormy apples), eighty-eight kinds on cutworms, and one hundred twenty-eight kinds on the click beetles or their larvæ, the wireworms.

Food of nestlings. Nestling birds require vast amounts of food and are fed frequently during the day beginning at sunrise and continuing till sunset. One pair of house wrens was observed to feed its young, two hundred and thirtyeight times in one day. During the two weeks these young were in the nest, they ate from four thousand to five thousand insects. Observations made of many young birds show that it is a common thing for birds to feed their young two hundred times in one day, or about once every four minutes.

One man, after watching a pair of marsh wrens carrying grasshoppers to their young, estimated that the grasshoppers eaten by all the birds in eastern Nebraska in one day would have destroyed about $\$$ I 700 worth of crops had it not been for the birds. Another man estimates that the birds of New York State destroy annually more than three million bushels of injurious insects.

\section{Field Exercise 9}

Purpose. To see how many times nestling birds are fed in one day.

Directions. A nest of some bird should be located that can conveniently be watched. The class may be divided into small groups, and each group assigned to watch the birds for a cer- 
tain length of time, say an hour. A record should be kept of the number of times the young birds are fed, and if the sexes can be distinguished either by color or song, the number of times each parent brings food should be recorded. The birds feed from sunrise till sunset, and if there are not enough groups to watch them all day, an estimate for the whole day may be made from the results obtained for the time the birds are watched.

Number of insects eaten. It is possible to make an estimate of the number of insects eaten by birds east of the Mississippi River. A census has been made of the number of birds found here, and observations have been made of the number of times young birds are fed. On this basis we get an estimate of ten trillion insects as the number eaten by the birds each summer east of the Mississippi River. If these were placed an inch apart, they would make a procession one hundred and sixty million miles long, which would reach to the sun and almost back. If it traveled at the rate of one milea minute, it would take three hundred years to pass a given point. If placed one inch apart each way, these would make a sheet that would completely cover the state of Delaware.

Birds as destroyers of weed seeds. A second way in which birds help man is in eating weed seeds. The most valuable birds for this purpose are the mourning dove, the bobwhite, and the native sparrows. Two thirds of the entire food of the dove, and about one half of the food of the bobwhite and sparrows is composed of weed seeds. The red-winged blackbird has been known to eat fourteen kinds of weed seeds, the horned lark thirty-eight kinds, and the bobwhite one hundred and twenty-nine kinds. A single bird eats an enormous number of seeds. In a single stomach of a chipping sparrow have been found one hundred and fifty seeds of crabgrass, and in that of a bobwhite, ten thousand seeds of pigweed. Professor Beal has estimated that the tree sparrows in the state of Iowa alone consume every year eight hundred and seventy-five tons of weed seeds. 


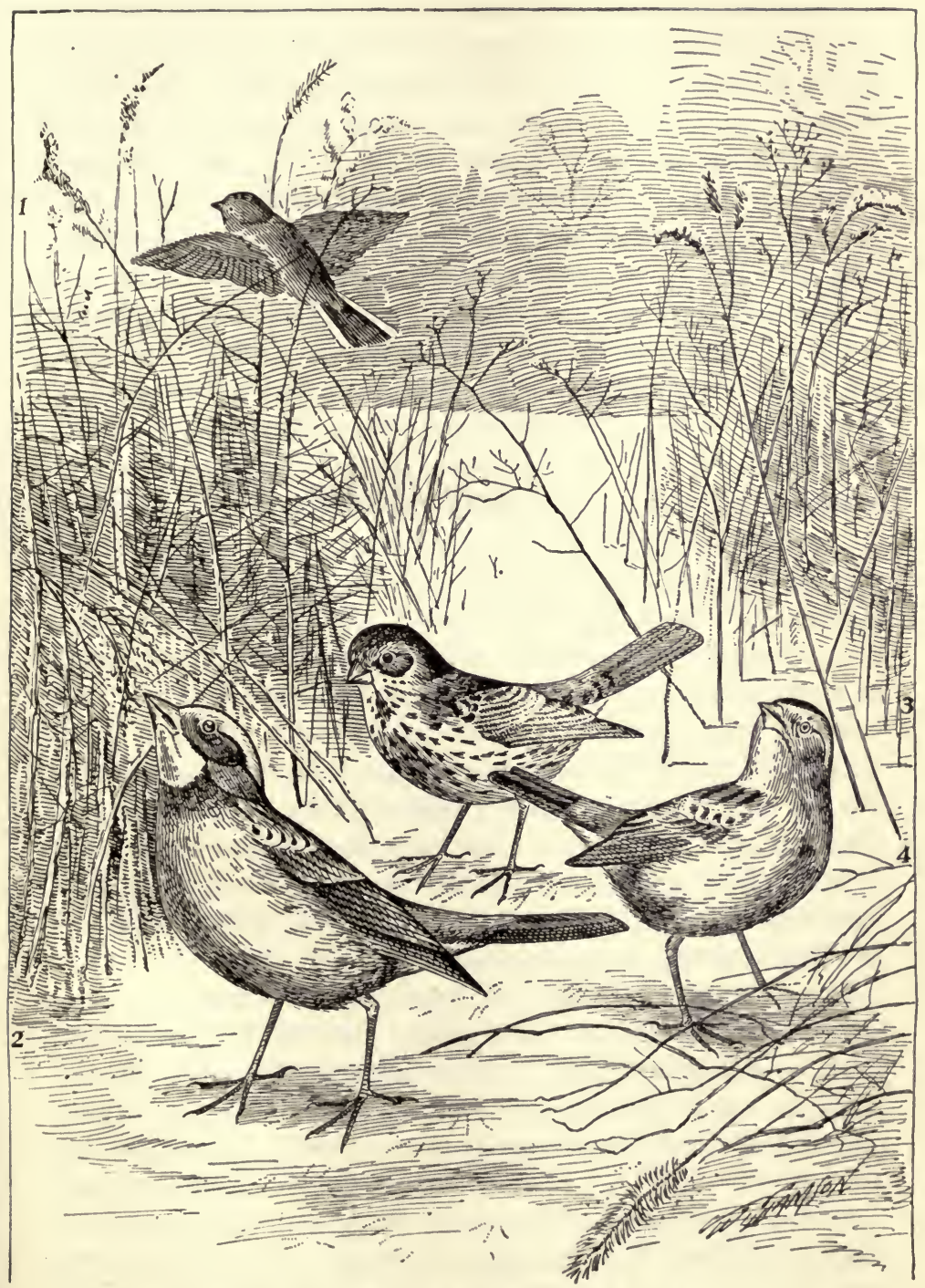

FIG. 182. - Four common seed-eating birds.

I, Junco ; 2, White-throated sparrow ; 3, Fox sparrow ; 4, Tree sparrow: 
Most of the work of eating weed seeds is done between early autumn and late spring. During the summer, birds feed largely on insects. This group of birds is beneficial then in two ways, in eating insects and in eating weed seeds.

Destroyers of rodent pests. Still a third way in which birds help man is in destroying rodent pests, such as rats, mice, and ground squirrels. The birds which are helpful in this way are the hawks and the owls. These birds have been greatly misjudged. Because a few hawks destroy some poultry, the wrong notion has got abroad that all hawks and owls are injurious. As a matter of fact only two common hawks, Cooper's hawk and the sharp-shinned hawk, are injurious, and no common owl is. There are several hawks which may occasionally take a chicken; but this is the exception and it is made up many times by the good they do. About ten per cent of the species of hawks and owls are injurious, fifteen per cent are neutral, and seventyfive per cent are beneficial. That is, more than seven times as many species are beneficial as are injurious.

Eight mice have been found in the stomach of a single hawk. It seems fair to suppose that a hawk or owl would destroy one thousand mice a year. It has been estimated that a mouse will do two cents' worth of damage in a year, so that these one thousand mice would do twenty dollars' worth of damage. A hawk or owl, then, may be said to be worth twenty dollars a year.

Harm done by birds. A little harm is done by some birds. Some birds, like the catbird and the cedar waxwing, feed on cultivated fruit. Other birds, such as the English sparrow, crow blackbird, and crow, feed on grain. About one half of this is waste grain, and so should not be counted against the bird. As already mentioned, some hawks and owls destroy poultry. The worst offender is Cooper's hawk. The sapsucker does damage to trees by drilling holes. Sometimes the tree is killed, but the chief damage is due to 
the fact that after the tree is cut down and sawed up into lumber, the little holes formed in drilling lower the value of the lumber. Some birds, such as the flycatchers and swallows, eat beneficial insects. And finally some birds destroy other valuable birds. More than half of the food of the sharp-shinned hawk consists of small valuable birds.

Summary. We may summarize briefly by saying that birds may be divided into three groups: injurious, neutral, and beneficial. To the injurious group belong four common birds : the English sparrow, the sapsucker, Cooper's hawk, and the sharp-shinned hawk. To the neutral group, in which the harm and good about balance, belong five common birds: the catbird, the cedar bird, the crow, the crow blackbird, and the bluejay. The remaining common birds are beneficial. If we take one hundred as the number of species of common birds that might be found in a locality, they would be divided as follows : injurious, four per cent; neutral, five per cent; beneficial, ninety-one per cent. To state the matter more briefly, four per cent do more harm than good, and ninety-one per cent do more good than harm; that is, for every species of harmful bird, there are twenty-two species of beneficial birds.

Mr. H. W. Henshaw, chief of the Bureau of Biological Survey, writes in a recent article: "What would happen were birds exterminated, no one can foretell with absolute certainty, but it is more than likely, nay, it is almost certain that within a limited time not only would successful agriculture become impossible, but the destruction of the greater part of vegetation would follow. It is believed that a permanent reduction in the number of our birds, even if no species are exterminated, will inevitably be followed by disastrous consequences."

The food habits of a few common birds are briefly summarized in the following table, which is based on the reports of the Bureau of Biological Survey. 
Table of Food of a Few Common Birds

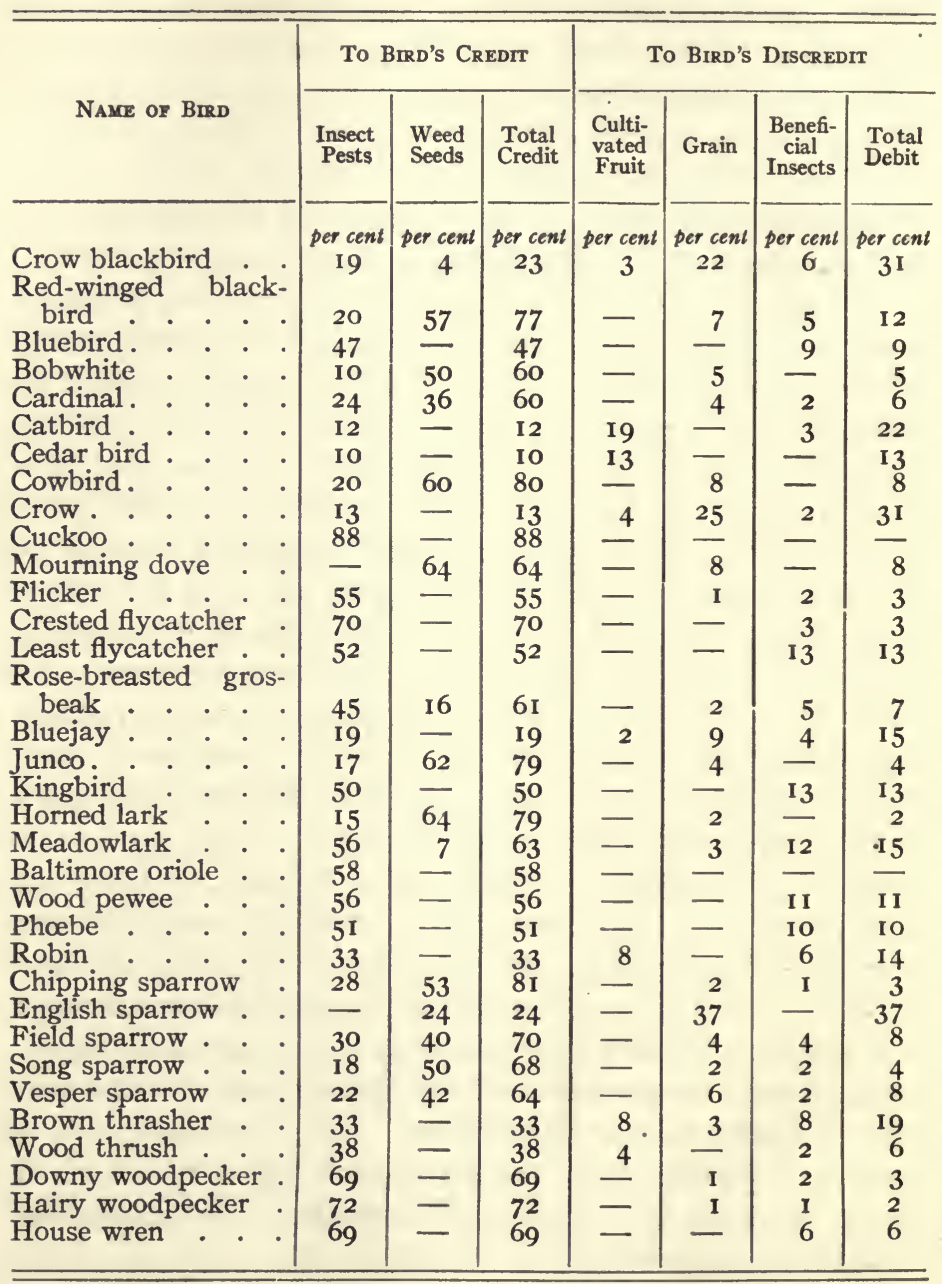

In putting down the amount of grain eaten, the per cent of waste grain has been subtracted from the total per cent 
of grain eaten, thus leaving only that portion which can be considered to the bird's discredit. The figures represent the per cent of the total food for the year that any item forms.

\section{Laboratory ExERCise 36}

Purpose. To study the food habits of some common birds.

Directions. From a study of the above food chart answer the following questions. Copy the following table in your notebook and write in it the answers to questions $1-6$ by writing the names of the birds in the proper column and the per cents in order, the largest first.

\begin{tabular}{|c|c|c|c|c|c|}
\hline \multicolumn{3}{|c|}{ BENEFICLAL EFfECTS } & \multicolumn{3}{|c|}{ INJURIOUS EFFECTS } \\
\hline $\begin{array}{c}\text { Insect Pests } \\
\text { (50\% or } \\
\text { over) }\end{array}$ & $\begin{array}{c}\text { Weed Seeds } \\
\text { (50\% or } \\
\text { over) }\end{array}$ & $\begin{array}{l}\text { Weeds and } \\
\text { Insects } \\
\text { (20\% of } \\
\text { each) }\end{array}$ & $\begin{array}{l}\text { Grain } \\
\text { (ro\% or } \\
\text { over) }\end{array}$ & $\begin{array}{l}\text { Cultivated Fruit } \\
\text { (I0\% or over) }\end{array}$ & $\begin{array}{l}\text { Beneficial Insects } \\
\text { (10\% or over) }\end{array}$ \\
\hline & & & & & \\
\hline & & & & & \\
\hline
\end{tabular}

I. Which birds are specially valuable as destroyers of insect pests ( $50 \%$ or over)?

2. Which are especially valuable as destroyers of weed seeds ( $50 \%$ or over)?

3. Which are valuable for destroying both insect pests and weed seeds $(20 \%$ or more of each)?

4. Which birds feed to any extent on grain ( $10 \%$ or more)?

5. Which birds feed to any noticeable extent on cultivated fruit (10\% or over)?

6. Which birds feed to any extent on beneficial insects (10\% or over)?

7. Which of those birds that feed on grain or cultivated fruit destroy enough insect pests or weed seeds to balance the harm done? 
8. Copy the following table and write in it the answers to questions 9 , Iо, I I.

\begin{tabular}{|l|l|l|}
\hline Birds Distinctly Injurious & Birds Neutral & Birds Distinctiy Beneficial \\
\hline & & \\
\hline
\end{tabular}

9. Which birds on the chart do very much more harm than good, that is, have the debit column fifty per cent or more greater than the credit column? Put these in the first column.

I0. With what birds are the good and harm done about the same, that is, not more than ten per cent difference? Put these in the second column.

II. What birds are decidedly beneficial, that is, have the credit column fifty per cent or more greater than the debit column? Put these in the last column.

12. Arrange the birds according to the ratio between the good and harm done. Place the cuckoo and oriole at the head of the list. For the others divide the percentage of good done by the percentage of harm done. For example, for the chipping sparrow divide 81 by 3 (27). Do the same with the others and arrange them in order, the bird with the largest number first. Which five birds stand first in the list? Which five last?

13. (Optional.) If you wish you may make a chart from this table similar to the one in Figure 183 . This chart is to represent the ratio between the good and harm done. Let one inch represent 5. Then for the chipping sparrow draw a line $5 \frac{2}{5}\left(\frac{27}{5}\right)$ inches long. In a similar way draw lines for the other birds, arranging them in the order of the length of the line, the longest first. Make the lines for the cuckoo and oriole two inches and one inch, respectively, longer than that for the chipping sparrow.

\section{Field Exercise to}

Purpose. To learn what beneficial birds are common in your locality.

Directions. I. In order to find what birds are common in the locality, field trips may be taken with the purpose of identify- 


$10 \% \quad 20 \% \quad 30 \% \quad 40 \% \quad 50 \% \quad 60 \% \quad 70 \% \quad 80 \% \quad 90 \%$

Cuckoo

Chipping Sparrow

3\%

Red-winged Blackbird

House Wren $6 \%$

$12 \%$

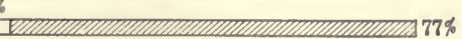

Downy Woodpecker

$13 \%$

Song Sparrow.

a\%

Mourning Dove

$8 \%$ c्wis

Meadowlark

$15 \%$

Rose-breasted Grosbeak $7 \%$ _ _

Bobwhite

$5 \%$

Baltimore Oriole (12)

Flicker

$3 \%$

Phoebe

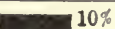

Kingbird

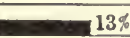

Bluebird

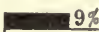

$3 \%$

Wood Thrush

$6 \%$

Brown Thrasher

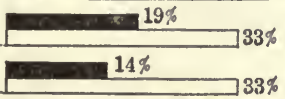

Robin

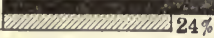

English Sparrow.

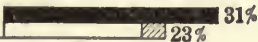

Crow Blackbird

Red-headed Woodpecker.

Blue Jay.

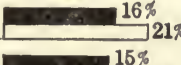

Crow.

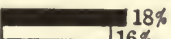

Catbird

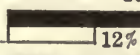

$22 \%$

Cedar Waxwing

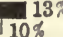


ing as many birds as possible. The spring is the best time to study birds in the field. For each bird seen, a record should be made in the field of some of the following points: I. size (compare with robin or English sparrow); 2. general colors above and below; 3 . more detailed description of colors found on head, back, tail, wings, and breast ; 4 . any peculiarity of flight ; 5 . characteristics of song; 6 . the most conspicuous field marks by which the bird may be identified again.

2. After returning from the field look up the economic standing of each bird seen by referring to the food chart on page 466 .

Enemies of birds. Having shown that birds are of great value to man, we may next inquire what are the enemies

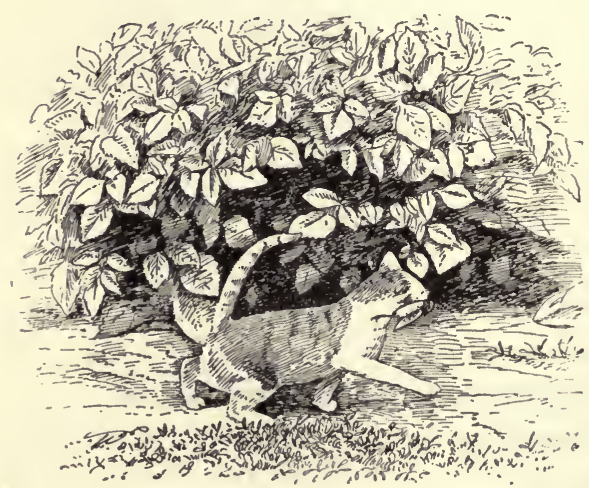

Fig. 184. - Cat with robin. This cat was seen to kill 58 birds in one season. against which birds need to be protected. The chief enemies of our common song birds are the cat and the English sparrow.

Cats. The cat does a great deal of harm during the nesting season, by feeding upon young birds while they are in the nests and just after they leave the nest. Oftentimes also, adult birds are caught while on the nest or while defending the young. Most of the harm is done in the early morning. Most bird students agree that the cat is the worst enemy of our song birds.

A number of observations have been made of the number of birds killed by a cat in a single season. One cat was seen to kill fifty-eight birds in a season. (See Fig. 184.) Cats have frequently been observed to kill two or three birds in a 
day and one cat has been observed to kill more than ten birds in one day. Mr. Forbush estimates that a mature cat in good hunting grounds kills fifty birds each year. Dr. Fisher estimates that cats destroy annually 3,500,000 birds in the state of New York alone. It has been estimated that in the United states east of the Mississippi River cats kill annually from seventy-five to one hundred million birds, mostly nestlings.

Bird students generally agree that one of the first steps necessary for the control of the cat is to require a license, similar to that now required for dogs. This would lead people to keep fewer cats and to take better care of those which they licensed. At the same time provision should be made for the disposition of stray homeless cats in some humane way. People who keep cats should see that during the nesting season, the cats are kept shut up during the night and early morning and that they are well fed.

English sparrow. The English sparrow is injurious to other birds both directly and indirectly. It attacks other birds and breaks up their nests, destroying their eggs and young. Indirectly, it is specially injurious to birds that nest in cavities, such as the wrens, bluebirds, and martins. It is so persistent in taking the nesting sites of these birds that gradually they leave localities where the sparrows are common.

Sparrows may be controlled in three ways: by shooting, by trapping, and by poisoning. In sections where shooting is allowed, this may prove an effective means if persisted in. In cities, however, shooting is not allowed. Trapping is a very effective means and may be used anywhere. If native birds are caught, they can be released without any injury. Under certain circumstances, poisoning may be used; but as there is danger that valuable birds may be poisoned, this method can be used only where sparrows alone are found.

Man as an enemy of birds. Man himself is one of the bird's worst enemies. In years past when men have hunted 
birds to sell in the market, enormous numbers have been killed, and our game birds have greatly decreased in numbers. In the case of the passenger pigeon, the birds have become extinct. Formerly these birds existed in tremendous numbers, single flocks being seen which were estimated to contain two billion birds. These birds were slaughtered for market in such numbers that they gradually became scarcer, until to-day not a single living passenger pigeon is left. To-day, however, there is very little hunting for market.

Another reason for the marked decrease in game birds has been excessive shooting by sportsmen. It is estimated that each year an army of about five million men and boys go out in the fall to shoot game birds. The open season has been so long and the bag limit so high, that the birds have gradually decreased. If the sportsmen were few, the danger would not be so apparent; but there is such an enormous number of them that even when all keep within the limits of the law, it is easy to see that large numbers of birds must be killed, and that many species may disappear altogether unless they are given better protection.

In years past, many birds have been killed for millinery purposes. As a result some species, like the egrets, have become very scarce and even almost extinct. But on the whole at the present time very few birds are being killed for their plumage.

Bird protection. Having shown that birds are of great value to man, and that these have certain enemies, we may next ask what is being done and can be done to protect birds from these enemies.

Audubon Societies. The most important agency in this country in the cause of bird protection is the National Association of Audubon Societies. At first, separate state Audubon Societies were formed. Later, this national organization was formed, the state societies coöperating with 
it. The work of the national association has been extended in many lines, including: I. legislation; 2. warden work; 3. publications; 4. Junior Audubon classes; and 5. field agents.

The association has been active in getting proper bird laws passed. A number of years ago a model bird law for song birds was proposed; this has now been adopted in

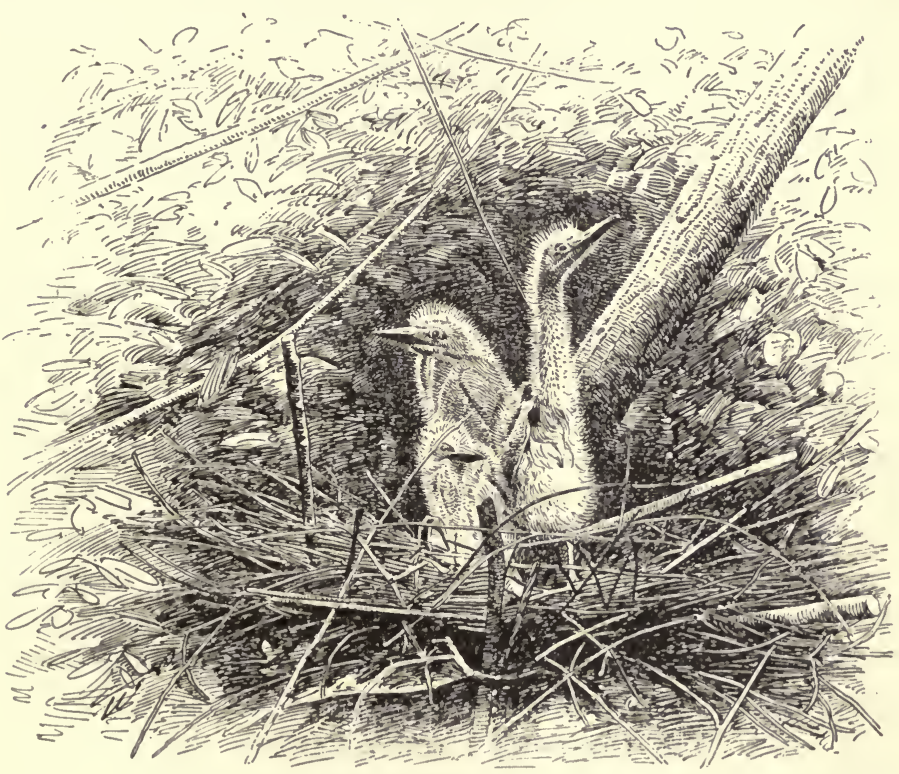

FIG. I85. - Nest and nestlings of little green herons.

forty states. Laws giving better protection to game birds have been passed as a result of the activities of this association.

Many water birds nest together in large colonies and the association hires wardens to protect these birds during the nesting season. It was estimated that during the season of r $_{913}$ about two million birds were protected in this way. 
The association publishes a magazine, called Bird Lore, which contains illustrated articles and notes on birds. A large number of colored pictures and leaflets are published, amounting to four million copies annually. These pictures are sold for three cents each.

During the past five or six years, a great work has been done in schools through the organization of bird clubs among the children. The work has grown in importance each year, and during I9I 7 there were organized II,935 classes, including 26I,654 members.

A number of lecturers, called field agents, are employed, who devote their time to lecturing on birds and aiding the work of the association in other ways.

There are now state Audubon societies in thirty-seven states and in the District of Columbia. These coöperate with the national association, and also carry on other lines of work independently.

Bird protection by governments. Much progress has been made in this country in protecting birds by state laws. The tendency has always been to give more complete protection to birds in the enactment of these state laws. During recent years the national government has taken important steps to protect birds, recognizing the fact that since birds migrate from one state to another, their protection is a matter for the national government.

In I9r3 Congress passed the migratory bird law. In accordance with this, all migratory birds that pass from one state to another are given some degree of protection by the national government. The exact regulations were worked out by a committee of experts from the Bureau of Biological Survey. These regulations are the most important scientific document ever issued in the cause of bird protection.

Migratory birds are first divided into two groups, the insectivorous birds and the game birds. Insectivorous birds are protected during all the year. Some game birds 
which are becoming scarce, such as most of the shore birds, were given complete protection for five years, until I9r8. The other game birds are given protection for about nine months, an open season of about three months being allowed in the autumn. In 1918 this migratory bird law was replaced by the bird treaty with Canada. This grants the same sort of protection provided by the migratory bird law, but it is more satisfactory and comprehensive.

Another thing the government has been doing to protect birds has been to set aside bird reservations, where birds receive complete protection at all times. The first reservation was set aside in 1903 . Since that time others have been added till there were sixty-nine in I9I5.

Bird clubs. Other agencies which have been active in protecting birds are the bird clubs which have been formed in various parts of the country. At the present time there are several hundred of these with adult membership, besides many children's clubs. The best known of these clubs is the Meriden Bird.Club, in New Hampshire. A large per cent of the population of this little village are members of this club. Special pains have been taken to attract and to protect birds here both in summer and in winter, with the result that many birds are found here. The English sparrow has been completely driven away from this village. A special bird sanctuary of thirty-two acres has been set aside, and special efforts are made to attract the birds there.

Other similar clubs have been formed in various parts of the country. Besides the Junior Audubon classes, to which reference has been made, there is another bird club composed chiefly of children, known as the Liberty Bell Bird Club. This has a membership of more than 700,000. All the bird clubs of this country have a total membership of about one million.

What remains to be done. The work now being done by these various protective agencies should be continued and 
progress should be made along other lines. Perhaps the chief needs are the enforcement of the existing laws, further protection of game birds from sportsmen by more stringent laws, shortening the open season, and reducing the number of species that may be shot. To protect our song birds, steps should be taken to control the cat and the English sparrow. In the cold northern states birds may be fed in winter. Every person can do something to help protect the birds.

\section{Community Project 6}

Purpose. To see what the class can do to help protect the valuable birds found in the locality.

Directions. I. Form a bird club. One way to protect birds is to form a bird club. It may be a club composed of just the members of the class or the club may be open to any one in the school or in the community. One of the best ways is to organize an Audubon Club. Write to the National Association of Audubon Societies, 1974 Broadway, New York City, for particulars. Good suggestions on forming bird clubs are found in the last chapter of Baynes' Wild Bird Guests, published by E. P. Dutton Co., New York City. For suggestions as to what may be done by the club, see Chapter 17, in Trafton's Bird Friends, published by Houghton Mifflin Co.

2. Build bird houses to put up in the city parks. See the official who has charge of the parks and secure permission to put up bird houses in the parks. The class may divide itself into four committees: one to look after the building of houses for small birds like the wren; a second to look after houses for medium-sized birds like the bluebird; a third to look after houses for large birds like the flicker; and a fourth committee to look after building open houses for birds like the robin and phœbe. Care should be taken that the houses are put up in the most desirable locations, as far as possible in the open.

3. Feed the winter birds. During the winter, many birds like the bobwhite perish for lack of food. Provide food in the parks and at feeding stations in the country. The girls in the 
class may help in securing the foods and the boys may distribute it. Read pages 129-136 in Baynes' Wild Bird Guests for suggestions.

\section{SUPPLEMENTARY QUESTIONS FOR CLASS DISCUSSION}

I. In which way do you think birds do more good, in eating weed seeds or in eating injurious insects?

2. What can you say regarding the amount of food that birds eat?

3. In what ways may some birds be harmful?

4. Which is greater, the good or harm done by hawks and owls?

5. What are the chief enemies of song birds?

6. In what ways is man an enemy of the birds?

7. What can be done to protect birds from the English sparrow?

8. What can be done to protect birds from the cat?

9. What is the National Association of Audubon Societies doing to protect birds?

I0. What is the national government doing to protect birds?

II. What can you do to protect birds?

12. Look up the laws of your state regarding both the song and the game birds.

13. Find out what organizations in your locality and state are interested in bird protection. What are they doing?

\section{REFERENCES}

Baynes, Wild Bird Guests, E. P. Dutton Co., New York City. Trafton, Bird Friends, Houghton Mifflin Co., Boston. 


\section{CHAPTER XXX}

\section{SHADE TREES AND FORESTS}

I. What care should be given the shade trees of your town?

2. Why should our forests be conserved?

3. What is the government doing to conserve our forests?

Kinds of shade trees. Shade trees are essential to make the streets of a town attractive. A town without trees is a barren-looking place. In the selection of trees for street planting those species should be selected which are longlived. Among the best trees for this purpose are the American elm, sugar maple, linden, red oak, sycamore, hackberry, Norway maple, and red maple. These should be planted at such distances that they will not be crowded when mature. This distance varies from thirty feet for trees like the catalpa to fifty feet for the white elm. The mistake is often made of planting the trees too close together. In order to get quicker results, temporary plantings of rapid-growing trees, such as box elder and white maple, may be made between the long-lived trees. When these rapid-growing trees have reached such a height as to interfere with the other trees, they should be cut down.

Trees are attractive in the winter as well as in the summer. At this time the framework is more easily seen than when the foliage is on the tree. Many trees are ornamental on account of the beauty of their branches. A close study of the twigs shows conspicuous markings by means of which 
the trees can be identified as easily as by their leaves in the summer.

Planting the tree. Trees may be transplanted either in the spring or fall, except in the extreme northern sections,

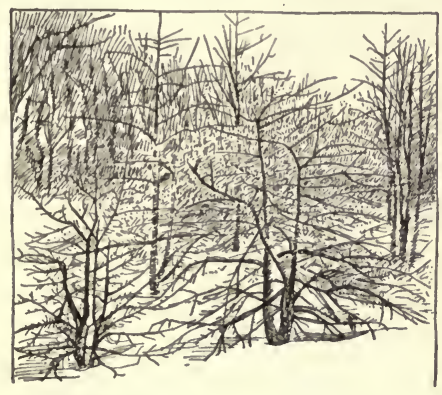

Sour Gum.

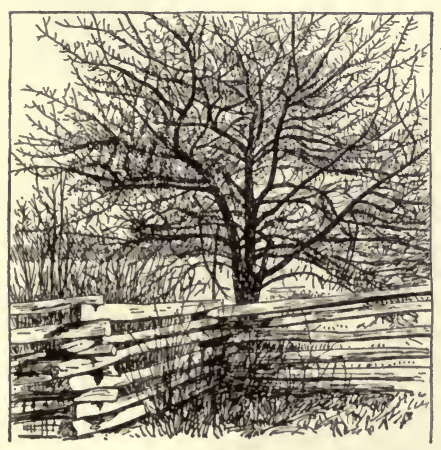

Wild plum.

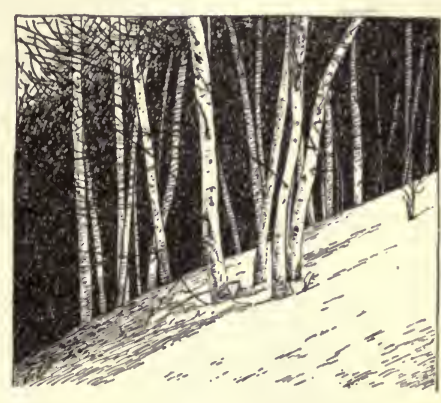

White birch.

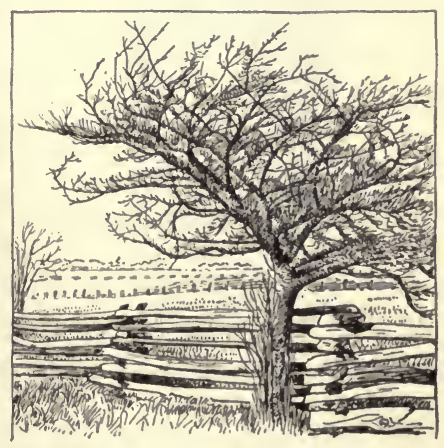

Wild thorn-apple.

FIG. 186. - Trees in winter, showing the beauty and variety of their branches.

where it is safer to plant in the spring. One of the chief things to consider in transplanting a tree is to reduce the amount of water given off by the leaf to the point where the roots can supply the amount lost by the leaves. When a tree is dug up in the nursery or woods, a part of the root 
system is left in the ground, and enough of the branches should be trimmed off to correspond with this loss of roots.

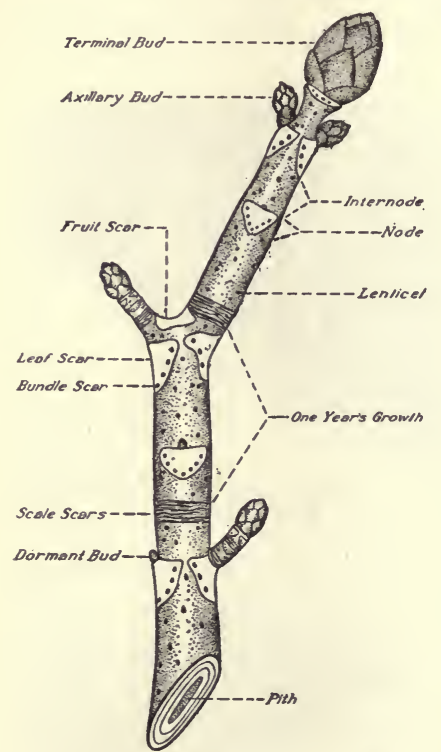

Fig. 187. - Twig of horse-chestnut.

It is safer to trim off too much than too little. A severe pruning is always safest.

It is important that the hole for the tree should be dug large. Many people err in making the hole too small. It should be dug both deep and broad so as to be larger than the root expanse. The purpose of this is to give the newly formed roots contact with a soft, freshly dug soil. The tree should be set a little deeper than it stood in the nursery. When filling the hole the soil should be trampled down firmly to make sure that the soil comes in contact with the roots. At the surface a layer of loose soil should be left for a mulch.

To protect the tree from mechanical injuries, it should be surrounded by a guard. A very effective one may be made of wire cloth with a one-inch mesh. This should be about six feet high and twenty inches wide so as to encircle the tree.

Care of shade trees. Pruning. During the

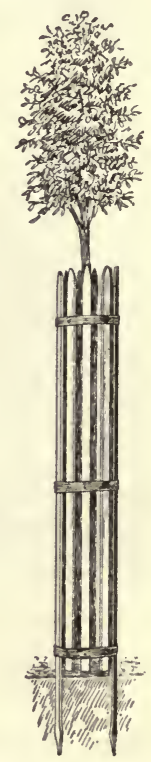

Fig. I8̌8.- - Lath tree guard. tree's growth some pruning may be necessary to preserve the symmetry of the tree or for other reasons. In cutting 
off a branch two things should be kept in mind; first, to cut in such a way that the branch will not split off a piece from the main stem; and second, to leave the wound favorable for healing. To prevent splitting, the limb should first be sawed half way through from the under side about six inches from the main stem, and then cut halfway through from the upper side about seven inches from the main stem.

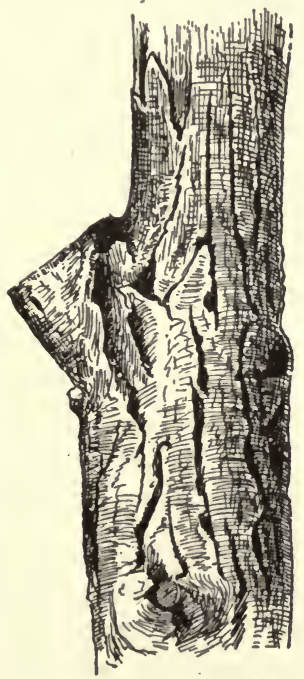

FIG. I89. - The wrong way to cut off a branch.

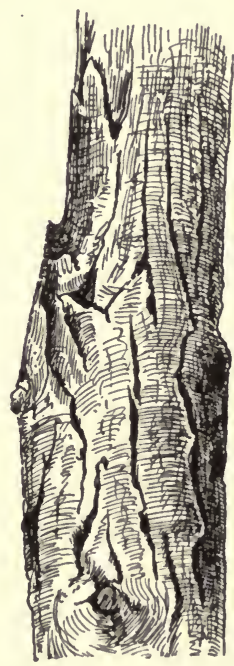

FIG. Igo. - The right way to cut off a branch.

This allows the branch to drop off. The remaining stub should then be cut off. This final cut should be made parallel to the main stem and close to it, instead of at right angles to the branch that is being cut, as is so often done.

If a stub is left it hinders the healing of the wound and offers opportunity for disease spores to enter. These spores grow and there forms a branching root-like mass which absorbs food from the tree and thus injures it. The large fruiting bodies of these fungi are often seen projecting 
from wounds in trees. The cut should be treated, unless it is one of a small branch two inches or less, with coal tar or paint, the tar being preferable. If the wounds are not thus treated, the wood cracks and furnishes a resting place for the spores of disease-producing fungi. In the case of large wounds this treatment should be renewed every two or three years. If the proper care has been given, in the course of a few years the wound will be covered by the growth of the bark around it.

Tree surgery. It frequently happens that. large cavities appear in some part of the tree and threaten the existence of the tree. Tree surgery is the name given to the methods now used to treat these cavities. The principles involved are - very similar to those underlying the filling of teeth. First, all decayed and diseased wood must be removed from the cavity. This is done by means of special chisels made for the purpose. Second, the cut surfaces are sterilized in order to kill any germs of disease or decay that may be present. This is done by painting with creosote. Third, the cut surfaces are waterproofed by painting with coal tar. Fourth, the cavities are filled with cement. In large cavities the cement is put in by sections separated by tar paper, to prevent the cracking of the cement by the bending of the tree in the wind. The edge of the cement is shaped to meet the wood so that it stands at the level of the cambium layer, which grows out over the cement and in time may cover it completely.

Some trees bear large branches at such angles that there is danger of their splitting down at the crotch. These may be guyed by means of bolts and chains. Holes are bored through the branches and the bolts inserted. If the branches are near together, one bolt may pass through both limbs. If too far apart for this, a bolt with a hook is passed through each branch and these hooks connected by a chain. The method sometimes used of passing bands of iron or wires around the branch girdles it and injures the tree. 
Miscellaneous injuries. Shade trees are subject to injury from a number of causes due largely to man's carelessness. Chief among these are gas escaping from the mains, the regrading of streets, the hitching of horses to trees, and the trimming of trees to make way for telephone and electric wires. Sometimes whole rows of trees may slowly die because the gas escapes from the pipes and reaches the roots. This may be avoided by requiring the gas company to lay pipes that do not leak. In grading streets oftentimes trees are cut down which could be saved by a little care. If the street is being cut down, the sidewalk may usually be run a little to one side of the tree and the dirt left as a mound around the tree. If the street is being filled in, a well of bricks may be built around the tree to prevent the dirt from filling up the space. When electric and telephone wires are being strung, the tops of trees are often cut out, leaving the tree unsymmetrical and disfigured. Every city and town should have ordinances protecting its shade trees from these and other injuries.

Insect enemies. Trees are subject to injury from a great variety of insects, which may attack every part of the tree. One group of insects, like the elm beetle and tussock moth, feed on the leaves, another group, called borers, gnaw their way into the bark and wood, destroying the cambium layer; others, like the scales, suck the sap from the leaves and other soft parts of the tree. Some insects injure the roots and some the flower and fruit. These insects may attack the trees in such numbers that serious harm is done in a short time, or the harm may be extended over several years, the trees gradually becoming weakened, sometimes eventually dying, and in other cases living for many years in this sickly condition. Many of these insects may be controlled by spraying. For biting insects, like the elm beetle, a poison such as Paris green or lead arsenate is sprayed on the leaves, and the insects are killed by eating the poisoned leaves. For suck- 
ing insects, a poison, such as kerosene emulsion, is sprayed directly on the insect, killing it by contact or by clogging its breathing tubes. The boring insects are very difficult to control, but if not present in large numbers, they may be cut out by a knife or killed by means of a wire. Sometimes insects may be prevented from reaching the foliage by wrapping bands of sticky material around the trunk of the tree.

\section{Field Exercise it}

Purpose. To learn what shade trees are growing in your town and if they are properly cared for.

Directions. I. One purpose of the field trip may be to identify the shade trees growing in the town. For this purpose the following points may be observed regarding each tree:

$A$. Character of bark as to color and roughness.

$B$. Method of branching.

C. Leaves.

$a$. Kind - simple or compound.

$b$. Arrangement - alternate or opposite.

c. Margin - entire, toothed, or lobed.

$d$. Drawing of leaf.

D. Flowers.

E. Fruit.

$F$. Chief characters by which identified.

2. Observe the trees to see if they are being properly cared for. Have the limbs been cut off correctly in pruning? Are there any wounds that need care to keep out spores of diseaseforming plants? Are there any broken branches that need pruning? Are any fungi found growing on the trees? Are insects doing any serious damage? Are trees being injured because horses are hitched to them?

3. If there is opportunity for planting trees around the school grounds, the class may plan to plant some on Arbor Day. 


\section{School Project 9}

Purpose. To make an exhibit of leaves of trees, to which you may invite your friends.

Directions. I. In connection with your studies of trees, it will be interesting for the class to prepare a special exhibit of tree leaves to which you may invite your parents and friends. This may be made a very pleasant social occasion. The class may be divided into about ten groups, each of which is to collect leaves of a certain family of trees, such as the following: the maples, the elms, the oaks, the birches, the willows, the poplars, the ashes, the nut trees, the locusts, and a miscellaneous group to include any other trees not mentioned. Each group will try to get all the different kinds of trees in his family found growing in the locality.

2. In order to press the leaves, put them between the folds of newspapers, place a board on top of the pile, and on the board put some weight, such as books or stones. Allow them to remain for about two weeks. In order to mount them, secure some plain, white paper and fasten the leaves to this by means of strips of gummed paper. When possible, collect the fruit as well as the leaves. These mounts may be placed around the walls of the room.

3. If these collections are made in the late autumn, they may be made more attractive by securing colored leaves.

4. In case any questions may be asked at the exhibit about the tree, look up the interesting facts about your trees, so that you will be ready to answer questions that may be asked.

Conservation of forests. When the white man first settled this country, he found the forests a barrier to his progress. He was obliged to cut down the trees in order to raise the crops that would keep him and his family from famine. Behind the shelter of the trees lurked the Indian, ready to massacre his family when a favorable opportunity appeared. As he looked westward, the long line of unbroken forest impeded his march in that direction, and we may well understand that it was with great joy that the early settlers saw 
the forests give way to fields of grain and saw the boundary of the unbroken forest gradually recede westward.

Conditions of forests to-day. In later years as the market value of trees for their different products attracted attention, the commercial spirit took control of the forests and there resulted a reckless devastation of forests carried on by private individuals without any effective effort on the part of the government to stop or control the waste. As' a result our commercial forests to-day are restricted to five areas: northern New England; the northern portion of Michigan, Minnesota, and Wisconsin; the southern states; a section along the Rocky Mountains; and a section along the Pacific Coast in Oregon and Washington. A bulletin published by the National Forest Service in 1907 says: "This much is true beyond doubt, that we are dangerously near a hardwood famine and have made no provision against it."

This bulletin estimates that there were four hundred billion feet of hardwood standing and that the country was using hardwood at the rate of twenty-five billions annually. This would furnish a supply for only sixteen years, not considering the amount of annual growth. This diminishing supply of hardwoods has been well reflected in the advancing prices. Between I 898 and 1907 the price of white oak rose from $\$ 55$ to $\$ 80$; of yellow poplar from $\$ 3$ I to $\$ 53$; and of hard maple from $\$ 20$ to $\$ 32$; or an increase of from 50 to 60 per cent in ten years.

Another bulletin published by the Forest Service estimates that the annual consumption of all kinds of wood in the United States is three times the annual growth. At this rate it is estimated that the supply of virgin forests will be exhausted in thirty or forty years, and then the country must depend on the second growth of timber for its supplies. In spite of the substitutes that are being used for wood in building, the use of wood is constantly increasing, so that more wood per capita is now being used than ever before in this country. 
Uses of forests. Forests serve three great purposes: first, they act as a protective covering on the area on which they are growing; second, as a source of wood; and third, as a source of beauty and pleasure. The first kind of forest is called the protective forest; the second, the supply forest; and the third, the recreation forest. The first and third uses are served while the trees are still standing, the second use after they are cut down. By proper management, a forest may be made to serve all three of these purposes.

The value of forests as a source of wood is so evident that it needs very little explanation. To appreciate this, one has but to think of the manifold uses to which wood is put every day.

\section{LABORATORY ExERCISE 37}

Purpose. To learn to tell the cuts of wood found in chairs and tables.

Materials. Collections of small samples of wood, showing different sections. Pieces may be obtained from a carpenter's shop, or small branches may be collected from trees. Pieces from one to two inches in diameter and four inches long make satisfactory samples.

Directions. A. Examine specimens of wood until you find each of the following:

I. Sapwood and heartwood. How do these two differ?

2. Annual rings of growth. What differences do you find among the different rings in the same piece of wood? How old is the piece?

3. Spring wood and summer wood in the rings. How do these differ?

4. The pores. Find:

$a$. A ring-porous wood, in which the pores in the spring wood are larger and more numerous than the pores in the summer wood.

b. A diffuse-porous wood, in which the pores are small and equally distributed through all the ring.

c. A non-porous wood, in which pores are absent. 
5. Pith rays.

6. Knots.

$B$. The appearance of woods depends on the way in which they are cut.

I. A cut made at right angles to the length is called a transverse section.

2. A cut made lengthwise, at about right angles with the rings, that is, nearly parallel with the pith rays, is called radial, or quarter-sawed.

3. A cut made tangent to the rings, that is, at right angles with the pith rays, is called tangent or bastard.

Find three pieces of wood, one cut in each of these ways, and make three labeled drawings to show whatever features mentioned under $A$ may be present in each section.

$C$. Make a drawing of a piece of the desk about three inches square, and label the parts that show. In which of the three ways was it cut? Look at a number of samples of wood in chairs, tables, etc., and determine the cut.

Forests as protective covers. As a protective cover, the forest serves two important purposes: first, it regulates the flow of streams; and second, it prevents erosion of the hillsides. On the forest floor is a thick layer of black humus, composed of the decaying leaves and twigs which fall every year to the ground. This humus covers the soil like a blanket and exerts a very important influence through its effect in controlling the water supply of streams. When rain falls some evaporates at once and goes back into the air; some runs off on the surface and quickly gathers into streams; the rest soaks slowly down into the soil and gradually comes out again through springs and streams and through evaporation from the leaves of plants. The humus and mossy vegetation act as a sponge. They absorb a large amount of water and give it out again gradually during the dry spells between rains. Thus they tend to prevent floods just after a rain and to prevent the drying up of the streams during the dry weather. Forests tend, therefore, to give streams 


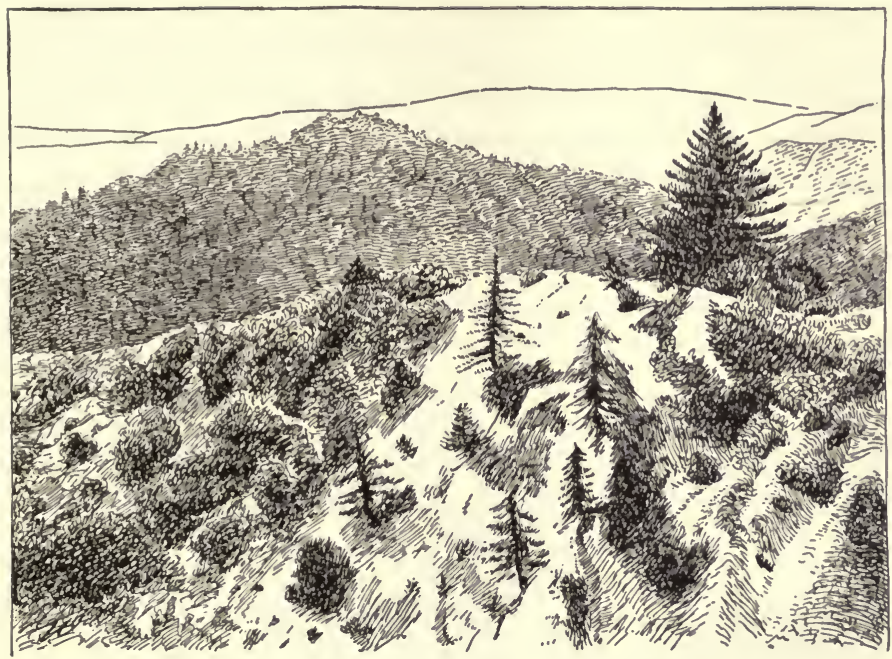

FIG. I91. - Forested watershed in the San Bernardino Mountains, California.

a regular, even flow during all the season, a matter that exerts important influences on our daily life, as we shall see in the paragraphs that follow.

Streams for water power. Coal now supplies us with most of the power to run our factories, to furnish our electricity, and to run our locomotives and other machines so essential in our life. But the supply of coal will some time be exhausted; then man must find some other source of power. Our streams will furnish a large part of that power, and the force of the flow may be used over and over at different localities on the stream. In order that the best use may be made of these streams, it is necessary that there should be an even flow throughout the whole year, so that machines may be run all the time and not be obliged to stop because the river is low. It is very important that the people look forward to the time when they must depend more upon water power. They should not allow private capital to 
secure control and monopoly of this power. Immediate steps should be taken by governments, both national and local, to secure supervision and control of this great resource.

Streams for navigation. As our country continues to grow, additional methods of transportation will be needed, and the navigable rivers furnish one important means. Here, too,

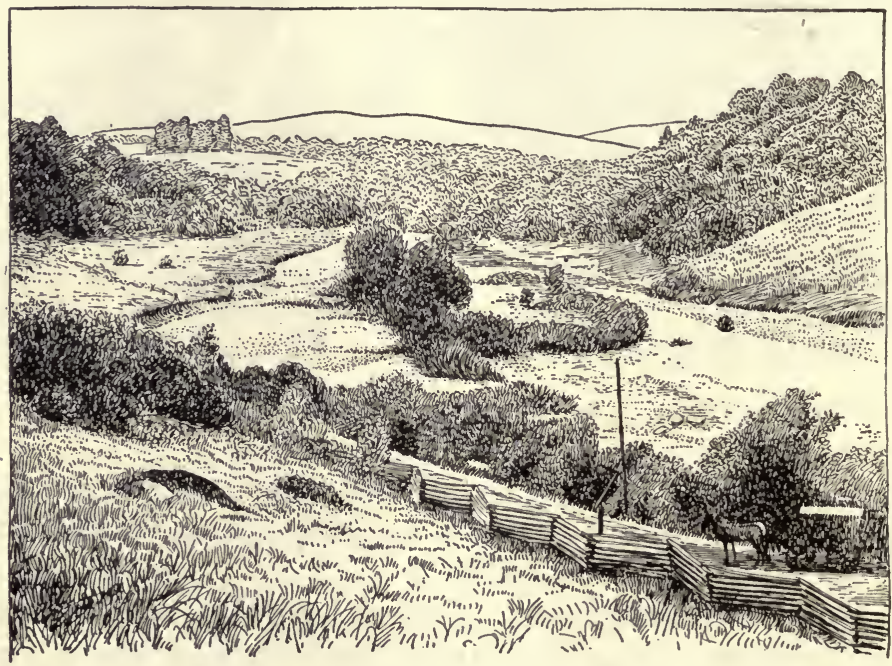

FIG. 192. - Destruction of farm land by flood. North Carolina.

it is necessary that there should be an even flow of water throughout the year; so that the river shall not be so flooded in spring nor become so low in summer that it is not navigable. It is also essential that the channel shall not become filled up with soil brought down from the hills.

Streams for irrigation. In the western part of our country are vast areas with rich soil, capable of producing the best of crops and thus supporting a large population, which nevertheless are barren at present on account of lack of sufficient rainfall. In many cases it is possible to irrigate the land by 
bringing water from neighboring rivers. The United States government is undertaking large enterprises in this connection. It is of special importance here that as much of the water as possible be available during the dry seasons. If no rains fall during this season, it is essential that the rain which has fallen earlier in the season shall be stored up and retained as long as possible on the mountain slopes so as to feed the streams constantly during the dry season. In all these cases forests are essential to regulating the water supply of the streams.

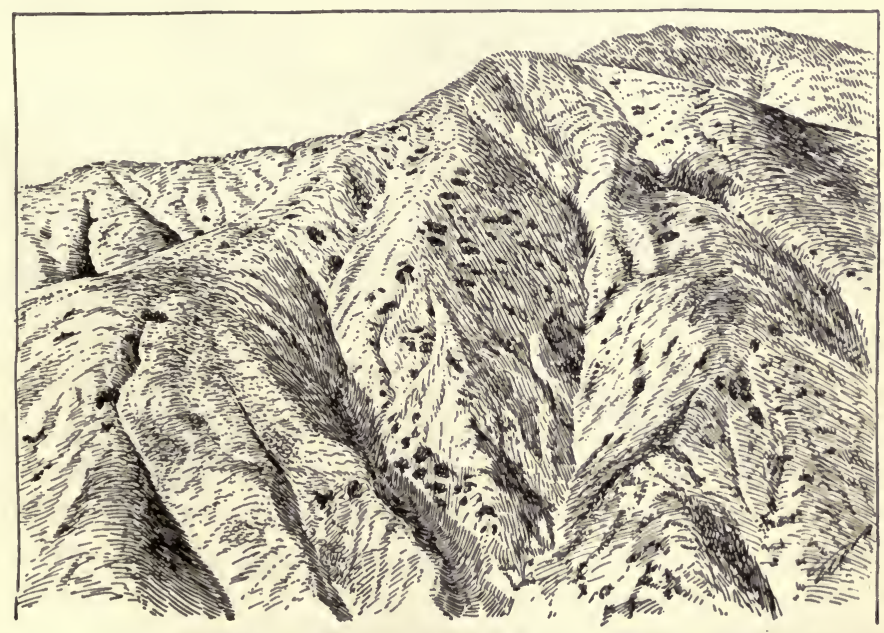

Fig. 193. - Unforested watershed in the San Bernardino Mountains, California.

Prevention of soil erosion. Another important use of the forest is to prevent soil erosion. The mulch prevents the rapid run-off which causes erosion, and the roots help to keep the soil in place. Where forests on hillsides have been removed, the floods wash down the soil, carrying it into the streams, thus interfering with navigation and sometimes spoiling the farms of the lowlands by deposits of gravel and sand. Sometimes these floods cause great injury to 
both property and life. On the steep hillsides, the soil may be washed away down to the solid rock, thus making it impossible for forests to grow there again.

In almost every country there are examples of this kind where millions of dollars' worth of property have been destroyed by floods owing to the careless removal of forests. In our own country, in the state of North Carolina, land which was formerly worth $\$ 125$ an acre is now useless, owing

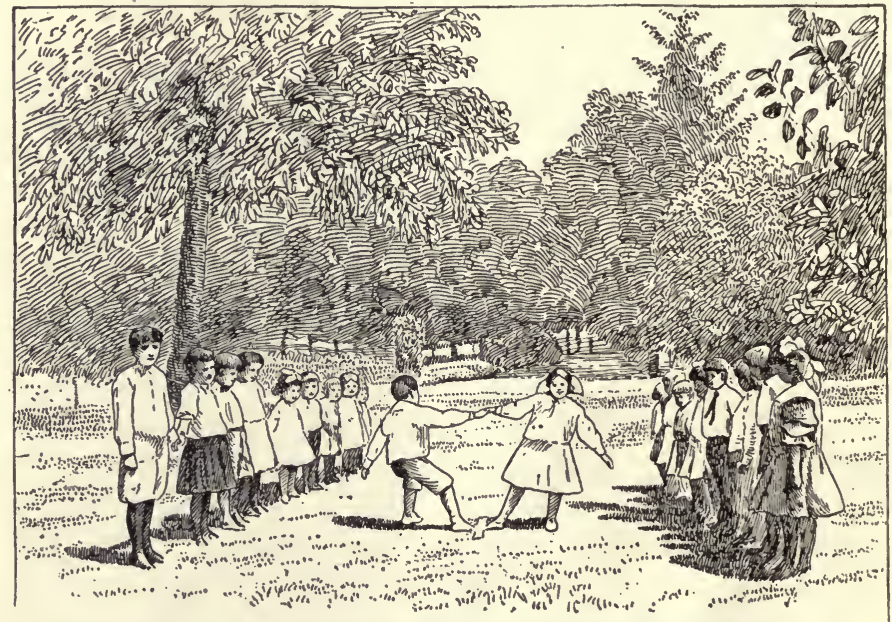

Fig. I94. - A park, a place where people may enjoy the outdoors.

to gullies and deposits of gravel due to floods. In the San Bernardino Mountains in California, torrents have been able to carry stones and sand into the orange groves of the San Gabriel valley, because of the destruction of forests on the mountains by fires and grazing.

Recreation forests. The recreation forest serves an important purpose as a source of pleasure. Many travelers and campers visit the national parks and forests each summer as a means of recreation, and the smaller parks found in cities and towns are of great value to the people living near. 
It is estimated that during the summer of $1917,3,000,000$ persons entered the national forests for some kind of recreation. The chief kinds of recreation are fishing, camping, hiking, packing, automobiling, and picnicking. Hundreds of miles of trails have been built for hikers and pack animals, and many miles of roadway for automobiles and wagons. To meet the needs of the tourists, the Forest Service has laid out and equipped a large number of camps along these trails.

\section{Community Project 7}

Purpose. To learn the value of your city parks.

Directions. I. Visit a park and make a list of the trees, shrubs, vines, and flowers growing there.

2. Find information regarding your city parks, on the following points: number and area, money spent each year on them, care given to them, improvements made, uses made of the parks, number of people using them.

National forests. Realizing the importance of conserving our forests, the national government began, during the administration of President Harrison, to set aside from the lands which it owned certain areas to be kept as national forests. Since that time, others have been added, till today there are $15 \mathrm{I}$ national forests, comprising an area of I $56,000,000$ acres, or about one fifth of the forests in the United States. These are located chiefly in the western states, although national forests have recently been set aside in the White Mountains and in the Appalachian Mountains. These forests generally constitute lands which are not adapted for purposes of agriculture and can serve their best purpose by being allowed to remain in forests.

It is the intention of the government to make the forests of the greatest use to all concerned. The forests are managed in such a way as to insure their permanency and only the 
fully matured trees are cut, the smaller trees being allowed to grow till ready to be cut. When sections of the forest lands are found which are adapted to agriculture these are given out as homesteads. In some forests cattle and sheep are allowed to graze. Campers and other pleasure seekers are encouraged to use the forests. Furthermore, opportunity is given here for game to increase. So that the purpose is not to withdraw the forests from use, as is sometimes erroneously thought, but to make them as useful as possible and to place them under scientific management.

The following figures suggest the extent to which they are being used. These forests are supplying annually fuel and fencing to the value of $\$ 196,000$ to 38 , ooo people living near. The receipts from the forests for the year ending June 30 , I9I 7 , were $\$ 3,45^{\circ}, 000$. The forests furnish opportunity for grazing to $\mathrm{I}, 500,000$ cattle and horses and to more than I 4,000,000 sheep. I I 75 towns and cities and 324 irrigation and power projects took their water from streams that had their headwaters in the national forests.

In the care of these national forests, scientific forestry is practiced. This consists essentially in three things: first, in cutting only the large, mature trees, leaving the others to grow; second, in providing seedlings and young trees to take the place of those being cut; and third, in protecting the forests from fires and other enemies.

The big trees. There has recently been set aside as a national park, an area in California that contains the famous big trees. These are the most marvelous trees in this country and perhaps in the world.

Some of the largest of these have received special names, such as General Sherman and General Grant. General Sherman, the largest of all, is 279.9 feet high and 36.5 feet in diameter. It is believed to be about 3500 years old. It was a seedling in the days of Moses. When Jesus was born, 
it was a youth of 1500 summers. Thousands of the trees now standing in the Sequoia National Park were growing during the time of Cæsar. Hundreds were flourishing while Babylon was in its prime. Several are older than the Pyramids of Egypt. Four thousand rings were counted on one prostrate tree. This tree probably sprouted while the tower of Babel was still standing. It was a large tree, two thousand years old, when David was born. It is believed by the best authorities that some of the trees now standing are five thousand years old. It is difficult to conceive that a single individual has lived that long.

State forests. The state governments are also beginning to set aside forests. Thirty states have a forestry department and twenty have trained foresters in charge of their work. These states have one hundred and forty-two forests with an area of three and a half million acres. New York State leads with I,600,000 acres; then comes Pennsylvania with nearly a million; Wisconsin with 400,000; Michigan with $23 \mathrm{I}, 000$ and other states with smaller forests. Fourteen states have set aside forests.

Some towns are beginning to set aside municipal forests. There are at the present time ninety-seven municipal forests situated in thirteen states. More than half of these, fifty-six, are situated in Massachusetts.

United States Forest Service. In connection with the development of the system of national forests, there has grown up as a part of the government, the United States Forest Service, a part of the Department of Agriculture, whose chief. duty is to look after the protection and use of the national forests. Some of the work of the service is done in Washington and some in the national forests.

The direct care of the forest is intrusted to the ranger. His most important duty is to protect the district in his charge against fires. During certain seasons he patrols his district by means of trails and bridges for the purpose 
of watching for fires. Another important duty of the ranger is to look after the sale of timber and to mark the trees that are to be cut. The ranger also supervises the use of the forest for the grazing of cattle and sheep. The guards are the assistants of the rangers and may be called upon to do the same kind of work.

The Forest Service has been an efficient agent in awakening the people of the country to the need of conserving our forests. Since 1900 , it has issued three hundred and seventy publications with a total circulation of almost twelve million copies. All together the Forest Service now numbers more than three thousand members.

Enemies of the forest. Fires. Fires are the most destructive enemy of the forests, the annual amount of damage being about fifty million dollars. Each year twenty million acres of forest land, an area nearly four times the size of Massachusetts, is burned over. It is estimated that the amount of timber destroyed by fire is equal to that cut and used. Some fires have become historic on account of the amount of damage done. The Hinckley fire in Minnesota in 1894 destroyed nine towns, burned twenty-five million dollars' worth of property, and killed six hundred people.

The chief harm done by fires is in the destruction of standing timber. Indirectly, harm is also done to those trees which are only partly destroyed by fire, for they are easily blown over by winds or fall easy victims to the attacks of insects and wood-destroying fungi. Another great injury is the destruction of seedlings and young trees on which the future of the forests depends. Sometimes enough of the humus is burned so as to interfere with the work of the forest in controlling the run-off and preventing floods.

Kinds of fires. Fires are frequently classified into surface, crown, and ground fires according to the manner in which they burn. Surface fires run along the ground, consuming only the leaves and twigs found there. The 


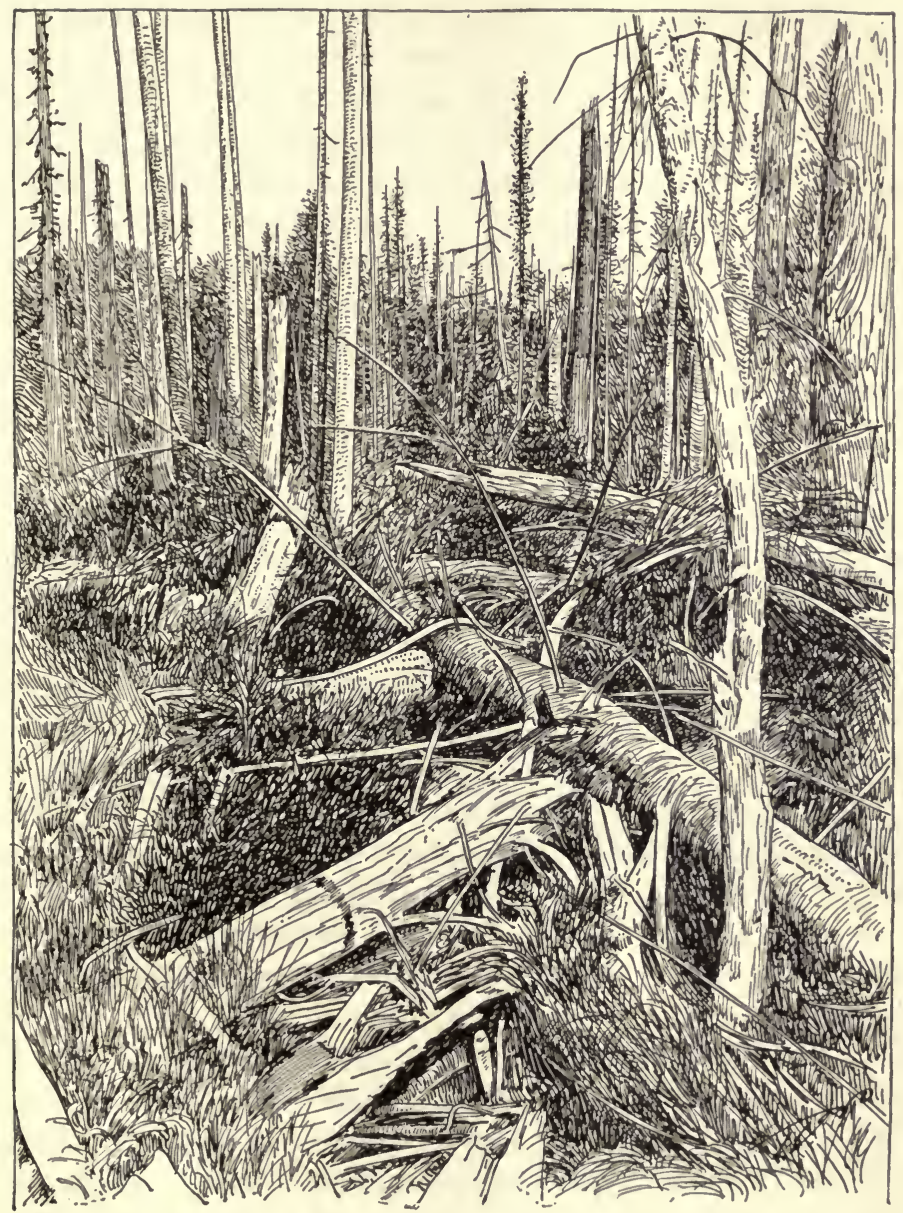

FIG. I95. - Fallen and standing fire-killed timber, Priest River Reserve, Idaho.

crown fires run up into the crowns of the trees and burn the leaves and small branches. These occur only in the evergreen forests. Ground fires burn in the duff below the surface and may burn for weeks and even months without 
showing any signs of life and then may break out in an unexpected place even after a heavy rain.

Causes of fires. The most common cause of forest fires is the railroad locomotive which sends out sparks that readily ignite the dry leaves and grass along the railroad. Other forest fires are caused by burning brush, by lightning, by fires which are started purposely to improve grazing or for other purposes, and by careless campers who fail to completely extinguish a camp fire when leaving it.

Prevention and control of fires. Most fires are due to carelessness and can be prevented if proper precautions are taken. In lumbering, proper disposal should be made of the small branches either by piling and burning them or by lopping and scattering the brush, which soon rots. Spark arresters may be placed on locomotives to prevent the sparks from being thrown out, or oil or electricity may be used in place of coal. Fire lanes from which inflammable material has been cleared may be constructed to prevent the spread of fires. In the national forests trails are made so that the rangers may patrol the forests; lookout points and observation towers are constructed, connected by telephone with the nearest town.

- Putting out fires. Small fires may be controlled by throwing dirt on them. In fighting ground fires, a trench must be dug through the forest floor down to the soil. Severe fires may be controlled by back-firing. A second fire is started some distance ahead and allowed to burn against the wind to meet the chief fire. Great care must be taken that the back-fire itself does not spread. This is prevented by starting it to the windward of a road or fire line, or other barrier which the fire can be kept from crossing.

Destructive lumbering. One of the chief causes for the decrease of our forests has been the wasteful method of lumbering. The general policy followed has been to cut down all the growth at one time, securing just one crop and making 
no plans for future returns. Usually the piles of brush left have been a prolific means for the spread of forest fires. Sometimes this short-sighted policy has been hastened by the fear of possible loss through fires and by high taxes which rendered it unprofitable to hold the land for more than one crop.

Grazing. Grazing may do injury to the forests if not properly regulated. The sheep trample the young growth

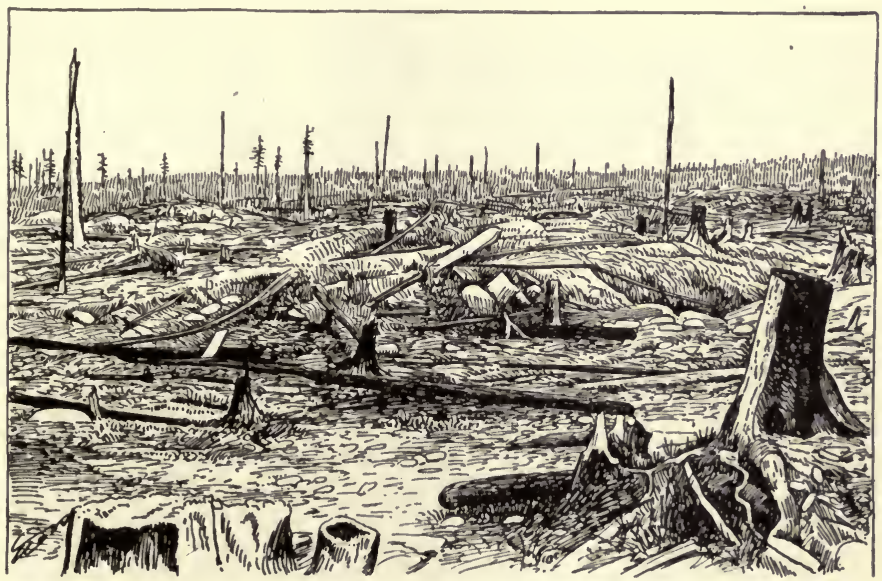

Fig. 196. - Destructive lumbering. The slash enabled fire to complete the ruin.

under foot and destroy small trees by browsing on the young shoots. Sheep may also pulverize the forest floor, allowing it to be washed away by storms. This matter is being carefully regulated in the national forests, and less harm is done than formerly.

Insects. It has been estimated that insects cause an annual loss to trees in this country of one hundred million dollars. There are hundreds of species of insects found attacking the forest trees, but the greater amount of the damage is done by a comparatively small number of species. 
Some attack the living tree, some attack only the dead and dying trees, and others do harm to sawed lumber and wood products.

Conservation of forests. Conservation of forests simply means that the forests should be cared for in a scientific manner. By proper methods of forestry, it is possible to cut some of the trees and still leave enough for protective cover. In cutting trees it is not well to cut all in a certain

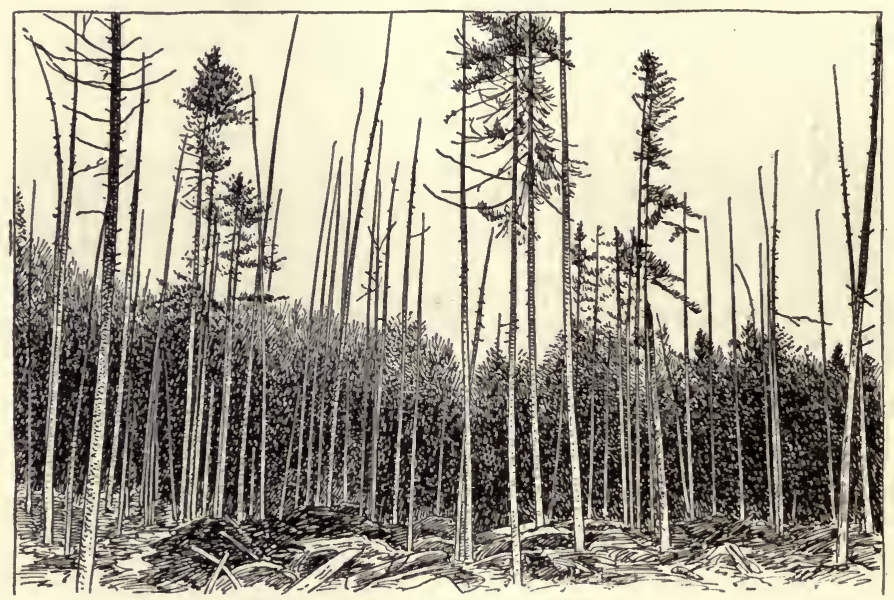

FIg. 197. - Larch trees killed by the larva of a small sowfly. Adirondack Mountains, New York.

area, but only a few of the largest should be cut each year, leaving the rest to serve their protective purpose. By leaving spaces where seeds may fall and germinate and seedlings grow, a supply of young trees is kept constantly growing to take the place of those which are being cut out. In this way a forest may be so managed as to give a constant supply of timber for centuries, unless it is overtaken by some calamity such as a fire or a ravage of insects.. Through proper care the forests still left may continue to furnish 
almost indefinitely the supply of timber needed. The great difficulty in the past has been the wasteful and unscientific methods used and the disregard for the future. Switzerland's forests have been properly cared for during the past centuries so that they are more efficient and valuable now than they were hundreds of years ago. We may attain the same condition in this country if the government will acquire a larger number of national forests and will regulate the

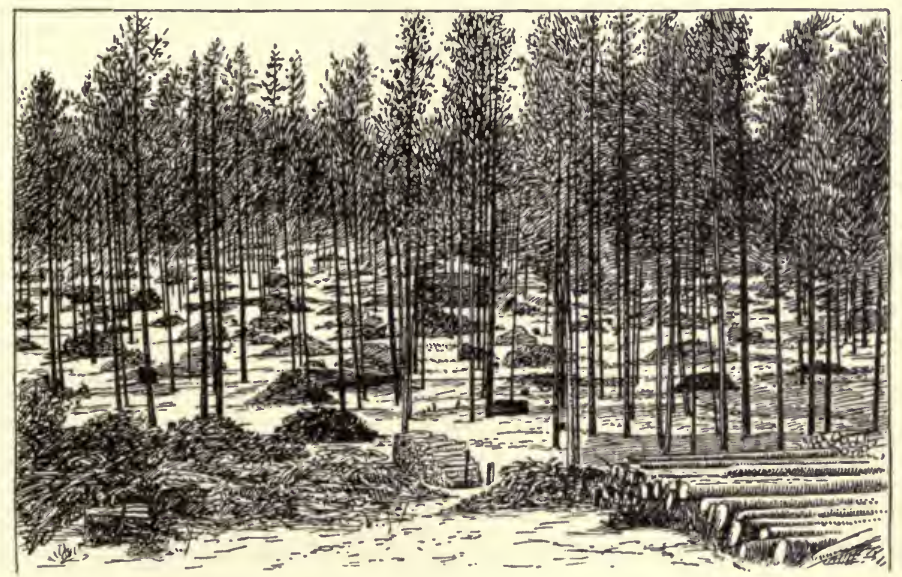

FIG. 198. - Conservative lumbering. Young growth saved, brush piled to prevent fire.

cutting in private forests as well. This is a matter of such concern to the general good as to require government supervision. The cutting of the forests does not concern merely the men owning the forests, but it concerns the welfare of the entire communities living near the streams which rise in the sections where these forests are situated. The government should make and enforce regulations which will stop the owners of these forests from treating their forests in such a way as to injure other people. 


\section{SUPPLEMENTARY QUESTIONS FOR CLASS DISCUSSION}

I. Which do you consider the most valuable type of forest: the protective, the supply, or the recreative? Why?

2. Why is it important that the flow of streams should be kept constant?

3. What harm results from removing forests?

4. What constitutes proper care of forests?

5. How may the forests be protected from their enemies?

\section{REFERENCES}

Going, Our Field and Forest Trees, A. C. McClurg Co., Chicago. Levison, Studies of Trees, J. Wiley and Sons, New York City. Peet, Practical Tree Repair, McBride Nast and Co., New York City.

Roth, A First Book of Forestry, Ginn and Co., Boston. 


\section{SECTION F \\ Protection from Weather}

\section{CHAPTER XXXI}

\section{THE UNITED STATES WEATHER BUREAU}

How is it possible to foretell the weather?

Use of weather forecasts. Value to fruit growers. In the springtime there is danger that the blossoms of fruit trees may be destroyed by late frosts. In some orchards arrangements are made for lighting fires quickly in order to save the orchards. When there is danger that a frost may occur, the United States Weather Bureau sends notice to the fruit growers. They then build fires and are thus able to save their crops by receiving this warning. Sometimes the value of the fruit thus saved in a single night in one state has been as high as $\$ 100,000$; and during a year throughout the whole country it has been as much as $\$ 3,000$,ooo. As we learned in Chapter XXII, a three-million-dollar fruit crop was saved in Colorado through a warning of approaching frost sent the fruit growers by the United States Weather Bureau. In the state of California alone, fruit valued at $\$ 14,000,000$ has been saved in a single year by warnings of cold waves issued by the Weather Bureau.

Protection of ships. Warnings of severe storms are sent to the leading ports on the oceans and Great Lakes. Ship owners are thus able to regulate the times of sailing of the 
boats; and in this way many dollars' worth of property and many lives are saved. A single storm warning has been known to keep in port vessels and cargoes valued at $\$ 30,000,000$.

Protection from floods. When floods are threatening on account of heavy rains, warnings are sent to the people living along the banks of rivers. In I9I2 the Weather Bureau sent warnings to the people living along the Mississippi River that there was to be a severe flood. As a result, the people living near the river were able to remove their cattle and other property and the freight at the wharves to a place of safety. It was estimated that property to the value of $\$ 6$ I, 000,000 was thus saved.

It is estimated that the total value of the property saved each year through the warnings issued by the Weather Bureau is $\$ 30,000,000$.

Besides the saving of lives and property thus effected, the weather forecasts made by the Bureau and printed in the daily papers are of some value to people in making their plans.

How is the Weather Bureau able to make these forecasts of weather so as to foretell frosts, storms, floods, and general weather conditions? This is done by means of the weather map. In order to understand the method of using it, we will look at the map shown in figure 199.

Description of weather map. Two sets of lines arranged in irregular curves are found on the map, the solid lines and the broken lines. The solid lines show the air pressure and are called isobars. They are marked in tenths of an inch. The line marked 30.2 means that all the places through which this passes have a pressure of 30.2 inches. These are made for every tenth of an inch. Two kinds of areas are found on the map, "high " and "low." This refers to the air pressure. In general a low area, called a cyclone, is accompanied by clouds, precipitation, and warmer temperatures. The 


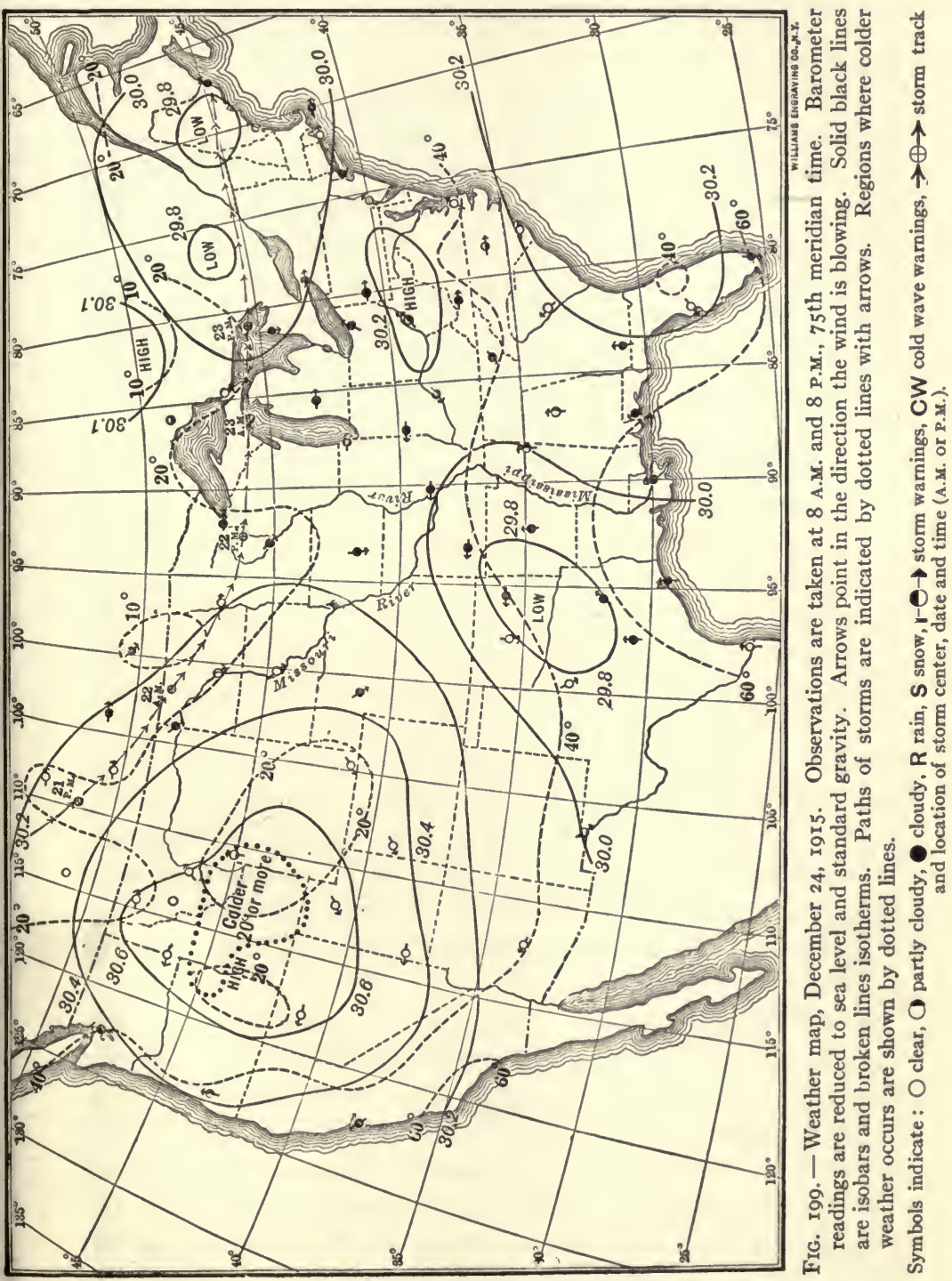


high areas are usually accompanied by clear weather and lower temperatures.

The broken lines are called isotherms and show places of equal temperatures. The line marked 40 degrees passes through all places with 40 degrees temperature. These are made for every ro degrees. Arrows are used to indicate the direction of the wind. These fly with the wind, just opposite to the way a weather vane points. For example, an arrow pointing like this $\longrightarrow$ means that the wind is blowing towards the east, and we call this a west wind because it blows from the west. The circles at the ends of the arrows indicate the state of weather. Their meanings are given in the explanation accompanying figure 199 .

On the complete maps shaded areas show precipitation of .or inch or more during the last 24 hours. A table at the lower right-hand corner gives the maximum and minimum temperatures, the wind velocity in miles per hour, and the precipitation in inches during the last 24 hours. In the lower left-hand corner are given the forecasts for the next day.

How figures are obtained. These facts regarding the weather are obtained daily from observers situated in about 200 stations in various parts of the United States and Canada. Each morning at eight o'clock these observers telegraph to Washington and to other leading cities the temperature, the air pressure, the precipitation, the direction and velocity of the wind, and the condition of the sky, whether clear or cloudy.

Weather instruments. In order to measure these conditions accurately instruments are used, the chief ones being the barometer, the thermometer, and the rain gauge.

Air pressure. The pressure of the air is measured by the barometer. The air that surrounds us has weight (as we have already seen in Chapter IV), although we do not ordinarily feel it. But when a strong wind is blowing, we get some idea of the reality of this weight. Some simple ex- 


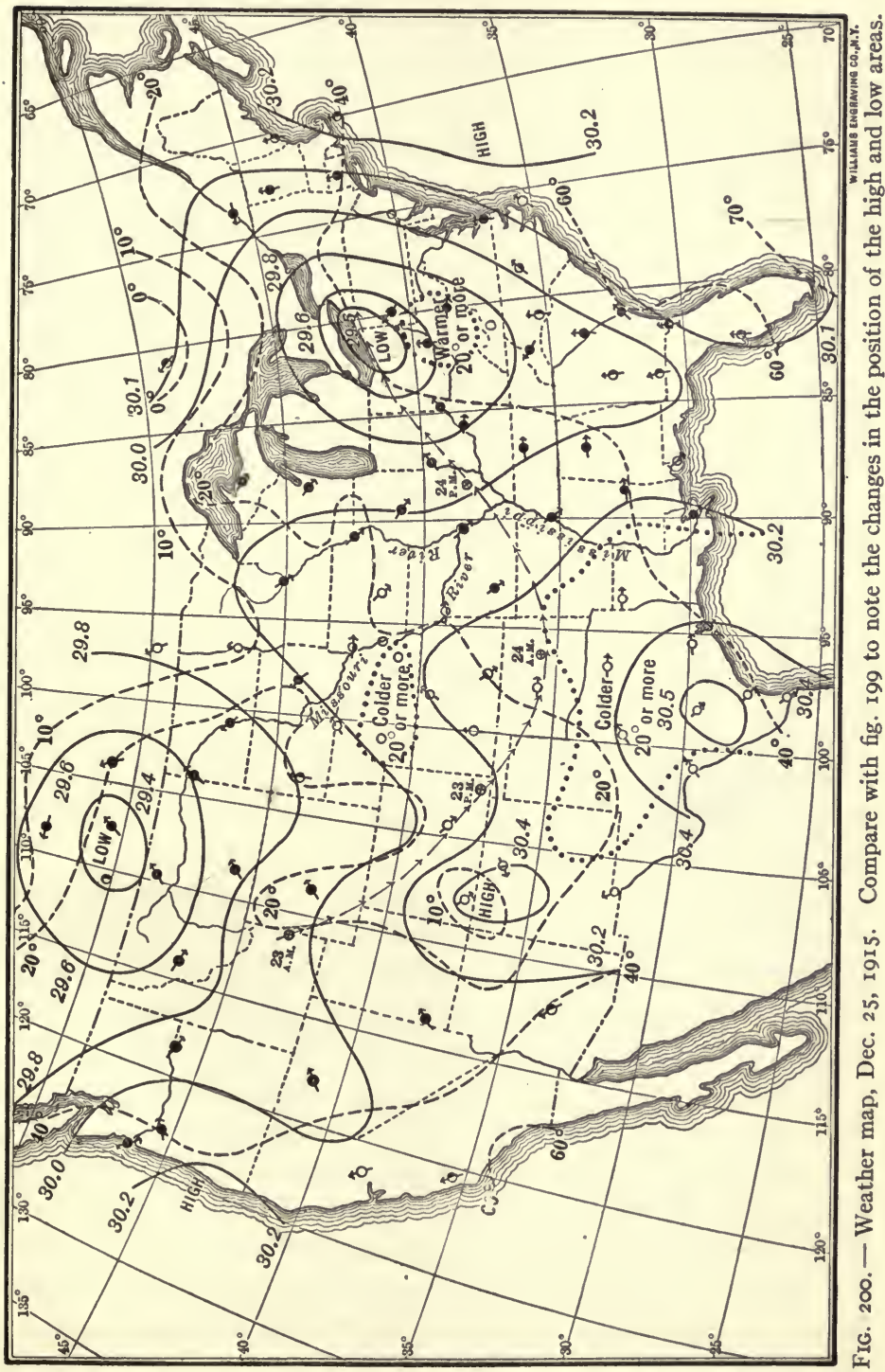


periments were performed in a previous chapter to show that air has weight. This fact has not been known for very many years.

Torricelli's experiment. Nearly three hundred years ago, a man named Torricelli first performed an experiment which showed that air exerts pressure. This experiment has become historic and has been performed many times since. We will perform it now because it will help us better to

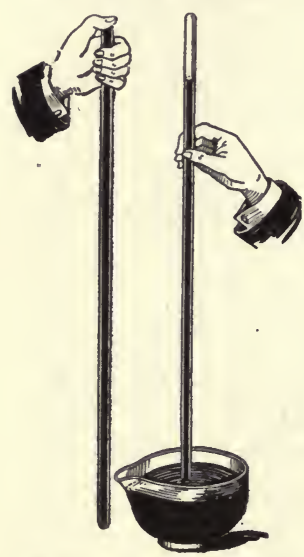

FIg. 20r. - Torricelli's experiment. understand the principle of the barometer by which air pressure is measured. We shall need a dish of mercury and a glass tube about three feet long, closed at one end. The tube is filled with quicksilver, the thumb placed over the end, and the tube inverted in the dish of mercury. The thumb is removed after the open end is under the surface of the mercury. The mercury in the tube falls about six inches and then stops. It is held up by the pressure of air exerted on the surface of the mercury.

The barometer. This shows the principle used in the construction of barometers. The height of mercury is a standard by which to measure the pressure of air. The weight of this column of mercury is just equal to the weight of a column of air of the same diameter and extending up as far as the air goes, which is fifty miles or so. So that a column of air fifty miles high is equal to the weight of a column of mercury about thirty inches high. Figure 202 shows an ordinary mercurial barometer. It is built on the principle of the apparatus used in Torricelli's experiment. The tube above the mercury contains a vacuum; there is no air there to prevent the mercury from moving up the tube. 
The pressure of the air is constantly changing. When the pressure becomes greater, the mercury in the tube rises; and when the pressure becomes less the mercury falls. Thus a change in the height of the mercury shows a change in the pressure of the air. This pressure is measured in terms of the height of the mercury column in inches. Thirty inches is the average pressure at sea level. This means that the air exerts a pressure of about fifteen pounds on every square inch on which it rests, or a pressure of about a ton on every square foot. The reason that buildings and other objects are not crushed by this weight is because the air pressure beneath and within hollow objects is equal to the pressure bearing down, and so the two balance.

Use for measuring heights. As one goes up a mountain or in a balloon, the amount of air above one becomes less and so bears down on the mercury of a barometer less heavily; there-

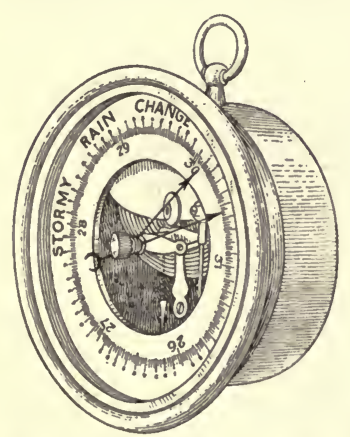

Fig. 203. - Aneroid barometer. fore the column of mercury falls. Because of this, the barometer can be used to determine heights of mountains and other elevations. The higher one goes, the lower the mercury Fig. 202. - A drops. For the first standard bamile the mercury drops

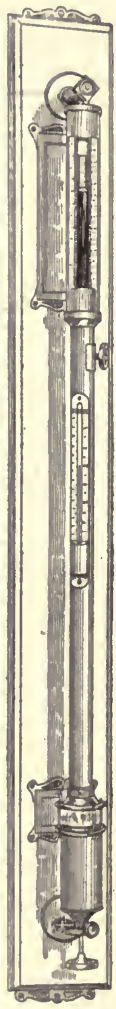
one inch for every nine hundred or thousand feet. At a height of two miles the mercury drops to twenty inches.

Aneroid barometer. As the mercurial barometer is awkward to carry, another form called the aneroid barometer 
is used to determine elevation; as shown in figure 203 , this looks something like a clock. The back is covered with a very thin diaphragm which is pressed down by the weight of the air. This is connected with a hand on the front which records the pressure.

\section{Demonstration 35}

Purpose. To find the height of a hill by means of a barometer.

Directions. Take the reading of the barometer at the top of the hill. Take it again at the bottom. Subtract these readings. The approximate height may be found by multiplying by ninety this difference expressed in tenths of an inch.

Barometer and weather predictions. The barometer is a very important instrument in making weather observations, because the air pressure is the most important factor in foretelling weather changes. In general a rising barometer indicates fair weather, while a falling barometer indicates stormy weather.

Thermometers. For measuring the prevailing temperature, the thermometer is used, as explained in Chapter I.

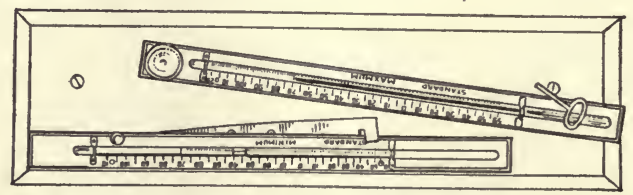

FIG. 204. - Minimum and maximum thermometers.

Besides this, maximum and minimum thermometers are used to record the highest and the lowest temperatures. These thermometers will register the highest and the lowest temperatures for the time they are left. They are usually set every day. The maximum thermometer is constructed so that some of the mercury remains at the highest point to which it is forced. The minimum thermometer is so constructed that a small index moves with the liquid and 
remains at the lowest point reached. Each of these can then be set again.

Rain gauge. In order to measure the amount of rain, a rain gauge is used (figure 205). This is so constructed that the area of the top of the funnel, which receives the rain, is ten times the area of the small tube in which it collects. This raises the level of the water ten times as high, and makes it easier to read. This is measured by means of a ruler and the result is divided by ten to get the true rainfall. In order to measure snow, a volume equal in area to the top of the funnel and as deep as the fall of snow is collected and melted, and the water is measured the same as the rain.

When the reports of the weather made by the observers in various parts of the country
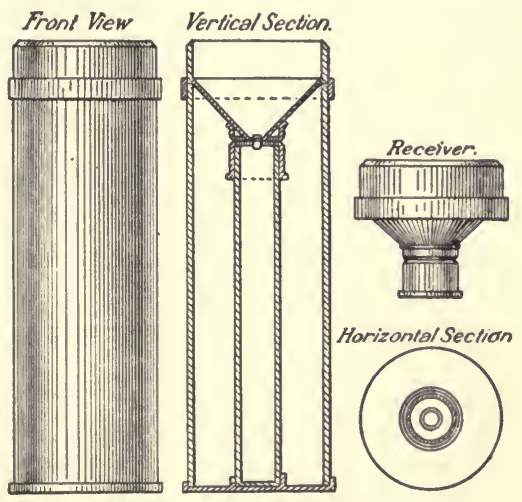

FIG. 205. - Rain gauge.

have been received at Washington and other cities, the figures are put down in their proper places on a blank map of the United States; from these a weather map like that shown in figure 199 is constructed.

Weather forecasts. This map when completed gives a general view of the weather conditions for the day throughout the whole country. Having made this map, how are the weather forecasters able to foretell what the weather for a certain place will be on the following day? A study of a great many maps for many years has shown that after a low area has formed in the western part of the country, it moves across the country in an easterly direction at the rate of several hundred miles a day. This speed varies 
according to season, being about eight hundred miles a day in winter and about five hundred miles in summer. In a similar way, the high areas move in an easterly direction. The weather experts are able to prophesy about how far the areas will travel by the next day, and hence what weather conditions will be brought to the various localities.

To put it in another way, if one wishes to ascertain the weather conditions that he will find in his locality at the end of twenty-four hours, he can look at the weather conditions found in the area situated several hundred miles west of him, as far west as a low area travels in one day.

These maps are made not only at Washington but in many other large cities and, with the forecast printed on them, are sent into the surrounding sections of the country. A brief forecast is given to the daily newspapers.

These forecasts are right in about ninety per cent of the predictions and constitute the only reliable method of foretelling weather. Sometimes forecasts are made for two days ahead; but the longer ahead the forecast is made, the more unreliable it is, because the low areas undergo so many changes as they pass across the country that it is possible to foretell for only a short time what the weather changes will be.

\section{LABoratory Exercise 38}

Purpose. To keep a record of weather conditions by means of instruments.

Materials. Barometer, ordinary thermometer, maximum and minimum thermometer, weather vane.

Directions. I. Copy the table given on page 513 in your notebook. Between eight and nine each morning make the observations called for and put the record in your notebook.

The record of the force of the wind may be kept in accordance with the following scale proposed by the U.S. Weather Bureau: o, calm; I, light, just moving the leaves of trees; 2, moderate, moving branches; 3 , brisk, swaying branches, blowing up dust; 
4, high, swaying whole trees, blowing up twigs from the ground; 5 , gale, breaking small branches, blowing loose bricks from chimneys ; 6, hurricane or tornado, destroying everything in its path.

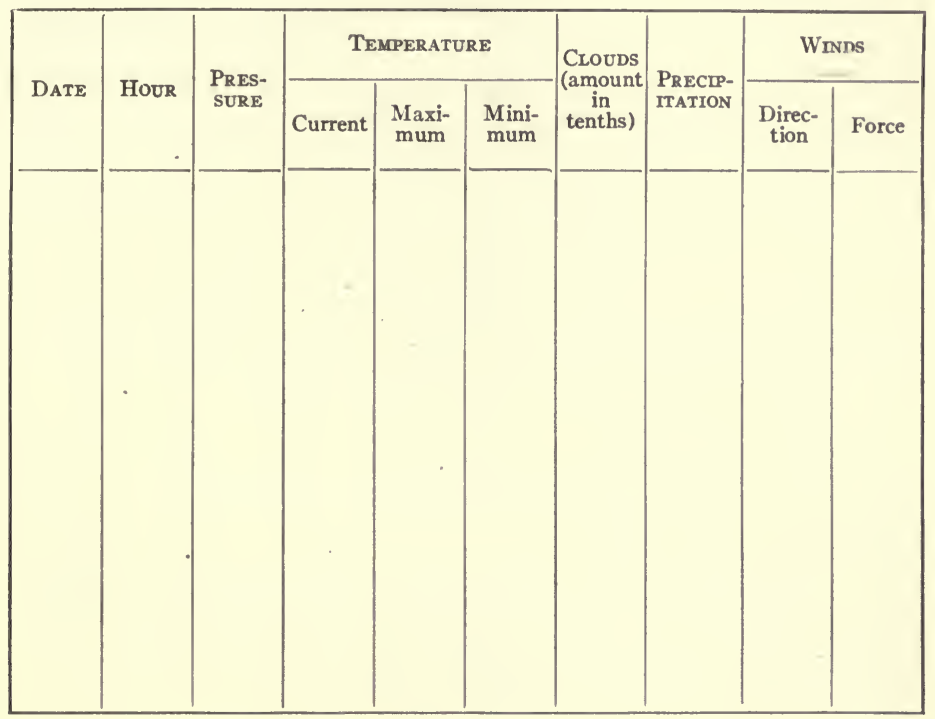

2. It may be well to have the class divided into sections and allow each section to keep the records for a certain time, so that all together may keep the record for a large part of the school year.

3. After the records have been kept for a month or longer study them to see if you find any relation between (a) pressure and temperature, $(b)$ pressure and precipitation, $(c)$ pressure and direction of wind, $(d)$ pressure and cloudiness, $(e)$ precipitation and direction of winds, $(f)$ temperature and direction of winds.

\section{LABORATORY Exercise 39}

Purpose. To learn how one may foretell the weather by a study of weather maps.

Materials. Series of consecutive weather maps.

Directions. I. Find each of the following on the map and explain what it signifies: $(a)$ the continuous black lines; $(b)$ the 
dotted black lines; $(c)$ the circles; $(d)$ the arrows attached to the circles; $(e)$ the shaded areas; $(f)$ the words " high" and "low."

2. On the map find the place that had $(a)$ the highest temperature, $(b)$ the lowest temperature, $(c)$ the greatest air pressure, (d) the least air pressure. In the columns find the place that had (a) the highest maximum temperature, (b) the lowest minimum temperature, $(c)$ the highest wind velocity, $(d)$ the greatest rainfall. In each case give figures and name of place.

3. State all the weather conditions shown on the map for your own city or the nearest Weather Bureau Station.

4. Compare a number of high and low areas on different maps and explain how the highs differ from the lows as regards (a) pressure, (b) direction of winds, $(c)$ temperature, $(d)$ state of weather (rainy or clear).

5. Follow the course of a low area on several consecutive maps and estimate $(a)$ about how far the area travels in a day, (b) and in what direction.

6. Secure the latest weather map and prophesy what you think the weather will be for your locality for the next day. When the time comes, make a note of the actual conditions and see how near you came to them.

\section{SUPPLEMENTARY QUESTIONS FOR CLASS DISCUSSION}

I. To what people are the weather forecasts of the Weather Bureau of greatest value?

2. What does a weather map show?

3. How is a weather map made?

\section{REFERENCE}

Harrington, About the Weather, D. Appleton, New York City. 


\section{SECTION G}

The Heavenly Bodies

\section{CHAPTER XXXII}

THE EARTH AS A PART OF THE SOLAR SYSTEM

I. In what ways are the sun and moon different?

2. How do stars differ from planets?

Solar system. The earth is but one of many heavenly bodies scattered through space. In this chapter we will try to obtain some idea of these bodies and of their relation to the earth. The earth, the other planets, the moon, and the sun are included together in what is called the solar system. The center of this system is the sun. Revolving around this sun are the planets situated at varying distances from the common center. Some of these, such as Mercury and Venus, are nearer the sun than is the earth; others, such as Mars, Saturn, Uranus, and Neptune, are farther away than the earth.

The positions of these planets may be illustrated by means of circles, as shown in figure 206. The dot in the center represents the sun. The circles represent the orbits of the various planets. If one inch be taken to represent the distance of the earth from the sun, then to represent the orbit of the moon, a circle should be drawn around the earth at a distance of one four-hundredth of an inch from it. This is too small to be shown on this diagram. All these 
bodies of the solar system, the planets, moons, and sun form a single group and are relatively very close together, compared with the distance from the stars. If we were to make a dot to represent the position of the nearest star on the same scale, it would be almost four miles away.

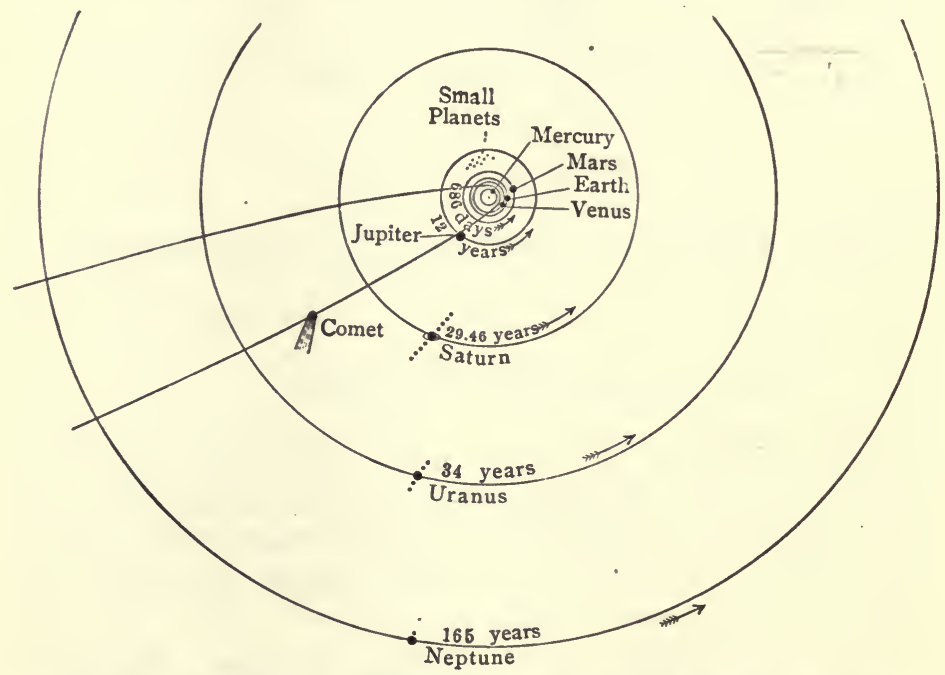

FIG. 206. - Solar system, showing the relative distances from sun, the relative size of the orbits, the number of satellites, and the period of revolution.

Relative distances of sun and stars. Hold the hand with the fingers spread so that the tip of the third finger is about six inches from the thumb. Let the thumb represent the sun, and the four fingers represent the position of the first four planets, Mercury, Venus, Earth, and Mars. Then, proportionately, the nearest star would be at a distance of almost twenty-five miles, and the North Star would be at a distance of over two hundred and fifty miles, while the most distant stars would be at a distance greater than the entire width of the United States from New York to San Francisco. This illustrates the fact that while the distances between the 
earth and sun and bodies of the solar system seem large as compared with the distances on the earth, yet they are very small when compared with the distances between the earth and the stars.

Motion of earth. The earth is traveling around the sun at a tremendous speed in its annual orbit. During the yearly journey we are traveling through space at the rate of eighteen miles every second. Every twenty-five minutes we travel a distance equal to the circumference of the earth, every four hours a distance equal to that to the moon, and every two months a distance equal to that to the sun.

At the same time we are moving in another direction, through the daily rotation of the earth. People at the equator travel at the rate of a thousand miles an hour. We do not realize that we are moving in these two ways because all the objects on the earth are moving with us and we are all held on the earth by the action of gravity.

Sun. The sun is the center of the solar system, around which the planets revolve, and it is by far the largest body in the system. Its diameter is almost nine hundred thousand miles, about one hundred times that of the earth. If the size of the earth were represented by a marble a half-inch in diameter, it would take a sphere four feet through to represent the sun. Or if a baseball were taken to represent the earth, it would take a sphere about twenty-five feet in diameter to represent the sun. If we could imagine the earth to be placed at the center of the sun with the moon at its average distance away, the sun would extend out to the moon and almost as far beyond it.

The distance from the earth to the sun varies from month to month. Strange as it may seem, we are nearer the sun in winter than in summer. The average distance is ninetythree million miles.

Sun's heat. The sun is the source of the heat and light that make life possible on the earth. Without the sun's 
heat every living thing on the earth would perish. We naturally wonder how the sun is able to give out so much heat for such long periods of time. We know that it is not by the ordinary process of burning with which we are familiar; because if it were so, the sun would have burned up before this. Astronomers tell us that the heat is given out by the contraction of the sun, and that the sun is all the time becoming smaller. The change is so slight, however, that even with the most powerful telescope, man cannot notice any difference in the size of the sun.

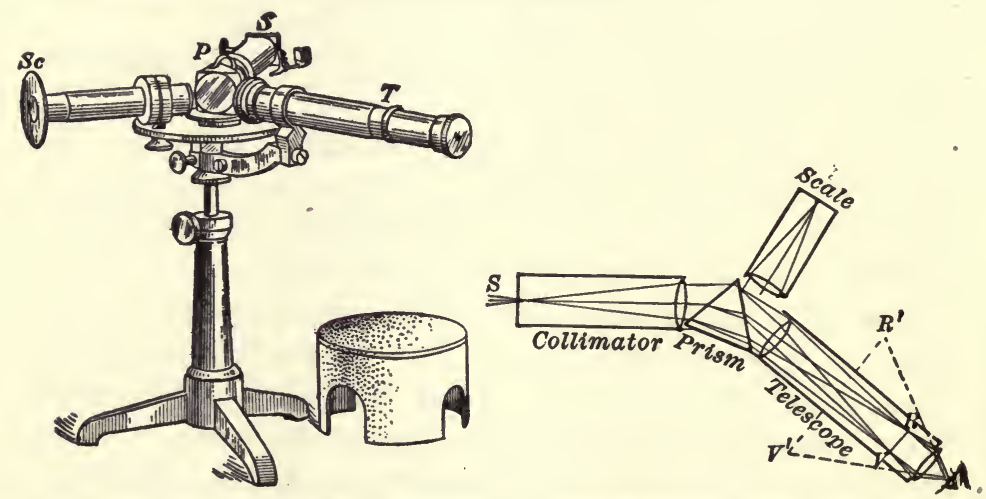

FIG. 207. - Spectroscope, an instrument by means of which many things have been learned about the sun and stars.

Composition of the sun. One very remarkable thing that man has been able to do is to find out some things of which the sun is made, although it is situated at such a great distance. This has been done by means of the spectroscope. This is an instrument for making and viewing a spectrum. When sunlight passes through a glass prism of a certain shape, the ordinary white light is broken up into a number of colored lights, as in the rainbow. When this spectrum is looked at with a telescope, it is found to contain a great many dark lines crossing it. From the number and position of these lines it is possible to tell what substances must be 
in the sun in order to make these lines, because these lines are the same as those made by certain substances found on the earth. Such metals as iron and nickel have been found to be present in the sun. It is to be expected that the same elements would be found in both the earth and sun, because it is believed that they came originally from the same mass. The outer surface of the sun is made up of hot gases, heated to an extremely high temperature. What are called sunspots are frequently seen on the surface of the sun. These are believed to be enormous.depressions or craters in these gases. Farther in from the surface, these gases become very dense and in the center may become liquid or even solid.

The sun is found to rotate on its axis like the earth, only its period of rotation is longer. Observation of sunspots shows that it takes the sun about twenty-five days to rotate once.

Changes in the solar system. All the bodies of the solar system are going through a series of changes. At one time all were intensely hot. The sun is in that stage now, and possibly Jupiter is. The earth represents a later stage, when the crust is cool but the interior is hot as shown by volcanoes. The moon represents a still later stage, for it has lost nearly all its heat and is probably cooled all the way through. In time the sun too will doubtless become cool and cease to give off heat and light, but that is many million years in the future.

The seasons. Our change of seasons is due to the varying amounts of heat we receive from the sun. In the summer the north pole of the earth points towards the sun and during the middle of the day the rays come down nearly straight. In the winter the north pole of the earth points away from the sun, which is low down in the sky at noon, and the rays strike the earth obliquely, so that less rays strike a given surface than in the summer when the rays are more nearly vertical. Hence the earth receives more heat during 
the summer than winter. This inclination of the sun's rays has more effect in producing the change of seasons than our distance from the sun. This explains the fact that we have our winter when we do, in spite of the fact that we are nearer the sun at that time. The fact that the sun shines for a longer part of the day in summer than in winter is another reason why our summers are hotter. In the southern hemisphere the conditions and the seasons are the reverse of those in the northern hemisphere.

Moon. As the earth revolves around the sun, so the moon revolves around the earth. While the earth's motion around the sun takes a year, the moon's motion around the earth

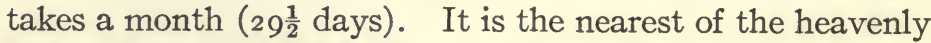
bodies, being situated about a quarter of a million miles distant. Its diameter is about two thousand miles, or one quarter that of the earth.

Light of moon. The moon affects man in two ways, by giving light and by causing the tides. The moon gives enough light so that in some towns and cities the electric street lamps are not lighted on clear moonlight nights, thus effecting a saving in expense. The light that we get from the moon is reflected sunlight, as the moon has no light-giving power in itself.

Tides. Another way in which the moon affects life on the earth is by causing the tides. The tides have a beneficial effect as they help to clear away decaying matter around the shores, which might otherwise collect and become offensive. The tides are caused by the attraction that the moon has on the oceans, by which the water is lifted a few feet toward the moon. As the earth rotates, these high tides follow the moon, though lagging behind it. As the moon rises later each day, so the high and low tides occur that much later each day. The sun also has some influence in forming the tides, but it is so far away that, in spite of its great size, it hasn't as much influence as the moon. 
Moon's phases. Each month the moon goes through certain changes or phases, first showing a small crescent, then increasing in size till the full moon is reached, and then decreasing. Only that half of the moon is lighted that is turned toward the sun, and the phase of the moon depends on the part of this lighted portion that we can see. When the moon is between the sun and earth we see none of the lighted portion and this is the new moon; then as the moon revolves around the earth a larger portion shows, the first quarter; and when the moon is on the opposite side of the earth from the sun we see the entire lighted surface, the full moon. Then as it revolves through the other half of its orbit, the lighted portion gradually grows less.

During this period of revolution the moon rotates once on its axis, so that it always keeps the same surface towards us. No human being has ever seen the other side of the moon.

Rising and setting of the moon. If the rising of the moon be watched for a few weeks, it will be seen that it rises on an average of about fifty minutes later each day. Sometimes this difference may be thirty minutes, and again it may be an hour and a quarter. There is also a difference in the exact place in the horizon where the moon rises and sets. Just as the sun has a north and a south motion in its place of rising and setting during the year, so the moon has a north and south motion during the month.

\section{Home Project 29}

Purpose. To observe the moon's changes for a month

Directions. Notice the changes that take place in the moon with reference to the three following points: I. shape; 2 . time of rising or setting; 3. place of rising or setting. Keep at least two records a week of as many points as you can as 
given below in the table. Copy this in your notebook and fill it out.

Observations on Moon

\begin{tabular}{|c|c|c|c|}
\hline Date & Shape & $\begin{array}{c}\text { Time of } \\
\text { Setring or Rising }\end{array}$ & \\
\hline & & & \\
\hline & & \\
\hline
\end{tabular}

Record the shape by making a drawing. Record the place of setting or rising by reference to the points of the compass.

Superstitions about the moon. From the earliest times we find reference to influences that the moon was supposed to have on weather and the growth of crops. One of these superstitions, connected with the best time for planting seeds, was that seeds would grow better if they were planted at certain phases of the moon. Another was that plants grow better just after the moon has passed the full. Another even more common superstition about the moon, still held even to-day by some intelligent people, is that the moon affects the weather. These supposed influences may be grouped under two classes.

In the first class are certain cloud effects produced in connection with the moon, such as a ring around the moon, and the supposed effect of the moon in clearing away the clouds. In both these cases the moon through its light simply discloses a condition that exists in the air, but in neither case did the moon cause the condition. A ring around the moon simply shows the gathering of clouds and the presence of moisture in the air, which may indicate the approach of a storm. When the new moon is supposed to clear away the clouds, it simply means that the light shines through the clouds and thus shows their thinness; this is misinterpreted to mean that the moon caused the thinning. 
Moon's phases and weather. In the second class of the supposed influences on weather are those based on the phases of the moon. It is said that as the phases of the moon change, the weather changes and that the kind of change depends on the hour of the day or night when these changes of the moon occur. In accordance with one prophecy, if the tips of the crescent moon point up, it means a wet season; while in accordance with another prophecy this means a dry season. This is seen to be a very convenient means of prophesying the weather, as one may take his choice as to whether he will have dry or wet weather.

As a matter of fact there are no abrupt changes of the moon, as the phases are gradually changing all the time. The phases of the moon and the position of the crescent points can be foretold thousands of years ahead, while the weather can be foretold only a few days ahead.

Careful records have been kept of weather changes and of the changes of the moon, and none of these show any definite fixed relation between the two. The relations that may exist in one part of the country are quite different from those in another part of the country.

There are three ways in which it might be possible for the moon to affect the earth's atmosphere: first, through its heat; second, through its light; and third, through its attraction. The amount of heat is so small that only the most delicate instruments are able to measure it. Likewise the amount of light received from the moon is very small. The attraction of the moon produces tides on the earth's oceans and possibly it might produce tides in the earth's atmosphere. Careful records have been kept from which it is found that the moon does have a slight effect in this way; but the changes are so small that they can just barely be measured with the barometer. All these possible influences are so slight that it would not be expected that they could influence the weather. 
In conclusion it may be said that there has been no evidence produced to show that the moon does influence weather; while the studies that have been made indicate that there is no constant relation between the moon's phases and the weather. If the moon does have any influence on the weather, it is so slight that it has not yet been detected.

The matter is summarized in a bulletin published by the United States Weather Bureau as follows: "A review of the foregoing remarks and opinions regarding the application of past and present astronomical and meteorological knowledge to the theory and practice of long-range weather forecasting leads to the following conclusions :

" I. That systems of long-range weather forecasting that depend upon planetary meteorology: moon phases, cycles, positions, or movements ; stellar influences, or star divinations; indications afforded by observations of animals, birds and plants; and estimates based upon days, months, seasons, and years have no legitimate bases.

" 2. That meteorologists have made exhaustive examinations and comparisons for the purpose of associating the weather with the various phases and position of the moon in an earnest endeavor to make advances in the science along the line of practical forecasting and have found that while the moon, and perhaps the planets, exert some influence upon atmospheric tides, the influence is too slight and obscure to justify a consideration of lunar and planetary effects in the actual work of forecasting."

Appearance of surface. When looked at with a telescope or even a field glass, the surface of the moon may be seen clearly, and it shows some interesting features. The most conspicuous one is the large number of volcanic craters scattered over its surface. They are much more numerous than on the earth. Thirty thousand craters have been counted on the half of the moon turned towards us. Some of these craters are over fifty miles in diameter, or more than 
five times that of the largest crater on the earth. Immense mountains are also found on the moon, some ranging from six to seven miles in height, exceeding any mountain on the earth. These craters show that formerly there was much

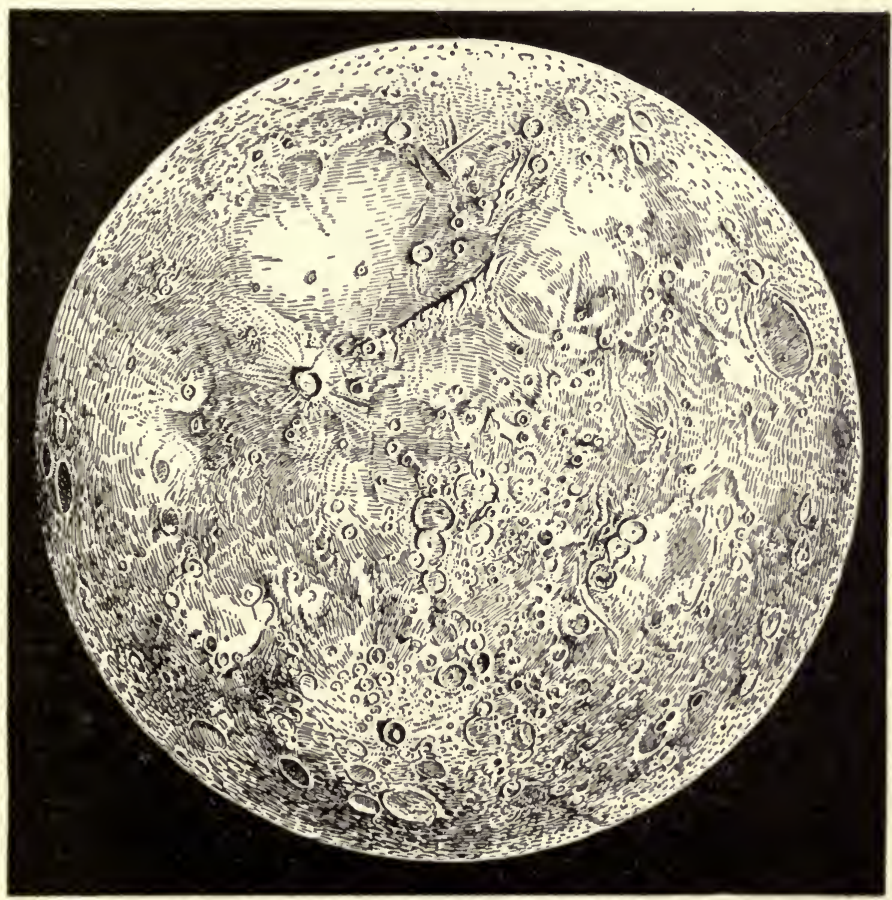

FIG. 208. - Features of the moon as seen in a telescope, showing the large number of volcanic craters.

volcanic activity on the moon; but now the moon has cooled down so that it is extremely cold.

There is no air on the moon, and there is no water. Hence there are no clouds and there is no diffused light. Only those objects can be seen that stand in the direct sunlight. As there is no air, no sound could be heard. The force of 
gravity is so small that a ball player could bat a baseball a half mile.

The moon represents the last state to which the heavenly bodies may come. It is the stage which the earth and the

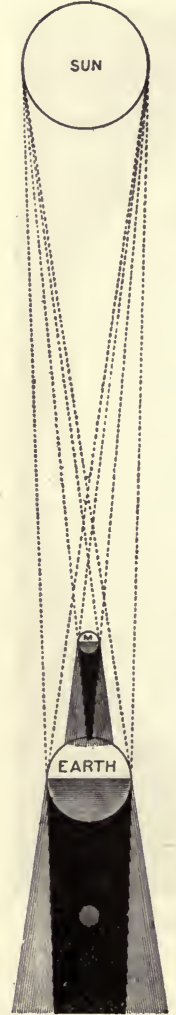

FIG. 209.-How eclipses of the sun and moon take place. other planets will probably reach many thousands of years hence.

Eclipses. When the sun shines on the earth and moon, a long shadow is thrown out on the side of these bodies away from the sun. This shadow is in the form of a cone extending out many thousands of miles, indeed farther than the distance between the earth and the moon. When the earth is between the sun and moon (figure 209), the moon at certain times passes into this shadow and so is eclipsed. This shadow is big enough so that the moon may be entirely covered. When the moon is between the earth and the sun, it sometimes happens that the moon's shadow falls on some part of the earth and this causes an eclipse of the sun. This part of the moon's shadow is very small, less than two hundred miles in diameter, so that the sun is eclipsed for only a small part of the earth at any one time. These eclipses can be foretold many years ahead with great exactness.

Planets. The earth is one of a group of eight planets, all of which revolve around the sun in the same direction. The four brightest of these that can be easily seen are Jupiter, Venus, Mars, and Saturn. The other three are Mercury, Uranus, and Neptune. At first sight these look like stars; yet two differences may be easily noticed. In the first place, the planets do not twinkle; and in the second, if the planets 
are watched for several weeks their position in the sky with reference to the stars changes, while the stars always keep the same position with reference to each other. The planets also show a change in brilliancy and apparent size from year to year, because their distance from the earth changes, according to whether the earth and planet are on the same side or opposite sides of the sun. Mars when farthest away from the earth is seven times as far as when nearest the earth. Those planets which are nearer the sun than is the earth, Mercury and Venus, are never seen at any great distance away from the sun, so that they are seen only for a few hours before sunrise or a few hours after sunset. Venus is the one most commonly seen as a " morning" or " evening" star.

The source of the light seen from the planets is the same as from the moon, reflected sunlight. It is thought that perhaps Jupiter may give out a small amount of light on account of its own luminosity.

These planets vary greatly in size. The two smallest, Mercury and Mars, are about one half the diameter of the earth. Venus is about the same size; while Jupiter, the largest, is about ten times as large as the earth. Mercury is the nearest to the sun of all the planets, less than one half as far as the earth. Neptune is the farthest away, about thirty times the distance of the earth. The time that it takes each planet to make a single revolution around the sun depends on the distance from the sun, those farther away taking a longer time. The period for Mercury, the planet nearest the sun, is about three months; while that for Neptune, the one farthest away from the sun, is one hundred sixty-five years.

Most of the planets have moons. Saturn has ten. Two, recently discovered, are very small. Another interesting feature about Saturn is its rings, which extend in broad, thin belts around the circumference of the planet. These are very beautiful when seen through a telescope. 
Is Mars inhabited? The most interesting of all the planets is Mars. This is the only one which seems even to make possible the existence of life at all similar to that found on the earth. Some astronomers believe that Mars

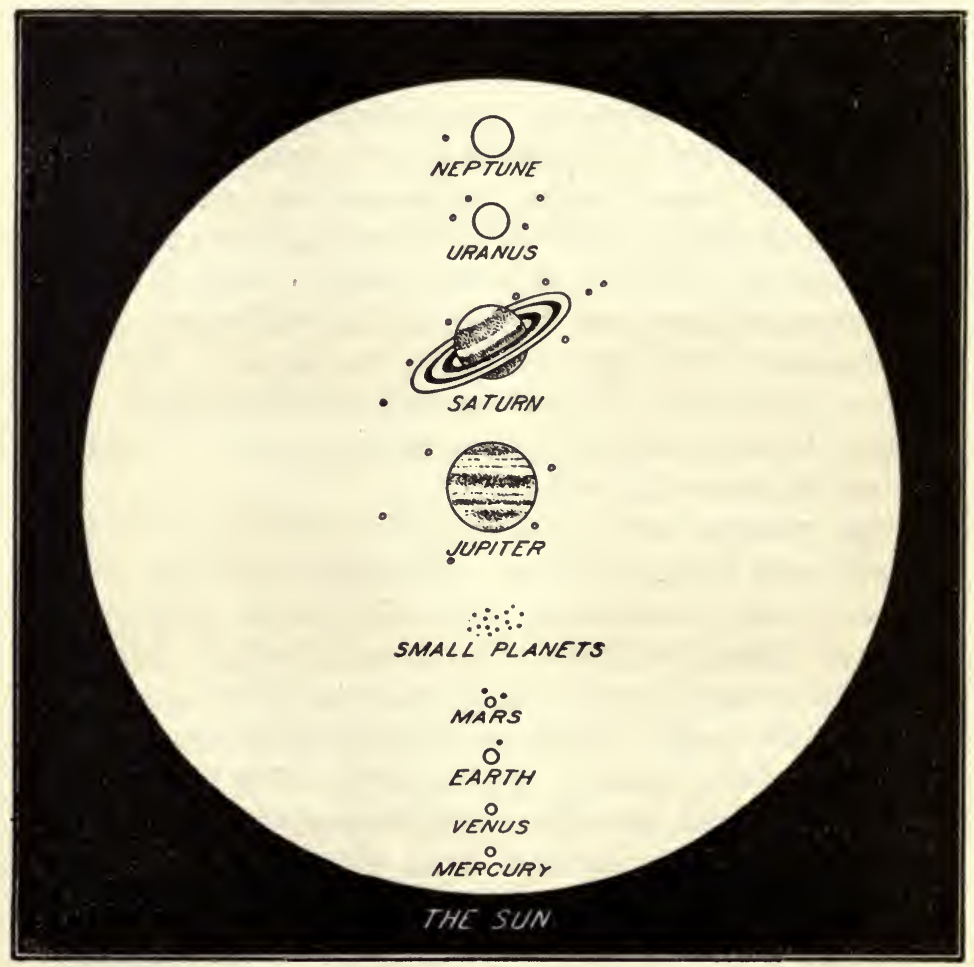

FiG. 210. - Relative sizes of planets. (Sun's diameter on same scale equals length of cut.)

is inhabited. Others think we have not yet secured enough evidence to prove that it is inhabited. The reasons for believing it inhabited are found in the appearance of the surface as seen with the telescope. There appear straight lines called canals, and sometimes these are in parallel pairs. 
Some astronomers argue that this arrangement could not happen by chance but that there must be intelligent beings there. Their explanation is that these are belts of vegetation along irrigation canals; that water is scarce, and that as the snow melts from about the poles in the summer, the water is carried by those canals to other parts of the planet to be used for irrigation. There are changes in the appearance, as though at one season of the year snow accumulated around the poles, and then melted during another season. While it cannot be considered proved that Mars is inhabited, it certainly is a very entertaining theory. Wells, the

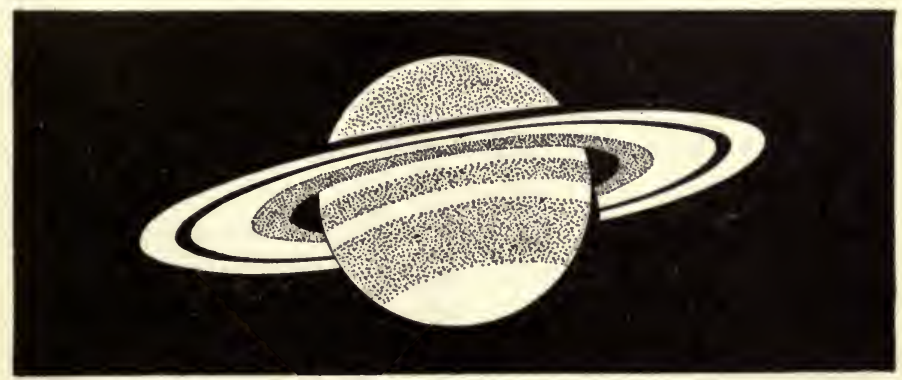

FIG. $211 .-$ The planet Saturn in 1894 , as seen with the telescope.

English novelist, has written a very interesting book called The War of the Worlds, in which he supposes that the inhabitants of Mars come to the earth and wage warfare against the inhabitants here, but are finally killed by bacteria.

Telescope. Many of the facts known about the heavenly bodies have been learned through the use of the telescope. This is an instrument for looking at distant objects and making them appear larger than they do to the naked eye. It is composed of two convex lenses mounted at the two ends of a tube. The one pointed toward the object is called the objective; the one at the other end, the eyepiece. The 
objective forms an image of a distant object somewhere inside the tube and the eyepiece is placed in such a position that it is focused on this image and enlarges it.

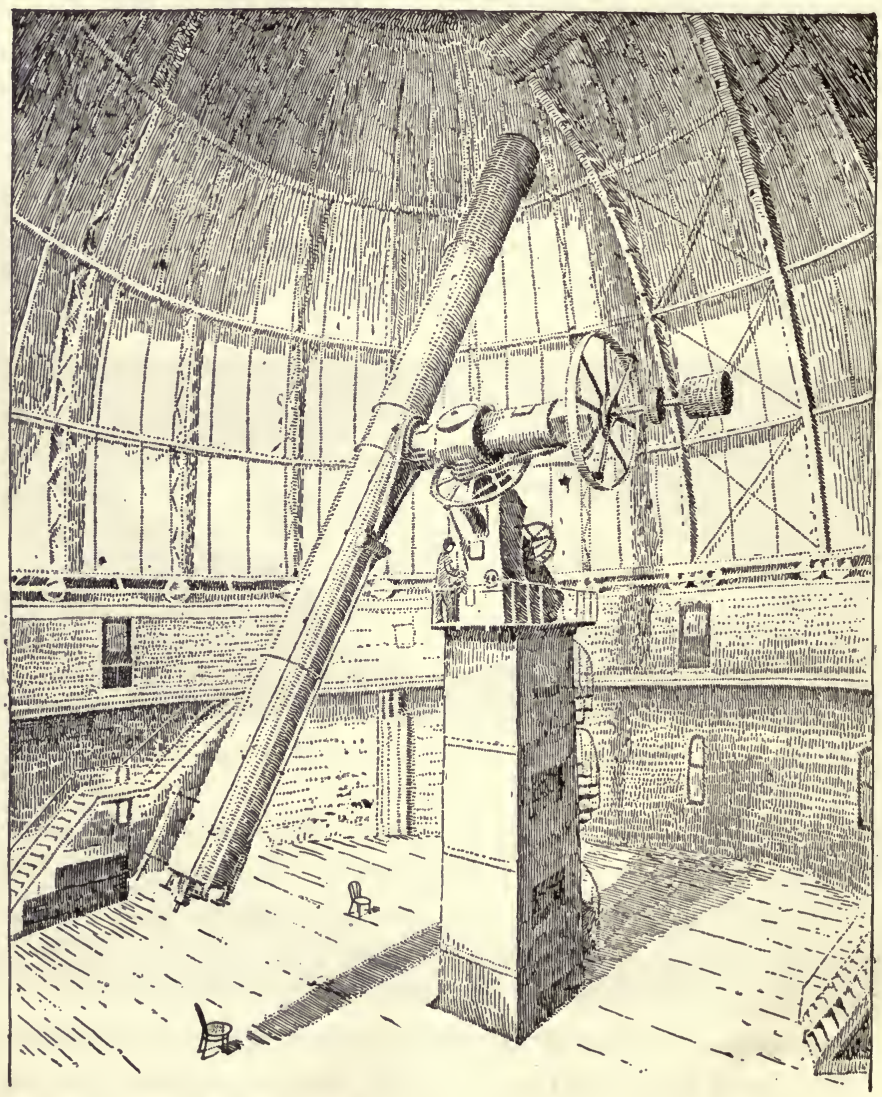

FIG. 212. - The Yerkes telescope of the University of Chicago. Cost about $\$ 125,000$. Lenses 40 inches in diameter.

Stars. The first thing that impresses one as he looks at the night sky is the number of stars. But while there are a great many, the number seen is not as great as one thinks. 
Only about two thousand stars can be seen by the eye at any one time. There are many other stars not visible to the eye that can be seen by the telescope; it has been estimated that there are one hundred million stars that may be seen by using this instrument. The camera takes pictures of stars that not even the telescope can detect.

Difference in brightness. Stars differ in their brightness. Some are very bright and can be easily seen, while others can just barely be seen and most cannot be seen at all without the telescope. This difference may be due to two things, to difference in distance and to a difference in the lightgiving power of the star. Stars are self-luminous like our sun. Indeed our sun is a small star, but it looks bright because it is so near. We may think of stars, then, as large suns scattered through space. The brightest of all the stars is Sirius, the Dog Star, seen during the winter months. It has been estimated that this gives out as much light as thirty of our suns.

Constellations. Every one has observed that stars are grouped in clusters, which are called constellations, each of which has been named. There is usually little similarity between the arrangement of the stars and the object for which the constellation is named. One of the best known of these is the Great Bear or Dipper. All the stars seem to revolve around a point in the heavens near the North Star. This star may be easily found by means of the Great Dipper. The two outer stars on the bowl of the Great Dipper are called pointers, because they point to the North Star. All the constellations found between that star and the horizon never set, and so they can be seen during all seasons of the year. On the other hand, there are stars near the south pole of the heavens, seen from the southern hemisphere, which we never see in this latitude.

There are many conspicuous constellations, and the ones that can be seen change from month to month. The stars 
that we see during the winter evenings are different from those we see during the summer evenings, excepting a few near the North Star that we can see all the year. It is an

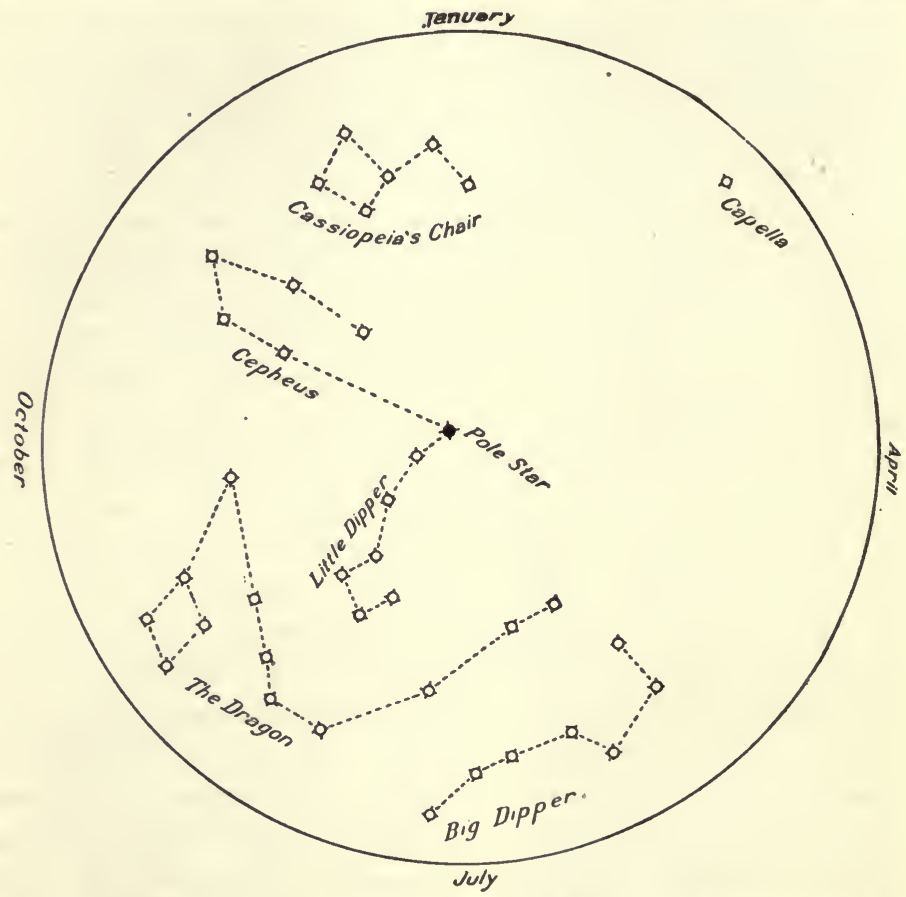

Fig. 213. - The polar constellations. To show their position at 9 o'clock for the different months, hold the chart with the name of the month at the top.

interesting study to learn to name some of these constellations and with the help of star maps it is not a difficult thing to do.

\section{Field Exercise I2}

Purpose. To learn to name some of the common constellations.

Directions. Secure some star book with star maps, such as Proctor, Easy Star Lessons, or Comstock, Handbook of Nature- 
study. Learn to name first the constellations that can be seen all the year, those near the North Star, such as the Great and Little Dippers and Cassiopeia's Chair. During the winter, study the winter constellations and during the last of the school year study the summer constellations. In order to get them fixed in mind, make a diagram in your notebook of each constellation showing the position of the stars with reference to each other.

(This may also be given as a home project, in preparation for which the instructor will make a diagram on the board of the constellations, showing the position of the stars and explaining how to find them.)

Distance of stars. The most marvelous and awe-inspiring fact about the stars is the enormous distance at which they are situated. They are so far away that the mile is too small a unit to use in measuring these distances. So astronomers have devised a new unit which is called the light year. This is the distance that light travels in a year. Light travels at the rate of 186,000 miles in a second; that is, it would travel around the earth seven times in a second. It takes light only five hundred seconds to come to us from the sun. In a year light would travel almost six trillion miles. This distance, called the light year, is taken as the unit in measuring distances of the stars. The very nearest of all the stars is so far away that it takes light more than four years to reach us. That is, the nearest star is twentyfive trillion miles away. It takes light from the North Star almost fifty years to reach us, so that the light you see from this star started a short time after the close of the Civil War.

A group of stars called the Pleiades is so far away that it takes light one hundred and ninety years to reach us. The light which we now see started fifty years before the Revolutionary War. The rays of light that left the star at that time traveled those fifty years preceding the war, during the remainder of that century, during the first half of the next century and up to the Civil War, and during the fifty 
years since then, - all the time at the tremendous rate of I86,000 miles a second. And yet this beam of light has just reached us.

Other stars are even farther away than this. It is believed that from the very farthest stars it takes light thousands of years to reach us, so that possibly the light that now reaches our eye from some stars started even before Jesus was born.

What the spectroscope shows about the stars. Since these stars are situated so far away, it would seem almost impossible to find out anything about them. But the light that comes from the stars tells certain facts about them, and by allowing this light to pass through a spectroscope, astronomers have learned two facts about stars, their composition and their motions. Spectra of starlight can be obtained the same as spectra of sunlight and these are so much alike that it shows that some of the elements found in the sun and the stars are the same.

But the spectroscope is able to tell us something more than this; it tells us whether the star is moving toward us or away from us, and at what speed it is moving. Some stars are moving at the rate of thirty miles a second. It is a mistake to speak of the stars as being fixed, because all heavenly bodies are in motion. Some stars have been traveling at the rate of twenty-five or more miles a second for countless years, and yet within historic times, since man has begun to make any accurate récords of the position of stars, they seem to be in the same relative positions as they were thousands of years ago. They are so far away that this distance they have traveled makes no appreciable difference that men can detect in the position of the stars. This illustrates again the enormous distances that separate us from the stars. 
THE EARTH AS A PART OF THE SOLAR SYSTEM 535

\section{SUPPLEMENTARY QUESTIONS FOR CLASS DISCUSSION}

I. What are the relative positions of the members of the solar system?

2. What does the spectroscope show about the heavenly bodies?

3. What are the superstitions still held regarding the moon?

4. What is the most important way in which the moon affects man?

5. Why is Mars the most interesting of all the planets?

6. In what ways is the earth like the other planets?

7. What interests you most about the stars?

\section{REFERENCES}

Milton, Children's Book of Stars, Adam and Charles Black, London.

Proctor, Easy Star Lessons, G. P. Putnam's Sons, New York City. 


\section{SECTION H}

\section{An Enemy of Home And Community}

\section{CHAPTER XXXIII}

\section{ALCOHOL: AN ENEMY OF HOME AND COMMUNITY}

I. Why did Congress pass a prohibition bill as a war measure ; and why have the states of the Union adopted an amendment to the constitution, prosibiting the manufacturing and sale of intoxicating liquors for use as a beverage?

2. What are the strongest arguments for total abstinence?

3. What are the chief ways in which alcohol injures the home?

4. What are the chief ways in which alcohol is an enemy of the community?

Alcohol and the war. During the Great War the American people were concentrating all their energy on bringing the war to a successful and speedy termination. Activities which helped win the war were encouraged; those which hindered were opposed. In England Lloyd George is reported to have said: "We are fighting Germany, Austria, and Drink, and so far as I can see, the greatest of these deadly foes is Drink."

After this country entered the war it was evident that alcohol was hindering the work of the government in many ways. The nation needed the full use of its man power, money, food, and railroads. The liquor traffic was using all of these in a way that hindered the work of the government. 
Man power was needed to build ships and mine coal. It was shown that the use of alcoholic liquors was interfering with this work.

Waste of food in making alcoholic liquors. One of the most critical situations was created by the world shortage of food. Many people were suffering from lack of food, and some were even starving. Unless the United States met the demand for food, the war might be lost. This situation led people to study every means of conserving food. It was found that there was a great waste of food in the manufacture of alcoholic drinks. The following table shows the amounts used annually.

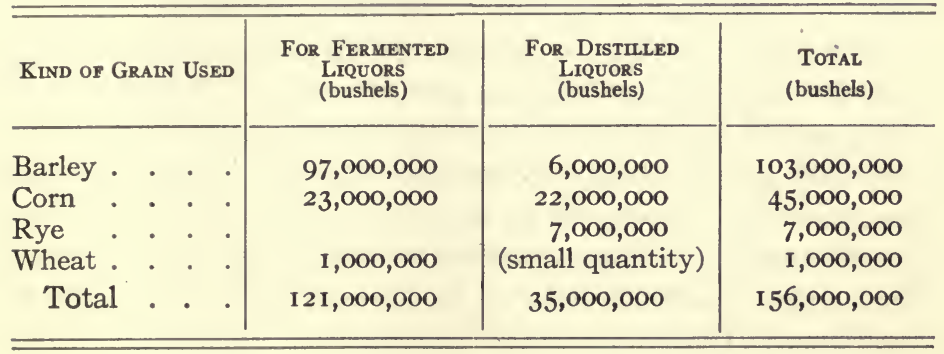

This means that $156,000,000$ bushels of grains that could be used for food were wasted to make alcohol. The grain used for liquors would make 4,000,000,000 loaves of bread. That is, the yearly bread supply of $22,000,000$ people was being wasted. The number of people that each of these grains would supply with bread for one hundred days is shown in the following table.

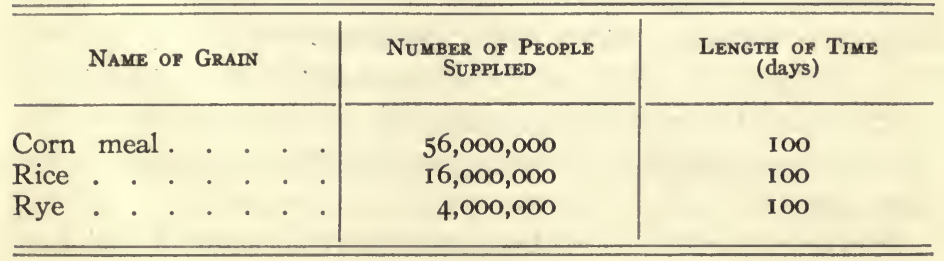


That is, the amount of these three grains used to make alcohol would supply enough food to keep $76,000,000$ people from starvation for one hundred days, or this would be enough to keep the people of the United States from starvation for more than two months. The population of England could subsist on these food supplies for nearly six months, or the population of France for nearly seven months.

Prohibition as a war measure. On account of the fact that alcoholic drinks were interfering with the work of the government in winning the war, lawis were passed by Congress to limit the manufacture and sale of alcoholic liquors. During the summer of I9I8, Congress passed a law forbidding the use of any foodstuffs in the manufacture of distilled liquors; such as whisky and rum. In I9I8, Congress passed a national prohibition bill as a war measure. Manufacture of fermented liquors, such as beer and wine, was forbidden after April 30, I919; and the sale of any intoxicating liquors after June 30. This was to remain in effect till the troops were demobilized. By a special proclamation of President Wilson the manufacture of beer was prohibited after November 30, I918.

Prohibition amendment to constitution. Before the war began, there was a movement well under way to make this country dry through an amendment to the constitution. During the summer of I9I 7 the United States Senate and House of Representatives passed, by the necessary two thirds vote, a proposed amendment prohibiting the manufacture, sale, or transportation of intoxicating liquors for beverage purposes. By March, I9I9, this amendment had been ratified by 45 states, 9 more than the necessary three fourths. The thirty-sixth state ratified the amendment on January I6, I919, so that in accordance with the provisions of the proposed amendment it will go into effect one year from that day.

It is worth while to understand why this amendment has 
been adopted by such an overwhelming majority. Furthermore, in some parts of the country the amendment may not be adequately enforced, so that for a few years some liquors will doubtless be sold illegally. As there is this possibility, it will be well to learn some of the facts regarding the harm done by alcoholic liquors and some reasons why total abstinence is the safest course.

The subject of the use of alcoholic liquors may be considered from three standpoints, that of the individual, that of the home, and that of the community.

Effect of alcohol on the individual. From the standpoint of the individual, one wishes to know what effect alcohol will have upon the organs of his body and their working, and hence upon his chance of success in life. One of the most critical times in a young man's life comes when he is invited to take his first glass of beer or wine. His success for his entire life may rest upon the decision he makes at that time. The danger of that first glass cannot be emphasized too strongly, because that may lead eventually to the regular use of alcoholic liquors with all the dangers that attend its use. The purpose of this chapter is to present some of the facts regarding this matter so that one may realize that total abstinence is the only safe course.

We will consider first the effect of alcohol on the body. This may be looked at from the standpoint of the effect on the activity of the organ and the permanent effect on the organ itself. For instance, we may consider the effect on the process of digestion and the effect on the digestive organs, the stomach and intestines. Alcohol is found both to interfere with the working of the organs of the body and to injure the organs themselves.

Alcohol a narcotic or stimulant. The question has been much discussed as to whether alcohol is a stimulant or a narcotic. A stimulant is something that induces to greater activity. A narcotic is something that deadens the activi- 
ties of the body. . Many people have the notion that alcohol acts as a stimulant, and they think that if they have a very difficult piece of work to do they will be helped by taking a glass of liquor. This is a mistake, because experiments have shown that the use of alcohol decreases a person's capacity to do either muscular or mental work. Of the many experts who have made a study of this question the great majority agree that alcohol is a narcotic. When a person drinks a glass of beer thinking it will stimulate him to do better work, he is deceiving himself. His own feelings in the matter are not trustworthy.

Effect of alcohol on mental activities. Frequently one hears a person say that he has used alcohol in moderation for many years and that it has never harmed him. He may think that he has not been harmed, but harm may have been done although he does not know it. Just as a person may have the incipient stages of tuberculosis and not know it, so an habitual user of alcohol may undermine his health and resistance so that although he may be unconscious of any weakness, an attack of pneumonia or other illness will find him an easy victim. While some of the ill effects due to alcohol are of such a character that they are easily seen, many others are of such a kind that it requires special experiments to detect them. But they may nevertheless be of a serious character, so that when a person says that alcohol has not harmed him, it proves nothing.

In one experiment it was found that a single dose of alcohol produced a lessening of mental activities and that this effect lasted more than two days. When alcohol was taken for twelve successive days, tests showed that the working capacity of the individual's mind was lessened by from 25 to 40 per cent. In another experiment after alcohol had been taken for twelve days, it was found that the power to add was reduced 40 per cent and the power to memorize was reduced 70 per cent. Still other experiments show that even 
small quantities of alcohol render the organs of sense less sensitive and hence less accurate.

A number of other experiments along similar lines have been performed to test the effect of alcohol on mental activities, and all the evidence goes to show that the mind is not capable of its best efforts when influenced by even small quantities of alcohol.

Effect of alcohol on ability to set type. One experiment was tried with four typesetters to test the effect of alcohol on

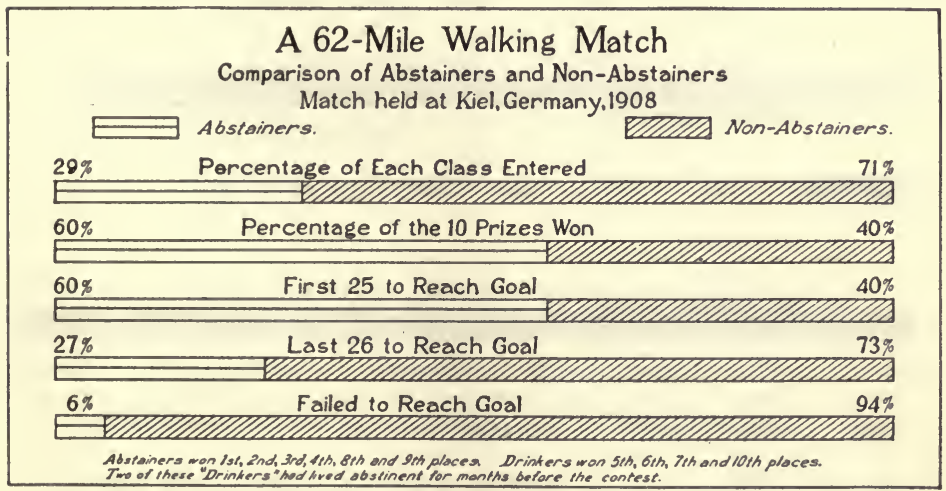

Fig. 214. - Comparison of abstainers and non-abstainers in a walking match.

their ability to set type. The experiment lasted four days. On the first and third days no alcohol was taken, on the second and fourth each worker took about three quarters of a tumbler of wine. It was found on the days that alcohol was taken that in three of the cases the rapidity of setting type was lessened, in one case ro per cent. As a typesetter is paid by the amount of work he does, this man actually earned Io per cent less on account of this one drink of wine.

Alcohol and athletics. Figure $2 \times 4$ shows the effect in an athletic contest of the use of alcohol. This was a sixty-two mile walking match in Germany. Of those who entered 7 I per cent drank beer and 29 per cent were abstainers. 
And yet the 7 I per cent (the drinkers) won only 40 per cent of the prizes, while the 29 per cent (the abstainers) won 60 per cent of the prizes. As a result of using beer these athletes won only about half as many prizes as they would have done had they not used beer. The injurious effects of alcohol are well understood in athletic circles in colleges, and men who are training for the football and other athletic teams are not allowed to use alcohol.

The effect of alcohol on the nerves in shooting is shown in figure $2 I_{5}$. Out of 30 shots, those soldiers who had not

1st Series. No Alcohol - Average No. of Hits 23

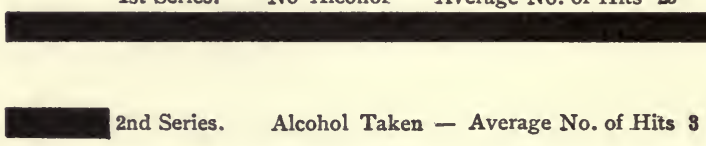

2nd Series. Alcohol Taken - Average No. of Hits 3

3rd Series. No Alcohol - Average No. of Hits 26

FIG. 215. - Rifle shooting in Sweden, showing effect of alcohol upon steadiness of nerve. Length of black bars shows average numbers of hits of soldiers in 30 shots. Three tablespoonfuls of alcohol were taken for the second series.

taken alcohol made $24 \frac{1}{2}$ hits, an average of $81 \frac{2}{3}$ per cent; while those who had taken alcohol made only 3 hits, an average of only ro per cent. What a difference this would make in a battle!

Effect of alcohol on length of life. One of the strongest arguments against alcohol is the fact that its use shortens life, so that a person who uses alcohol will probably die sooner than he would if he were an abstainer (barring, of course, death by accident). This is known from records that have been kept for many years by life insurance companies. One company in England divides its members into two classes, abstainers and moderate drinkers. Records of forty years show that among total abstainers deaths were but 7 I. 5 per cent of the calculated probabilities, while among 
the moderate drinkers the deaths were 94 per cent of the calculated probabilities. In another British insurance company, the figures were 53 and 80 per cent. That is, the average difference in favor of the total abstainers is 25 per cent. Stated in another way this would be about the same as saying that the moderate drinkers live only three fourths

Average Death Rate among all Policy Holders

Death Rate among those using 2 Glasses of Beer or 1 Glass of Whiskey Daily

Death Rate of those with History of Past Intemperance, but Apparently Cured

Death Rate of those using more than 2 Glasses

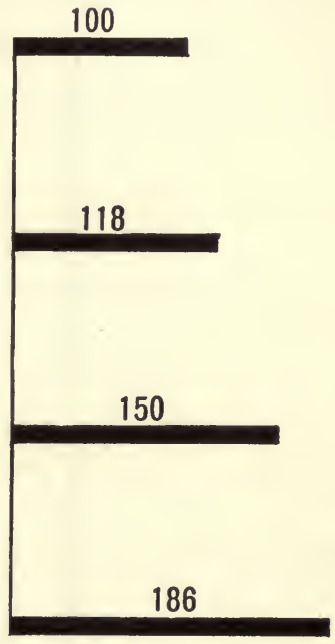
of Beer or 1 Glass of Whiskey Daily

FIG. 216. - Chart showing effect of moderate use of alcohol on death rates.

(Based on records of 43 American life insurance companies.)

as many years as the abstainers. This is shown graphically in figure 217 .

A doctor in Switzerland made a study of the records of the city of Basle and found that alcohol was one of the causes of the death of every tenth man. Another study made in Sweden showed that among adults 18 per cent of the deaths were due directly or indirectly to alcoholism.

Alcohol and disease. Some cases of sickness and death are due directly to alcohol, and many cases are due indirectly to it. The alcohol has so weakened the body that it is more 
apt to be sick, and when it is attacked by disease, it is less able to fight the disease successfully and as a result a drinker

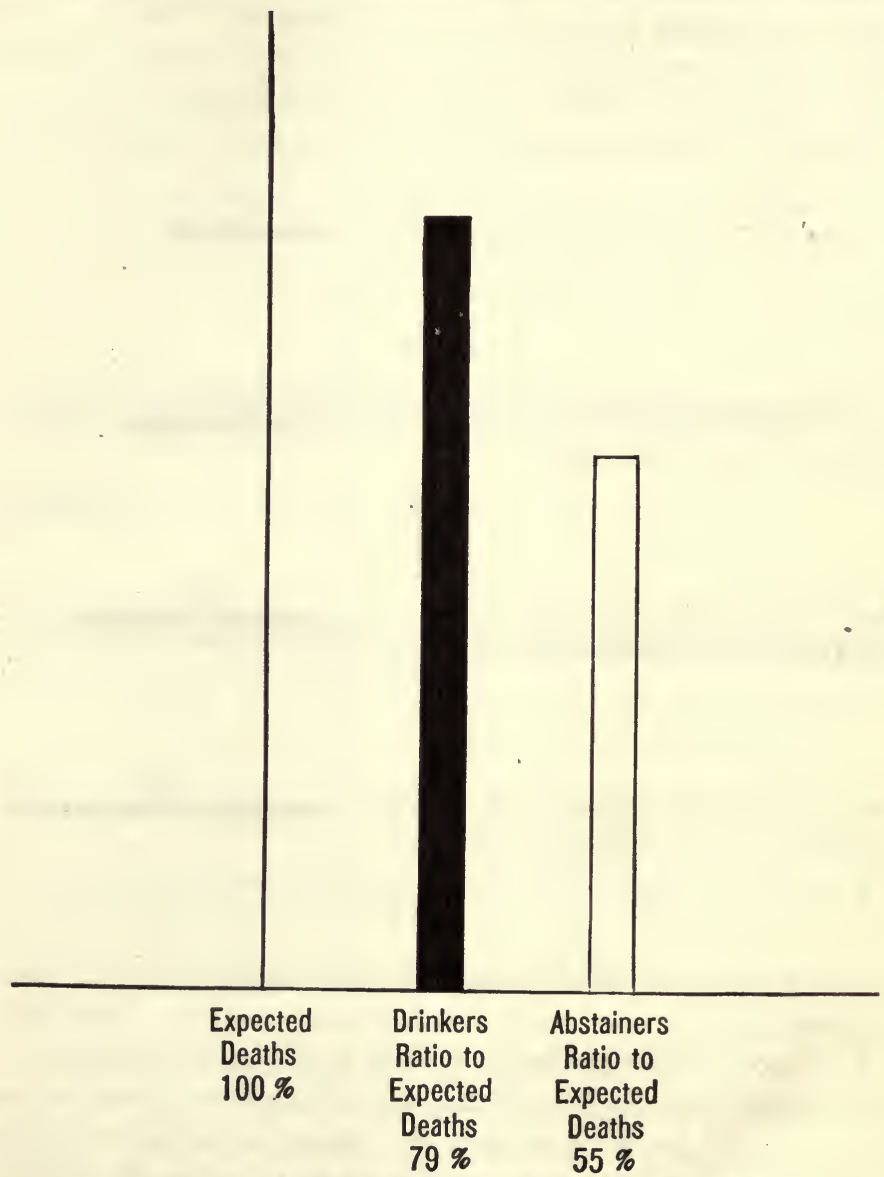

Fig. 217. - Chart showing effect of alcohol on death rate.

(Based on the records of three British life insurance companies.)

has less chance of recovering from a disease than an abstainer. Drinkers are the first to succumb to such diseases as pneumonia, typhoid fever, and tuberculosis. 
Appetite. One of the strongest arguments against the use of alcohol is that it is a habit-forming drug and many people acquire an appetite which they cannot control, and as a result they go to such excess that they are ruined. Many people are able to control this appetite and do not go to excess, but when one starts to drink he cannot tell whether he will be among those who can or those who cannot control the appetite. To begin the use of alcohol even in small quantities is an extremely dangerous risk for a young man to take, because he can never foresee where it will eventually lead him.

Differences in effect of alcohol. The effect of alcohol depends on several factors, chief among them being the person who uses it and the amount taken. We find here, as everywhere else in life, a great difference in individuals. Two persons may be drinking the same amount of alcohol, and yet while one seems to be but little affected by it, the other may be seriously injured. Likewise the amount of harm depends on the quantity of alcohol used. The evidence given in this chapter indicates that even in small quantities alcohol is harmful in some way. As the amount used is increased, the harm done becomes greater, until the point of excess is reached where the injurious effects are very evident. On account, then, of this difference in people, and in the amount used, one cannot make any definite dogmatic statement that will apply to all people and in all cases. But the evidence so far given has been largely taken from positive exact experiments and statistics, and while we cannot say that the same results that occurred in these cases would apply in every case, yet the evidence is overwhelmingly on one side, as indicating the harmful results of the use of alcohol even in small quantities.

The arguments against the use of alcohol are briefly summarized by Dr. Henry S. Williams in the following appeal to any one who uses alcohol habitually. 
"So I am bound to believe, on the evidence, that if you take alcohol habitually in any quantity whatever, it is to some extent a menace to you. I am bound to believe, in the light of what science has revealed: (I) that you are tangibly threatening the physical structures of your stomach, your liver, your kidneys, your heart, your blood-vessels, your nerves, your brain; (2) that you are unequivocally decreasing your capacity for work in any field, be it physical, intellectual, or artistic; (3) that you are in some measure lowering the grade of your mind, dulling your higher esthetic sense, and taking the finer edge off your morals; (4) that you are distinctly lessening your chances of maintaining health and attaining longevity; and (5) that you are entailing upon your descendants yet unborn a bond of incalculable misery.

"Such, I am bound to believe, is the probable cost of your 'moderate' indulgence in alcoholic beverages. Part of that cost you must pay in person; the balance will be the heritage of future generations. As a mere business proposition: Is your glass of beer, your bottle of wine, your highball, or your cocktail worth such a price?"

Effect of alcohol on adolescents. The cases which have been cited show the effect of alcohol on adults. All authorities are agreed that the effects are much worse on growing boys and girls in the adolescent stage (from twelve to sixteen years). There are two reasons why alcohol is especially injurious to boys and girls at this stage. One is because the growing body is more susceptible to the injurious effects of the alcohol, and hence more harm is done than to an adult. The second reason is that during this age habits are more easily formed than later in life. A habit once formed at this age is more apt to become fixed, and, on the other hand, the longer a person goes without forming the drink habit, the less chance there is that he will form it in later life. 
Effect of beer drinking on children. Mr. Bayer investigated the habits of some children in a school in Vienna. Some of these children were total abstainers, some were occasional drinkers, some drank beer or wine once daily, and others drank it twice daily. The rank of these children was obtained from their teachers as "good," "fair," or "poor." The following table shows how the different groups of children compared in their rank.

\begin{tabular}{|c|c|c|c|}
\hline & Goop & FATR & POOR \\
\hline $\begin{array}{l}\text { Total abstainers } \\
\text { Occasional drinkers } \\
\text { Drinkers (once daily) } \\
\text { Drinkers (twice daily) }\end{array}$ & $\begin{array}{l}42 \% \\
34 \% \\
28 \% \\
25 \%\end{array}$ & $\begin{array}{l}49 \% \\
57 \% \\
58 \% \\
57 \%\end{array}$ & $\begin{array}{r}9 \% \\
9 \% \\
14 \% \\
18 \%\end{array}$ \\
\hline
\end{tabular}

This shows that the work of those children who drank beer was not as good as that of those who were abstainers, and that those who drank the most did the poorest work.

Getting a position. Still another great drawback that attends the use of alcohol is the fact that it handicaps a young man in looking for a position. There are some positions, such as those on certain railroads, for which a man will not be engaged if he uses alcohol, and in many other situations employers hire abstainers in preference to the drinker. So all along the line a young man who drinks finds himself seriously handicapped in life.

Alcohol an enemy of the home. The ill effects of the use of alcohol on the man who uses it are bad enough, but vastly worse are the indirect effects on the drinker's wife and children. It is pitiful to think that young children who have done nothing to deserve it should be punished because their father uses alcohol. And yet this is what is happening in thousands of homes all over the country. In some cases the condition is so bad that it is generally known to the public; in other cases it is partly concealed. 
When the drinking man begins to go to excess he harms his family in two ways. First, the money that should be spent to support his family is thrown away for drink. As a result the family suffers for lack of food, clothing, and shelter. Second, frequently while under the influence of liquor, the father abuses his children, causing physical harm and pain. In some cases, a father who is ordinarily kind to his family becomes a brute under the influence of liquor. To be sure, these cases of extreme neglect form only a small per cent of those who drink, but nevertheless the entire total for the whole country is appalling.

As a result of the excessive use of alcohol, the father may lose his power to earn a living and be discharged from his job. Then the mother is forced to work to support her children, and hence the home will be neglected, and the children deprived of the benefits of a happy home that rightfully belong to them.

In some cases, children are even deliberately deserted. An investigation of deserted children made by the Committee of Fifty showed that nearly 45 per cent of the children owed their destitution to the intemperance of parents.

In an investigation made in Boston of the cases of three hundred and fifty-two able-bodied men who failed to support their families, it was found that 70 per cent of them were drunkards.

A former Commissioner of Labor says: "I have looked into a thousand homes of the working people of Europe; I do not know how many in this country. In every case as far as my observation goes, drunkenness was at the bottom of the misery."

There is spent annually in this country for alcoholic liquors about $\$ 2,000,000,000$, an amount equal to our first liberty loan, or five times as much as is spent on our whole educational system. How different would be the condition of drinkers' families if this amount were spent for 
the necessities and pleasures of the home life, instead of for alcohol.

Alcohol an enemy of the community. Lastly we come to consider the effect of alcohol on the community. And here we find that every citizen of a town, including those who do not use alcohol, has to pay the penalty for the consequences of those who do use it. For alcohol helps to make criminals, paupers, and insane people. Every taxpayer has his taxes raised in order to look after these people in the way of supporting prisons, poorhouses, and insane asylums.

Alcohol and paupers. In most communities there are paupers who are not able to support themselves and so are cared for by the town. Investigations have shown that about two fifths of the paupers cared for in the almshouses of this country owe their condition to alcohol. Of many dependents not living in almshouses, who are given relief by charity organizations, it was found that one quarter were brought to their position through the influence of liquor, either directly or indirectly.

Alcohol and crime. Many investigations have been made, both in this country and in Europe, regarding the part that alcohol plays in causing crimes, and without exception all show that it is a very common cause of crime. A judge in the District of Columbia, who had tried ${ }_{150,000}$ cases, said that at least 75 per cent were due to strong drink. The Committee of Fifty made an investigation of the records of 13,000 convicts in seventeen prisons and reformatories scattered through twelve states. They found that in one half of the cases intemperance was a recognized cause of crime.

Similar investigations made in other countries give somewhat similar results, and it is a fair summary of the situation to say that about one half of the crimes committed are due to alcohol.

Alcohol and insanity. Alcohol is also a common cause of insanity. The asylum statistics of the various states in 
this country indicate that from 25 to 30 per cent of all the insane patients admitted to the asylums owe their misfortune directly or indirectly to the abuse of alcohol. In England and Wales it is estimated that alcohol claims $I 7,000$ victims from among a total asylum population of II 6,000 , that is about I 5 per cent. Estimates from Paris indicated that 28 per cent of the men owed their insane condition to alcoholism. In the asylums of Vienna 25 per cent were the victims of alcohol. Returns from numerous sources in Germany give the estimate that at least one fourth of all the insane men in Germany are victims of alcoholism. These estimates from different countries so nearly agree that it is fair to say that one fourth of all cases of insanity are due to alcohol.

We may summarize briefly by saying that the evidence shows that alcohol is responsible for one fourth of the insanity, one third of the pauperism, and one half of the crime in the world.

The United States census of I9Io shows that there were in this country at that time 187,000 insane people in hospitals, 84,000 paupers in almshouses, and I I I,000 prisoners in penal institutions. Taking the per cents given above, this means that alcohol is responsible for 46,000 insane people, 28,000 paupers, and 55,000 criminals; an army of I29,000 of the most unfortunate people in the country. If these were lined up two abreast and three feet apart in the row, they would make a procession thirty-five miles long. If they should march at an ordinary gait, it would take them ten hours to pass a given point. This is alcohol's army.

The taxpayers of the country are put to an enormous expense to support this army. The following table shows the annual expense in this country in looking after criminals, paupers, and insane people, and the proportion due to alcohol. 


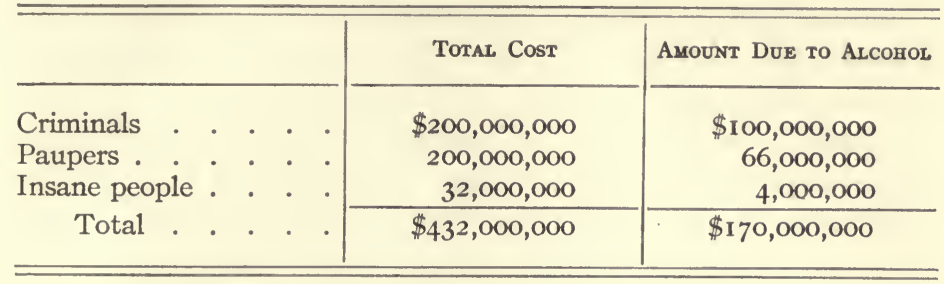

This means that alcohol, through causing criminals, paupers, and insane people, costs the taxpayers of this country $\$ 170,000,000$ each year, that is an average of over a dollar and a half for every man, woman, and child in the United States; or an average of about eight dollars to every family.

Besides the II I,000 criminals in prison, it has been estimated that there are running at large 250,000 criminals and that these cost the community $\$ 400,000,000$. One half of this means $\$ 200,000,000$ expense more due to alcohol.

Alcohol and accidents. People who are not even related to those who drink alcoholic liquors may nevertheless suffer ill consequences from the drinker's negligence. Many accidents on automobiles and railroads have been due to drinking on the part of the chauffeurs and drivers. In the year I9I I more than three hundred children were killed in the streets of New York, and it was found that more than half of these accidents were due to drunken drivers or chauffeurs. So that in one city alone during one year, more than one hundred and fifty children (enough to fill five schoolrooms) were killed through the use of alcohol by other people.

Patent medicines. In this connection something should be said about the danger of using patent medicines, because they contain large per cents of alcohol. Figure 2 I 8 shows the amount of alcohol contained in patent medicines in comparison with the amounts contained in alcoholic liquors. The average medicine contains much more alcohol than beer or wine and some contain as much as whisky. In a 
list of 36 patent medicines analyzed by the Massachusetts state board analyst, the one with the smallest amount of alcohol contained I 2 per cent, while the one with the most contained 47.5 per cent. The average for all the thirty-six was 23 per cent. That is, about one fourth of these patent medicines was alcohol. Since the passage of the pure food law by Congress a number of years ago, manufacturers of
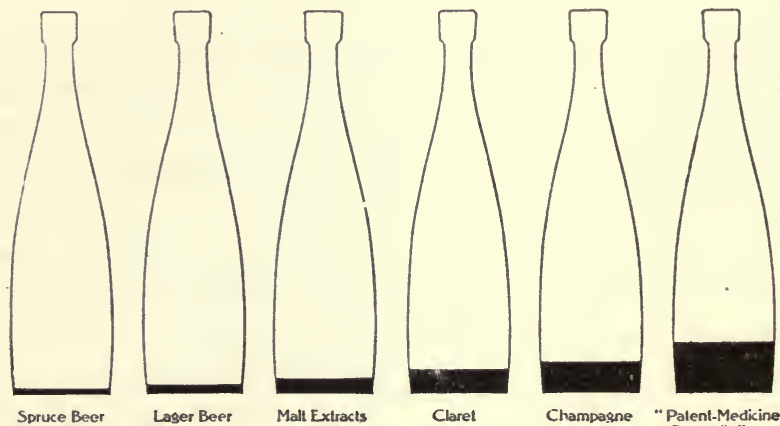

"Patent-Medicine

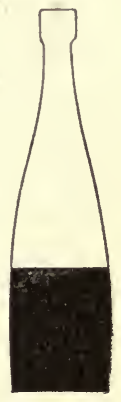

Whisky

FIG. 21 8. - Proportions of alcohol in patent medicines and in alcoholic beverages.

patent medicines are obliged to state on the label the per cent of alcohol contained, so that a person may tell by reading the labels how much alcohol is present in a medicine. One patent medicine found recently on sale in a drug store contained 87 per cent of alcohol.

There is danger in using patent medicines the same as in using alcoholic liquors, because both contain alcohol, only the medicines contain much more than the light liquors. Doubtless some people have acquired the appetite for alcohol through using patent medicines. Before the manufacturers were obliged to state on the labels the per cent of alcohol, people who would not think of touching alcoholic liquors drank even stronger doses of alcohol in the medicines without knowing it. Some patent medicines contain other harmful drugs. These facts show that patent medicines 
ALCOHOL: AN ENEMY OF HOME AND COMMUNITY 553

have in them possibilities of great harm and hence should be avoided.

\section{SUPPLEMENTARY QUESTIONS FOR CLASS DISCUSSION}

I. What advantages has the abstainer over the moderate drinker in his chances for success in life?

2. How does a man show that he is under the influence, of liquor?

3. Why is it not conclusive when a man says that alcohol has not harmed him?

4. What harm has alcohol done to your own community?

5. Which do you think is better for your town, to have prohibition or to have saloons? Why? 

Relative Humidity, Per Cent.-Fahrenheit Temperatures

Difference between Dry-bulb and Wet-bulb Temperature

\begin{tabular}{|c|c|c|c|c|c|c|c|c|c|c|c|c|c|c|c|c|c|c|c|c|}
\hline $\begin{array}{l}\text { DRY-BULB } \\
\text { TEMP. }\end{array}$ & 1 & 2 & 3 & 4 & 5 & 6 & 7 & 8 & 9 & 10 & 11 & 12 & 13 & 14 & 15 & 16 & 17 & 18 & 19 & 20 \\
\hline $\begin{array}{l}30 \\
3 \mathbf{I} \\
32 \\
33 \\
34\end{array}$. & $\begin{array}{l}89 \\
89 \\
90 \\
90 \\
90\end{array}$ & $\begin{array}{l}78 \\
79 \\
79 \\
80 \\
81\end{array}$ & $\begin{array}{l}68 \\
69 \\
69 \\
71 \\
72\end{array}$ & $\begin{array}{l}57 \\
58 \\
60 \\
61 \\
62\end{array}$ & $\begin{array}{l}47 \\
49 \\
50 \\
52 \\
53\end{array}$ & $\begin{array}{l}37 \\
39 \\
4 \mathrm{I} \\
42 \\
44\end{array}$ & $\begin{array}{l}27 \\
29 \\
31 \\
33 \\
35\end{array}$ & $\begin{array}{l}17 \\
20 \\
22 \\
24 \\
27\end{array}$ & $\begin{array}{r}8 \\
10 \\
13 \\
16 \\
18\end{array}$ & $\begin{array}{l}1 \\
4 \\
7 \\
9\end{array}$ & $\mathbf{I}$ & & & & & & & & & \\
\hline $\begin{array}{l}35 \\
36 \\
37 \\
38 \\
39\end{array}$ & $\begin{array}{l}91 \\
91 \\
91 \\
91 \\
92\end{array}$ & $\begin{array}{l}82 \\
82 \\
83 \\
83 \\
84\end{array}$ & $\begin{array}{l}73 \\
73 \\
74 \\
75 \\
76\end{array}$ & $\begin{array}{l}64 \\
65 \\
66 \\
67 \\
68\end{array}$ & $\begin{array}{l}55 \\
56 \\
58 \\
59 \\
60\end{array}$ & $\begin{array}{l}46 \\
48 \\
49 \\
51 \\
52\end{array}$ & $\begin{array}{l}37 \\
39 \\
41 \\
43 \\
44\end{array}$ & $\begin{array}{l}29 \\
31 \\
33 \\
35 \\
37\end{array}$ & $\begin{array}{l}20 \\
23 \\
25 \\
27 \\
29\end{array}$ & $\begin{array}{l}12 \\
14 \\
17 \\
19 \\
21\end{array}$ & $\begin{array}{r}4 \\
6 \\
9 \\
\mathbf{1} 2 \\
14 \\
\end{array}$ & $\begin{array}{l}\text { I } \\
4 \\
7\end{array}$ & & & & & & & & \\
\hline $\begin{array}{l}40 \\
4 \mathrm{I}\end{array}$ & $\begin{array}{l}92 \\
92\end{array}$ & $\begin{array}{l}84 \\
84\end{array}$ & $\begin{array}{l}76 \\
77\end{array}$ & $\begin{array}{l}68 \\
69\end{array}$ & $\begin{array}{l}6 \mathrm{I} \\
62\end{array}$ & $\begin{array}{l}53 \\
54\end{array}$ & $\begin{array}{l}46 \\
47\end{array}$ & $\begin{array}{l}38 \\
40\end{array}$ & $\begin{array}{l}3 \mathrm{I} \\
33\end{array}$ & $\begin{array}{l}23 \\
26\end{array}$ & $\begin{array}{l}16 \\
18\end{array}$ & $\begin{array}{r}9 \\
\text { II }\end{array}$ & $\begin{array}{l}2 \\
5\end{array}$ & & & & & & & \\
\hline 42 & 92 & 85 & 77 & 70 & 62 & 55 & 48 & $4 \mathrm{I}$ & 4 & 28 & 21 & 14 & 7 & 0 & & & & & & \\
\hline $\begin{array}{l}43 \\
44\end{array}$ & $\begin{array}{l}92 \\
93\end{array}$ & $\begin{array}{l}85 \\
85\end{array}$ & $\begin{array}{l}78 \\
78\end{array}$ & $\begin{array}{l}70 \\
71\end{array}$ & $\begin{array}{l}63 \\
64\end{array}$ & $\begin{array}{l}56 \\
57\end{array}$ & $\begin{array}{l}49 \\
5 \mathrm{I}\end{array}$ & $\begin{array}{l}43 \\
44\end{array}$ & $\begin{array}{l}36 \\
37\end{array}$ & $\begin{array}{l}29 \\
31\end{array}$ & $\begin{array}{l}23 \\
24\end{array}$ & $\begin{array}{l}\text { I6 } \\
\text { I8 }\end{array}$ & $\begin{array}{r}9 \\
122 \\
\end{array}$ & $\begin{array}{l}3 \\
5\end{array}$ & & & & & & \\
\hline 45 & 93 & 86 & 79 & 71 & 65 & 58 & 52 & 45 & 39 & 33 & 26 & 20 & 14 & 8 & 2 & & & & & \\
\hline & 9 & 86 & 79 & 72 & 65 & 59 & 53 & 46 & ० & 34 & 28 & 22 & 16 & Io & 4 & & & & & \\
\hline $\begin{array}{l}47 \\
48\end{array}$ & 9 & 86 & 79 & 73 & 66 & 60 & 54 & 47 & $4 \mathrm{I}$ & 35 & 29 & 23 & 17 & I 2 & $\begin{array}{l}6 \\
8\end{array}$ & $\begin{array}{l}\mathbf{I} \\
3\end{array}$ & & & & \\
\hline 49 & $\begin{array}{l}93 \\
93\end{array}$ & $\begin{array}{l}07 \\
87\end{array}$ & $\begin{array}{l}80 \\
80\end{array}$ & $\begin{array}{l}73 \\
74\end{array}$ & $\begin{array}{l}07 \\
67\end{array}$ & $6 \mathrm{I}$ & $\begin{array}{l}54 \\
55\end{array}$ & $\begin{array}{l}48 \\
49\end{array}$ & $\begin{array}{l}42 \\
43\end{array}$ & $\begin{array}{l}36 \\
37\end{array}$ & $\begin{array}{l}3 \mathrm{I} \\
32\end{array}$ & $\begin{array}{l}25 \\
26\end{array}$ & \begin{tabular}{|l|}
99 \\
21
\end{tabular} & \begin{tabular}{|l|}
14 \\
15
\end{tabular} & 10 & $\begin{array}{l}3 \\
5\end{array}$ & & & & \\
\hline 50 & 93 & 87 & $8 \mathrm{r}$ & 74 & 68 & 62 & 56 & 50 & 44 & 39 & 33 & 28 & 22 & 17 & 12 & 7 & 2 & & & \\
\hline 51 & 9 & 87 & 81 & 75 & 69 & 63 & 57 & $5 \mathrm{I}$ & 5 & 40 & 35 & 29 & 24 & I9 & 14 & 9 & 4 & & & \\
\hline 5 & 9 & 88 & $8 \mathbf{I}$ & 75 & 69 & 63 & 58 & 52 & 46 & $4 \mathrm{I}$ & 36 & 30 & 25 & 20 & 15 & 10 & 6 & 0 & & \\
\hline 53 & 94 & $\begin{array}{l}88 \\
88\end{array}$ & 82 & 75 & 70 & 64 & 58 & 53 & 47 & 42 & 37 & 32 & 27 & 22 & 17 & 12 & 7 & 3 & & \\
\hline 5 & 94 & 88 & 82 & 76 & 70 & 65 & 59 & 54 & 48 & 43 & $3^{8}$ & 33 & 28 & 23 & 18 & I 4 & 9 & 5 & o & \\
\hline $\begin{array}{l}55 \\
56\end{array}$ & $\begin{array}{l}94 \\
94\end{array}$ & $\begin{array}{l}88 \\
88\end{array}$ & $\begin{array}{l}82 \\
82\end{array} \mid$ & \begin{tabular}{|l|}
76 \\
77
\end{tabular} & $\begin{array}{l}7 \mathrm{I} \\
7 \mathrm{I}\end{array}$ & $\begin{array}{l}65 \\
66\end{array}$ & $\begin{array}{l}60 \\
6 \mathrm{I}\end{array}$ & $\begin{array}{l}55 \\
55\end{array}$ & $\begin{array}{l}49 \\
50\end{array}$ & $\begin{array}{l}44 \\
45\end{array}$ & $\begin{array}{l}39 \\
40\end{array}$ & 34 & $\begin{array}{l}29 \\
31\end{array}$ & \begin{tabular}{|l|}
25 \\
26
\end{tabular} & $\begin{array}{l}20 \\
2 \mathrm{I}\end{array}$ & $\begin{array}{l}15 \\
17\end{array}$ & $\begin{array}{ll}\text { II } \\
\text { I }\end{array}$ & $\begin{array}{l}6 \\
8\end{array}$ & $\begin{array}{l}2 \\
4\end{array}$ & \\
\hline 57 & 94 & 88 & $8_{3}$ & 77 & 72 & 66 & $6 \mathrm{I}$ & \begin{tabular}{|l|}
33 \\
56
\end{tabular} & 51 & $\begin{array}{l}45 \\
46\end{array}$ & $\begin{array}{l}40 \\
4 \mathrm{I}\end{array}$ & \begin{tabular}{|l|}
35 \\
36
\end{tabular} & $\begin{array}{l}31 \\
32\end{array}$ & 27 & 23 & \begin{tabular}{|l|}
17 \\
18
\end{tabular} & $\begin{array}{l}12 \\
14\end{array}$ & 10 & $\begin{array}{l}4 \\
5\end{array}$ & I \\
\hline 58 & 94 & 89 & 83 & 77 & 72 & 67 & 62 & 57 & 52 & 47 & 42 & 38 & 33 & 28 & 24 & 20 & 15 & II & 7 & 3 \\
\hline 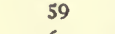 & 94 & 89 & 83 & 78 & 73 & 68 & 63 & 58 & 53 & 48 & 43 & 39 & 34 & 30 & 25 & $2 I$ & 17 & I3 & 9 & 5 \\
\hline 60 & 94 & 89 & 84 & 78 & 73 & 68 & 63 & 58 & 53 & 49 & 44 & 40 & 35 & $3 I$ & $\begin{array}{r}27 \\
28\end{array}$ & 22 & 18 & $I_{4}$ & 10 & 6 \\
\hline $6 \mathrm{r}$ & 10 & 89 & 84 & 79 & 74 & 68 & 64 & 59 & 54 & 50 & 45 & 40 & 30 & 32 & 28 & 24 & 20 & 16 & 12 & 8 \\
\hline 62 & 94 & 89 & 84 & 79 & 74 & 69 & 64 & 60 & 55 & 50 & 46 & $4 \mathrm{I}$ & 37 & 3.3 & 29 & 25 & $2 \mathrm{I}$ & 17 & 13 & \\
\hline 63 & 98 & 90 & 84 & 79 & 74 & 70 & 65 & 60 & 56 & 51 & 47 & 42 & 38 & 34 & 30 & 26 & 22 & 18 & 14 & II \\
\hline 64 & 95 & 90 & 85 & 79 & 75 & 70 & 66 & $6 r$ & 56 & 52 & 48 & 43 & 39 & 35 & $3 I$ & 27 & 23 & 20 & 16 & 12 \\
\hline 65 & 95 & 90 & 85 & 80 & 75 & 70 & 66 & 62 & 57 & 53 & 48 & 44 & 40 & 36 & 32 & 28 & 25 & $2 \mathrm{I}$ & 17 & 13 \\
\hline & & 90 & 85 & 80 & 76 & 71 & 66 & 62 & $\begin{array}{l}58 \\
58\end{array}$ & 53 & 49 & 45 & 4I & $\begin{array}{l}37 \\
38\end{array}$ & 33 & ? & 6 & 22 & 8 & $\begin{array}{l}15 \\
16\end{array}$ \\
\hline 68 & $\begin{array}{l}95 \\
95\end{array}$ & $\begin{array}{l}90 \\
90\end{array}$ & $\begin{array}{l}85 \\
85\end{array}$ & $\begin{array}{l}80 \\
8 \mathrm{I}\end{array}$ & $\mid \begin{array}{l}76 \\
76\end{array}$ & $\begin{array}{l}71 \\
72\end{array}$ & $\begin{array}{l}67 \\
67\end{array}$ & \begin{tabular}{|l|}
63 \\
63 \\
63
\end{tabular} & $\begin{array}{l}58 \\
59\end{array}$ & $\begin{array}{l}54 \\
55\end{array}$ & $\begin{array}{l}50 \\
5 \mathrm{I}\end{array}$ & $\begin{array}{l}46 \\
47\end{array}$ & $\begin{array}{l}42 \\
43\end{array}$ & $\begin{array}{l}38 \\
39\end{array}$ & $\begin{array}{l}34 \\
35\end{array}$ & 3 & $\begin{array}{l}27 \\
28\end{array}$ & 24 & $\begin{array}{l}20 \\
21\end{array}$ & $\begin{array}{l}10 \\
17\end{array}$ \\
\hline 69 & 95 & 90 & 86 & $8 \mathrm{I}$ & 77 & 72 & 68 & 64 & 59 & 55 & $5 \mathrm{I}$ & 47 & 44 & 40 & 36 & 32 & 29 & 25 & 22 & 19 \\
\hline 70 & 95 & 90 & 86 & $8 \mathrm{I}$ & 77 & 72 & 68 & 64 & 60 & 56 & 52 & 48 & 44 & 40 & 7 & 33 & 30 & 26 & 23 & 20 \\
\hline & 9 & 90 & 86 & 82 & 77 & 73 & 69 & 64 & 60 & 56 & 53 & 49 & 45 & 4I & 38 & 34 & 31 & 7 & 24 & 21 \\
\hline 72 & 9 & $9 \mathrm{I}$ & $\begin{array}{l}86 \\
86\end{array}$ & 82 & 78 & 73 & 69 & 65 & $6 \mathrm{r}$ & & 30 & 49 & 46 & 42 & 39 & & 32 & 28 & 5 & 22 \\
\hline 73 & 9. & $9 \mathrm{I}$ & 86 & 82 & 78 & 73 & 69 & 65 & $6 \mathrm{x}$ & 58 & 54 & 50 & 46 & 43 & 40 & 36 & 33 & 29 & 6 & 23 \\
\hline 74 & 90 & $9 \mathrm{r}$ & 86 & 82 & 78 & 74 & 70 & 66 & 62 & $5^{8}$ & 54 & $5 \mathrm{I}$ & 47 & 44 & 40 & 37 & 34 & 30 & 27 & 24 \\
\hline $\begin{array}{l}75 \\
76\end{array}$ & 06 & 91 & 87 & 82 & 78 & 74 & 70 & 66 & 63 & 59 & 55 & $5 \mathrm{I}$ & 48 & 44 & $4 \mathrm{I}$ & 38 & 34 & 31 & 28 & 25 \\
\hline & & $9 \mathrm{r}$ & 8 & 8 & 78 & 74 & 70 & 67 & 60 & 59 & 56 & 52 & 48 & 45 & 42 & 8 & 35 & 32 & 29 & \\
\hline & 9 & 91 & 8 & 83 & 79 & $\begin{array}{l}75 \\
75\end{array}$ & 71 & $\begin{array}{l}07 \\
67\end{array}$ & $\mathrm{D} 3$ & 60 & 50 & $\begin{array}{l}52 \\
53\end{array}$ & 49 & 40 & 42 & 39 & 36 & 33 & 30 & \\
\hline 79 & 96 & $9 \mathrm{I}$ & 87 & 83 & 79 & 75 & 71 & 68 & 64 & 60 & 57 & 54 & 50 & 47 & $\begin{array}{l}43 \\
44\end{array}$ & $\begin{array}{l}40 \\
4 \mathrm{I}\end{array}$ & $\begin{array}{l}31 \\
37\end{array}$ & 34 & $\begin{array}{l}32 \\
31\end{array}$ & \\
\hline 80 & 96 & 91 & 87 & 83 & 79 & 76 & 72 & 68 & 64 & 61 & 57 & 54 & $5 \mathrm{I}$ & 47 & 44 & $4 \mathrm{I}$ & $3^{8}$ & 35 & 32 & 29 \\
\hline
\end{tabular}




\section{List of Apparatus for Demonstrations and LABORATORY EXERCISES}

Flasks, rubber stoppers, glass tubing, rubber tubing, alcohol lamp or Bunsen burner, tumblers, beakers, lamp chimney, test tubes, touch paper, candle, ringstand, thermometer, pneumatic trough, wide mouthed bottles, iron picture wire, deflagrating spoon, wire gauze, plates, bicycle pump, kerosene lamp, sling psychrometer, plates of glass, air pump, bell jar with open top, rubber membrane, pint milk bottle, glass model of pump, tin cup, red and blue litmus paper, tuning fork, sonometer, camera, convex and concave lenses, kodak film tank, printing frame, printing papers, flowerpots, window boxes, bulbs, two bar magnets, horseshoe magnet, iron filings, small pieces of various metals, darning and knitting needles, insulated wire, large bolt, dry cells, electric bell, push button, sal ammoniac cell, strips of sheet zinc and copper, compass, rulers, insect breeding cage, outfit for candling eggs, collection of types of bird houses, pair of field glasses for bird study, model of steam engine, galvanometer, primary and secondary coils (the inner one removable), small motor, and dynamo, coffee pot, small gas engine or a model of one, induction coil, small gyroscope, spring balance, overflow can, catch bucket, shot, thistle tube, set of telegraph instruments (sender, sounder, relay), small demonstration form of wireless outfit, dissectible telephone, pipette, petri dishes, culture medium, Snellen's vision chart, collections of samples of woods, aneroid barometer, weather maps. 


\section{Chemicals}

Nitric acid, hydrochloric acid, sulfuric acid, ammonia, limewater, potassium chlorate, manganese dioxid, sulfur, calcium carbide, distilled water, potassium permanganate, silver nitrate, calcium sulfate, potassium bromide, lead acetate, iron alum, iodin solution, granulated zinc, hypo, developing powders, formalin, baking powder, baking soda, cream of tartar, vinegar, salt, washing soda.

TABLE OF INVENTIONS

\begin{tabular}{|c|c|c|c|c|c|}
\hline NAME & & & Date & INVENTOR & Nationality \\
\hline Steam engine . & & . . & $\mathbf{I} 774$ & Watt & English \\
\hline Steamboat . . & . & . . & 1807 & Fulton & American \\
\hline Locomotive. . & . &. & I $8 \mathbf{r}_{4}$ & Stephenson & English \\
\hline Telegraph . . . & . & . . & I 844 & Morse & American \\
\hline Telephone . . & & . . & 1876 & Bell & American \\
\hline Phonograph . & & . . & I 877 & Edison & American \\
\hline Incandescent lamp & & . . & I 880 & Edison & American \\
\hline Electric trolley & & .. & I 880 & Siemens & German \\
\hline Automobile. & & . & I 883 & Daimler & German \\
\hline Wireless telegraph & & . . & 1896 & Marconi & Italian \\
\hline Wireless telephone & & . & 1900 & Poulsen & Danish \\
\hline Airplane . . . & & . . & 1903 & Wright Brothers & American \\
\hline
\end{tabular}





\section{INDEX}

Acetylene, 40

Adulteration of foods, 356

Air currents, 2 I

Airplanes, 305

Air pressure, 50

Airship, 3 I 6

Alcohol, 536

Animated cartoons, 455 newspaper, 453

Annuals, I73

Antitoxin, 376

Appetite, 87

Automobile, 279

Bacteria, 365

Baking powder, 99

Balloons, 3or

Banjo, 123

Barometer, 508

Bees, 220

Bell, Alexander, 335

Bird clubs, 475 music, 226

Birds and insects, 460

Birds and rodents, 464

Birds and weed seeds, 462

Bluebird box, 230

Blue prints, 136

Bottle, thermos, 103

Bread making, 99

Breathing, I 8

Breeds of poultry, 21 5

Brooks, 49

Bulbs, 143, I69

Burning, Chemistry of, 12

Calories, $78^{\circ}$

Camera, 127,448

Candle, 33

Canning, roo

Capillarity, 37

Carbohydrates, 63

Cats, 233, 470

Cells, 156
Central, 340

Chemistry of kitchen, I 14

Chittenden, Professor, 80

Cistern, 49

Clermont, 286

Clutch, 279

Coffee, 95

Coldframe, r9I

Combs of bee, 220

Compass, 289

Conservation of forests, 500

Controller, 26r

Cooker, Fireless, ro3

Cooking, 98

Cornet, 124

Cultivation of soil, 192

Cuttings, 142, 212

Dark room, 133

Defects in children, 434

Developing, I3I

Digestion, 60

Diphtheria, 376

Diseases and bacteria, 368

Diseases, contagious, 4 I 9

Dispatcher, 254

Drying fruits, 107

Duplex telegraphy, 324

Dynamo, 259

Ear, 440

Eclipses, 526

Edison, Thomas A., I 19

Eggs, Candling, 77

Eggs, Storing, 76

Electric bell, 153

fan, 152 iron, $15 \mathrm{I}$

Electricity, Heating by, I I Lighting by, 4I

Enemies of birds, 470

English sparrow, 47 I

Exercise, 62

Eye, 436 
Fats, 63

Feeding birds, 235

Filter beds, 348 .

Fireplace, 45

Fisher, Irving, 82

Flashlights, I 30

Flower garden, I 68

Flowers and bees, 222

Flute, 124

Fly, 405

Foods, 71, 356

Forest fires, 496 service, 495

Fountains, Drinking, 433 for birds, 238

Freezer, Ice cream, IO4

Fruits, 64

Fuels, I02

Fulton, Robert, 286

Furnace, 4

Gas, 38

Gas engine, 278

Glass, 43

Grape, 2 Io

Guitar, 123

Gyro-compass, 29I

Hatching eggs, 2 I 7

Health officers, 4 I 7

Hive of bees, 223

Hotbed, I9I

Hot water system, 7

House plants, I 39

Humidity, 24

Ice, 380

Insects, I4I, 194

Kinetoscope, 446

Kodak, 127

Kodak film tank, I34

Lamp, Mazda, 42

Lamps, 33, 36

Landscape gardening, I62

Layering, 213

Lighting schoolroom, 426

Lily, Chinese, 145

Locomotive, Parts of, 248

Uses of, 243

Lușitania, 287
Magnet, I55

Malaria, 394

Mars, 528

Martin house, 232

Mastication, 90

Matches, I 5

Medical inspection, 44I

Meter, Gas, 39

Milk, 69, 352

Molds, 105

Moon, 520

Morse, Samuel, 320

Mosquitoes, 394

Motor, I 53

Mounting prints, I $_{3} 6$

Moving pictures, 444

National forests, 493

Nesting boxes, 228

Nesting of birds, 227

Newcomen, 246

Nutrients, 59

Nuts, 66

Overeating, 92

Oxygen, Preparation of, I 3

Pasteurization of milk, $38 \mathrm{I}$

Patent medicines, $55 \mathrm{I}$

Percolator, 149

Perennials, 168

Periscope, 298

Phonograph; I1 8

Photography, 126

Piano, 122

Planets, 526

Planting seeds, 128

Porch, Sleeping, 3 I

Poultry house, 217

Preserving foods, 107

Printing, I35

Propagation of plants, 142 of fruits, 212

Protection of birds, 472

Proteins, 63

Pumps, 49, 52, 53

Rain Gauge, 5 I I

Ram, Hydraulic, 53

Recreation forests, 492

Refrigerator, 104 
Relay, 323

Runners, 212

School hygiene, 426

Shade trees, $47-48$

Shrubs, I63, 238

Smallpox, 372

Soaps, I 15

Solar system, 5 I 5

Sounder, 322

Spectroscope, 518

Springs, 48

Stains, I 16

Stars, 530

Steamboat, 286

Steam engine, 255

Steam heating, 9

Stereopticon, 450

Storing vegetables, 196

Stove, 4

Strawberries, 206

Submarines, 294

Suet box, 236

Swarming of bees, 221

Talking movies, 456

Tank, Hot-water, 56

Tea, 95

Teeth, 93, 435

Telegraph, 318

Telephone, 333

Telescope, 529

Temperature, 22
Thermometer, 23, 5 Io

Thinning, 189

Toaster, 149

Tools for garden, 187

Transplanting, 19I

Traps, Fly, 413

Trick pictures, 454

Tuberculosis, 384,409

Turbine, Steam, 288

Typhoid fever, 379,408

Vaccination, 372,383

Vacuum cleaner, I 50

Vegetables, 64

Ventilation, 19, 28, 427

Vines, 166

Violin, I 23

Water supply, 45, 347

Watt, 246

Weather map, 504

Weeds, 193

Wells, 45,48

Windmill, 54

Window box, $\mathrm{r}_{3} 8$

Winter birds, 235

Wintering bees, 224

Wireless telegraph, 326

Wireless telephone, $34 \mathrm{r}$

Yeast, 99

Yellow fever, 397

Zeppelin, 304 




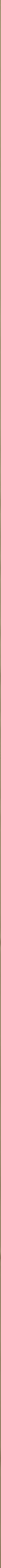



toin

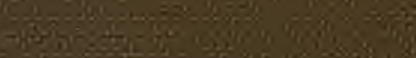

0.028

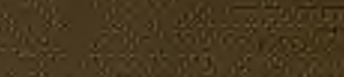

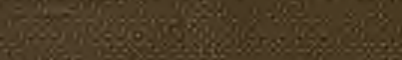

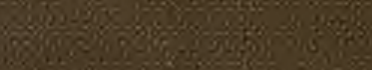

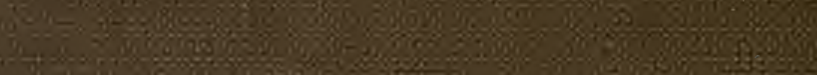

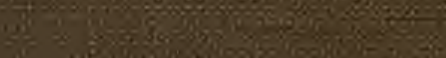

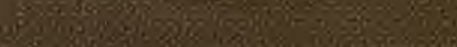

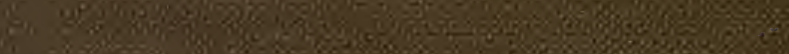

a

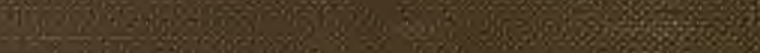

ans W.

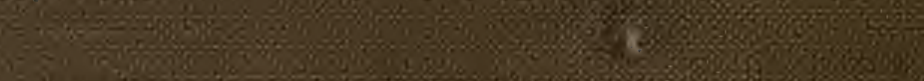

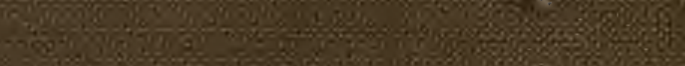

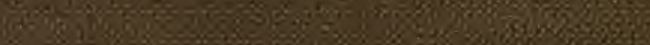

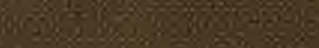

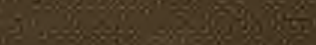

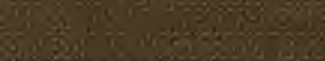

19.8

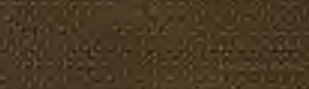

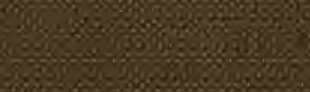

2olges

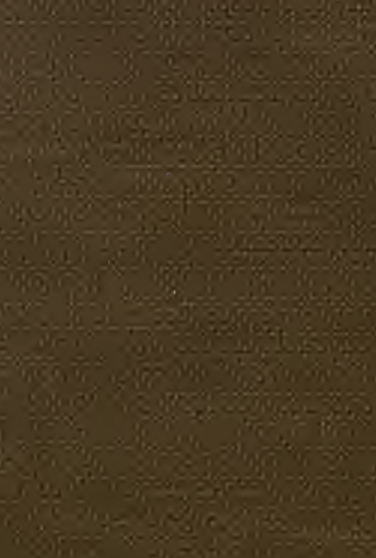

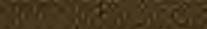

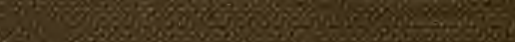

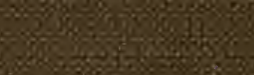

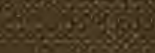

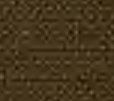

$56 x^{2}=7$ n.9.8. 